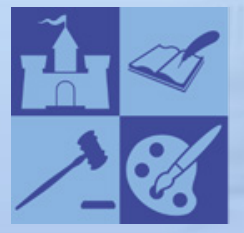

\title{
humanities
}

Ethics and Literary Practice

Edited by

Adam Zachary Newton

Printed Edition of the Special Issue Published in Humanities 
Ethics and Literary Practice 



\section{Ethics and Literary Practice}

Special Issue Editor

Adam Zachary Newton

MDPI • Basel • Beijing • Wuhan • Barcelona $\bullet$ Belgrade $\bullet$ Manchester $\bullet$ Tokyo $\bullet$ Cluj $\bullet$ Tianjin

\section{MDPI}


Special Issue Editor

Adam Zachary Newton

University Professor Emeritus,

Yeshiva University

USA

\section{Editorial Office}

MDPI

St. Alban-Anlage 66

4052 Basel, Switzerland

This is a reprint of articles from the Special Issue published online in the open access journal Humanities (ISSN 2076-0787) (available at: https://www.mdpi.com/journal/humanities/special_ issues/ethics).

For citation purposes, cite each article independently as indicated on the article page online and as indicated below:

LastName, A.A.; LastName, B.B.; LastName, C.C. Article Title. Journal Name Year, Article Number, Page Range.

\section{ISBN 978-3-03928-504-4 (Pbk)}

ISBN 978-3-03928-505-1 (PDF)

Cover image courtesy of Ryuta Lida (Artwork) and Shin Suzuki (Photograph).

(C) 2020 by the authors. Articles in this book are Open Access and distributed under the Creative Commons Attribution (CC BY) license, which allows users to download, copy and build upon published articles, as long as the author and publisher are properly credited, which ensures maximum dissemination and a wider impact of our publications.

The book as a whole is distributed by MDPI under the terms and conditions of the Creative Commons license CC BY-NC-ND. 


\section{Contents}

About the Special Issue Editor $\ldots \ldots \ldots \ldots \ldots \ldots \ldots$ vii

Preface to "Ethics and Literary Practice" $\ldots \ldots \ldots \ldots \ldots \ldots \ldots \ldots \ldots$

\section{Adam Zachary Newton}

Introduction: Alienated Majesty: On Reading as Othering

Reprinted from: Humanities 2020, 9, 16, doi:10.3390/h9010016

\section{Steven B. Katz}

Ethics and Time: After the Anthropocene

Reprinted from: Humanities 2019, 8, 185, doi:10.3390/h8040185 . . . . . . . . . . . . . . 17

\section{Richard Deming}

Senses of Echo Lake: Michael Palmer, Stanley Cavell, and the Moods of an American Philosophical Tradition

Reprinted from: Humanities 2019, 8, 98, doi:10.3390/h8020098 _ . . . . . . . . . . . . 23

Mette Blok

Endlessly Responsible: Ethics as First Philosophy in Stanley Cavell's Invocation of Literature Reprinted from: Humanities 2019, 8, 114, doi:10.3390/h8020114 . . . . . . . . . . . . . . 35

\section{Josephine Donovan}

Ethical Mimesis and Emergence Aesthetics

Reprinted from: Humanities 2019, 8, 102, doi:10.3390/h8020102 . . . . . . . . . . . . . . . 45

\section{Donald R. Wehrs}

Interlocutors, Nonhuman Actors, and the Ethics of Literary Signification

Reprinted from: Humanities 2019, 8, 108, doi:10.3390/h8020108 . . . . . . . . . . . . . . 55

\section{Hille Haker}

Towards a Decolonial Narrative Ethics

Reprinted from: Humanities 2019, 8, 120, doi:10.3390/h8030120 _ . . . . . . . . . . . . . 71

\section{Andreea Deciu Ritivoi}

Reading (with) Hannah Arendt: Aesthetic Representation for an Ethics of Alterity

Reprinted from: Humanities 2019, 8, 155, doi:10.3390/h8040155 . . . . . . . . . . . . . . . 103

\section{Eugene $\mathrm{O}^{\prime}$ Brien}

'A Pause for Po-Ethics': Seamus Heaney and the Ethics of Aesthetics

Reprinted from: Humanities 2019, 8, 138, doi:10.3390/h8030138 . . . . . . . . . . . . . . . . 121

\section{Thomas Claviez}

Neorealism, Contingency, and the Linguistic Turn

Reprinted from: Humanities 2019, 8, 176, doi:10.3390/h8040176 . . . . . . . . . . . . . 137

\section{Adia Mendelson-Maoz}

The Fallacy of Analogy and the Risk of Moral Imperialism: Israeli Literature and the Palestinian Other

Reprinted from: Humanities 2019, 8, 119, doi:10.3390/h8030119 _ . . . . . . . . . . . . . . 153

\section{Michelle Boulous Walker}

Affect and Porosity: Ethics and Literature between Teresa Brennan and Hélène Cixous 
Jay Rajiva

The Answer is Paracritical: Caribbean Literature and The Limits of Critique

Reprinted from: Humanities 2019, 8, 126, doi:10.3390/h8030126 . . . . . . . . . . . . . . 189

\section{Cynthia R. Wallace}

Attention, Representation, and Unsettlement in Katherena Vermette's The Break, or, Teaching and $(\operatorname{Re})$ Learning the Ethics of Reading

Reprinted from: Humanities 2019, 8, 164, doi:10.3390/h8040164 . . . . . . . . . . . . . . . . 201

\section{Steven B. Katz}

Sonic Rhetorics as Ethics in Action: Hidden Temporalities of Sound in Language(s)

Reprinted from: Humanities 2020, 9, 13, doi:10.3390/h9010013 . . . . . . . . . . . . . . . . 217 


\section{About the Special Issue Editor}

Adam Zachary Newton. Now Emeritus, Adam Zachary Newton was University Professor, Chair of the English Department, and Stanton Chair in Literature and Humanities at Yeshiva University from 2007-2014. Prior to that, he held appointments at the University of Texas at Austin in English, Comparative Literature, Middle Eastern Languages and Cultures, and Jewish Studies as the Jane and Roland Blumberg Centennial Professor. More recently, he has held appointments as Distinguished Visiting Professor as at Emory University and Agnes Scott College. A cross-disciplinary scholar, he has written and taught at the boundaries of three knowledge practices: literary studies, philosophy, and religion. Alongside essays in a range of fields, he is the author of six monographs: Jewish Studies as Counterlife: A Report to the Academy (Fordham, 2019); To Make the Hands Impure: Art, Ethical Adventure, the Difficult and the Holy (Fordham, 2014); The Elsewhere: On Belonging at a Near Distance: Reading Literary Memoir from East-Central Europe and the Levant (Wisconsin, 2005); The Fence and the Neighbor: Emmanuel Levinas, Yeshayahu Leibowtz, and Israel Among the Nations (SUNY, 2001); Facing Black and Jew: Literature as Public Space in 20th-Century America (Cambridge, 1998); and his award-winning first book, Narrative Ethics (Harvard, 1995), which first formalized the term for a developing sub-field. 



\section{Preface to "Ethics and Literary Practice"}

As a resurgent theoretical trend in humanities scholarship now in its fourth decade (cf. Nussbaum 1985, Miller 1987, Booth 1988, Siebers 1988, Phelan 1989, Newton 1995, McCance 1996, Eaglestone 1997, Posner 1997, Altieri 1998, Adamson, Freadman, Parker 1998, Attridge 1999, Buell 1999, Gibson 1999, Garber, Hanssen, Walkowitz 2000, Davis and Womack 2001, George 2005, Attridge 2006, Levine 2009, Rossiter 2010, Altes 2014, Biwu 2014, Gregory 2019, Serpell 2014, Kingwell 2014, Doran 2017, Meretoja and David, 2018), "ethics and literary practice" names an inquiry that remains productively open to question. This special issue of Humanities explores intersections between its organizing concepts as provocations rather than givens within a range of fields, heuristic frames, analytical categories, and discourses. Take the following as illustrative.

1. "II]insofar as we take literature to be ethically significant in an exemplary way, we may want to start thinking about locating its ethical force not so much in its referential makeup and thematics as in, among other things, what I would call, for lack of a better term, its discursive transformational "capaciousness," that is, in its ability to absorb and transform virtually any kind of discourse, including the discourse of ethics" (Eskin, 2004).

2. "How to think of ethics? Can one think of ethics? As the locus of otherness, ethics seems to lack integrity 'in itself,' and perhaps ought to be considered a matrix, a hub from which various discourses, concepts, terms, energies, fan out, and at which they meet, crossing out of themselves to encounter the other, all the others. E]thics exerts whatever force it does by virtue of its singular capacity to adhere to, affiliate with, bury itself in, provoke, or dislodge other discourses; ethics realizes its full creative potential not in 'itself' but as a kind of $x$-factor, a bracingly alien incitement to inquiry and discrimination" (Harpham, 1999).

Each of these meta-statements lays claim to either ethics or literature as the more multiplicative factor, the integer that boasts coefficient pride of place. A conjunction as ancient as any topic in the philosophical tradition evidently remains just as protean and generative for post-traditional thought-perhaps even more so.

Traditionally, ethical questions about literary practice have taken the form of, "is this book morally praiseworthy?"; or, "does this character model virtue and the good life?"; or, "does that story satisfactorily emplot life's moral complexity?"; or, "has my reading of this text enlarged or deepened me?" More recently, such problematics have been formulated as questions about otherness and witnessing, i.e., how are readers obliged for responsible to what they read (Attridge 2006)? What, in turn, do such texts owe their readers as imaginative vehicles for the representation and productive misrepresentation of reality? How, accordingly, do texts remain answerable to themselves, to their own formal, and deforming, dictates? How does the act of reading train or practice answerability? Which modality of reading, say, symptomatic vs. surface (Best and Marcus, 2009), am I being called upon to exercise and report on, and how do they differ, ethically speaking? Do I read alone or in company? How is the question of ethics also a question of politics: or are these different questions? How might such concerns be adapted for other kinds or orders of textuality, say, the scriptural and religious, or for photography and cinema, which utilize an alternative "grammar or ethics of seeing" (Sontag, 1977)? Loss, accord, appeal, wound, insomnia, touch: what does literary reading make happen? How exactly does a text "advene" (Barthes, 1980)? What does it mean to read "like a professor"- - or for that matter, like an insurgent, like a native, like Proust, like Thoreau, Baldwin, like (Zadie) Smith, like another?

What changes ethically if literature names an "act" (Derrida, 1992) as opposed to a "thing done" (James, 1904), an event or eventuation alongside a deed? What, indeed, are the ethics of literature, 
and further, of reading, of genre, of performance, of translation, of fiction, of critique, of practice? With the late Philip Roth, are we satisfied that literature's "high calling" is a function of an "ethical dimension that had to do with being true to the words, with being true to the imagined thing" (2008), the moral perfectionism, as it were, of sentences? What other dimensions lie alongside or even vie with rhetorical/imaginative fidelity, of truth-telling? Similarly, do acts of reading and criticism do more or otherwise than tell truth? If criticism, for example, "exists as a public's mode of comportment... detach[ing] art from its irresponsibility by envisaging its technique" (Levinas, 1968), where does annotation end and adjudication begin? What is "the ethical turn" in literary questioning turning from or towards or around or against, as overseen by modulations in the last thirty years or so of humanities research? Under this special issue's governing rubric, propositions and citations like those above map provisional coordinates for its conceptual focus.

Adam Zachary Newton Special Issue Editor 


\title{
Editorial \\ Introduction: Alienated Majesty: On Reading as Othering
}

\author{
Adam Zachary Newton \\ Professor Emeritus, Yeshiva University, New York, NY 10033, USA; aznewto@emory.edu
}

Received: 21 January 2020; Accepted: 21 January 2020; Published: 6 February 2020

Diese Gewähr eines moralischen Gewinns liegt in einer geistigen Disziplin, die gegenüber dem einzigen, was ungestraft verletzt werden kann, der Sprache, das höchste Maß einer Verantwortung festsetzt und wie keine andere geeignet ist, den Respekt vor jeglichem andern Lebensgut zu lehren.

This guarantee of a moral gain lies in a spiritual discipline that ensures the highest degree of responsibility toward the sole thing that can be violated with impunity-language-and that is better suited than anything else to teach respect for all the other values in life.

Karl Kraus, “Die Sprache" ${ }^{1}$

What hope is there in a book about a book?

Stanley Cavell ${ }^{2}$

The second of the two epigraphs above contemplates the shadow-fate of reinscription: namely, that to read is to repeat another's words, to make them one's own or simply channel them, letting them be. ${ }^{3}$ As the late philosopher Stanley Cavell explains, this is "a question of criticism," which examines the "prompting" of one text by another, disciplinary practice (in his case, philosophy, in ours, literary interpretation) thus taking shape as the "history of such promptings." ${ }^{4}$ Attending to such a prompt—being called upon or called out by the words of another-is the particular concern of these introductory remarks to our essay-compilation.

Insisting that a cultivated attentiveness to language models moral decision, Krauss's loftier rhetoric would seem to more forcefully articulate the spirit of the ongoing humanistic inquiry commonly known as "the ethics of reading." ${ }^{\prime 5}$ While the freighted cartography shared by readers and texts continues to be mapped across a range of disciplines, arguably the scholar most closely associated with this academic practice in direct relation to the American public sphere, ${ }^{6}$ comparatist Peter Brooks, defines his task (in comparatively less orotund, Krausian tones) this way:

Many have assumed that I propound the notion that reading great books makes you a moral person (I don't); or, in a more nuanced variant, that I use great books as a vehicle for teaching the ethical life. But I am not a philosopher, and I don't deal in virtue or even morality in any direct way. What I mean by "the ethics of reading" is simpler, more basic, perhaps more

\footnotetext{
(Kraus 1932).

(Cavell 1977).

(Norris 2014).

A related account of this model is outlined by (Day 2011).

In the 1980s, the phrase itself was most prominently associated with by J. Hillis Miller's deconstructionist (Miller 1986). Since then, it has been diversely interpreted, e.g., (Dagenais 1994; Rorty 1997; Attridge 2005; Gallup 2000; Deming 2008; Freed 2017; Moya 2015). Relevant bibliographies include (Antor 2012; Jiang 2015).

6 In a June 2019 Google search of the phrase "ethics of reading," four of the first seven results return Brooks's work.
} 
radical. I believe that careful, detailed, close analytic reading of texts of all sorts, rightly understood and practiced, can itself be an ethical activity. ${ }^{7}$

To demonstrate, Brooks turned to the "Torture Memos" released by the U.S. Department of Justice's Office of Legal Counsel on 1 August $2002,{ }^{8}$ a document plainly non-literary in intent, style and form, but more relevantly for Brooks, a stunning display of interpretive bad-faith. ${ }^{9}$

The "torture memos" suggest the pernicious effect of unscrupulous reading, whatever its origin. Can we affirm - as I hope we can — that our practice and pedagogy of reading leads our students to a reflective engagement with those "reasons assignable": with the tough and supple work of language in representing the world and clarifying its moral dilemmas? ${ }^{10}$

Fusing moral corrective and performative practice, Brooks called upon the special training in fine-grained textual analysis known as "close reading," 11 which, while it may certainly resemble the lineaments of a "spiritual discipline" (Kraus) ${ }^{12}$ is, optimally speaking, "rightly understood and practiced" (Brooks) by those academicians qualified in the rigors of literary studies-more specifically, the explication of its various speech genres. Where Kraus speaks of "the highest degree of responsibility," Brooks proposes that "[ $t$ ]he kind of reading I have described may lie at the very heart of professional responsibility. It makes us more skeptical and self-aware. It might prevent us from falling into the moral abyss of the Torture Memos." Less abstractly framed, this, presumably, is what is meant by "the sole thing that can be violated with impunity."

Still, the thesis is debatable. Brooks's documented fascination with the poetics of detective fiction notwithstanding, ${ }^{13}$ readers act as investigators (even for putative crime scenes) only up to a point; likewise, reading holds out abyssal possibilities in the very midst of the drive to explication. ${ }^{14}$ Alongside a host of books, articles, and review essays that have sought some rapprochement between the discourses of literature and philosophy for the past four decades or so, Brooks's own model has been directly engaged by philosophers (Charles Larmore, Judith Butler, Kwame Anthony Appiah), literary scholars (Jonathan Culler, Derek Attridge), and other disciplinary peers (Patricia Williams, Jonathan Lear) in a symposium that grew out of a graduate seminar he supervises, "The Ethics of Reading and the Cultures of Professionalism," published as the essay-volume The Humanities and Public Life.

Even apart from the question of presumptive definition, the area of inquiry itself exceeds the boundaries of a single methodological approach, with theory and method alike tied to variable criteria such as genre, literary tradition, and not least, the text(s) at issue. This author's own recent work, for example (growing out of an earlier focus on narrative ethics) ventures a rather different exploration

7 (Brooks 2017). Brooks first expatiated on the topic a decade ago in (Brooks 2008a, 2008b). He presented some of the same ideas as recently as 2018 in the lecture-presentation "The Chameleon Poet and the Ethics of Reading." The most sustained critique of Brooks's argument in the context of ethical criticism belongs to (Mcdonald 2010).

8 https://nsarchive2.gwu.edu//NSAEBB/NSAEBB127/02.08.01.pdf. Compare the more recent strained efforts to gloss the transcript of a July 25, 2019 phone call between the Presidents of the US and Ukraine.

9 (Brooks 2005)

10 https://www.chronicle.com/article/The-Ethics-of-Reading/20323.

11 Brooks himself prefers the qualifier "slow" to "close." Among a number of recent pieces on the subject, see (Love 2010; Dubois 2007; Lentricchia and Dubois 2003; Colás 2007).

12 On Krauss's "ethics of language," see (Perloff 2014), the essay by (Heller 1984), and (Stern 1966). If the Austrian satirist seems a surprising spokesperson here, I follow the precedent that specifically invokes him in connection with that enterprise, as the Krauss epigraph above appears at the end of Charles Larmore's "The Ethics of Reading" in (Brooks and Jewett 2014). The entire volume is reviewed in (Di Lio 2016).

13 (Brooks 1984).

14 A rejoinder to Brooks's argument by Peter Kerry Powers concludes, "While the ability to read closely and industriously and with technical proficiency may further the ends of people seeking to do good, it seems just as plausible that the ability to do so can serve the ends of those who seek to do ill. We accept that great artists may not be great people, and that their art may even serve both good and bad ends at the same time. Why should we believe differently about great readers?" (Powers 2008). 
of its terrain that conforms more to certain features of surface, than of close, reading. ${ }^{15}$ Centered around the event of tactility or embodiment, an ethics of reading from this vantage takes shape as "the-book-in-hand," denoting the embodied plane on which critic-reader and text (sacred or secular) come into palpable contact, where touch ramifies in manifold senses. For Brooks, though, "ethical activity" correlates primarily with disciplinary method. ${ }^{16}$

One contribution to The Humanities and Public Life that cuts athwart the forensic lineaments of close reading, however, is "The Call of Another's Words," by philosopher-psychoanalyst Jonathan Lear. ${ }^{17}$ "[I]n the tradition of the humanities," as he notes, Lear relates an exemplary story (narrative ethics transacted according to disciplinary custom), whose topical burden unpacks a twinned motif of vulnerability and contact: the singular circumstance, the affective exigency, of "being struck by the words of another" (110). He tells a story about a story: the postscript to a valedictory narrative by Plenty Coups, the last great chief of the Crow Nation (1848-1932), as recorded by his interlocutor Frank B. Linderman in his 1930 biography.

As the coda to a larger performative act of storytelling, Lear's anecdote expounds his essay's central argument, which centers on an ethic of "aesthetic receptivity" and the enactive reading practices it legitimates. Through a kind of transformative mimesis, Lear writes, "We need the poetic words of another to wake us up" (114), to draw us "out of ourselves and towards our own humanity and the humanity of others" (115). This is the lesson in affective exigency and narrative ethics he draws from his protagonist, who models for him something both deeply personalized and also culturally redemptive. Among other things, ethics, here, means the conjuring forth of "some kind of response" (110), in this case, the very book that Lear composes, which narrates a secondary witnessing to a prior act of witness - lodging a kind of hope, one could say, in a book about a book.

By way of introducing this special issue of essays on ethics and literary practice, I want to proceed in a somewhat similar fashion. My limited focus will be (literary) reading as ethical practice. If the philosophically superintended discourse of ethics can lay justifiable claim to "its singular capacity to adhere to, affiliate with, bury itself in, provoke, or dislodge other discourses,"18 then its actual work will always prove primarily discursive, whatever epistemological or deontological reasoning is brought to bear. Any potential hinge to literary practice, specifically, the task of criticism, would seem to express itself just there, as the very engine of altered reading-of reading as alteration.

What does such doubled character-the ethical-literary or literary-ethical—look like concretely? And how might one take up Cavell's pointed challenge for the critical project, which takes place as a staging of exemplarity within a series or history of intertextual promptings, reading underwritten by re-inscription? How might we embody Kraus's language-ethics? For an illustration, consider a rather different sort of anecdote than the one related by Lear: a richly prosaic lesson in reflexivity from a 1998 essay by the Israeli novelist David Grossman, in which ethical 'X-factor' ${ }^{\prime 19}$ meets mimetic X-ray through the random call of another's words:

One morning I got on a bus and sat down next to a fleshy older man with a red face. He gave me a doubtful look as if he were considering whether I was reliable enough to hear what he had to say. Then he said, with a quiet sigh, "nobody knows what the other guy keeps

15 (Newton 2015). "Surface reading" is outlined by Stephen Best and Sharon Marcus in their introduction to (Best and Marcus 2009). Compare also critic James Woods's characterization of criticism as sedulous redescription: "In [Virginia Woolf's] criticism, the language of metaphor becomes a way of speaking to fiction in its own accent, the only way of respecting fiction's indescribability .... To describe literature critically is to describe it again, but as it were for the first time" (108-9). (Wood 2010).

16 For instance, (Cox 2015).

17 In the book Lear published a few years earlier on how a culture staves off and recovers from its own exhausted history, (Lear 2008), Lear renders this extremity as a temporal "breakdown in happenings" (6), to which an audience of virtual interlocutors is thus made witness.

18 (Harpham 1999).

19 (Harpham 1999). "Ethics, I argue throughout, realizes its full creative potentiality not in 'itself,' but as a kind of X-factor, a bracingly alien incitement to inquiry and discrimination (xiii)." 
inside." Before I had a chance to ask what he meant, he lifted up a brown envelope, drew out an X-ray, and held it up to the light. "That's me," he said with unrestrained pride. I took a careful look, but wasn't able to identify the picture with the person. "Those are my kidneys," he explained. "They're always making sand and stones." He lifted the picture higher so that other people could enjoy it, and explained his entire inner world to an interested crowd that had gathered around him. For a moment I was able to view the colorful crowds of Jaffa Street, Jerusalem's main street, through this man's inner organs. I saw high-school kids with earrings, a squad of soldiers gathered around two blond tourists, Hasidim in black coats, a procession of Japanese philo-Israeli cultists in clad in lemony yellow, two policemen frisking an Arab, a group of three-year old kids from a nearby heder running and shouting in the throng. That noisy swarm was visible through a single pair of kidneys! ${ }^{20}$

In the language of rabbinic midrash, the nimshal (referent) that corresponds to this story's mashal (exemplum), i.e., the essential point it is designed to illustrate, ${ }^{21}$ would be grounded in a particular Israeli penchant, says its author, for being "intimate with total strangers" (socially liberating at best, but also very possibly intrusive-chutzpah as cultural virtue.) In other words, it belongs to the rhetoric of exemplarity. ${ }^{22}$ To that extent, the anecdote does culturally representative work, whose rhetorical task literary critic Frank Lentricchia spells out this way: "stand[ing] in for a bigger story, a socially pivotal and cultural pervasive biography which it illuminates - in an anecdotal flash it reveals the essence of the larger unspoken story, and in that very moment becomes exegesis of a public text" (136). ${ }^{23}$

According to this view, Grossman's fable fulfills the anecdotalist's directive for "a social form which instigates cultural memory: the act of narrative renewal, the reinstatement of social cohesion" (137). And insofar as Grossman relates this story in the context of larger and more troubled reflections on Israel's fiftieth anniversary in 1998, it serves convincingly as cultural metonym. "Anecdotes," we're told again, "would appear by their very nature to depend on a stable outside narrative, given and known, but in fact-most dramatically in their written, high literary style, they work at critical turning points of cultural crisis" (137).

Could we call that operation, the work of cultural politics, "ethical?" Certainly, a case could be made, which, much like Brooks' critical method in concert with the particular prooftext he selects, highlights an almost inevitable reciprocity between the ethical and political as adjacent, often interpenetrating critical categories. Thus, in his own virtuosic demonstration of critical practice, ${ }^{24}$ Lentricchia scrutinizes Wallace Stevens' recondite lyric, "Anecdote of a Jar," detailing its relentless re-entanglement with politics, aesthetic ideology, national and social history. In the hands of a close reader by profession, anecdotes can assuredly mean that much.

As to Grossman's anecdotal exercise in descriptive panorama, we might confine ourselves first to the more restrictive labor of how its staging unfolds according to its local rhetorical elements: an especially artful play with metonymy and metaphor, the literary radiography, so to speak, of poetry and literary fiction. What are this text's particulars? How should a close reading attend to its narrative and figural surfaces as well as its perfectly apposite thematic burden: topographical surface in relation to (putatively occluded) depth?

In an ethically counter-reading spirit, we might begin by reading the text against itself. It commences with the casually inserted but crucial detail that the narrator, like many of his compatriots, rides the bus, the quintessentially demotic mode of transport, where chance rendezvous with otherness

\footnotetext{
(Grossman 1998).

(Stern 1981).

The title of the edited volume by (Gelley 1995), whose own "The Pragmatics of Exemplary Narrative" (142-61) is particularly edifying.

23 "How to do Things with Wallace Stevens" in (Lentricchia and Dubois 2003).

24 Itself critiqued by (Vander Zee 2007).
} 
prevail as a matter of course. ${ }^{25}$ Tucked into and to be glimpsed among the climactic ensemble of disparate figures at the end-adjacent to tourists on one side and schoolboys on the other-are "two policemen frisking an Arab," a casual detail that signals a rather different social calculus entirely. Indeed, one could plausibly venture that it spoils the otherwise vivid pageant of passers-by enabled by a culturally representative bus ride and the casual radiolucent interposition of the human interior.

Is it intended to signify just another everyday occurrence on Jaffa Street? The detail startles, but only if we pause the list and consider it for a moment by itself: one more instance of color and swarm, and yet categorically different from all the others. Among other things, the Arab counts as the only element in an inventory of plural instances to be literally singled out, even relative to the two policemen who frisk him. From high-school kids to three-year old kids, a squad of soldiers to two policeman, blond tourists to Hasidim to Japanese, "the Arab" remains entirely singular-even if, syntactically speaking, the catalogue functions as an "open series," with each element grammatically identical to all the others. The X-ray itself is at once shadow and image, medium and picture, objectively neutral yet still enframing.

Yet, what does it mean to descry ever so briefly through it the enforcement of state power, as witnessed under the general auspices of the Ministry of Transportation? Does the act of frisking reward the tribute to Israelis" characteristic "intimacy with total strangers?" Or, by casually introducing a very specific category of stranger-in-our-midst, does it not also ever so slightly compromise that affirmation? Does it mean to, in fact-given an author justly famous for his principled stance on the Israeli left, a pained and conscientious observer of an occupation and its moral cost, whose fiction does not casually record such details. ${ }^{26}$

On all such questions, the anecdote at hand would seem to keep its own counsel; its implied exemplarity tracks accordingly. Like Jonathan Lear on his initial reaction to reading about Plenty Coups' decision to cut short his narrative from Linderman's afterword, that only much later began to haunt him as a figure for foreclosed history, I myself must confess to having missed the anomalous character of the detail upon initial readings-a cautionary lesson in any reader's accountability. ${ }^{27}$ It was only subsequently that the detail came alive for me, upon discovering "An Arab at Ben Gurion Airport" (2015) by Palestinian poet and civil engineer Marwan Makhoul:

I'm an Arab!

I shouted, at the doorway to departures, short-cutting the woman soldier's path to me. I went up to her and said: Interrogate me! But quickly, if you don't mind. I don't want to miss departure time.

$\ldots$

The security guard hands me over to the police officer

who frisked me all of a sudden and called out:

What's that?

My national organ, I say.

and my progeny, the fold of my family and two dove's eggs

to hatch, male and female, from me and for me."2828(Makhoul 2007).

25 In this light, Grossman's prose-poem recalls the famous lyric by Israel's national poet Amichai (2003), "Mishlosha o arbaa baheder [Of Three Or Four In A Room], whose opening stanza reads, "Of three or four in the room/[There is] always one [who is] standing at the window./He must see the injustice amongst the thorns/And the fires (burning) on the hills./And how men who departed whole/Are brought back to their homes in the evening, like small change." (Amichai 2003).

26 For example, the profile in (Packer 2010) The New Yorker (27 September 2010) and the interview in (Cooper 2016).

27 The name means "many achievements." Lear's anecdote represents, so to speak, the photonegative to Grossman's insofar as its subject had to be reluctantly drawn out: "It is only when repeatedly pressed that Plenty Coups uttered these haunting words. As a psychoanalyst I am fascinated by speech that does not want to be spoken" (110). 
Yet, surely, to pose such questions, to disturb this story's aesthetic surface, to dialogize it, to make the straightforwardly grammatical agrammatic, is part of what its "ethical X-factor" must signify? As has been argued for the narrative act of self-accounting, transparency and opacity, openness and hiddenness, ethical success and failure will always nest inside each other in such instances of crosshatched revelation, which a related and especially apt formulation I admire renders as "the creative act of letting the other appear." 29

If we turn now to the specifics of narrative chronology, the fellow passenger's unprompted remark, "Nobody knows what the other guy keeps inside" serves as the motivating platitude that becomes, at first, literalized into object (kidney stones), and subsequently transposed into perceptual metaphor (X-ray). That sequence itself, the story's figural armature, narrates a signifying chain from banal to veridical to poetic truth. In parallel, the series of speech and gestural acts proceeds from dialogue to group exposition to personal epiphany. Synecdochally, person transposes into viscera while the vernacular metonymy itself ("sand and stones") displaces from interior (kidney) to exterior (limestone-faced Jaffa Street ${ }^{30}$ ) — the whole complex of inside/outside figuration prefigured by the drawing out of the radiograph from within its plain brown envelope, and perhaps even inversely, boarding the bus from without in the first place. (On the most literal level, we should also remember that, unlike the comic book version, X-ray vision through radiographic shadows would permit a much-occluded view at best.)

As Stevens' "Anecdote of a Jar" allegorizes the very condition of literary form—“its resistance to formalist closure, [that] there is always something outside the text" (Lentricchia, 139)—so Grossman's anecdote teaches a prose lesson about the poetics of intimacy and publicity, and the stubborn fact that exteriority will have its due. Metonymy nests inside metaphor, the hidden becomes exposed, and transcendent, or at least transformative, vision becomes a matter of ethical accident or grace-not, significantly, without blemish. As readers glimpse the same colorful crowd and noisy swarm made visible through a single pair of kidneys—including that possibly truant detail—so the anecdote lends itself to an allegory of generous surface reading, repaying analytical scrutiny with a very particular kind of semiotic remainder. ${ }^{31}$ Significantly, all of this happens in plain textual sight.

That ethical shadow also signifies as political surplus merely underscores that the story is free to perform the full extent of its figural work. ${ }^{32}$ Its final exclamation point may add a self-celebrating touch. It does not, however, entirely absolve the cataloguing eye, with which, structurally, our own perspective must coincide. Shadows on the ethical belong as much to it as those it casts, which merely affirms the adhesive, affiliative, discourse-dislodging latency of its X-factor. The "careful look" Grossman's anecdote endorses-even if it does happen to chime adventitiously with the essential component of close reading-may well not guarantee an expected symmetry between person and identifying picture-image. But open-ended viewing, especially when refracted through a creatively choreographed literary device, is never entirely innocent anyway, since it can never wholly predict what will come into view. ${ }^{33}$

To complicate both Brooks and Grossman, then, a less "applied" or instrumentalist ethics of reading will also entail our exposure as readers, or as Stanley Cavell captured this dimension psychoanalytically, "that it is not, first of all the text that is subject to interpretation, but we in the gaze and hearing of the text." 34 Whatever else such reorientation suggests, it positions us not primarily as sovereign reading

29 (François 2008). On narrative ethics in the first-person: (Butler 2005; Cavarero 2006).

30 Described in the section "Holy Stone" from (Mendel 2013).

31 As novelist China Miéville puts it, "Fiction is always more interesting when there's an evasive surplus and/or a specificity ... Allegories are always more interesting when they overspill their own levees." (Miéville 2010).

32 According to Best and Marcus, as "attentiveness to the artwork itself is a kind of freedom" so "reading becomes what [New Formalist critic Marjorie] Levinson calls 'learned submission' ... because in submitting to the artwork, we come to share its freedom" (14). A critique of this position is ventured by (Kaul 2013).

33 (Newton 1995).

34 "The Politics of Interpretation," (Cavell 1984). "[Turning the picture of interpreting the text into one of being interpreted by it" and the twin possibility that such a model of reading is "therapeutic or redemptive" is a significantly different argument 
subjects who project their understanding, but rather as being disclosed in front of the text, with our reading majesty gainfully alienated, ethically altered..$^{35}$

This insight intersects with the more obviously political point about the lyric poem that calls itself an anecdote: it cannot seal off the exterior world. Extrapolated purely as method, an ethics of reading stands in need of some modification, for it conduces not merely to something we employ or construct, but also to an event that happens to us, an alteration we undergo. Reading troubles mastery even while providing an instrumental platform for it, just as ethics does not solve problems (says Harpham), it structures them. If Grossman's story allegorizes enlarged, or altered, vision, it also captures a peculiar pathos that underpins human sympathy in life and through reading. ${ }^{36}$

We constantly present to one another the image of a dissonance between what in the end we cannot avoid being-embodied, contextual, and turning toward the uncontextual-and what through chance, ambition, and failure we occasionally and apparently become. This incongruity between what we seem to be and to want, on the one hand, and what happens to us and what we make of ourselves, on the other, recounts the master tale of humanity. It summarizes all our other misadventures and accomplishments. ${ }^{37}$

"What happens to us and what we make of ourselves"-or more saliently here, of ourselves while reading-limns a horizon for the pathos of the ethical itself. It opens onto a critical terrain where reading practice becomes its own emergent Other, its X-factor subject to auto-generated X-ray: reading, in short, as othering. Beyond the efficacy of method, what ethical criticism ideally discloses is reading's Uncanny, ${ }^{38}$ the incongruity or stubborn remainder aslant fulness of knowledge and exercise of mastery. While literary reading may well aspire to the adventurous (a word, incidentally, that Levinas connects directly with the ethical ${ }^{39}$ ) and even disobedient, ${ }^{40}$ it can also open a space for precarity and the unforeseen-for example, the call of another's words.

Our anecdote discloses such an (ethical) shadow at the outset: "He gave me a doubtful look as if he were considering whether I was reliable enough to hear what he had to say." Whether or not what "he had to say" offers the most useful guarantee of moral gain, and notwithstanding the redemptive bewilderment ${ }^{41}$ it promises-“That noisy swarm was visible through a single pair of kidneys!"- the claims of scrutiny remain intact. As an ethics of practice, then, such sensibility, resourcefully cultivated, attests to the intuition that we participate in, are made answerable to, a circuit of transferential promptings generated by and through the act of reading. Like so many shadowgraphs, opaque

from the aesthetic propounded by Elaine Scarry's "Poetry, Injury, and the Ethics of Reading" in (Brooks and Jewett 2014) and also (Scarry 2012).

35 (Ricoeur 1998; Robbins 1999). See also the important discussion of narrative ethics in relation to "the possible" by (Meretoja 2018).

36 An intricate tutorial in narrative ethics (and Jewish humor), Grossman's 2014 novel A Horse Walks Into A Bar satirically restages this same principle, i.e.,-—"How, in such a short time, did he manage to turn the audience, even me to some extent, into household members of his soul? And into its hostages" (57) (Grossman 2017)? Its plot features a stand-up comedian, grotesquely self-exposed, holding forth before a diversely assembled crowd, painstakingly witnessed by a spectator-narrator in the throes of his own self-accounting.

37 (Unger 1984). Philosopher, social and legal theorist Roberto Mangabeira Unger's non-literary take on sympathy distinguishes it from a conventional argument for empathy in reading, as critically appraised by Namwali Serpel in (Serpel 2019).

38 (Hoffman 2001). "In reading, understood as an archaeology of the text, one digs into terrain that is not manifestly one's own and yet in which one has a personal stake. Why read, then? In order to not know, I want to say, in order to preserve the trace of experience, unknown, within oneself. The shock of recognition one experiences in reading does not require full acknowledgment; its incompleteness is guaranteed by the very otherness of the text." (75-76).

39 "Substitution," in (Levinas 1996, 1981).

40 (Blackler 2007). Readers disobey their own fixedness in pursuit of the adventure, the vagrancy or "vagabondage" of reading (xiv). In demurral of that central thesis, however, one of this book's reviewer remarks that its "positing of 'the Sebaldian reader' seems to be far less a celebration of disobedience than of an ideal reading practice carried out by highly literate and astute readers who have at long last found an object suitable to their intellectual capabilities." See also the review by (Schmidt 2008).

41 Compare Geoffrey Hartman's claim in (Hartman 1980). Given “the seductive boast of every book, [that] we are tempted to enter an unknown or forbidden realm" (20), the ideal critical posture locates us as "charmed and bewildered readers, who feel that hermeneutic hesitation is the essential quality of philosophic art" (38). 
windows onto altered selves, acts of literature ambiguously hold us as much as we-belated and decentered readers that we are-hold them.

Beyond these local questions for an ethics of reading, this special issue of Humanities in "Ethics and Literary Practice" was designed to invite an array of interventions, approaches, and foci, and the contributions summarized below realize that purpose to edifying effect, with attention to philosophy, politics, postcolonialist and feminist theory, genre, religious discourse, and literary practice, as multiple instances of analytic (or performative) convergence: more succinctly put, ethics and its Others.

Two cull from the formative synthesis of philosophical and literary thinking practiced for six decades by the late Stanley Cavell: Richard Deming's "Senses of Echo Lake: Michael Palmer, Stanley Cavell, and the Moods of an American Philosophical Tradition" and Mette Blok's "Endlessly Responsible: Ethics as First Philosophy in Stanley Cavell's Invocation of Literature." Where the one puts the philosopher in direct conversation with a contemporary poet, the other sketches a dialogue between Cavell and continental philosopher Emmanuel Levinas.

In seeking to "bring the weight of philosophy and its concerns to bear in the practice of reading poetry," Deming reads Cavell's long-evolving consideration of Emerson and Thoreau as the progenitors of a distinctly American philosophical tradition by way of his former student, poet Michael Palmer. As Cavell's Emerson proposes nor just a new form of philosophy but also "a reform of the possibilities of philosophy, of how we might imagine philosophy might act and sound," so for Deming, Palmer's Notes for Echo Lake "locates itself, its language, and the way we might be called to read it in a series of echoes and locations." And as Cavell had already modeled for Thoreau, as well-Deming underscores the proximity in time and space of Notes for Echo Lake and the expanded edition of Senses of Walden, both having been published in the same year (1981) and through the same press (North Point)—so in Palmer's poems, "the acknowledgement of one's own subjectivity becomes the means by which others-by comparison, through contrast—can come to recognize their own," the point of convergence and even overlap between the sometimes co-implicated practices of philosophy and poetry.

Mette Blok's essay was composed in the aftermath of Cavell's passing in 2018. Starting from the premise that "that the theme 'ethics and literature' in Cavell requires an investigation of the concepts skepticism, romanticism, and moral perfectionism and their internal relations," Blok argues that "they gr[o]w out of each other, not only chronologically but also logically, and that romanticism is what binds skepticism and moral perfectionism together: Romanticist texts are both the expression of and the potential recovery from skepticism, thus making possible the achievement of moral perfectionism." All three concepts comprise a singular ethical standpoint (or theory), constellated through Cavell's wholly individualized voice, which takes shape through the specifically literary particulars that he gleans.

Not by accident, those texts Cavell assembles as instances of perfectionist sensibility, for example, Kleist's The Marquise of $O$ and Ibsen's A Doll's House, in league with his idiosyncratic readings of Emerson and Thoreau, exemplify, for Blok, the work of Bildung: "they are all in one way or another edifying; there is some story of education, cultivation or transformation of the protagonist or of his or her society for the better." The essay's concluding section, "Levinas or Emerson?" places Cavell midway between two contrastive versions of philosophical practice and the ethical-literary/literary-ethical, with each intellectual figure being brought to bear on the essay's valedictory insight, that "skepticism or tragedy is only half of our lives, and not the most important one ... [;] the other half is romance."

Three contributions-Josephine Donovan's "Ethical Mimesis and Emergence Aesthetics," "Interlocutors, Nonhuman Actors, and the Ethics of Literary Signification" by Donald Wehrs, and Thomas Claviez's "Neorealism, Contingency, and the Linguistic Turn" - track the convergence of ethics and literary practice with reference to large-scale theoretical paradigms. From the physical sciences, Donovan retools emergence theory towards an emergence aesthetics, "the idea that something qualitatively new sometimes spontaneously emerges when a constellation of isolated heterogeneous materials combines into a new whole or system." In the service of what he calls an "ethics of contingency," Claviez takes a poststructuralist approach to both the metaphor/metonym bifold (Roman Jakobson's 
1953 essay "Two Aspects of Language and Two Types of Aphasic Disturbances" as complicated by Paul de Man's "Semiology and Rhetoric" from 1973), and contemporary philosophies of recognition. Wehrs makes a case for a theory of literary autonomy whereby texts act as quasi-interlocutors in a Levinasian sense.

Taking her cue from emergence theory as formulated in the sciences, Donovan begins with the claim, previously elaborated in her 2016 book, The Aesthetics of Care, that the nexus of mimetic art, its production, and its reception, embodies a "transfigurative resurrectory process." Appealing to a range of theoretical perspectives including Theodor Adorno's concept of "mimetic comportment," Hubert Zapf's literary ecology, and Laurence Buell's eco-aesthetics, Donovan provisionally models the application of emergence aesthetic theory with reference to Richard Powers's 2018 novel, The Overstory.

Donald Wehrs's paper proposes a model for how "ethics and literary practices may intersect in ways that allow one to attribute an autonomous signifying agency to literary discourse without lapsing into decontextualized aestheticism or neoliberal conceptions of subjectivity." Marshalling figures such as Levinas, Derek Attridge, Rita Felski, and Bruno Latour, Wehrs addresses the nonhuman and ambassadorial agency of literary practices, and more particularly for an ethics of reading, "literary signification's irruptive reformative potency." The literary examples project a deliberate sweep: in the spirit of Erich Auerbach, two scenes of anagnorisis from antiquity, Telemachus' intimation of divinity (Odyssey 1: 319-24) and Judah's encounter with Tamar (Gen. 38); and from the discursive world of the modern novel, two moments from Jane Austen's Sense and Sensibility (1811) and Chimamanda Ngozi Adichie's Americanah (2013).

Claviez's article follows upon his earlier work on critical theory and literary history with the more immediate aim of pinpointing "the ethical stakes" in metonymy as a representational device. Beginning with the Aristotelian problematic of historical contingency rendered through the formal of machinery of narrative poetics, and elaborating a distinction between two categories of contingency, "epistemological" and "representational," the argument concentrates on a specific literary movement (neorealism) and topos (the intersubjective drama of recognition). "For centuries," Claviez argues, "we have been telling ourselves the story of human development as a story of the succession of allegedly ever more successful strategies to overcome contingency; usually along the lines of Myth, Monotheism, and syllogistic Reason." In reviewing what has come to be known as "the philosophy of recognition" (Jürgen Habermas, Axel Honneth and Nancy Fraser), Claviez looks to Jonathan Franzen's 2010 novel Freedom (cited by Honneth) and Dave Eggers's Circles (2013) as his literary examples, allowing the strong possibility that to "induce us to take a different stance towards contingency might be part and parcel of the project of Neorealism."

Two essays anchor themselves with regard to discourses of (post)colonialism, Hille Haker's "Towards a Decolonial Narrative Ethics" and Jay Rajiva's "The Answer is Paracritical: Caribbean Literature and The Limits of Critique." Haker enlists Kafka's short fiction "A Report to the Academy" and Uwe Timm's 1978 historical novel Morenga as a platform for tracing both the limits and the obligations of intercultural understanding overseen by structures of colonialism. In contriving her own rapprochement between history and literary practice, Haker cites Paul Ricœur's model of the "crossed reference" of empirical and narrative truth and his differential analysis of reciprocity and mutuality. The essay's core concern centers on the problematics of recognition, its misfires or incompletions as well as its exemplary conditions.

Apropos the reception of Rita Felski's The Limits of Critique (2015), conducted (much like the book itself), almost entirely within the ambit of an Anglo-American literary tradition, Rajiva wonders pointedly, "Why does the postcritical "turn," which urges scholars to abandon the detachment and suspicion of critique in favor of affect, sympathy, and enjoyment, seem to be unaware of the blindspots of its own literary-cultural lineage?" Towards an answer, he looks to an African-American and Afro-Caribbean corpus of texts that "predate and complicate the critical-postcritical binary." Triangulating Philosopher-poet Édouard Glissant's Poetics of Relation on the origins of Creole speech, writer-critic Nathaniel Mackey's collection of essays and interviews, Paracritical Hinge, 
and Trinidadian-Canadian author Dionne Brand's 2005 novel What We All Long For, Rajiva wishes us to interrogate not only the cultural implications of the reading "postures" we ordinarily assume but also the kinds of texts we take to be paradigmatic. From Mackey, he borrows and elaborates the concept of paracritical hinge, which extends Mackey's earlier investment in collaborative/discrepant encounters into further realms of expressive contingency: "paracriticism functions as a type of traffic, a vibrant mix marked by tenuousness and risk, the outpouring of improvisation as literary creativity," an interpretively contrapuntal move Rajiva also calls "reading for the blue notes."

Two contributions, Andreea Deciu Ritivoi's "Reading (with) Hannah Arendt: A Literary Ethics for a Politics of Belonging" and "The Fallacy of Analogy and the Risk of Moral Pretension: Israeli Literature and the Palestinian Other" by Adia Mendelson-Maoz, situate their analyses on a critical fault line. Mendelson-Maoz asks the politically- as much as ethically-inflected question, "Can Israeli literature find different venues to discuss the Palestinian catastrophe without drawing on analogies to catastrophes experienced by Jews?" Her essay contrasts two instances in modern Hebrew fiction where the logic of analogy appears to undermine or even neutralize narrative-ethical possibilities, S. Yizhar's short story "Hirbet Hiz'a" (1949), Amos Oz's autobiographical novel Sipur al ahava ve-hoshekh [A Tale of Love and Darkness] (2005), with two instances of a novelistic counter-tradition by the late Ronit Matalon foregrounding the experiences of Israel's Mizrahi population, Sarah, Sarah [Bliss] (2002) and Kol tse'adenu [The Sound of Our Steps] (2015).

For Ritivoi, the political subjectivity of the displaced person, doubly inscribed by immigration discourse and humanitarianism but also narrativized by statelessness and "bare life," transposes into literary space as the ethical object of compassion and pity. "To articulate an ethics of alterity from the perspective of the refugee," she writes, "is to be concerned with the ways in which difference gets erased rather than embraced." Toward that end, she appeals to Hannah Arendt, specifically the essay "We Refugees" (1943), the critique of Stefan Zweig's assimilationist allegiance to Bildung in The Crisis in Culture (1961), and writings collected in Reflections on Literature and Culture (2007). Moving to Arendt's reading of Melville's Billy Budd, Sailor in On Revolution (1963), Ritivoi asks, "what are the implications of an implicit or explicit ethics of literature for broader political visions and philosophical insights that claim to originate from literary configurations?" The essay concludes with a brief reading of the novella "Rock Crystal" by Austrian writer Adalbert Stifter (alongside Brecht, Broch, Kafka, and Zweig, a revered author for Arendt), which prompts this concluding gesture: "If the state claims the individual already at birth and identifies us as either citizens or alien, engaging with another's standpoint through aesthetic representations gives us a chance to begin anew, to 'read ... (stories and poems) as though nobody had ever read them before'."

Eugene O’Brien's "'A Pause for Po-Ethics': Seamus Heaney and the Ethics of Aesthetics elaborates on the late Irish poet's own neologism, which, in establishing a discursive conjunction for the discourses of poetry-as a form of epistemology-and moral agency "allows for a slanted perspective, a swerve, which will look at the ethical demands on life from just such a different perspective." Following Levinas and Derrida, O'Brien traces the ethical component of Heaney's poetics as "a form of redress against the instrumentality of the contemporary world." Drawing from classical texts by Shakespeare, Dante, and Homer as well as modern authors like Bishop, Hopkins, Miłosz, Levi, and Camus, the essay's particular virtue lies with its careful attention to the Heaney's concept of "po-ethics," distributed among a number of his own essays but which has not figured prominently in the critical literature to date.

Michelle Boulous Walker's and Cynthia Wallace's papers explore parallel feminist approaches to a literary ethics of attention: the former, building on psychoanalytic theorist Teresa Brennan's The Transmission of Affect, and the latter, with specific regard to Simone Weil and the religious question. In "Porosity: Ethics and Literature Between Teresa Brennan and Hélène Cixous," Walker looks at energetic transfer across intersubjective boundaries, affective pathways rooted in "the intelligence of the flesh," dramatizing the way "the body is implicated in its own thinking." Following Brennan, Walker connects such embodied transmission, the "paradoxical detaching and embracing of affect," to 
the work of philosophy, whose practice, she argues, "reunites us with what we might call attentive discernment," pointing the way in turn to "the need for personal and political transformation." In her conclusion, Walker invokes Cixous's concept of the entredeux, the interspace where ethical and literary energies meet and a discursive site of "play between destructive force and regenerative openness."

As its title indicates, Cynthia Wallace's "Attention, Representation, and Unsettlement in Katherena Vermette's The Break, or, Teaching and (Re)learning the Ethics of Reading" explores the specifically pedagogical dimension of an "ethics of literary attention." Interpretive practices that grow out of such an ethics, Wallace suggests, "can help us resist the blend of hyperattention and attention deficit that grows out of the current digital economy." Beginning with an initial analysis of Vermette's novel and pivoting to a discussion about the current state of literary-ethical theory, Wallace writes, "while I have been arguing that The Break has a great deal to teach scholars about the New Ethical Criticism, the New Ethical Criticism may not have quite so much to teach us about The Break," a claim that implicitly hearkens back to Brooks, Lear, and the question of method, and also invokes the figure of Emmanuel Levinas. As to the specific literary text on which her essay focuses, Wallace entertains the crucial proposition that "which texts we bring into our theorizing of literary ethics makes all the difference in the world." Thus, Vermette is a Métis writer from Treaty One territory in Canada; and The Break begins, provocatively, with a rape. Relying on justifications both pedagogical and theoretical, an ethics of attention, of literary witnessing, in Wallace's view, "means returning to the humbling space of non-mastery" - with obvious relevance for the thesis already propounded here.

In "To Read Matthew's Gospel After Auschwitz is Barbaric,"-an essay from the special issue not included in this e-book-Gary Phillips focuses on the conundrum of a world-historical religious text that also "excels as a script of violence that implicates not only antisemitic fanatics but even the Christian faithful." To that degree, Matthew's Gospel challenges not only general readers (and believers) but also biblical scholars "who face a heightened ethical accountability for the material effects of their readings and to take responsibility for the ongoing barbarism directed against the suffering innocent." Using Adorno's famous hyperbole as its point of departure, as refracted through both the Matthean narrative and paintings by Holocaust survivor Samuel Bak, Phillips reflects on the ethical contradictions of "the barbaric beauty of aesthetics and analysis under the sign of Auschwitz."

Finally, from Steven B. Katz, we include two pieces: an essay on ethics, language, and time, and a lyric sequence, "The Ghost of Objects: A Villanelle for the End of the Anthropocene" and "Time, Proust, Being, You," underscoring the link between ethics and literary practice. The two poems probe the question of human time in a framework drawn from Heidegger and Levinas, triangulating the dimensions of prosody, temporality, and ethics. Where the first-an experiment in the tightly structured Renaissance French verse form known as the villanelle—asks, "can objects survive physicality?" the second laments that "Time does not heal ... but kills itself, and dies in us, so oblivious, and Other." In tandem, the sequence "examines the nature of time in relation to the end of the human-the death of the species in the Anthropocene, and the death individual personally-and speculates on what might come in the rhetorical-after that we can never know except poetically."

"Sonic Rhetorics as Ethical Action: Hidden Temporalities of Sound in Language(s)" examines what Katz calls "hidden sonic dimensions of time and ethics in language," as briefly exemplified by poetic, classical Greek, and Biblical Hebrew texts. In parallel with certain, "unconcealed" temporal dimensions on display in prosody and etymology, the essay seeks to explore a "sonic rhetoric in which language is not only a manifestation of time but the cause and content of it, a rhetoric in which time is already a moral reality, and the material world a shadow of signifiers, signs."

In conclusion and along with the editorial staff of Humanities, I commend the diverse group of contributors who brought such multifarious perspectives to a topic that feels only more urgent as 
language, meaning, and expression experience their own public and civic drama of transparency and occlusion in a monitory age of "post-truth." 42

\section{Contributors}

Mette Blok lectures in the departments of Communication and Arts and Aesthetic Culture at Roskilde University. Her publications include "Literature as Ethics: Stanley Cavell, Robert Musil, and the Scope of Moral Perfectionism" (Res Cogitans, 2018) and "Robert Musil's Literary Ethics: The Man without Qualities Reconsidered" (New German Review, 2014).

Thomas Claviez is Professor for Literary Theory and Director of the Center for Cultural Studies (CCS) at the University of Berne. His publications comprise books and essays on Environmentalism, Aesthetics, American Philosophy, Native American and African American Literature, American Studies, Otherness and Ethics, and, most recently, Theories of Community. He is the author of Grenzfälle: Mythos-Ideologie-American Studies (Wissenschaftlicher Verlag Trier, 1998) and Aesthetics E Ethics: Moral Imagination from Aristotle to Levinas and from Uncle Tom's Cabin to House Made of Dawn (Universitätsverlag Winter, 2008) and the co-author, with Dietmar Wetzel, of Zur Aktualität von Jacques Rancière: Einleitung in sein Werk (Springer VS, 2016). He is also the editor of The Common Growl (Fordham, 2016) and The Conditions of Hospitality: Ethics, Politics, and Aesthetics on the Threshold of the Possible (Fordham, 2015).

Richard Deming teaches at Yale University, where he is Lecturer in English and Director of Creative Writing. He is a poet, art critic, and theorist, whose work explores the intersections of poetry, philosophy, and visual culture. His collection of poems, Let's Not Call It Consequence (Shearsman, 2008), received the 2009 Norma Farber Award from the Poetry Society of America. His most recent book of poems, Day for Night, appeared in 2016. He is also the author of Listening on All Sides: Toward an Emersonian Ethics of Reading (Stanford, 2008), and Art of the Ordinary: the Everyday Domain of Art, Film, Literature, and Philosophy (Cornell, 2018). Winner of the Berlin Prize, he was the Spring 2012 John P. Birkelund Fellow of the American Academy in Berlin.

Josephine Donovan is Professor Emerita of English in the Department of English at the University of Maine, Orono. Her research and expertise have covered feminist theory, feminist criticism, animal ethics, and both early modern and 19th-century American women's literature. She is the author of nine books of nonfiction and the editor of five. Her most recent books include The Aesthetics of Care: On the Literary Treatment of Animals (Bloomsbury, 2016) and The Feminist Care Tradition in Animal Ethics, co-edited with Carol J. Adams (Columbia, 2007). Feminist Theory: The Intellectual Traditions, first published in 1985, is now in its fourth edition (Continuum, 2012).

Hille Haker is the Richard McCormick, S. J., Chair of Moral Theology at Loyola University Chicago. She earned her doctorate (1997) and habilitation (2001) at the University of Tübingen, where her dissertation- "Moralische Identität: Literarische Lebensgeschichten als Medium ethischer Reflexion" ("Moral Identity: Literary Life Stories as a Medium of Ethical Reflection") —was awarded the dissertation prize in Catholic Theology in 1998. Her research interests include meta-ethics, normative ethics and hermeneutical/experiential ethics, social and political ethics, bioethics, feminist ethics, and aesthetics. She has edited the Values in Bioethics (Brill) series since 2017, and is the author, most recently, of Recognition and Responsibility: Critical Theory and Christian Ethics and Renewal of Catholic Social Ethics: Towards A Critical Political Ethics (Herder, 2019) and, with Molly Greening, co-edited Unaccompanied Migrant Children: Social, Legal and Ethical Perspectives (Lexington, 2019).

Steven B. Katz is Pearce Professor Emeritus of Professional Communication, and Professor Emeritus of English at Clemson University. His scholarly interests range from ethics in technical communication to the nexus of rhetoric, poetry, and science. His research foci include rhetorical analyses of ideologies of new technologies; conventions and ethics of styles in biotech and medical

42 I dedicate the introduction to my באליבט זון, Emmanuel Josiah, tender to my loco., heard clamoring for his die-cast toy race car while this special issue took shape, "I want my 'Altered Ego!";

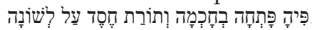


communication with the public; and the materialities and uses of language in different forms of writing, in religion, and in electronic media. His books include 9/11: Terministic Screens, Rhetoric, and Event, with Emily Ligon (Parlor Press, forthcoming), Nana! (poems) (Moses, Ink, 2005), and The Epistemic Music of Rhetoric: Toward the Temporal Dimension of Affect in Reader Response and Writing (Southern Illinois, 1996).

Adia Mendelson-Maoz is Associate Professor in Israeli literature and culture at the Open University of Israel. She investigates the multifaceted relationships between literature, ethics, politics, and culture, mainly in the context of Hebrew Literature and Israeli culture, specifically the literature of minority groups in Israel, questions of space and ethics in contemporary Israeli literature, and the work of novelist Yoram Kaniuk. Her books include Borders, Territories and Ethics-Hebrew Literature in Shadow of the Intifada (Purdue, 2018), Multiculturalism in Israel: Literary Perspectives (Purdue, 2014), and Literature as a Moral Laboratory: Reading Selected 20th Century Hebrew Prose (Bar Ilan, 2009. [Hebrew])

Eugene $\mathbf{O}^{\prime}$ Brien is Senior Lecturer and Head of the Department of English Language and Literature at Mary Immaculate College. He is also the editor for the Oxford University Press Online Bibliography project in literary theory. His research interests include the poetry of Seamus Heaney; Irish culture and writing; literary and cultural theory. His recent publications include Seamus Heaney as Aesthetic Thinker: A Study of the Prose (Syracuse, 2016), The Soul Exceeds its Circumstances: The Later Poetry of Seamus Heaney (Notre Dame, 2016), Representations of Loss in Irish Literature, with Deirdre Flynn) (Palgrave Macmillan, 2018), and Tracing the Cultural Legacy of Irish Catholicism: From Galway to Cloyne, and Beyond, with Eamon Maher (Manchester, 2018).

Jay Rajiva is Assistant Professor at Georgia State University. His research interests include Global Anglophone and Postcolonial Literature, and Trauma Theory, focusing on South Asian and pan-African literature. His book, Postcolonial Parabola: Literature, Tactility, and the Ethics of Representing Trauma (Bloomsbury, 2017), analyzes literature of partition and civil war on the Indian subcontinent alongside apartheid and post-apartheid South African fiction. His next book project examines the relationship between animism and trauma in contemporary literature of India and Nigeria.

Andreea Deciu Ritivoi is Professor of English and Department Head at Carnegie Mellon University. Her research interests include rhetorical theory and Continental philosophy, narrative and identity, exile and transnationalism, Eastern European societies, and controversy. She is the author of Yesterday's Self: Nostalgia and the Construction of Personal Identity (Rowman and Littlefield, 2002) and Paul Ricoeur: Tradition and Innovation in Rhetorical Theory (SUNY, 2006), and the editor of Interpretation and Its Objects: Studies in the Philosophy of Michael Krausz (Rodopi 2004) and (with Richard Howells and Judith Schachter) of Outrage! Art, Controversy, and Society (Palgrave MacMillan 2012).

Michelle Boulous Walker is Associate Professor at the University of Queensland. Her research interests span the fields of European philosophy, aesthetics, ethics, and feminist philosophy. Her current research engages with the work of Emmanuel Levinas, Theodore W. Adorno, Luce Irigraray, Michèle Le Doeuff, and others; a new project focuses on questions of philosophy and laughter. Her books include Slow Philosophy: Reading Against the Institution (Bloomsbury, 2017) and Philosophy and the Maternal Body: Reading Silence (Routledge, 1998).

Cynthia Wallace is Assistant Professor at St. Thomas More College, University of Saskatchewan, teaching and researching in the areas of religion and literature, postcolonial literature, women writers, and literary ethics. Her current research explores embodied suffering and the prevalence of attention as an ethical ideal among women writing in the twentieth and twenty-first centuries, especially against a backdrop of attention deficits and surpluses, and the surprising influence of philosopher-mystic Simone Weil. Her book, Of Women Borne: A Literary Ethics of Suffering was published by Columbia University Press in 2016.

Donald Wehrs is Hargis Professor of English Literature at Auburn University. He specializes in novel genre and history, British eighteenth-century studies, literary theory, postcolonial studies, and comparative literature. His books include the Palgrave Handbook of Affect Studies and Textual Criticism, co-edited with Thomas Blake (Palgrave Macmillan, 2017), Cognition, Literature, and History, 
co-edited with Mark J. Bruhn (Routledge, 2014), Levinas and Twentieth-Century Literature: Ethical Trauma and the Reconstitution of Subjectivity (Delaware, 2013), and Levinas and Nineteenth-Century Literature: Ethics and Otherness from Romanticism through Realism, co-edited with David P. Haney (Delaware, 2009).

\section{About the Special Issue Editor}

Now Emeritus, Adam Zachary Newton was University Professor, Chair of the English Department, and Stanton Chair in Literature and Humanities at Yeshiva University from 2007 to 2014. Prior to that, he held appointments at the University of Texas at Austin in English, Comparative Literature, Middle Eastern Languages and Cultures, and Jewish Studies as the Jane and Roland Blumberg Centennial Professor. More recently, he has held appointments as Distinguished Visiting Professor at Emory University and Agnes Scott College. A cross-disciplinary scholar, he has written and taught at the boundaries of three knowledge practices: literary studies, philosophy, and religion. Alongside essays in a range of fields, he is the author of six monographs: Jewish Studies as Counterlife: A Report to the Academy (Fordham, 2019); To Make the Hands Impure: Art, Ethical Adventure, the Difficult and the Holy (Fordham, 2014); The Elsewhere: On Belonging at a Near Distance: Reading Literary Memoir from East-Central Europe and the Levant (Wisconsin, 2005); The Fence and the Neighbor: Emmanuel Levinas, Yeshayahu Leibowtz, and Israel Among the Nations (SUNY, 2001); Facing Black and Jew: Literature as Public Space in 20th-Century America (Cambridge, 1998); and his award-winning first book, Narrative Ethics (Harvard, 1995), which first formalized the term for a developing sub-field.

Funding: This research received no external funding.

Conflicts of Interest: The author declares no conflict of interest.

\section{References}

Amichai, Yehudah. 2003. Mishlosha o arbaa baheder [Of Three Or Four In A Room]. In The Modern Hebrew Poem Itself. Edited by Stanley Burnshaw, Susan Glassman, T. Carmi, Ezra Spicehandler and Ariel Hirschfeld. Translated by Robert Friend with commentary. Wayne State: Wayne State University Press, pp. 166-67.

Antor, Heinz. 2012. Literary Ethics. In English and American Studies: Theory and Practice. Edited by Martin Middeke, Christina Wald and Hubert Zapf. Berlin: Springer, pp. 243-47.

Attridge, Derek. 2005. J. M. Coetzee and the Ethics of Reading: Literature in the Event. Chicago: University of Chicago Press.

Best, Stephen, and Sharon Marcus. 2009. The Way We Read Now. Representations 108: 1-21. [CrossRef]

Blackler, Deane. 2007. Reading W. G. Sebald: Adventure and Disobedience. Rochester: Camden House.

Brooks, Peter. 1984. Reading for the Plot: Design and Intention in Narrative. Knopf: Oxford University Press.

Brooks, Peter. 2005. The Plain Meaning of Torture? Literary Deconstruction and the Bush Administration's Legal Reasoning. Slate Magazine. February 9. Available online: https://slate.com/news-and-politics/2005/02/theplain-meaning-of-torture.html (accessed on 3 February 2020).

Brooks, Peter. 2008a. The Ethics of Reading. The Chronicle of Higher Education, February 8.

Brooks, Peter. 2008b. The Humanities as an Export Commodity. Profession 2008: 33-39. [CrossRef]

Brooks, Peter. 2017. An Ethics of Reading? Washington, DC: Association of American Colleges \& Universities. Available online: www.aacu.org/diversitydemocracy/2017/winter/brooks (accessed on 3 February 2020).

Brooks, Peter, and Hillaty Jewett, eds. 2014. The Humanities and Public Life. New York: Fordham University Press. Butler, Judith. 2005. Giving an Account of Oneself. New York: Fordham University Press.

Cavarero, Adriana. 2006. Relating Narratives: Storytelling and Selfhood. Translated by Paul A. Kottman. Abingdon: Routledge.

Cavell, Stanley. 1977. The Senses of Walden: An Expanded Edition. New York: North Point Press.

Cavell, Stanley. 1984. Themes Out of School: Effects and Causes. Chicago: University of Chicago Press.

Colás, Santiago. 2007. Toward an Ethics of Close Reading in the Age of Neo-Liberalism. The New Centennial Review 7: 171-211. [CrossRef]

Cooper, Marilyn. 2016. David Grossman: The Dissenting Patriot. Moment. May 24. Available online: https://momentmag.com/david-grossman-dissenting-patriot/ (accessed on 3 February 2020). 
Cox, Sandra. 2015. An Ethics of Reading: Interpretative Strategies for Contemporary Multicultural American Literature. Cambridge: Cambridge Scholars Publishing.

Dagenais, John. 1994. The Ethics of Reading in Manuscript Culture: Glossing the Libro de buen amor. Princeton: Princeton University Press.

Day, William. 2011. A Soteriology of Reading: Cavell's Excerpts from Memory. In Stanley Cavell: Philosophy, Literature and Criticism. Edited by James Loxley and Andrew Taylor. Manchester: Manchester University Press, pp. 76-91.

Deming, Richard. 2008. Listening on All Sides: Toward an Emersonian Ethics of Reading. Stanford: Stanford University Press.

Di Lio, Jeffrey R. 2016. Review of Peter Brooks, ed. with Hilary Jewett, The Humanities and Public Life. The Comparatist 40: 352-59. [CrossRef]

Dubois, Andrew. 2007. Ethics, Critics, Close Reading. University of Toronto Quarterly 76: 926-36. [CrossRef]

François, Anne-Lise. 2008. Open Secrets: The Literature of Uncounted Experience. Stanford: Stanford University Press.

Freed, Joanne Lipson. 2017. Haunting Encounters: The Ethics of Reading across Boundaries of Difference. Ithaca: Cornell University Press.

Gallup, Jane. 2000. The Ethics of Reading: Close Encounters. Journal of Curriculum Theorizing 16: 7-17.

Gelley, Alexander, ed. 1995. Unruly Examples: On the Rhetoric of Exemplarity. Stanford: Stanford University Press.

Grossman, David. 1998. Fifty is a Dangerous Age. The New Yorker. April 20, pp. 55-59. Available online: https:/www.newyorker.com/magazine/1998/04/20/fifty-is-a-dangerous-age (accessed on 3 February 2020).

Grossman, David. 2017. Sus ehad nikhnas le-bar [A Horse Walks Into A Bar]. Translated by Jessica Cohen. New York: Knopf.

Harpham, Geoffrey Galt. 1999. Shadows of Ethics: Criticism and the Just Society. Durham: Duke University Press.

Hartman, Geoffrey H. 1980. Criticism in the Wilderness: The Study of Literature Today. New Haven: Yale University Press.

Heller, Eric. 1984. In the Age of Prose: Literary and Philosophical Essays. Cambridge: Cambridge University Press, pp. 87-104.

Hoffman, Anne Golomb. 2001. Topographies of Reading: Agnon through Benjamin. Prooftexts 21: 71-89. [CrossRef]

Jiang, Wenying. 2015. Selected Bibliography for the Study of Fiction and Ethics. CLCWeb: Comparative Literature and Culture 17: 15. [CrossRef]

Kaul, Suvir. 2013. Reading, Constraint, and Freedom. The Eighteenth Century 54: 129-32. [CrossRef]

Kraus, Karl. 1932. Die Sprache. Die Fackel. December, 34. Available online: http://languagehat.com/die-fackelonline/ (accessed on 3 February 2020).

Lear, Jonathan. 2008. Radical Hope: Ethics in the Face of Cultural Devastation. Cambridge: Harvard University Press.

Lentricchia, Frank, and Andrew Dubois, eds. 2003. Close Reading: The Reader. Durham: Duke University Press.

Levinas, Emmanuel. 1981. Otherwise than Being, or Beyond Essence. Translated by Alphonso Lingis. Pittsburgh: Duquesne University Press.

Levinas, Emmanuel. 1996. Emmanuel Levinas: Basic Philosophical Writings. Edited by Adriaan Theodoor Peperzak, Simon Critchley and Robert Bernasconi. Bloomington: Indiana University Press.

Love, Heather. 2010. Close but not Deep: Literary Ethics and the Descriptive Turn. New Literary History 41: 371-91. [CrossRef]

Makhoul, Marwan. 2007. An Arab at Ben Gurion Airport. Ard al-passiflora al-hazinah [Land of the Sad Passiflora] Beirut: Al-Jamal Publishers, 2007). Translated into English by Raphael Cohen. Available online: http://thetanjara.blogspot.com/2013/01/palestinian-poets-marwan-makhoul-and.html (accessed on 3 February 2020).

Mcdonald, Peter D. 2010. The Ethics of Reading and the Question of the Novel: The Challenge of J. M. Coetzee's Diary of a Bad Year. Novel: A Forum on Fiction 43: 483-99. [CrossRef]

Mendel, Yonatan. 2013. New Jerusalem. New Left Review 81: 35-56.

Meretoja, Hanna. 2018. The Ethics of Storytelling: Narrative Hermeneutics, History, and the Possible. Oxford: Oxford University Press.

Miéville, China Tom. 2010. The City and the City. New York: Random House, pp. 320-21.

Miller, J. Hillis. 1986. The Ethics of Reading: Kant, De Man, Eliot, Trollope, James, and Benjamin. New York: Columbia University Press. 
Moya, Paula M. L. 2015. The Social Imperative: Race, Close Reading, and Contemporary Literary Criticism. Stanford: Stanford University Press.

Newton, Adam Zachary. 1995. Narrative Ethics. Cambridge: Harvard University Press.

Newton, Adam Zachary. 2015. To Make the Hands Impure: Art, Ethical Adventure, the Difficult and the Holy. Fordham: Fordham University Press.

Norris, Andrew. 2014. Thoreau, Cavell, and the Foundations of True Political Expression. In A Political Companion to Henry David Thoreau. Edited by Jack Turner. Louisville: University Press of Kentucky.

Packer, George. 2010. The Unconsoled. The New Yorker. September 27. Available online: https://www.newyorker. com/magazine/2010/09/27/the-unconsoled (accessed on 3 February 2020).

Perloff, Marjorie. 2014. Avant-Garde in a Different Key: Karl Kraus's The Last Days of Mankind. Critical Inquiry 40: 311-38. [CrossRef]

Powers, Peter Kerry. 2008. Deconstruction and Reading. The Chronicle of Higher Education, March 2, vol. 54, B29.

Ricoeur, Paul. 1998. Hermeneutics and the Human Sciences: Essays on Language, Action and Interpretation. Translated by John B. Thompson. Cambridge: Cambridge University Press.

Robbins, Jill. 1999. Altered Reading: Levinas and Literature. Chicago: Chicago University Press.

Rorty, Amelie Oksenberg. 1997. The Ethics of Reading: A Traveler's Guide. Educational Theory 47: 85-89. [CrossRef]

Scarry, Elaine. 2012. Poetry Changed the World: Injury and the Ethics of Reading. Boston Review. July/August. Available online: http://www.bostonreview.net/poetry-arts-culture/poetry-changed-world-elaine-scarry (accessed on 3 February 2020).

Schmidt, Gary. 2008. Reading W.G. Sebald: Adventure and Disobedience. German Quarterly. Hoboken: Wiley, vol. 81, pp. 365-66.

Serpel, Namwali. 2019. The Banality of Empathy. The New York Review of Books. May 19. Available online: https://www.nybooks.com/daily/2019/03/02/the-banality-of-empathy/ (accessed on 3 February 2020).

Stern, J. P. 1966. Karl Kraus's Vision of Language. The Modern Language Review 61: 71-84. [CrossRef]

Stern, David. 1981. Rhetoric and Midrash: The Case of the Mashal. Prooftexts 1: 261-91.

Unger, Roberto Mangabeira. 1984. Passion: An Essay on Personality. New York: Free Press.

Vander Zee, Anton. 2007. Printed Evils and Painted Veils: Anecdote of an Error by Frank Lentricchia. The Wallace Stevens Journal 31: 189-96.

Wood, James. 2010. The Broken Estate: Essays on Literature and Belief. London: Picador.

(C) 2020 by the author. Licensee MDPI, Basel, Switzerland. This article is an open access article distributed under the terms and conditions of the Creative Commons Attribution (CC BY) license (http://creativecommons.org/licenses/by/4.0/). 


\title{
Creative
}

\section{Ethics and Time: After the Anthropocene}

\author{
Steven B. Katz \\ Emeritus College, Clemson University, Pendleton, SC 29670, USA; skatz@clemson.edu
}

Received: 13 November 2019; Accepted: 9 December 2019; Published: 13 December 2019

check for updates

\begin{abstract}
This "treatise" on ethics and literary practice is a self-reflective piece that argues and enacts ethical criticism through poetic form as well as content. That is, I deliberately employ poetry not only as a literary genre but also as rhetorical arguments-investigative, demonstrative, and evidentiary - and as forms of ethical action. The two previously unpublished poems here are drawn from a larger, lyrical discourse sequence tentatively entitled "Heidegger, Ethics, and Time: After the Anthropocene." The "poetic arguments," then, concern the possible interrelations and effects of time and ethics within the philosophical context of post-human "being" collectively, and also of personal death as a shared event. There are a couple of famous theories of time and ethics that ebb and flow within the different formal abridgements of time in these two poems. One set of theories is expounded in Martin Heidegger's major work, Being and Time, as well as many of his other treatises on language, poetry, and ethics. Another set of theories is founded in Emmanuel Levinas' work on time and alterity. But unlike these philosophies, the two poems here deal in detail with (1) the potential particularities of lived sensation and feeling (2) as they might be experienced by sentient and non-sentient 'being' (3) that survive death—of our species (poem II) and/or individual death (poem III). However, rather than simply rehearsing philosophy or recasting it into poetic form, these two poems argue for and against the notion that time is a physical and thus materially moral absolute, necessary for any (conscious) life to exist at all; and these two poems also argue physically, through their structure and style. They argue that physical dimension of time is not only a material force that is "unkind to material things" (aging, decay), as articulated in the content of one poem for example, but also a moral force that is revealed and played against in the constricted temporal motion and music of the poems (i.e., their forms, and variations within). In addition to philosophical arguments that poetry by its nature deliberately leaves ambiguous (indeterminate, but also will-free), the aural, temporal forms of the poems themselves flow in or move through but also reshape time. A simple instance of this is the way meter and rhyme are activated by time, yet also transform time, pushing back against its otherwise unmarked inexorable ineffable ... The temporal properties of poetic forms in conjunction with content therefore constitute "lyrical ethics" in literary practice. Thinking (and putting aside as well) Heidegger and Levinas, these poems as temporal forms may physically shift, even if only momentarily, the relation of the listener or reader to Being/Death, or Alterity/Other. For example, the enhanced villanelle and modified Spenserian stanza offered here each shapes time differently, and thus differently shapes the intuitive, affective, cognitive responses of readers. With its cyclical repetition of lines, usually over five tercets and a quatrain, the villanelle with every advancing stanza physically 'throws' time (the concept and the line) back on itself (or perhaps is "thrown forward" [Geworfen]). In contrast, the pattern of the Spenserian nine-line stanza allows time to hover around a still but outward-expanding point (like a partial mini-[uni]verse) before drifting to the next stanza (especially here, where the final rhyme at the end of each stanza is much delayed.). Within and without the context of Heidegger and Levinas, I assert that these structural features are ethical statements in literary practice. The choice of these traditional forms of poetry in itself is an ethical statement. Stylistically as well as thematically, these two poems argue "all sides" of ethical positions in relation to the end of being human. Perhaps more importantly, these two poems explore the inevitably human experience of philosophically different ethical positions on death "post anthropocentrically"-what might come in the rhetorical after we can never know except poetically.
\end{abstract}


Keywords: Heidegger; Levinas; Proust; time; poetry; literary form; Being; Alterity; ethics; Anthropocene

\section{The Ghosts of Objects \\ (A Villanelle for the End of the Anthropocene)}

"[T]ime remains destitute not only because God is dead, but because mortals are hardly aware and capable even of their own mortality. Mortals have not yet come into ownership of their own nature. Death withdraws into the enigmatic."-Heidegger 1971c, p. 96.

Time is not kind to material things.

Eventually, all things are ravaged.

Only spirit can survive and not be.

Time can't be seen, but is heard in the ring of a phone call that says you are average. Time is not kind to material things.

Time is not a dimension, but the zing of a force that bends, crumples you with age.

Only a ghost can survive and not be.

Time carries you forward in its quickening spring; without time you might be frozen in space. But time's not kind to material things.

Can objects survive physicality?

What about all the human alphabets of rage?

Only spirit can survive nonbeing.

(You may ask questions; you may wonder, why?

I will tell you we do not know the sage

for whom time is Open, forthcoming, sings.

Haggard, look me straight in the awful eye and tell me we are not all savages.

Only a ghost can survive, not being.)

What will remain after the Anthropocene?

We can only hazard what catastrophes gather.

Can only spirit survive nonbeing?

Time is not kind to material things.

\section{Time, Proust, Being, You}

For Dr. Whitney Jordan Adams

"[L]anguage alone brings what is, as something that is, into the Open for the first time. Where there is no language, as in the being of stone, plant, and animal, there is also no openness of what is, and consequently no openness either of that which is not and of the empty".-Weidegger 1971b, p. 73

Putting up books that went astray,

the house of eternity far away,

I came upon my Marcel Proust, 
and could not help but think of you, who loves his work so ardently and took the time when in Paris walking over all of France to desist in the constant dance to visit his temporal chez.

As always, resplendent, to him you all a sudden appear in time that moves above him like a wave; then slowly on and through his grave. It feels like anxiety on our skin, and joy at the prospect of something unseen, distant

a distant, final peace when time has had enough to eat; when time is like a memory, slow, and kind, a holiday, from ourselves; when time becomes a companion, a lover, succumbs to the still point of a mind, as if balanced from some twine unraveling from heaven, sleeps

life's continuous wings, the wind-pendulum that swings to which we desperately hang on, precipitously, dangle, as if on a thread that becomes a thin bed, then back again, until we become utterly useless, numb, an emotion that clings

to any everything around on which we discover solid ground, and rest from the motion that constitutes us, our notion of ourselves, who we are in relation to reality, a star in yet another galaxy, another looked-for fallacy that we may hear as pure sound.

O we all look for, and dread the long night of the end, the temporal crease, the infinite surcease of our entire existence, and so push on the resistance that we make ourselves deliberately, hesitant, but inexorably, and also have to fend 
off as it moves under and over and through us, sunders our successes forward from self-awareness toward our own best selves, takes us somewhere we don't discuss, don't really want to go, but inevitably must flow. In the end, time renders

all. The dust awaits, shudders, becomes us, becomes another. Proust finds rest in rust, his repose an eternal bust. Time does not heal, as if a pardon, or repeal as is so often said, but kills itself, and dies in us, so oblivious,

and Other

Funding: This research received no external funding.

Acknowledgments: The author would like to acknowledge and thank Adam Newton for his extraordinary encouragement, patience, and assistance with the reconceptualization and development of the project for this special issue of Humanities. Every author should be as fortunate to have an editor who is as brilliant and empathetic as AZN, and whose very words are gold.

Conflicts of Interest: The author declares no conflict of interest.

\section{Bibliography}

Aristotle. 1991. On Rhetoric: A Theory of Civic Discourse. Translated by George Kennedy. New York: Oxford University Press.

Aristotle. 2017. Poetics. Translated by Ingram Bywater. Digireads.com Publishing.

Altieri, Charles. 1998. Lyrical Ethics and Literary Experience. Style 32: 272-97.

Bruns, Gerald. 2009. Should Poetry Be Ethical or Otherwise? In SubStance. Baltimore: Johns Hopkins University Press, vol. 38, pp. 72-91.

Burke, Kenneth. 1968. Language as Symbolic Action. Berkeley: University of California Press.

Burke, Kenneth. 1974. The Philosophy of Literary Form. Berkeley: University of California Press.

Cicero, Marcus Tullius. 1942. De Oratore Book III. In De Oratore III, De Fato, Paradoxa Stoicorum, De Partitiones Oratoriae. Translated by H. Rackham. Cambridge: Harvard University Press, pp. 1-185.

Heidegger, Martin. 1971. On the Way to Language. New York: Harper and Row.

Heidegger, Martin. 1971. The Origin of the Work of Art. In Poetry, Language, Thought. New York: Harper and Row, pp. 73-90.

Heidegger, Martin. 1971. Poetically Man Dwells. In Poetry, Language Thought. Translated by Albert Hofstadter. New York: Harper and Row, pp. 213-29.

Heidegger, Martin. 1971. What are Poets For? In Poetry, Language Thought. Translated by Albert Hofstadter. New York: Harper and Row, pp. 91-142.

Heidegger, Martin. 2010. Being and Time: A Revised Edition of the Stambaugh Translation. Translated by Joan Stambaugh. Albany: The State University of New York.

Heidegger, Martin. 2010. Country Path Conversations. Bloomington: Indiana State University Press.

Katz, Steven B. 1996. The Epistemic Music of Rhetoric: Toward the Temporal Dimension of Reader Response and Writing. Carbondale: Southern Illinois University Press.

Katz, Steven B. 2004. The Alphabet as Ethics: A Rhetorical Basis for Moral Reality in Hebrew Letters. In Rhetorical Democracy: Discursive Practices of Civic Engagement. Selected Papers from the 2002 RSA Conference. Edited by Gerald Hauser and Amy Grimm. Hillsdale: Lawrence Erlbaum Associates, pp. 195-204. 
Katz, Steven B. 2015. Burke's New Body? The Problem of Virtual Material, and Motive, in Object Oriented Philosophy. KB Journal 11. Available online: https://kbjournal.org/katz_burkes_new_body (accessed on 11 December 2019).

Katz, Steven B. 2019. On the Occasion of the 25th Anniversary of the Publication of 'The Ethic of Expediency: Classical Rhetoric, Technology, and the Holocaust'. Enculturation: A Journal of Rhetoric, Writing, and Culture 28. Available online: http://enculturation.net/Rhetoric_Ethics_Poetics_Katz_Interview (accessed on 11 December 2019).

Katz, Steven B. 2017. Pentadic Leaves (poem and video of performance). KB Journal 12. Available online: https://kbjournal.org/pentadic-Leaves (accessed on 11 December 2019).

Katz, Steven B., and Nathaniel Rivers. 2017. A Predestination for the Posthumanism. In Ambiguous Bodies: Burke and Posthumanism. Edited by Chris Mays, Nathaniel A. Rivers and Kellie Sharp-Hoskins. Columbia: University of South Carolina Press, pp. 142-61.

Lacoue-Labarthe, Philippe. 2007. Heidegger and the Politics of Poetry. Translated by Jeff Fort. Champaign: University of Illinois Press.

Levinas, Emmanuel. 1969. Entre Nous. Translated by Michael B. Smith. New York: Columbia University Press. Levinas, Emmanuel. 1987. Time and the Other [and Additional Essays]. Pittsburgh: Duquesne University Press.

Levinas, Emmanuel. 1969. Totality and Infinity. Translated by Alphonso Lingis. Pittsburgh: Duquesne University Press.

Scanlon, Mara. 2007. Ethics and the Lyric: Form, Dialogue, Answerability. College Literature 34: 1-22. [CrossRef]

(C) 2019 by the author. Licensee MDPI, Basel, Switzerland. This article is an open access article distributed under the terms and conditions of the Creative Commons Attribution (CC BY) license (http://creativecommons.org/licenses/by/4.0/). 



\title{
Article \\ Senses of Echo Lake: Michael Palmer, Stanley Cavell, and the Moods of an American Philosophical Tradition
}

\author{
Richard Deming \\ Department of English, Yale University, New Haven, CT 06520, USA; richard.deming@yale.edu
}

Received: 11 April 2019; Accepted: 15 May 2019; Published: 19 May 2019

check for updates

\begin{abstract}
This essay explores a philosophical tradition that Stanley Cavell has traced out and which he emphasizes as being American inasmuch as it is arises out of the thinking of Ralph Waldo Emerson and Henry David Thoreau. It then investigates how the poems of the avant-garde poet Michael Palmer link with, overlap with, this strain of American philosophy in terms of how it enacts an understanding of what we might call "philosophical mood," on outlook based on the navigation of representation, generative self-consciousness, and doubt that amounts to a form of epistemology. The essay does not trace the influence-direct or otherwise of Cavell and his arguments for philosophy on the poems, despite a biographical connection between Cavell and Palmer, his former student. Instead it brings out the way that one might fruitfully locate Palmer's work within an American literary/philosophical continuum. The article shows how that context opens up the work to a range of important existential and ethical implications. I endeavor to show that Notes for Echo Lake, Palmer's most important collection, locates itself, its language, within such a frame so as to provide a place for readerly encounters with the limitations of language. These encounters then are presented as an opportunity for a deeper understanding of subjectivity and for attuning oneself to the role that active reading and interpretation might play in moral perfectionism.
\end{abstract}

Keywords: Ethics; Stanley Cavell; Michael Palmer; poetry; American philosophy; Ralph Waldo Emerson; poetics; language poetry; moral perfectionism

These days, we may be beyond a pro forma gesture justifying or rationalizing why it is that we might bring the weight of philosophy and its concerns to bear on the practice of reading poetry. In poetry, from the German, British, and American Romantics forward to the Modernists, and in philosophy, from Hegel to Heidegger to Simon Critchley, the models that give us precedent for locating the interdisciplinary dialogues of poetry and philosophy are legion. With this in mind, although it may be a generalization, it is not too much a claim to begin to say that poetry and philosophy, whatever else they might be, are both enactments of a preoccupation with how the mind fashions an ordering of the world by which one can come to perceive a life-one's own life, the lives of others-lived among particularities. Poets and philosophers who go beyond boundaries of discourse in order to engage the parallel nature of these approaches seek ultimately to get at the foundations upon which these preoccupations rest.

This is not to say all poetry and all philosophy can be brought productively into dialogue with one another, of course. Nonetheless, bringing philosophy to bear on the reading of certain poets seems unavoidable for a variety of reasons-from the methodological to the thematic. In fact, in the case of discussing the work of Michael Palmer, one of the most influential avant-garde poets of the past fifty years, philosophy and philosophers are referenced commonly enough in the poems themselves (quite often through epigraphs and other tropes and devices) that the possibilities for philosophical interventions are perhaps more than a valuable approach for engaging the work; they 
are quite explicitly evoked. Palmer does, after all, open the first poem included in Notes for Echo Lake, one of the most important collections of poetry published in the 1980s, a book that interrogates the very nature of the connection between language and subjectivity, with an epigraph from Bruno Schulz's Street of Crocodiles that insists "An outlook based upon philosophy became obligatory." 1 At the very least, this proclamation suggests the epistemological conditions with which the poems establish themselves. I want to consider this claim seriously in terms of what it means for Palmer's poetics, however, and I want to think of "outlook" and "obligation" as keywords because he places the epigraph so prominently at the beginning of the collection's first poem. ${ }^{2}$ Very often Palmer's work is read in terms of its formal complexity and how it reworks lyric tradition. However, this epigraph announces the poem's desire to be taken as a form of thinking that by its very nature acknowledges the literary text as a contact point between subjectivities-where one being's understanding of the limits of language encounters another's. It is a claim that the poems themselves must reckon with, even as it articulates the perspective from which the poems speak. What is an outlook based on philosophy? How does that shape perception? Also, what makes this obligatory? To what or to whom is one obliged?

If Palmer's epigraph announces the collection's investment in philosophy, it becomes important to know what tradition of philosophy it may be drawing upon in order to construct its perspective. "Outlook" and "obligation" are two words that both resonate with a particular philosophical inheritance that Stanley Cavell traced out over the course of his career insofar as "an outlook based upon philosophy" describes what we might otherwise call a philosophical mood, and such a mood is at the center of Cavell's particular interest in Ralph Waldo Emerson, whom he takes to be a philosopher of moods (Cavell 1977). An outlook is one's subjectivity traveling outwards and projecting itself onto everything, falling upon anywhere one's gaze alights. We could read the word outlook nearly literally as suggesting that one's vision moves outward. As Emerson writes in "Experience," "Thus inevitably does the universe wear our color, and every object fall successively into the subject itself. The subject exists, the subject enlarges; all things sooner or later fall into place." ${ }^{3}$ In this way, "outlook" informs not only a writing practice that is the transposing of an experience of the world back into language, but a reading practice as well. In looking at writing, in the act of reading - if what we mean by reading is an attention coupled with active interpretation-we are then discovering our own subjectivity by means of encountering and grappling with someone else's attempts at articulating their own subjective experience. That experience of the ethics of reading is at the heart of Emerson's thinking and is the battery for any tradition that begins with him.

Cavell emphasizes such an inheritance as being American inasmuch as it is Emersonian, with the term itself not signifying any specifically nationalistic bearing. For Cavell, Ralph Waldo Emerson and Henry David Thoreau stand as the initiating figures for what it might mean to write philosophy in a mode that recognizes its debt to the past while simultaneously seeking to locate its authority in something besides a mere fealty to prior modes of thinking and their modes. What makes this American is simply-though not merely-the conditions that made such a question possible. Standing in the still early days of its existence, America needed to distinguish American thought and culture from Europe as well as from past intellectual traditions so as to be responsive to the "newness" of America and to its specific conditions. ${ }^{4}$ America was birthed from revolution, and this sense of the sovereignty of the individual and a need to question imposed authority—to push against any authority

\footnotetext{
(Palmer 1981) The line is taken from Schulz's story, "The Comet." (Schulz 1977).

Schulz's sentence is originally written in Polish, and it would make sense for one to be reluctant to put weight on the words in their translated version, yet since Palmer uses the English version without having in mind the Polish, we are free to think about the implications of the words in English.

3 "Experience," p. 489. For the sake of convenience, all citations of Emerson are to be found in (Emerson 1983).

4 Of course, it hardly needs to be said that there were people living in North America when it was colonized and that there was a diversity of cultures present that were not Eurocentric. Still, The United States became a political entity in the $1770 \mathrm{~s}$, and that overwhelmed what was already present. To distinguish a country as a distinct nation is one thing, to determine its culture is another, especially as culture is one way a people shows itself to itself. Emerson's call was for thinkers, scholars, artists, and writers to produce a culture by which America could represent itself to itself, as well as to others.
} 
that had not earned consent-is a necessary part of how it understands itself philosophically, and how it comes to understand what philosophy might contribute to culture. As Emerson writes in "The American Scholar," "Our day of dependence, our long apprenticeship to the learning of other lands, draws to a close. The millions, that around us are rushing into life, cannot always be fed on the sere remains of foreign harvests" (Emerson 1983, p. 53). With that in mind, "American" in this context is not a descriptor of nationality so much as it identifies an originating condition calling for creative (as opposed to reactionary) thinking that actively distinguishes itself from the past by (1) not simply adhering to an ideological system that valorizes the past and tradition; and (2) investing in the belief that philosophical truths are not fixed, but remain in the process of being discovered (as Emerson writes, "the quality of the imagination is to flow, and not to freeze") (Emerson 1983, p. 463). These aspects can, then, be broadly available, regardless of one's location or nationality. ${ }^{5}$

Emerson focused on the intrinsic genius of every person as the source of legitimate insight into the qualities of Being itself. He writes in the deservedly famous opening to "Self-Reliance":

A man should learn to detect and watch that gleam of light which flashes across his mind from within, more than the lustre of the firmament of bards and sages. Yet he dismisses without notice his thought, because it is his. In every work of genius we recognize our own rejected thoughts: they come back to us with a certain alienated majesty. Great works of art have no more affecting lesson for us than this. (Emerson 1983, p. 259)

It is a bold statement to say that a work of art's greatness is measured by how it facilitates a consciousness of our own alienated thoughts. Moreover, the thoughts are both familiar, as they are our own, as well as strange, since we encounter them in another's context. Literally, the "great work of art" brings us to think again (to re-cognize) the very thoughts that we have exiled from ourselves. Art then is an aid for perceiving the movement of our own insights. The writing in essays by Emerson and by Thoreau-in its artfulness, in its idiosyncrasies-is a form of philosophy that seeks, therefore, to determine an expansive and expanding vocabulary for philosophy drawn from one's own experience rather than merely depending on redeployed, familiar habits of thought that conform to received conventions of discourse. Paradoxically, it eschews the objective-a framework which Emerson takes to be an illusion, if not a delusion-in order to find the universal.

From this perspective, Cavell might describe Emerson's writing as not just a form of philosophy but as a reform of the possibilities of philosophy, of how we might imagine philosophy could act and sound. In his being essayistic, impressionistic, and in his literary attention to style as evincing thought, Emerson undertakes a kind of writing that is attuned to its very processes of thinking and expression. In the very ways that Emerson and, by extension, Thoreau break with the conventions of philosophical writing — at least the conventions of academic, professional philosophical writing-they enact philosophical thinking. This resistance to conventions is what Emerson calls "self-reliance" and what Cavell will describe as Emerson's "aversive thinking." In its resistance to the demands of society for conformity of expression, Cavell argues, Emerson's writing expresses

his self-consciousness, his thinking as an imperative to an incessant conversion or reconfiguration of society's incessant demands for his consent-his conforming himself-to its doings; and at the same time to mean that his writing must accordingly be the object of aversion to society's consciousness, to what it might read in him. ${ }^{6}$

In "The American Scholar," Emerson insists that to gain a consciousness of self and subjectivity, and in that way lay claim to such things, to assert responsibility for our own agency, we must first forgo an unquestioning dependency on past knowledge ("the sere remains") as that breeds repetition rather than creation, fosters reiteration rather than imagination. Instead, writes Emerson,

5 The fullest account of Cavell's thinking of this can be found in his essay "Finding as Founding" in (Stanley Cavell 1981). "Aversive Thinking: Emersonian Representations in Heidegger and Nietzsche," (Cavell 1990). 
Whatever talents may be, if the man create not, the pure efflux of the Deity is not his; cinders and smoke there may be, but not yet flame. There are creative manners, there are creative actions, and creative words; manners, actions, words, that is, indicative of no custom or authority, but springing spontaneous from the mind's own sense of good and fair. (Emerson 1983, p. 58)

Cavell reads such insistences "to create" as a call to stop turning away from one's own inspiration, away from one's own intuition, in order to discover or recover one's relationship to the ordinary and the everyday, "something which for Emerson," writes Cavell, "is the same matter of salvation in the intellectual life as it is in the religious life" (Cavell 1977, p. 148). Experience, Emerson argues, then becomes the arbiter for what it means to know. "So much only of life as I know by experience," Emerson writes, and then adds that experience "is the raw material out of which the intellect molds her splendid products. A strange process too, this by which experience is converted into thought, as a mulberry-leaf is converted into satin" (Emerson 1983, p. 60). That is, the stuff of one's life is the grounds, the conditions for philosophy to take root. Ultimately, I would argue, this describes an "outlook of philosophy" that is "obligatory" to the extent that it we have an obligation to ourselves to know ourselves.

With this context in place, I want to look at the possibility that Palmer's poems link with, and overlap with, American philosophy—at least the kind found within a Cavellian key—regarding its interest in what we might otherwise call "mood" or "outlook." In saying this, however, I am not citing influence-direct or otherwise - of a certain strain of philosophy on the poems, but will bring out the way that we might read and locate Palmer's work within an American literary/philosophical continuum and indicate how reading the work within that context matters in regards to how that opens up the work to a range of important existential and experiential implications by suggesting that subjectivity-even one's own-is a text ever being written and ever being read. Such a move has a great deal to do with what it means to say that an outlook based on philosophy has become obligatory and what that has to do with poetry.

My placing Cavell and Palmer in conversation is not happenstance. ${ }^{7}$ Beyond their shared elective affinities, Palmer was at one time Cavell's student. Within the context of this forum on literature and ethics, it is most likely not necessary to introduce Stanley Cavell, a contemporary philosopher whose importance and influence has continued to deepen over the last two decades; it is, however, useful to give some context for Palmer. Born in New York City in 1943, Palmer was educated at Harvard and Columbia. The author of numerous books of poetry including Codes Appearing: Poems 1979-1988 (2001); The Promises of Glass (2000); The Lion Bridge: Selected Poems 1972-1995 (1998); At Passages (1996); and Sun (1988), Palmer is undoubtedly one of the most important experimental poets of his generation with Notes for Echo Lake, published in 1981, being one of his most influential collections. Although critics often place Palmer alongside the Language poets of the 1970s and 80s, a group of experimental writers including Charles Bernstein, Bruce Andrews, Lyn Hejinian, and Ron Silliman (just to name a few), who often drew on elements of Russian formalism and Marxism to create a form of counter-lyric poetry.

Although linked to these writers due to social connections, particularly in San Francisco, one of the hubs of radical poetics in the U. S., Palmer is perhaps more accurately described as an inheritor of the poetics of the New American poets of the 1950s and 1960s, such as Robert Duncan, Robert Creeley, and George Oppen. Throughout his career, Palmer has been less invested in the polemics

7 It is important to note that Palmer is not the only poet whose work has been shaped by an encounter with Cavell's philosophy. Poets from John Hollander to Susan Howe and Ann Lauterbach have acknowledged their interest in how Cavell's philosophical interventions have been generative in terms of thinking about language and the ways that it describes the possibilities for an ethics of reading. Charles Bernstein has frequently acknowledged Cavell as his mentor, their close relationship having begun with Bernstein's own undergraduate days at Harvard in the 1970s. It is well beyond the scope of this essay, but there does seem to be a need for a sustained investigation into the ways that Cavell's thinking-directly and indirectly-has impacted American poetry over the last few decades. 
of Marxist literary theory than other Language writers have been, and he rarely treats poetry as the means of opening up the possibilities of ideological critique in the ways that such contemporaries as Bruce Andrews or Ron Silliman might. Palmer himself will cite Duncan and Creeley as direct mentors and acknowledges his presence at the 1963 Poetry Vancouver Conference, a landmark gathering of such figures as Charles Olson, Creeley, Allen Ginsberg, Denise Levertov and others of what would be called New American Poetry as a pivotal moment for him in terms of his exposure to the possibilities of a radical poetics that remained committed to aesthetic experience. ${ }^{8}$ In an interview in 2006, Palmer described the arc of his work as,

moving a little bit away from radical syntax into the mysteries of ordinary language, in the philosophical if not every day sense. It probably looks less unusual on the page. And I've been interested in the infinite, ingathering potential of the lyrical phrase-not confession, but the voicing of selves that make up the poetic self, from Greek lyrics to the Italians, to modern poets like Mandelstam. (Bullock 2006)

Arguably, however, Palmer's sense of the lyric as being primarily the representation of subjectivity finding itself through language is consistent throughout his career and is what differentiates him from many of the Language writers who sought instead to decolonize language and "denaturalize" conceptions of poetic voice and authenticity by laying bear the mechanisms of ideology that are encoded within traditions of the lyric. Although he shares with other Language poets an interest in disjunction, fragmentation, and formal complexity, the underlying impulses are quite distinct. ${ }^{9}$

This interest in the "mysteries of ordinary language" is one of the ideas that ties Palmer to Cavell, a foremost figure in Ordinary language philosophy. In 1965, Cavell served as one of the readers for Palmer's senior project at Harvard College, a long paper analyzing the work of the proto-surrealist French author Raymond Roussel. In many ways, Palmer's early association with Cavell was pragmatic and somewhat ad hoc: Harvard at that time had the policy that faculty could choose, from a pool, which undergraduate projects they could and would be willing to advise. In effect, Cavell was late to choose and took on Palmer's project by default. That initial relationship between Cavell and Palmer was more a practical arrangement than the product of ongoing tutelage or mentoring. Indeed, although Palmer had occasionally joined the philosophy tables Cavell ran in those days, he never actually contributed, preferring to be what these days we would call a "lurker." That is to say, until the senior project, the two had never actually had a substantive conversation. After working together on the senior project, a friendship did take root and Palmer would be a regular reader of Cavell's work as it began appearing in the 1970s and onward. Although the connection between this particular philosophical poet and this poetic philosopher is almost definitively anecdotal, it does provide an interesting entry point, if not justification, for thinking about the ways that Palmer's poetry, specifically Notes for Echo Lake, might be read through the lens of Cavell's work on the intersection of language and ethics that starts appearing in 1970 and becomes so crucial in the 1980s.

The connection between Palmer's Notes for Echo Lake and Cavell's philosophical work of the time is especially compelling if we also consider that Notes for Echo Lake came out the same year (1981) and with the same press (North Point) that published the expanded version of the seminal Senses of Walden, Cavell's philosophical reading of Henry David Thoreau. Cavell first wrote Senses of Walden in 1970, just a few years after he had worked with Palmer at Harvard. The reprinted version appeared with the addition of two important essays about Ralph Waldo Emerson and the book is Cavell's first sustained attempt at discovering through these two 19th century writers the ways that America began to express

8 "New American Poetry" is a loose descriptor that is shaped by the Donald Allen anthology of that name published in 1963, a collection that sought to establish a context for various strains of post-war avant-garde poetry in the U.S.

9 Of course, Language poetry was not a monolithic school or movement so much as it was a network of elective affinities, and so any number of exceptions and counterexamples can be offered in describing what might constitute the basic constellation of poetics that held these figures together in conversation. It is Palmer's interest in expanding notions of lyric subjectivity rather than the dismantling of it that sets him apart. 
itself philosophically in a mode that was distinct from a European body of thought that stretched back centuries. ${ }^{10}$

There is also another perhaps less obvious triangulation between Thoreau's Walden and Notes for Echo Lake in terms of narrative sequencing in the way that Palmer collapses a longer period of time into a single year, just as Thoreau had done in his own book. In a talk from 1982, Palmer states, "At some point in working on Notes for Echo Lake I realized that the 'notes' themselves should number twelve and that the larger period, so-to-speak, of the book would be a year, an entirely metaphoric year since the book is drawn from work extending over about three years." 11 This time of relative seclusion as the condition for writing a book is not limited to Palmer and Thoreau. Cavell wrote both Senses of Walden and The World Viewed, his landmark study of film as a form of philosophy, during a year he spent as a fellow at Wesleyan University's Humanities Center, withdrawing from Cambridge, MA, to the somewhat quieter village of Middletown, CT. In essence, Cavell had no commitments that year and worked all day at a kitchen table, free from the usual distractions of teaching and departmental toiling. Let us call these moments of overlapping biographical resemblances resonances, or perhaps echoes, occurring between Thoreau, Emerson, Cavell, and Palmer.

Yet, these texts signal a shared sense of how a specific place becomes generative in terms of its serving as a meditative space, which in part establishes the conditions for a philosophical outlook that takes on an ethical dimension. "A writer in meditation is literally a human being awaiting expression," Cavell notes in his reflection on Thoreau's withdrawal to Walden, the pond itself, and that author's withdrawal into Walden, the text he is writing (Cavell 1977, p. 59). In "Notes for Echo Lake 3," Palmer, commenting on a kind of silence from a "he" who remains undefined, writes, "In silence he would mark time listening for whispered words" (Palmer 1981, p. 17). The "he" perhaps remains unnamed and undefined - a pronoun in search of a noun-because he is listening. The formation of an identity comes after that, when the listening is turned outward and becomes expression. As Emerson writes in "The Poet," "The man is only half himself, the other half is his expression" (Emerson 1983, p. 448). Palmer complicates this conception of subjectivity even further, "And I as it is, I as the one but less than one in it" (Palmer 1981, p. 15). The words of one's experience, whispered from the interior, are what await expression, and the articulation of that experience, by such means made available to others, is a way that one manifests one's subjectivity.

The idea that we must express to come to some sort of wholeness is compelling, and we might come to wonder about how that expression might be received. As Thoreau writes in Walden, "I, on my side, require of every writer, first or last, a simple and sincere account of his own life, and not merely what he has heard of other men's lives; some such account as he would send to his kindred from a distant land; for if he has lived sincerely, it must have been in a distant land to me" (Thoreau 1992). The acknowledgement of one's own subjectivity becomes the means by which others-by comparison and through contrast—can come to recognize their own. With that, however, comes the risk of not being heard. A "Sign that empties itself at each instance of meaning, and how else to reinvent attention," writes Palmer in "Notes for Echo Lake 1" (Palmer 1981, p. 5). Is it the emptying out of one's self-the expression-that creates the possibilities for one's own attention to others? Or is it that the emptied sign calls for another's attention?

The untethered referent "he" of Palmer's line, "In silence he would mark time listening for whispered words" is not the only challenge in reading the work. The poems of Notes for Echo Lake are often largely comprised of paratactic statements, fragmented sentences, and free-floating aphorisms. Take this passage from "Notes for Echo Lake 3" as representative:

10 In the preface to Senses of Walden, Cavell will explain that in turning to Thoreau he hoped to find a moment before the radical split between the English and German traditions of philosophy "began to shun one another" so as to find the means to "reenact an old exchange between these traditions," p. xiv.

11 "Period [senses of duration]," in (Palmer 1983). 
The letters of the words of our legs and arms. What he had seen or thought he'd seen, within the eye, voices overheard rising and falling. And if each conversation has no end, then composition is a placing beside or with and is endless, broken threads of cloud driven from the west of the afternoon wind. ${ }^{12}$

In some ways, this passage is recognizable in regards to its vocabulary-the words themselves are common enough-yet in grammatical terms, the words don't easily knit together to indicate the expected sequencing of either an argument or a developing narrative. Nevertheless, it feels meaningful, perhaps because of that fact of its being between straightforward legibility and obscurity. Such a situation demands interpretation, and we begin by interrogating the language itself-that is, how the words mean. This is true not only of texts, but of life, yet a it is a poem whose very existence, pace Modernism, is predicated on the belief that activating the polysemous nature of language is a necessary condition for representing the world's complexity of meaning. Called to such effort, "[when] the mind is braced by labor and invention," writes Emerson, "the page of whatever book we read becomes luminous with manifold allusion. Every sentence is doubly significant, and the sense of our author is as broad as the world" (Emerson 1983, p. 59). In "Notes for Echo Lake 11," Palmer writes in a variation on Emerson's theme, "Words listen to the words until you hear them," which itself is a way of describing the self-conscious process of interpreting, as we use our understanding of words as the means of trying and sounding the depths of the words whose meanings are unknown though the words themselves be familiar.

Without the guidance of a clarifying or determining apparatus of a larger narrative to offer context, within the sentences we start to see the poem commenting on itself. Turning to the passage from Palmer that I cited earlier, we might begin, say, in reading "the letters of the words of our legs and arms" by noting that legs and arms are part of our body language and their position communicates desire or fear or openness or distrust—or all these at once. "Eye" is a homophone with "I," which is where our acts of perception take place. Conversations are not necessarily composed; they occur and develop and so do not have a proper ending. In the end of Palmer's prose poem, we find a single sentence: "In the poem he learns to turn and turn, and prose always seems a sentence long" (Palmer 1981, p. 17). The line plays with the notion of verse and also "conversation," indicating their shared etymology in the Latin word for "to turn." That is, "if no conversation has an end," it too will continue to turn and turn. The line itself being itself a sentence, points back to itself, precisely because of the fact that although it looks like prose, it does not behave like prose. The self-reflexivity does not necessarily lead to an endless loop, but rather gets us to think about the very nuances of the word and how we determine the meaningfulness of their conversation. This process never ends if we never come to certainty but keeps turning and turning. Cavell might see this as a manifestation of an Emersonian moral perfectionism. ${ }^{13}$ That is, since we never reach an end, there is an openness that remains open.

Such openness remains important if legibility and interpretation is counted as part of how we determine the nature of the world and our relationship to it. In Palmer's "The Comet," the opening poem of Notes for Echo Lake, the world is represented as a textual space to be read: "That year the end of winter stood under a sign. All days were red in the margin/ writ large against the ochre rooftops ...." (Palmer 1981, p. 1). In the homophonic slippage of "red" the color and "read" as the past tense of "to read," Palmer also calls to mind the ways that, conventionally, textual corrections are made in the margins with red ink while at the same time that pun foregrounds the word as a signifier-the lexical "a," a visible but unheard difference, that might set us up for a misreading, substituting "red" for "read." Which sounding of the word is the mistake and which is the correction? In a later poem in the collection, Palmer offers a sentence that is in the form of a question but does not actually end with

12 (Palmer 1981, p. 12) Cavell offers an interesting discussion of "being next to" or neighboring or "nextness" in regards to one's sense of nature, landscape (neighbors), and ourselves when we grow self-conscious in (Cavell 1977, pp. 104-10).

13 The fullest discussion of Cavell's understanding of Emersonian moral perfectionism is to be found in Conditions Handsome and Unhandsome, beginning with the extensive introduction. 
a question mark: "Or was the question in the letters themselves, in how by chance the words were spelled." Palmer seems to be underlining the arbitrary nature of the structure of words and what the telling difference comes to when small differences are brought to the fore. It has a skeptical force: "how do I know which red (or read) you mean"? Arguably, it is because of the ever-present uncertainty of communication and incomplete expression built out of language that never escapes inexactitude that the impetus for conversation continues and never really ends.

Earlier I was suggesting that the meditative space of Echo Lake or Walden, or perhaps Middletown, $\mathrm{CT}$, are places that are important for the ways that they create meditation from which flows expression. I say that place is important, and yet Notes for Echo Lake begins with an epigraph from Augustine that troubles that claim: "Place there is none; we go forward and backward, and there is no place" (Palmer 1981, n. p.). Might that be an argument against the specificity of place? It is hard to read it in any other way. Yet in the context of Augustine's confessions, these lines indicate that there is no outside, no division of one place from another place, except subjectively. Or as we see in the first poem, a prose poem, of Palmer's "Echo Lake" series, "If one lives in it. 'Local' and 'specific' and so on finally seeming much less interesting than the particular wherever that may locate" (Palmer 1981, p. 4). We note that "particular" in being particular also always reminds us of its being part of something larger. By extension, this applies to one's subjectivity in regards to its situation. "I am dependent on everything," says the speaker of Palmer's "Notes for Echo Lake 11" and if we are reading the poems as being also a meditation on writing, then this is not simply an expression of the self but is also a description of grammatical construction (Palmer 1981, p. 69). In other words, the personal pronoun, that which is named by "I" is such, as such, only in relationship to the things and people around it. As Cavell writes, "language is everywhere we find ourselves," which I take to mean that we find ourselves, the selves that we are, in language through language. This brings again to mind, "Words listen to the words until you hear them."

Allow me to linger a bit more over Palmer's quoting Augustine since it raises the question of what debt the epigraph creates between where it is cited (Palmer's book of poems) and the source text. How much, for instance, of a transcendental sentiment or tendency is imported with those lines and then grafted onto the poems that follow? Or perhaps we might ask this another way: Is Palmer's book of poems then a form of spiritual meditation, a genre both signaled and activated by its opening citation, which is drawn from just such a text? If Notes for Echo Lake is indeed such a meditation, and the citation seeks to place it within that tradition, then what follows that epigraph-that is to say, the poems themselves-offers a different version of what one means when one says "spirit" as well as meditation, a form of inquiry that is not religious, yet no less deeply felt. The same can be said of Walden.

Inasmuch as Augustine's confessions move between philosophy, theology, and biography—-between rhetoric and narrative—-so too do Palmer's poems, through this engagement with relationships based on, built out of language - which is to say all relationships. I raise the possibility of the poems being a form of meditation because the problem of the epigraph and the relationship between texts remain connected to the idea of how a poet inherits a tradition, crafts a genealogy-how he or she wishes to be heard and to whom he or she is addressing such acts of language. These issues have other implications as well, because the unsettled space between poetry and argument-based claims might be a space for a certain kind of philosophy, or at least what we might call "thinking," and even the emphasis that the poems are "notes" suggests that the work acknowledges at every moment that it is writing, that the notes are the mechanisms of language that point to their incompleteness. Being caught between those modes of the philosophical and the literary might call for an "outlook based on philosophy." When I say that these are modes, I do not merely mean they are forms of writing, but rather are the kinds of thinking that attend, that are enacted through the writing itself. In this way, Palmer's work is not a form of philosophy, but it is an activity of language that by way of its difficulties acknowledges that philosophy and ethics underwrite all interpretive processes. The poems share with Emerson a certain resistance to conformity that requires the reader fall back on his/her/their 
own experiences with words and how they mean in order to find some shared sense of language, some glimpse into what we do and do not share as common experience.

So what are we to make of (make out of) the thinking of Notes for Echo Lake? From the beginning, we see a title that indicates that there is a form of address (the notes are intended for, addressed to Echo Lake). Or is it best to read the work as something else if we take the other meaning of "notes"? I also take this as the first step in seeing the poems as being about the act of writing, the attempt to bring experience back into language, and therefore to make language itself an experience of itself. Behind the title, we might hear Wittgenstein's description of Philosophical Investigations as "sketches of landscapes" (Landschaftskizzen). ${ }^{14}$ That is, we would take it that the poems are notes, drafts, sketches that point towards representation, and specifically the representation of something coming to be, an expression of futurity-as if to say the poems are notes that will represent what is to come, in this case, a "new yet unapproachable" Echo Lake. ${ }^{15}$

Both readings of the title are possible. In the first place, the poems then are the address that pushes back to the origin of the words, lines, and sentences. The address, in other words, reveals the addresser's sense of language and ethics - the sense of how to approach the addressee in language is enacted by, expressed by the language and the particulars of its use. Address creates a relationship and the language reveals the architecture, the poetics - the ebb and flow of ethical responses, the shuttling of perceived debts and obligations between the addresser and the addressee. "Who did he talk to/Did she trust what she saw/Who does the talking/Whose words formed awkward curves," Palmer's propositional, interrogative lines both ask and posit in "Notes for Echo Lake 4" (Palmer 1981, p. 22). In this case, the complex syntax at work in Palmer's poems reveals that the addressee is not easily described as a "voice" or a "speaker," if we are to imagine those tropes conjured by these terms as stable, consistent, and continuous figures. But why is it we would be apt to assume that a "voice" —any voice-is that consistent, that stable? We might say that the speaker is not the origin of a word-that is, a word's meaning does not derive specifically or at least not wholly from the person saying it. Rather, the voice provides a location, a context for the words. It arranges without defining, or that definition is never settled as it comes to test the terms of its arrangement at each moment.

In his essay "Autobiography, Memory and Mechanisms of Concealment," Palmer includes a long discussion of Augustine, and offers the reading that insists, "Augustine investigates both the subject-object relationship in discourse and the structural relationships that constitute the linguistic sign in order to reveal what he is doing, to confess the nature of his activity" (Palmer 2008). In other words, with other words, according to Palmer, Augustine's self-interrogation confesses that all language is mediated. Yes, one wants to say, but what is part of that mediation? What necessitates negotiation and interrogation, self or otherwise? This is the question of whether or not we can communicate that revelation to the Other. "The relationship between signifier and signified must be reconstituted at each moment of the act of telling, in a constant state of uncertainty," writes Palmer. ${ }^{16}$ That state of uncertainty is what we might call skepticism. If we need to constantly restate and rediscover how our words mean, then we always have to find the means and conditions for what we say so that others might hear or acknowledge what we have to say.

I have not forgotten that my rationale for wanting to place Palmer's work in dialogue with Cavell arises not simply because of some personal history they shared or because I necessarily want to foreground some regional element of these poems by Palmer, a poet who is usually read in a consciously_even self-consciously_cosmopolitan and international context. My emphasis on that

14 Wittgenstein calls his remarks "eine Menge von Landschaftskizzen" ["a set of landscape-sketches"] in the preface of his book. (Wittgenstein 2001).

15 I am alluding to both Cavell's book This New Yet Unapproachable America as well as a passage from Emerson's essay "Experience": "I feel a new heart beating with the love of the new beauty. I am ready to die out of nature, and be born again into this new yet unapproachable America I have found in the West." (Emerson 1983, p. 485).

16 Ibid., p. 276. 
element of "America" that is "American thought" is shot through with a double need of determining the ground by which one makes claims (for others or for ourselves) and of doubting the grounds for those claims at the same time. Cavell describes the situation this way:

Any American writer, any American, is apt to respond to [America's declaring its independence] in one way or another; to the knowledge that America exists only in its discovery and its discovery was always an accident; and to the obsession with freedom, and with building new structures and forming new human beings with new minds to inhabit them; and to the presentiment that this unparalleled opportunity has been lost forever. (Cavell 1977, pp. 8-9)

He will go on to say that Thoreau's writing-and by the extension all American writers of the tradition I have been sketching out- "must admit this pressure and at every moment resolutely withstand it," adding further that it "must live, if it can, pressed between history and heaven." With "admit" we see Cavell saying that the pressure must be allowed into the work, but also that pressure must be confessed. Thus, the state of uncertainty that Palmer describes in Augustine, that he clearly enacts in the ambivalences of the syntax of Notes for Echo Lake (with "Words that come in smoke and go," Palmer says in "Notes for Echo Lake 3"), may also amount to the pathos that Cavell describes as something inherent in American philosophy that comes to us from Emerson and Thoreau and then gets absorbed and redistributed back through Nietzsche and Heidegger, among others (Palmer 1981, p. 17). Although Palmer himself may again and again invoke European thinkers and philosophers-just as Thoreau or Emerson do as well-he does so to create his notes for Echo Lake, the poems that will add up to an experience of (but not be reducible to) a specific place in America, as if to indicate that Echo Lake still is left unfounded even if we know where to find it. This need to discover where one is- "Where do we find ourselves?" Emerson asks at the beginning of his essay "Experience"—-suggests that we can never simply be where we are, since to name it is to begin to place ourselves outside of the experience. This also seems to be evoked in the reference to Augustine.

Now that I have highlighted the problems of language and identity that Palmer wrestles with in his poems, let me place the conversation in another frame that has to do with skepticism. I turn to Cavell's essay "Finding as Founding," one of his most crucial readings of Emerson, for a passage that seems to echo the claims of Palmer's I cited just a moment ago. Cavell writes,

The feeling as if we have to penetrate phenomena is evidently produced by a feeling of some barrier to or resistance in phenomena (as if the conditions of a thing's appearance were limitations in approaching it; as if skepticism accurately registered the world's withdrawal from us, say it's shrinking) as if language has difficulty in reaching phenomena, let alone grasping them. (Stanley Cavell 1981, p. 88)

Cavell is responding to a moment in Wittgenstein's Philosophical Investigations: "we feel as if we had to penetrate phenomena."17 This acknowledgment of language's difficulty is threaded through Notes for Echo Lake and is in part enacted by the ways that the poem's language is at times so difficult to understand. In a passage that seems colored by Cavell's comments, Palmer writes in the poem "Seven Lines of Equal Length":

The simple past has weight

but where are the fountains you spoke of

17 (Wittgenstein 2001, p. e36.) Cavell is using Anscombe's translation, which translates "Erscheinungen" as "phenomena". It also can be translated as "appearances," which seems relevant given the references to eyes and eyesight throughout Notes for Echo Lake. Furthermore, in this section, Wittgenstein himself cites Augustine: "Thus Augustine calls to mind the different statements that are made about the duration, past, present, or future, of events. (These are of course not philosophical statements about time, the past, the present, and the future.)". 
she wonders in perfect innocence

and the flowering trees

and what is the word that stands for these things

he asks her between the branches. (Palmer 1981, p. 43.)

That compulsion to use language to get beyond language is what we might call a will to know, though in reality, through our efforts, we draw near not the phenomena themselves but the kinds of statements we make about phenomena. The compulsion to name a thing exactly-and we feel it often enough in moments of great pleasure, joy, grief, and horror-might be a Romantic one, granted, but it would be a problem insofar as it is inadequate and unsatisfying, to halt just there, to stop in stupefaction, gobsmacked, as it were. There is a further step one can take in the face of the compulsion, the endlessly frustrated will to know, the awe that this is a version of skepticism. For instance, this is how Emerson describes this sense of a prevailing somewhat unanswerable skepticism around language: "I know that the world I converse with in the city and in the farms, is not the world I think. I observe that difference, and shall observe it. One day, I shall know the value and law of this discrepance" (Emerson 1983, pp. 491-92). We see here a sense of that next step. Emerson does not drive towards resolving the discrepancy between word and thing, language and experience, but towards knowing the value of that gap and what the endless deferral offers us, which is at last a reason to keep trying.

In the self-reflexivity and self-consciousness of Palmer's poems, we see reflected the conditions by which poetry both offers a possibility — what we might call hope-of connection and address to the Other even while it exposes to doubt that same possibility that we can ever reach the Other. With that doubt in mind, we can see Palmer's participation in that "reformation of philosophy" that Cavell describes. It does not stand outside of that struggle but manifests it. One limitation of philosophical discourse is that in its insistence on its own logicality, it seeks to be objectivity. Palmer's poetry does not describe the obligation of a philosophical outlook, but establishes the conditions by which we note ourselves seeking out a way of understanding our own frustrations with language, what causes these frustrations, and how we might navigate them. I almost hesitate, though I suppose that is itself a hesitation, to say that what we hold in common is that doubt. This might be, then, what philosophy can learn from poetry. That which holds us apart is what binds us fast. It seems that this connection built on shared distance has something to do with the obligation of having an outlook based on philosophy. As I posited it earlier, to what and to whom are we obligated? Ourselves? Others?

In essence, then, if we often ask how philosophy flows into poetry, we might just as well ask how poetry and literature flow into philosophy? Poetry, particularly Palmer's, does not offer an argument or a consistent worldview, but it does enact the difficulties of interpretation that happen at the most local and specific level. Rather than ignoring or overlooking skepticism and the failures of expression, poetry foregrounds these conditions as the very medium of daily life and poetry's difficulties are amplified versions of the problems that are shot through the language we use to represent everyday life to others as well as to ourselves. We return, then, to the obligation of a "philosophical outlook," which Palmer's book positions as a call for acknowledging how we attune ourselves to the demands of language.

Within the frame of such an essay, I should perhaps offer, given the compactness of the context, something specific, a clear, portable, reading; however, I am arriving at perhaps even more questions, certainly more ambitious questions than I began with. To a certain degree, that seems most apt, given that Palmer's poems are themselves "notes." Call this a reader's notes, then: noting what I read, reading how I note.

At the outset of Senses of Walden, Cavell asks, "what hope is there in a book about a book"? (Cavell 1977, p. xiii.). His question is related to seeing how one philosophical text is prompted by another, and that, largely, is something I see having happened in Notes for Echo Lake-it is a book of prompted articulations and prompting provocations in its deployments of fragments and aphorisms; it is a book of poems about writing and reading in the largest sense, that is, the negotiating of the 
ways that we negotiate meaning. What Cavell's philosophy tells us about language is parallel to what Palmer's poetry tells us about language: words are an unsettledness that seeks to ground itself in experience. In the processes of discovering our acts of interpretation, the warp and hew of how we read, in fits and spurts, it is not simply the words, but how we hang them together with a kind of hope of drawing the attention of the Other through what is recognizable as well as what is opaque that creates a conversation about how we recognize the Other or how, imperfectly, we recognize ourselves through the Other-through that which returns via an echo of our soundings, or what Emerson states as the fact that "In every work of genius we recognize our own rejected thoughts: they come back to us with a certain alienated majesty. Great works of art have no more affecting lesson for us than this." We recognize ourselves by way of that unfamiliarity, that intimate strangeness. Notes for Echo Lake locates itself, its language, the same way we might be called to read it in a series of echoes and locations. What we read is the proximity and distance of texts and words. The poems provide a place for our encounters with our limitations of language as readers, as language workers, a space built from our continued hope against that impossibility of knowing and saying exactly, in persisting against that again-and-again face of failure that measures the shape and sound of what it means to be human at this time and in this place.

Funding: This research received no external funding.

Conflicts of Interest: The author declares no conflict of interest.

\section{References}

Bullock, Ken. 2006. Arts: Michael Palmer and Douglas Blazek Read at Moe's. The Berkeley Daily Planet, April 7. Available online: http://www.berkeleydailyplanet.com/issue/2006-04-07/article/23854 (accessed on 18 May 2019).

Cavell, Stanley. 1977. The Senses of Walden: An Expanded Edition. San Francisco: North Point Press, p. 151.

Stanley Cavell. 1981. This New Yet Unapproachable America. Albuquerque: Living Batch Press.

Cavell, Stanley. 1990. Conditions Handsome and Unhandsome. Chicago: Univerist of Chicago Press, p. 37.

Emerson, Ralph Waldo. 1983. Essays and Lectures. Edited by Joel Porte. New York: Library of America.

Palmer, Michael. 1981. Notes for Echo Lake. San Francisco: North Point Press, p. 1.

Palmer, Michael, ed. 1983. Code of Signals: Recent Writings on Poetics. Berkley: North Atlantic Books, p. 262.

Palmer, Michael. 2008. Active Boundaries: Selected Essays and Talks. New York: New Directions, p. 276.

Schulz, Bruno. 1977. The Street of Crocodiles. Translated by Celina Wieniewska. New York: Penguin, p. 143.

Thoreau, Henry David. 1992. Walden and Other Writings. Edited by Brooks Atkinson. New York: Modern Library, p. 3.

Wittgenstein, Ludwig. 2001. Philosophical Investigations, 3rd ed. Translated by G. E. M. Anscombe. With the German Text. London: Blackwell.

(C) 2019 by the author. Licensee MDPI, Basel, Switzerland. This article is an open access article distributed under the terms and conditions of the Creative Commons Attribution (CC BY) license (http://creativecommons.org/licenses/by/4.0/). 


\title{
Article \\ Endlessly Responsible: Ethics as First Philosophy in Stanley Cavell's Invocation of Literature
}

\author{
Mette Blok \\ Department of Communication and Arts, Roskilde University, 4000 Roskilde, Denmark; mblok@ruc.dk \\ Received: 31 March 2019; Accepted: 12 June 2019; Published: 17 June 2019 \\ check for
updates
}

\begin{abstract}
This essay aims to give an overview of the topic ethics and literature in Stanley Cavell's complete oeuvre. It argues that Cavell's preoccupation with literature is, from beginning to end, primarily ethical, even though he takes his point of departure in epistemological skepticism. Recent research on the affinities between Cavell's early writing on Shakespearean tragedy and the ethics of Emmanuel Levinas has helped to establish this but the question of how this part of Cavell's work is related to his later development of Emersonian perfectionism is rarely touched upon. Consequently, this essay further argues that skepticism and perfectionism in Cavell's thinking are two sides of one and the same ethics, which are bound together by the genre of romanticism. While Cavell's work on skepticism is primarily concerned with the other, his work on perfectionism is primarily concerned with the self. Finally, this essay marks the point where Cavell's and Levinas' overall thinking part ways due to the fact that Cavell embraces Emersonian perfectionism.
\end{abstract}

Keywords: Stanley Cavell; ethics; literature; skepticism; tragedy; romanticism; Emersonian perfectionism; Emmanuel Levinas

\section{Introduction}

The death of Stanley Cavell last summer makes it appropriate to say something overall about the relation between ethics and literature in his work and about the surprisingly strong unity of his oeuvre. Viewed chronologically, Cavell's occupation with literature can be divided roughly into three internally related and partly overlapping phases, an early one focusing on skepticism in Shakespeare, a middle one focusing on romanticism primarily in Thoreau, Emerson, Coleridge, and Wordsworth, and a late one focusing on moral perfectionism in a very broad range of works spanning the whole of the Western literary and filmic tradition ${ }^{1}$. Cavell's occupation with traditional philosophical ethics shows a similar but not quite overlapping structure: In The Claim of Reason Part III, he criticizes 20th century analytical moral philosophy from the perspective of ordinary language philosophy; from the 1990s onwards he develops his moral perfectionism, and late in his career he has an essay on his relation to Levinas, What is the Scandal of Skepticism? In this essay, he tries, as if in hindsight, to place his early thinking about acknowledgment and avoidance, developed in two essays of Must We Mean What We Say? and Part IV of The Claim of Reason, as belonging to an ethics of the other, though in a sense different from Levinas' (Newton 1995; Hammer 2002; Rudrum 2013). It is worth noting that this ethics mainly grows out of his readings of Shakespeare, which could be a reason why it is often omitted in philosophical treatments of ethics in Cavell.

The above sketch indicates that the theme 'ethics and literature' in Cavell requires an investigation of the concepts skepticism, romanticism, and moral perfectionism and their internal relations. I am going to argue that they grew out of each other, not only chronologically but also logically, and that

1 This is a rough sketch. Shakespeare, for instance, is a recurring theme in Cavell, also in what I call the middle and late phases. 
romanticism is what binds skepticism and moral perfectionism together: Romanticist texts are both the expression of and the potential recovery from skepticism, thus making possible the achievement of moral perfectionism. (Cavell does not primarily understand romanticism as a literary period but as a genre, which is also to be found in Wittgenstein and Heidegger, for instance.) While Cavell's treatment of skepticism focuses on Shakespearean tragedy, i.e., dramas which are not narrated but performed in the presence of spectators, his engagement with perfectionism tends to prefer film or poetry or narrative fiction-if he includes drama, like Ibsen's A Doll's House, he focuses solely on the content of the play. This essay presents the argument that Cavell's treatment of skepticism and perfectionism are two equally necessary sides of the same ethics: while the concepts of acknowledgment and avoidance stress our relation to the other, perfectionism highlights our relation to ourselves and our endless responsibility for ourselves.

\section{Skepticism}

It seems uncontroversial to say that from his earliest essays in Must We Mean What We Say? (1969) to what would become his last in Philosophy the Day after Tomorrow (2005) —and in a different way in his philosophical autobiography Little Did I Know (2010)—one of Stanley Cavell's main themes, if not the main theme, is the relation between philosophy and literature. It may be somewhat controversial, however, to qualify this by saying that Cavell's work, from beginning to end, is concerned with the relation between ethics and literature. This depends on seeing his early essays on skepticism in Shakespeare as not primarily an exercise in epistemology but rather as a contribution to ethics, and also on accepting his work on romanticism as having to do with ethics in some broad sense (or senses). Furthermore, it seems to involve finding a way to strike the balance, or perhaps even to negotiate, between what could be called Cavell's two main concerns, those of skepticism and moral perfectionism. Notably, Cavell himself hardly ever addresses this issue as a problem, thus indicating that he sees his two concerns as perfectly compatible. Yet this leaves open the question of their internal relation and their respective weight in his overall thinking. If we turn to the growing secondary literature on Cavell or to readings of literature inspired by his readings, we find remarkably little help on this issue; most commentators concentrate either on skepticism or on moral perfectionism, and if they consider both by way of introducing Cavell's complete oeuvre, they tend to treat them separately and have next to nothing to say about their internal relation ${ }^{2}$. Thus, for instance, in recent years Cavell scholarship has offered welcome contributions to the elucidation of the unlikely similarities between Cavellian and Levinasian ethics, prompted by Cavell's own late article from Philosophy the Day after Tomorrow ${ }^{3}$. These comparisons are important, not least because they stress the ethical character of Cavell's early work on Shakespeare, but they sometimes give the impression (Cavell's own article included) that this is all there is to Cavellian ethics whereas, strictly speaking, this is only part of what there is to Cavellian ethics. How do the skepticist part and the perfectionist part of his ethics fit together?

To begin answering this question, I think we should look at the development of Cavell's work chronologically, and I agree that the article What is the Scandal of Skepticism? is a clue to how Cavell himself would have his early work understood. (There are interesting parallels here to Nietzsche's late forewords to his earlier works: he, too, gave them an unequivocally ethical interpretation.) About halfway into his treatment of Levinas, Cavell states: "A measure for me of progress in The Claim of Reason lay in working to do what I called discover the problem of the other, discover it within the means of a tradition of philosophy that has thought to sidestep Fichte and Hegel [ ... ] and, speaking for myself, finds no help in Heidegger's appeal to Mitsein (being with others), which feels to me to

2 As paradigmatic examples of this tendency, I would mention (Mulhall 1994; Hammer 2002; Rudrum 2013; Norris 2017) but there are countless other examples. I do not so much want to criticize this tendency as understand why this is so and what it tells us about Cavell's position.

3 Apart from (Hammer 2002; Rudrum 2013), the relation between Cavell and Levinas is taken up in (Dahl 2014; De Vries 2006; Standish 2007; Stricker 2012). An early contribution from before Cavell's article is (Newton 1995). 
represent something of a philosophical afterthought." (Cavell 2005, pp. 148-49). Clearly, Cavell sees in this early ambition to "discover the problem of the other" the undeniable kinship of his treatment of skepticism regarding others with Levinas' ethics of the other ${ }^{4}$. With this fundamental agreement in place, however, Cavell seems more concerned to probe his differences from Levinas than his similarities with him. These differences all originate in the different role they allow the idea of God and the infinite to play in their respective philosophies. While generally sympathetic towards the use of religious concepts, Cavell stresses that, unlike Levinas, he sees no need for the idea of God in establishing the responsibility for the other; a particular finite other suffices. Thus he asks, almost rhetorically: "But why is the existence of a finite other not sufficient to create the reality of such claims [of gratitude or sympathy or protection or duty or debt or love, M.B.] upon me?" (Cavell 2005, p. 144). Indeed, Cavell draws attention to the fact that in The Claim of Reason his idea or "experiment" was exactly that of "replacing God by a human other" (Cavell 2005, p. 146), be it in acknowledgment of the process of secularization or of his own limitation. That "the other now bears the weight of God", as he expressed it in The Claim of Reason (Cavell 1979, pp. 470, 482), means for Cavell that the self's relation to the other is not primarily characterized by union but by separation. In a pivotal passage at once marking his closeness to and his distance from Levinas, Cavell writes: “Now when I say, in response to Descartes's Third Meditation proof, that in Shakespearean tragedy (immediately in connection with Othello) this traumatic effect of the recognition of the existence of God is replaced by the idea of a finite other, violence and some sense of an infinite nevertheless remain. But in originating now in the face of a finite other, violence and infinitude cannot be thought to arise from a comparison of myself with the other but from a recognition that this particular other, this creature among all the creatures of the earth similar to me, is also, or rather is therefore, absolutely different, separate from me, I would say, wholly other, endlessly other, the one I single out before whom I am I, eternally singled out. It is the unbearable certainty of this separation to which the torture of skepticism over Desdemona's faithfulness is preferable." (Cavell 2005, pp. 145-46). Thus, the other in Cavell is at one and the same time more similar to the self and more different from the self than the other in Levinas ${ }^{5}$. This takes us back to Cavell's early work on skepticism as tragedy and the reason why he turns to Shakespeare and literature.

In The Claim of Reason, Cavell distinguishes between skepticism with respect to external objects and skepticism with respect to others. In the first two parts of the book, he reaches the conclusion that Wittgensteinian criteria are not meant to refute skepticism about the outer world; rather, this kind of epistemological skepticism is always a possibility but the problem does not generalize and-here, Cavell declares his agreement with the philosophical tradition-it cannot be lived. When in the fourth part of the book he turns to skepticism about others, things change dramatically. This kind of skepticism, Cavell contends, can be lived, and it takes the form not primarily of doubt about the other's existence but of denial, avoidance, even annihilation of him or her. What is more, this kind of skepticism also generalizes in the sense that there is no everyday alternative to it; it stems not from doubt in a particular case, but from a general disappointment over the knowledge we (think we) can have about others in their separateness from us. This is what Cavell calls skepticism's interpretation of "a metaphysical finitude as an intellectual lack" (Cavell [1969] 2002, p. 263): we convert the fact of our separateness into a doubt about the other, about his or her faithfulness, for instance. In two essays dating from before The Claim of Reason, Knowing and Acknowledging and The Avoidance of Love, Cavell famously argues that our relation to the world and to others in it is not primarily one of knowing but one of acknowledging, where he wants the concept of acknowledgment to be understood as an existentiale in Heidegger's sense: "The world is to be accepted; as the presentness of other minds

4 Cavell refers primarily to Levinas' essay "God and Philosophy" (Levinas 1998) and also briefly to "Ethics and Spirit" from Difficult Freedom (Levinas 1990).

5 For the loci classici of Levinas' treatment of the other, see Totality and Infinity (Levinas 1969) and Otherwise than Being or Beyond Essence (Levinas 1981). 
is not to be known, but acknowledged." (Cavell [1969] 2002, p. 324). At this level, the concept of acknowledgment is not yet clearly an ethical concept, but it becomes one as soon as the relation to a particular other or particular others comes into play. Cavell shows this in a series of readings of Shakespeare's tragedies, maintaining that "skepticism with respect to the other is not skepticism but is tragedy" (Cavell 2005, p. 150). Here, at the latest, it becomes evident that Cavell's concept of skepticism is not identical with that of the philosophical tradition; his is a much broader concept, encompassing both epistemological and ethical concerns, and indeed, Cavell sometimes says that he regards skepticism with respect to others as more fundamental than skepticism with respect to external objects, thus indicating the primacy of ethics over epistemology in his thinking. This is why it can be confusing that he sometimes speaks of his "epistemological reading of Shakespearean tragedy" (Cavell [1987] 2003, p. 1) or of his "taking tragedy as an epistemological problem" (Cavell [1987] 2003, p. 143). Strictly speaking, it is the other way around: epistemological skepticism is already an interpretation, or intellectualization, of something tragedy is also an interpretation of, namely our human finitude and separateness. Why did Cavell need Shakespeare to show this?

As already mentioned, in The Claim of Reason Cavell took himself to have shown that skepticism cannot be refuted and that there is no alternative to living our skepticism with respect to others. Characterizing the problem of the other in terms of acknowledgment or its failure, avoidance, and further taking the best case of acknowledgment to be the self's exposure to a particular other, Cavell needed descriptions of intersubjectivity or human relationships which were sufficiently detailed or fleshed out to show what acknowledgment or avoidance amounts to in particular cases. He is not claiming that philosophy never provides this or could not in principle provide it, but he found in Shakespearean tragedy a confirmation of his interpretation of skepticism with respect to the other with vast ramifications. First, he could show that Shakespeare's tragic characters are cousins of Descartes in that they take knowledge and doubt to constitute their fundamental relation to the world and others, thus bypassing the acknowledgment we owe each other and shutting themselves out of our common world. In a recapitulation of his work on Shakespeare in Cities of Words, Cavell writes: "My claim for Shakespearean tragedy has been that, in the generation preceding Descartes's beginning of modern philosophy, Shakespeare was already, in the main characters of his tragedies, exploring characters whose destructiveness can be seen to arise out of this epistemological lack of assurance, but in each case directed to a different topic, a different way in which the foundation of a life seems to give way before a moment of doubt, casting the world into a hostile, worthless chaos. In Othello's case it is a doubt, expressed as jealousy, about Desdemona's faithfulness; in the case of King Lear it is about whether he is loved; in Hamlet's case about the worth of human existence, about the curse of being born, of being mortal; in Macbeth's case about the identity or nature of his wife." (Cavell 2004, p. 425). Shakespeare's tragic characters prove for Cavell that skepticism with respect to the other is a cover for a more fundamental failure of acknowledgment and thus ultimately belongs to the order of ethics, not to the order of epistemology. This passage also touches on the question whether skepticism is a historical phenomenon. While it is clear that Cavell sees modern skepticism as arising in the wake of the new science in the sixteenth and seventeenth centuries and culminating in Shakespeare and Descartes, it is also clear that skepticism to him constitutes a possibility inherent in our language and thus our conceptualizing of the world which is not limited to a specific historical period: Skepticism is played out in Wittgenstein's Philosophical Investigations no less than in Shakespeare's tragedies. Second, Cavell's invocation of Shakespeare allowed him to point out a feature of drama in particular and of (some kinds of) literature more generally which was to become increasingly important in his subsequent readings of literature. Not only were these tragedies about the failure of acknowledgment on a thematic level, they were also enacting or performing a best case of acknowledgment for us as spectators, attending the present of the characters in the theatre. Acknowledging a character in a play can teach us something about acknowledgment outside the theatre, and this direct relation to an other, or investment in an other, on the part of both spectator and reader, is something which is rarely found in philosophy. Thus, Shakespeare's dramas allowed Cavell to begin asking what a play or a text does, 
what its work on the spectator or reader is, and why art can have the importance it has for us, why we care about it so much.

\section{Romanticism}

Along with his readings of Shakespearean tragedy, Cavell turned to certain romanticist texts, primarily works by Thoreau, Emerson, Wordsworth, and Coleridge, as further investigations of the skeptical problematic. But while he took skepticism in Shakespeare as having to do with others, the skepticism he found in the romanticists was rather concerned with the self and its relation to (or with) the world. And while there was no sign of an overcoming of skepticism in Shakespeare's tragedies, the romanticist texts pointed to what Cavell would come to call a recovery from skepticism. In itself, Cavell's turn to romanticism was natural and unsurprising. After all, romanticism can be seen as the bonding of philosophy and literature (or poetry), and Cavell's claim for Emerson's writing in particular is exactly that it constitutes "a fair realization" of this bonding (Cavell 1988, p. xii). Furthermore, Cavell uncontroversially took romanticism to be an answer to what he calls Kant's settlement of the skeptical problematic, where knowledge of the thing in itself is given up for knowledge of appearances (Cavell 1988, pp. 29-31). Thus, he describes his understanding of romanticism's struggle with skepticism and with philosophy's responses to skepticism as "the thought of romanticism as working out a crisis of knowledge, a crisis I have taken to be (interpretable as) a response at once to the threat of skepticism and to a disappointment with philosophy's answer to this threat, particularly as embodied in the achievement of Kant's philosophy [ ... ]. Romanticism's work here interprets itself [ ... ] as the task of bringing the world back, as to life. This may, in turn, present itself as the quest for a return to the ordinary, or of it, a new creation of our habitat; or as the quest, away from that, for the creation of a new inhabitation" (Cavell 1988, pp. 52-53).

If Cavell's turn to romanticist texts is thus quite logical, his claim as to what constitutes skepticism and the alleged recovery from skepticism in these texts is innovative and surprising. Again, it helps to think of Cavell's understanding of skepticism as moving from an epistemological to a more fundamental ethical or existentialist register. While in The Claim of Reason he took Shakespearean tragedy to be the working out of skepticism with respect to the other, now, in the romanticist texts, he takes skepticism with respect to the self, its language, and its world to be "the playing out of a tragedy" in such a way that "our ordinary lives partake of tragedy in partaking of skepticism" (Cavell 1988, p. 9). This skepticism takes on different forms in the different writers but common to them is a certain distance from the world, a lost intimacy with the world, causing despair both linguistically and existentially. Thus, Cavell describes this skepticism of our ordinary lives as follows: "Thoreau calls this everyday condition quiet desperation; Emerson says silent melancholy; Coleridge and Wordsworth are apt to say despondency or dejection; Heidegger speaks of it as our bedimmed averageness; Wittgenstein as our bewitchment; Austin both as a drunken profundity [ . . ] and as a lack of seriousness." (Cavell 1988). This quotation also testifies to the fact that Cavell counts Heidegger, Wittgenstein, and Austin as romanticist writers in his sense, and in particular, he claims that Emerson and Thoreau "underwrite" the concept of the ordinary in the ordinary language philosophy of Wittgenstein and Austin in their attention to the concepts of "the common, the familiar, the near, the low" (Cavell 1988, p. 4). This is a bold claim because like the concept of skepticism, the concept of the ordinary now takes on a meaning which is much closer to ethical and existentialist concerns than what we were used to from standard readings of ordinary language philosophy. This concept of the ordinary is central to Cavell's description of the potential recovery from skepticism in romanticist texts.

In his book Hearing Things, Timothy Gould briefly states that what binds skepticism and perfectionism together in Cavell is the concept of the voice: while skepticism suppresses the individual voice, perfectionism exalts in it (Gould 1998, p. 210). Even though I do not disagree with this, I think that the concept of the ordinary is a better candidate for this role because of its centrality to Cavell's readings of his romanticist texts (an implication of the interpretation in this essay is that these texts 
are both skepticist and perfectionist $)^{6}$. So what does recovery from skepticism look like in Cavell's readings? Again, it takes on different forms in the different writers but common themes are, as we saw above, the restoration of the lost intimacy with the world and the return to the ordinary or everyday which is connected to ideas of domestication and inhabitation. More concretely, it can consist in taking a (new) interest in our ordinary lives or in presenting marriage as intimacy on a small scale, in its turn interpreting the concepts of domestication and the everyday. The relation to the world, which is won in this recovery from skepticism, is still one of acknowledgment, or of reception, and the promise for the self is the promise of nothing short of redemption. To Cavell, this relation of the self to the world is epitomized in the following quotation from Thoreau's Walden, which he keeps coming back to throughout his writings: "You only need sit still long enough in some attractive spot in the woods that all its inhabitants may exhibit themselves to you by turns." (Cited after Cavell 1988, p. 21).

As in his readings of Shakespeare's tragedies, Cavell's claim for his romanticist texts is that they are not only about skepticism on a thematic level but that they enact or perform skepticism and the recovery from it in a way that directly implicates the reader. Thus, for instance, he says of his reading of Coleridge's The Rime of the Ancient Mariner that it "takes the poem as an enactment [... ] of skepticism's casual step to the path of intellectual numbness, and then of the voyage back to (or toward) life, pictured as the domestic." (Cavell 1989, p. 57). In this case, the idea is that the mariner is an example, or representative, to the reader of a working through and recovery from skepticism. A prominent Cavellian inversion here is that of the reader being read by the text, so that the text works as an other to the reader and makes possible a transformation of the self, in some cases even promises redemption. Thus, Cavell develops an idea of what he calls redemptive reading, again immediately in connection with Thoreau's Walden, where reading is understood as a therapeutic endeavor on the model of psychoanalysis. Again, this is not a defense of psychoanalytic readings of texts, but a question of the reader being subjected to analysis through the work of the text (cf. Cavell [1984] 1988, p. 52). So while there is still an other in play here, the focus of interest seems to have shifted with Cavell's turn to romanticist texts: where in the case of Shakespeare's tragedies the main focus was on the self's acknowledgment of the other, in the case of romanticism the main focus is on, we could say, the self's acknowledgment of itself, or on self-recovery. But the claim is that this is impossible without some intervention of an other.

\section{Perfectionism}

Cavell's development in Conditions Handsome and Unhandsome (1990) of what he calls "Emersonian Perfectionism" is the most straightforwardly ethical of his invocations of literature. As the name indicates, it takes its point of departure in Emerson and thus constitutes a natural extension of Cavell's writing on romanticism. (Tellingly, very many romanticist works find their way to Cavell's open list of perfectionist works in Conditions Handsome and Unhandsome, p. 5.) Emersonian perfectionism is meant to be in dialogue with prominent ethical theories, especially Kantianism and utilitarianism, but Cavell always stresses that it is not itself an ethical theory but rather a dimension of moral thinking to be found from Plato (another founding father of Cavell's version of perfectionism) to our day, and not only in philosophy but also in literature and film. The central idea of Emersonian perfectionism is that of being true to oneself, and the main focus is not on good or right action in particular situations but on the whole of one's life and the state of one's soul, i.e., on the questions of how one should live and what kind of person one aspires to be (cf. Cavell 2004, p. 11). Summing up his work on perfectionism in Cities of Words, Cavell says that there are two dominating themes of perfectionism, the first being that the self is always becoming, so that it is best thought of as on a journey of education or cultivation or

6 By saying that what binds skepticism and perfectionism together in Cavell is the concept of the ordinary found in romanticist texts, I do not mean to imply that these are similar concepts but rather that the ordinary is the cure for skepticism, thus paving the way for perfectionism. 
transformation, and the second being that the other, who inspires or accompanies this process, is best thought of as "the Friend" (Cavell 2004, pp. 26-27). Perfectionism thus places tremendous value on friendship which explains why marriage becomes so important in Cavell's thinking. This bears on a worry one could have regarding perfectionism's inherent individualism and the impression it can give of not having to do with ethics after all, since it is focused primarily on the self and not on the other. Cavell is acutely aware of this worry and addresses it as follows: "From the perspective of these theories [Kantianism and utilitarianism, M.B.], Moral Perfectionism, seeming to found itself, let us say, on a concept of truth to oneself, may appear not to have arrived at the idea, or to disdain it, of other persons as counting in moral judgment with the same weight as oneself, hence to lack the concept of morality altogether." (Cavell 1990, p. 2). Cavell's answer to this worry would be that Emersonian perfectionism is concerned with the other in a positive way and that in a certain sense the other even carries more weight than the self but this other is thought of as an exemplary friend, who attracts the self to his or her higher standard, not as an object of duty or obligation. Central to Emersonian perfectionism is the idea of becoming morally intelligible to oneself and to others, and here again the friend is indispensable as "the figure [ .. ] whose conviction in one's moral intelligibility draws one to discover it, to find words and deeds in which to express it, in which to enter the conversation of justice." (Cavell 1990, p. xxxii). Indeed, if there is an imperative in Emersonian perfectionism it is an "imperative to conversation" (Cavell 2004, p. 174), where conversation is understood not only as talking but as a way of living together (with one other or in society at large) - a way of living which mostly favors the virtues of "listening, the responsiveness to difference, the willingness for change" (Cavell 2004). Thus, when Cavell says that the self has "absolute responsibility to itself" (Cavell 1990, p. xxvii), this is not meant as if in competition with the responsibility for others but as a statement of the fact that only the self can be responsible for expressing itself, for making itself morally intelligible to itself and others. The work on the self undertaken in Emersonian perfectionism is related to Aristotle's concept of philautia and Foucault's care of the self where being on friendly terms with oneself is seen as a precondition for being on friendly terms with others, so that the self is also an other to itself and the other is another self.

What characterizes the works of literature for which Cavell claims perfectionism or perfectionist features? In one word, we could say that they are all in one way or another edifying; there is some story of education, cultivation or transformation of the protagonist or of his or her society for the better. The prototype of a perfectionist work is the "Bildungsroman"; indeed, some of the plays Cavell draws on, like Ibsen's A Doll's House or Shaw's Pygmalion, evidently participate in this genre even though they are not novels. (Of course, this also holds for the genre of films Cavell investigates in Pursuits of Happiness, the so-called "remarriage comedies".) Likewise, even if the literary works Cavell points to are very often realist and early modernist novels by for instance Dickens, Eliot, Melville, Twain, Dostoevsky, or James, he also includes poetry, like Whitman, Dickinson, or Stevens, and even Beckett's Endgame. What these works have in common is a call for change, a call for transformation of the self and of society, which Cavell describes as follows: "The vision of the demand for a transfigured future, expressed as a sense of the exhaustion of present culture, perhaps accompanied by a demand for the renewal of culture, call it a vision of modernity, seems shared by many of the major writers [ ... ] of the nineteenth and twentieth centuries." (Cavell 2004, p. 218). The critique of society inherent in these works is often a critique of society's values, specifically of its morality, and thus "a major theme of modern literature" emerges: "the salvation of the self through the repudiation of morality" (Cavell 1979, p. 269). For instance, this is how Cavell reads Kleist's The Marquise of O and Ibsen's A Doll's House: The marquise and Nora both repudiate the morality of their societies, and they repudiate some of our most prominent ethical theories as well, since we cannot make sense of their actions on deontological or utilitarian grounds. Yet we feel that the marquise is right when she forgives the count and that Nora is justified when she leaves Torvald. To Cavell, this is literature at its best: teaching philosophy an ethical lesson. 
When it comes to perfectionist literature's work on the reader, there is a clear difference from the situation of a spectator at a Shakespearean tragedy: whereas the tragedy, in Cavell's words, could not happen without us, because it takes place in the present and the spectator's acknowledgment of the characters' separateness is needed for the tragedy to do its work, narrative fiction typically takes place in the past and is not in the same way dependent on the reader's acknowledgment of its characters: it happened without us. What we can do as readers and what we are invited to do by perfectionist works, is to see the work (or its protagonist) as an exemplary other and let it transform us. But what about Ibsen's and Shaw's plays, one could ask? Are not Nora and Eliza dependent on the spectator's acknowledgment for the plays to do their work? I think we would have to say that in a straightforward sense they are, but that since $A$ Doll's House and Pygmalion are not tragedies but something like the opposite of tragedies (by which I do not mean comedies), there is no specific problem with acknowledgment here, we grant it gladly and, as it were, unawares. Perhaps this even goes some way to explain the relation between skepticism and perfectionism in Cavell: They are two different modi of acknowledgment where skepticism is the deficient modus (this is not to say that it is less common, of course). This would also seem to be confirmed by the fact that Emersonian perfectionism conceives of the other as the Friend, since a friend is per definition someone we acknowledge (though of course we can fail to acknowledge a friend in a particular case).

\section{Levinas or Emerson?}

It is time to try to reach a conclusion about skepticism's place in Cavell's overall thinking and thereby about his general similarities and dissimilarities with Levinas. I hope to have shown that Cavell's invocation of literature is, from beginning to end, primarily ethical and that ethics is in this straightforward sense first philosophy to him. It is also first philosophy in the sense that ethics has primacy over epistemology in Cavell: acknowledgment is more fundamental than knowledge. But this is in itself, unproblematically, an ontological assertion because, unlike Levinas, Cavell does not understand ethics metaphysically or religiously as opposed to something called ontology. (Neither does he understand ontology metaphysically.) ${ }^{7}$ To return to Cavell's invocation of Heidegger, acknowledgment is an existentiale; it is our way of being in this world, not something which is put into us from outside this world.

It is telling that Cavell (and his interpreters) always invoke Levinas in connection with skepticism, never in connection with perfectionism. What Cavell recognizes of his own thinking in Levinas, apart from "phenomenological coincidences" (Cavell 2005, p. 152), is the description of the failure of acknowledgment and the idea that in our encounter with the other a certain passiveness is called for. This is what he says about it in Cities of Words: "What I have said about skepticism with respect to the other can be related to Levinas's claims for the other. Levinas requires our recognition of the other to be taken in passiveness, a way of saying that we are subject to the other and, contrariwise, that the other is presented to us in an accusatory mode, as if reflecting our inability to recognize him or her. As if the alternative to passiveness - receptiveness - is rejection, which I take as a certain kind of confirmation of the intuition I have expressed in saying that skepticism with respect to the other, the failure of a proof of the existence of the other, is not a discovery but an annihilation." (Cavell 2004, p. 117). In this passage, Cavell avoids commenting on the generality of Levinas' idea that the other is presented to me as accusatory or persecutory and also on the fact that there is a fundamental asymmetry in our relation according to Levinas ${ }^{8}$. In What is the Scandal of Skepticism? he addresses these issues a little more directly but still primarily in an effort to understand Levinas, not to distance himself from him. I think, however, that Cavell and Levinas part ways on exactly these points. From What is the Scandal of Skepticism?: "Take the repeated idea of the other as accusatory or persecutory, as naming me-so

7 For Levinas' mature understanding of ontology or "Being", see Otherwise than Being or Beyond Essence (Levinas 1981).

8 For these ideas in Levinas, see the classical formulations in Totality and Infinity and Otherwise than Being or Beyond Essence. 
Levinas likes to put the matter-in the accusative case. Do I understand this as directed to, perhaps as a projection of, my murderousness? Or is my original narcissism (that is, my state before God's infusion of infinity has shattered it) in itself a sufficient cause of moral guilt, or debt? Either way, beginning with murderousness or with narcissism, I might imagine a basis for recognizing responsibility toward the other, as a kind of reparation for my having failed to acknowledge the other." (Cavell 2005, pp. 147-48). Again, this is a perfect description of Cavell's description of skepticism. But the trouble is that Cavell's ethics does not generally begin with murderousness or narcissism, and his primary figuration of the other is not as in Levinas "the widow, the orphan, and the stranger" (Cavell 2005, p. 147) but, as shown, the Friend. Furthermore, the self's relation to this friend is not asymmetrical but has a reciprocity, which is underscored by the weight Cavell assigns to the concept of conversation. (One may ask if the relation to the unacknowledged other is asymmetrical in Cavell. I would say that it is not, at least not in any fundamental or ontological sense, only in the sense that I am the one who has failed if I do not acknowledge the other.) Indeed, if there is an ethical asymmetry between the self and the other according to Cavell, it consists in the fact that I have infinite responsibility for myself and only finite responsibility for others (cf. Cavell 2005, p. 144). Again, this does not mean that I come before others or count more than them but that I must take responsibility for all of my life, all my interactions with others included. As Cavell says: "It is the idea of the finite human being as possessed of infinite responsibility - or say of the unending demand for responsiveness, to itself and others (a function of its perpetual expressiveness)" (Cavell 2005, p. 143). The responsibility is infinite, the demand for responsiveness unending, because skepticism does threaten our everyday lives with each other in the form, as Cavell sometimes says, of the little deaths we afford each other, often without even noticing. But skepticism or tragedy is only half of our lives, and not the most important one, according to Cavell. The other half is romance.

Funding: This research received no external funding.

Acknowledgments: I am very grateful to Adam Zachary Newton for inviting me to contribute to this special issue on a topic so central to me.

Conflicts of Interest: The author declares no conflict of interest.

\section{References}

Cavell, Stanley. 2002. Must We Mean What We Say? A Book of Essays. Updated Edition. Cambridge: Cambridge University Press. First published 1969.

Cavell, Stanley. 1988. Themes Out of School. Effects and Causes. Chicago: The University of Chicago Press. First published 1984.

Cavell, Stanley. 2003. Disowning Knowledge. In Seven Plays of Shakespeare. Updated Edition. Cambridge: Cambridge University Press. First published 1987.

Cavell, Stanley. 1979. The Claim of Reason. Wittgenstein, Skepticism, Morality, Tragedy. Oxford: Oxford University Press.

Cavell, Stanley. 1988. In Quest of the Ordinary. Lines of Skepticism and Romanticism. Chicago: The University of Chicago Press.

Cavell, Stanley. 1989. This New Yet Unapproachable America. Lectures after Emerson after Wittgenstein. Albuquerque: Living Batch Press.

Cavell, Stanley. 1990. Conditions Handsome and Unhandsome. The Constitution of Emersonian Perfectionism. Chicago: The University of Chicago Press.

Cavell, Stanley. 2004. Cities of Words. Pedagogical Letters on a Register of the Moral Life. Cambridge: The Belknap Press of Harvard University Press.

Cavell, Stanley. 2005. Philosophy the Day after Tomorrow. Cambridge: The Belknap Press of Harvard University Press.

Dahl, Espen. 2014. Stanley Cavell, Religion, and Continental Philosophy. Bloomington: Indiana University Press.

De Vries, Hent. 2006. From "ghost in the machine" to "spiritual automaton": Philosophical meditation in Wittgenstein, Cavell, and Levinas. International Journal of Philosophy of Religion 60: 77-97. [CrossRef] 
Gould, Timothy. 1998. Hearing Things. Voice and Method in the Writing of Stanley Cavell. Chicago: The University of Chicago Press.

Hammer, Espen. 2002. Stanley Cavell. Skepticism, Subjectivity, and the Ordinary. Cambridge: Polity Press.

Levinas, Emmanuel. 1969. Totality and Infinity: An Essay on Exteriority. Translated by Alphonso Lingis. Pittsburgh: Duquesne University Press.

Levinas, Emmanuel. 1981. Otherwise Than Being or Beyond Essence. Translated by Alphonso Lingis. The Hague: Martinus Nijhoff.

Levinas, Emmanuel. 1990. Ethics and Spirit. In Difficult Freedom: Essays on Judaism. Translated by Sean Hand. Baltimore: Johns Hopkins University Press.

Levinas, Emmanuel. 1998. God and Philosophy. In Of God Who Comes to Mind. Translated by Bettina Bergo. Stanford: Stanford University Press.

Mulhall, Stephen. 1994. Stanley Cavell: Philosophy's Recounting of the Ordinary. Oxford: Oxford University Press. Newton, Adam Zachary. 1995. Narrative Ethics. Cambridge: Harvard University Press.

Norris, Andrew. 2017. Becoming Who We Are: Politics and Practical Philosophy in the Work of Stanley Cavell. Oxford: Oxford University Press.

Rudrum, David. 2013. Stanley Cavell and the Claim of Literature. Baltimore: The Johns Hopkins University Press. Standish, Paul. 2007. Education for Grown-ups, a Religion for Adults: Skepticism and Alterity in Cavell and Levinas. Ethics and Education 2: 73-91. [CrossRef]

Stricker, Bernhard. 2012. Die ethische Bedeutung des Skeptizismus: Stanley Cavell und Emmanuel Lévinas. Phänomenologische Forschungen 127-61.

(C) 2019 by the author. Licensee MDPI, Basel, Switzerland. This article is an open access article distributed under the terms and conditions of the Creative Commons Attribution (CC BY) license (http://creativecommons.org/licenses/by/4.0/). 
Article

\title{
Ethical Mimesis and Emergence Aesthetics
}

\author{
Josephine Donovan \\ University of Maine, Orono, ME 04469, USA; Josephine.Donovan@maine.edu
}

Received: 10 April 2019; Accepted: 14 May 2019; Published: 22 May 2019

check for updates

\begin{abstract}
In nature the transformation of dead matter (objects) into living matter endowed with green energy or subjectivity is called emergence. Art itself, I argue, is an emergence phenomenon, enacting and replicating in theme and form emergence in nature. Literature thus conceived is about the emergence of spirit. It depicts forces that suppress spirit and enables the spiritual in nature to find expression. It gives voice to spirit rising. Mimesis is thus reconceived as a replication of the natural phenomenon of emergence, which brings to life what has hitherto been seen as object, dead matter. This article outlines the concept of emergence in current philosophical and scientific theories; examines the aesthetic precursors of emergence theory in certain Frankfurt School theorists, notably Theodor Adorno; and applies emergence aesthetic theory to a contemporary novel, Richard Powers' The Overstory (2018).
\end{abstract}

Keywords: emergence; aesthetics; mimesis; Adorno

All creation or passage of nonbeing into being is poetry or making [poiein]

-Diotima to Socrates

Symposium (Plato 1937, 1:330)

Art is an emergence phenomenon; that is, it is a transfigurative process whereby spirit emerges from matter; whereby, as the ancient Greek priestess Diotima explained to Socrates, being arises from non-being. "Works of art do not imitate reality", Frankfurt School theorist Theodor Adorno once wrote; "they exemplify its transfiguration" (Adorno 1974, p. 199, as cited in Wolin 1979, p. 122).

Emergence as a concept is becoming a dominant paradigm in the sciences today: the idea that something qualitatively new sometimes spontaneously emerges when a constellation of isolated heterogeneous materials combines into a new whole or system. Otherwise inexplicable natural phenomena, such as the development of living forms from nonlife materials; of consciousness or mind from matter; or of physical material from nonphysical "virtual" information ("its from bits", in John Wheeler's celebrated phrase (Wheeler and Ford 1998, p. 341)) are examples in nature of emergence. Why or how emergence occurs is not understood, though various theories have been proposed to explain the nature of the process, from the strictly materialistic to the panpsychic to the religious. But that emergence occurs is undeniable. Life and consciousness are thus emergent properties; they are ontologically different from their component material bases—or at least, as some claim, derive from unrealized aspects of those component constituents. A live mouse and a dead mouse may have an identical molecular make-up (their material parts), but those parts do not explain the essential difference between the two creatures. That essential difference-life-is an emergence property (Kim 2006, p. 192).

Art, I proposed in The Aesthetics of Care (2016),

Replicates nature's emergence, whereby the viewer or reader, along with the author creator, participate in [a] transfigurative resurrectory process, the bringing forth into recognition 
[or, indeed, into reality] what is not otherwise seen or recognized [or realized]. Art enacts mimesis - not in the traditional sense of an imitation of a surface reality-but ... as a recognition of and a representation of [a realization of] the spiritual power that inheres in physical reality and which comes to life in the phenomenon of aesthetic emergence. (Donovan 2016, p. 204, parenthetical material added)

I adhere in this regard to an emergence theory closely akin to that proposed by the panpsychists, who maintain that life and mind inhere in the most minute particles of matter and therefore are latent and ready to emerge when a constellation of materials and energies come together enabling their expression or emergence. Through this process of realization-of making real or enabling the real to emerge, otherwise dead matter comes to life. There is, Virginia Woolf once observed, "some real thing behind the appearances, and I make it real by putting it into words" (Woolf 1985, p. 72).

The matter of art-whether it be paint on a canvas or sound waves in a Bach fugue or words printed on a page-becomes transfigured through the minds of the creator and the receiver into a spiritual universe - an unreifiable, subjective, qualitative realm—an "other" dimension that is ultimately only accessible through human semiotics, signifying symbolic forms.

French poet Paul Valéry explained the transformative aesthetic process of emergence by analogy to physical processes of emergence. "The sound" one hears in a symphony, for example-inanimate physical acoustical waves-dissolves as it is transfigured into the nonphysical world of the "musical universe", just as, Valéry notes, "in a saturated salt solution a crystalline universe awaits the molecular shock of a minute crystal in order to declare itself" (Valéry 1971, p. 915). "Art", therefore, as Theodor Adorno maintained, "is an imitation ... of the act of creation itself" (Adorno 1962, p. 171). In this essay, I am adapting Adorno's statement to stipulate that art is an imitation and a replication of the act of emergence itself - an imitation via both its form (replication) and its content (imitation).

Such a conception —of an emergence aesthetics — entails a mimesis that is inherently ethical in that the emergence of spirit necessarily obviates objectification and reification of alterity in all its forms. An emergence aesthetics — one identified by its character as an emergent process—is therefore an aesthetics of care, which involves a participatory form of empathic mimesis-what Adorno called "mimetic comportment" (Adorno 1997, p. 110), which dissolves subject-object duality into conversation, a dialogue that occurs in a realm beyond the composite physical words, notes, paint. "The thingly structure" of artworks, Adorno posited, "makes them into what is not a thing; their reity is the medium of their own transcendence" (Adorno 1997, p. 92).

In order to further explicate these ideas, it may be useful to review the root concept of emergence as seen in current scientific theory. Many theorists believe that we are in the early twenty-first century in the process of a paradigm shift away from classical reductionism, as articulated in Cartesian/Newtonian theory, toward emergence theory, in which "consciousness" is established "as a fundamental property of the universe" (Davies 2006, p. xiii). For, as philosopher Thomas Nagel recently asserted, "The great advances in the physical and biological sciences were made possible by excluding the mind from the physical world. ... But at some point it will be necessary to make a new start on a more comprehensive understanding that includes the mind" (Nagel 2012, p. 8). That "new start" appears to be at hand in the emerging theories of emergence. One theorist goes so far as to propose that the twenty-first century may ultimately be called "the age of emergence" (Pearce 2015, p. 14).

Emergence at its most elementary level occurs when two chemically different molecules (having a different atomic make-up) combine to form a qualitatively new substance. When hydrogen molecules combine with oxygen molecules they form a new substance, water. Neither oxygen, nor hydrogen have the qualities of liquidness or wetness, so the resulting substance-water-is qualitatively new. "Emergence properties are irreducible to, and unpredictable from, the lower-level phenomena from which they emerge", philosopher Philip Clayton explains (Clayton 2006, p. 2).

Some maintain that qualities such as wetness only emerge or become realized when there is an experiencing subject. A sodium chloride molecule is not in and of itself salty. Saltiness only emerges when experienced by a tasting subject. "For there to be something having the property of saltiness 
one needs something that experiences this property", Patrick Spät asserts. The saltiness "is in the sodium chloride as an unrealized disposition - and with the intervention of an experiencing subject this disposition becomes realized" (Spät 2009, pp. 162-63).

This theory connects to certain aspects of quantum physics theory where wave phenomena are seen to "collapse" into particles in the presence of an observing subject or a measuring/monitoring instrument. I will not further explore this connection here (see Donovan 2014), but one of its most intriguing aspects is the position held by some theorists that it is the environment itself that makes the unseen, nonphysical "wave"-universe "collapse" into physical form. That collapse is referred to in physics as "decoherence". It occurs when "quantum objects acquire classical [ordinary, everyday] properties only through the interactions with their natural environment" (Joos 2006, p. 53). "The properties of the 'ordinary' objects of our experience ... emerge from, or are created by irreversible interactions with the environment" (Joos 2006, p. 71). For such objects "the environment [therefore] acts in a manner similar to a measuring device" (Joos 2006, p. 59). Since the measuring device is effectively a subjective observer, the implication here is that it is subjectivity that causes reality-the real world of "ordinary" objects-to emerge.

Beyond physiochemistry, emergence also occurs on the biochemical level where the appearance of self-replicating cells and clusters of cells-living forms-is held to be unpredictable from their physiochemical components. The DNA molecule, for example, is an emergent phenomenon: its "structure represents a high level of chemical improbability, since the nucleotide sequence is not determined by the underlying chemical structure" (Clayton 2006, p. 17).

And, finally, the phenomenon of consciousness and subjectivity is an emergent property, not causally explicable by the physical components that appear to be its base. "It is not enough to say that mind is the brain", Clayton maintains; "a mental event is ... composed out of individual neural events and states, and something more" (Clayton 2006, p. 26).

It is that "something more" that remains the mystery at the heart of the creative process (Diotima's poiein) and thus of emergence aesthetics. What that "something more" is and where it comes from remains a question. Many scientists and philosophers of science believe that increasing physiochemical complexity triggers emergence in the natural world. Others-especially those inclined toward panpsychism, such as Patrick Spät cited above-hold that there is something latent in the component materials that is activated in the emergent process; that is, brought to life or realized therein. Still others maintain that-especially in the most mystifying ontological emergences such as the arising of life and mind - there is a divinity at work. The latter, especially those espousing process theology, note that life forms are guided by a telos, a formal purposive design that is not reducible to the laws of physics. Philosophers from Aristotle to Kant to certain twenty-first-century biologists take this view (Donovan 2018 for a further discussion).

Art replicates the process whereby life and mind emerge from inert matter. The material of art (the physical world) emerges as - is transfigured into—spirit through the subjective consciousness-the mind - of the artist. In this way art may be seen as a replication of the emergence character of quantum decoherence. Art turns a virtual subject into a representative object (mimesis), which is transformed into a subject again (existing in the mental universe of the artist and receiver) through the aesthetic process. As philosopher Martin Buber explained in his aesthetic theory, a work of art, though an object in concrete form, becomes alive as a thou in the encounter with a subject. Artworks thus may be termed geistige Wesenheiten, translated (by Buber) as "spirit in phenomenal forms" (Kepnes 1992, p. 23). "A geistige Wesenheit, a work of art, or form of spirit, although an It, can 'blaze up into presentness,' into the status of a Thou, again" (Kepnes 1992, p. 24).

Karl Steel, writing in a New Materialist vein, posits that "subjects are objects that are cared about" (Steel 2012, p. 33) — that is, paid attention to. The caring attentiveness of the artist brings out the latent subjectivity - expressed as the "aura", to reprise Walter Benjamin's celebrated term (which Adorno defined as "whatever goes beyond ... factual givenness" (Adorno 1997, p. 45)—of the material she is processing, causing it thus to emerge, transforming non-being into being. 
Michael Pearce, himself a visual artist, proposed that art objects are materials isolated and shaped by the artist for the sole purpose of providing recipients (viewers, listeners, readers) with an emergent experience. In art, Pearce claims, "mind is expressed in material" (Pearce 2015, p. xv). The aesthetic "emergent experience [is] the moment when mind reaches out to mind through an object" (p. 41). "Creativity is emergence in action, when ... an answer flowers from [the imagination] ... as an emergence product of its nutritional home" (p. 146). This "spiritual experience is ontologically irreducible, like consciousness itself-we can't eliminate the spirituality of mind by reducing it to the action of neurons" (p. 44).

Pearce espouses a version of process theology in which the evolution of the universe in its living and mental forms is teleologically structured toward fulfillment or completion. "If we accept the idea of an evolving universe and its emergent phenomena as mind, then an artist's work is an imitation of mind, producing emergent works of art" (Pearce 2015, p. 85). The aesthetic experience of "transcendence is beautiful, sublime and humbling because we become aware of something that is awesome-the universal mind" (p. 85).

Pearce thus offers a definition of art as

an expression of mind in material made solely for the purpose of providing for the emergent experience for another's mind.... The emergent experience is one of evolutionary affirmation in which the consciousness of the beholder evolves as a result of its unity with the appreciated thing ... [contributing to] the evolution of consciousness. (Pearce 2015, p. 125)

Pearce, like process theologians in general, sees this evolution as a "gradual evolutionary movement toward goodness and harmony" (p. 127), in which "emergent qualities that are not cooperative are less likely to succeed in the long run because they turn inward upon themselves" (p. 127); "hubris and nihilism [are thus] the opposite of emergence" (p. 128).

One might question, of course, whether there is in today's world much evidence of such an evolution toward the good. Flannery $\mathrm{O}^{\prime}$ Connor effectively skewered a similar notion proposed by Teilhard de Chardin (in The Phenomenon of Man) in her short story "Everything that Rises Must Converge" (O'Connor 1962), which demonstrates inter alia that evil—“hubris and nihilism"—are alive and well. But, while Pearce's optimism may seem unwarranted, his theory of art as emergence contributes usefully to the project at hand.

The basic outlines of emergence aesthetics were laid out decades ago (and before scientific theories of emergence arose) by Theodor Adorno, who wrestled with the complex dialectical relationship between subject and object throughout his work. Adorno proposed "mimetic comportment" (mimetisches Verhaltung) as the requisite aesthetic "attitude toward reality" that is "distant from the fixated antithesis of subject and object" (Adorno 1997, p. 110). Through such "comportment" art "assimilates itself to the other rather than subordinating it" (Adorno 1997, p. 331). "Art's mimetic element" is therefore "incompatible with whatever is purely a thing" (Adorno 1997, p. 17). The artist thus sees into the spiritual heart of nature-its thou, in Buber's terms-and enables its expression through the aesthetic process. "If the language of nature is mute, art seeks to make this muteness eloquent" (Adorno 1997, p. 78). Art, therefore, gives expression to what is otherwise silent (or silenced by human domination). "What is waiting in the objects themselves", Adorno explains in Negative Dialectics, "needs ... intervention to come to speak" (Adorno 2007a, p. 29). Art thus operates as an emergence, bringing to life what is latent and mute in the natural world but brought to consciousness, to spiritual life in the aesthetic process.

Adorno's fellow Frankfurt School theorist Max Horkheimer elaborated the idea further, explaining that through mimesis "nature is given the opportunity to mirror itself in the realm of spirit" (Horkheimer 1987, p. 179). Such mimesis is cast by both Horkheimer and Adorno as the opposite of fascist cultural forms of domination (both were Jewish refugees from Nazi Germany). "Fascism treated language as a power instrument. ... for use in production and destruction in both war and peace. The repressed mimetic tendencies were cut off" (Horkheimer 1987, p. 179). It is important, therefore, as a counter 
to fascism, Horkheimer notes, to allow language and art "to fulfill [their] genuine mimetic function, [their] mission of mirroring the natural tendencies" (Horkheimer 1987, p. 179).

Adorno characterizes the "natural tendencies" that ethical mimesis mirrors in utopian terms as "the affirmative ineffabile", expressed through "the iridescence that emanates from artworks" (Benjamin's aura) (Adorno 1997, p. 233). Art thus inherently "negates the spirit that dominates nature" (Adorno 1997, p. 118). "Brutality ... the subjective nucleus of evil—is a priori negated by art" (Adorno 1997, p. 2232). For art, Adorno maintained, "must speak for what is oppressed by domination of any kind" (Adorno 1961, 2:150).

Without using the term emergence, philosopher Richard Wolin identifies Adorno's aesthetics as an emergence theory. All works of art, according to Adorno, Wolin notes, "inherently surpass their somatic side and thereby give rise to a force that transcends the sum total of their individual moments.... This is their 'surplus' [das Mehr], the moment of ... Unwirklichkeit" (Wolin 1979, p. 118). Unwirklichkeit (Adorno's term) means Un-reality. This "surplus", Wolin explains, is "the spiritual element that arises from the interplay of tensions, the constellation of moments that comprise a work of art" (Wolin 1979, p. 118). Art, therefore, to reprise scientific theories of emergence noted previously, expresses the "something more" that emerges when the mental arises from the physical (Clayton 2006, p. 26).

Nature, whose subjective voice Adorno saw as repressed by human domination and objectification, includes all living life forms, especially nonhuman animals whose suffering he and Horkheimer were acutely aware of (see especially their Dialectic of Enlightenment). In Eclipse of Reason Horkheimer maintains that art's purpose is to "be the voice of all that is dumb, to endow nature with an organ for making known her sufferings" (Horkheimer 1987, p. 101). For, "nature's text ... if rightly read, will unfold a tale of infinite suffering" (Horkheimer 1987, p. 126). And, Adorno noted in Negative Dialectics, "the need to lend a voice to suffering is a condition of all truth" (Adorno 2007a, pp. 17-18).

Ethical mimesis for Adorno (his "mimetic comportment") therefore entails "treating nature and animals as subjects, as ends in themselves" (Flodin 2011, p. 146). In his 1958-59 lectures on aesthetics Adorno specified that the mimetic process involves a transfigurative dialectic between subject and subjectified object. Mimesis is "the impulse to so to speak make yourself into the thing you stand before, or make the thing you stand before into a self" (Adorno 2007b, p. 70, as cited in Flodin 2011, p. 146). In other words, mimesis requires meeting the other half-way, realizing her subjectivity by entering empathetically into her reality. In short, Adorno's "mimetic approach ... respects the other as a subject" (Flodin 2011, p. 154).

In my article "Aestheticizing Animal Cruelty" (Donovan 2011) and my book The Aesthetics of Care (2016) (see especially Chapter 4), I detail that much literature of the past, and indeed, of the present fails to consider animals and/or the natural world as subjects. Rather, they are either dismissed as trivial and unworthy of full consideration, or they are objectified and treated as aesthetically interesting "local color". (There are notable exceptions, of course; Tolstoy, for example (Donovan 2009).) Especially deplorable is the all-too-common aestheticization of animal cruelty and human violence. Such aestheticization requires denying the subjectivity of the material being treated by the writer or artist. In an earlier article, "Beyond the Net: Feminist Criticism as a Moral Criticism" (Donovan 1983), I contended that much literature of the past denied or ignored the subjectivity of women, treating them as stereotyped objects of interest only insofar as they amplified the projects of the male protagonist (Kappeler 1986).

In a more recent article, "Literary Ecology and the Ethics of Texts" (Zapf 2008), Hubert Zapf provides an interesting example of Adorno's "mimetic comportment" in action (though Zapf does not identify it as such), showing how a writer-in this case, Emily Dickinson-effectively introduces animal subjectivity and agency into her literary work.

The poem, Dickinson's \#986, concerns a snake in the garden—not demonized as an avatar of evil, but existing in his own right as a subjective presence. 
The Grass divides as with a Comb-

A spotted shaft is seen-

And then it closes at your feet

And opens further on-

$$
\text { a Whiplash }
$$

Unbraiding in the Sun....

It wrinkled and was gone-

(Dickinson 1979, p. 711, as cited in Zapf 2008, p. 856)

As Zapf points out, "the snake is presented as an independent, fascinating, yet uncanny presence" (p. 857). But the presence that emerges in Dickinson's poem is not just of the snake but of the ineffabile, the "something more".

Dickinson then refers to the snake as a person, including him in the designation "Nature's People".

Several of Natures People

I know, and they know me-

I feel for them a transport

$$
\text { Of cordiality- }
$$

(Dickinson 1979, p. 711, as cited in Zapf 2008, p. 857)

Dickinson thus posits that mutual knowledge and understanding are exchanged between subjects, with sympathy expressed on the part of the human subject for the animal subject. "What is conveyed here", Zapf notes, "is the vital interconnection of the human subject with a symbolic life force ... with an 'other' that is radically alien yet also affects the innermost core of the self" (Zapf 2008, p. 858).

In poem \#1068 the poet conjures up the sacrality of the natural world by seeing it as the site of an unseen religious rite conducted by its creatures. "A minor Nation celebrates/Its unobtrusive Mass" such that "a Druidic Difference/Enhances Nature now" (Dickinson 1979, p. 752, as cited in Zapf 2008, p. 857). As Zapf notes, we have here "the focus of attention of an observing consciousness that almost seems to merge into the observed microworld of nature, which is perceived in the imagery of an ancient highly ritualized culture [the Druidic]" (Zapf 2008, p. 858).

In his pathbreaking work on ecocriticism, The Environmental Imagination, Lawrence Buell (1995) establishes four ethical criteria for an eco-aesthetics: among them, that "the nonhuman environment [should be] present not merely as a framing device but as a presence" and that "the human interest is not understood to be the only legitimate interest" (p. 7). Buell calls for "disciplined extrospection" (p. 104) on the part of the artist as a means of realizing nature's presence. Extrospection means focusing the mind outside the self so as to attempt "to see or articulate the natural environment on its own terms" (p. 81). Dickinson clearly manifests such extrospection-which seems but another term for Adorno's "mimetic comportment" - in her poetry.

Another, more recent example of a work that evidences such a sensibility is Richard Powers' contemporary novel, The Overstory (2018). In this work, trees are presences that affect the human characters in various ways and afford the structural model that unifies the work.

It is a novel about emergence-in both the natural world and in the transformations of the human characters. The work is structured on these transformations in a way that replicates the emergence of a group of trees into a forest community.

The novel traces the life-trajectories of nine human characters who are affected by specific trees in their youths and who later experience epiphanies in which they realize the subjectivity of trees and other creatures of the natural world. These epiphanies constitute a kind of metanoia or conversion experience 
in which their sensitivity to the suffering-in Adorno and Horkheimer's terms-that humans inflict upon the natural world-particularly trees-becomes more acute. Through this awakening each becomes moved toward ethical political commitment, motivated by a desire to save the trees and prevent further destruction. In becoming eco-activists their lives intertwine like the branches of trees that form the canopy in a forest, emerging thus as "an overstory" (the technical term for such a canopy). "They are humans on their way to turning into greener things. Together, they form one great symbiotic association" (Powers 2018, p. 141).

Unlike most "humans [who] hear nothing" (p. 168), several of the characters in the novel hear the "voices" of nature, but it is the women who seem to have the most sensitivity to these otherwise mute communications. ${ }^{1}$ Olivia Vandergriff, an Ohio college student, begins to hear or experience "beings of light" after she is electrocuted in a near-death event: "they're ... unbearable beauty, they pass into and through her body. ... They speak no words out loud.... They aren't even they. They're part of her.... Emissaries of creation" (p. 163). These divinities, so to speak, guide her toward commitment as an eco-warrior; they tell her: "the most wondrous products of four billion years of life need help" (p. 165). Olivia says she hears "the trees. The life force ... like a Greek chorus in my head" (p. 322). Her intensity attracts others who form a circle of political activists around her. She and her partner Nick Hoel end up spending nearly a year high up in the branches of a redwood tree as a protest against logging. Mima, the tree who harbors them, is a subject, a thou. (The tree is referred to with the personal pronoun "who" (p. 295).) Olivia "speaks the creature's name like it's an old friend" (p. 262).

Patricia Westerford is another who hears the voices of nature. A botanist, she is likely modeled on Professor Suzanne Simard of the University of British Columbia, who discovered that trees communicate via biochemical signals through their roots (Wohlleben 2016, pp. 247-50). Westerford makes a similar discovery: maple trees under attack by insects signal to other unaffected trees nearby, who express the same endogenous chemical insecticide as the affected trees. It is apparent therefore, that "the wounded trees send out alarms that the other trees smell. Her maples are signaling... Life is talking to itself, and she has listened in" (p. 126).

Westerford publishes her astonishing results in a major scientific journal, but they are immediately refuted by the scientific community: she is ridiculed, loses her job, and spends several years in the wilderness (literally) before her discovery is validated and she is rehabilitated as an esteemed scientist. Her words thus, while long repressed, "have gone on drifting out on the open air, lighting up others, like a waft of pheromes" (p. 137).

As Patricia continues her research, she comes to realize

Her trees are far more social than even [she] suspected. There are no individuals.... Everything in the forest is the forest. Competition is not separable from ... cooperation.... It seems most of nature isn't red in tooth and claw, after all. (p. 144)

In the end she concludes, "A forest knows things ... There are brains down there, ones our own brains aren't shaped to see.... Link enough trees together, and a forest grows aware" (p. 453). In other words, an emergence occurs in nature when a certain conjunction of elements comes together.

Despairing of saving existing forests, Westerford begins a seed bank to save all existing species, so that in some distant, more enlightened era they may be planted and brought back to life.

She's surrounded by thousands of sleeping seeds, cleaned, dried, winnowed, and X-rayed, all waiting for their DNA to awaken and begin remaking air into wood at the slightest hint of thaw and water. The seeds are humming. They're singing something—she'd swear it—just below earshot. (p. 389)

Mimi Ma's epiphany occurs as she is sitting against a pine tree on the Pacific Coast. She has just learned that two of her co-conspirators in an eco-warrior arson action years before have been imprisoned, one of whom, Doug Pavlicek, has saved her from prosecution by refusing to reveal her participation in the event. "Mimi gets enlightened": "her mind becomes a greener thing". "Messages 
hum from out of the bark she leans against" (p. 499). "A chorus of living wood sings to the woman: If your mind were only a slightly greener thing, we'd drown you in meaning" (p. 4).

Powers seems to envisage that the human species is transforming or emerging into a new species, one that "will learn to translate between any human language and the language of green things" (p. 496). Each of the characters in the novel is engaged in the process of this evolutionary emergence-becoming a "greener thing" who is able to respond through Adorno's mimetic comportment to the languages and voices of the natural world.

There are several references in the novel to Ovid's Metamorphosis. Patricia, for example, reads the work as a teenager. "She loves best the stories where people change into trees" (p. 117). "She wants to ... say, like Ovid, how all life is turning into other things" (p. 122; see also pp. 394, 466).

In the end, however, Powers' vision is more dystopian (from a human point of view) than utopian. Adam Appich, for example, reflects, "Humankind is deeply ill. The species won't last long. It was an aberrant experiment. Soon the world will be returned to the healthy intelligences, the collective ones. Colonies and hives" (p. 56). ${ }^{2}$ Doug sends a silent message to the trees: "Hang on. Only ten or twenty decades. ... You just have to outlast us. Then no one will be left to fuck you over" (p. 90).

There is a sense in which trees have a higher far-reaching intelligence than humans: "Human wisdom", Patricia thinks, "counts less than the shimmer of beeches in a breeze" (p. 115). Trees even seem to be using humans or "toying" with them (p. 131), making it clear that "the world is not made for our utility. What use are we, to trees?" (p. 222). In the end, Adam thinks, he and his "green-souled friends" have been "used by life" (p. 495) in its never-ending self transcendence. "Life is going someplace. It wants to know itself" (p. 496).

Sitting up in their redwood bower, Olivia says of the loggers and of humankind in general, "They can't win. They can't beat nature". Nick replies sardonically, "But they can mess things over for an incredibly long time".

Yet on such a night as this, as the forest pumps out its million-part symphony, and the fat blazing moon gets shredded in Mima's branches, it's easy for even Nick to believe that green has a plan that will make the age of mammals seem like a minor detour. (p. 292)

An emergence aesthetics, which inherently opposes any objectification of nature-whether it be via Cartesian scientific reductionism or stereotypical models that elide the subjectivity of various human groups, nonhuman animals, or other life forms-embraces instead an epistemology that sees the subjectivity — the mind, the spirit—inherent in these forms, and liberates it from human objectivist domination through the artistic process.

"Life is going someplace", a character in The Overstory observes. "It wants to know itself" (p. 496). Art, as envisaged in emergence aesthetics, plays a vital role in this evolutionary process. Through ethical mimesis it is nature emerging as a geistige Wesenheit, nature reflecting back on its spiritual self.

\section{Notes}

1 Otherwise, unfortunately, some of the minor women characters verge on stereotypes: Adam's dissertation advisor and Doug's camp visitor (pp. 236, 417) (seductress), Adam's wife Lois (p. 461) (shrew); Neelay's teacher (schoolmarm) (p. 99). All of these women threaten to thwart noble and idealistic projects of the men.

2 Here, it must be said, Adam and/or Powers veers toward what animal ethicist Tom Regan characterized as "environmental fascism" (Regan 1983, p. 362). Such thinking is found in "deep ecology" theory, for example, Aldo Leopold's Sand County Almanac (1949). Leopold asserted that the interests of the "biotic community" supercede that of any individual member (including human) of that community (Leopold 1966, p. 262). Echoes of Leopold's work recur in The Overstory. For example, one character states that the new human species "will come to think like rivers and forests and mountains" (p. 496)—one of Leopold's central ideas (Leopold 1966, p. 137). 
Funding: This research received no external funding.

Conflicts of Interest: The authors declare no conflict of interest.

\section{References}

Adorno, Theodor W. 2007a. Negative Dialectics. Translated by E. B. Ashton. New York: Continuum.

Adorno, Theodor W. 2007b. Nachgelassene Schriften: Vorlesungen. Vol. 3. Aesthetik (1958/59). Edited by Eberhard Ortland. Frankfurt-am-Main: Suhrkamp.

Adorno, Theodor W. 1997. Aesthetic Theory. Edited by Gretel Adorno and Rolf Tiedemann. Translated by Robert Hullot-Kentor. Minneapolis: University of Minnesota Press.

Adorno, Theodor W. 1974. Aesthetische Theorie. Frankfurt-am-Main: Suhrkamp.

Adorno, Theodor W. 1962. "Valéry's Deviations". In Notes to Literature. Edited by Rolf Tiedemann. Translated by Sherry Weber Nicholson. New York: Columbia University Press, vol. 1, pp. 137-73.

Adorno, Theodor W. 1961. Parataxis on Hölderlin's Late Poetry. In Notes to Literature. Edited by Rolf Tiedemann. Translated by Sherry Weber Nicholson. New York: Columbia University Press, vol. 2, pp. 109-79.

Buell, Lawrence. 1995. The Environmental Imagination: Thoreau, Nature Writing, and the Formation of American Culture. Cambridge: Harvard University Press.

Clayton, Philip. 2006. Conceptual Foundations of Emergence Theory. In The Re-Emergence of Emergence: The Emergentist Hypothesis from Science to Religion. Edited by Philip Clayton and Paul Davies. New York: Oxford University Press, pp. 1-31.

Davies, Paul. 2006. Preface. In The Re-Emergence of Emergence: The Emergentist Hypothesis from Science to Religion. Edited by Philip Clayton and Paul Davies. New York: Oxford University Press, pp. ix-xiv.

Dickinson, Emily. 1979. The Poems of Emily Dickinson. Edited by Thomas H. Johnson. Cambridge: Harvard University Press.

Donovan, Josephine. 2018. Subjects-of-a-Life, Entelechy, and Intrinsic Teleology. Between the Species 20: 2-27.

Donovan, Josephine. 2016. The Aesthetics of Care: On the Literary Treatment of Animals. New York: Bloomsbury.

Donovan, Josephine. 2014. Participatory Epistemology, Sympathy, and Animal Ethics. In Ecofeminism: Feminist Intersections with Other Animals and the Earth. Edited by Carol J. Adams and Lori Gruen. New York: Bloomsbury, pp. 75-90.

Donovan, Josephine. 2011. Aestheticizing Animal Cruelty. College Literature 38: 207-32. [CrossRef]

Donovan, Josephine. 2009. Tolstoy's Animals. Society \& Animals 17: 38-52.

Donovan, Josephine. 1983. Beyond the Net: Feminist Criticism as a Moral Criticism. Denver Quarterly 17: 40-57.

Flodin, Camilla. 2011. Of Mice and Men: Adorno on Art and the Suffering of Animals. Estetika 2: 139-56.

Horkheimer, Max. 1987. Eclipse of Reason. New York: Continuum.

Joos, Erich. 2006. The Emergence of Classicality from Quantum Theory. In The Re-Emergence of Emergence: The Emergentist Hypothesis from Science to Religion. Edited by Philip Clayton and Paul Davies. New York: Oxford University Press, pp. 53-77.

Kappeler, Susanne. 1986. The Pornography of Representation. Minneapolis: University of Minnesota Press.

Kepnes, Steven. 1992. The Text as Thou: Martin Buber's Dialogical Hermeneutics and Narrative Theology. Bloomington: Indiana University Press.

Kim, Jaegwon. 2006. Being Realistic about Emergence. In The Re-Emergence of Emergence: The Emergentist Hypothesis from Science to Religion. Edited by Philip Clayton and Paul Davies. New York: Oxford University Press, pp. 189-202.

Leopold, Aldo. 1966. A Sand County Almanac. New York: Ballantine.

Nagel, Thomas. 2012. Mind and Cosmos: Why the Materialist Neo-Darwinist Conception of Nature Is Almost Certainly False. New York: Oxford University Press.

O'Connor, Flannery. 1962. Everything That Rises Must Converge. New York: Farrar, Straus \& Giroux.

Pearce, Michael J. 2015. Art in the Age of Emergence. Newcastle upon Tyne: Cambridge Scholars Press.

Plato. 1937. The Dialogues of Plato. Edited by Benjamin Jowett. New York: Random House, vol. 1.

Powers, Richard. 2018. The Overstory. London: William Heinemann.

Regan, Tom. 1983. The Case for Animal Rights. Berkeley: University of California Press.

Spät, Patrick. 2009. Panpsychism, the Big Bang Argument and the Dignity of Life. In Mind That Abides: Panpsychism in the New Millennium. Edited by David Skrbina. Amsterdam: John Benjamins, pp. 159-76. 
Steel, Karl. 2012. With the World, or Bound to Face the Sky: The Postures of the Wolf-Child of Hesse. In Animal, Vegetable, Mineral: Ethics and Objects. Edited by Jeffrey Jerome Cohen. Washington: Oliphaunt Books, pp. 9-34.

Valéry, Paul. 1971. Poetry and Abstract Thought. In Critical Theory Since Plato. Edited by Hazard Adams. New York: Harcourt Brace Jovanovich, pp. 909-19.

Wheeler, John, and Kenneth Ford. 1998. Geons, Black Holes, and Quantum Foam: A Life in Physics. New York: Norton.

Wohlleben, Peter. 2016. The Hidden Life of Trees: What They Feel, How They Communicate. Translated by Jane Billinghurst. Vancouver: Greystone.

Wolin, Richard. 1979. The De-Aestheticization of Art: On Adorno's Aesthetische Theorie. Telos 41: 105-27. [CrossRef]

Woolf, Virginia. 1985. A Sketch of the Past. In Moments of Being. Edited by Jeanne Schulkind. San Diego: Harcourt Brace Jovanovich, pp. 61-160.

Zapf, Hubert. 2008. Literary Ecology and the Ethics of Texts. New Literary History 39: 847-68. [CrossRef]

(C) 2019 by the author. Licensee MDPI, Basel, Switzerland. This article is an open access article distributed under the terms and conditions of the Creative Commons Attribution (CC BY) license (http://creativecommons.org/licenses/by/4.0/). 
Article

\title{
Interlocutors, Nonhuman Actors, and the Ethics of Literary Signification
}

\author{
Donald R. Wehrs \\ Department of English, Auburn University, Auburn, AL 36849, USA; wehrsdr@auburn.edu
}

Received: 11 April 2019; Accepted: 27 May 2019; Published: 30 May 2019

check for updates

\begin{abstract}
Associating autonomy with art has long been viewed with suspicion, but autonomous signifying agency may be attributed to literary discourse without lapsing into decontextualized aestheticism or neoliberal conceptions of subjectivity. Through literary practices that "move" readers in a "singular" manner, a work becomes what Rita Felski, following Bruno Latour, calls a "nonhuman actor." Such an actor, Felski observes, "modifies a state of affairs by making a difference," participating "in chains of events" so as to "help shape outcomes and influence events" (2015, pp. 163-64). Autonomous signifying agency within works and literary discourse more broadly enables them to become actors within what Latour terms "networks of associations" through which "the social" is constantly "reassembled." But literary works also act as interlocutors, in the sense Levinas gives the word (1996a, pp. 2-10). Though not full-fledged ethical others, they nonetheless, as interlocutors, are sufficiently invested with the attributes and agency of ethical others to be their extensions or ambassadors. Nonhuman, interlocutory literary agency may be explored in iconic passages of ancient literature-Telemachus' recognition that he is being visited by a god (Odyssey Book 1: 11. 319-24) and Judah's recognition that Tamar is more "righteous" than he (Gen. 38: 26). In being authoritative but not authoritarian, literary discourse becomes a potently autonomous actor within the networks of associations in which it participates.
\end{abstract}

Keywords: ethics; literary theory, autonomous signification; literary singularity; Homer; Genesis; interlocutor; nonhuman actor; Felski; Latour; Levinas; evolutionary studies

\section{Literary Singularity and Autonomous Ethical Signification}

Associating autonomy with art has long been viewed with suspicion. While arguing that a literary work's "singularity" gives it an agency unacknowledged by "instrumental" readings that treat literary texts as examples of or evidence for claims and interests "behind" the work, Derek Attridge carefully differentiates singularity from autonomy by stressing that a work's agency is going to vary as it interacts with different contexts and circumstances (Attridge [2004] 2017, 2015). The singularity comprising a work's specific network of textual features and thus its distinctive agency reflects and is directed to contexts that Hans-Georg Gadamer describes as shaping historical cultural, conceptual interpretative "horizons" shared by the writer and the work's first audience. These in turn are brought into contact with different "horizons" informing and constraining the interpretative activity of later generations of readers (Gadamer 1989). The work's singularity, on Attridge's account, becomes an agent in shaping what Gadamer describes as a "fusing" or melting into one another of different horizons ("Horizontverschmelzung") — that is, placing them into pluralistic dialogue (Haney 2001, pp. 21-22, 47, 85-86).

Though literature certainly acts in the ways Attridge and Gadamer describe, it does not just address readers on levels involving ever-shifting historical and cultural contexts. While literature induces readers to construct and to become transported into imagined worlds (Werth 1999; Gavins 2007; Gerrig 1993), it also presents itself as an interlocutor, thus making the experience of encountering and 
attending to its discourse what Emmanuel Levinas calls an "event of sociality" (Levinas 1996a, p. 8). That is, literature presses us to transcend the horizons, or conceptual phenomenological frameworks, into which we assimilate phenomena we encounter so as to "make use" of them-either instrumentally (to prove a thesis) or for a more diffuse self-enrichment.

Valuing self-enrichment may be seen as a human elaboration of the endeavor to flourish that underlies organic evolution generally (Damasio 2003, 2010, 2018). Similarly, the moral norms and moral sense woven into contexts and horizons may be understood as diverse historical-cultural efforts to articulate what individual and societal wellbeing is and how to achieve it. If literary singularity interacts dialogically with readers' notions of morality, as well as other aspects of their contexts and horizons, in ways that improve them, make them more conducive to procuring wellbeing, then readers ought, rationally, to welcome its agency, for they will be beneficiaries of its effects. To the extent that this is the case, what literary works do have an adaptive, evolutionary value akin to that of normative moral sense. Just as taking turns, considering others' feelings, and monitoring actions for fairness are more likely than not to contribute to success and wellbeing, so welcoming literary singularity and cultivating skill in "taking in" its effects is apt to be at once self-enriching and socially useful.

Literary works in their role of interlocutor, however, model and invite simulations of "events of sociality" that disrupt instrumental assimilation and call into question the intrinsic goodness of self-enriching endeavors. They thus engage and elicit an ethical sense incommensurate with what proceeds from a hyper-prosocial species' endeavor to maximize flourishing within its peculiar biocultural ecological niche. The primate behavioral ecologist Richard Wrangham notes that just as many "morally reprehensible" tendencies "clearly evolved, including numerous kinds of sexual coercion, lethal violence, and social domination", so "many morally delightful tendencies did not evolve, such as charity to strangers and kindness to animals" (Wrangham 2019, pp. 192-93). Charity to strangers lies at the heart of ethics for Levinas, which he places in explicit opposition to moralities predicated on evolutionary logic (for Levinas on animals, see Calarco 2010).

By "moving" readers in its own "singular" manner, a work becomes what Rita Felski, following Bruno Latour, calls a "nonhuman actor." Such an actor, Felski observes, "modifies a state of affairs by making a difference", acting as a participant "in chains of events" so as to help shape outcomes and influence events" (Felski 2015, pp. 163-64). The determinate features of a literary work-its melding of earlier conventions, its thematic or formal innovations and refinements-acquire participatory agency within what Latour terms "networks of associations" through which "the social" is constantly "reassembled" (Latour 2005, esp. pp. 1-17, 62-86, 247-62; Latour 2013, pp. 233-57). This sort of agency, consistent with Attridge's and Gadamer's theorizing, is explored by literary and cultural history. For example, The Odyssey combines oral discursive traditions celebrating trickster cunning with those admonishing self-restraint and deferred gratification, uniting vividly dramatized narrative with stately hexameter cadences and lofty diction to depict a model of virile morality who is transformed into a figure of amoral realism in Greek tragedy. Ongoing shifts in material social contexts and conceptual interpretative horizons inform the travestying of the poem's generic, stylistic grandeur by Petronius and Virgil's separation of cunning and piety in the figures of Ulysses and Aeneas, an uneasily maintained dichotomy amplified in Dante's portrayal. But by using Odysseus' journey as the model for Aeneas', Virgil also brings The Odyssey into indirect contact with another network of actors, the one molding medieval moral allegory, through which it enters into networks shaping romance. Later, after the work's recovery in the West, Homeric style informs and is contested by modern narrative poetry and novelistic prose. Through it all, at once giving rise to reconfigurations and pushing back against their totalizing and reductive aspects, the poem remains a participant in considerations of how, or if, self-assertive shrewdness contributes to or is reconcilable with social morality.

While determinate agency predicated on this kind of singularity is certainly important, literary works are not just "participants in the course of action waiting to be given a figuration" [emphasis in original] (Latour 2005, p. 71), but also interlocutors in the sense Levinas gives the word (Levinas 1996a, pp. 2-10). As interlocutors, they are ethical others, albeit virtual or simulated ones. "[K]nowledge of 
the other [as opposed to knowledge about an object] requires", Levinas argues, "outside all curiosity, also sympathy or love, ways of being distinct from impassible contemplation", for "[t]he other (autrui) is not an object of comprehension first and an interlocutor second. The two relations are intertwined" (p. 6). If literary works are not exactly full-fledged ethical others, they are nonetheless sufficiently invested with the attributes and agency of ethical others to be their extensions or ambassadors.

Literary works are peculiarly hybrid. They are not persons, and thus nonhuman actors. Nonetheless, they act through discourse, which puts them in a double relation to listeners or readers. As an interlocutor, as what Levinas calls "a face", the work acts not as an intentional subject but on an intentional subject by eliciting consciousness of the colonizing, appropriative aspect of all contexts and horizons. However, the other is also, Levinas notes, "an object of comprehension", and what is comprehended in a work is its discourse, the particularities of which activate a kind of intentional agency. As Levinas notes, these "two relations", with an ethical interlocutor and with an "object of comprehension", "are entwined", and this is the case whether the "object" is a person endowed with intentional consciousness or a work marked by determinate, singular discourse.

While the ethical dimension of literary works both speaks to and transcends culturally specific contexts, it also enters into dialogue with moral norms and values rooted in more expansive, species-wide neurocognitive evolutionary contexts. The anthropologist and evolutionary psychologist Robin Dunbar notes that "[a]lthough other neurotransmitters and neuroendocrines such as oxytocin ... play an important role in mammalian sociality, the evidence points to a unique role for endorphins in the maintenance of close relationships in anthropoid primates" (Dunbar 2016, p. 39). Grooming, touching, and cuddling provide mild opiate "highs" that ameliorate pain and communicate affection, thus fostering trust. By combining tactile contact and pressure with rhythmic stroking, companionability is imbued with ordering, comforting expectancies, fulfillments, and variations. Touch-mediated nascent prosody and touch-generated proto-narrative anticipations, interlaced with audiovocal assurances of caring presence, link memory and trust. What is so experienced is then attested to in and communicated by determinate shapes, gestures, and pulsations that literary signification acknowledges and shares, and that literary agency builds on.

The conjunction of interlocutor-mediated "events of sociality" and textually instantiated, singular nonhuman but intentional agency may be explored in iconic passages of ancient literature-Telemachus' recognition that he is being visited by a god (Odyssey Book 1: 11. 319-24) and Judah's recognition that Tamar is more "righteous" than he (Gen. 38: 26). The Odyssey and Hebrew scripture are selected because of their foundational role in shaping Western literary traditions, and because they illustrate divergent ways that literary discourse may be authoritative without being authoritarian. In the passage from Homer, Athena plays the role of an ideal interlocutor (both listener and speaker), standing in alternatingly for the audience and work. At the same time, the passage is representative of how the work, both in narrative details and the manner of narration, directs its audience to attend to the ethical significance of actions and words. By contrast, in the biblical text, there is no interpretative aid equivalent to Athena. Instead, ethical signification seems to irrupt from narration focused on attitudes and priorities inhospitable to engaging with ethical interlocutors. In this respect, the passage from Genesis is emblematic of many such passages in Hebrew scripture. Together, the Homeric and biblical examples illuminate some of the ways that literary works achieve an autonomous signifying agency, and so become actors within the networks in which they participate. Literary signification involves three aspects that may be heuristically distinguished but in practice are artfully interwoven: an eliciting of fellow feeling and imaginative sympathy predicated on somatic empathy shared by humans with other animals accompanies engagement with culturally sanctioned moral norms and an internalized moral sense associated with rational pursuit of personal and communal wellbeing, to which is added an evocation of ethical significance as enjoining one to make others' wellbeing, apart from and at the risk of one's own, the focus of attention and the motive of action. The way these signifying aspects are entwined generates a work's distinctive singularity, but the effect of the entwinement gives the work an internal autonomous signifying agency, as the readings here seek to sketch. 


\section{Attending to Interlocutors and Ethical Enjoining in The Odyssey}

Telemachus' recognition that he has been conversing not with a mere stranger but with a divine being is linked discursively, textually, to his own "godlike" attributes. As she departs, Athena is said to put (thekê) into his heart (thumo) strength and courage (menos kai tharsos) (Book 1: 11. 320-21). Homer's use of "put" (Homer 1995, p. 37) at the beginning of line 321 may be read, in accord with archaic Greek horizons, as a preemptory supernatural event, the goddess at that moment infusing the youth with spiritual moral attributes that make him "godlike" (isotheos) (1: 324). But it may also be read as denoting the effect of his having attended to Athena as an interlocutor, a narrative sequence that begins at line 122 . Indeed, the appellation "godlike" in alternative form (theoeides) is applied to Telemachus prior to his seeing and speaking to Athena (1: 113), in the context of describing his being "troubled at heart" (p. 21) (tetiemenos ètor, 1: 114) while thinking of, daydreaming of, his father's returning to rout the suitors and reclaim his honor and house (1: 115-17). Since -eides denotes "like" and iso- "the same as", the sequence of terms implies both growth and movement from godlike thoughts to godlike actions, as though Athena's intervention calls forth her own qualities already latent in Telemachus. His welcoming the other in the vocative, "Hail, stranger" (p. 21) (Chaire, xeine, 1; 122), and offering hospitality crucially precedes access to divine wisdom's speech and companionship. Moreover, describing the as yet untried Telemachus as "godlike" shifts what is like (-eides) from contexts involving physical power, martial valor, and beauty to ones involving qualities of heart and mind-having a sense of what is due others, of what conduct is worthy of emulation. Telemachus is "godlike" in his aversion to submitting cravenly to any order of things in which might is the only right.

The poem's opening scene, set on Olympus, prepares its audience for so hearing the word. It recounts how the marooned Odysseus is "pitied" (p. 13) (eléairon, 1: 19) by all the gods except Poseidon and how Athena, in urging Zeus to let Odysseus return home, appeals to his sense of justice (1: 46-62). If to be godlike involves feeling pity and being concerned with justice, then humans who possess such qualities integral to moral sociality will be, in effect, "godlike", and so in contact with the divine. Giving narrative expression to logical, causal, and moral inferences, in the manner of mythic discourse generally (Blumenberg 1985), Homer portrays Telemachus' welcoming of the disguised Athena as the consequence of his being angrily indignant and ashamed (nemessethe) "in his heart (thumo, 1: 119) ... that a stranger should stand long at the gates" (p. 21). As an apparently needy stranger, Athena is an interlocutor for Telemachus. To the extent audiences simulate Telemachus' experience, she is an interlocutor for them as well. Still, the work, through the singular intricacy of verbal associations and narrative construction noted above, also functions as an interlocutor to be welcomed and given attention. It is able to act intentionally, to interact with others' intentional subjectivities in a dialogic, pluralistic manner, by virtue of its being approached, as is Athena, ethically. The more intently this is done, the more the work speaks to and with individual readers. To the extent it is allowed to do so, its participation in shifting Greek culture from archaic to early philosophical interpretative horizons comes into view, which in turn illuminates what literary discourse does and why its modes of signifying matter.

Indignation at another's not being treated properly and shame at his own (inadvertent) role in allowing it to happen not only puts Telemachus in contact with a god, but also invests his discourse with reasoned, sociable eloquence: he is able to speak "with winged words" (p. 21) (phonesas ... pteróenta, 1: 121). There are of course culturally historically specific aspects to the feelings moving Telemachus to action: the idea that hospitality to strangers is enjoined by Zeus, apprehensions that strangers may be gods in disguise (as indeed this one is) and thus fear of incurring divine wrath, an aristocratic sense of decorum and of responsibility for the actions of those attached to one's household, etc. Still, cultural distance does not preclude imaginative participation in Telemachus' emotions, for they do not depend solely on sociocultural moral peculiarities (the value tribal and chieftain societies worldwide place on elite generosity (Flannery and Marcus 2012, pp. 91-183; Boehm 1999, pp. 90-124)). They also reflect species-wide human evolutionary legacies, building on mammalian primate empathy but also shaping moral sociality generally. These include affective attunement to others' intentions, needs, dispositions, 
and judgments, rooted in biocultural dependence on others' goodwill and trustworthiness (Gopnik 2016; Colombetti 2014; Klimecki and Singer 2013; Zaki and Ochsner 2011; Machin and Dunbar 2011; Hrdy 2009; Dissanayake 2000; Bowlby 1999). Such attunement is inseparable from an experiencing of second-order consciousness; that is, consciousness of consciousness (LeDoux and Brown 2017; Hirstein 2012; Metzinger 2003). This in turn enables us—indeed, impels us—to see and judge ourselves from a third-person perspective detached from selfish aims but invested in communal wellbeing (Tomasello 2016, pp. 85-134; Tomasello 2019).

The signifying work of The Odyssey as a nonhuman actor, however, goes beyond simply inducing audiences to simulate, in an abstract, spectator-like manner, the qualities of consciousness that, on Homer's account, move Telemachus to ethical sociable action and thus toward companionship with the divine. Homer also calls on the audience to recognize that angry ashamed indignation is precisely the emotion that Telemachus should feel-not only because it is appropriate to his character or social status, but also because it is ethically enjoined. By bringing to mind a web of related terms through his word choice, Homer or the work "acts on" and "reassembles" networks of neural connections: since neurons that fire together wire together (Hebb 1949), poetic diction's triggering of synaptic links within and among brains makes its interventions consequential materially, biochemically (Buck 2014, p. 36; Lamprecht and LeDoux 2004). Nemeseáo denotes "to feel just indignation" [my emphasis], nemesomai "to be displeased or vexed with oneself; to be ashamed", nemesetós "causing indignation or wrath, worthy of it", and némesos "just or deserved indignation, anger at anything unjust" (Liddell and Scott 1958, pp. 460-61).

One may, certainly, understand and thus simulate the suitors' shameless arrogance; one may even appreciate, from a disinterested aesthetic viewpoint, the suitability of their actions to their characters and circumstances-and thus enjoy, in recitation or imagination, impersonating them. One may, in accord with Text World Theory, be incited by Homer's words to construct a mental representation of how the suitors perceive and feel (Werth 1999; Gavins 2007), or be transported by the work's evocation of their perspective into an immersive co-experiencing of it (Gerrig 1993), but only to a limited degree. The poem as interlocutor calls us to a different relation to Telemachus' "winged speech", one anchored in shared experiencing of the ethical as an order of significance that cannot be escaped or relativized. It is not simply that we can detach ourselves from our perspective and enter into that of a collective intentionality, assessing our actions and thoughts in terms of their effects on communal wellbeing (Tomasello 2016, 2019), nor is it just that we project on gods, ancestors, and spirits the judgments we would make if we were unaffected by self-interest or desire (Boyer 2001). Narrative action in the poem begins, in Ithaca as on Olympus, with the effects of pity and concern for justice, thus intimating narratively what Levinas insists phenomenological analysis reveals, that the ethical is experienced as enjoined, as already there "prior to my freedom", before the time of "representable" presences, "the time of beginnings or assumings" (Levinas 1989b, p. 180).

In The Odyssey, Book 1, Telemachus is already theoeides through feeling the emotions proper to one susceptible to and respectful of ethical registers of significance. He is thus brought into association with an apparent ethical other whose effects upon him, making him isotheos, disclose divine solicitude. Once moved out of self-preoccupation and into the world of action and social relations, Telemachus promises the stranger food and invites him to speak of what he needs: "[I]n our house you shall find entertainment (philéseai-friendly, affectionate welcome), and then, when you have tasted food, you shall tell (muthéseai) what you have need of (se chpé)" (p. 21, 1: 11. 123-24). Solicitude for the other's bodily wellbeing modulates into welcoming an interlocutor from whom comes discourse concerning justice leading to companionable association. This narrative sequence, beginning with a Levinasian sense of being unconditionally enjoined, then unfolds in a way that uncannily anticipates evolutionary accounts of moral sense: susceptibility to experiencing somatic empathy and to simulating how others likely view us yields sufficient moral consciousness to make concern for justice the basis of cooperative sociality (Tomasello 2014, 2016, 2019; Buck 2014; Boehm 1999, 2012; Krebs 2011; Kitcher 2011; Joyce 2006). 
After providing the stranger abundant food, and placing him apart from the "proud suitors" (p. 23) (mnestêres agénores, 1: 144), Telemachus asks him about his circumstances, noting that they will not be overheard because the suitors are consuming the household's minstrel's song with the same greedy insouciance with which they have consumed its food. The word translated as "proud" (agénor) has a semantic range-from manly and splendid to headstrong and haughty—that requires ethical sense to discern what in context it denotes (the same applies to "godlike"). Homer's selection of terms ambiguously perched between celebrating power and subordinating it to considerations of pity and justice underscores poetic signification's potential to educate moral perception and right feeling, while his calling the audience's attention to the suitors' egocentric, unreflective pleasure in hearing a "sweet lay" (p. 25) (kalòn àeidein, 1. 155) intimates that attending to the interplay of ethical sense and literary significance in his own discourse requires a kind of understanding, and yields a quality of pleasure, to which they have no access and in which they have no interest.

Moreover, the suitors are occupied with lyre and song "without misgiving" (p. 25) or lightly, carelessly ('rê̂) (1. 160), for they "without atonement [nèpoinon-with impunity, like heedless children] ... devour the livelihood of another ..." (p. 25). In sharing a world through discourse in which significance is regulated by ethical sense, Telemachus and Athena are united in moral outrage at the suitors' bullying rapaciousness. Their "just or deserved indignation", the némesos binding them to one another, proceeds from "anger at anything unjust", and thus entails outrage not simply at the effects of the suitors' predation on themselves, but also at the very idea of arrogant rapacity determining the order of things within actual or possible humanly inhabited worlds.

Since she is an immortal and cannot be affected in relation to life prospects by what the suitors do, Athena's interest in events in Ithaca notably resembles that of the poem's audience to its imagined world. What connects humans to gods and audiences to narratives is a concern for pity and justice that transcends such cooperative sociality as "altruistic reciprocity" engenders; that is, concern for others' wellbeing motivated, directly or indirectly, by the selective advantage it provides oneself or one's affiliates - through fostering teamwork, building goodwill, enhancing reputation (Tomasello 2016, pp. 9-38; Kitcher 2011, pp. 17-66; Krebs 2011, pp. 75-160; Joyce 2006, pp. 13-44; Alexander 1987; Trivers 1971). Moral sociality accommodates biological endeavors to flourish to the ecological conditions of human communal life. By contrast, to be godlike for Homer is to be moved by consideration of what sort of behavior and what order of things sustains for others a flourishing, caring, just, and humanly meaningful quality of life.

This requires empathy, but also exceeds it. The primatology-trained cultural anthropologist Christopher Boehm notes abundant evidence (Melis and Warneken 2016; Warneken and Tomasello 2006; Boesch and Boesch-Achermann 2000; Whiten and Byrne 1988; Goodall 1986) that chimpanzees resemble "normal [non-psychopathic] humans" in "feeling the pain and needs of others", in demonstrating "empathetic perspective taking" behavior, but adds, "There is no sign that chimpanzees have a conscience with moral feelings that involve internalizing group rules (e.g., Gintis 2003), or a shameful, self-judgmental sense of right and wrong" (Boehm 2017, p. 748). Thus, while "chimpanzees understand very well the rules imposed on them by a dominant other, ... when rule-breaking becomes attractive, and they believe there are no rule enforcers present, there is no sign that they are reining themselves in" (Boehm 2012, p. 748). The same may be said of at least the most aggressive of Homer's suitors.

A "sense of morality", Boehm argues, hinges on not just knowing but also internalizing rules so that "[w]e make 'right or wrong' judgments about others, and also about ourselves, based on shame and a moralistic sense of remorse" (p. 749). Homer depicts moral sense and moral social regulation in relation to Telemachus. Once internalized, rules governing a group are applied to self and others and discussed (via gossip). This in turn prompts "joint opinions", which can lead to "group action" fostered by "consensus" so that "the disruptive free-riding behaviors of cheaters and bullies can be curbed" (p. 752). Homer's narrative depicts such a process fairly closely, with the difference that conduct and judgments are made answerable not just or primarily to calculations of what courses of action most likely promote our own and our group's wellbeing, but to an ethical order of significance 
rooted in feeling pity and valuing justice disinterestedly, not merely in regard to oneself and others, but also for others in worlds we may attend to without being subject to. Thus, gods as well as humans experience moral outrage, and humans partake in "godlike" qualities of caring about the maintenance and renewal for others of sustainable ethical sociable human life.

"[S]tirred to anger" (p. 31) or troubled and grieved (èpalastésasa) (1: 252) by Telemachus' account of the suitors' "shameless" (anaidés) (1: 254) conduct, Athena models an ideal auditor's responsiveness to Homer's poem. By this means, the work itself, through its narrative and verbal structures, through the analogy it develops at this point between Athena and the audience, highlights the paradoxical "disinterested interest" linking ethics and narrative. Being so affected by what she hears and imagines, Athena offers Telemachus, in addition to fellow feeling and shared judgment, wise counsel-both by devising a plan of action (that Telemachus consult Nestor and Menelaus) and by urging trust in a better, more just future. The instigator of narrative action at this point, she, but through her the work, moves from modelling ethical responsiveness to assuming intentional agency. Maintaining her disguise, she prophesies, not on claims of supernatural insight or skill in augury (1: 202), but on the basis of what the immortals have placed in her heart (thumô) (1: 200), that Odysseus will find a way to return, as he is a man "of many devices" (poluméchanos) (1: 205). Initiating movement from "joint opinions" to "group action", Athena sets in motion a plot exemplifying patterns that contemporary primate and early human studies place at the center of evolutionary accounts of the origins of human morality.

Groundbreaking social analysis of chimpanzees and other apes in the wild and captivity (Goodall 1986; de Waal [1982] 1998, 1996, 2009) has fostered a body of scholarship delineating the intricate interplay of competition and cooperation, dominance and submission, shaping the hierarchical but unstable group life of the species most nearly related to humans. While violent encounters between groups, involving raiding to ambush isolated males and abduct females, and to extend or protect territory, are common (Wilson and Glowacki 2017), documented in-group violence invariably involves attacks on overbearing "alpha males" by gangs of bullied males (and sometimes females) (Boehm 2017, pp. 754-61). Effectively, the same pattern is commonly observed in forager and hunter-gatherer communities (Boehm 2017, pp. 764-79; 2012, pp. 75-87; Boehm 1999, pp. 90-224; Flannery and Marcus 2012, pp. 91-183). Social mechanisms of balancing prestige and egalitarianism, managing competition and promoting cooperation, allow small-scale societies to discourage in-group self-aggrandizement and protect less competitively able group members, thus fostering a level of social cohesion and affective wellbeing that gives communities or cultures selective survival and flourishing advantages (Krebs 2011, pp. 116-42; Kitcher 2011, pp. 104-37; Boyd and Richerson 2005; Boehm 1999, pp. 149-224; Boehm 2012, pp. 133-212).

What may be inferred about prehistoric social life from ethnographic research is necessarily limited (Kitcher 2011, p. 105). Still, combined archaeological and anthropological evidence suggests that for at least "forty thousand years" after the development of language and symbolic culture, people dwelt in "small bands, each elaborating a socially embedded mode of normative guidance" intended to prevent or minimize the consequences of in-group "altruism failure" (p. 107), for unchecked lack of pity and disregard for justice imperils group survival. Though societies may "choose to fail" in multiple ways (Diamond [2005] 2011), the prevalence of functionally equivalent "normative guidance" in small-scale societies worldwide suggests a non-arbitrary selective process. Cheaters and bullies are curbed in analogous, escalating ways everywhere: social disapproval expressed by mild, then harsher remonstrance, is followed by lesser and greater ostracism and, then as a last resort, exile or execution.

In accord with this pattern, The Odyssey's suitors are given repeated opportunities to mend their ways before finally being killed. Homeric social worlds vividly illustrate what comparative anthropology and historiography document: core "normative guidance" characteristic of small-scale, egalitarian societies continues, with modifications, in early hierarchical polities: the elite are expected to be generous and protective, the non-elite grateful and loyal, and everyone considerate, merciful, and just (Flannery and Marcus 2012, pp. 187-337; Tu 1986). Actual practice, of course, can diverge 
sharply from such expectations, but as ideals made socially visible, for example, in the appellation Homer frequently gives an elite male, "shepherd of the people" (poimena laon-as in The Iliad Book 10: 1. 73), such expectations nonetheless become potent nonhuman actors within networks of associations. They offer "ideological" justifications or "naturalizations" of power differentials, to be sure, but also valorize consideration of others and press toward some measure of social justice.

\section{Ethical Sense and Natural Histories of Morality}

Contemporary rethinking of moral philosophy in light of evolutionary research helps explain why literary practices that appeal to a socially cultivated moral sense (somatic empathy enhanced by regard for fairness and reciprocities) seem to partake of an autonomously signifying agency that moves any auditor not, like the suitors, aberrantly or willfully antisocially arrogant. Humans' sense of and concern about morality can now be explained in terms of species adaptation, viewed as effects of "pragmatic naturalism" - that is, a hyper-prosocial organism's discovery over time of what works to promote its survival and flourishing (Kitcher 2011, pp. 3-13). The very plausibility of natural historical accounts of why humans experience moral sociability as obligatory, however, threatens to divest such experiences of what has traditionally been associated by philosophy with the ethical-namely, that its claims appeal to transcendent, enjoining, or meta-ethical warrants, that the good is distinct from what is advantageous to oneself and one's genetic or social affiliates (Joyce 2006, pp. 179-219). Dennis L. Krebs argues, "When viewed from the perspective of evolution, an important reason that children and adults resist the temptation to behave in selfish and aggressive ways is because these forms of conduct evoked fitness-reducing consequences in ancestral environments, just as they do today .... The reason that people copy the moral behavior of some people and not of other people is because being selective paid off in ancestral environments, just as it does today" (Krebs 2011, p. 273).

If humans experience appeals to the value of moral sociability as compelling for the same reason that polar bears grow white fur, then its valorization within the imagined worlds in which humans dwell (whether through phenomenological consciousness of biosocial life or vicariously via literary art) may well be adaptively useful, but nonetheless constitute a type of ruse conflating subjective projections with objective attributes. This distinction's importance for moral philosophy has a complex prehistory. Drawing on both primatology and early childhood research, Michael Tomasello argues that through joining others in shared attention to something (an object or animal), humans become aware of discrepancies of perspective between self and other, which spurs them to postulate an "objective" view (neither mine nor another's but showing what "really" is) (Tomasello 2019, pp. 45-90). Joint attention and shared intentionality make possible imagining an "objective" view, first attributed to society as a collective and to gods, but then sought after by philosophers and later scientists in efforts to determine what is "in" external reality, as opposed to what is "projected" on it by human minds.

If a sense of being ethically enjoined, as opposed to being morally inclined by temperament or interest, may be accounted for as simply an adaptively useful "projection", then natural histories of morality would appear to imperil what moral philosophy calls ethical naturalism—-the view that "there are moral properties and facts" that exist objectively, apart from human projections and intentions (Nuccetelli and Seay 2012, p. 1). Richard Joyce suggests that skepticism toward any "objective" basis for morality need not impede acting as though ethical significance adhered to natural properties and facts, because doing so remains adaptive (Joyce 2006, pp. 229-30; Joyce 2012). Kitcher argues further that our dispositional and cognitive propensities have been bioculturally primed to attribute "normative guidance" to transcendent authority: "Commands promulgated by elders can be identified with the wishes of the gods or spirits (or with the tendencies of the impersonal forces affecting human success). ... Crude fear of punishment is transmuted into more positive emotions-awe, reverence-and the commands are welcomed as a mark of the favor of an extraordinary being" (Kitcher 2011, p. 113). While the natural selective value of moral judgments lies in their "encouraging successful social behavior", this end is facilitated by having moral judgments "seem like they are depicting a realm of objective 
moral facts", thus imbuing "practical considerations with inescapable and authoritative force" (Joyce 2006, p. 131, his emphasis).

To the extent that "inescapable and authoritative force"; that is, autonomous signifying agency, is felt within moral judgments, they in practice function, Joyce argues, as what Daniel Dennett calls "conversation-stoppers" (Joyce 2006, pp. 111-12; Dennett 1995): they constitute points beyond which one cannot argue, put limits on what can be objected to, what needs to be explained or legitimated, and thus endeavor to restrict what moral skepticism may unravel or dissolve (Joyce 2006, p. 131, his emphasis). Levinas' insistence that ethics is first philosophy, that signification and rationality presuppose rather than ground or explain ethical sense, might well appear to be such a "conversation-stopper" (Levinas 1989a, pp. 76-87). Claiming that ethical sensibility registers the enjoining significance of what is "otherwise than being", what exceeds ontology and disrupts totality (Levinas 1981, pp. 61-97), Levinas rejects ethical naturalism. At the same time, he likewise rejects what evolutionary natural histories put forth as the only alternative- the equation of "the good" with enhanced biosocial flourishing (Levinas 1981, pp. 3-20).

Levinas addresses "skepticism" at the end of Otherwise Than Being, with Derrida in mind, but his argument speaks equally to the moral skepticism of Joyce, Kitcher, and Krebs. The ethical, he maintains, is not "in" the world of being. It is neither an "essence" nor an ontological "natural property." Skepticism rightly deconstructs metaphysics (and distinguishes adaptive from objective value). Still, for Levinas, the ethical as a "preoriginal" (p. 167) relation, one in which "[n]on-indifference, humanity, the-one-for-the-other is the very signifyingness of signification, ... and thus reason" (p. 166). What is felt (non-indifference) is felt as enjoining. This simultaneity of affect and imperative transforms somatic empathy from a sensation into a call and distinguishes the impress of unconditional obligation from assessments of some choices as better than others in moral pursuit of wellbeing. As such, the ethical demarcates, for Levinas, the point beyond which skepticism cannot press, because to the extent that skepticism reasons, it speaks to the other as an interlocutor, recognizes the ethical relation as the basis for speech and for concern for truth, for what may "objectively" be affirmed. Sensibility to ethical significance makes acknowledging the other, as in welcoming the stranger standing at the door, an inescapable and authoritative enjoining presupposed by all winged speech, all reasoning-including that of skepticism. This acknowledging and welcoming is inscribed into a dimension of language different from that used to articulate skeptical claims about being (or objective fact), a dimension Levinas call "the saying", in which welcoming an "other", acknowledging an interlocutor, precedes and traverses reasoned speech (p. 171). Whereas Tomasello suggests that the very idea of objectivity is an effect of humanity's deep sociality, its need for and refinement of joint attention, Levinas argues that ethical interlocution enjoins a disinterested interest that breaks with or transcends endeavoring to maximize one's own flourishing.

This is not to say that "encouraging successful social behavior" is unimportant either objectively or morally, but its importance lies in bringing to bear upon the world of biosocial success the relation to others and their worlds presupposed by reason, shared by Athena and Telemachus, enjoined by Homer's discourse and given witness to in his audience's ability to follow and be moved by its sense. Without this third, ethical dimension, a work lacks the signifying agency distinctive to literature. It lacks singularity, becoming simply one example of among others of topical rhetoric dressed up in the fashions of imaginative discourse. It remains immured in its original contexts and horizons, unable to interact with those beyond its time and place, and so may be a source of historical, sociological information, but have little or none of the autonomous signifying agency that allows literature, in the qualitative sense of the term, to be recognized and appreciated. Of course, there is a continuum of artistry and achievement, diverse forms can become vehicles for more or less literary signification, and receptivity to its effects may be improved with skill and experience. Still, the difference between a work that acts on a reader and one that a reader may simply make use of is readily apparent and needs to be accounted for. 
Levinas himself appeals to the example of a "work" (oeuvre) to explain how the orienting sense of the ethical, in being concerned for and working toward a future beyond its own time, disentangles the good from proximate personal- or group-enhanced flourishing (Levinas 1996b, pp. 48-51). By urging Telemachus to trust in the prophecy put in a stranger's heart by the immortals and vouched for through the effects of speech attesting to ethical solicitude and solidarity, Athena puts into Telemachus' heart strength and courage (I: 320-21). She moves, inspires him "to believe in a nonrevealed future and ... to work in the present for the most remote things of which the present is an irrecusable denial" (Levinas 1996b, p. 51). From that trust or faith derives "very great nobility in the energy liberated from the hold of the present" (p. 51). For Homer, that energy makes Telemachus a "godlike man" (1: 324). To the extent the audience enters imaginatively into Telemachus' experience, what Athena as interlocutor and agent does in relation to him, the work does in relation to its listeners or readers.

To be sure, Athena began cultural life as an invented "unseen enforcer" of social norms (Kitcher 2011, p. 113) and Homer's narrative would affirm that underlying and shaping human events is an order of things responsive to pity and concerned with justice-themis, at once a metaphysical principle, a divinity, and a quality (righteousness). Still, Homer's literary practices go to some lengths to indicate that susceptibility to ethical significance precedes communion with the divine, and that experience of ethical solicitude mediated by discourse gives rise to the trust in others and in the world's amenability to reparation that puts strength and courage in the "heart" (thumos), that arouses sufficient "spirit" (also thumos) to challenge egoistic rapacity's assertion that might is right. In Homer, there is already in literary discourse the "philosophical exegesis" (Levinas 1989c, p. 142; Wood 2009) that separates myth (and by extension poetic representation) from idolatry (that is, naïve assent to claims about what is "in" natural properties or true about being). Myth, "at the same time untruth and the source of philosophical truth", is "interpret[ed]" (pp. 142-43) by the work's instigation of entwinements of ethical sense and literary significance. In the case of Homer, his poetry's participation in reassembling the social begins with it both provoking traditions of moralizing allegory and resisting their reductive, conventionalizing effects (Brisson 2004; Struck 2004; Dawson 1992; Lamberton 1986).

An anti-idolatrous thrust inheres in Homer's insistence that insensibility to the ethical sociable regulation of any world inhabitable by humans seals the suitors' doom. Their acting as though pity and justice did not matter, as if force, guile, and interest were the only nonhuman actors who counted, proves both unsustainable and undesirably dehumanizing (a practical judgment that much contemporary evolutionary theory supports). Still, Homer's literary art interprets the problem only secondarily as misperceiving what forces govern advantage. The primary fault is making advantage the sole measure of significance. By contrast, being "godlike" in acting out of a sense of being enjoined opens one to becoming "godlike" through others' words and deeds eliciting trust, giving one "heart." Though Athena is rarely associated with the maternal, and though her guises are masculine (first the stranger, then Mentor), her engagement with Telemachus, like that of a mother with a child, gives rise to a shared imagined world marked by sheltering ethical sociality.

That world which Homer's audience is invited to share is one that may be inhabited and acted on, for it encourages confidence that wherever one moves within it the qualities and attributes interfusing it will remain at hand, either companionably at one's side or abidingly in one's heart. The question is not whether humans will habit imagined worlds, but what kinds—and that is where literary works as singular nonhuman interlocutors intervene. They so interpret myth as to suspend the displacement of one "untruth" (ontological schema) by another in favor of "philosophical truth" that exceeds ontological and thus idolatrous measures of value. If susceptibility to pity and concern for justice order and sustain such worlds, ethical sense's signifying autonomy also opens them to iconoclastic critique and tireless reform. What gives authority to condemnation of the suitors may also put in question Homeric attitudes about patriarchal privilege, slavery, the scope of warranted violence, and "honorable" ways of attaining wealth, but the same iconoclastic energies allow the work to sharpen our awareness of the suitor-like attributes of neoliberal corporatism and fascistic politics in our time, and perhaps give us some faith, like Telemachus', that the order composed of such forces need not be all that can be. 


\section{Anarchic Ethical Sense and Autonomous Literary Signification in Genesis}

The reading here highlights aspects of The Odyssey neglected in Levinas' own citing of the poem as epitomizing Greek assimilative, self-enriching, instrumental rationality as opposed to non-egocentric, non-intentional responsiveness to the other enjoined by Hebrew scripture (Levinas 1969, pp. 102, 176-77). In making such contrasts, Levinas neglects much in biblical narrative that presents advantage, in terms of conquest, plunder, enslavement, and extermination of ethnic cultural rivals, as the reward for a piety largely, though not entirely, comprised of doctrinal and ritual purity (Gen. 17: 3-8; Ex. 3: 7-8; Num. 33: 50-34: 12; Deut. 1: 6-8, 7: 1-6; Josh. 6: 15-21, 8: 18-29, etc.). Even so, the biblical texts act as literature to the extent they are punctuated by moments in which significance and value are configured quite differently from what is normative or valorized within terms of first millennial BCE "adaptive" endeavors to flourish (even if only in relation to an imagined past). In these moments of transcending contexts and breaching horizons, of iconoclastic rebuke, literary quality and autonomous signifying authority are notably combined.

One such instance illustrating literary signification's irruptive reformative potency occurs in Genesis 38, a chapter which interrupts the Joseph narrative (Genesis 37-50) to describe how Judah told Tamar, the widow of his firstborn son, that he would marry her to his younger son once he came of age. Instead, he seems to forget her. When Tamar sees that the younger son is full grown, while she remains a widow, she conceives a ruse. Pretending to be a harlot, she induces Judah to give her a signet ring, bracelet, and staff in exchange for her favors. She resumes her widow identity but becomes pregnant and is brought before Judah for judgment. He condemns her to be burnt to death, but when she brings forth the signet, bracelet, and staff, he looks at them and then declares, "She is more righteous than I

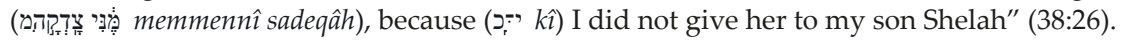

The ethical sense that penetrates Judah upends, if only temporarily, hierarchies of gender, wealth, class, and political power (indicated by the signet ring, bracelet, and staff). What makes the passage an interlocutor whose agency exceeds the contexts of its composition are not problematic codes for disposing of widows, or Judah's notions of customary right, but rather the provocation of his grace in seeing in a forgotten underling's bed-trick a righteousness superior to his own. One can dismiss as myth's "untruth" all ontological claims supposed by custom, positive law, Judah's self-understanding, and the text itself without slipping away from entanglement in the ethical sense that breaks in on Judah. In such moments, literary discourse's signifying agency becomes not just autonomous, but also "anarchic" in Levinas' sense of the word.

Levinas argues that subjectivity experienced as a modality of being, in which "possessing oneself, the moment of having in being", leads one to identify consciousness with "self-possession, sovereignty" (Levinas 1981, p. 99). But self-identifications functioning as archai (beginnings, principles) are undone when "[m]y responsibility for the other", as "the very signifyingness of signification", puts me "anarchically [in] a relationship with a singularity without the mediation of any principle, any ideality" (p. 100). This "anarchy" does not denote "another order", but rather "brings to a halt the ontological play which ... is consciousness" (p. 101), for ethical responsibility attests to obligation anterior to all archai. Instead of being "a constituted, willful, imperialist subject,... I am 'in myself' through the others" (p. 112). Narrative evocation of this traumatic being "turned inside out" (Shankman 2017) triggers simulations attesting to the reader's already knowing what being pierced by ethical sense "feels like." The text itself is notably spare, indicating only that Judah saw and then spoke. It provides gaps that the reader fills in (Iser 1978). This is done with a facility, an automaticity, which places the reader alongside Judah within a world whose ethical sociable textures push inexorably toward "anarchic" iconoclasm.

\section{The Scope of Literary Signifying Agency}

The exorable push of this third, ethical dimension of literary signification yields of itself, autonomously, implications that once felt cannot be unfelt. They enjoin, partake of non-authoritarian 
authority, move us in ways that inform interactive dialogues among contexts and horizons, but are irreducible to them. Of course, as empirical studies of readers indicate, responses to configurations of textual features and patterns vary (Gerrig and Mumper 2017; Gerrig 2011). No work, Attridge reminds us, can preclude its instrumental appropriation, and certainly there has been plenty of that in the reception histories of both Homer and the Bible. Still, in constituting a singularity irreducible to just an example of something else, and in presenting itself as an interlocutor rather than an object or tool, literary works act and make their actions available for responsive engagement. Certainly, the form and character of that engagement is going to vary as contexts and horizons shift, and as literary scholarship and criticism help illuminate with increasing skill (one may hope) diverse strands of philosophical exegesis implicit in the work's own discourse and differing tenors of iconoclasm enfolded into its artistry.

As the passages discussed above suggest, entwinements of literary signification and ethical sense give rise to an autonomous signifying agency through which the work participates within the social as a peculiar hybrid of nonhuman actor and interlocutor. While singular conjunctions of discursive features and sociocultural contexts shape literary and generic histories, and while works engage somatic empathy and intervene in considerations of moral sociality's bearing on personal and communal flourishing, evocations of the impress of the ethical as enjoined underlie the imagined worlds that literature offers and sustains. Diverse literary practices call forth modes of disinterested interest once attributed to gods, but now perhaps more imperative than ever if material and ethical sociable worlds hospitable to human flourishing are to endure.

Funding: This research received no external funding.

Conflicts of Interest: The author declares no conflict of interest.

\section{References}

Alexander, Richard D. 1987. The Biology of Moral Systems. New York: Aldine de Gruyter.

Attridge, Derek. 2017. The Singularity of Literature. New York: Routledge. First published 2004.

Attridge, Derek. 2015. The Work of Literature. Oxford: Oxford University Press.

Blumenberg, Hans. 1985. Work on Myth. Translated by Robert M. Wallace. Cambridge: MIT Press.

Boehm, Christopher. 1999. Hierarchy in the Forest: The Evolution of Egalitarian Behavior. Cambridge: Harvard University Press.

Boehm, Christopher. 2012. Moral Origins: The Evolution of Virtue, Altruism, and Shame. New York: Basic Books.

Boehm, Christopher. 2017. Ancestral Precursors, Social Control, and Social Selection in the Evolution of Morals. In Chimpanzees and Human Evolution. Edited by Martin N. Muller, Richard W. Wrangham and David R. Pilbeam. Cambridge: Belknap Press of Harvard University Press, pp. 746-90.

Boesch, Christophe, and Hedwige Boesch-Achermann. 2000. The Chimpanzees of the Tai Forest: Behavioural Ecology and Evolution. Oxford: Oxford University Press.

Bowlby, John. 1999. Attachment and Loss, 2nd ed. New York: Basic Books, vol. 1.

Boyd, Robert, and Peter J. Richerson. 2005. The Origins and Evolution of Cultures. Oxford: Oxford University Press. Boyer, Pascal. 2001. Religion Explained: The Evolutionary Origins of Religious Thought. New York: Basic Books.

Brisson, Luc. 2004. How Philosophers Saved Myths: Allegorical Interpretation and Classical Mythology. Translated by Catherine Tihanyi. Chicago: University of Chicago Press.

Buck, Ross. 2014. Emotion: A Biosocial Synthesis. Cambridge: Cambridge University Press.

Calarco, Matthew. 2010. Faced by Animals. In Radicalizing Levinas. Edited by Peter Atterton and Matthew Calarco. Albany: State University of New York Press, pp. 113-33.

Colombetti, Giovanna. 2014. The Feeling Body: Affective Science Meets the Enactive Mind. Cambridge: MIT Press.

Damasio, Antonio. 2003. Looking for Spinoza: Joy, Sorrow, and the Feeling Brain. Orlando: Harcourt.

Damasio, Antonio. 2010. Self Comes to Mind: Constructing the Conscious Brain. New York: Random House.

Damasio, Antonio. 2018. The Strange Order of Things: Life, Feeling, and the Making of Cultures. New York: Pantheon.

Dawson, David. 1992. Allegorical Readers and Cultural Revision in Ancient Alexandria. Berkeley: University of California Press. 
de Waal, Frans. 1998. Chimpanzee Politics: Power and Sexuality Among Apes, rev. ed. Baltimore: Johns Hopkins University Press. First published 1982.

de Waal, Frans. 1996. Good Natured: The Origins of Right and Wrong in Humans and Other Animals. Cambridge: Harvard University Press.

de Waal, Frans. 2009. The Age of Empathy: Nature's Lessons for a Kinder Society. New York: Harmony.

Dennett, Daniel C. 1995. Darwin's Danger Idea. New York: Simon and Schuster.

Diamond, Jared. 2011. Collapse: How Societies Choose to Fail or Succeed. New York: Penguin. First published 2005.

Dissanayake, Ellen. 2000. Art and Intimacy: Where Art Comes from and Why. Seattle: University of Washington Press.

Dunbar, Robin Ian MacDonald. 2016. Human Evolution: Our Brains and Behavior. Oxford: Oxford University Press.

Felski, Rita. 2015. The Limits of Critique. Chicago: University of Chicago Press.

Flannery, Kent, and Joyce Marcus. 2012. The Creation of Inequality: How Our Prehistoric Ancestors Set the Stage for Monarchy, Slavery, and Empire. Cambridge: Harvard University Press.

Gadamer, Hans-Georg. 1989. Truth and Method, 2nd ed. Translated by Joel Weinsheimer, and Donald G. Marshall. New York: Continuum.

Gavins, Joanna. 2007. Text World Theory: An Introduction. Edinburgh: Edinburgh University Press.

Gerrig, Richard J. 1993. Experiencing Narrative Worlds: On the Psychological Activities of Reading. New Haven: Yale University Press.

Gerrig, Richard J. 2011. Individual Differences in Readers' Narrative Experiences. The Scientific Study of Literature 1: 88-94.

Gerrig, Richard J., and Micah L. Mumper. 2017. How Readers' Lives Affect Narrative Experiences. In Cognitive Literary Studies: Dialogues Between Literature and Cognition. Edited by Michael Burke and Emily T. Troscianko. Oxford: Oxford University Press, pp. 239-57.

Gintis, Herbert. 2003. The Hitchhiker's Guide to Altruism: Gene-Culture Coevolution and the Internalization of Norms. Journal of Theoretical Biology 220: 407-18. [CrossRef] [PubMed]

Goodall, Jane. 1986. The Chimpanzees of Gombe: Patterns of Behavior. Cambridge: Harvard University Press.

Gopnik, Alison. 2016. The Gardener and the Carpenter: What the New Science of Child Development Tells Us about the Relationships between Parents and Children. New York: Farrar, Straus, and Giroux.

Haney, David P. 2001. The Challenge of Coleridge: Ethics and Interpretation in Romanticism and Modern Philosophy. University Park: The Pennsylvania State University Press.

Hebb, Donald Olding. 1949. The Organization of Behavior: A Neuropsychological Theory. New York: Wiley and Sons.

Hirstein, William. 2012. Mindmelding: Consciousness, Neuroscience, and the Mind's Privacy. Oxford: Oxford University Press.

Homer. 1995. The Odyssey, Books 1-12. Translated by A. T. Murray. Revised George E. Dimock. Cambridge: Harvard University Press.

Hrdy, Sarah Blaffer. 2009. Mothers and Others: The Evolutionary Origins of Mutual Understanding. Cambridge: Belknap Press of Harvard University Press.

Iser, Wolfgang. 1978. The Act of Reading: A Theory of Aesthetic Response. Baltimore: Johns Hopkins University Press. Joyce, Richard. 2006. The Evolution of Morality. Cambridge: MIT Press.

Joyce, Richard. 2012. Metaethical Pluralism: How Both Moral Naturalism and Moral Skepticism May Be Permissible Positions. In Ethical Naturalism: Current Debates. Edited by Susanna Nuccetelii and Gary Seay. Cambridge: Cambridge University Press, pp. 89-109.

Kitcher, Philip. 2011. The Ethical Project. Cambridge: Harvard University Press.

Klimecki, Olga, and Tania Singer. 2013. Empathy from the Perspective of Social Neuroscience. In The Cambridge Handbook of Affective Neuroscience. Edited by Jorge Armony and Patrik Vuilleumier. Cambridge: Cambridge University Press, pp. 533-49.

Krebs, Dennis L. 2011. The Origins of Morality: An Evolutionary Account. Oxford: Oxford University Press.

Lamberton, Robert. 1986. Homer the Theologian: Neoplatonic Allegorical Readings and the Growth of the Epic Tradition. Berkeley: University of California Press.

Lamprecht, Raphael, and Joseph LeDoux. 2004. Structural Plasticity and Memory. Nature Reviews Neuroscience 5: 45-54. [CrossRef] [PubMed]

Latour, Bruno. 2005. Reassembling the Social: An Introduction to Actor-Network Theory. Oxford: Oxford University Press. 
Latour, Bruno. 2013. An Inquiry into Modes of Existence: An Anthropology of the Moderns. Translated by Catherine Porter. Cambridge: Harvard University Press.

LeDoux, Joseph, and Richard Brown. 2017. A Higher-Order Theory of Emotional Consciousness. Proceedings of the National Academy of Sciences 114: e2016-25. [CrossRef] [PubMed]

Levinas, Emmanuel. 1969. Totality and Infinity: An Essay on Exteriority. Translated by Alphonso Lingis. Pittsburgh: Duquesne University Press.

Levinas, Emmanuel. 1981. Otherwise Than Being, or Being Essence. Translated by Alphonso Lingis. Pittsburgh: Duquesne University Press.

Levinas, Emmanuel. 1989a. Ethics as First Philosophy. In The Levinas Reader. Edited by Seán Hand. Oxford: Blackwell, pp. 76-87.

Levinas, Emmanuel. 1989b. God and Philosophy. In The Levinas Reader. Edited by Seán Hand. Oxford: Blackwell, pp. 167-89.

Levinas, Emmanuel. 1989c. Reality and Its Shadow. In The Levinas Reader. Edited by Seán Hand. Oxford: Blackwell, pp. 130-43.

Levinas, Emmanuel. 1996a. Is Ontology Fundamental? In Basic Philosophical Writings. Edited by Adriaan T. Peperzak, Simon Critchley and Robert Bernasconi. Bloomington: Indiana University Press, pp. 2-10.

Levinas, Emmanuel. 1996b. Meaning and Sense. In Basic Philosophical Writings. Edited by Adriaan T. Peperzak, Simon Critchley and Robert Bernasconi. Bloomington: Indiana University Press, pp. 34-64.

Liddell, Henry George, and Robert Scott. 1958. Greek-English Lexicon, Abridged, 26th ed. Rev. George Picker Berry. Chicago: Follett Publishing Company.

Machin, Anna J., and Robin I. M. Dunbar. 2011. The Brain Opioid Theory of Social Attachment: A Review of the Evidence. Behavior 148: 985-1025. [CrossRef]

Melis, Alicia P., and Felix Warneken. 2016. The Psychology of Cooperation: Insights from Chimpanzees and Children. Evolutionary Anthropology 25: 297-305. [CrossRef] [PubMed]

Metzinger, Thomas. 2003. Being No One: The Self-Model Theory of Subjectivity. Cambridge: MIT Press.

Nuccetelli, Susanna, and Gary Seay. 2012. Introduction. In Ethical Naturalism. Edited by Susanna Nuccetelli and Gary Seay. Cambridge: Cambridge University Press, pp. 1-7.

Shankman, Steven. 2017. Turned Inside Out: Reading the Russian Novel in Prison. Evanston: Northwestern University Press.

Struck, Peter T. 2004. Birth of the Symbol: Ancient Readers at the Limits of Their Texts. Princeton: Princeton University Press.

Tomasello, Michael. 2014. A Natural History of Human Thinking. Cambridge: Harvard University Press.

Tomasello, Michael. 2016. A Natural History of Human Morality. Cambridge: Harvard University Press.

Tomasello, Michael. 2019. Becoming Human: A Theory of Ontogeny. Cambridge: Harvard University Press.

Trivers, Robert L. 1971. The Evolution of Reciprocal Altruism. Quarterly Review of Biology 45: 35-57. [CrossRef]

Tu, Wei-Ming. 1986. The Structure and Function of the Confucian Intellectual in Ancient China. In The Origins and Diversity of Axial Age Civilizations. Edited by S. N. Eisenstadt. Albany: State University of New York Press.

Warneken, Felix, and Michael Tomasello. 2006. Altruistic Helping in Human Infants and Young Chimpanzees. Science 311: 1301-3. [CrossRef] [PubMed]

Werth, Paul. 1999. Text Worlds: Representing Conceptual Space in Discourse. New York: Prentice Hall.

Whiten, Andrew, and Richard. W. Byrne. 1988. Tactical Deception in Primates. Behavioural and Brain Sciences 11: 233-44. [CrossRef]

Wilson, Michael L., and Luke Glowacki. 2017. Violent Cousins: Chimpanzees, Humans, and the Roots of War. In Chimpanzees and Human Evolution. Edited by Martin N. Muller, Richard W. Wrangham and David R. Pilgeam. Cambridge: Belknap Press of Harvard University Press, pp. 464-508.

Wood, Lorna. 2009. Emmanuel Levinas and the American Renaissance Canon. In Levinas and Nineteenth-Century Literature: Ethics and Otherness from Romanticism through Realism. Edited by Donald R. Wehrs and David P. Haney. Newark: University of Delaware Press, pp. 166-206. 
Wrangham, Richard W. 2019. The Goodness Paradox: How Evolution Made Us More and Less Violent. London: Profile. Zaki, Jamal, and Kevin Ochsner. 2011. You, Me, and My Brain: Self and Other Representation in Social Cognitive Neuroscience. In Social Neuroscience: Toward Understanding the Underpinnings of the Social Mind. Edited by Alexander Todorov, Susan T. Fiske and Deborah A. Prentice. Oxford: Oxford University Press, pp. 14-39.

(C) (

(C) 2019 by the author. Licensee MDPI, Basel, Switzerland. This article is an open access article distributed under the terms and conditions of the Creative Commons Attribution (CC BY) license (http://creativecommons.org/licenses/by/4.0/). 

Article

\title{
Towards a Decolonial Narrative Ethics
}

\author{
Hille Haker \\ Department of Theology, Loyola University Chicago, Chicago, IL 60660, USA; hhaker@luc.edu; \\ Tel.: +1-773-508-2368
}

Received: 19 April 2019; Accepted: 30 June 2019; Published: 3 July 2019

check for updates

\begin{abstract}
This essay explores the contribution of two works of German literature to a decolonial narrative ethics. It analyzes the structures of colonialism, taking narratives as a medium of and for ethical reflection, and reinterprets the ethical concepts of recognition and responsibility. This essay examines two stories. Franz Kafka's Report to an Academy (1917) addresses the biological racism of the German scientists around 1900, unmasking the racism that renders apes (or particular people) the pre-life of human beings (or particular human beings). It also demonstrates that the politics of recognition, based on conditional (mis-)recognition, must be replaced by an ethics of mutual recognition. Uwe Timm's Morenga (1978) uses the cross-reference of history and fiction as an aesthetic principle, narrating the history of the German genocide of the Nama and Herero people at the beginning of the 20th century. Intercultural understanding, the novel shows, is impossible when it is based on the conditional, colonial (mis-)recognition that echoes Kafka's unmasking; furthermore, the novel illuminates the interrelation of recognition and responsibility that requires not only an aesthetic ethics of reading based on attentiveness and response but also a political ethics that confronts the (German) readers as historically situated agents who must take responsibility for their past.
\end{abstract}

Keywords: narrative ethics; recognition; responsibility; decoloniality; Kafka; Timm; racism; genocide; German Empire

\section{Introduction}

Human beings, the "language animals", as Charles Taylor argues alongside Aristotle and modern Western hermeneutics, receive symbolic codes of meaning from the traditions they are born into as much as they actively give meaning to their lives (Taylor 2016). By telling the stories of their tradition in their own way and telling their own stories, they also change the codes and the narratives that shape the traditions to which they belong. We end up in the infinite hermeneutic endeavor that we call history: the interpretation of experiences and events over time in and through stories and histories. Stories, narratives, and/or histories have been examined in view of what they represent, how they represent it, in which medium and with what forms, and how they are received by readers. ${ }^{1}$ Because narratives are the medium of giving meaning to experiences as well as the medium to explore the past and the future using historical analyses as well as imagination, narrative theories intersect implicitly or explicitly with other disciplines: history, philosophy, cultural theory, art theory, and aesthetics are closest to narrative theory but it also intersects with ethical theories. Ethical theory addresses questions of moral identity, character formation, moral conflicts, the actualization of social and/or moral values and norms in concrete contexts, and institutions that establish the normative structures of actions; narrative theory informs it how to analyze narratives in light of the scholarly works.

1 Several overviews and analyses are available that discern the different approaches to narrative theory in the 20th century. For my interest, the more recent trends of the pragmatic turn in narrative theory over the last decades is most important, especially feminist or postcolonial narrative theories. Cf. (Herman et al. 2012; Phelan and Rabinowitz 2008). 
In this essay, I will take up a specific task that complements that of critical postcolonial narrative theory, as an effort of decolonizing patterns of thinking and acting. Ultimately, this is an ethical endeavor, seeking to transform habits and structures of coloniality, but here, I want to show how literature is a medium that may contribute to such a transformation by way of storytelling. In other words, I want to inquire into the resistance of literature to the racism and depiction of racial superiority that has dominated European modernity's account of themselves. How has Western literature, and works in German literature in particular, dealt with the colonial history? From a critical, pragmatic rather than a narratological, structuralist, or poststructuralist perspective, power is the currency that defines whose stories and what stories are being told, heard, read, and shared publicly. For instance, what becomes part of a particular tradition is not merely limited by the finite perspective of any of the narrators (historians and authors of fiction alike), ${ }^{2}$ but it is also a reflection of their position within the social, political, and cultural reality from which they speak or write. Works of fiction often play with social expectations and norms, revealing but also potentially disorienting unquestioned power systems and/or epistemologies that are reflected in social orders, even though no storyteller can entirely transcend their own position and perspective that is shaped by the multiple factors that constitute their identity. Power is an intrinsic part of any story as well as extrinsic to it, because to be completely transparent about the choices, selections, perspectives, or positions a storyteller may take would undermine the narrative pact that readers make with narrators: reading means to follow a story's interest and partiality, albeit not uncritically.

Obviously, it is impossible in one essay to even attempt to grapple with the complexities of narrative theory, aesthetics, and ethics; my contribution therefore takes up only one particular question that is highly contested in current debates, namely the relationship of literature and historical events. I will limit my inquiry to literary ethics rather than narrative ethics, because my interest concerns the way literature may contribute to the knowledge, the self-understanding, and the critique of a particular historical tradition. In this essay, I will address the colonial history of Germany. First, I will analyze the habitus (Bourdieu 1990) of coloniality (Mignolo 2018) that guides the racial epistemology of superiority and inferiority in Germany at the beginning of the 20th century, and second, I will analyze the elements of German colonialism over the course of the 19th and 20th century, as depicted in a novel that also attends to the German genocide of the Nama and Herero at the beginning of the 20th century. Overshadowed by the Shoah, it has only recently become the topic of public reckoning.

Literary narratives have sparked renewed interest over the last decades in trans- and interdisciplinary studies, and narrative ethics has emerged as an umbrella term that is used in literary narrative studies as well as in ethics, albeit with different meanings. On the one hand, scholars of literature and/or narratology inquire about basic ethical concepts as they are constructed in art (using the term "narrative" loosely), such as personal and moral identity, social values and norms, agency and virtues, and the reflection of moral conflicts and moral imagination; they examine narratives and factual or fictional literature-from everyday storytelling to narratives used in medical deliberations or in novels, yet often without extended reception of ethical theory. Others have reflected upon the pedagogical and public function of moral affects and emotions or the shifts and changes of the modes of communication over time. Ethicists often use narratives as complements or counterpoints to philosophical arguments, and they reflect especially upon unique personal experiential reflections as corrective to the norms that orient judgments and actions. Narrative ethics has become an important conversation partner for hermeneutics, too, and within ethical theory, I see it as part of the hermeneutical ethics that complements normative judgments. ${ }^{3}$ With a new interest in phenomenology and hermeneutics, the ethics of reading has become a part of reception aesthetics or, for example, is

2 For the relationship of history and fiction cf. (Ricœur 1988).

3 Cf. (Meretoja 2018), whom I follow in many ways, for a good overview of narrative ethics approaches. Her own approach seeks to connect literary narrative studies with the hermeneutical and ethical endeavor to engage with one's "being in the world" through storytelling. Cf. also the works in ethical theory on a hermeneutical ethics in (Haker 2010; Wils 2001). 
further explored in a deconstructive literary theory that focuses on responsibility. ${ }^{4}$ In this essay that explores the relationship of history and literature, I will use Ricœur's concept of the "crossed reference" of empirical and narrative truth. I will explore how fictional narratives may generate concepts central not only for a decolonial narrative theory but also for a decolonial narrative ethics. ${ }^{5}$

In the first part, I will read Franz Kafka's short story A Report to an Academy, written in 1917 (Kafka 1971), followed in the second part by a reading of Uwe Timm's novel Morenga, from 1978 (Timm 2003). ${ }^{6}$ I will discuss how Kafka responds to the scientific theory of race at the beginning of the 20th century, and analyze the elements of German colonialism that Timm illuminates in a complex narrative that assembles documentary and fiction. The interweaving of history and fiction in narrative, which Ricœur coined as crossed reference, serves as my guide in this essay. David Walter Price provides a good summary of Ricœur's hermeneutics and the way how literature is linked to the "real world of action," the area of ethical reflection:

Ricœur's hermeneutic approach emerges, in part, from the philosophy of Hans-Georg Gadamer, who acknowledges 'the universal linguality of behavior relative to the world' (Hermeneutics, p. 65). Ricœur stresses the narrative function of all historical explanations. In doing so, he develops a three-part argument in opposition to positivist interpretations of history. First, 'there is more fiction in history' than positivists care to admit. Second, narrative fiction is more mimetic than positivists will allow. And third, there is the concept of 'crossed reference' (reference croisée), by which Ricœur means that the references of fiction and history "cross upon the basic historicity of human experience" (Hermeneutics, pp. 293-94). In other words, Ricœur sees the two narrative modes of fiction and history as interweaving and thereby bringing historicity to language. The tripartite argument leads Ricœur to conclude that "the world of fiction leads us to the heart of the real world of action". (Hermeneutics, p. 296). (Price 1999 , p. 24). ${ }^{7}$

\section{Franz Kafka: A Report to an Academy}

\subsection{German Colonialism and Carl Hagenbeck's Zoo}

At the end of the 19th century, the German zoo and circus company of Carl Hagenbeck became famous. Its zoo exhibited many animals, including never seen wild animals from non-European continents that captured the imagination of the German citizens, especially the bourgeois class. At the turn of the century, colonialism had become part of the cultural context and cultural life in Germany. The scientific landscape had changed, too: biology, anthropology, and sociology developed as new disciplines, often intertwining in language and concepts. Academies were established as scientific societies in late 19th century, and members discussed current affairs of their disciplines. Both biology and sociology had embraced the new evolution theory, for which Darwin on the one hand, and Malthus on the other, had become the most popular figures (Kjaergaard 2011).

Zoos and circuses function as mediator between the sciences and (popular) culture; they stir curiosity of the "exotic" other by entertaining people, thereby blending societal education (of race theory) and cultural entertainment (Anhalt 2007). Carl Hagenbeck is the only historical name that is

4 For the reader-response theory cf. (Iser 1979; Jauss 1982).

5 In this essay, I understand decolonial theory in line with Walter Mignolo's and Catherine Walsh's analyses of "decoloniality" (Mignolo 2018). My own approach is informed by the early Frankfurt School and their critical theory, especially M. Horkheimer, Th. W. Adorno, W. Benjamin, and by E. Fromm's studies on the authoritarian character. This essay is part of a larger project that tries to develop a decolonial ethics through the lens of recognition and responsibility, which also serve as my lens here. For the connection of critical theory and decolonial theory cf. (Mignolo 2007).

6 Quotes in this essay are from the English translations of both texts.

7 Ricœur put that first forward in (Ricœur 1981) In Time and Narrative and his later works, Paul Ricœur spells out the relation of historical and literary narrative more extensively, but the basic idea of crossed reference remains the same. Cf. especially (Ricœur 1983 and Ricœur 1992) For a broader discussion, in view of the question of moral identity and literary life stories cf. (Haker 1999). 
presented in Kafka's story, but his name is telling in the German colonial history. Hagenbeck was an honorable member of the Berlin "Society of Anthropology, Ethnology, and Prehistory", and he was well connected to the most famous evolutionary scientist and theorist of race in Germany, Ernst Haeckel (Weikart 2003). ${ }^{8}$ The epistemological overlap between biology, sociology, anthropology, and ethnology created an opportunity for the German Academy of Science to pursue multiple inter-disciplinary studies. Many scholars shared Haeckel's view that "negroes" are "savages" and close kin to apes. 9 Hierarchies are not only established between animals and humans but also among human peoples, informed not to the least by Haeckel's and his students' regular interactions with Carl Hagenbeck who let them use his "exhibits" for their studies.

Africa was only one of the continents Hagenbeck chose for his expeditions; peoples and animals were exhibited either in the peoples shows, in the zoo in Hamburg, or in his traveling circus. ${ }^{10}$ Hagenbeck invested a lot of energy and money in his hunting expeditions, intended for the exhibitions in Hamburg. His role in modern German culture at the turn of the century can hardly be underestimated: he introduced a "new aesthetic experience" to the general audience, a new gaze at the animal as well as other peoples who were categorized along the lines of the Darwinist theory of species, promoted by Haeckel and others. Darwinism, race theory, and anthropology thereby shape the gaze at the other as an othering: an exotic projection of one's own fantasies. Apes play a particular role in this gaze, because they are seen as the transitionary species between animals and humans, the "missing link" between animals and humans. The ape-human relationship is fascinating and "uncanny" at the same time, because for the evolution theorists, it is in this relationship that the otherness and the sameness of the alien, almost human animal is negotiated. Hagenbeck experimented with the humanization of apes; for example, he let Orangutans eat at his table. A chimpanzee called "Moritz" traveled with him all over Europe, performing in zoos, circuses, and European royal courts. Dressed in a tailcoat,

"... Moritz is always completely dressed (...) he sleeps in his bed, smokes his cigars, drinks his wine, and when he travels, he travels in 2nd class cabin (...) right now, he is again gone for a trip, because he has engagements in several European cities." 11

This is the historical context of Kafka's story. Like millions of others in Europe and North America, Kafka had visited a peoples show, in his case in Prague in 1911, and the famous ape Moritz is echoed in the story's narrator Red Peter. ${ }^{12}$ In Kafka's story, "an Academy" has invited an ape to report (berichten) about his former life (literally: pre-life or Vorleben) as an ape. In the short story, Kafka constructs an artistic double-speak that undermines the history of evolutionary biology by "deconstructing" the linear hi-story ${ }^{13}$ within the report, at the same time fulfilling and ridiculing the task the Academy has set for him. The ape thereby demonstrates his mastery of language and the poetic art of the storyteller. He not only tells the history of his humanization as a history of subjugation but also destroys the "missing link" theory, pointing to the epistemological faults and the moral failures engrained in colonial-evolutionary theory and the colonizing practices of the European men. ${ }^{14}$

8 Weikart shows that Haeckel was one of the first who argued that "extermination" of several "races" was inevitable, thus paving the way for the genocidal racism of German colonialism (and National Socialism).

9 For the connection of simianization and race theory cf. (Hund et al. 2015)

10 Peoples shows in which the "authentic life" of indigenous groups were to be represented are to be distinguished from so-called "freak-shows". Focusing on the "otherness" in form of disabilities or deviations from the norm of normality, these shows were much more the topic of festivals.

11 Carl Hagenbeck records this in his book Von Tieren und Menschen, p. 220, published in 1908. Quoted in: (Anhalt 2007, p. 191) (translation: $\mathrm{HH}$ ).

12 Another context is the literary history of the early 19th century, especially E.T.A. Hoffmann's Kreisleriana from 1804 that entails a letter that an ape named Milo writes to his girlfriend Pipi from North America. In this essay, I only attend to the German scientific context of race theory and colonialism; many interpretations point to the racialized antisemitism that Kafka was very aware of and often addressed, ignoring, however, the connection of the German colonialism and race theory.

13 The hyphen marks the crossed reference of history and story that I am using throughout this essay.

14 Margot Norris has read the story in view of Darwin's and Nietzsche's theory of mimesis, which is not at the center of my essay. Still, for the narrative strategy of the text her analysis is very helpful. Cf. (Norris 1980). 


\subsection{The Ape's Report}

The "report" that Red Peter submits is a performative enactment that is correlated to the ape's performances in the vaudevilles. Red Peter demonstrates his mastery of language, which according to Darwin, qualifies him as a human being and which is at the same time the symbol of intellectual education, through multiple rhetorical techniques: he takes metaphors literally and uses them against his audience; he comments and judges in sentences that appear to be descriptive; he hides behind the veil of innocence while unmasking the contradictions of the linear progress culminating in the white race; he speaks about the cruelties he has been subjected to, with calculated glimpses of repressed anger inserted into the descriptive form of the report. The reader must imitate the narrator's double-speak in a double-reading: on the one hand, they must imagine themselves as part of the Academy-audience who separates between the animal and the human, while on the other hand attending to the critique that undermines the whole construct of race theory. ${ }^{15}$

Bowing to the academic customs, Red Peter thanks the Academy for the opportunity to report to them: "You have honored me with the invitation to submit a report about my former life as an ape." (Kafka 1971, p. 81) This introduction entails multiple presuppositions regarding the origin of the human: the Academy, Red Peter must assume from this invitation, presupposes that the origin of human beings can be traced back to their past as animals, which humans have by now surpassed. Asking for the "report", Red Peter is once more exhibited as an exemplar of this pre-human past.

Red Peter's narrated life story begins with his capture by Hagenbeck's hunters at the Gold Coast of Africa, historically the coast of the big human slave trade. Constantly correlating the origins of humans (phylogenesis) with child development and formation through education (ontogenesis), Red Peter expresses the dilemma of memory: the "former life" cannot be remembered; it is forgotten and inaccessible for self-consciousness, sensed rather than known (I will return to this shortly). Red Peter does not have the insights that the Academy has asked for: for that, "if I ever had the desire to run all the way back there, I would have to scrape the hide off my body" (Kafka 1971, p. 81).

The "wild animals" are transported to Europe in cages on a ship, leaving Red Peter "sobbing" and in constant pain. He remembers the torture, although he "can only sketch from hindsight and in human words, what I then felt as an ape" (Kafka 1971, p. 83). ${ }^{16}$ As a "civilized" European human being who will justify the torture as the price of civilization and forgive the torturers, he nods to the Academy: "They're good sorts, despite everything" (Kafka 1971, p. 84). Blending his "humanization" with enslavement, coercion, and being dominated ("determined") by others, as a rite de passage from Africa to Europe (both geographical and symbolic), the "ape" reverses the trajectory from nature to freedom: "avoidance of all willfulness", i.e., any free will, in order "to move forward, to move forward! Anything but standing still with raised arms, flattened against the sides of a crate." (Kafka 1971, p. 84). Mimesis, or imitation, and mimicry, or camouflage, two central concepts of evolution theory, become Red Peter's strategies of survival: survival is linked to imitation, the "otherness" transformed into the "same". "Nobody promised me that, if I became like them, the bars would be removed." (Kafka 1971, p. 85); "I was looking for a way out" (Kafka 1971, p. 87). Humanization is a far cry from individuation as a unique human being; rather, it is a process of becoming like everybody else:

I watched those human beings walk back and forth, always the same faces, the same motions; it often seemed to me as if it was just a single person. Well, that person or those persons were walking around unmolested. (Kafka 1971, p. 85)

15 Posthumanist approaches and animal studies both provide valuable insights for ethics; for an overview of the current discussion of the human-animal relation cf., for example, (Creedon 2014).

16 Cf. (Coetzee 2004) who, in the "lesson" The Rights of Animals, offers an intertextual commentary of Kafka's story, reflecting the ethical questions of torture in the context of the Shoah. There, Elisabeth Costello shocks her audience with the comparison of treatment of animals and human beings. 
The ape, Red Peter interprets this transition, must become human because he cannot otherwise survive. He therefore learns to shake hands— "shaking hands indicates candidness" (Kafka 1971, p. 82); he learns to spit, "within the first few days" (Kafka 1971, p. 86), observing that these human beings "mutually spit in each other's faces; the only difference being that I licked my face clean afterwards, and they didn't." (Kafka 1971, p. 86) He learns to smoke the pipe, to drink liquor from a bottle, and finally, he utters his first word in human language. ${ }^{17}$ Following the aesthetic theory of Aristotle, the peripeteia of his transformation is carefully prepared for and then staged as the performance of an artist: "one evening, before a large group of spectators" Red Peter empties a bottle of the liquor as he has learned, and then, intoxicated and not being himself, "no longer like someone in despair, but like an artist ... because I had to, because I had the urge to, because my senses were in an uproar", he utters his first word- "Hello", the greeting formula of every "civilized" culture. ${ }^{18}$

Red Peter applies the same categories that the Academy uses in its scientific studies of race and European civilization, i.e., the colonization of what they consider the un-civilized lands and cultures they invade: ape and human, savages and Europeans, nature and history, forgetting and remembering, freedom and necessity, sameness and difference etc. are all categories that shape Western (modern) philosophy. Red Peter's metamorphosis entails all elements of this process of civilization, and they are listed meticulously. The result is the formation of an "average person", an artist who becomes his own persona, literally a mask, performing on the stages of European vaudevilles. Yet, the story constantly disrupts and displaces the categories: at one time, the animal is free and the humans are unfree; at another time, all differences are cancelled out; the speaking ape is indeed a human being, but the human beings he speaks to act like apes; he is speaking as a human being and an ape; to become a human being, he has to imitate the actions of humans, yet, as agents, humans seem to merely imitate the life of apes. In short: the neat categories that separate the animal from the human collapse.

\subsection{The Paradox of Recognition}

Irony allows literature to subvert the categories of Western philosophy of history as well as the categories of self-constitution as emergence of the sovereign self. Both categories are at the same time deconstructed and newly constructed in Kafka's story, to wit, in the visibility and audibility of the story's other, resting on the "double-speak" as the code of irony. Kafka does not merely reverse the judgment: the animal nature, associated with power, force, and instinct is not an end that the self can strive for to regain a "natural instinct". Red Peter reminds the Academy: the "great past" is immemorable and "forgotten". Kafka, who was largely influenced by Freud's writings on the subconscious, has Red Peter demonstrate the hopelessness of reaching one's "pre-history": all that is left is the "cool breeze" that once was a "storm that blew out of my past". ${ }^{19}$ It is a remote memory that every "wanderer on earth" feels as a "tickling in his heels: the little chimpanzee and the great Achilles". Whereas the Greek hero, who is echoed in the imagery of heroic masculinity of the white man, is ultimately brought down because of this spot of his body, Red Peter interprets it as the drive that is a trace of freedom and pleasure. ${ }^{20}$ The alternative humanism must therefore integrate both dimensions: "speaking frankly: your own apehood, gentlemen, to the extent that there is anything like that in your past, cannot be more remote from you than mine is from me." (Kafka 1971, p. 81).

With this, Kafka acknowledges the intertwining of the "natural" and the "spiritual" dimension of the self, unmasking the grand narrative of evolution as the myth of the European man; instead, he

17 In the theory of evolution, but also in the older approaches to natural history, language marks the decisive step in human development. Its origin, however, had long been a riddle and the topic of many treatises. Cf., for example, Herder's Treatise on the Origin of Language (Herder 2002). Ethnologists such as Alexander of Humboldt took it as their task to explore the languages of indigenous peoples.

18 Ironically, in the 18th century aesthetics of the artist as genius, this loss of control is a perquisite of "authentic" art.

19 Walter Benjamin uses this formulation in his "Thesis" on the philosophy of history, clearly echoing the critical interpretation of the philosophy of progress (Benjamin 2003).

20 The German term kitzeln can also refer to something that makes one curious. 
is violent, cruel, and detached from any moral sense. In this myth of European civilization, it serves the Europeans well to call the enslavement of other people liberation, and oppression a necessary phase in the process of civilization. The construction of a teleological narrative of progress in history requires a narrator, Red Peter reminds us, who constructs rather than discovers the "promises" of history in the past. It presupposes that the "African" history is merely a pre-history. When history is told from the perspective of the "other", however, this narrative is debunked. The art of performance (in the double sense of performance and performativity) enables Red Peter to "survive", to wit, to be socially recognized, but at the same time, it enables him to unmask the "figure" of Red Peter that the Academy recognizes. Red Peter may not remember his "origins", but he does remember who inflicted upon him the wounds of the shotgun and torture, and it is no coincidence that Hagenbeck is identified by name, as a historical figure of German colonial history. Early 20th century race theory did not embrace the dialectic of nature and spirit that German idealism grappled with and saw as necessarily intertwined dimensions of human nature. This is not to say that Kant, Hegel, or Schelling, did not reiterate the well-known hierarchies of Western philosophy, associating "nature" with women and non-Europeans, and "spirit" with maleness and the European culture. Kafka demonstrates, however, how different the philosophy of history becomes when the story is told from the perspective of those who are dehumanized as animals or "sub-humans". In the reception history of the short story in Germany, it was mostly read in light of Kafka's Jewishness and the racialized antisemitism that had emerged together with the reception of Darwin and social Darwinism since the late 19th century, and after the Shoah, the animal metaphors seemed to support this allegorical reading. While this is certainly an obvious reading of the text, it forgets the intertwining of racialized antisemitism and racialized colonialism.

Once in Europe, Kafka's ape becomes a true follower of the enlightened, European culture: "That progress! That penetration of rays of knowledge from all sides into my awakening brain! I won't deny it: it made me happy!" (Kafka 1971, p. 87) But he also internalizes the habitual attitude of the European master: "Through an effort that hasn't found its match on earth to the present day, I have attained the educational level of an average European." (Kafka 1971, p. 87) Now, at "the pinnacle of my career", (Kafka 1971, p. 82) a point at which his "success probably can't get much greater", (Kafka 1971, p. 88) he is one of the honorable members of society, receiving invitations to banquets, to academic societies, living a life in prosperity, in short: he is recognized in the bourgeois society of early 20th century. Kafka makes sure the reader notices that the ape who is "honored" to speak to the Academy is morally corrupt. Looking back at the many incidents of having "drained many a fine bottle of red wine" with Carl Hagenbeck (Kafka 1971, p. 82), Red Peter is proud of the social recognition he has gained. He echoes the European judgment that this was "worth the trouble" (Kafka 1971, p. 88). He does not seek anybody's "opinion", merely wishes to "disseminate information", merely "making a report" (ibid.). When he comes back from his public engagement, in his private life he engages in "ape" acts, sexuality that seems to be exempt from being "humanized" and must therefore be tabooed. Red Peter "has a good time" with his female companion, in an "ape fashion":

"When I come home late at night from banquets, learned societies or friendly gatherings, a little half-trained female chimpanzee is waiting for me and I have a good time with her, ape fashion; in the daytime I don't want to see her, because her eyes have that deranged look which bewildered trained animals have; I'm the only one who recognizes it, and I can't stand it." (Kafka 1971, p. 87)

The woman's gaze is "deranged" and "bewildered", which only he recognizes. For both, the male and the female human, social recognition is a granted gesture that can be withdrawn at any time-a conditional status that conceals the humiliation and the habitual effects of moral misrecognition. Fanon saw the paradox of recognition clearly:

"The Negro is a slave who has been allowed to assume the attitude of a master. The white man is a master who has allowed his slaves to eat at his table." (Fanon 1967, p. 219) 
This gaze of the tortured, captured, and raped human being entails the moral verdict over the European, repressive, violent "humanism". The "sub-human's" rise to humanity does indeed entail a limited social recognition, but it does not transcend the structure of power that justifies moral harm and the damage of a person's identity as "collateral damage" of historical progress-in other words, it does not change the underlying biological racism but merely allows for the "survival" of the one who adapts to the "superior" human behavior (Bernstein 2015; Mills 2015). An ethically valid concept of recognition must therefore not only critically attend to these structures of domination and coerced submissions, but it must break entirely with them.

For Darwin - as for Kafka-humanity is not only tied to language but also to the moral sense of shame. Shame is the opposite of the master's gaze, and it starkly contrasts with the voyeurism of exotic animals and peoples that Hagenbeck's exhibitions wanted the audience to adopt. ${ }^{21}$ Shame, in contrast to the self-distancing, aesthetic experience of the voyeur, means to see oneself from the perspective of the other or from an internalized moral perspective. Red Peter, who has done everything to prove that he is not the "former ape" as the Academy will always see him, but a "human being" just like the Europeans, has so internalized the habitus of coloniality that he interacts with his companion with the violence and domination he has been taught. On the other hand, he remains ambiguous towards her, appalled by the humiliation he has experienced himself, too. Repressing this connection between himself and the female other, he demonstrates the "success" of his education; his apparent discomfort, ethically termed "bad conscience," however, remains as the potential to be or become a different kind of a moral self, namely one that would indeed be challenged by the other (cf. Derrida 2002).

\subsection{Decolonizing Recognition: Critique and Renewal}

Over the last decades, recognition theory has emerged as an important normative concept of personal and social relations as well as political or legal equality. Featured as a central concept in the works of Western modern philosophers such as Rousseau, Fichte, and Hegel, recognition theory has been taken up in multiple contemporary works, most famously by Axel Honneth (Honneth 1995) who argues for recognition as a normative concept of social theory, but also by Charles Taylor (Taylor 1992) who argues for a politics of recognition in multicultural societies, and more recently by Paul Ricœur who develops an ethics of recognition (Ricœur 2005). ${ }^{22}$ In the US, recognition theory is predominantly discussed as a strand of the politics of recognition, multiculturalism, and identity politics, often centered on how Charles Taylor framed it. ${ }^{23}$ In this, postcolonial studies are no different (Balaton-Chrimes and Stead 2017; Markell 2003). In these studies, Frantz Fanon's Black Skin, White Masks is a prominent reference text for critique because the politics of recognition is seen as one element of colonial power, concealing the well-known colonial gaze of misrecognition by framing it as the paternalistic generosity of the colonial and neocolonial powers. And indeed: as long as recognition is only expanded to "other", "different", or "alien" cultures, it does not change the position or question the underlying Western, European, or Anglo-American identity as superior to the "other" cultures.

Coloniality is constituted by an ethical structure that I call conditional recognition or recognition under the condition of terms set by only one party, in contrast to mutual or moral recognition. A critique of the concept of recognition is therefore necessary when it conceals an underlying misrecognition, disrespect, and humiliation, grounded in an epistemology of superiority and inferiority. In contrast to this concept that is often associated with a Western "politics of recognition", an ethically sound

21 As noted above, John Coetzee addresses shame and voyeurism in The Problem of Evil, a staged intervention by the writer Costello that emphasizes the intertwining of racialized colonialism, racialized antisemitism, and all kinds of (sexual) violence based on power asymmetries among humans. Cf. (Coetzee 2004; Haker 2003).

22 Feminist philosopher Margaret Urban Walker analyzed different forms of moral recognition in the context of Strawson's reactive feelings, thereby departing from the Hegelian reading that is the dominant lens of continental philosophy's recognition theory. Cf. (Walker 1998).

23 Honneth's reinterpretation of Hegel's theory of recognition is therefore also mostly read with this lens, causing many misunderstandings but also fruitful debates. Cf. (Honneth 1995; Fraser and Honneth 2003; Honneth et al. 2010). 
concept of recognition must be grounded in a radically different phenomenological and hermeneutical understanding of encounters and interactions. The colonial epistemology and social, ethical, and cultural hierarchy of superiority and inferiority generates patterns and structures of domination, in which only one party has the power of defining the constitutive rules of practices, with multiple ramifications for the religious, cultural, social, economic, and political structures of pluralistic and globalized societies. Ethics provides the necessary conceptual tools for a structural and social-ethical critique of misrecognition or disrespect that renders even instrumental hierarchies (in companies, social institutions, or bureaucracies) prone to harm and injustice and therefore in need of procedures that protect the moral equality of all, and that protect, for example, critics of violence and injustices. This means, furthermore, that recognition concepts that are grounded in value judgments about one's own and the other's worth, one's merit or one's contribution to society, for example, are also misleading-such concepts presuppose that persons, social groups, religions, or cultures could be weighed on a scale of value.

Moral recognition must mean something else. In a phenomenological approach, Bernhard Waldenfels, among others, has argued that recognition requires a particular response, namely one that is attentive and respectful of the other (Waldenfels 1994, 2002, 2006, 2011). Since any perception is concrete, another (animal and/or human) being is perceived as welcoming or threatening, invitation or intrusion etc.; responses, too, cannot be abstracted from the address (and encounter) of the other-both are like rolled-up stories that need to be unrolled or unfolded, as Husserl's student Wilhelm Schapp argued (Schapp 1953). Yet, since perceptions are learned and habituated, shaped by the social norms to which one is adapted, phenomenology alone does not necessarily break the spell of misrecognition. An ethically grounded concept of recognition must be understood as an encounter in which both parties are open to each other and willing to be transformed. In contrast, in Kafka's story the colonial premise renders only the ape in need of being transformed or "lifted up" to the level of the "humans" while his counterparts cannot even think they, too, could be transformed by the encounter with the ape. Reciprocity is not necessarily mutuality. Misrecognition may function differently in different spheres, but its premise is always the same, namely that one party is convinced that their mere presence to the other is a "gift" that carries with it a sense of entitlement, often spelled out as the other's work, property, freedom, or body.

Not every asymmetry, however, is an expression of conditional recognition, as psychoanalyst Jessica Benjamin has shown convincingly: in her example of breastfeeding, inter-action is seen as "attunement" between mother and child that transforms both in the attentiveness to the respective other without denying the asymmetry of the relation. Recently, Jessica Benjamin has sharpened her previous works and reinterpreted recognition as a broader concept (Benjamin 2017) that goes "beyond the doer and done-to" understanding. My understanding of ethical recognition is informed by her work, especially by her emphasis of the commitment to act together and be transformed together in and through interactions, in order to create something new.

Waldenfels' work is a similarly promising step to reinterpret the perception, experience, and encounter of the "alien" within oneself and the "alien" other. In contrast to Benjamin's concept that emphasizes the shared space of interaction, Waldenfels emphasizes the passive Widerfahrnis or pathos of experience as address followed by the active re-action as response, however this may look like. Waldenfels' "responsoric" phenomenology describes the "pause", the "diastasis" between the passive experience and the re-action as creating a deferment that cannot be overcome: address and response cannot completely overlap, as Benjamin's "attunement" seems to suggest, and hence it creates an infinite process of understanding and acting, and acting together. With respect to reflective responses, Waldenfels, like Benjamin, stresses the necessity of attentiveness (Aufmerksamkeit, Achtsamkeit), which adds a sensual layer to the concept of respect (Achtung), and Benjamin adds the necessity of witnessing in the case of past injuries that have been inflicted upon the other, which creates several overlaps of practical-ethical and therapeutic work. Waldenfels' approach gives the ethical concept of recognition a phenomenological foundation that complements the insights from psychoanalysis. 
Paul Ricœur who is closest to my interest in an ethical interpretation of the self-other encounters, acknowledges the effects of coloniality (though not in these terms) by emphasizing the negative effects of misrecognition. Ricœur insists on the difference between reciprocity and mutuality, examining the epistemological and social roots of the concept of recognition and misrecognition. In the encounter of the European settlers with the colonies, a "grand narrative" (Lyotard 1984) was constructed around the concept of "aid" of development and civilization as the gift of progress that the colonizers bring to the "undeveloped" countries they politically claim to be the "colonies" of their empires. In return of this original "gift", the colonies owe the colonizers gratitude, land, labor, or their bodies, if not their lives. The Europeans never asked whether their presence was even welcomed. Moreover, they chose the "return gifts" themselves, and when these were not given voluntarily, they declared them a debt. In effect, land grabs were called "protection treaties", physical violence and brutality were called disciplinary punishment or "educational" measures, sexual abuse and rape were considered an entitlement that did not affect the victims. Resistance was considered illegitimate, ungrateful, and ultimately a crime. This understanding of recognition as the givers' claim on a return of their "gift," in "gratitude" and submission to one's oppression, creates the double consciousness that is reiterated in the double-speech of the artist; to agree to the moral misrecognition is the only way out when faced with the alternative of death or suicide. The "Academy" expects the "former ape" to be thankful for his humanization; having become a master in his own right, Red Peter believes he, too, is now entitled to the services of the "half-tamed" chimpanzee. In both relationships, the former ape and the female chimpanzee are not free, and certainly not recognized in an ethical understanding of the term: entitlement, the posture as the "giver", and the expectation of gratitude is the condition that defines the relationships. Misrecognition is therefore not merely reification or dehumanization; it is a radical self-centeredness of the party that sets the rules and upholds their unchangeable indifference towards the other, while at the same time utilizing them for their own ends. Being misrecognized therefore means that one's identity is pre-defined and ascribed; to actively misrecognize means to create a "reciprocity" that is based upon this predefined hierarchical relation.

In contrast, the mutual work of recognition and the transformation of both parties' understanding of each other as a result of it can be compared to a two-way translation. Ricœur's works on translation as a hermeneutic and ethical concept, first developed in view of the translation of texts and in his later works used to interpret the possibility of understanding among strangers in pluralistic and multicultural societies, is especially instructive for the further development of a decolonial narrative ethics. I follow Alison Scott-Bauman who has shown in her comprehensive works on Ricœur how hermeneutics and ethics are interwoven (Scott-Baumann 2009, 2013). In an essay on Ricœur's take on translation she writes:

Translation from one language to another provides both a metaphor and a real mechanism for tolerance, for 'gifting' oneself to the other. Ricœur presents the act of translating languages as a two-way ethical paradigm for action, in which the existence of the other must be acknowledged in the form of respect for the ways in which the other expresses him/herself. (Scott-Baumann 2010, p. 72)

Ricœur accepts the imperfection, finitude, and the "unrecognizable" otherness in this mutual work of understanding that is, I hold, at the same time the mutual work of recognition. The "unbridgeable gap" should exactly not, following Ricœur's understanding, impede but rather enable a "humane" way of agency, to wit, the capability to act and the acknowledgment of one's—and the other's-fallibility: the translator, Ricœur holds, unable to find the "perfect translation", "instead tries and tries again, accepting partial success in the ultimate untranslatability of some of the meaning." (Scott-Baumann 2010, p. 80). The same is true, I hold, for the work of recognition as interaction and mutual transformation of the interacting agents or groups.

Listening to stories, for example in testimonies or in oral history, or reading historical documents, reports, letters, diaries, short stories, or novels certainly requires a responsiveness that can be schooled in the practice of reading (Gadamer 1975; Derrida 2004; Attridge 2010, 2017). Literature offers an 
indispensable way to understand, interpret, and practice the encounter with the other (the foreign, the alien) in an aesthetic, i.e., experimental fashion, that in a way explores as much one's own alienness as the alienness of others. With respect to exploring the past, cultural memory, too, requires hermeneutical work, enabling the infinite process of understanding through the process of being addressed by the narratives of the past and the attentiveness in the response through a "responsoric" reading. In the context of narrative ethics, reading has indeed been interpreted as responsibility to and for the "other" (Attridge 2004, 2010). Ethically speaking, this is indispensable especially as part of a decolonizing virtue ethics that is aimed to transform the habitual formations of the normative order of whiteness, racism, and coloniality that is so deeply ingrained in the cultures shaped by the structures of conditional recognition, which has turned out to be just another way of misrecognition. As postcolonial writers from Fanon (Fanon 1967), Appiah (Appiah 2008) to Mbembe (Mbembe 2017) and African-American writers like Patricia Williams (Williams 1991) show, racial and colonial thinking shapes both those who remain structurally privileged and those who are always seen as inferior, in need to be "lifted up" before they are regarded as equal. But equality is impossible when it is based on the "inclusion" of others or the "expansion" of rights without changing the underlying epistemology and ethics; change will not happen, because the colonial past is habitually present in both parties and not addressed as such. This is the lesson of Red Peter who will always be the "former" ape.

In the next section, I will turn to a novel that was written in the midst of the radical questioning of the Nazi generation in Germany, culminating in the student revolts in the late 1960s. Uwe Timm's novel, published in 1978, must be seen in this context: it wrestles with the unspeakable cruelty that was committed by Germans who after World War II were often seen as "honorable people" of the German society, maintaining their positions as judges, scientists, engineers, bankers, or entrepreneurs after having quickly put to rest the crimes against humanity which they committed or were complicit with during Hitler's dictatorship. The Nazi ideology is present everywhere in the novel Morenga, raising the question whether Germany's colonial genocide in the early 20th century was a harbinger of the Nazi crimes and which therefore must be seen in continuity with their antisemitism and the Nazi ideology. Explicitly, however, Timm tells the almost-forgotten history of the genocide itself. Timm's novel represents the radical shift of political ethics that had taken place between 1945 and 1978. But at the same time, it is a cautionary tale with respect to Germany's history and the dangers of selective historical memory. Timm uses the metaphors of animals and humans as the dividing line between the Germans/Europeans and the Nama and Herero, and similar to Kafka's story, he undermines the colonial and racial distinction utilizing multiple rhetorical strategies. Overwriting the colonial with a critical perspectives in the novel, Timm echoes the critique of European civilization and the underlying development theory that guided Kafka's story, too. In Timm's novel, however, the colonial habitus is spelled out on multiple levels, unmasking the structures of misrecognition in the religious, social, economic, and political elements of coloniality.

\section{Uwe Timm: Morenga}

The German post-Holocaust "memory culture" that emerged since the 1970s, in stark contrast to the silence after World War II, is often quoted as an exemplary, collective, and national effort of dealing with the atrocities of the past. With respect to Germany's history of colonialism, however, amnesia and aphasia dominate up to today. The "forgotten" history includes the first genocide of the 20th century: between 1904 and $1908,{ }^{24}$ German soldiers destroyed the Herero and Nama cultures almost completely in a colonial war, ${ }^{25}$ detaining the surviving people in concentration camps, and starving them to death on Shark Island, all this as a declared policy of the German Empire that had been instated in 1871.

24 Some older studies state the period as ending in 1907, but I follow the thorough analysis provided by (Kossler 2015).

25 The Herero population of 80,000 was decimated to 15,000; and the Nama population was reduced from 20,000 to 10,000. Figures from https://ahrp.org/germanys-colonial-genocide-in-namibia/. 
The German government did not recognize the genocide of the Nama and Herero until 2016, and notwithstanding multiple other efforts to rectify its colonial history, Germany has been sued by the descendants of the Nama and Ovaherero over reparations. ${ }^{26}$

From a historical perspective, this genocide precedes the racial politics of the National Socialists that unfolded under Hitler a few decades later, yet the underlying habitus is intertwined in many ways. For example, during and after the colonial genocide, thousands of human body parts, including decapitated heads of Nama and Herero, were transported from the colony of German South West Africa (GSWA) to Berlin, becoming part of the race and eugenics studies of German scientists. Eugen Fischer, then director of the Kaiser Wilhelm Institute of Anthropology, who in the 1930s became Hitler's chief "racial hygienist", wrote his dissertation on the Rehobot "Bastards" in 1908 with the support of the Prussian Academy of Science (Fischer 1913). ${ }^{27}$ It took the German government a century to return the human remains to Namibia, and the German museums have only recently begun negotiations about the return of artifacts the Prussians often bought from the other colonial powers. Without a doubt, responsibility for the past that is at the center of Germany's memory culture, and a politics and ethics of remembrance requires the acknowledgment, apologies, and reparations on the side of the German state. But there is no memory or remembrance without a historical narrative, or more precisely, multiple narratives that must be told from different perspectives. ${ }^{28}$

Literature plays an important role as a medium to shape and promote a nation's cultural imagination, both as national ideology or as its critique. In Germany, colonial stories such as Peter Moor's Travels to the Southwest, a bestselling novel written in 1906, were part of the German colonial narrative of supremacy that reflected the "imperial" and "genocidal gaze" of German colonialism, as Elisabeth Baer has coined it (Baer 2017). ${ }^{29}$ Unsurprisingly, in postwar German literature theory and works of German literature, biological racism and white supremacy was debunked as ideology. Culturally, it was supposed to disappear as habitus (Bourdieu 1994; Celikates 2012) through strong humanistic education programs. ${ }^{30}$ All the more surprising is the fact that Germany's colonial history never played a big role in these reflections. Narrative Ethics as a literary and ethical approach must therefore be reflective and critical on both levels, i.e., in the aesthetic analysis of literature and in the ethical analysis of the values and/or convictions underlying a literary work.

Morenga is a documentary novel that entails multiple narrative forms and multiple narrative voices. It can be read as the story of the (fictional) German Veterinary Lieutenant Gottschalk's military placement in the German colony of South West Africa (GSWA) from October 1904 to September 1907. ${ }^{31}$ As such, the novel is a counter-story to the colonial novel Peter Moor's Travel to South West Africa, exploring the history of the Nama leader Morenga. ${ }^{32}$ Apart from the two juxtaposed figures, Morenga and Gottschalk, the novel entails two different approaches to history, which are offered in numerous stories, told without guidance from the assumed narrator how to read them. The narrator broadly follows Gottschalk's time in the colony and the places of his deployment, but the chronology and topology is disrupted by multiple side-stories that the reconstruction requires an extraordinary effort. With this strategy, the reader's assumptions are constantly disoriented, to the effect that the

26 Unfortunately, the Nama and Ovaherero also fight against the obliteration in Namibia itself, where their history is being "overwritten" by the official memory of the liberation struggle from South Africa in the 1980s. Cf. (Hamrick and Duschinski 2018).

27 Cf. For a concise overview of the history: http://ahrp.org/germanys-colonial-genocide-in-namibia/.

28 In this, I follow the diatopical hermeneutics that has been introduced by (de Sousas Santos 2014).

29 Baer's study examines the ties of the GSWA genocide to the Shoah through the lens of literature. She dedicates a chapter to "Peter Moor" and reads Timm's novel as an intertextual commentary to this early colonial novel.

30 In West-Germany, the new habitus was tied to human dignity and human rights while in East-Germany, it was depicted as the Socialist identity. In contrast to the mid-19th century to the mid-20th century, biological racism had no place in either part of the country.

31 Gottschalk, like all other German figures, is not granted a first name in the novel, while many Herero and Nama have Christian first names. Gottschalk is a common German name and literally means "God's joke".

32 Cf. for the overall context and the focus on intertextuality: (Baer 2017). 
cohesion of the plot, the authenticity of characters, the linearity of time, the perception of space, and the meaning of words all lose their narrative function of orientating the reader. On the one hand, the novel resembles a Bildungsroman, a formation story of Gottschalk. As a young German man, he imagines Africa as an exotic world that he experiences, for example, in form of the spices sold in his father's colonial store, sparking his interest in this "foreign" world. Over the course of the novel, however, he transforms from a naïve, adventure-seeking man to a deeply disillusioned soldier who sees the German war against the Herero and Nama as a crime against humanity. Observing the starving Nama in the concentration camps and the arbitrary killings, trying to stand at the margins of the battles, Gottschalk is paralyzed in indecision and inaction. With respect to the history of German colonialism, the novel entails, on the other hand, several historical documents and multiple stories depicting the interactions of European colonizers with the different tribes, strictly told from a European perspective. These stories trace the main elements of German colonialism from the early 19th century until 1918, when Germany loses its colonies after World War I. The novel therefore entails a chronicle of the German history of colonialization, told in fragments, in which fiction and historical documents constantly intersect. It reflects the underlying religious, economic, and political epistemologies of colonialism. This epistemology is challenged repeatedly, with inserted testimonies to the Nama and Herero narratives of their history.

Gottschalk's story, which structures the main timeline and spatial sites of the novel, is therefore interrupted by multiple stories from different perspectives, assembled by the narrator without a strict order, contradicting in the narrative style the German obsession with "order", which is the topic of several conversations and reflections in the novel. While Gottschalk's story certainly provides a thread through the novel, it intersects constantly with the title figure Morenga who is implicitly present throughout the novel, appearing and disappearing just like the historical leader of the Nama guerilla war appears and disappears in the war. At the beginning of the novel, the narrator points the reader to the difficulty of finding historical sources of Morenga's life, thereby revealing that historiography cross-reference with fiction in any narrative, as Ricœur had argued (Ricœur 1988); the answer to his question "Who was Morenga?" is given by a "District officer of Gibeon": Morenga's life story is largely unknown-or unknown to the German sources. What is known seems fragmentary and sparse: there are rumors about the legendary status he has gained in GSWA, that people associate superhuman powers with him, that he is also called Marengo, that he is the son of a Herero father and Nama mother, a Christian who may have been educated in a missionary school. A little later, more information is added: Morenga, the reader now learns, has indeed been educated in a missionary school, he speaks two colonial languages fluently, English and Dutch, and he also understands German, contradicting the imagery of the uneducated "savage" that is spread in Germany (Timm 2003, p. 28). Like Red Peter, Morenga masters language well, using irony and sarcasm in letters he writes to the military (ibid.), and like Gottschalk, he keeps a diary that is, however, preserved only in fragments. Since central elements of colonialism are depicted in the novel, I will give some examples of how the novel tells the history of coloniality as the German habitus of misrecognition, before turning to Morenga' and Gottschalk's intersecting story.

\subsection{Colonial Life I: Religion}

Missionaries from the Lutheran Rhenish Mission begin their missionary work on the African continent in the early 1800s, and the novel painfully describes the priests' ignorance and indifference towards the Herero and Nama, contradicting their self-perception as the saviors of their souls. The novel therefore calls for the analysis of theology's own history that often conceals its complicity and role in colonialism, and rarely reflects its theological racism. ${ }^{33}$

33 Mills rightly explains that theological racism is one important element of the different facets of racism. Cf. (Mills 2015). 
The story of the (fictional) missionary Gorth is a cautionary tale of the German mission in Africa. Ironically, the Nama compare his physiognomy to a Merino sheep and a "friendly and undemanding animal" (Timm 2003, p. 89); unlike the "savages", he never learns to speak or understand the Nama language. He is drawn to "Africa" as a young boy when he sees "three naked little black children [who] were sitting around a nest containing three ostrich eggs" (Timm 2003, p. 93) in the Missionary newspaper that his father subscribed to at his home in Heddersheim. The Church's gaze on the "Africans" is paternalistic, infantilizing, and dehumanizing: "At the entrance to the church stood a small metal statue of a nodding black boy, with a slot for coins in his head" (ibid.). Gorth, who arrives at the English Missionary Bethany in 1852, has his own ideas of civilization, which are told with scathing irony, contradicting the "humanist" mission: he has brought a piano and some pigs, the latter aimed at countering the Islamic missionary by introducing pork to the "Hottentots". ${ }^{44} \mathrm{He}$ is disappointed that the "Africans" do not live up to his exotic imaginations, the women in particular, and he imagines to take a Nama called Lukas to Germany for a fundraising campaign on behalf of the African "savage", which resembles the peoples shows' voyeurism, sublimated by the religious charity work:

"tall and well built, with a high, broad forehead, and a calm, direct gaze. This figure demonstrated, so Gorth felt, the ennobling and formative effect of Christianity, how it could turn a savage into an upright human being. With a Lukas like this, he could tour German cities and missionary societies." (Timm 2003, p. 95)

The religious education has not always the intended effect, as an English missionary, ironically called Rumbottle, observes, unmasking the Church's education program as theological racism:

"natives, once they could read the holy scriptures, always picked out those passages that were aimed against the rich, the authorities, and in the end against even the missionary church itself. So sects kept arising. The only way to avoid this problem was not to teach the natives to read and write in the first place. And this in fact was Rumbottle's approach." (Timm 2003, p. 100)

Missionaries shape the way Germans see the "Africans" in many ways. Gorth writes letters to his fiancée, depicting the way the Nama raise their children (without the disciplining violence known in Prussian Germany), how they go about their life, and have their own tradition transmitted in the history of their cattle. In this history, the lines between humans and animals are blurred, oxen can speak, remember, and narrate the story of the tribes who are traditionally cattle traders, and these stories entail the genealogy of the Nama people that the Germans are ignorant of because they do not understand their language. ${ }^{35}$ The traditional wisdom of the Nama cultural history is thereby juxtaposed to the paternalistic gaze of the missionaries, just as the earnest study of the bible by the newly-baptized is juxtaposed to the colonial racist theology of the missionaries. Ultimately, the intercultural encounter is shaped by misunderstandings and the lack of effort on the part of the German missionaries to change or correct their own pre-judgments through the experiences with the Nama and Herero. While the life of the latter is changed radically, it never occurs to the missionaries that they, too, could learn from their African counterparts. The oppressive colonial missionary hermeneutics prevents a "diatopical" (de Sousas Santos 2014 hermeneutics to emerge, thereby also preventing an intercultural theology based on moral recognition and responsoric encouters of alienness in the context of the missionary work.

34 The denigrative term of the Nama is used in the German protocols of the army, in politics, the writings of colonial business, the missionaries, and in German culture. I still heard it as a child in the 1970s, albeit without understanding the connection to the history of Germany. I will use it here when the novel does that, too. The narrator points to the fact that the "Hottentot" are the Nama right at the beginning of the novel (3).

35 Interestingly, Timm's text could be easily read as a commentary to Nietzsche's concept of memory and history, e.g., regarding the "ruminating" memory, the human exposure to the documents of the past and the alien, and the tricks of the historian to pretend his mastery of the material. Cf. for an analysis of Nietzsche's concept (Meyer 1998). 


\subsection{Colonial Life II: Trade and Capitalism}

Morenga entails multiple intersecting narratives of the missionary work in the colonies with the trading of colonial goods in European countries. Timm's narrative strategy is to bring together multiple stories from different places and times in the nonlinear, associative way of memory. Often, they are initiated by Gottschalk who hears names or fragments of stories that are then unfolded in relative independence of his consciousness, or they are stories associated with the places he visits, the people he encounters, all told by the narrator who assembles them as a historian. One of these stories concerns the development of the colonial trade in the 19th century in accordance with the economic theory of Adam Smith. The "end" of biological race theory, generally dismissed as scientific theory after the Shoah, is thereby contrasted with the continuity of an economic theory that still shapes, at least in general, the rules of capitalism; neocolonial exploitation still defines much of late 20th century's capitalist economies, raising the question, of course, how post-racial Western societies can even be in theory if they still function under an economic theory that intersects so closely with colonialism.

In mid 19th century, colonial goods become symbols of bourgeois life in Europe. In addition to exotic spices and foods, metals that are extracted from the mines (Morenga, for example, is said to have worked in a mine before the rebellion), the textile industry and fashion companies are also highly dependent on the goods from the colonies. One of the stories told in the novel is emblematic of the colonial trade with the tribes of GSWA; it begins with one particular good, namely ostrich feathers, and expands to the whole system of colonial exploitation in 19th century capitalist economy. In 1859, the narrator tells us, ostrich feathers become utensils of women's hats in Paris and Berlin, the cultural centers of the day, and quickly become the "must haves" in the bourgeois circles. These hats are often depicted by the Parisian impressionists in their paintings of the city life, which Timm may presuppose as collective knowledge of his readers. They are, of course, imported from the African colonies, and function as an introduction to the world of colonial trade, exemplified by the businessman Klügge, in the German language connotated to "klug" or clever. The story of the ostrich feathers is, however, interrupted by a long detour that enables the narrator to give his account of colonial history: Klügge starts out his colonial business in Cape Town in 1842, after an apprenticeship as accountant in Düsseldorf. ${ }^{36}$ He first works in an import-export business, trading colonial goods such as buttons, belts, and combs, and later goes independent, trading buttons, pots, and pans for cattle. This business does not result in the wealth he has imagined for himself, not the least because he encounters the "natives" as smart traders, "something Jewish, which was not surprising, since all the Hottentots were semitic in origin" (Timm 2003, p. 146); their economy is based on sustainable rather than throw-away consumers. This is not an attitude that capitalism welcomes: for example, Klügge complains, the natives have "the annoying tendency to search for any button they had lost-and they were constantly losing them-until they found it." (ibid.). Similar to the ostrich feather, the buttons are an allegory for the requirements of particular consumers in a capitalist economy, and this cannot function when it becomes part of a lifeform that has another purpose than consumption: Klügge is horrified to see that the search "could take hours or even days, it didn't matter, it became a form of public entertainment, turned into a sort of small-scale festival until the button was found." (ibid.). Observing this uneconomic behavior, Klügge concludes that capitalism will not work with sustainable goods: "This willingness to waste time made any long-term business plans impossible. All the natives wanted were the bare necessities and then they would laze away the day." (Timm 2003, p. 147). He therefore turns to the business idea of selling brandy, utilizing its unsustainable value:

"Ideally, sale and consumption occurred almost simultaneously, and with brandy thirst was quenched in a way that produced an even greater thirst afterward, so that the disparity

36 The narrator is precise in locating the homes and towns in Germany, illuminating that the stories he tells are grounded in the German terra cognita, whereas the names of the GSWA's missionaries and towns often sound like a terra incognita to the German readers. 
between drink and thirst grew increasingly greater, and the intervals of sobriety increasingly shorter, supply and demand driving each other constantly upward. Here was an economic impulse of compelling and therefore beautiful logic." (ibid.)

In Cape Town, Klügge finds an English business partner, Morris, who immediately exploits him for his own purposes and his own business of trading alcohol. But he convinces Klügge to work for him in Windhoek, because the "savages" must first learn to "think in economic terms" (Timm 2003, p. 148). The Rhenish Mission, Morris states, is helpful in this endeavor, especially in its battle against the "cattle cult" - the alternative to the Christian tradition. Christianity is not enough to educate the tribes in modern economy, the Englishman Morris lectures Klügge (and the reader). In order to build a flourishing business, the "awakening" of new needs is required, and the economy must transition to the "more highly-developed labor" that Adam Smith had introduced, i.e., the Capitalist division of labor. For this transition from subsistence economy to capitalism, the Nama need to engage in "systematic cattle theft on economic principles" instead of theft for food (ibid.). In other words, the capitalist mechanism of buying on credit had to be installed:

It was necessary, then, to awake the Hottentot's self-interest to create new needs; they were a people capable of pleasures, the wares would have to be given to them on credit to begin with, the payment would come later in the form of cattle, which, since they had so few themselves, would have to be stolen from the Hereros, for which they would in turn need powder and lead and guns, for which they would also have to pay in cattle. [....] Everything was in place, but how were these tired limbs to be set dancing? Brandy, said Klügge, taking his hand from his throat.

Exactly, said Morris, brandy will awaken the slumbering market. (Timm 2003, p. 149)

Citing Smith's economic mechanism, Morris ends his economic lecture with the core colonial-Capital principle: "in the end an invisible hand will create humanistic acts out of even the most selfish motives." (Timm 2003, p. 150).

Klügge and Morris begin to trade "utility" and "beauty" goods in Windhoek with the Nama in order to "awaken" both their economic and aesthetic senses, as Morris calls it. ${ }^{37}$ The business thrives for quite some time, not the least because of the help of the missionary who not only preaches to his flock: "Have dominion over the earth", but also that "trade and traffic" are pleasing in the eyes of God (Timm 2003, p. 152). Alcohol becomes a defining exchange good in the colonial cattle trade, but Smith's "invisible hand" results in the alienation that German economic philosopher Marx describes around the same time in Europe and which Timm evokes indirectly, resting on instrumental rationality, the objectifying, economic gaze that measures every practice for its exchange value. In the colony, too, the Capitalist economy seeps into all practices, rendering the tribes addicted to alcohol; sugar, needed for the black-market brewing of beer, becomes the currency of social relationships (even the women, Klügge complains, now want to be paid for their sexual services, or paid more than before). After a while, however, violence breaks out between the Herero and the colonists: ${ }^{38}$ public floggings, torture, and shootings of thieves demonstrate the rising tensions. On the other side, white farmers begin to complain about too many (and hence, too cheap) cattle being channeled into the market due to Morris' business, ultimately forcing the Governor to intervene. Timm thereby explains the conditions that lead to the colonial war with the Herero: the missionary work, the trade, the emerging modern

37 Timm knows that readers are familiar with the exotic pictures of African woman in European dresses, hats, and other utensils, complementing other postcards that often show bare-breast women looking into the camera. Historians have proven that these women were often forced to remove their clothes and expose their breast, instilling the image of the "savage" tribes in "Africa" in the European minds.

38 Morris, who has hired an African employee named Jonker, has him punish the Herero drastically. With this "division of labor", Timm alludes to the later exploitation of the Jewish Council in the deportation of Jews to the death camps, and to the perfidious system of Kapos and oversight by other inmates in the concentration camps. 
capitalism, and the outright cheating of the tribes not only by the government but also by independent entrepreneurs who regard the African colonies as a space of lawlessness all contribute to the so-called "rebellion" in the colony.

With this detour that has prepared the reader for the symbolic meaning of the ostrich feather, the narrator finally tells the tale of modern capitalism as the exploitation of land, animals, and humans alike. A chief of the Bondelswarts, the same tribe that Gorth encountered in the mission of Bethany, had engaged in the trade with ostrich feathers for a while, and now trades them with Klügge who has finally departed company with Morris. After a while, however, all ostriches are killed and the tribes are left in poverty and dependency, a predictable effect of a non-sustainable economy. As the ostrich story is emblematic of the exploitation of resources and the deceit of the tribes, it is also emblematic of the narrative strategy, namely, to construct a narrative order by connecting stories that the reader only understands in hindsight. Under the surface of the title and Gottschalk's experiences in the colony, "Morenga" emerges as the colonial destruction of the cultural, religious, and economic order long before the war completes this process with the literal destruction of the Herero and Nama people. Intertwined with the Christian mission work and the politics of the German empire, German colonialization functions as an economic order aimed at creating a transnational export-import market that is meant to resemble the British system: Germany exports industrial goods to its colonies, builds a new transportation system, and creates a "haven" for emigrants from Germany who purchase land in the "protection zone" of the German empire. Instead of creating a market for the African tribes themselves, the import of "colonial" goods to the European market is managed exclusively by the white settlers, rendering their African counterpart in complete dependence to their colonizers.

\subsection{Colonial Life III: Technological and Cultural Development}

Morenga depicts two different approaches to the relationship between people and peoples, clearly favoring one of them over the other: the European understanding is based on the development theory that presupposes the superiority of the white race-development means to "lift up" the uncivilized "savages". It is therefore as unnecessary as it is futile to engage in the effort of understanding the African cultures and traditions.

In the 19th century, capitalism is complemented by a plethora of technological developments, and many German engineers engage in furthering the "development" of the continent. ${ }^{39}$ These inventions play an important role in the narrative about the "development aid" the colonizers bring to the African continent. In 1885, the German Colonial Company for South West Africa is established, with the task of "the country of poets and thinkers to civilize the savages" (Timm 2003, p. 213f), but in fact as an enterprise to extract the natural resources from the resource-rich colony, especially copper and diamantes. One employee of the land company, Treptow, embodying the stereotypical German engineering ingenuity, is sent to GSWA as a land surveyor. He is an idealist who believes in progress through technological development: he is convinced that any "imperfection" of nature will be "eliminated sooner or later by technical means." (Timm 2003, p. 219). Having thought about the "development of the earth", he looks forward to contributing to the bright future of the land he will survey:

Deserts would be irrigated, rivers that flooded vast stretches of land would be controlled, dammed, or rechanneled. Anything could be accomplished with technology in a way that would serve mankind.

39 Timm inserts several of such ideas to ridicule the colonial "business ideas" of the German technological and manufacturing genius, and the overall idea of inserting ideas into cultures one doesn't know, beginning with the language, geography, climate, or culture. The dentures that Gottschalk constructs for the Nama cows underline the blurring of humans and animals and contrast strikingly with General Trotha's military orders given around the same time, namely to kill all "Hottentots". 
Still in Germany, Treptow dreams of an irrigation system for the Sahara desert that will change the climate of the whole region, ${ }^{40}$ or emptying the Caspian Sea, and rerouting the Volga river-the reader is reminded of multiple so-called development projects that were pursued over the 19th century, such as the Suez Canal, that only served the Colonial interests. Treptow also imagines the construction of a "tropical car" - "a locomotive on moveable wheels with an engine fueled by coal or wood" (Timm 2003, p. 220). His partner in the mission Bethany, where he arrives some decades after Klügge, is a geologist named Hartmann who discovers the veins of ore that the Colonial Company is seeking to turn into business. Surveying the land, Treptow soon discovers that in the land-purchases to the English colonists the tribes had been tricked, which by now could only be changed by the Company, owned not only by Deutsche Bank and Dresdner Bank but behind these by their multiple shareholders. The narrator lets Treptow tell an interesting story about the clash of European and African knowledge systems: the council of elders-which is repeatedly presented in discussions about the course of action in relation with the colonists-does not reach a consensus about a contract. An elderly, "Old Salomon Matroos", asks a wise old woman, Snuffle-Lip (who has refused to be baptized) to come to help. Snuffle-Lip sometimes "would dispose of particularly stubborn and troublesome rivals by making a doll, casting a spell, and then placing it on a termite mound." (Timm 2003, p. 228). She prepares a voodoo doll that embodies the "Company" and waits for it to be eaten by the termites. Unfortunately, it does not happen, the termites do not touch it, and Snuffle-Lip is so undone by this that she dies immediately after her failure. Treptow, however, does not believe in any magic power and seeks an explanation for the magic of the voodoo. There is nothing he can find in the doll but keeps it anyway as a souvenir, even taking it with him when he leaves the country. And then, one day, the narrator concludes this side-story, transmitting to the reader the "folk tale" that Treptow tells his grandchildren many years later as a story from the colonies, the doll disappears from the sideboard where he has kept it-"devoured by ordinary domestic ants, which had quickly swarmed through the house and just as quickly disappeared. A few days later, in 1918, the Land Company was dissolved." (Timm 2003, p. 229).

Treptow's story demonstrates the narrator's contempt, hidden in the double-speak of irony as a narrative weapon against ideology. Treptow, the narrator comments, is concerned that the mentality he encounters in the colony is so "communist" that it has become a second nature to the people, hindering them in their "development". The land-grabbing practices, Treptow reasons, may ultimately serve them well, because it will "set in motion an evolution that will teach them to work and gradually lead them toward civilization." (Timm 2003, p. 230). He witnesses firsthand the tricks with which land is grabbed from the Nama and corresponds with his former professor who is developing a new method to survey the land. He invents the Molotov-Cocktail and then invents the car for the second time, although he is deprived of the patents when his inventions are either dismissed or stolen by others. Like Gottschalk, Treptow is a non-political figure who contributes to the colonization of GSWA through his professional expertise and naivety. He is not interested in the culture and societal structure of the Nama; he considers them as child-like, communists, habitually lazy, and in need of the German's development aid. He shares the sexualized and dehumanizing gaze at the Nama women but is too afraid to follow his sexual desires: intercourse with them is an animal-like endeavor, he tells his assistant Bansemer who raves about his nightly adventures. At one point, Treptow accompanies the Company's land agent Kleinschmidt who has come to quite some wealth in Windhoek through a land purchase (or landgrab) from one of the Nama chiefs. Kleinschmidt is a realist, expecting a revolt sooner or later. "War is the father of all things", he claims, and quoting Missionary Knudsen (whom the reader knows from an earlier story of the Missionaries): "take the land away from the natives. That's the only way they will ever be useful members of society. Only hunger will force them to work." (Timm 2003,

40 Later on, the reader learns that Gottschalk spends most of his last months in the colony observing changes of the climate, as a digression from the reality that is happening around him. It repeats one of the stereotypes associated with the German culture that contrasts strikingly with the very "efficient" activities of Germany's military in the cleansing of the colony. 
p. 243). Kleinschmidt regards (the historical) Governor Leutwein's effort to acquire land peacefully as naïve yet has developed his own efficient method to get treaties signed. Treptow witnesses this on one of the trips, when Kleinschmidt cheats a chief named Klaas Hendriks into selling his land.

Treptow resembles Gottschalk in his professional interest, and like the veterinarian, he is convinced that he cannot intervene even when he has proof that the "natives" have been misled, cheated, or exploited. He is complicit with the colonial politics under Governor Leutwein, doing nothing to stop the escalating tensions that end with the shift of politics in the fall of 1904, when General von Trotha orders the German military to kill any Herero and Nama. Gottschalk differs from Treptow, however, in several ways: while he resembles Treptow in his ingenuity-after all, he engages in the most ridiculous developmental aid at the moment when the Nama tribe is exterminated, i.e., constructing dentures for the Nama cows-but like is colleague Wenstrup, he learns the Nama language and acts in small gestures of charity towards the Nama who are held in concentration camps.

The colonial voices dominate in the novel's multiple documents and stories that unfold in the intersection of religion, economics, science, anthropology, politics, and military power. Through Wenstrup, however, Gottschalk — and with him, the reader-learns about an alternative to the racist colonial theory of development. Wenstrup, who brings Kropotkin's book to the colony, gives it to Gottschalk before his desertion. It offers a vision of development that is based on "mutual aid", as the title says. Together with Gottschalk's friend's marginal notes, Kropotkin's book guides Gottschalk in the judgment of the German war, especially after Wenstrup's disappearance; it thus becomes the lens through which Gottschalk begins to see his environment. Kropotkin argues for cooperation and solidarity that will lift up everybody, and he rejects the central hypothesis of evolution theory, i.e., the survival of the fittest as the motor of development. Timm traces the two ideological systems to their origins in the 19th century, but for his own generation in the 1970s, politics and personal lives often intersect: the division line between the two worldviews runs through Germany, the divided country during the Cold War, and Timm uses the novel among other things to reflect upon the consequences of colonial capitalism over and against the anarchist socialist vision; Wenstrup is the only moral German hero: he learns the Nama language, sabotages some of the military attacks, and finally deserts from the troops in the midst of their massacres. Gottschalk, in contrast, is painted as the stereotypical obedient German soldier: doubtful and increasingly disgusted by the German soldiers' brutality, he is not able to move from contemplation of resistance to action. Early on, he begins to have doubts about the developmental enterprise lest it is based on the understanding of the other:

How can we expect to colonize a land if we don't take the trouble to understand the natives, Gottschalk once asked in Keetmanshoop. (Timm 2003, p. 82)

Politically, however, Gottschalk remains a bystander, stuck in ineffective subversive gestures. While Gottschalk cannot agree with the racist social Darwinism, he also does not have Wenstrup's courage to switch sides. He remains the "dreamer" (Timm 2003, p. 12) who in the beginning takes delight in the thought "that at some point there will be eyes in this wilderness reading Goethe, ears listening to Mozart" (Timm 2003, p. 16), and in the end is consumed by observing the "clouds". The English language speaks of the "bystander" as the person who is neither perpetrator nor victim. The German language calls this the Mitläufer, someone who "goes along" with events enacted by others, whether agreeing with them or not. The relationship between colonizer and colonized is a constant topic of Gottschalk's diary, but he is "stuck" in between the two sides. Sometimes he dares to apply the arguments he has learned from his Kropotkin reading and Wenstrup's marginal notes. One example is a conversation between Gottschalk and his colleague, medical lieutenant Dr. Haring. Haring argues:

The weak die off so the strong will have more room and light. That was the only way things could evolve onward and upward. The struggle for existence was the basic law of life. (Timm 2003, p. 197)

Gottschalk, in contrast, evokes Kropotkin's view: "The struggle for existence was not the only important factor, mutual aid within the species was equally important." (ibid.). When Haring responds: 
"exactly, [ ... ] within the species", implying that there are different human species (in line with Haeckel's racist polygenesis thesis that departs from Darwin's monogenesis thesis), Gottschalk counters that even cross-species "empathy" and "solidarity" is possible. He recounts a story of a sailor who would have drowned but for the help of dolphins who carry him in turns and thereby save him.

Against Hobbes' theory of natural rights, but also against Kant's ethics of the "good will" or Hegel's philosophy of consciousness, Kropotkin repeats the Marxian materialist thesis to the effect that the environment determines the behavior of animals and humans alike; Wenstrup draws the following conclusion from it, noted in one of the marginal notes of the book: "German philistines are wrong in thinking that morality is based on good intentions; it is based instead on living conditions." (Timm 2003, p. 196). While the European worldview is centered on freedom from nature, wealth, and well-being, Kropotkin's worldview is centered on freedom as absence of oppression and exploitation. Gottschalk reads Kropotkin who in turn is quoting Bakunin:

Man is truly free only among free men, and since he is only characteristically human when he is free, the subjugation of a single human being on earth is an injury to the principle of humanity itself, and a negation of the freedom of all men. Bakunin (Timm 2003, p. 123)

Whereas the German idea of civilization is shaped by discipline and uniformity, as seen in the military order and the assumption of the linear upward development of humans, the history of the Nama since the German colonization is narrated as the story of oppression. The Herero and Nama revolt against the German idea of freedom that they experience as force and coercion; they fight for their own understanding of freedom, because, as Wenstrup tells Gottschalk, "a man who can't freely develop a sense of things makes no sense. That's why the rebels seem to have so much sense on their side." (Timm 2003, p. 47).

Gottschalk observes that Kropotkin often draws analogies between the world of animals and the world of human beings, which may especially appeal to the veterinarians Wenstrup and himself. ${ }^{41}$ Throughout the novel, the relationship between humans and animals is constantly renegotiated. Human and animal metaphors, for instance, are used interchangeably, blurring the lines of the species and thereby questioning the "humanist" anthropology and ethics. When helping the wounded soldiers after a battle, Gottschalk remembers a quote from Kropotkin: even rats are sufficiently intelligent, Kropotkin states, "not to quarrel when they plunder our larders, but to aid one another in their plundering expeditions and migrations, and even to feed their invalids." (Timm 2003, p. 202). Claiming moral behavior as exclusive to the rational human being is unmasked as an ideology of racist superiority that reverses the criteria for moral behavior: if "good" is determined by the power of the "strong", empathy disappears together with the notion of "mutual aid", which is one possible translation of solidarity. Ultimately, only Wenstrup draws the conclusions from his readings in his desertion from the army while Gottschalk flees to the contemplation of "bushes, rock formations" the "landscape", or Kant's "starry heaven" that fills him with awe and sentimental memories, but which is also a sign that he is searching for a sense of direction at a moment of utter disorientation.

The oppression of the colonized people and peoples is symbolized by the "oxen" who are as enslaved as the tribes to whom they belong. Whoever hears their voices understands the meaning of the Nama language. In contrast to Gottschalk, the narrator seems to move swiftly between the two cultures, trans-lating (in Latin: carrying over) and trans-mitting (in Latin: sending over) elements of both to the reader. Though almost hidden in the many strata, the history of the Nama people is sedimented underneath the colonial history, retrieved by the work of the narrative archaeologist who translates the Nama genealogy from the "language of the oxen" into meaningful language when Gottschalk or others understand nothing. The novel entails two longer tales that are told by a lead ox named "Big Red". He not only tells the story of how the first "Hottentot" named "Hurt Knee" tricked

41 The "animalization" of the Nama and Herero is made clear from the beginning, in racist jokes that often invoke the veterinarians as the specialists for the "natives", too. 
a cow into the "yoke" (Timm 2003, p. 105ff) but also how the rivalry between the Nama and Herero emerged due to their competition for land. From the perspective of the cattle the decisive shift comes, however, with the English businessmen who begin to steal cattle from the Herero. Here, the narrative of the ox and the story of Morris and Klügge intersect. Contrary to Gottschalk, the narrator also understands what the "mooing cow" says while Gottschalk operates on her using a surgical method unknown to the Herero:

[Gottschalk] understood nothing. Otherwise he could have heard all about Big-Red, who pulled Missionary Gorth's wagon into this land, or of Christopherus, who had brought Klügge's mighty brandy barrel to thirsty Bethany, or of the most famous pathfinder of all draft oxen, Fork-Horn, who pulled the surveyor Treptow safely and surely through the plains and deserts. Of these prodigious feats Gottschalk knew nothing. (Timm 2003, p. 127)

When Dr. Haring asks Gottschalk after the successful operation why he even bothered about one cow, he gives him an explanation that does not require much sophistication but human decency. Any medical professional ought to understand this-yet the reader also knows how decisive physicians were for the euthanasia program of the Nazis, and therefore may well associate Dr. Haring with his Nazi successors. Gottschalk, in contrast, knows what to do in his own profession: "The cow would have died" (ibid.). Obviously, his morality is not understood in the unfolding genocide.

\subsection{Colonial Life IV: Biological Racism and Violence}

Two thirds into the novel, the reader finds a Report to the Royal Prussian Academy of Sciences regarding the relationship of the "Hottentots to other races" (269) ${ }^{42}$ by a (fictitious) Dr. Leonhardt Brunkhorst who has undertaken an expedition to "Namaland and Kalahari" between 1903 and 1905. In this report, which may be read both as an intertextual commentary to Kafka's Report to an Academy and one more intratextual commentary from yet another perspective, Brunkhorst presents the German theory of races - the voice of the Academy that we can now add to Kafka's Report, because here it is explicit what Red Peter alluded to as the position of the Academy, represented, too, in Eugen Fischer's dissertation on the Rehobot (Fischer 1913).

First, "Hottentots" are seen in relation to the Boers who are depicted with denigrating, hateful comments. The Boers, Brunkhorst states, held the Nama as slaves for centuries, and their cruelty and religious bigotry, including their supersessionism, is juxtaposed with the German missionaries who, in contrast to the Boers, granted the Nama certain rights. In the 1850s, missionaries like Gorth shared the hard life of the Nama and sometimes even "went so far as to marry a native, to achieve a deeper and more intimate empathy with them." (Timm 2003, p. 271). Thanks to the protection treaties with the German Empire, "strongly promoted by the Missionary Society", the Nama are by now sedentary and the mission is flourishing. In fact, it functions as a link between the two "heterogeneous races" as long as it finds an equilibrium between the interests of the native and the "invading race". Between the two extremes of befriending the natives and eradicating them, Brunkhorst argues, the colonists' interests must be linked with the natives' own interests (ibid.). Realistically, this "race" is not made for work; the "Hottentots" are lazy and hedonistic, "sitting around, drinking schnapps, dancing or dreaming away beneath blue clouds of pipe smoke." (Timm 2003, p. 273). ${ }^{43}$ They select from Christianity what resembles their own "heathen past", although their "social norms" that discourage competition clearly hinder economic development:

"brotherly love among the Hottentots in the form of mutual aid, respect for the elderly and for women, their tender affection for children, their abstemiousness with regard to the

42 The German is more drastic, emphasizing the objectifying tone: "Das Verhältnis der Hottentotten zu anderen Menschenrassen"

43 In a conversation with Treptow, geologist Hartmann argues that smoking the pipe is a sophisticated cultural technique that requires a fine taste, and seen in that respect, the "Hottentots have a highly developed culture". 
property of others (although limited to the property of their own tribe) - all these are such autochthonous laws." (Timm 2003, p. 272)

Clearly, Brunkhorst wants them to adopt the Lutheran Protestantism that Weber had described as driving force of capitalism, so that the "systematic training of the natives for work" (in other words: forcing them into labor) ought to be "a religious demand of the Christian mission as well" (Timm 2003, p. 273). Brunkhorst then recommends some competition between the Catholic and Protestant mission to be stirred, in order to find out which of the two produces the more willing workers and supporters of the government.

The "relation" of the Nama to the German "master" is mostly described in terms of punishment and disciplining, with Brunkhorst complaining about the inconsistency of the German soldiers who are "wielding a blow and then immediately apologizing for it." Any transgression (or the assumed transgression) of a norm must be punished. While everyone is responsible for the relationships, Brunkhorst complains about the immaturity of the Germans in this respect: instead of wavering between fraternization and mastery posture, "sympathy for foreign qualities joined with a calm, firm preservation of our own superiority, does not appeal to us." (Timm 2003, p. 275). This is misrecognition masked as recognition as described by Fanon. The reader, however, has at this point already read the (historical) instructions on "flogging" which Timm quotes, involving a discussion of which material should be used for what "crimes" and to what effect (Timm 2003, pp. 115-19). The academic language Brunkhorst uses conceals the brutality of the content of his suggestions. At the end of his report, Brunkhorst points to the "Hottentot's" ability to imitate their masters, to the point of caricaturing them, and warns the Academy not to underestimate their capabilities in matters "that touch the core of their being". 44

\subsection{Colonial Life V: Politics and War}

The encounters of human beings, and moreover between strangers, are initiated by ritualized forms of greeting and welcoming, which function as a structure of one's recognition of the presence of the other: under military and colonial rule, greeting rituals express the power structure-hierarchal order and the relation of domination and submission. But rituals of greetings may also express the norms of hospitality, and as such, they are codified as social and ethical norms in the Jewish tradition. ${ }^{45}$ Greeting, this means, is never ethically neutral. It plays a prominent role in Morenga, too. Almost at the same time as Kafka's Red Peter is brought from the African Gold Coast to Hamburg in a cage, Veterinarian lieutenant Gottschalk travels from Hamburg to the African colony in a navy ship. While Red Peter is caged and tortured, Gottschalk is part of the "other side", in this case the military hierarchy that entails strict rules of encounters among the German ranks, the "Regulations for Saluting":

On ships a superior officer is saluted once a day, the first time he is encountered. A Veterinary N.C.O. salutes a Veterinary Lieutenant by touching the brim of his cap or hat. The Lieutenant gives an identical salute to a Medical Lieutenant. All three ranks, N.C.O., Veterinary Lieutenant, and Medical Lieutenant, must salute first, as indicated above when meeting a Second Lieutenant. (Timm 2003, p. 7)

This ritual of salutation actualizes the hierarchical order of the military regime on a regular basis, expressing the morality of "order" and discipline that must be followed meticulously while the moral transgressions, i.e., the humiliation, flogging, starving, and killing of thousands of Nama and Herero people, are never questioned but instead justified as necessary means to an end. The strict military

44 The German reads: the "nerve of their life" or "Lebensnerv", alluding to the killing order by General Trotha on 2 October 1904.

45 J. Derrida recalls the importance of the A-Dieu as a greeting formula for E. Levinas, which entails in a nutshell the well-meaning for the other. Cf. (Derrida 1999). 
hierarchy mirrors the categorization of the human "races" that underlies the legitimatization of the genocide. In the fall of 1907, a few months before his return to Germany, Gottschalk notes in his diary:

The other, the new: the Jumping Bean Tree. Its exact opposite: clicking your heels. Clack. Standing at attention. The German eagle. The abstract. Asking no questions. Saying yes, sir. The love of law and order. Isn't it telling that we Germans always say: Geht in Ordnung when we mean that's fine. (Timm 2003, p. 288)

The other, the new, Gottschalk notes a little later, "would be a new perception of time, based on the logic of the senses. Not on the logic of ends and means. The properly hedge of meaning." (Timm 2003, p. 289). The jumping bean tree, an old Nama has told him a few months earlier, is the tree where the wishes of the African people grow.

On 2 October 1904, General Trotha orders the killing of every "Hottentot". In November, his military successor, Colonel Deimling, is fighting against the Herero in the North, while the Nama leader Morenga lays siege in the South, the town of Warmbad, which will be the station where Gottschalk will spend most of his time. The military leaders consider Morenga at least as great a threat as the Herero leader Hendrik Witbooi (Timm 2003, p. 27). Morenga is admiringly called a "general" by German military, and the more Gottschalk doubts the justification for the colonial war, the more visible Morenga becomes in the narrative. Empirical history and narrative history "cross-reference," and both are needed to understand the colonial war.

Not only is Morenga the topic of several consultations between General Deimling and Trotha who disagree about the strategy how to defeat him, an interview to the newspaper Cape Time quotes Morenga mocking the German army for not being prepared to fight a "guerilla war" (29). ${ }^{46}$ In contrast to the Herero leader Witbooi who copies the German killing of prisoners: "The Germans take no prisoners. We will take no prisoners" (Timm 2003, p. 71), Morenga is said to treat prisoners humanely. The siege of Warmbad at the end of 1904 is told in detail, however entirely from the perspective of the German military that ultimately holds the town, "warding off a potentially serious blow to German prestige in Africa" (Timm 2003, p. 79). When Morenga reappears after almost a hundred pages, the reader has become familiarized with the facets of the colonial life, with the Nama history, and the cruelty with which the German soldiers treat the Nama and Herero in the concentration camps.

Like the Warmbad siege, the novel depicts the battle in the South of the Colony in great detail, mirroring the well-known war stories from soldiers after World War II that Timm remembers from his own childhood. ${ }^{47}$ In contrast to the siege of Warmbad, however, the narrative shifts increasingly between the perspectives of Morenga's and the German troops, and it repeatedly refers to the admiration German officers felt for Morenga's strategic warfare, recounted in their reports. The narrator describes a photograph that shows Morenga with three other guerillas, pointing to the similarity between him and Che Guevara (a legendary revolutionary, admired in the students' movement of the early 1970s). Some entries from a fragmentary diary that Morenga is said to have written are inserted, though the narrator laments that most of it is lost, just as numerous other documents from the genocide. With this, the novel emphasizes the need for a "diatopical" method of historiography (de Sousas Santos 2014) that is impeded because the narrator has difficulties in obtaining documents after the murder of those who would have been interested in preserving them. Yet, with the fragments it has, the narrative begins the process of correcting the German military history that rests upon the "orderly" preserved empirical documents, complementing these with the fragmentary documents that represent

46 Written in 1978, Timm who had participated in student demonstrations against the Vietnam War, alludes to a similar assessment of the US army by the Vietcong.

47 In this autobiographical book (Timm 2005), written many years later, in 2008, Timm gives an account of his brother's diaries and the many war stories he heard from his father and his friends throughout his childhood in the late 1940s and 1950s in Hamburg (his brother, 15 years older than Timm, was a member the SS and died in the Ukraine in 1943), recalling that many of these veterans blamed Hitler's bad strategies for the loss of the war. Timm is struck by their indifference to any other perspective. These experiences may have inspired him to include the long battle stories in Morenga. 
the Nama's own voices. Through its story-telling, literature-fictitious and documentary-thereby contributes to the process of correcting the injustice to the Nama; yet, Timm is careful to tell their stories indirectly, subversively, and without claiming that a German novel can speak in the voices of the Nama or on behalf of them. Rather, Morenga corrects Germany's own colonial narrative, engages in the historical work of analyzing Germany's colonial genocide in the medium of literature that plays with the cross-reference of history and fiction, and addresses the (German) reader to take responsibility for their history beginning with historical knowledge.

\subsection{Gottschalk and Morenga}

Warmbad becomes the town in which Gottschalk spends most of his time during his stay in GSWA, arriving there in January 1905 just after the siege and leaving the country about the same time of Morenga's death in the fall of 1907. This time span is told as a thorough transformation, resulting from the damage of Gottschalk's "moral equilibrium" through his new moral perception of the whites and the blacks in the colony. Upon his arrival, however, he still dreams about building a new existence here: "[i]ndependent and free, a calm, comfortable life" (Timm 2003, p. 121). He muses about building a house, a garden, a school, water pumps driven by windmills, and introducing "the nightingale to this songless country" (ibid.). Gottschalk stumbles into the war with little knowledge of the African culture, a deeply unpolitical man of 34 years who is caught in a conflict that he believes he will survive unchanged. But less than six months into his stay he senses the changes of his moral compass, especially the normalization of the "genocidal gaze" that he is adopting. He is shocked about "his own failure to be shocked" about the shooting of a rebel. Looking at himself one day, he sees a "stranger" staring at him "from the splinter of mirror" (Timm 2003, p. 125): "They shot a man, and all I thought was, I hope no one hears it." Repeatedly he thinks "one must do something", noticing how he thinks of himself in the third person, referring to himself as "one" and "he" (Timm 2003, p. 126), just like Kafka had depicted the "human" he encountered as the "civilized" Europeans. Gottschalk slowly transforms into the disillusioned soldier who is caught between the two sides of the war, the two cultures he encounters, and between the two moralities; the "civilized superiority" of the Germans turns out to be of bestial brutality that goes far beyond the violence Gottschalk knows from his studies of animals-and is therefore a moral inferiority-while the Nama and Herero value their communal solidarity, the freedom they express happily in celebrations, dances, and songs, and a sense of justice that compares their poverty and oppression to the wealth and power of the colonizers. Gottschalk, his colleagues think, is slowly losing his (European) mind, more often than not seen among the "Hottentots", and ultimately beginning to "smell like them", at least in the eyes of his fellow soldiers.

Gottschalk knows that he is not able to bridge the distance to the Nama people whom he encounters with the generous, paternalistic respect of the colonizer, depicted above as conditional recognition as one way of misrecognition. Though he tries to imitate Wenstrup in his efforts to learn the Nama language and learn about their culture, Gottschalk realizes that the German colonial and military logic of discipline, order, and instrumental rationality (that includes the legitimacy of genocide) is incompatible with the Nama logic that is based on subsistence rather than accumulation of goods, cultural rituals rooted in aesthetic, communal expression (dance, music, celebrations), decision-making upon consultation, and the social adaption to the colonial religion, colonial language, economics, and governance that has left many of the their families in dire poverty. Men are depicted as addicted to alcohol, women as prostitutes, and young men as the servants of the settlers. Gottschalk observes these structures, but he does not gain an objective view "from above" but is positioned at the margins of events. His struggle with the translation between the two languages is emblematic for his failure to remain the same, yet unable to become another: he often fails in translating the Nama terms into his own language, or vice versa, explain the meaning of German words into the Nama language. He learns to pronounce the Nama words but he often misunderstands their meaning. His dream of a bourgeois German life with a house, wife, children who together listen to and play classical European 
music (Timm 2003, p. 14) in the midst of the African continent crushes when he sees his future in the face of his Nama friend's mother. While Katharina has become his companion, her attempt to introduce him into her family ends their relationship: Gottschalk sees her father, drunk in the morning, babbling in Cape Dutch, and constantly repeating the only German word he knows, namely "it's okay" or "Gehtinordnung" (Timm 2003, p. 251), and he suddenly sees the future Katharina in her mother, depicted in the stereotypical image of the colonial "savage", well known from photographs sent to Germany from the colonies:

A fat woman appeared, her breasts hanging out of her tattered dress as if these large lumps of flesh did not belong to her. Her backside was the size of a barrel. Everything small and delicate in Katharina was colossally enlarged in this woman. The frightening thing was that Gottschalk saw the mother in the daughter. (Timm 2003, p. 252)

Despite the feeling of physical intimacy, he will remember months later, he knows that their distance is "unbridgeable" (ibid.).

In mid-March 1905, Gottschalk and Morenga cross ways for the first time, albeit only indirectly, in a battle Gottschalk is partaking in. His sympathies clearly are with Morenga, although Gottschalk is disappointed when the Nama show little resistance to the German troops. In Warmbad, Gottschalk had confessed to Doctor Haring that he would not actively fight or shoot a "Hottentot" (Timm 2003, p. 253). Now, engaged (or entrapped) in the battle, he thinks about the possibility of some act of resistance: "something to break through this indifference, the internal frost in the midst of the singeing heat", shooting the colonel, taking off, joining the fleeing Nama-but in the end, he only runs "aimlessly about in the terrain" (Timm 2003, p. 203). The Nama are defeated, and Morenga only escapes with a gunshot injury. A few days later, Gottschalk obtains Morenga's white horse that had been caught running "back and forth between the front lines", just as Gottschalk had, both connected in their disorientation: the white veterinarian soldier running about the German and the Nama troops, and the white horse running about the Nama and the German front lines.

A parliamentary report recounts a meeting of a German officer with Morenga in April 1905, on Morenga's terrain. It mentions the colonial greeting ritual as a demonstration of power:

I seated myself and remained intentionally seated as Morenga [ . . ] approached. It was not until he greeted me and I saw it was clearly difficult for him to stand that I permitted him to seat. (Timm 2003, p. 189)

The officer also reports that in his view Morenga's leadership is declining, projecting how this would happen in the German army to Morenga's people:

Such power, which only hereditary chiefs have otherwise, is shaken the moment his followers begin to lose their unconditional faith in their leader's lucky start and the certainty of victory is undermined. (ibid.). ${ }^{48}$

Gottschalk, for his part, notes in a remark on "the gestures of masters and the facial expressions of power":

"Finer, sublimated forms one no longer notices back home, because one is used to them: [ ...

] Instead of looking subordinates in the eye, one glances at the cap rim, up and slightly past it." (Timm 2003, p. 193)

Finally, when Gottschalk meets Morenga in September in 1905 (and a hundred pages later), the novel has taken so many detours that Morenga's behavior no longer comes as a surprise. The reader

48 For the German readers, these sentences are tainted in their reminiscence of the Führer Hitler and his "unconditional followers". 
is given a report that Gottschalk must write to his superiors, because they are suspicious that he was released by Morenga's troops unscathed after they captured him in the midst of the battle in Heirachabis. Ironically, Gottschalk describes his mental state at the time of his capture as "slightly dazed", which he relates to a fall when his camel is shot. The report itself is a masterpiece of ironic story-telling, resembling the subversive strategy that Kafka uses in his story. Unlike Kafka's story, however, it entails some comments as "marginal notes", added by the Colonial Guardian Headquarter to whom the report is addressed, complementing Gottschalk's voice with the military commentary, again reflecting the archaeological "assembly" of the sediments of history as different narrative voices. Gottschalk reports that the rebels engaged in a long conversation with him about his rank: "I tried to explain that I wasn't an officer in the true sense, but simply a veterinarian, an animal doctor." (Timm 2003, p. 300). In spite of being an animal doctor, he treats Morenga's gunshot wound, which he describes in detail. In view of the commentator, Gottschalk acts strangely and out of bound:

"I asked his conditions for peace. (Marginal note: Is he crazy?) He said his demands were quite simple: to let them live freely in their own country. [ . . ] But Morenga also emphasized that he would keep fighting to the last man. And when I asked why, he offered the surprising answer: So that you and we can remain human. (Marginal note: native logic!)" (301)

Contrasting his observation with the officer's report, Gottschalk finds the Nama rebels in good morale and Morenga's leadership uncontested: "The recognition Morenga received as their leader seemed equally voluntary." (ibid.). In the evening before he is released, Gottschalk is finally immersed into the Nama culture, joining the singing and dancing (as a Prisoner of War!). Yet, even after this encounter with Morenga and his people that clearly leaves Gottschalk deeply impressed, he realizes:

These people were near to him and yet infinitely distant. Had he remained, he would have had to learn to think and feel differently. Radically change his thinking. Think with his senses.

(Timm 2003, p. 321)

In the investigation against Gottschalk, another wounded soldier is questioned who reveals that this conversation between Gottschalk and Morenga was held in Nama, and apart from this, he had noticed only one more remarkable thing: "when taken to Morenga, the veterinarian held out his hand, which the other man simply ignored, which Lämmer found unbelievably impertinent" (Timm 2003, p. 302). When they left, however, "Morenga held out his hand to Gottschalk" (ibid.). Tragically, some of Gottschalk's statements about Morenga's intentions lead to some changes in the German military strategy (or so he thinks); in violation of colonial rules, they attack the Nama in British territory to where they have withdrawn in the spring of 1906; Morenga is severely wounded again, and he turns himself in to the English a little later, asking for asylum, reflecting Morenga's knowledge of his rights.

The military battles of the year 1906 until the official ending of the war in March 1907 are only summarized: after Morenga's defeat, mirrored by the Herero's defeat, it is clear that the rebels have no chance against the soldiers Germany has by then deployed to the colony. The laws become ever-more gruesome: all land and livestock is confiscated, the "natives" are forced into labor leaving them without any cultural or political organization; they have to wear a pass token around their neck; they either work as forced laborers or are held in concentration camps. Many of them die on Shark Island-in a breach of the treaty but following through the military order given by General Trotha: "a good Hottentot is a dead Hottentot" - resulting in the eradication of their culture. The narrative ends with the confirmation of the beginning: Morenga's life is surrounded by multiple legends, elevating him to mythical status. In the fall of 1907, he is killed in a united attack by German and British forces. The "end" of the war is summarized in the (fictitious) military report, reaffirming the colonial order:

The natives of South Africa will now realize they're not fighting the Germans, or the English, or the Dutch, but that now the entire white race stands united against the black. (Timm 2003, p. 337)

Throughout 1906 to the fall of 1907, the time of Morenga's death and Gottschalk's return to Germany, Gottschalk stays in Ukamas as one of three veterinarians. Having little to do, Gottschalk 
becomes apathetic, spends his time mostly alone observing the clouds and the weather, absorbed by daydreams of a future that he knows will not come true; he is tormented by his bad conscience because of his complicity and complacency but remains unable to act, even hesitant in petitioning to be discharged, "as if he were waiting for something" that he cannot name. Others see him as a "sleepwalker" (Timm 2003, p. 314) and "eccentric" (Timm 2003, p. 316); they see how "he sat silently staring into the distance, surrounded by a cool reserve. It was the loneliness of total apathy" (ibid.). Finally, he submits his petition in May of 1907, but only after learning about what the Germans call Morenga's "surrender" to the British. Asked for his reason for the petition, he says "he no longer wished to take part in the slaughter of innocent people" (Timm 2003, p. 323), which his superior repeatedly narrates to others as the unheard-of anecdote of the guy who had begun to resemble the "Hottentots" in his appearance and even his smell.

\subsection{Narrative Ethics and the Responsibility for the Past}

In the "time in between" the battles and his discharge Gottschalk begins to reflect upon his transformation, seeking answers in metaphors and analogies of nature and humans. He compares the geology of the land to the inner self "with its fissures, displacements, sediments, deposits, and erosions" (Timm 2003, p. 318). As for the "Gottschalkian cloud morphology", Gottschalk's observations are "a passionate attempt to restore to a fossilized and desensitized language an element of the spontaneity, diversity, and individuality that Gottschalk seemed to recognize in the formation of the clouds" (ibid.). Combining the sound —-the Nama language is known for its "clicking sounds" that the Germans find difficult to learn, the novel repeatedly states-with meaning that one can understand is part of learning a language. Gottschalk, however, runs into multiple difficulties of translation, which becomes the symbol of bridging the "unbridgeable" alienness (Waldenfels 2011), but increasingly also between him and his fellow Germans. This is the reason why he turns to the "clouds" as well as to the sediments of history preserved in the geology of a land. Both entail Timm's poetics, captured in these metaphors. While geology requires the work of a geologist, meteorology follows the movements of weather in real time; hence, Gottschalk interprets the events while they occur, while the narrator reconstructs the history like a geologist. Yet, like Gottschal, the narrator seeks to bridge the empirical documentation of the movement of the clouds, i.e., the events over time, in a "constant series of new descriptions" with "at least some degree of abstraction" that allows for "conceptual generalization". The latter are needed to enable an "intelligible transmittal" of observations. In this way, the Nama meaning of "cloud", namely "infinite" (Timm 2003, p. 50), receives a late recognition as another metaphor of historical narratives: they, too, are indeed ever-changing and infinite, because the events cross-reference with the forms of the narrative.

Gottschalk, it is said, reinvents the mechanism of the "free balloon" around this time, invoking the metaphor for the narrator of history who is, at the same time, a participant in history: the "balloon pilot, who would be completely at the mercy of the momentary direction of the wind if he were sailing freely, is able to navigate the balloon to some degree by means of the resistance of ropes that drag along the ground." (Timm 2003, p. 318). The metaphor of meteorology is repeated in the epilogue, with a slightly different turn, now revealing the poetics of the novel that anticipates Ricœur's term of the crossed reference of empirical and narrative knowledge in historical and fictional narratives: observing the weather resembles the observation of historical events over time, abstracting to a certain degree is as necessary in meteorology as in historical narratives (and fiction), and constructing some conceptual generalization are the tools needed for the narrative of historical events, too. Furthermore, balloon flights, the narrator now holds, are "a work of art in which the pilot, the balloon, the wind and weather, and the landscape as well, unite" (Timm 2003, p. 338), which can also be read as an aesthetic ideal. In this utopian world, symbolized by a balloon flight, there is no exploitation, "except for the fuel", no torment or mistreatment of people. The balloon flight is of no economic value, because it can only be navigated in limited ways; it is, as Gottschalk's friend says, "like working with precision scales" (ibid.). But if the balloon flight is indeed a metaphor for the work of art in which the narrator 
unites with the story and the events that contribute to it, it is presented as a cautionary tale: art may also be an escape, the illusion of freedom in forgetting. In the final scene, Gottschalk sees the world from above; it seems to be as it has always been, as if history could be forgotten-he sees the German landscape and culture, recognizing all the familiar sounds of life as if nothing had changed, and as if he had never been to the foreign country in which the cruelest crimes imaginable were committed: nothing, it seems, not even the genocide that he participated in and let him lose his moral compass, has motivated him to act and/or remember differently.

Years later, Timm writes in his book about his brother (Timm 2005), that one of the most shocking facts concerning the soldiers who refused to take part in the mass killings of World War II was that they did not have to fear much punishment-mostly, those who deserted or refused the orders were discharged or sent to another unit. The figure of Gottschalk can therefore also be read as the harbinger of these later soldiers. He embodies the disinterested, forgetful, and joyful postwar German soldier who continues to claim that he was no more than a bystander, while in fact he was a Mitläufer who did not merely stand by but who "went along"with the mass atrocities. They certainly did not live up to the concept of enlightenment that the Western world celebrated as the its biggest achievement. For one of its most prominent representatives, Immanuel Kant, enlightenment did indeed mean freedom. But he saw freedom as capability and responsibility, an autonomy that is the moral capacity to only live by that moral law that one has, at the same time, given oneself and that could be shared by all others as a universal moral law (Kant 2013). Coloniality does not only contradict human decency; it also contradicts the very tradition that it claims to adhere to.

\section{Towards a Decolonial Narrative Ethics}

In addition to the critique of recognition theory that requires a break with the ethically flawed concept of conditional recognition and a reinterpretation of recognition from an ethical point of view, I want to draw some conclusions from the fictional narrative of history that Kafka's short story and Timm's novel offer. I hope that the two examined texts in this essay can help to further develop a decolonial ethics, and as part of it, a decolonial narrative ethics.

My reading of the two stories illuminated racist coloniality as a structure of misrecognition of concrete others (animals, humans who are rendered animal-like, African cultures under colonial rule, and Europeans who are socialized to repress their drives and sensitivities). It calls, in a first step, for a hermeneutical virtue ethics that is informed by literature as a medium of and for ethics. Narrative ethics shows that this must be concrete and situated-as any storyteller and story is. As long as the "other" who speaks, who addresses the reader, and to whom the reader responds, is not concretized in historical terms, a "responsoric" recognition or recognitive responsibility remains in the aesthetic realm, without ramifications for the concrete personal, social, or political action-reading Timm's novel does not in itself change Germany's relation to the Nama and Ovaherero, for example. Without a doubt, unlearning of the colonial habitus, the social character that Fromm analyzed as the patterns of human destructiveness (Fromm 1973), and learning recognition as inter-action and acting together is necessary and a huge task. But it must not replace the other elements of responsibility, i.e., accountability on the one hand, and the responsibility to transform structures of injustice into justice as political practice. ${ }^{49}$ Readers, among others, respond to narratives as moral agents who engage in an ethical deliberation how to see-and change- the world they live in. Storytelling therefore serves practical reasoning both as an aesthetic-hermeneutic responsoric ethics that aims at recognition, and as responsibility of a moral agent who is, like every other agent, "aiming for a good life with and for others in just institutions" (Ricœur 1992). Ethics must ask who is responsible for what practices and structures, and in what way,

49 This is the point of Ricœur's theory of threefold mimesis, i.e., the prefiguration of a text, the configuration in a narrative and the refiguration in the reception history. Cf. (Ricœur 1992). 
and who is most urgently in need of actions, and in what way. ${ }^{50}$ Decolonial ethics comes with an interest that goes beyond its counterpart in literature: it does not only aim to understand the structures of colonial thinking and acting, it also aims to correct and rectify past-and present-injustices, in order to restore justice or establish justice for the first time. Ethical theory uses different terms to describe this transformation of injustice into justice, but in any case, restitutive, reparative, or restorative justice models are social-ethical and political-ethical efforts that attend to the different positions of agents in regard to justice. In the case of Germany's history that I have examined here from a narrative ethics perspective, perpetrators of the colonial genocide-who are named in Timm's novel just like Hagenbeck is named in Kafka's story-have never been held accountable, just like how only a few perpetrators after the Shoah were put on trial. The present generation, even though not directly accountable, is still responsible for Germany's past, because it is still present, independent of the outcome, for example, of a lawsuit over reparation claims. ${ }^{51}$ The present generation's ethical duty is to engage in the work of recognition that begins indeed with re-cognition, the looking back in order to know one's past, and acknowledge what happened in the former German colony. This engagement must be guided by respect, attention, and care for the present and future well-being of the descendants of the genocide. The descendants of the victims must not only be heard in their address, in testimonies and their accounts of the suffering and humiliation of the past and, moreover, of the effects on their life at present in Namibia. Their address must also be responded to, in the practical, imperfect and finite, yet mutual work of recognition that ultimately may result in the transformation of both parties, the goal of reconciliatory justice. Whether it is through reparations or other, necessarily imperfect, ways of recognition aimed at rectifying what cannot be rectified (Derrida 2001), mutual recognition is "accepting partial success" of reconciliation, instead of being paralyzed by the inability to reach the state of perfection, just as any storyteller accepts the partiality of the story they tell, instead of falling silent in the wake of the unspeakable cruelty that only human beings are capable to inflict upon others.

Funding: This research received no external funding.

Conflicts of Interest: The author declares no conflict of interest.

\section{References}

Anhalt, Utz. 2007. Tiere und Menschen als Exoten: Exotisierende Sichtweisen auf das "Andere" in der Gründungs- und Entwicklungsphase der Zoos. Ph.D. dissertation, Hannover, Germany. Available online: http://edok01.tib.uni-hannover.de/edoks/e01dh07/524261350.pdf (accessed on 2 July 2019).

Appiah, Kwame Anthony. 2008. The Ethics of Identity. Princeton: Princeton University Press.

Attridge, Derek. 2004. The Singularity of Literature. London and New York: Routledge.

Attridge, Derek. 2010. Reading and Responsibility Deconstruction's Traces. Edinburgh: Edinburgh University Press. Attridge, Derek. 2017. The Singularity of Literature. London: Routledge.

Baer, Elizabeth R. 2017. The Genocidal Gaze: From German Southwest Africa to the Third Reich. Detroit: Wayne State University Press.

Balaton-Chrimes, Samantha, and Victoria Stead. 2017. Recognition, power and coloniality. Postcolonial Studies 20: 1-17. [CrossRef]

Benjamin, Walter. 2003. On the Concept of History. In Selected Writings IV, 1938-1940. Edited by Howard Eiland and Michael W. Jennings. Cambridge: Harvard University Press.

Benjamin, Jessica. 2017. Beyond Doer and Done to: Recognition Theory, Intersubjectivity and the Third. New York: Routledge.

50 For a discussion of the difference between accountability (or liability) and social responsibility in the case nobody does anything wrong yet together creating a structure that is unjust cf. (Young 2011).

51 In March 2019, the lawsuit by the descendants of the Nama and Ovaherero tribes against the German state was rejected by a New York court. Cf. https://www.dw.com/en/us-judge-dismisses-namibian-genocide-claims-against-germany/a-47816283. 
Bernstein, Jay M. 2015. Torture and Dignity: An Essay on Moral Injury. Chicago and London: The University of Chicago Press.

Bourdieu, Pierre. 1990. The Logic of Practice. Stanford: Stanford University Press.

Bourdieu, Pierre. 1994. Language and Symbolic Power. Cambridge: Cambridge University Press.

Celikates, Robin. 2012. Systematic misrecognition and the practice of critique: Bourdieu, Boltanski and the role of critical theory. In Recognition Theory and Contemporary French Moral and Political Philosophy. Edited by Alice Le Goff and Miriam Bankowsky. Manchester: Manchester University Press, pp. 160-72.

Coetzee, John Maxwell. 2004. Elizabeth Costello: Eight Lessons. New York: Random House.

Creedon, Genevieve. 2014. Analogical Animals: Thinking through Difference in Animalities and Histories. Configurations 22: 307-35. [CrossRef]

de Sousas Santos, Boaventura. 2014. Epistemologies of the South: Justice against Epistemicide. Boulder: Paradigm Publishers.

Derrida, Jacques. 1999. Adieu to Emmanuel Levinas. Stanford: Stanford University Press.

Derrida, Jacques. 2001. On Cosmopolitanism and Forgiveness. Lodon and New York: Routledge.

Derrida, Jacques. 2002. The Animal That Therefore I Am (More to Follow). Critical Inquiry 28: 369-418. [CrossRef]

Derrida, Jacques. 2004. Uninterrupted Dialogue: Between Two Infinities, the Poem. Research in Phenomenology 34: 3-19. [CrossRef]

Fanon, Frantz. 1967. Black Skin. White Masks. New York: Grove Press. First published 1952.

Fischer, Eugen. 1913. Die Rehobother Bastards und das Bastardisierungsproblem beim Menschen. Jena: Gustav Fischer Verlag.

Fraser, Nancy, and Axel Honneth. 2003. Redistribution or Recognition? A Political-Philosophical Exchange. London and New York: Verso.

Fromm, Erich. 1973. The Anatomy of Human Destructiveness. New York: Holt.

Gadamer, Hans-Georg. 1975. Truth and Method. London: Sheed Ward.

Haker, Hille. 1999. Moralische Identität. Literarische Lebensgeschichten als Medium ethischer Reflexion. Mit einer Interpretation der "Jahrestage" von Uwe Johnson. Tübingen: Francke.

Haker, Hille. 2003. Ban graven Images. Literatur als Medium ethischer Reflexion. In Literatur ohne Moral. Literaturwissenschaften und Ethik im Gespräch. Edited by Christof Mandry. Münster and Berlin: Lit, pp. 67-88.

Haker, Hille. 2010. Narrative Ethik. Zeitschrift für Didaktik der Philosophie und Ethik 2: 74-83.

Hamrick, Ellie, and Haley Duschinski. 2018. Enduring injustice: Memory politics and Namibia's genocide reparations movement. Memory Studies 11: 437-54. [CrossRef]

Herder, Johann Gottfried. 2002. Treatise on the Origin of Language. Philosophical Writings, 65-164. First published 1772. [CrossRef]

Herman, David, James Phelan, Peter J. Rabinowitz, Brian Richardson, and Robyn Warhol. 2012. Narrative Theory: Core Concepts and Critical Debates. Columbus: The Ohio State University Press.

Honneth, Axel. 1995. The Struggle for Recognition: The Moral Grammar of Social Conflicts. Polity Press: Cambridge and Oxford: Blackwell.

Honneth, Axel, Amy Allen, and Maeve Cooke. 2010. A conversation between Axel Honneth, Amy Allen and Maeve Cooke, Frankfurt am Main, 12 April 2010. Journal of Power 3: 153-70. [CrossRef]

Hund, Wulf D., Charles W. Mills, and Silvia Sebastiani. 2015. Simianization: Apes, Gender, Class, and Race. Münster: LIT Verlag, vol. 6.

Iser, Wolfgang. 1979. The Act of Reading: A Theory of Aesthetic Response. Baltimore: Johns Hopkins University Press. Jauss, Hans Robert. 1982. Aesthetic Experience and Literary Hermeneutics. Minneapolis: Minnesota University Press.

Kafka, Franz. 1971. A Report to an Acadamy. In Franz Kafka. The Complete Stories. Edited by Nahum N. Glatzer. New York: Schocken, pp. 81-88.

Kant, Immanuel. 2013. An Answer to the Question: 'What Is Enlightenment?'. London: Penguin.

Kjaergaard, Peter C. 2011. 'Hurrah for the missing link!': A history of apes, ancestors and a crucial piece of evidence. Notes and Records of the Royal Society of London 65: 83. [CrossRef] [PubMed]

Kossler, Reinhart. 2015. Namibia and Germany: Negotiating the Past. Windhoek: University of Namibia Press.

Lyotard, Jean-François. 1984. The Postmodern Condition: A Report on Knowledge. Minneapolis: University of Minnesota Press, vol. 10.

Markell, Patchen. 2003. Bound by Recognition. Princeton: Princeton University Press.

Mbembe, Achille. 2017. Critique of Black Reason. Durham: Duke University Press. 
Meretoja, Hanna. 2018. The Ethics of Storytelling: Narrative Hermeneutics, History, and the Possible. New York: Oxford University Press.

Meyer, Katrin. 1998. Asthetik der Historie: Friedrich Nietzsches "Vom Nutzen und Nachteil der Historie fur das Leben". Wurzburg: Verlag Konigshausen \& Neumann.

Mignolo, Walter. 2007. Introduction: Globalization and the De-Colonial Option. Cultural Studies 21: 155-67. [CrossRef]

Mignolo, Walter. 2018. On Decoloniality: Concepts, Analytics, Praxis. Edited by Catherine E. Walsh. Durham: Duke University Press.

Mills, Charles W. 2015. Bestial Inferiority. Locating Simianization within Racism. In Simianization. Apes, Gender, Class, and Race. Edited by Wulf D. Hund, Charles W. Mills and Silvia Sebastiani. Berlin, Münster, Wien, Zürich and London: Lit, pp. 19-42.

Norris, Margot. 1980. Darwin, Nietzsche, Kafka, and the Problem of Mimesis. MLN 95: 1232-53. [CrossRef]

Phelan, James, and Peter J Rabinowitz. 2008. A Companion to Narrative Theory. Hoboken: John Wiley \& Sons.

Price, David Walter. 1999. History Made, History Imagined: Contemporary Literature, Poiesis, and the Past. Champaign: University of Illinois Press.

Ricœur, Paul. 1981. Hermeneutics and the Human Sciences: Essays on Language, Action and Interpretation. Cambridge: Cambridge University Press.

Ricœur, Paul. 1983. Time and Narrative. Chicago: Chicago University Press, vol. 1.

Ricœur, Paul. 1988. Time and Narrative, Vol 1-3. Chicago: Chicago University Press, vol. 3.

Ricœur, Paul. 1992. Oneself as Another. Chicago: University of Chicago Press.

Ricœur, Paul. 2005. The Course of Recognition. Cambridge: Harvard University Press.

Schapp, Wilhelm. 1953. In Geschichten verstrickt. Vom Sein von Mensch und Ding. Hamburg: Meiner.

Scott-Baumann, Alison. 2009. Ricœur and the Hermeneutics of Suspicion. London: Bloomsbury Publishing.

Scott-Baumann, Alison. 2010. Ricœur's translation model as a mutual labour of understanding. Theory, Culture $\mathcal{E}$ Society 27: 69-85.

Scott-Baumann, Alison. 2013. Ricœur and the Negation of Happiness. London: A\&C Black.

Taylor, Charles. 1992. Multiculturalism and the Politics of Recognition: An Essay. Edited by Amy Gutmann. Princeton: Princeton University Press.

Taylor, Charles. 2016. The Language Animal: The Full Shape of the Human Linguistic Capacity. Cambridge: The Belknap Press of Harvard University Press.

Timm, Uwe. 2003. Morenga. New York: New Directions Publishing.

Timm, Uwe. 2005. In My Brother's Shadow: A Life and Death in the SS. New York: Farrar Straus Giroux.

Waldenfels, Bernhard. 1994. Antwortregister. Frankfurt am Main: Suhrkamp.

Waldenfels, Bernhard. 2002. Bruchlinien der Erfahrung: Phänomenologie, Psychoanalyse, Phänomenotechnik. Frankfurt am Main: Suhrkamp.

Waldenfels, Bernhard. 2006. Schattenrisse der Moral. Frankfurt am Main: Suhrkamp.

Waldenfels, Bernhard. 2011. Phenomenology of the Alien: Basic Concepts. Evanston: Northwestern University Press.

Walker, Margaret Urban. 1998. Ineluctable Feelings and Moral Recognition. Midwest Stud Philos Midwest Studies in Philosophy 22: 62-81. [CrossRef]

Weikart, Richard. 2003. Progress through Racial Extermination: Social Darwinism, Eugenics, and Pacifism in Germany, 1860-1918. German Studies Review 26: 273-94. [CrossRef]

Williams, Patricia. 1991. The Alchemy of Race and Rights. A Diary of a Law Professor. Cambridge: Harvard University Press.

Wils, Jean-Pierre. 2001. Handlungen und Bedeutungen: Reflexionen über eine hermeneutische Ethik, Studien zu Theologischen Ethik. Freiburg: Freiburger Universitätsverlag.

Young, Iris Marion. 2011. Responsibility for Justice. Oxford and New York: Oxford University Press.

(C) 2019 by the author. Licensee MDPI, Basel, Switzerland. This article is an open access article distributed under the terms and conditions of the Creative Commons Attribution (CC BY) license (http://creativecommons.org/licenses/by/4.0/). 



\title{
Article \\ Reading (with) Hannah Arendt: Aesthetic Representation for an Ethics of Alterity
}

\begin{abstract}
Andreea Deciu Ritivoi
Department of English, Carnegie Mellon University, Pittsburgh, PA 15228, USA; aritivoi@andrew.cmu.edu

Received: 28 May 2019; Accepted: 12 September 2019; Published: 24 September 2019

Abstract: Hannah Arendt's interest in literature was part of a broader concern, which was inspired by her reading of Kant, with the role played by aesthetic representation in ethical and political judgment. Her rich repertoire of writings about literature deserves to be considered alongside the works more commonly associated with the ethical turn in literary studies. Arendt's unique contribution, I argue here, is a heightened awareness of the assimilative tendencies of aesthetic and cultural representation, coupled with a critique of empathy as potentially illusory or even condescending when confronted with a political judgment that is set up to absorb difference. To recognize alterity requires us, if we follow Arendt, to understand otherness "in acting and speaking," as she argued in The Human Condition. Much of her philosophical and political work was dedicated to understanding the obstacles facing human togetherness, so that she could suggest ways for us to overcome them. Aesthetic representation, in her view, was one of the most effective strategies for achieving community because it offers a reconstruction of another's viewpoints that invites both an imaginative projection and a sustained cognitive effort.
\end{abstract}

Keywords: alterity; compassion; enlarged thinking; human rights; judgment; refugees; sensus communis

\section{Introduction: Hannah Arendt and the Ethical Turn}

"If we want to know what absolute goodness would signify for the course of human affairs ... we had better turn to the poets," advised (Hannah Arendt [1963] 2003, p. 262). The answer she found in literature was perhaps unexpected: absolute goodness, she learned from Herman Melville, is not preferable to absolute evil—at least in political affairs. More interested in the political value of ethical relativism than moral absolutes, Arendt grounded ethics in aesthetics because she viewed aesthetic representation as a way of understanding how the world appears to different human beings. To let the imagination "go visiting" another's world, as she put it, was all the more important when it could recover marginalized or repressed perspectives. Arendt shared with Bertolt Brecht a "passionate longing for a world in which all can be seen and heard, the passionate wrath against a history that remembered a few and forgot so many" (Arendt [1948] 2007a, p. 141). In that regard, her work anticipated strikingly the ethical turn we commonly place in the 1980s (Harpham 1995; Eskin 2004; Davis and Womack 2001). Normally situated under the auspices of Emmanuel Levinas's and Jacques Derrida's philosophical work, the ethical turn brought along an orientation toward alterity that had not only a moral aim but an emancipatory political mission as well. In the aftermath of the ethical turn, we have become accustomed to assuming that through "detailed descriptions," literary representation can nurture our "imaginative ability to see strange people as fellow sufferers" (Rorty 1989), instill compassionate responses to "acts of injury (Scarry 2014), and be "a valuable source of deliberative enrichment", which would make us into better citizens (Nussbaum 1992). The ethical turn has drawn attention to the "experience of otherness," and has led to "a certain ethics: a self-dispossession in favor of the text, another voice in the room" (Brooks 2014). 
Arendt belonged to the Central European Jewry for whom the experience of otherness was connected to the erasure of difference-both as a violent act of destruction and, in the form of assimilation, a strategy of survival. Embedded in, and justified by the ideal of Bildung, ${ }^{1}$ assimilation promised to erase or at least disguise origin, and make one a member of the good society: "Every Jewish youth who was able to rhyme passably played the young Goethe, as everyone able to draw a line was a future Rembrandt, and every musical child was a demonic Beethoven. The more cultured the parental homes, the more coddled were these imitative Wunderkinder" (Arendt [1943] 2007, p. 63). Imitation erases otherness. Yet despite her condemnatory tone, Arendt recognized that the pull of aesthetic and cultural models was part of a humanism committed to the ideals of universalism. These ideals, she argued, had emerged along Roman and Greek lineages into a vision of cultura animi, which defined aesthetic cultivation as appreciation for what matters and endures in the form of a painting, a cathedral, a symphony, or a poem (Arendt 1961).

The ideal universalism of cultura animi can disguise a colonization of difference, whereby we see others as resembling us and thus reduce them to a humanity defined by our criteria. If the essence of ethical behavior is to acknowledge otherness, as Levinas urged us, our first task is to protect it against assimilative, or "subsumptive" practices (Meretoja 2017) that reduce the other to the expectations or demands of the self. We encounter alterity as an appearance in a multitude of appearances, seeking, inviting, and fearing disclosure. To recognize and respect alterity requires us to understand another's standpoint and see how it came about, as well as what beliefs and values it makes possible. Finding the "viewpoint from which to look upon, to watch, to form judgments, ... to reflect upon human affairs" (Arendt 1989, pp. 43-44) is at the core of an ethics of alterity that demands that we neither presume to know another's standpoint by positing similarities to our own, nor seek to approach it from an abstract view from nowhere.

Arendt's ethics of alterity was inspired by her reading of Immanuel Kant's political philosophy, in his Critique of Judgment, and revolved around his concept of enlarged thinking, as an understanding that is informed by looking at the world from a variety of standpoints. However, she was skeptical of the virtues of empathy and compassion in creating an enlarged thinking, which, she insisted, "does not consist in an enormously enlarged empathy through which one can know what actually goes on in the minds of all others" (Arendt 1989, p. 43). She was equally skeptical of compassion, the "most devastating passion" (Arendt [1948] 2007a, p. 254), in guiding an enlarged thinking into political judgment, and the French Revolution was her cautionary tale. ${ }^{2}$ Hungry men acting on behalf of the hungry masses everywhere, the Revolutionaries relied on compassion to open "the heart of the sufferer to the suffering of others, whereby it established and confirmed the 'natural' bond between men which only the rich had lost" (Arendt [1963] 2003, p. 261). Such a natural bond, to Arendt, is either an illusion or a fleeting experience. Responding with compassion to another's suffering does not require judgment. The hungry men and women of the French Revolution did not have to convince one another of the shortcomings of a corrupt aristocratic regime. They felt each other's pain because each of them experienced it individually. Their compassion was not an enlarged thinking because it did not require an imaginative reconstruction of another's standpoint.

For Arendt, aesthetic representation is not only a way of entering another's standpoint, but also an escape from "the demands of oikos" (Lupton 2014, p. 289) and the everyday world of "pragmata" and into "political time" (Gottlieb 2007, p. xiii). Her rich repertoire of writings about literature

1 Such an assimilation is different from religious conversion, but their result is similar as both require an erasure and radical reconstruction of identity.

2 To the failure, in her reading, of the French Revolution, Arendt counter-posed the success of the Founding Fathers. Arendt's representation of the American Revolution might be an idealized one, as she's been reproached, a byproduct of her faith in a political rationality formed around argument, or even of her optimism as a European refugee finding freedom in America (Nisbett 1977; Barber 2010). Her admiration for the Founding Fathers, against her reservations toward the French Revolutionaries, stems not only from her privileging of the civic over the ethnic, but also from her particular understanding of politics and the role of argument in a political context. 
deserves to be considered alongside the works more commonly associated with the ethical turn. Arendt's unique contribution, I argue here, is a heightened awareness of the assimilative tendencies of aesthetic and cultural representation, coupled with a critique of empathy as potentially illusory or even condescending when confronted with a political judgment that is set up to absorb difference. What we first need is to create ethical and political conditions for self-disclosure, and to achieve, in Arendt's terms, "human togetherness," as an ethical framework for being "with others and neither for nor against them" (Arendt [1958] 1998, p. 180). Much of her philosophical and political work was dedicated to understanding the obstacles facing "human togetherness," so that she could suggest ways for us to overcome them.

For the purposes of this essay, I adopt Geoffrey Galt Harpham's definition of ethics as "the arena in which the claims of otherness-the moral law, the human other, cultural norms, the Good-in-itself, etc.-are articulated and negotiated" (Harpham 1995, p. 394). For Arendt, this arena is fundamentally a political one, emerging out of an ontology of plurality (Sjöholm 2015). Arendt's ethics were connected to her ideal of political community as a space "in which we are judged not through the characteristics which define us at birth, but through our actions and opinions, by what we do and say and think" (Benhabib 2004, p. 59). The reality of a political community, as she experienced it, was drastically different. Whether writing about a Jewish socialite hosting the most prominent salons in 18th century Berlin or about anonymous refugees of World War II, Arendt was consistently preoccupied with questions of belonging and otherness. She herself was a figure of alterity in the political tragedy of the 20th century: arrested by the Gestapo for participating in anti-fascist political activities; interned as an enemy alien at Gurs, France; and, forced to leave Europe and become a political refugee in the United States. Her identity, anchored first and foremost in her Jewishness, was in turn that of a political prisoner, an enemy alien, and a stateless person. She experienced, as millions of other refugees then and now, the anguish of disclosing an alterity through the identity stamp in a passport or entry visa that could be a death sentence. Across several countries and two continents, Arendt followed the path of the quintessential figure of modernity-the refugee.

Giorgio Agamben has urged us to turn the figure of the refugee into a foundational political subjectivity in order to interrogate the distinction between citizens and aliens as the basis of the political order, which renders the former natural and the latter deviant. Prioritizing the refugee as the "truth of humanity" forces us to recognize that our sense of belonging and shared life risks is the result of how we conceal alterity rather than disclose it. ${ }^{3}$ The refugee embodies an alterity tempted, urged, and pushed to assimilate rather than self-disclose, ready to receive recognition. To articulate an ethics of alterity from the perspective of the refugee is to be concerned with the ways in which difference gets erased rather than embraced.

\section{Arendt's Literary Ethics}

Arriving in New York in 1941 as a refugee, Arendt entered the American professional scene first through its literary community—which she significantly impacted. At Schocken Books—where she worked as an editor between 1946 and 1948—-she was responsible for the first American edition of Kafka (King 2017). Her friendship with poets Randall Jarrett and W.H. Auden, novelist Mary McCarthy, and literary critic Alfred Kazin, among others, inducted her, even if ex officio, into the world of the literati before she claimed, always reluctantly, membership in the philosophical profession (Arendt [1964] 2000). Unencumbered by any disciplinary commitments to literary study and free

3 Agamben urges us as well to question the assumption of a sovereign people and pushes his critique of the citizen-refugee opposition to the point of questioning the political necessity of the nation-state. Most scholars do not see Arendt going in the same direction, and the nation-state remains the frame of reference for her (Agamben 1995). 
to flaunt any theory in vogue, ${ }^{4}$ she could foray the depths of a literary text and make it part of a philosophical reflection instead of using a particular philosophical angle to interpret it.

Arendt's literary ethics was defined by the pained cosmopolitanism of the exile and a bilingual writer's "condensation of ... different facets of personae" (Weigel 2012, p. 77). Alterity was at the core of this ethics. The author of many literary reviews, Arendt played an important part in introducing American audiences to books by German writers who might have otherwise eluded them: Bertolt Brecht, Hermann Broch, Stefan Zweig, and Adalbert Stifter, in addition to Kafka. Her attention to literature, however, went far beyond that of a broker for German culture, and some of her most insightful literary reflections focus on American authors such as Herman Melville and Ralph Waldo Emerson. Whether she wrote about poetry or about fiction, Arendt often found political allegories in these texts. This deciphering impulse reveals her pursuit of literary works with an "ethical substance and truthfulness" (Heller 1977, p. 7), which to her often amounted to capturing the struggles of the individual in an oppressive environment. Arendt not only resonated with the toll such struggles took on individual lives, but pondered them as well for a larger meaning that could provide insight into the general political phenomena underlying them.

This political-cum-moral concern led her to Kant's political philosophy, and along with him, to ask: how can judgment allow us to participate in the public life of a political community, as good citizens, regardless of whether we are morally good as persons (Arendt 1989, p. 17)? In a Kantian sense, to be a good citizen means to be able to process difference and to enlarge one's thinking through "taking the viewpoints of others into account" (Arendt 1989, p. 42). The foundation of public and political morality, for both Kant and Arendt, lies not in adherence to norms but in perspective-taking. Kant defined judgment as the ability to look at the world from another standpoint than my own and to see the difference between representations informed by distinct viewpoints. To access another's standpoint requires an imaginative projection as we can never be in the mind of another. We train our imagination on compelling examples that are singular yet also generalizable. This view is also present in scholarship associated with the ethical turn, which points out that, while "resisting or exceeding all pre-existing general determinations" (Attridge 2004, p. 63), aesthetic representations orient us toward alterity because they have exemplary validity. Arendt's interest in aesthetic representation is also connected to her desire to articulate a conception of political agency that emphasizes an ethical concern for others as well as the ability to formulate judgment about particular situations (Singer 1997). Faced with the unexpectedness of contingency, political agency requires the ability to see general patterns in particular situations, and then to extract new general principles that can be recognized, re-affirmed, or reviewed later on. Ethical and moral judgments are embedded in this form of thinking as well. Consider Arendt's illustration of how we come to understand a virtue such as courage, and emulate it in our own lives-rather than knowing what it means in an abstract manner, we deduce it from exemplary manifestations that become emblematic, and come to life in heroic figures such as Achilles. We never encounter Achilles, but his exemplary courage becomes the kernel that we recognize in manifestations of courage in our everyday life. Whether or not it is Achilles we associate with courage, or another exemplary figure, our moral understanding is grounded in exemplarity.

To view literary representation as exemplary means that we assume it can offer us, as readers, "some truth about [life, and the world, and man]," as Arendt noted about the kind of reader Kafka addressed. (Arendt [1948] 2007b, p. 105). Exemplarity reveals the phenomenon - in the sense Walter Benjamin attributed to the term-or blueprints of reality, in the sense she attributed to Kafka. "The wonder of appearance" that was "always at the center of all (Benjamin's) concerns" (Arendt 1968, p. 12) is resistant to the mode of enunciation. Likewise, "blueprints," she explains, "cannot be understood except by those

4 Arendt's skepticism regarding the value of much of the professional literary criticism produced at the time she was writing comes across clearly in several of her essays, but perhaps is the bluntest in her essay on Kafka. 
who are willing and able to realize by their own imagination the intentions of architects and the future appearances of buildings" (Arendt [1948] 2007b, p. 77).

The metaphor of the blueprint conveys the emergent nature of aesthetic representation, which does not reproduce an observable reality or invents a purely fictional one, but rather captures configurations in which we can discern both a world now around us and the world as it is most likely to take shape. Building his narrative forms on the "abstractness of the general" Kafka created characters we could never "meet in a real world, for they lack all the many superfluous detailed characteristics which together make up a real individual" (Arendt [1948] 2007b, p. 75). For Arendt, the feeling of absurdity we get from reading his stories is a strategy for exposing the arbitrariness of what we come to take for necessity. Arendt's interest in Kafka is connected to his avoidance of "emotional excess," as Judith Butler aptly put it, which makes room for referential restraint and allows exemplarity to emerge "out of factors contributing to typical human failure, and not out of a real event" (Butler 2011, p. 79).

The importance of balancing the generality of representation with the particularity of experience comes through in Arendt's admiration for the linguistic precision of good writing. In Stifter-one of her favorite authors-semantic precision is the mark of a stylist who seeks to project the reader into the palpable reality—or phenomena—of another's world. "He will never write of a rider on a horse," she comments about Stifter, "but rather of a certain well-described man on a dapple gray" (Arendt 2007a, p. 111). Beyond vivid detail, such representation delivers what Benjamin calls "thought-things" (Arendt 1968, p. 48). Thought-things give appearance to life and direct our attention to "the actions, gestures, words, and movements of other people (that) underlie our sensible experience" (Sjöholm 2015, p. 6). To make sense of aesthetic appearance through thought-things requires judgment that resembles a kind of "drilling," which Arendt contrasts with "excavating" or creating explanations that "seek to provide a causal or systematic connection" (Arendt 1968, p. 48). "Drilling" projects us into another's world without rendering it predictable or making it easily recognizable by identifying a comparable experience in our own life. As a metaphor for judgment, "drilling" reminds us, to use Svetlana Boym's terms, that "judging requires a double movement-defamiliarizing experience through the practice of thought and defamiliarizing habits of thought in response to changing experience" (Boym 2012, p. 265).

Benjamin cultivated an aesthetic Arendt describes as "pearl diving," a deliberately fragmented writing relying on collected quotes with minimum commentary or exegesis, in an attempt to recreate the interrupted, discontinuous nature of our perception and understanding. Although influenced by Benjamin, Arendt's aesthetic vision places a stronger emphasis on its capacity for creating structures of intelligibility and a "particularly powerful medium for reflection on the relation between absence and presence, the 'then' and the 'now'" (Gottlieb 2007, p. xiii). Reading William Faulkner's work reinforced for Arendt her conviction "that a political order cannot exist without talk about, and hence remembrance of, past deed and events" (King 2017, p. 117). However, it is in Brecht where she finds poetry wielding "the political power ... to perform the essential democratic function of bringing silenced people and experiences into the public space" (Storey 2015, p. 871). Brecht's "anti-psychological insistence upon the events themselves" (Arendt [1948] 2007a, p. 137) gave him an affective agnosticism in representing the political reality of his time. By not qualifying events, he remained detached from any given viewpoint. To depict the war as awful is to communicate a particular standpoint on the war; by withdrawing from any particular viewpoint, Brecht could capture the manifold of perspectives. ${ }^{5}$ This simultaneously political and aesthetic commitment is consistent, in Arendt's view, with Brecht's selection of genres expressing the political subjectivity of the everyday man or woman: the ballad and the epic theatre. Brecht chose aesthetic genres that could capture common sense, a sensus communis acting both as mode of thinking and as set of beliefs that inform the political judgment shared by the

5 According to Arendt, when Brecht started becoming an explicit supporter of Stalinism, the quality of his poetry deteriorated because he was no longer expressing a poetic truth, but rather telling political lies. "It is entirely to Brecht's credit that he writes badly when he does not see the truth" (Arendt [1948] 2007a, p. 141). 
members of a community. Sensus communis requires a continuous creative reconstruction of others' thinking, if it is to avoid its reduction to preconceived ideas, and it achieves this reconstruction by gathering the members of a community in the act of sharing their judgment over what brings them pleasure and what they regard as beautiful. Jonathan Peter Schwartz explains: "to the extent judging subjects participate in sensus communis-no matter what their cultural backgrounds and practices may be-as they 'quarrel' or debate about objects of taste, they will over time move toward consensus as they cultivate more sensitivity in their common sense structures of judgment" (Schwartz 2015, p. 117).

Arendt's conception of common sense, Andrew Norris has argued, "is an affect, a feeling caused by the harmonious play between our understanding and our imagination. It is a kind of pleasure that, while involving the cognitive faculties, is not itself the result of any cognitive process" (Norris 1996, p. 182). While I disagree that Arendt views in common sense an "affect," which to me would not be consistent with her dismissal of empathy, Norris helps us understand the equal importance of imaginative projection and cognitive effort required for reconstructing another's standpoint and articulating a sensus communis that recognizes distinct standpoints. However, Arendt was preoccupied by the erasure of standpoints that can be rendered incommensurate with the aesthetic and political paradigm of sensus communis. She was interested in community as much as she worried about estrangement-both in the key of a modernist aesthetic and even more so as a political condition. It is no surprise, then, that one of her earliest incursions into literary analysis focused the poignant modernist metaphysics of estrangement as she discovered it in the work of Rainer Maria Rilke.

In an essay co-authored with her then husband Günther Anders, Arendt reads in the Duino Elegies a meditation on the realm of the possible as "estrangement from the world" (Arendt [1930] 2007, p. 6), in which the focus is not solely on what we can imagine but also on how we acquire knowledge of something not yet in existence, hovering at the threshold of reality. Rilke's tropes of loss and absence are listening and hearing. For Arendt, he is the poet of an "acoustic world" in which sound, voices, supplication, and invocation create a "being-in-hearing" (Arendt [1930] 2007, p. 4). Such emphasis on sound, which might be connected to her Jewish background, ${ }^{6}$ reaffirms her concern with alterity. As Dominic Pettman has argued, "the abstract Other ... is registered aurally, and the rest of the universe is assembled from this mobile but steady sonic source, including the listening self" (Pettman 2017, p. 2).

To what extent does an aesthetic grounded in estrangement desire to be understood, and to what extent can it be understood? These were questions Arendt asked in her reading of the Duino Elegies (Arendt [1930] 2007, p. 1). The same questions could be raised about understanding another's subjectivity under conditions of political estrangement such as those directly experienced by Arendt. In response, she analyzed the representational mechanism of such an understanding, and tried to extrapolate from it the conditions for a sensus communis that is cosmopolitan-even in the face of political institutions that seek to erect boundaries and maintain the strict separation between outsiders and insiders. Her conception of sensus communis stretched the "built-in cosmopolitan structures and inclinations" of the original Kantian notion (Schwartz 2015, p. 121) by affirming the value of plurality in assembling an enlarged thinking that can inform our understanding of a particular situation and its moral significance (Benhabib 1988). However, the question remains: how does sensus communis fulfill its cosmopolitan potential and aspirations? To answer this question, we must first understand what stands in the way of cosmopolitan aspirations.

\section{Being Human: Statelessness and "Surplus Subjects"}

“One judges always ... guided by one's community sense, one's sensus communis. But in the last analysis, one is a member of a world community by the sheer fact of being human; this is one's 'cosmopolitan existence.'" (Arendt 1989, p. 76). There seems to be no irony in this summary and interpretation of Kant that Arendt offered to her students at the New School, where she delivered her

6 Arendt's attraction to Rilke's auditory images might be rooted in the importance of listening in Judaic thought. See (Sacks 2016). 
lecture series on the third Critique. Yet, Arendt was one of the harshest critics of cosmopolitanism viewed in conjunction with a discourse of human rights, as it was emerging in the aftermath of World War II. In one of the political essays she published soon after arriving in the United States, "We Refugees," Arendt offers a searing, albeit indirect, critique of the assimilative ethics of cosmopolitanism, read through the lens of the fate of World War II Jewish refugees. Arendt wrote the essay with the awareness that within the nation-space, a person exists not as a human being but as a citizen or an alien. As Giorgio Agamben would put it later, "rights ... are attributable to man only in the degree to which he is the immediately vanishing presupposition (indeed, he must never appear simply as man) of the citizen" (Agamben 1995, p. 117). Seeing either a citizen or an alien in the human being in front of us entails a shift in perspective that is not only political, but also aesthetic insofar as it implicates a mechanism of representation. One of the characters featured in the essay is the sorry figure of a Mr. Cohn, who is "150\% French in France, 150\% American in America," as metaphor of a desperate eagerness to escape the refugee condition, and tragi-comic awareness that the only escape possible is citizenship.

The cold affect of the essay speaks to Arendt's unique rhetorical persona, which I have described elsewhere as detached and impersonal (Ritivoi 2014). This persona, as I view it, emulates impartiality and invites thinking in the place of another, rather than compassion. Impartiality is "not the result of some higher standpoint that would then actually settle the dispute" of different representations "by being altogether above the melee (Arendt 1989, p. 42). The explicit denial of pity functions in the essay the same way as emotional restraint did for Kafka, to reconstruct the experience of refuge in its generality, while Arendt's use of irony works, in Brechtian fashion, as a way of magnifying differences and zooming in on the particular. Arendt offers a first-person standpoint, explicitly self-identifying as a Jewish refugee both deictically (through the pronoun we) and through an objective designation of her own political status at the time. However, at the same time she questions what it means to assert one's identity against political and cultural practices that constrain us. "The chief trap in life," Arendt wrote in her reflections on Isak Dinesen, "is one's own identity" (in Gottlieb 2007, p. 262). This statement has a double meaning: on the one hand, it shows Arendt's skepticism regarding an identity defined along norms and expectations. However, on the other hand, it acknowledges that the disclosure of identity can function as a political entrapment as well. "We don't like to be called 'refugees,'" warns the essay. To be called a refugee is to occupy a political space always haunted by the threat of violence. Arendt signals the dangers of the appellative as semantic dilemmas associated with the politically charged efforts to disclose oneself while immersed in an anguished search for safety:

We ourselves call each other 'newcomers' or 'immigrants.' Our newspapers are papers for 'Americans of German language;' and, as far as I know, there is not and never was any club founded by Hitler-persecuted people whose name indicated that its members were refugees. ... With us the meaning of the term 'refugee' has changed. Now 'refugees' are those of us who have been so unfortunate to arrive in a new country without means and have to be helped by refugee committees. (Arendt [1943] 2008, p. 264)

The standpoint of the refugee is defined by the difficulty of self-disclosure. Listing the refugees' naming devices as strategies of avoiding self-disclosure, Arendt exposes the conflation of assimilation and rejection in a political order predicated on the distinction between aliens from citizens. The freedom that awaits the refugee on the shore of their new country is a "gift (that) inevitably calculates and coheres an ordered taxonomy of what is deemed necessary for a human being" (Nguyen 2012, p. 15). Therefore, as Arendt put it, "if we are saved we feel humiliated, and if we are helped we feel degraded." Help brings along a reification, and thus potential dismissal of otherness. The fact that Arendt reads this dismissal in moral terms as humiliation and degradation points to the necessity she sees in maintaining one's right to self-disclosure. At the same time, as soon as difference is read antagonistically, the impulse to control and subsume it places the autonomy of the other under threat.

Deferring the explicit mention of the word Jew and its cognates until halfway through the essay, Arendt represents a standpoint that does not merely belong to another but is that of an alien. 
Otherness becomes estrangement, as "Arendt's 'we' linguistically enacts its own historical unhoming" (Stonebridge 2011, p. 74) through irony that vacillates between somberness and detachment. "The less we are free to decide who we are or live as we like," Arendt writes, "the more we try to put up a front, to hide the facts, and to play roles.... Our identity is changed so frequently that nobody can find out who we actually are" (Arendt [1943] 2008, p. 270). Such emphasis on asserting an identity might be surprising in a thinker who was primarily interested in literary works with an "anti-identitarian character" (Storey 2015, p. 884), but it reveals Arendt's political concern with how we access the standpoint of another human being. Arendt frequented writers who turned their artistic gaze outwards rather than inwards, scrutinizing the world and trying to make sense of it rather than probing the depths of a mysterious psyche. Her preference for poets such as Brecht, Auden, or Jarrell is part of her larger quest for an expressive language with political heft, language in which to communicate the "least welcome truths" (Arendt quoted in Storey 2015, p. 879). Such is the truth of the fact that, deprived of an identity they can own and disclose, forced to take on a protective disguise, the refugees are left outside a sensus communis and ultimately forced into worldlessness. For them, there is no basis upon which they can connect to others as autonomous, self-disclosing agents.

The refugees' standpoint is not only different from that of the citizen with full rights issued by his membership in a community, but also incommunicable in its utter difference. What the refugees have lost includes, in addition to the freedom of thinking as authentic expression of their selves, the very possibility of communicating their experience.

We lost our home, which means the familiarity of daily life. We lost our occupation, which means the confidence that we are of some use in this world. We lost our language, which means the naturalness of reactions, the simplicity of gestures, the unaffected expression of feelings. We lost our relatives in the Polish ghettos and our best friends have been killed in concentration camps, and that means the rupture of our private lives. (Arendt [1943] 2008, p. 264, my emphasis)

This cumulated loss defies any easy attempt at restoration, but similar to the estrangement evoked by Rilke in the Duino Elegies, it serves as an adumbration of another's standpoint and obligates us ethically to recover it by insisting on how far removed it is from our own experience. For an alterity under siege, self-disclosure is haunted by the futility poetically described in the Duino Elegies as perpetual estrangement. At the same time, as Arendt commented on Rilke, "in contrast to every other historically recorded estrangement from the world, this estrangement is not directly or originally determined as transcendence, nor does it escape into transcendence; it is rather characterized by the detour it takes" (Arendt [1930] 2007, pp. 6-7). For Rilke, this detour was the very act of rescuing estrangement through naming, which becomes a form of "preservation from destruction" (Ibid). Naming the refugee's loss is a way of preserving in effigy what was lost as well as disclosing the attachment.

"We Refugees" was published in the Jewish-American periodical Menorah Journal, but its rhetorical construction suggests that it was addressed to a larger American audience as well; the audience of citizens, rather than immigrants. ${ }^{7}$ The essay serves as a reminder that the assimilative pull of a sensus communis claiming to be cosmopolitan uses the promise of survival to contain difference, and it does so by promoting a political rationality of individualism, which amounts to political anomie. "We Refugees" does not identify any real cases, but it is not hard to recognize Stefan Zweig as one of Arendt's reference points in her mention of the tragic recurrence of suicides among refugees.

7 By Berel Lang's distinction between contingency- and coherence-based models of reasoning undergirding philosophical writing, Arendt's style fits best in the first category. Lang's distinction is useful because it draws attention to the fact that styles of argument are moral modalities as well: how writers choose to formulate ideas and present them to the reader reveals their own ethical assumptions vis-à-vis their audience. In a coherence model, the author remains distanced from the audience and offers arguments that are intended to convince based on their decontextualized, absolute logical force rather than by appealing to a reader's values. In the contingency model, the author and the writer are engaged in a dynamic relationship as equals, focused on shared values through familiar examples (Lang 2010). 
Zweig's suicide represents to her an abdication from the need to survive that constitutes, in the context of the Nazi genocide of the Jews, a political responsibility. Suicide for a refugee was not only cowardly, in her view, but evidence as well that the seeming willingness to start over and acquire a new self in a different political and cultural paradigm of a new country is a form of self-negation.

Born in 1881 in Vienna in a wealthy Jewish family, a friend of Sigmund Freud and Theodor Herzl, interested in Jewish matters but without identifying primarily as a Jew, Zweig became a successful writer at a time when Jewishness could appear secondary to the social standing of a respected intellectual. The utopianism of cosmopolitan spaces such as Vienna was their seeming indifference to ethnic or racial difference. Similar to many other secular or assimilated Jewish intellectuals of his generation, Zweig identified as a citizen of the world. However, this was a world that only respected them for having assimilated through their upbringing and cultural accomplishments-and tolerated them despite the fact that they were Jewish rather than because their Jewishness did not register. After the Anschluss, Zweig fled Austria, first to England, then the United States, and finally Brazil—where he and his wife committed suicide in 1942. In the suicide note he sent to his friend, French writer Jules Romain, Zweig explained his decision as the result of an "inner crisis" caused by his inability to reconcile himself to having become an anonymous exile, estranged from his environment. In her review of Zweig's memoir The World of Yesterday, Arendt interprets his decision to commit suicide consistent with the views she had expressed in her 1943 essay, as based on the fact that he "considered it unbearably humiliating when the hitherto wealthy and respected citizens of Vienna (i.e., of Jewish origin such as himself) had to be begging for visas to countries which only a few weeks before they would have been unable to find on a map" (Arendt [1943] 2007, p. 59). To her-the space where Jewish artists and intellectuals such as Zweig had felt so much at home-that exile seemed unbearable and unfathomable, was phantasmagorical, no more on a map of political realities than Brazil had been on Zweig's map of desirable destinations.

Zweig's and others' illusion of belonging to a polity of artists and intellectuals had led them to perceive their refugee status as "social humiliation," she argued, at a time when political resistance was the only way they might have saved themselves. While to Zweig being a refugee was a disgrace and a personal defeat, Arendt views it as a mark of an alterity from which one can only "escape into a political attitude and a struggle for the honor of an entire people" (Arendt [1943] 2007, p. 68). The "international society of the successful ... in which Jews enjoyed equal rights" (Arendt [1943] 2007, p. 68) was a political fiction disguising the omnipotence of the citizen as metonym of the state. Before being deported to extermination camps, Jews were first denationalized. Reducing them to merely human was the preamble to taking their humanity away. Zweig sought a "world citizenship" that could offer him "the possibility of being recognized by unknown people, of being admired by strangers" (Arendt [1943] 2007, p. 67), but his daily existence never ceased to unfold in the context of a nation-state that fully controlled his rights. Once being a Jew was a disgrace, it did not matter who the individual Jew was. All Jewish people became identical to one another regardless of how social standing grounded in education and cultural attainment might have once differentiated them. Anonymity was only one step behind annihilation. Zweig's "world of yesterday," the cultured international society of cosmopolitan intellectuals who deemed themselves above discrimination, vanished not swept away by a new era of intolerance and hatred but collapsing onto its own inauthenticity. The cosmopolitan sensus communis affirmed by Zweig was the framework of an assimilative ethics that would eventually erase his standpoint. Zweig's tragedy began with his abdication from affirming his alterity.

The refugees' standpoint is defined by the perpetual threat of the nation-state: identified, or rather exposed by their passports, birth certificates, "sometimes even income tax receipts" they can always become victims to "discrimination as the social weapon by which one may kill men without bloodshed" (Arendt [1943] 2008, p. 273). An assimilative ethics faced the refugee with the standpoint of the citizen, and thus revealed the "possibilities of human existence, which are infinite as is creation," while reminding her as well that "the recovering of a new personality is as difficult-and as hopeless—as 
a new creation of the world" (Arendt [1943] 2008, p. 271). Refugees such as Mr. Cohn, who, hard as they might try, can never belong, show that an assimilative ethics creates a subjectivity in excess-150\% French in France, or 150\% American in America-which is at the same time one reduced to "bare life." Assimilation is a costly fantasy, since the nation-state always flags alterity, making the refugee's difference dangerous to disclose. Mr. Cohn's Frenchness (or his Americanness, or his Germanness) is inevitably in excess because as a refugee he will be an add-on to the nation so long as his difference is what demands assimilation. Always only legible in conjunction with the nation-state, the refugee "breaks into the political scene as the alien" (Arendt [1951] 2003, p. 43). The refugee is a "surplus subject" (Ranciere 2004, p. 305).

With the emergence of stateless people, "mankind, for so long a time considered under the image of a family of nations, had reached the stage where whoever was thrown out of these tightly organized closed communities found himself thrown out of the family of nations altogether" (Arendt [1951] 2003, p. 34). Arendt's kinship metaphor emphasizes that so long as the nation-state is the measuring rod by which we capture humanity, we always posit similarity rather than difference as the point of reference. "The Russian refugees," Arendt pointed out, "were only the first to insist on their nationality and to defend themselves furiously against attempts to lump them together with other stateless people. Since then, not a single group of refugees or Displaced Persons has failed to develop a fierce, violent group consciousness and to clamor for rights as-and only as-Poles or Jews or Germans, etc." (Arendt [1951] 2003, p. 33). The refugees' "group consciousness" was the moral reflex of seeking a community inside which they could feel they belonged. Rather than allegiance to their country of origin, the refugees' remaking of a national community beyond the nation is similar to the fantasy of a missing limb, only marking the absence of a shared world. The refugee is stranded in a liminal space where she is not (yet) a future citizen of the country where she happens to be seeking refuge any more than she is (still) a citizen of the country she has left behind. It is indeed telling that the site of refuge is not a country, but a camp. "Bare life," as Agamben would put it, is life at the disposal of the state, life that can be taken without it registering as anything other than a mechanism for reinforcing the state.

The nation-state was a given for Arendt, as she did not believe in a world government (Benhabib 2004, p. 64). To view the refugee rather than the citizen as the "truth of humanity," as Arendt and Agamben urged us, require us to articulate an authentic cosmopolitan sensus communis that is not merely a synonym for generic humanity. This would have to be a sensus communis predicated on the concept of the rights to have rights" and on the contingency of rights (Balibar 2007, p. 729). Individuals do not own rights generically; rather, rights are qualities that individuals grant one another within a community (Balibar 2007, p. 732). Rights are protected and endorsed through the political feature of antinomy, or the right to difference. Antinomy facilitates autonomy by directly challenging an assimilative ethics, and focuses instead on the political value of community formed not only through the coming together of individuals around shared values and commitments, but formed through distinctions as well.

"To live together in the world," wrote Arendt in The Human Condition, "means essentially that a world of things is between those who have it in common, as a table is located between those who sit around it; the world, like every in-between, relates and separates men at the same time" (Arendt [1958] 1998, p. 52, my emphasis). This is a metaphor of conviviality, which recognizes, respects, and cultivates difference. Unlike imagining humanity through the metaphor of a family of nations, which uses kinship to suggest an inherent parceling into communities of similarity, the metaphor of conviviality reminds us to value the demands of difference that accompany others' points of view. The question then is: how to access another's standpoint against the pressures of an assimilative ethics disguised as cosmopolitan sensus communis—as in Zweig's case? This was an important question to Arendt. Kant, as she read him, had insisted that "when one judges and when one acts in political matters, one is supposed to take one's bearings from the idea, not the actuality, of being a world citizen and, therefore, also a Weltbetracher, a world spectator" (Arendt 1989, p. 76). Read alongside 
her reflections on statelessness and refuge, the notion of beholding the world from the perspective of the Weltbetrachter seems more normative than descriptive, and verges on (Zweig's) political anomie. The Weltbetrachter standpoint might have been a fit for Kant, the armchair traveler, but it was not a fit for Arendt the refugee. In what way, then, did Arendt endorse the notion of judging from the perspective of the world citizen?

The response might come from adjusting, along with Lisa Jane Disch, how we understand Arendt's notion of the basis of judgment, as realized rather than hypothesized intersubjectivity. In contrast to Kant, Arendt believed that judgment has to be shared with others and "cannot simply be imputed to them" (Disch 1994, p. 151). Sharing judgment requires just as much conveying one's own standpoint as it requires understanding the standpoints of others. Her rejection of empathy as a way of producing enlarged thinking along with her dismissal of compassion and pity—as I show shortly—stem from her insistence on the need to reveal and respect alterity through "predicative or argumentative speech, in which someone talks to somebody about something that is of interest to both because it inter-est, it is between them" (Arendt [1951] 2003, p. 266). This is how we create a bond with others rather than merely notice them from a distance, how we acknowledge their presence rather than merely their existence. An ethics of alterity, then, must become an ethics of communicability.

\section{The World Citizen and the Ethics of Communicability}

Melville and Dostoevsky presented Arendt, through the characters of Billy Budd and Jesus Christ of Nazareth in the Grand Inquisitor novella, ${ }^{8}$ with a dramatization of the difficulty of knowing another's standpoint without having access to his voice, and thus without being able to reconstruct his standpoint as a discursive universe. Billy suffers from a speech impediment; Jesus Christ is silent. Both are outside the realm of argument, and their moral purity either turns into evil or remains insignificant from a legal perspective.

The plot of Melville's novella, which has inspired many scholarly debates, ${ }^{9}$ is well known. Billy is a young and handsome man serving aboard the Bellipotent in 1797, when the royal navy is recovering from a series of mutinies and facing the threat of the French Revolution. Billy is liked by everyone except the master-at-arms, Claggart, who tries to frame him for a crime Billy never committed. Outraged by the accusation, Billy loses his temper and kills Claggart. The ship's captain, Vere, sentences Billy to death in accordance with legislation imposed by the Mutiny Act, which sanctions severely any act of violent disturbance in the royal navy. Billy does not protest the sentence and dies crying out "God bless Captain Vere!" In Dostoevsky's novella, Jesus Christ returns to earth in Seville at the time of the Inquisition and starts performing miracles in the adoration of the people. He is arrested as a heretic and sentenced to death, but the Grand Inquisitor visits Jesus at night in his cell and offers him freedom if Christ agrees to leave and never return again. Christ listens and departs quietly.

While Arendt does not explicitly read in the protagonist of Melville's Billy Budd, Sailor the figure of the refugee, she notes that Billy is a foundling. He has no known origin. Billy's angelic beauty and innocent mind are descriptors of a humanity both idealized and laid bare. Billy joins Captain Vere's ship Bellipotent after serving on the Rights of Man. The conspicuous symbolism of names aside, the ships serve as metonyms of statehood, as well as of the camp. Billy has no say in leaving one ship for the other, and once on the Bellipotent, he cannot go anywhere else. Similar to the refugee, Billy lacks not only "the right to freedom, but ... the right to action; not ... the right to think whatever (he) please(s), but ... the right to opinion (Arendt [1951] 2003, p. 39). He accepts his sentence. Billy's last words-“God bless Captain Vere!"- not only present him as acquiescing, but also render his standpoint opaque: we do not know if he is resigned or remorseful.

8 I will mostly focus here on Arendt's reading of Melville's novella, to which she herself devotes more attention than to the Brothers Karamazov excerpt.

9 For detailed reviews of the scholarship dedicated to interpreting the political allegory of Billy Budd, Sailor see (Schiffman 1950; Rosenberry 1965; Ramirez and Ronner 2004; Solove 2005). 
Melville presents Billy's recourse to violence as a consequence of his inability to articulate discourse. He stutters in emotionally charged moments, when he is angry or fearful. Violent emotions breed violent actions, whereas judgment can create agreement and establish peace-as Vere does. Richard Bernstein has pointed out that Arendt's vision of the political excludes violence, because it deems it too bluntly instrumental (Bernstein 2011). Billy is powerless because he has no speech when he would most need it. His standpoint is incommunicable or a-rhetorical, reducible to mute anger or absolute candor.

Political judgment, as Arendt understood it, has a requirement of communicability and intelligibility. Claggart's death demands from Vere, as captain of the ship, a judgment that starts with making sense of the event publicly. From a moral perspective, the crime can be seen as righteous revenge against an evil man, but from Vere's political standpoint it is inscribed in the larger logic of mutiny. Vere's political judgment establishes the structures of intelligibility in which characters and actions are embedded. ${ }^{10}$ As captain of the ship, Vere represents the sovereign state, and as such he can only see Claggart's death as challenging the legitimacy of the only authority that can claim to use violence legitimately: the state itself. ${ }^{11}$ While Arendt does not mention this aspect, it is worth noting that after the execution, Billy is identified in a newspaper article as a foreign influence on the ship, trying to incite to the violence of revolution. Billy's ultimate culpability is his alienness.

Melville offered Arendt an allegory of political judgment that must be exercised in a situation in which an absolute good is "hardly any less dangerous than absolute evil" (Arendt [1951] 2003, p. 262). Billy represents an angelic figure of utmost beauty and kindness, yet he strikes a man to death. In her reading, "Melville reversed the primordial legendary crime, Cain and Abel to take away the consolation that violence is the characteristic of evil" (Arendt [1951] 2003, p. 266). Without a clear demarcation of good and evil, compassion loses ethical ground: can the reader, or indeed Vere, feel compassion toward Billy, as he meets his death punishment for having killed another man, and still recognize that killing is an evil act? The moral contrast upon which Melville's novella is built is not only a contrast between Billy and Claggart, but between Billy and his own violent act as well, and is designed to show that "the absolute ... spells doom to everyone when it is introduced into the political realm" (Arendt [1951] 2003, p. 264). What we are missing is a relational ethics focused on opening up one's standpoint, before we can presume to access it.

Much of the work produced under the auspices of the ethical turn would point to empathy as compassion as the access to another's standpoint. Arendt would disagree. She dismissed the role of compassion in re-creating another's standpoint because she followed the Aristotelian treatment of pity and compassion. We feel pity, Aristotle maintained, for those who are "like us but, not us and in situations that are proximal, yet not imminent." This assumption of similarity between the sufferer and the witness is in counter-distinction to Arendt's emphasis on difference as a feature of the political. Pity and compassion, as envisioned by Aristotle, do not entail alterity. On the contrary, their rhetorical mechanism is one of similarity: we feel pity for the misfortune of others insofar as we can imagine the same fate might befall us. The Rhetoric takes a dramatic approach to the production of pity and recommends that suffering be put clearly on display and acted out (Aristotle 1984).

To Arendt, such theatricality could only have been suspect of kitsch from an aesthetic perspective, as well as of moral shallowness and political ineffectiveness. Theatricality puts suffering on display and thus keeps the sufferer at a distance precisely as pitiable, in a way that discourages any attempt at action. ${ }^{12}$ Billy's simple-mindedness, his stutter, and his seeming history of trauma make him not

10 The faculty of judgment, as Beiner argues, is "in the service of human intelligibility" (Beiner 1989, p. 100).

11 Vere sacrifices his private morality-according to which Billy was justified in striking Claggart-in order to enact a public justice based on a political principle. Arendt's reading of Melville's novella is consistent with her view of political action, which, as Donald Klusmeyer observes, "required individuals to put a commitment to the public good before their personal interest in preserving their own moral purity" (Klusmeyer 2009, p. 345).

12 Arendt's was critical of a political culture emerging from societies in which theatre played an important role, because these societies were under the spell of fame and stardom. "A culture built around an actor or virtuouso," she writes about 
only piteous but pitiful as well. As pity risks sliding into condescension, an ethics driven primarily by empathy and compassion not only fails to articulate an enlarged thinking, but risks sliding into mere display of self-righteousness and moral (or intellectual) arrogance as well.

Aaron Ben-Ze'ev concept of sympathetic sorrow captures what happens when feeling sorry for another allows us to consume a tragic story precisely as a story: we believe ourselves to be "unable to offer ... real help," and pay attention only to the suffering itself rather than thinking of ways to end it. "The perceived impotence and lack of obligation in pity," Ben Ze'ev writes, "is not necessarily real. In many cases we could help but perceive ourselves as being unable, or not obliged, to do so because of certain perceived constraints (Ben Ze'ev 2000, p. 6). Sympathetic sorrow can function as a moral alibi for inaction.

An ideal polity, if we follow Arendt's thinking, develops ethical ties that avoid at once the hollowness of sympathetic sorrow, the condescension of pity, and the ineffectiveness of compassion. The vision of such a polis appears in her commentary of a little-known story by Adalbert Stifter, "Rock Crystals," translated into English by Marianne Moore-significantly by a poet particularly attuned to Stifter's semantic nuance. The story features two children who get lost in the snow as they return home from their grandparents' house in the neighboring village. The kids, brother and sister, travel regularly across a mountain between two villages as the only emissaries connecting feuding people. They are progenies of parents who had defied the interdiction and had married someone from the enemy group. Because they are unaware of the danger, the children are never afraid of the mountain or the ice and remain fully trusting that they will find the way home, unlike the adults who meanwhile are searching for them anxiously, gradually losing hope. The children experience their night in the ice storm aesthetically, awed by the beauty of the nature surrounding them, described in precise detail by Stifter. The emotional tension of the text derives from the contrast between the children's confidence and the reader's awareness of the threat, which creates the adumbration of a tragic ending. We logically anticipate that the children will freeze to death. Stifter's mastery lies in shifting the narrative focus entirely onto the children against the backdrop of the rich description of a sublime and merciful nature. We can see the world through the children's eyes, and it is only from their morally pure perspective that we can see beauty rather danger.

Beautiful and benevolent, the icy world in which the children are lost is a powerful political utopia. The children's innocence, Arendt comments, "fits so well in the sublime majesty of the mountain that they can patiently wait until the village comes to their rescue" (Arendt 2007b, p. 113). Unlike Billy the orphan, the children are defined by their belonging — to a family and to a community. The happy ending of the story, a reunification, becomes an opportunity for reconciliation for the adults. They enter a bond of solidarity in the name of shared love for their children, transcending any difference that had separated them into residents of two villages. To frame it in Rilkean terms: the children rescue the adults from their estrangement.

The topoi of absolute freedom featured in Stifter's story, nature and childhood, are in marked counter-distinction to the topos of nation-state. These topoi create a utopia of a sublime and peaceful world in which harm is not possible. The children illustrate Arendt's concept of natality, the capacity of human beings to bring new human beings into the world, and with them, to begin anew. While for Agamben birth bears the ominous ascription of citizenship, Arendt's notion of natality is defined by hope. If the state claims us as individuals already at birth and identifies us as either citizens or aliens, engaging with another's standpoint through aesthetic representations gives us a chance to begin anew, to "read ... (stories and poems) as though nobody had ever read them before" (Arendt 1961, p. 204). We can read Stifter's representation of a sublime frozen forest as a metaphor for cultural traditions that can be continuously renewed as objects of beauty rather than as inherited, forbidding, norms.

Viennese society and its fascination with theatre, "established standards that were as novel as they were dubious" (Arendt [1948] 2007a, p. 64). 
This metaphor can be a reminder that the task of our cultural ethics is not to maintain or restore tradition, but rather, as Dana Villa points out, "to deconstruct and overcome the reifications of a dead tradition" (Villa 1996, pp. 8-9), so that, we might add, we can continuously rediscover its beauty. Such a view can let us imagine a cosmopolitan sensus communis in which our judgments are always provisional, embedded in ongoing acts of persuasion that are never complete, or limited to expressing a given set of beliefs, customs, or even norms. Configured in Arendt's terms, ethically defensible judgment emerges across different viewpoints that can be connected and rendered mutually intelligible in the tissue of sensus communis, ready to withstand the pressures of conformity and assimilation. What it takes to achieve this goal is the courage of self-disclosure as an act of individual affirmation-even at the risk of self-annihilation - as well as a commitment to entering another's world looking for its structures of intelligibility as the lines and shapes of a reality blueprint we can all share.

\section{Conclusions}

Arendt's literary ethics was keenly attuned to fulfilling the promise of a cosmopolitan sensus communis, without letting it use the pretext of a general humanity to obtain assimilation and thus to contain alterity. She pursued, through her reflections on literary practice, a political need to transcend "individual limitations by seeing "things not only from one's own point of view but in the perspective of all those who happen to be present" (Arendt 1961, p. 221). For Arendt, literature's task is to immerse us into our present and sharpen our understanding of our reality, rather than release us from it. If she was so critical of Zweig's suicidal despair, "turning on him with surging venom" (Steinberg 2007, p. 879), it is not because she was detached from the tragedy of Jews, but because she believed she understood the standpoint of the Jewish refugee too well, and from that standpoint the action she saw necessary was one of political resistance instead of capitulation. Contemplating others' actions and judgments from a distance-or seeking to come close to them through empathy and compassion but without trying to understand the viewpoint from which they originate-makes no real ethical demands on us. If we regard another's perspective as part of our achieving a self-righteous catharsis, or feeling satisfied with our ability to feel sorry for others without any responsibility for alleviating their suffering, our response to it is unethical as well as a failure to open up to the cognitive and affective demands of representation.

Our ethical and moral decisions are informed by the aesthetic representations that nourish our imagination and establish the "company we keep" (Beiner 1989, p. 113). Arendt's company included poets such as W. H. Auden and W. B. Yates, whom she admired because they were "hurt into poetry" (Arendt [1975] 2007). She, too, was "hurt" into seeking in literature structures of intelligibility that could shed light into the tragic events humanity experienced throughout her lifetime. In the eulogy he delivered at Arendt's death in 1976, Hans Jonas summed up her philosophy of life: "persecution aroused her ... moral indignation armed her, extreme distress called her into the active life" (Jonas 1976, p. 3).

Our ethical practices might require at times resistant readings through which we can distance ourselves from the beliefs and attitudes represented in a text. However, in so doing, we can devalue others' values and behaviors and re-affirm the primacy of our own. Ethical difference, then, is recognized but at the same time suppressed through our acts of evaluating moral choices. By contrast, to engage in "ethics while reading" is to turn our attention "to moral issues generated by events described within an imagined world" (Schwartz 2001, p. 12) and to challenge ourselves to imagine what kind of a response makes sense from the standpoint of those who are in it, even if, or especially when such a standpoint is alien to us. "Messenger of ill tidings," to use Brecht's metaphor (Arendt [1948] 2007a, p. 237), the refugee is a figure of alterity that can remind us of how our cultural traditions perpetuate values that continuously inform an aesthetic-political judgment hostile to difference, no matter how much we declare our ethical allegiance to the other.

Funding: This research received no external funding.

Conflicts of Interest: The authors declare no conflict of interest. 


\section{References}

Agamben, Giorgio. 1995. We Refugees. Symposium: A Quarterly Journal of Modern Literatures 49: 114-19. [CrossRef] Arendt, Hannah. 2007. Rilke's Duino Elegies (with Günther Stern). In Reflections on Literature and Culture. Stanford: Stanford University Press, pp. 1-23. First published in 1930.

Arendt, Hannah. 2007. Stefan Zweig: Jews in the World of Yesterday. In Reflections on Literature and Culture. Stanford: Stanford University Press, pp. 58-68. First published in 1943.

Arendt, Hannah. 2008. We Refugees. In The Jewish Writings. Edited by Jerome Kohn and Ron H. Feldman. New York: Schocken Books. First published in 1943.

Arendt, Hannah. 2007a. Beyond Personal Frustration: The Poetry of Bertolt Brecht. In Reflections on Literature and Culture. Stanford: Stanford University Press, pp. 133-42. First published in 1948.

Arendt, Hannah. 2007b. Franz Kafka, Appreciated Anew. In Reflections on Literature and Culture. Stanford: Stanford University Press, pp. 94-109. First published in 1948.

Arendt, Hannah. 2003. The Perplexities of the Rights of Man. In The Portable Hannah Arendt. Edited and with an introduction by Peter Baehr. New York: Penguin Books, pp. 31-45. First published in 1951.

Arendt, Hannah. 1998. The Human Condition, 2nd ed. Introduction by Margaret Canovan. Chicago: The University of Chicago Press. First published in 1958.

Arendt, Hanna. 1961. The Crisis in Culture: Its Social and Political Consequences. In Between Past and Future. Six Exercises in Political Thought. New York: Viking Press.

Arendt, Hannah. 2003. The Social Question. In The Portable Hannah Arendt. London: Penguin Classics, pp. 247-77. First published in 1963.

Arendt, Hannah. 2000. What Remains? The Language Remains: A Conversation with Gunter Gauss. In The Portable Hannah Arendt. New York: Penguin Books. First published in 1964.

Arendt, Hannah. 1968. Introduction. Walter Benjamin: 1892-1940. In Benjamin, Walter. Illuminations. Edited by Hannah Arendt. Translated by Harry Zohn. New York: Schocken Books.

Arendt, Hannah. 2007. Remembering Wystan H. Auden, Who Died in the Night of the Twenty-eight of September, 1973. In Reflections on Literature and Culture. Stanford: Stanford University Press, pp. 294-302. First published in 1975.

Arendt, Hannah. 1989. Lectures on Kant's Political Philosophy. Chicago: The University of Chicago Press.

Arendt, Hannah. 2007a. Great Friend of Reality: Adalbert Stifter. In Reflections on Literature and Culture. Stanford: Stanford University Press, pp. 110-14.

Arendt, Hannah. 2007b. Reflections on Literature and Culture. Edited and with an introduction by Susannah Young-ah Gottlieb. Stanford: Stanford University Press.

Aristotle, Rhetoric. 1984. The Complete Works of Aristotle. Edited by Jonathan Barnes. Princeton: Princeton University Press.

Attridge, Derek. 2004. The Singularity of Literature. Abingdon: Routledge.

Balibar, Etienne. 2007. (De)Constructing the Human as Human Institution: A Reflection on the Coherence of Hannah Arendt's Practical Philosophy. Social Research 3: 727-38.

Barber, Benjamin. 2010. Hannah Arendt between Europe and America. In Politics in Hard Times: Encounters with Hannah Arendt. Cambridge: Cambridge University Press.

Beiner, Ronald. 1989. Interpretive Essay. In Lectures on Kant's Political Philosophy. Chicago: The University of Chicago Press.

Ben Ze'ev, Aaron. 2000. The Subtlety of Emotions. Cambridge: MIT Press.

Benhabib, Seyla. 2004. The Rights of Others. Aliens, Residents, and Citizens. Cambridge: Cambridge University Press. Benhabib, Seyla. 1988. Judgment and the Moral Foundations of Politics in Arendt's Thought. Political Theory 16: 29-51. [CrossRef]

Bernstein, Richard. 2011. Hannah Arendt's Reflections on Violence and Power. Iris 3: 3-30.

Boym, Svetlana. 2012. Another Freedom. The Alternative Vision of an Idea. Chicago: The University of Chicago Press. Brooks, Peter. 2014. Introduction. In The Humanities and Public Life. Edited by Peter Brooks and Hilary Jewett. New York: Fordham University Press, pp. 1-14.

Butler, Judith. 2011. Who Owns Kakfa. London Review of Books, March 3.

Davis, Todd F., and Kenneth Womack. 2001. Mapping the Ethical Turn. A Reader in Ethics, Culture, and Literary Theory. Charlottesville: University of Virginia Press. 
Disch, Lisa Jane. 1994. Hannah Arendt and the Limits of Philosophy. Ithaca: Cornell University Press.

Eskin, Michael. 2004. On Literature and Ethics. Poetics Today 25: 573-94. [CrossRef]

Gottlieb, Susannah Young-ah. 2007. Introduction. In Reflections on Literature and Culture. Stanford: Stanford University Press, pp. xi-xxi.

Harpham, Geoffrey Galt. 1995. Ethics. In Critical Terms for Literary Study. Edited by Frank Lenttrichia and Thomas McLaughlin. Chicago: The University of Chicago Press.

Heller, Erich. 1977. Hannah Arendt as a Critic of Literature. Social Research 44: 147-59.

Jonas, Hans. 1976. Hannah Arendt. Social Research 43: 3-5.

King, Richard. 2017. Hannah Arendt and the Uses of Literature. Raritan A Quarterly Review 36: 4.

Klusmeyer, Douglas. 2009. Beyond Tragedy: Hannah Arendt and Hans Morgenthau on Responsibility, Evil and Political Ethics. International Studies Review 11: 332-51. [CrossRef]

Lang, Berel. 2010. The Ethics of Style in Philosophical Discourse. In Literary Form, Philosophical Content. Historical Studies on Philosophical Genres. Edited by Jonathan Lavey and Louis Groarke. Madison: Farleigh Dickinson University Press.

Lupton, Julia Reinhardt. 2014. Hannah Arendt and the Crisis of the Humanities? Political Theology 15: $287-89$. [CrossRef]

Meretoja, Hanna. 2017. The Ethics of Storytelling. Narrative Hermeneutics, History, and the Possible. Oxford: Oxford University Press.

Nguyen, Mimi Thi. 2012. The Gift of Freedom. War, Debt, and Other Refugee Passages. Durham: Duke University Press. Nisbett, Robert. 1977. Hannah Arendt and the American Revolution. Social Research 44: 63-79.

Norris, Andrew. 1996. Arendt, Kant, and the Politics of Common Sense. Polity 29: 165-91. [CrossRef]

Nussbaum, Martha Craven. 1992. Love's Knowledge: Essays on Philosophy and Literature. Oxford: Oxford University Press.

Pettman, Dominic. 2017. Sonic Intimacy. Voice, Species, Technics (Or, How to Listen to the World). Stanford: Stanford University Press.

Ramirez, Juan, Jr., and Amy D. Ronner. 2004. Voiceless Billy Budd: Melville's Tribute to the Sixth Amendment. CWSL Scholarly Commons. Available online: http://scholarlycommons.law.cwsl.edu/cwlr/vol41/iss1/3 (accessed on 27 August 2019).

Ranciere, Jacques. 2004. Who is the Subject of the Rights of Man? The South Atlantic Quarterly 103: $298-310$. [CrossRef]

Ritivoi, Andreea Deciu. 2014. Intimate Strangers: Arendt, Marcuse, Solzhenitsyn, and Said in American Political Discourse. New York: Columbia University Press.

Rorty, Richard. 1989. Contingency, Irony, and Solidarity. Cambridge: Cambridge University Press.

Rosenberry, Edward H. 1965. The Problem of Billy Budd. PMLA 80: 489-98. [CrossRef]

Sacks, Rabbi. 2016. The Spirituality of Listening. Available online: http://rabbisacks.org/spirituality-listeningekev-5776/ (accessed on 16 September 2019).

Schiffman, Joseph. 1950. Melville's Final State, Irony: A Re-Examination of Billy Budd Criticism. American Literature 22: 128-36. [CrossRef]

Schwartz, Jonathan P. 2015. To Choose One's Own Company: Arendt, Kant, and the Political Sixth Sense. European Journal of Political Theory 18: 108-27. [CrossRef]

Schwartz, Daniel. 2001. A Humanistic Ethics of Reading. In Mapping the Ethical Turn. Charlottesville: University of Virginia Press, pp. 3-15.

Singer, Alan. 1997. Aesthetic Community: Recognition as an Other Sense of Sensus Communis. Boundary 224 : 205-36. [CrossRef]

Sjöholm, Cecilia. 2015. Doing Aesthetics with Arendt: How to See Things. New York: Columbia University Press. Solove, Daniel J. 2005. Melville's Billy Budd and Security in Times of Crisis. Cardozo Law Review 26: 2443-70.

Steinberg, Michael. 2007. Hannah Arendt and the Cultural Style of German Jews. Social Research 74: 879-902.

Stonebridge, Lyndsey. 2011. Refugee Style: Hannah Arendt and the Perplexities of Rights. Textual Practice 25: 71-85. [CrossRef]

Storey, Ian. 2015. The Reckless Unsaid: Arendt on Political Poetics. Critical Inquiry 41: 869-92. [CrossRef]

Villa, Dana. 1996. Arendt and Heidegger. The Fate of the Political. Princeton: Princeton University Press.

Scarry, Elaine. 2014. Poetry, Injury, and the Ethics of Reading. In The Humanities and Public Life. New York: Fordham University Press, pp. 41-48. 
Weigel, Sigrid. 2012. Sounding Through-Poetic Difference-Self-Translation. In Hannah Arendt's Thoughts and Writings Between Different Languages, Cultures, and Fields. Edited by Eckart Goebel and Sigrid Weigel. Berlin: De Gruyter, pp. 55-79.

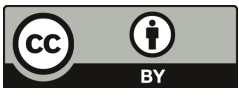

(C) 2019 by the author. Licensee MDPI, Basel, Switzerland. This article is an open access article distributed under the terms and conditions of the Creative Commons Attribution (CC BY) license (http://creativecommons.org/licenses/by/4.0/). 

Article

\title{
'A Pause for Po-Ethics': Seamus Heaney and the Ethics of Aesthetics
}

\author{
Eugene O'Brien \\ Department of English Language and Literature, Mary Immaculate College, Limerick V94VN26, Ireland; \\ Eugene.OBrien@mic.ul.ie
}

Received: 9 April 2019; Accepted: 9 August 2019; Published: 12 August 2019

check for updates

\begin{abstract}
In this paper, I examine the connections between ethics and aesthetics in the writing of Seamus Heaney. Looking at Heaney's neologism of 'po-ethics', I move through his poetry and especially his translation of Sophocles' Philoctetes, entitled The Cure at Troy, and focus on his Fourth Irish Human Rights Commission Annual Human Rights Lecture: Writer \& Righter, wherein he traces a number of strong connections between human rights workers and creative writers. The essay is written through a theoretical matrix of the ethical theories of Jacques Derrida, Emmanuel Levinas and Simon Critchley. It looks at poems from Heaney himself, as well as work from Shakespeare, Dante Alighieri, Czeslaw Miłosz, and Primo Levi. It focuses on poetic language as a discourse that can act as a counterweight and as a form of redress on behalf of the dignity of the individual human being against the pressures of mass culture and society.
\end{abstract}

Keywords: Seamus Heaney; Jacques Derrida; Emmanuel Levinas; Seamus Heaney's Human Rights Lecture; po-ethics; ethics; aesthetics; the other; politics; redress; the individual; Shakespeare; Dante Alighieri; Simon Critchley; Czeslaw Miłosz; Primo Levi

\section{Introduction: Po-Ethics}

In the sequence 'Ten Glosses', from Seamus Heaney's 2001 collection, Electric Light, the seventh section is entitled 'W. H. Auden, 1907-73'. In this poem, writing of Auden's political and cultural influences, Heaney includes a single sentence: 'A pause for po-ethics' (Heaney 2001, p. 55). This neologism, while specific to the context of the poem, also has a broader resonance in Heaney's writing and in some broader thinking about poetry. It embodies, I will argue, Heaney's own strong imbrication of ethics and poetics in his work. For Heaney, poetry as a form of discourse is also a form of epistemology, in that it allows language to articulate aspects of the somatic, of the emotional, and of the unconscious that are not available to other more rational, normative forms of discourse. He sees ethics and aesthetics as inextricably bound up, because poetry allows for the creation of an alternative vision of how a fairer and more ethically driven world could be. Heaney has spoken of poetry as a 'moral and ethical force' (Heaney 1988, p. 40), and he has addressed issues concerning the role of poetry and the 'moral and ethical imperatives subsumed in it' (Heaney 1989, p. 37). In his writing, he is also acutely aware of the dangers of any over-simplistic conflation of the poetic and the politic, citing the words of Joseph Brodsky, who stated: 'If art teaches us anything, it is that the human condition is private' (Heaney 2010, p. 12); nevertheless, just as there is a defined relationship between the private and the public, so is there also a relationship between the aesthetic and the ethical realms and between the individual as an individual and the individual as a citizen.

The term 'poethics' has a history in academic discourse, though whether Heaney was aware of this or whether he coined the word independently is unclear (his use of the hyphen would seem to differentiate his use of the term from other uses of the term). What is clear, however, is that there is a serendipity of approach in the uses of the term, which is useful in the present context. Perhaps the 
main proponent of this term is Joan Retallack in her book, The Poethical Wager (Retallack 2004), wherein she speaks of this concept as 'a poetics of the swerve'. She sees swerves as 'opportunities to usefully rethink habits of thought' and goes on to cite 'relativity theory, the quantum mechanical principles of complementarity and uncertainty' as 'major conceptual swerves with consequences in the culture at large, [and] ... Freud's theory of the unconscious and, more recently, chaos theory' (Retallack 2004, p. 1). For Retallack, poethics is a poetics of just such a swerve, of a movement away from the norm towards something new. She posits a particular connection with literature:

Literature (in contrast to journal writing) is an entry into public conversation. At its best it enacts, explores, comments on, further articulates, radically questions the ethos of the discourses from which it springs. Hence my use of the word poethics. Every poetics is a consequential form of life. Any making of forms out of language (poesis) is a practice with a discernible character (ethos). (Retallack 2004, p. 11)

For Heaney, poetry and ethics are similarly entwined, as he sees poetry as a genre wherein the truth can be told, arguing that 'there's such a thing as truth and it can be told-slant' (Heaney and O'Driscoll 2008, p. 467). I would contend that his notion of po-ethics is just this-seeing poetry as a genre through which forms of truth can be accessed and expressed in a way that is not accessible to the more normative discourse of what Jacques Lacan would term the Symbolic Order. Po-ethics allows for a slanted perspective, a swerve, which looks at the ethical demands on life from just such a different perspective.

Heaney has spoken of poetry as a 'moral and ethical force' (Heaney 1988, p. 40), and he has addressed the role of poetry and the 'moral and ethical imperatives subsumed in it' (Heaney 1989, p. 37). Significantly, Lacan also sees the locus of the unconscious as ethical, as he makes the point that the 'status of the unconscious, which, as I have shown, is so fragile on the ontic plane, is ethical' (Lacan 1977, p. 33). To obtain a true sense of the ethical dimensions of knowledge, the unconscious must be involved in the mode of inquiry, and Heaney's work, in poetry and prose, is predicated on such an involvement. Heaney interrogates the seeming truths of political essentialisms by positing intersubjective positions that are 'all throughother' (Heaney 1990, p. 48), to quote another of his neologisms, which is, again, interestingly, associated with ethical issues.

\section{Derrida and Levinas on Ethics}

In this paper, the term 'ethics' will be used in a sense that derives from the work of Emmanuel Levinas.

There are a number of theories on the relationship between ethics and literature: one could redact these as the Levinasian-Derridean tradition and that of Martha Nussbaum. This reading will focus on the former rather than the latter mode of thinking, as it offers greater insight into the connection I am positing between ethics and a particular use of language, specifically poetic language. Nussbaum is seen as the voice of a traditional, liberal, universal humanitarian mode of ethics. Robert Eaglestone has characterised her critical style as 'epi-reading', where 'ethical positions shine through like light through a perfect window' (Eaglestone 1999, p. 93). According to him, Nussbaum offers 'a reductive and over-simplified understanding of the act of reading' (Eaglestone 1999, p. 46), and while this may oversimplify her position, my own approach here will focus very much on language: my perspective will view language less as a transparent window and more like a stained glass one, which filters and affects what can be seen through it.

My own perspective has affinities with the work of Derek Attridge, who, in The Singularity of Literature, claims that 'literature, understood in its difference from other kinds of writing (and other kinds of reading) solves no problems and saves no souls' but notes that it 'is effective, even if its effects are not predictable enough to serve a political or moral programme' (Attridge 2004, p. 4). Unlike Nussbaum, whose understanding of the ethical in literature is underpinned by the system of Aristotelian ethics, Attridge is instead focussed much more on language and its inherent ambiguity 
and undecidability. His style of responsible or responsive reading has strong affinities with the work of Emmanuel Levinas, who speaks of a similar undecidability at work in the consciousness of the author-of the 'possibility of being the author of what had been breathed in unbeknownst to me, of having received, one knows not from where, that of which I am author' (Levinas 1981, pp. 148-49). For Levinas:

I exist through the other and for the other, but without this being alienation: I am inspired. This inspiration is the psyche. The psyche can signify this alterity in the same without alienation in the form of incarnation, as being-in-one's-skin, having-the-other-in-one's-skin. (Levinas 1981, pp. 114-15)

Attridge sees literature and the responsible reading of literature as a cultural process that 'involves the irruption of otherness or alterity into the cultural field' (Attridge 2004, p. 136). In this sense, his view differs from Nussbaum's work, as she sees literature as being about empathy and identification, whereas he sees it as a way of disrupting our normal understanding. As Attridge has summarised elsewhere, 'reading a work of literature entails opening oneself to the unpredictable, the future, the other, and thereby accepting the responsibility laid upon one by the work's singularity and difference' (Attridge 2005, p. 111). I would go further and see literature as a way of offering a new type of ethical epistemology, one that is embodied in synecdoche by the term 'po-ethics'.

Such an ethics has been defined by Simon Critchley, in The Ethics of Deconstruction, as the 'putting into question' of the ego, the subject, the self-consciousness, or 'what Levinas, following Plato, calls the Same (le même, to auton)' (Critchley 1992, p. 4). For Levinas, the ethical 'is the location of a point of alterity ... that cannot be reduced to the Same' (Critchley 1992, p. 5). Levinasian ethics is the domain of the other and of an inbuilt responsibility to the other. Given Levinas's view that the imperative to enter into some form of relation with alterity can turn poetry from an aesthetic discourse into an ethical one, which brings forth the necessity of critique (Levinas 1989, p. 147), literature as a genre can serve as a penetrating critique of the ethicity of socio-political discourses. Levinas sees the 'ethical essence of language', from which derives our sense of obligation as originating in 'the sensibility of the skin of the Other's face' (Critchley 1992, p. 179). This image of the face is contemporary and present; it is grounded in a sensibility to the other, a sensibility that is situated 'on the surface of the skin, at the edge of the nerves' (Levinas 1981, p. 15). The face, for Levinas, is the guarantee of the humanity of the other; it is definitely not some form of verbal construct, manufactured from the cultural psyche of sameness. As Simon Critchley puts it, 'ethics is always already political, the relation to the face is always already a relation to humanity as a whole' (Critchley 1992, p. 226). In Levinasian ethics, humanity is signified by this very otherness, as symbolised by the face, and literature is a mode of discourse that expresses this 'relation with the other' (Levinas 1989, p. 143).

A similar stress on the importance of the 'other' is also found in the work of Jacques Derrida, whose relation to alterity, involving his responsibility to the other, is also a 'responsibility toward the future, since it involves the struggle to create openings within which the other can appear' and can hence 'come to transform what we know or think we know' (Derrida and Attridge 1992, p. 5). Here, one thinks of Levinas's statement that 'language is born in responsibility' (Levinas 1989, p. 82), implying that the responsibility involved is to the other-other traditions, other ideas, but, most essentially, other people in the present and future. For Derrida, an ethical decision is one which must make an 'undecidable leap' beyond all prior preparation for that decision (Derrida 1995, p. 47); it is a 'trial of undecidability' (Derrida 1988, p. 210). Keeping in mind the sense of responsibility to the other and the fact that each decision will be singular and individual, the decision, 'must advance towards a future which is not known, which cannot be anticipated' (Derrida 1994, p. 37).

Both Levinas and Derrida see ethics as this combination of the need for a decision in the absence of any rulebook and the need to predicate such a decision on a respect for the other as a human being-as an entity to whom we have an a priori responsibility. Derrida makes the point that ethics is precisely what is required for these decisions: 
There are ethics precisely because there is this contradiction, because there is no rule. There are ethics because I have to invent the rule; there would be no responsibility if I knew the rule. There is responsibility only because there are these two aporetic structures in which I have to respond to two injunctions, different and incompatible. That's where responsibility starts, when I don't know what to do. Ethics start when you don't know what to do, when there is this gap between knowledge and action, and you have to take responsibility for inventing this new rule which doesn't exist. An ethics which guarantees is not an ethics. (Derrida 2003, p. 32)

In much of his poetry, Heaney writes about just such an ethics, and he uses the aesthetic as a way of giving such ethics a voice and of probing just such ethical predicaments. I would argue that his neologism 'po-ethics' is indicative of this strain in his thinking. There has been very little written about this term in Heaney's writing, but Rubin Moi has focussed on both the poem and the term. He sees the term as suggestive of 'at once Italian rivers, theoretical torrents, multiple abbreviations and scatological humour' and goes on to suggest, perceptively in my view, that the term can also 'be read as a defence of the collection's recuperation of Italian art from Virgil to the Renaissance, as a humanist stay against the subjection of standard values to critical scrutiny' (Moi 2007, p. 177) —in other words, as a form of redress against the instrumentality of the contemporary world.

\section{Heaney: Poetry and Ethics}

Heaney makes a telling point about the fusion of ethics and aesthetics in poetry as a form of discourse:

Poetry, let us say, whether it belongs to an old political dispensation or aspires to express a new one, has to be a working model of inclusive consciousness. It should not simplify. Its projections and inventions should be a match for the complex reality which surrounds it and out of which it is generated. The Divine Comedy is a great example of this kind of total adequacy, but a haiku may also constitute a satisfactory comeback by the mind to the facts of the matter. As long as the coordinates of the imagined thing correspond to those of the world that we live in and endure, poetry is fulfilling its counterweighting function. It becomes another truth to which we can have recourse, before which we can know ourselves in a more fully empowered way. (Heaney 1995, pp. 7-8)

The sense of poetry as a counterweighting force against the lived actuality of normal existence is significant here, as is the idea that it must account for all of the complexities that are involved in the human condition. Clearly, Heaney sees poetry as having a force in the public sphere-perhaps a light and individual force but one that, nonetheless, has a power to offer a different kind of knowledge to us about ourselves and about the dilemmas and decisions that we are forced to confront. As a 'comeback' and a 'counterweight', he seems to be suggesting that the aesthetic is a way of looking differently at ethical issues, offering a swerving of perspective.

It is not that he sees the ethical and the aesthetic in dialogue per se, nor that he sees one as supervening over the other; rather, he sees poetry as a way of 'telling' ethical stories in a way that has the ability to reach parts of a reader's understanding that is not strictly available to the more rational syntax and structural expectations of prose, be that literary theory or philosophy: hence the need for the neologism 'po-ethics', which describes the imbrication and complexity of the action of poetry in the public and private spheres as he sees it. In Heaney's writing, the connections between signifier and signified - between word and idea being represented by that word - are foregrounded, as he tries to use connections of figural language (namely rhyme, neologisms, homonyms, and homophones) to foreground connections at the level of the word to create epistemological depth charges, which will explode in the underwater of the unconscious and create new perspectives on notions of ethics and aesthetics. 
Po-ethics is one of these, and it echoes an aspect of the thinking of Martin Heidegger. Heaney, similar to Heidegger, forces us to recognise the 'complicity between the matter and the manner of thinking as the presence of figurality itself, as the folding or thickening of the limits of language' (Allen 2007, p. 95). Language, while it can be logical, must also necessarily be more than logical, as it enunciates, albeit in slanted form, the unconscious; for Heaney, as well as Heidegger, 'buried in all language is the rift between world and earth. Poetry reveals that rift. Revealing that rift poetry lets words speak' (Harries 2009, p. 116). Far from seeing poetry as a decorative addition to language, Heaney sees it as a substantial mode of inquiry into many aspects of our human being. Heaney, in looking at the descriptive and the hallucinatory, is attempting to signify aspects of the unconscious as a form of knowledge that can be accessed, albeit in an indirect form, through poetic discourse or slant, as has already been noted. This term is borrowed from Emily Dickinson's poem 'Tell the Truth but Tell It Slant', poem number 1129 in her Collected Poems (Dickinson 1924, pp. 506-7), and the fact that this term is borrowed from such an oblique poet as Dickinson is interesting in itself, as the many dashes and ellipses in her writing can be seen as opening a space for the unconscious dimension of her thinking and as giving a form to the undecidable that is central to poetry. It is as if she knows that there are aspects of her thought and feeling that cannot be written: 'the Truth must dazzle gradually' (Dickinson 1924, p. 507).

Dickinson's idea of truth being told in a circuitous manner suggests that a valid telling of truth will allow for a gradual unfolding of a new and different perspective that will upturn previous expectations, and the slant that Heaney uses will be the associative and phonetic aspects of language, as well as images, which upturn normative perceptions. An example of such linguistic swerves is found in the seventh poem in the 'Lightenings' sequence in his volume Seeing Things, which refers to a medieval legend that recounts the story of a magical event. When the monks of the monastery at Clonmacnoise were at prayer, a 'ship appeared above them in the air', the anchor lodged in the 'altar rails', and then a crewman 'shinned and grappled with the rope/And struggled to release it' (Heaney 1991, p. 63). The poem ends with an abiding synecdoche of poetic thinking as that complex counterweight to the actual of which Heaney spoke in the earlier quotation:

'This man can't bear our life here and will drown,'

The abbot said, 'unless we help him.' So

They did, the freed ship sailed, and the man climbed back

Out of the marvellous as he had known it. (Heaney 1991, p. 63)

Poetry, the aesthetic, allows for an alternative definition of the marvellous and the mundane, for a revision of the normal perspective, and the po-ethic is that space where alternate notions of ethics can be trialled and embodied in a mode of language where the rhymes of the signifier can create non-syntactical attachments to the notions of the related signified. In this poem, the 'marvellous' is really a matter of perspective and context as opposed to anything magical, and poetry is the genre that allows for this altered perspective: the poem really is a working model of inclusive consciousness. Poetry offers a different, skewed relationship to the normal paradigms of society and culture. It definitely does not simplify.

What is key for Heaney is that poetry, while outlining a different and possibly better-imagined reality, should nevertheless be connected to our own reality and have some sense of responsibility to that reality. In this sense, Heaney's ideas are in line with those of a number of other aesthetic thinkers, who have pondered and probed the role of poetry in the public sphere as a space wherein alternative ethical paradigms can be given face and voice. For Theodor Adorno, art is a force field encompassing 'ethical, metaphysical and logical, as well as aesthetic in the immediately recognisable sense of that term' (Wilson 2007, p. 44), while Lacan's view of the locus of the unconscious as being ethical has already been noted. Heaney's po-ethics can be seen as analogous to Simon Critchley's views on the role of poetry with respect to philosophy and to reality: 
Poetry is the imagination touching reality. Poetry allows us to see things as they are. It lets us see particulars being various. Nevertheless, and this is its peculiarity, poetry lets us see things as they are anew, under a new aspect, transfigured, subject to a felt variation. The poet sings a song that is both beyond us yet ourselves. Things change when the poet sings them, but they are still our things: recognizable, common, near, low. We hear the poet sing and press back against the pressure of reality. (Critchley 2005, p. 11)

Pressing back against reality is exactly what Heaney is describing in his above-cited notion of poetry as a counterweighting function against 'the purveyors of ready-made meaning' (Heaney 1988, p. 91). However, this can never be an overt declaration, a constative demand to be ethical, as this is not the affective domain of poetry. Instead, poetics signifies a type of language that is performative and that, through linguistic defamiliarisation, suggests new connections and a slanted perspective on truth, and one of these core po-ethic terms that he uses to explore the impact of poetry on ethical matters is the notion of redress.

This idea of poetry as a genre that offers access to, and expression of, a specific notion of ethics is at the core of this reading of Heaney. It is the genre, I would argue, that allows expression of 'being-in-one's-skin', while at the same time 'having-the-other-in-one's-skin' (Levinas 1981, pp. 114-15). As Critchley puts it:

Poetry allows us to see things as they are. It lets us see particulars being various. Nevertheless, and this is its peculiarity, poetry lets us see things as they are anew, under a new aspect, transfigured, subject to a felt variation. The poet sings a song that is both beyond us yet ourselves. Things change when the poet sings them, but they are still our things: recognizable, common, near, low. We hear the poet sing and press back against the pressure of reality. (Critchley 2005, p. 11)

I would agree with Critchley here that there is a level of knowledge that can only be expressed by poetry-by a specific discourse wherein the sound, shape, placement, and connections across sense and meaning are all valued signifiers of the complexity and scope of poetry as a mode of thinking. In poetry, 'language does not simply efface itself in delivering us over to that of which it speaks, but rather the tonality of the word is brought to resonate' (Sinclair 2006, p. 141), and this in itself is a different form of knowing about the world. It can be philosophical and epistemologically valid but in a different way: 'all philosophical thinking, even the severest and most prosaic, is in itself poetic, yet never is poetry' (Mugerauer 1990, p. ix). For both Heidegger and Heaney, poetry is a form of thinking, albeit thinking differently, that includes the other and the unconscious, the unknown and the other. It is a form of knowledge that involves thinking, feeling, and a response to the associative connections of words, sounds, and unconscious felt connections within language as connections between self and other.

\section{Poetry and Redress}

In his 1995 collection, The Redress of Poetry, Heaney probes the etymology of the term 'redress', demonstrating once again the centrality of the signifier, as he speaks of 'fifteen separate meanings' of the verb, noting that almost all of them are 'obsolete', before observing a single core meaning: 'to set (a person or a thing) upright again' - to 'restore, re-establish' (Heaney 1995, p. 15). Having set up this quite social meaning of the word, a meaning replete with ethical overtones, pointing as it does to 'poetry's possible service to programmes of cultural and political realignment', Heaney goes on to stress that he is not looking for poetry to exercise its force in 'earnest, morally premeditated ways'; instead, he is professing 'the surprise of poetry as well as its reliability' and what he terms 'its given, unforeseeable thereness, the way it enters our field of vision and animates our physical and intelligent being' (Heaney 1995, p. 15), and he gives what might be termed a very po-ethic image to underline this aspect of the power of the poetic image, which he sees as having something of the same force as:

those bird-shapes stencilled on the transparent surfaces of glass walls or windows must suddenly enter the vision and change the direction of the real birds' flight. In a flash, the shapes 
register and transmit their unmistakable presence, so the birds veer off instinctively. An image of the living creatures has induced a totally salubrious swerve in the creatures themselves. (Heaney 1995, p. 15)

Here, the image has a real effect and impact on reality, but it always remains an image. It is this 'both/and' logic that Heaney sees as central to po-ethic thinking. It is connected to the real world, as Critchley has noted, while at the same time being of a different order. So, the images of the birds on the glass are linked with the real-world birds but are nevertheless qualitatively and ontologically different from them: they mimic nature but are different from nature and can have an effect on nature - an effect that is a swerve from the normal — and here, we return to Retallack's ideas of poethics and the swerve from the normal. It is as if art has a value qua art, but also has a value through its swerving slanting effect on the reality that it touches and, in some way, transforms.

Here, we see Heaney embodying a point made by Roland Barthes about poetic language, which 'initiates a discourse full of gaps and full of lights, filled with absences and over-nourishing signs' and which is opposed to the social function of language, because 'to have recourse to a discontinuous speech is to open the door to all that stands above Nature' (Barthes 1978, pp. 48-49). Poetic language has an ability to express and access aspects of experience that are silenced in normal discourse, as it belongs, as Maurice Blanchot observes, 'neither to the day nor to the night but always is spoken between night and day and one single time speaks the truth and leaves it unspoken' (Blanchot 1982, p. t276). In his final discussion of the polysemic meanings of the word 'redress', Heaney cites a hunting context, where the word can mean 'to bring back (the hounds or deer) to the proper course', and sees this meaning as significant in that 'there is no hint of ethical obligation; it is more a matter of finding a course for the breakaway of innate capacity, a course where something unhindered, yet directed, can sweep ahead into its full potential' (Heaney 1995, p. 15). It is here that his sense of the po-ethic can be seen at its fullest: it is not that 'redress' means one or the other; it is, rather, that 'redress' means an imbrication of all of these different senses of the term. It is another example of an undecidable. So, while poetry may not have a de jure claim to instruct others to act ethically, it can, de facto, by embodying ethical stances in its own language, have an ethical affect and effect on its readers, just as the stencilled bird-shapes can have an effect on the real birds with whom they come into contact.

Of course, there is a poetry that verges on the role of public prophecy or what Heaney has termed 'the solitary role of the witness' (Heaney 1995, p. 4), and here, the ethical warrant is clear on the words on the page. However, there is what might be called an undermusic to poetry, and here, too, ethical messages are held and sometimes voiced gently so that their effect is not sudden but gradual. Citing a review by Eavan Boland of the work of Elizabeth Bishop, Heaney notes approvingly Boland's views on poetic tone. For Boland, tone is far more than the surface voice through which the poem is uttered; instead, 'its roots go deep into the history and sociology of the craft', and for Boland, 'tone is not a matter of the aesthetic of any one poem. It grows more surely, and more painfully, from the ethics of the art. Its origins must always be in a suffered world rather than a conscious craft' (Heaney 1995, p. 134). Heaney has quoted this comment, as it segues very much with his own views on the embedded nature of the ethical perspective in the very genre of poetry: 'this last sentence is a wonderful formulation of what we seek from any poet's undermusic' (Heaney 1995, p. 134). In a deep sense, the very heart of poetry can be seen as ethical, as it is written about the suffering in the world and can be a way of transcending such suffering — of aestheticising such suffering and turning it into a cathartic form of beauty-or else a way of universalising such suffering, giving rise to empathy. Po-ethics allows for the centrality of ethics within the aesthetic, and in the Fourth Irish Human Rights Commission Annual Human Rights Lecture, which Heaney delivered on 9 December 2009, he teases out the intrinsic textual and subtextual connections between poetry and ethics.

\section{Writer \& Righter}

The title of this lecture is po-ethic in its imbrication of the ethical and the aesthetic. It is entitled 'Writer $\mathcal{E}$ Righter', as through the homophones involved, it focuses attention on the chiming of the 
signifiers, which then leads us to look for a deeper connection at the level of the signifieds. It is a classic example of what Roman Jakobson has termed 'the poetic function', where the principle of equivalence is projected from 'the axis of selection onto the axis of combination. Equivalence is promoted to the constitutive device of the sequence' (Jakobson 1971, p. 704). In this sense, the connections between words are no longer purely syntactically connected but are also driven by associative, aleatory types of relationships at the level of phonetic association-relationships that are redolent of the unconscious: in a sense, signifier and signified are throughother in such cases. Poetry as a discourse, through sonic connections such as rhyme, assonance, alliteration, and para-rhyme, sets up different paradigms of connection between words at the level of sound-connections that can also liberate other meanings from these words. For Lacan, the 'unconscious, which tells the truth about truth, is structured like a language' (Lacan 2006, p. 737), with imagination touching reality, and it is through the full range and power of language that aspects of the unconscious can be expressed and accessed. Thus, the structure of poetry, which posits connections at the level of the signifier, the word, as well as at the rational level of the signified, the meaning, enables the different levels of connection to reinforce each other and complicate the meaning, thus allowing for an ethical undermusic to reach the reader in an unusual and counterweighting manner. I would suggest that these connections at the level of sight, sound, and rhyme are all signifiers of the unconscious charges that surround words and sentences. Meaning both coheres and inheres, and poetic language, through its associative and imagistic dimensions, is highly attuned to this aspect of signification.

In the lecture, Heaney begins by quoting the United Nation's Universal Declaration of Human Rights, specifically the first article: 'All human beings are born free and equal in dignity and rights. They are endowed with reason and conscience and should act towards one another in a spirit of brotherhood' (Heaney 2010, p. 7). This declaration is not poetic or po-ethic; it is a constative statement that sets out a truth that is shared between the members of the United Nations. However, Heaney gradually weaves a po-ethic strand into the essay as he points to connections between the focus on human dignity in this article and the echoes of what he terms 'many of the great foundational texts of western civilization', such as those from Sophocles' Antigone, Christ's Sermon on the Mount, the American Declaration of Independence, and the French Declaration of the Rights of Man, which can be heard in the imaginative hinterland of the declaration (Heaney 2010, p. 7). Rightly, he sees these as foundational public texts, whose remit is to persuade and inspire large groups of people, and identifies an ethical connection between such texts and the United Nations Declaration. However, Heaney also speaks of how 'the imaginative work of individual creative writers has been equally influential and ameliorating in the formation of human consciousness', citing Lear on the heath as he feels empathy with other 'poor naked wretches' (Heaney 2010, p. 7).

In this speech, Lear, abandoned by his daughters, bereft of all his retainers and the trappings of wealth, comes to a moment of catharsis and anagnorisis as he realises the nature of humanity:

Poor naked wretches, whereso'er you are,

That bide the pelting of this pitiless storm,

How shall your houseless heads and unfed sides,

Your looped and windowed raggedness, defend you

From seasons such as these? O, I have ta'en

Too little care of this! Take physic, pomp;

Expose thyself to feel what wretches feel,

That thou mayst shake the superflux to them

And show the heavens more just. (Shakespeare 2009, III. 4, pp. 28-36)

This is a powerful poetic statement of the need to ensure human dignity, and it offers a counterweight to, and a redressal of, the previous behaviour of Lear when he was insulated from storms, both physical and emotional, by his wealth and power: 'Through tattered clothes great vices do appear;/Robes and furred gowns hide all' (Shakespeare 2009, IV, 6. pp. 64-65). It is interesting that this moment of anagnorisis comes when Lear has no actual power so that the change is an individual one, as Lear no 
longer has the authority to initiate any broader societal change; thus, here, the swerve in attitude is personal as opposed to social. However, generations of readers have been influenced by the ringing tones of this speech and by the core appeal for human dignity across all social classes and barriers: it is a po-ethic swerve from his previous perspective, which focuses on responsibility to the other.

Heaney also cites Dante's 'mighty affirmation of the privileges and elevated destiny of our species' in the in the 36th Canto of The Inferno (Heaney 2010, p. 7):

Considerate la vostra semenza:

fatte non foste a vivere come bruti

ma per seguir virtute e conoscenza. (Inferno, XXVI 118-120)

Remember who you are, what you were made for;

Not to live like brutes, but for the quest

Of knowledge and the good. (Alighieri 2002, p. 184)

In this canto, Ulysses is asking his crew to sail into unknown waters and into unknown territory, and thus, they become symbols of the human desire and ability to 'transcend the boundaries of pettiness and self-interest' (Heaney 2010, p. 7). The idea that the goal of humanity is a search-an ongoing search-for 'knowledge and the good' is profoundly ethical, and again, in an imaginative piece of writing, this phrase, while not capable of changing a society or a culture, does, in the words of Critchley, touch reality and, to some extent, transform it for the reader of the canto. An imaginative scene can often have a very insightful effect on reality, and just like the stencilled birds, the words of Shakespeare and Dante have deeply influenced what we see as core human qualities and abilities. They exemplify the role of literature as a critique of the actual. As such, these literary texts fuse the personal with the societal and the aesthetic with the ethical, offering guidelines through imagined example. In short, they are po-ethic. Both Shakespeare and Dante, while creating works of imaginative beauty, also express a responsibility to other humans, to the dignity of the human condition, and to the intrinsic value of the other.

\section{The Cure at Troy}

Heaney shows the same quality in his translation of Sophocles' drama Philoctetes, entitled The Cure at Troy. In this play, the Greeks come looking for the wounded Philoctetes with the mission of stealing his bow, without which Troy cannot be taken. They attempt to do this by deceit; as Odysseus puts it, they were 'Greeks with a job to do' (Heaney 1990, p. 3), and ethical considerations were very much secondary to the aim of getting the bow and bringing it back to Troy. Odysseus can rationalise almost anything, telling Philoctetes that his 'aim has always been to get things done/By being adaptable' (Heaney 1990, p. 57), and this adaptability is grounded in his tribal loyalty. In answer to the ethical question about the lies that have been told, he gives the classic response of political pragmatism: 'But it worked! It worked, so what about it?' (Heaney 1990, p. 65). The repetition here underlines the performative aspect of the sentence. For Odysseus, the end does justify the means, and the repetition serves to underline his confidence in this mode of action: his responsibility is to the same '(le même, to auton)', in this case, the Greeks as opposed to the other.

In the climactic confrontation of the play, Neoptolemus, who had shared this perspective earlier-'I'm under orders' (Heaney 1990, p. 51) —and who had lied to Philoctetes in order to obtain his bow, realises the error of his ways and becomes a more complex character through the introduction of an ethical strand to his persona. In a colloquy with Odysseus, the gradual opposition between pragmatic tribal politics and a more open humanistic ethics is unveiled. In response to Neoptolemus's statement that 'I did a wrong thing and I have to right it' (Heaney 1990, p. 52) and to his further remark that he is going to 'redress the balance' and cause the 'scales to even out' (Heaney 1990, p. 65) by handing back the bow, Odysseus replies in clichés: 'Act your age. Be reasonable. Use your head.' Neoptolemus' reply demonstrates the gulf that exists between the two: 'Since when did the use of 
reason rule out truth?' (Heaney 1990, p. 66)—a comment that echoes Dante's view of the human need to find knowledge and truth.

For Odysseus, 'rightness' and 'justice' are values that are immanent in the ideological perspective of the tribe or community. There is no critical distance between his notions of myth and history. He sees no sense of any transcendental or intersubjective form of justice in what Neoptolemus is attempting: for him, the dignity of the individual is fine, as long as that individual is a Greek. When Neoptolemus speaks of 'doing the right thing', he is answered by the voice of the tribe: 'What's so right about/Reneging on your Greek commission?' Their subsequent interchange deserves to be quoted in full, as it is a locus classicus of the conflict between ethics and politics-between a view of self and other as connected and mutually responsible, as opposed to that of self and other as opposed and in conflict:

\section{ODYSSEUS}

You're under my command here. Don't you forget it.

\section{NEOPTOLEMUS}

The commands that I am hearing overrule

You and all you stand for.

ODYSSEUS

And what about

The Greeks? Have they no jurisdiction left?

NEOPTOLEMUS

The jurisdiction I am under here

Is justice herself. She isn't only Greek.

ODYSSEUS

You've turned yourself into a Trojan, lad. (Heaney 1990, p. 67)

In this exchange, the critical distance already spoken of is evident in the value-ethic of Neoptolemus. The view of Odysseus is binary-one is either Greek or Trojan; there is no other alternative. In a ringing assertion earlier in the play, as Neoptolemus begins to have some form of sympathy with Philoctetes, he says 'I'm all throughother. This isn't me. I'm sorry' (Heaney 1990, p. 48).

'All throughother' is a neologism that captures the imbrication of self and other in an ethically driven aesthetic of identity. The term 'throughother' itself, though, has a poetic history-one of which Heaney may have been aware. In Gerard Manley Hopkins' poem 'Spelt from Sibyl's Leaves', the title refers to the Cumaean Sibyl, who wrote prophecies on oak leaves arranged inside the entrance of her cave, but if the wind blew and scattered them, she would not reassemble the leaves. Therefore, the poem speaks to a form of knowledge that needs to be interpreted without any transcendental validation or guidance. It is a knowledge that is 'throughother':

For earth her being has unbound, her dapple is at an end, astray

or aswarm, all throughther, in throngs; self ín self steedèd and páshed—qúite

Disremembering, dísmémbering áll now. (Hopkins 2014, p. 72)

One can see that Heaney would be attracted to this notion of a genre-specific knowledge that is dependent on the relationship between the now randomly arranged oak leaves. There are numerous permutations, but no absolute redeemable meaning. Moreover, these notions of alterity have permeated the self, and the singular has become more plural and more complex.

The word also appears in the poetry of Robert Burns, in his poem 'Halloween'. Here, Burns is writing about prophecy and occult knowledge that are seen as central to this festival:

Then, straught or crooked, yird or nane,

They roar an' cry a' throu'ther;

The vera wee-things, toddlin, rin,

Wi' stocks out owre their shouther. (Burns 2013, p. 163) 
Mortal and immortal; self and other-once again, the term has an ethical origin. Heaney has written about both poets, and while it might seem like special pleading on the part of my argument, the two poets from whom this term originates are among the most linguistically defamiliarised in the poetic spectrum; thus, the word can be seen as a synecdoche of a sense of ethics that can be voiced by poetic language and expressed in poetic thinking.

In his poem 'A Birl for Burns', Heaney praises the poet's ability to go beyond poetic norms:

For Rabbie's free and Rabbie's big,

His stanza may be tight and trig

But once he gets the sail and rig

Away he goes. (Burns 2008, p. viii)

As so many philosophical systems have probed and problematised that difference between self and other, this neologism is po-ethic in its ability to take a new signifier to create new signifieds of identity and selfhood. In both the writing of Hopkins and Burns, this process is furthered, and in terms of language and of the Levinasian sense of the skin of self and other, only poetry or po-ethic thinking can fuse selfhood and alterity in such an ethical construct. It is worth noting that, above, Neoptolemus is talking about himself and is not trying to persuade anyone else. It is a poetic statement of an imagined sense of identity that does not exist but that could. It speaks to the dignity of the relationship between human beings-between self and other-and it is allowed by the swerve of po-ethic language.

By speaking about an alternative sense of identity to that espoused by Odysseus, Neoptolemus does not set out to proclaim the need for change; instead, he plants a counterweight-something alternative, a differential choice-in the minds of others. However, the important thing here is that change-po-ethic change brought about through a defamiliarisation of language-has occurred in the individual. In Writer $\mathcal{E}$ Righter, Heaney sees this achievement of change as a trope that connects writers and human rights workers: 'that need for justification which writers feel when faced with a world of pain and troubles and how the need gets fulfilled' (Heaney 2010, p. 8). He goes on to cite the importance of how the aesthetic engages with the ethical by citing a term coined by the Italian Modernist poet Eugenio Montale, 'the second life of art', which Montale equates with art's 'obscure pilgrimage through the conscience and memory .... Its entire flowing back into the very life from which it took its first nourishment' and its emergence into 'the life of everyday circulation' (Montale 1982, p. 22).

For Heaney, the second life of art's pilgrimage is fuelled by po-ethics, by a broadening of language so as to stretch the imagination and the realm of meaning into new dimensions. As already noted, he uses a po-ethic device here by looking at the homophonic connections between the artist and the activist:

However, I begin also with that old familiar unease which I always feel before an audience that includes the doers rather than the discoursers, people more active on a daily basis in the courts of law than in the courts of poetry, people who would incline to spell the word writer with the letters r-i-g-h-t-e-r rather than the letters w-r-i-t-e-r. My concern, therefore, is with the serious question posed by that bit of wordplay: the question whether it is 'right on', in the faded old idiom of the Sixties Californian counter culture, whether it is 'right on' to write on, as the term is usually understood by an author, to write on for the sheer joy of it in face of the miseries of the world. Whether, to put it another way, ethical obligation shadows the aesthetical vocation. (Heaney 2010, p. 9)

This is po-ethic in the extreme, as the image of the ethical shadowing the aesthetic and vice versa, is one that cuts to the core of Heaney's lecture. He is looking very much at the individual writer and reader and how change and development in the writerly sphere are generally individual as opposed to group centred. As he did in The Government of the Tongue, in this lecture, Heaney looks to writers from totalitarian regimes and those from post-war Europe as test cases of how poetry can be both true to itself as well as being ethically valid in times of stress. 


\section{Miłosz, Levi, and Camus}

Here, as elsewhere, the figure of Czesław Miłosz is significant. Having survived the Nazi occupation of Warsaw, he went on to write some highly significant poetry, and for Heaney, his status is due, in no small way, to his posing of the following question with respect to the interplay of the ethical and the aesthetic:

What is poetry that does not save

Nations or peoples?

A connivance with official lies.

The song of drunkards whose throats are about to be cut. (Miłosz 2001, p. 77)

For Heaney, it is Miłosz's awareness of 'poetry's frailty in the face of the atrocious' that makes him a strong voice, both ethically and aesthetically. The fact that poetry as a discourse has no real societal effect makes its raising of its voice all the more ethically valuable. Heaney goes on to look at a poem by the survivor of Auschwitz, Primo Levi, called 'Shema' and sees it as being of value in terms of the connection between ethics and aesthetics:

You who live secure

In your warm houses,

Who return at evening to find

Hot food and friendly faces:

Consider whether this be a man,

Who labours in the mud

Who knows no peace

Who fights for a crust of bread

Who dies at a yes or a no.

Consider whether this is a woman,

Without hair or name....

Consider that this has been:

I commend these words to you.

Engrave them on your hearts

When you are in your house, when you walk on your way,

When you go to bed, when you rise.

Repeat them to your children.

Or may your house crumble,

Disease render you powerless,

Your offspring avert their faces from the sun. (Levi 1988, p. 9)

What is most interesting about this poem is the fact that it focuses, not on the society or the countries that are expected to deal with such atrocities and such barbarous treatment of people, but rather on the ordinary people who live in houses and whose context is that of the familial as opposed to the political or cultural. Heaney's attraction to the poem is precisely because its language is so different from the Declaration of Human Rights, whose force is political and moral; here the force of the language, what might be termed its po-ethic force, is rhetorical and personal. It may have the same theme as the Declaration, but the po-ethic force is different. Heaney notes the 'mighty rhetorical and emotional power' of the structure of the poem, 'beginning with a note of implied accusation and ending with a potential curse, commanding attention because of its repeated imperatives-'consider, consider, consider, engrave, repeat' - but commanding also because of its agonized awareness of human cruelty and human suffering' (Heaney 2010, p. 11). The fact that is written by someone who we know has survived one of the most horrendous regimes in history also adds depth to the words and to the feelings and emotions that are signified in these words. 
What is also po-ethically significant is the role of the family and the home in the poem. The addressees are seen as people with homes, children, and friendly faces-people who 'live secure'. These people are asked to 'consider' the plight of those who are bereft of these human connections, but it is more than this. The core question is whether, without these conditions, one is still human at all, and the poem asks the reader to consider and weigh this. The poem asks us to consider whether one is still a man when one knows no peace, works in mud, fights for food, and dies on command. In a way, it is the same question as the one posed by Lear on the blasted heath, where he notes that each person, regardless of social condition, has a dignity and a common humanity. Indeed, there is an echo in these lines of the 'houseless heads and unfed sides' and the 'looped and windowed raggedness' of the wretches who are exposed (Shakespeare 2009, III. 4, pp. 30-31), as both poets look to value another who seems almost valueless. The tone here of this poem is very much redolent of Boland's idea of the suffered world. The language used to decide on life or death has no notion of considering or weighing ideas; it is monosyllabic and declarative: 'dies at a yes or a no'. Such imperative declaratives are probably the polar opposite of poetry-a form of counterweight or redress where language is used to probe the edges of the existing paradigms. Instead, the language here is cut and dry. The question of whether a woman can be a woman without hair or a name develops the interrogation of the ontology of humanity, but as is typical with poetic language, further questions float in the poem's undermusic: if the victims of a regime that denudes them of seminal aspects of humanity are having their humanity questioned, surely further questions can be asked about the people who are exercising the power of life and death over these victims and of the people in houses with families who do nothing to stop this. The poem ends with a demand for a common humanity, where, again, language is used to underscore this demand, as the words are commended and the readers are enjoined to 'engrave them on your hearts' and to 'repeat them to your children'. For Heaney, in this poem, 'the etymological relationship between the words 'author' and 'authority' is more than usually intimate and fortifying' (Heaney 2010, p. 11).

Heaney also invokes Brodsky in his reading of this poem and in his discussion of the po-ethic work of poetry. Brodsky 'believed steadfastly in poetry's ability to work to good emotional and spiritual effect within each individual', and once again, it is on the individual that poetry works best:

Poetry, however, was not in the business of mass education. It was not there to brainwash people. Instead, Joseph equated it with that which is heard at a profound level on the individual's inner ear, that which is truly h-e-a-r-d as opposed to that which is a mass produced message directed at the h-e-r-d. (Heaney 2010, p. 12)

Once again, the defamiliarisation of language works very well to outline the connections between listening to an inner voice and listening to the official lies of which Miłosz spoke. Poetry is often the voice of the human without a name or without a voice, and Heaney quotes the work of Albert Camus, from his Nobel Address, who notes that the silence of an unknown prisoner is enough to provoke the writer when 'he manages not to forget that [prisoner's] silence, and to transmit it in order to make it resound by means of his art' (Camus 1957). The writer attempts to make the silence of the prisoner h-e-a-r-d even though that voice has been drowned out by the voices, or the official lies, of the h-e-r-d.

So, the notion of a pause for po-ethics is one that, while central to this reading of the ethical and aesthetic imbrications that are to be found in the writing of Seamus Heaney, is also something that inhabits a lot of poetic language. Poetry as a space wherein the individual can be restored to him or herself is a given of such work, and poetry as a genre allows for that self-reflective space. When Seamus Heaney was awarded the Nobel Prize for literature in 1995, the citation mentioned his poetry's 'combination of lyrical beauty and ethical depth which exalt everyday miracles and the living past'. Bernard O'Donoghue has made the telling point that 'this summary is impressively comprehensive, not least in emphasizing the "combination" of the lyricism and the ethics. The two cannot easily be untangled in Heaney's work' (O'Donoghue 2016, p. 219). I hope this essay has demonstrated that this is the case: for Heaney, po-ethics is at the very centre of his poetic thinking, and to paraphrase the poet himself, it does not simplify. 
Funding: This research received no external funding.

Conflicts of Interest: The author declares no conflict of interest.

\section{References}

Alighieri, Dante. 2002. The Inferno of Dante Alighieri. Translated by Ciarán Carson. London: Granta.

Allen, William S. 2007. Ellipsis: Of Poetry and the Experience of Language after Heidegger, Hölderlin, and Blanchot. Albany: State University of New York.

Attridge, Derek. 2004. The Singularity of Literature. London: Routledge.

Attridge, Derek. 2005. J. M. Coetzee and the Ethics of Reading. Chicago: University of Chicago Press, Pietermaritzburg: University of KwaZulu-Natal Press.

Barthes, Roland. 1978. Writing Degree Zero. Translated by Annette Lavers, and Colin Smith. New York: Hill and Wang.

Blanchot, Maurice. 1982. The Space of Literature. Translated by Ann Smock. Lincoln: University of Nebraska Press.

Burns, Robert. 2008. A Night Out with Robert Burns. Arranged by Andrew O'Hagan. Edinburgh: Canongate Books Ltd.

Burns, Robert. 2013. Complete Works of Robert Burns. Delphi Classics. Delphi Poets Series Book 19. Edited by Robert J. Burns. East Sussex: Electronic Book.

Camus, Albert. 1957. Banquet Speech. Available online: https://www.nobelprize.org/nobelprizes/ (accessed on 24 July 2019).

Critchley, Simon. 1992. The Ethics of Deconstruction: Derrida and Levinas. Oxford: Blackwell.

Critchley, Simon. 2005. Things Merely Are: Philosophy in the Poetry of Wallace Stevens, 1st ed. London: Routledge.

Derrida, Jacques. 1988. Limited Inc. Translated by Alan Bass, and Samuel Weber. Evanston: Northwestern University Press.

Derrida, Jacques. 1994. Nietzsche and the Machine: Interview with Richard Beardsworth. Journal of Nietzsche Studies 7: 7-66.

Derrida, Jacques. 1995. The Gift of Death. Translated by David Wills. Chicago: University of Chicago Press.

Derrida, Jacques. 2003. Following Theory: Jacques Derrida, Frank Kermode, Toril Moi and Christopher Norris. In Life After Theory. Edited by Michael and John Schad Payne. London: Continuum.

Derrida, Jacques, and Derek Attridge. 1992. Acts of Literature. London: Routledge.

Dickinson, Emily. 1924. The Complete Poems of Emily Dickinson. Boston: Little, Brown, and Company.

Eaglestone, Robert. 1999. Ethical Criticism: Reading after Levinas. Edinburgh: Edinburgh University Press.

Harries, Karsten. 2009. Art Matters: A Critical Commentary on Heidegger's 'The Origin of the Work of Art'. Contributions to Phenomenology. Dordrecht: Springer.

Heaney, Seamus. 1988. The Government of the Tongue: The 1986 T. S. Eliot Memorial Lectures and Other Critical Writings. London: Faber.

Heaney, Seamus. 1989. The Place of Writing, Emory Studies in Humanities No. 1. Atlanta: Scholars Press.

Heaney, Seamus. 1990. The Cure at Troy: A Version of Sophocles' Philoctetes. London: Faber.

Heaney, Seamus. 1991. Seeing Things. London: Faber.

Heaney, Seamus. 1995. The Redress of Poetry. London: Faber.

Heaney, Seamus. 2001. Electric Light. London: Faber.

Heaney, Seamus. 2010. Writer \& Righter. Dublin: Irish Human Rights Commission.

Heaney, Seamus, and Dennis O'Driscoll. 2008. Stepping Stones: Interviews with Seamus Heaney. London: Faber.

Hopkins, Gerard Manley. 2014. Poems 1876-1889. Edited by Neil Azevedo. Omaha: William Ralph Press.

Jakobson, Roman. 1971. Selected Writings Volume 2: Word and Language. The Hague: Mouton.

Lacan, Jacques. 1977. The Four Fundamental Concepts of Psycho-Analysis. Translated by Alan Sheridan. London: Hogarth Press.

Lacan, Jacques. 2006. Écrits: The First Complete Edition in English. Translated by Bruce Fink in Collaboration with Héloïse Fink and Russell Grigg. London: W. W. Norton.

Levi, Primo. 1988. Collected Poems. Translated by Ruth Feldman, and Brian Swann. London: Faber and Faber.

Levinas, Emmanuel. 1981. Otherwise Than Being or Beyond Essence. Translated by Alphonso Lingis. The Hague: Nijhoff.

Levinas, Emmanuel. 1989. The Levinas Reader. Translated by Seán Hand. Oxford: Basil Blackwell.

Miłosz, Czesław. 2001. New and Collected Poems, 1931-2001. New York: Ecco Press. 
Moi, Ruben. 2007. The Cure by Poetry that Cannot be Coerced: Text, Canon and Context in Seamus Heaney's Electric Light. In Seamus Heaney Poet, Critic, Translator. Edited by Ashby Bland Crowder and Jason David Hall. Basingstoke: Palgrave Macmillan.

Montale, Eugenio. 1982. The Second Life of Art. Translated by Jonathan Galassi. Edited by Jonathan Galassi. New York: Ecco Press.

Mugerauer, Robert. 1990. Heidegger's Language and Thinking. Atlantic Highlands: Humanities Press.

O'Donoghue, Bernard. 2016. Crediting Marvels or Taking Responsibility: Vocation and Declarations of intent by Seamus Heaney after Seeing Things. In The Soul Exceeds its Circumstances: The Later Poetry of Seamus Heaney. Edited by Eugene O’Brien. Notre Dame: University of Notre Dame Press.

Retallack, Joan. 2004. The Poethical Wager. Berkeley: University of California Press.

Shakespeare, William. 2009. King Lear. Edited by George Ian Duthie and John Dover Wilson. Cambridge: Cambridge University Press.

Sinclair, Mark. 2006. Heidegger, Aristotle and the Work of Art: Poiesis in Being. London: Palgrave.

Wilson, Ross. 2007. Theodor Adorno, Routledge Critical Thinkers. London: Routledge.

(C) 2019 by the author. Licensee MDPI, Basel, Switzerland. This article is an open access article distributed under the terms and conditions of the Creative Commons Attribution (CC BY) license (http://creativecommons.org/licenses/by/4.0/). 



\title{
Article \\ Neorealism, Contingency, and the Linguistic Turn
}

\author{
Thomas Claviez \\ English Department, University of Bern, 3012 Bern, Switzerland; thomas.claviez@ens.unibe.ch
}

Received: 7 October 2019; Accepted: 6 November 2019; Published: 8 November 2019

\begin{abstract}
Since the publication of Roman Jakobson's famous 1956 essay "Two Aspects of Language and Two Types of Aphasic Disturbances", we have tended to read the relationship between metaphor and metonymy as a dialectical one. The essay argues that this approach stands in need of revision, since metonymy, as a trope — and as a trope, moreover, of contingency-undermines the dialectical relationship between the syntagmatic and the paradigmatic axes. This has far-reaching implications, specifically for the assessment of literature and its ethics. Since metaphor functions structurally analogous to dialectics itself, metonymy and its role in realism and neorealism might offer us a way to think an "ethics of contingency" that acknowledges the role of contingency, rather that suppressing it and its role in preventing closure through sublation.
\end{abstract}

Keywords: metonymy; metaphor; neorealism; contingency; dialectics

\section{Introduction}

In what follows, I would like to connect my first foray into neorealism-my introductory essay to the special edition of Amerikastudien/American Studies with the title Neorealism Between Innovation and Continuation to a more recent one that came out in the volume Literatur und Politische Philosophie, edited by Michael Festl and Philipp Schweighauser, with the title "Dramas of Mis(re)cognition: Critical Theory as Literary History" (Claviez 2004; 2018). In the first essay from 2003, I argued that the two realms of epistemology and representation would have to be kept apart in order to assess neorealism as not simply a 'return' to traditional strategies of representation; that is, neorealist works are not simply an expression of a nostalgic desire to return to (1) a pristine, transparent language prior to the onslaught of the linguistic turn; and to (2) classical realism's agenda to base an understanding of the world upon a (preferably violent-free) process of dialogical deliberation and an aesthetics of verisimilitude. In my more recent essay, I approached both realism and neorealism from another vantage point. Here I argued that critical theory's recent neglect of aesthetics and the realm of culture-specifically as it is observable in Habermas' oeuvre, but even more so in what has become known as philosophy of recognition, as pursued by Axel Honneth and Nancy Fraser-constitutes a step back prior to modernism, and specifically modernism's emphasis on self-alienation. In what follows, I would like to draw out some of the ethical ramifications of these critiques, and to connect them with an overarching project devoted to the concept of a "Metonymic Community" and an "Ethics of Contingency" that I have laid out in more detail elsewhere (cf. Claviez 2014; 2016). In order to do so, however, I will have to ask my readers to indulge in a kind of longer excursus in order to show where the ethical stakes as regards metonymy and contingency lie, and what both neorealism and recognition have to do with it. After sketching some of the problems that I claim have not been sufficiently assessed and addressed in recent recognition theory, I will take a closer look at some of the implications of the metaphor/metonymy dichotomy as it has been taken up—and partly perpetuated—by structuralism and poststructuralism, to then address the ramifications that both the concept of contingency and its trope, metonymy, have for a literary ethics. In order to do so, I will offer a reading of Jonathan 
Franzen's novel Freedom and try to lay open the limits of a philosophy of recognition as regards such literary ethics.

\section{Recognition, Modernism, and the Problem of Alienation}

As regards the above-mentioned connection between contemporary philosophies of recognition and literary practice — or rather, their disconnect-here is how Winfried Fluck assesses this process:

In both of these cases, Habermas as well as Honneth, a programmatic rejection of theories of self-alienation is designed to pave the way for an alternative theory of subject-formation: the shift is one from self-alienation to intersubjectivity, from a theoretical framework in which the subject is cut off from self-knowledge, either by forces of modernity or by an anthropological lack, to a theory of subject-formation in which the subject is constituted through intersubjective relations. (Fluck 2015, p. 126)

And, in the vein already pointed out above, he also notes that

[... ] in the case of Honneth (but in the final analysis also Habermas) the price for exchanging a narrative of self-alienation by a narrative of intersubjectivity is to analytically disregard the realm of culture (in the sense of cultural practices and cultural representations) as a sphere of subject-formation. In Honneth's intersubjective theory of recognition, culture plays hardly any role at all. (ibid, p. 130)

While I wholeheartedly agree with this assessment, I argued that we would have to raise two questions: (a) whether, if that diagnosis is correct, we can simply assume that the concept of intersubjectivity can simply leave all modernist claims of alienation behind; and (b) if the neglect of recent critical theory of the realms of literature and culture is in some way connected to the former assumption. I concluded that theories of recognition simply constitute a step back prior to modernism, as it shares with classical realism the assumption (a) that self-alienation does not constitute a problem (which, as I will show below even with regard to James's short story "Daisy Miller" begs the question); that (b) processes of recognition can be assumed to take place through dialogical deliberation (which, as Fluck argues, explains realism's didactic dialogic structure); and that (c) these processes of recognition can be assumed to work unperturbed by either the insights of deconstruction and phenomena of alienation and self-alienation. It is on the basis of such questionable assumptions that, in the case of Honneth, literature can have only one function: that of the diagnosis of 'pathologies' which disturb the processes of recognition. Consequently, Honneth can only offer a rather poor description-I would not call it an interpretation-of Franzen's recent novel Freedom (Franzen 2010). Thus he discerns in it the (questionable) "tendency [ ... ] to use friendship in order to construct advantageous relationships and thus to abuse it for instrumental purposes" (Honneth 2010, p. 355, FN 35). Furthermore, he reads it as an indication "that the troubles and conflicts that arise in the heretofore intact family Berglund are triggered by the increased chances to openly articulate one's needs and moods, but are solved through the caring of the children for their parents, who thus turn into something like their parents' parents" (ibid, p. 361, FN 116). Besides the fact that such a reading flies in the face of Honneth's own assumptions about recognition, I would venture to say-and I think many of us would agree-that the novel has much more to tell us than that. And in order to do that, please allow me to take a little detour through Aristotle, Jakobson and de Man in order to take up once again the two main issues that I addressed in the first essay: those of epistemology and representation, and the latter specifically after the linguistic turn. I will try to show that the assumption of an allegedly 'dialectical relationship' between metaphor and metonymy, on which most structuralist and poststructuralist writings on the matter rely, does not work, and that metonymy's defiance to be forced into such relationship has important consequences for a reassessment of its literary function. 


\section{Metonymy, Contingency, and Representation}

In his philosophy, Aristotle points at two different strategies to overcome what he considers to be the inherent contingency of the world that surrounds us: In his Poetics, one is the fabula or muthos that he considers poetry to provide us with, in order to impose order upon the sheer contingency of history; the latter of which he delegates to the historiographers to represent (Aristotle 1995, para. 23.1459a16-24). Myth, as we all know, is a narrative; its job is thus to impose a narrative order-through selection, omission and compression; a process which necessarily means to distance oneself from the pure contingency of reality. Or, to make the point even stronger: The more we try to create order out of the contingency of historical reality, the more we by default distance ourselves from this very reality. Narrative is, however, a process that takes place on what structuralists would call the syntagmatic axis; and I will come back to this soon. The other strategy to impose order is conceptual thinking, the early form of which Aristotle inherits from Plato: that of dialectics.

As far as the Poetics are concerned, Aristotle clearly favors metaphor over metonymy-an attitude that he shares with about $95 \%$ of his colleagues to come, including Jakobson. Still, in De Memoria, he reminds us of the fact that one is reminded of a thing by something "either similar, or contrary, to what we seek, or else from that which is contiguous with it" (Aristotle 1906, para. 451b 24-25). While similarity clearly belongs to metaphor, and contiguity belongs to metonymy (with certain reservations as regards Aristotle's definition of contiguity), opposition occupies a very strange position in this triangle; it will be, however, a central part of Hegel's later dialectics. There, the third that relates tenor and vehicle in metaphor finds its analogy in the prior unity of thesis and anti-thesis. Interestingly enough, any abstraction, be it philosophical or poetic is (indeed, can only be) based upon the assumption of - a third! A third that, in both instances, takes us away from the true contingency of history, in order to establish—order. Thus it might not come as a surprise that a structural similarity can be discerned: that between philosophical dialectics (Figure 1) and poetic metaphor (Figure 2):

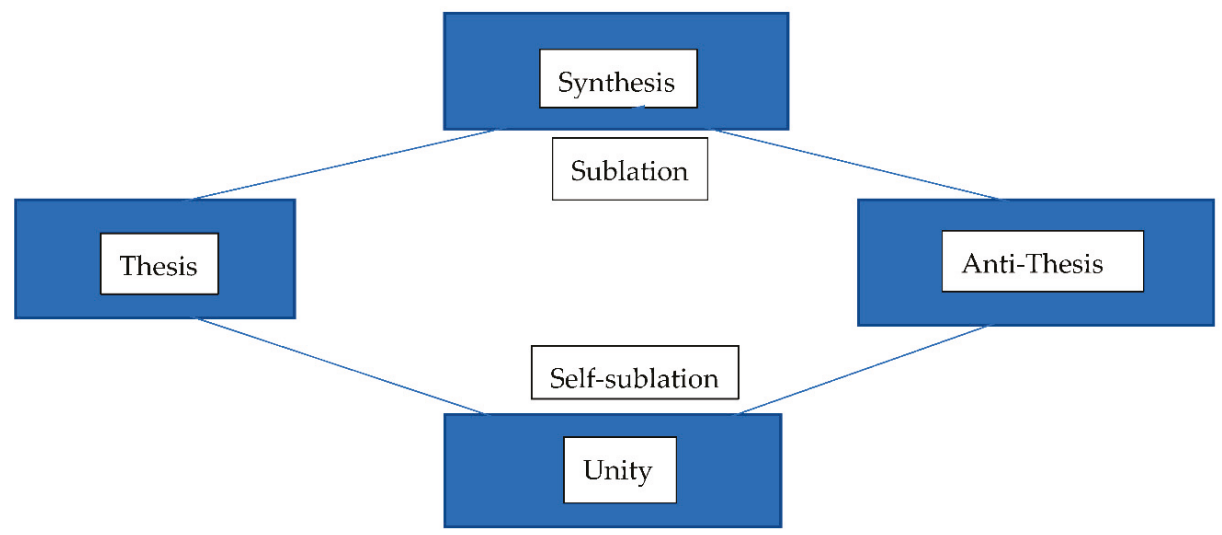

Figure 1. Dialectics.

Interestingly, contingency is what is categorially excluded by, through being juxtaposed to, both dialectics and metaphor (and the dialectics of metaphor). Moreover, it also forms a highly problematic sting in Hegel's dialectical philosophy. ${ }^{1}$

In fact, dialectics can only work if it assumes a prior unity-and thus a basis for comparison or a 'third' - that self-sublates itself into thesis and anti-thesis, in order to then be, in a second step, sublated into a synthesis. That is, dialectics is in fact a process that implies not a triangle, but a quadrangle;

1 On the problematic role of contingency, cf. (Thompson 2014; Siani 2015; Padui 2010). 
a unity that is being undone by what Hegel calls the self-sublation of the previous unity into thesis and anti-thesis, which is in turn sublated again by the dialectical process into the synthesis. The same, interestingly, holds true for a metaphor: Only on the basis of a presumed third, which guarantees the similarity and comparability of tenor and vehicle, can a metaphor be successful. As in dialectics, a presumed unity (1) is split up into tenor; (2) and vehicle; (3) to be reunited by the reader; (4) on the basis of the presumed former similarity (cf. Hegel 1991, pp. 79—81).

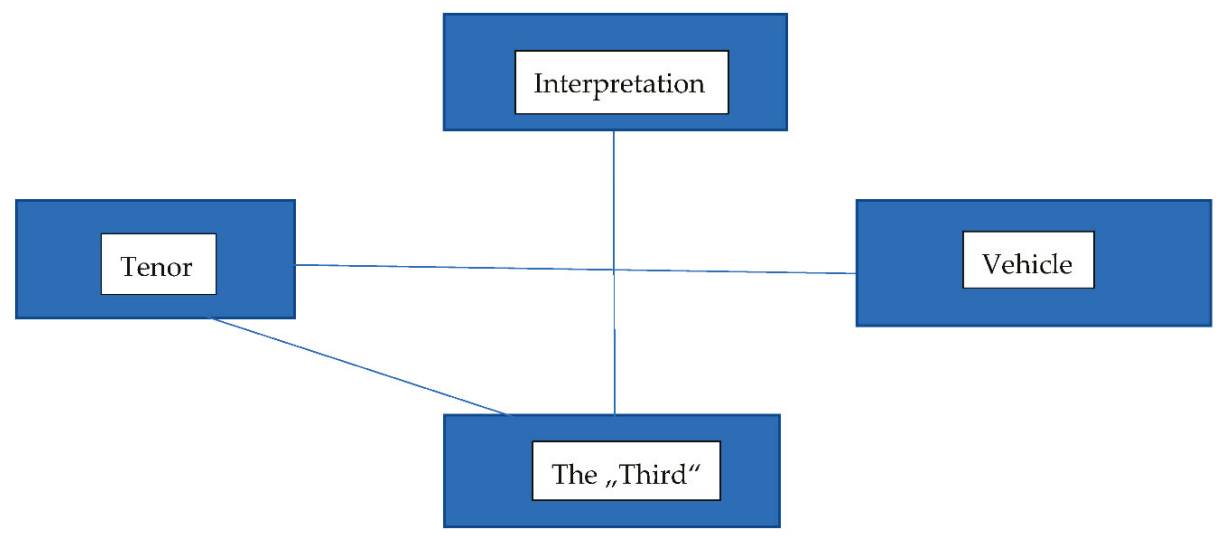

Figure 2. Metaphor.

Fast forward to Roman Jakobson's famous essay “Two Aspects of Language and Two Types of Aphasic Disturbances"; a text that has massively influenced structuralist and post-structuralist thinking. While evoking the distinction between metaphor and metonymy-the former of which Jakobson connects with the paradigmatic axis of selection, substitution and similarity, while the latter he relates to the aspect of contiguity and syntagmatic combination-he defines the two tropes as follows: While metaphor relies on an abstract 'third' (similarity is just that, since otherwise metaphor would not work) to establish the conjunction of tenor (that which should be expressed) with vehicle (that with which it is actually and figuratively expressed), metonymy relies on the concept of 'contiguity in space'.

Furthermore, he attributes metaphor to romanticism and modernist surrealism, and metonymy to the more prosaic forms of realism. And although he identifies metaphor-very much in the tradition of Aristotle-as a sort of 'queen of tropes', he surprisingly adds:

[... ] when constructing a metalanguage to interpret tropes the researcher possesses more homogeneous means to handle metaphor, whereas metonymy, based on a different principle, easily defies interpretation. Therefore nothing comparable to the rich literature on metaphor [ ... ] can be cited for the theory of metonymy. (Jakobson 1995, p. 132; emphasis mine)

Now, what is so strange about this quote is that, on the one hand, he connects metonymy with the prose of realism - which, in order to achieve its closeness to reality, tends to avoid figurative language and is thus less focused on metaphor; however, on the other hand, he tells us that metonymy "easily defies interpretation", which is what one would certainly not usually accuse realism of. So what is it that makes prosaic metonymy the 'ugly duck' of tropology-one, at least that, as Jakobson notes, has by far not attracted attention comparable to that given metaphor-and such a difficult one at that? And does the fact that it is hard to decipher have any repercussions on the role it could possibly play to think of realism in a new way? In what way might realism's and neorealism's metonymic quality "easily defy interpretation"?

Moreover, another problem arises, as Jakobson, in another essay, establishes the following-and in the meantime almost classical—distinction between metaphor and metonymy: 
The selection is produced on the base of equivalence, similarity and dissimilarity, synonymity and antonymity, while the combination, the build-up of sequence, is based upon contiguity. The poetic function projects the principle of equivalence from the axis of selection into the axis of combination. (Jakobson 1960, p. 358) ${ }^{2}$

And he adds a little later: "Poetry and metalanguage, however, are in diametrical opposition to each other: in metalanguage the sequence is used to build an equation, whereas in poetry the equation is used to build a sequence (ibid)".

Now, the problem that arises is as follows: Metonymy occupies a very strange position in this "equation": Qua trope it belongs to the paradigmatic axes, which is the axis of selection; and I select a metonymic expression to express something it is not. This becomes even clearer when we take into account that metonymy originally means 'misnomer'. ${ }^{3}$ On the other hand, it 'embodies' the syntagmatic principle of contiguity - that which emphatically belongs to combination, and not selection. This would suggest the following conclusion: If the poetic — which would be the metaphoric-function "projects the principle of equivalence from the axis of selection into the axis of combination", does then not metonymy do the exact opposite, namely "project the principle of contiguity from the axis of combination into the axis of selection"? This would be a feasible-and, indeed, the only logical—conclusion to draw. However, there arises another, huge problem: Because that option is already taken, in Jakobson's scheme, by the metalinguistic function, the most important aspect of which is to "interpret" the poetic one. If, however, the poetic function of language seems to be reserved to metaphor-which embodies the paradigmatic in a much more straightforward way than metonymy, since the latter dances on both weddings, and thus undercuts any clear dialectical opposition-this would imply that we interpret metaphor by means of a metonymic operation, which could then explain the difficulties as regards interpretation that Jakobson mentions. That, however, does not really help because he explicitly singles out metonymy as the trope 'easily defying interpretation'. Moreover, this would go straight against the assumption of David Lodge, who, in his Modes of Modern Writing, concludes that the metalinguistic operation would have to be by default metaphoric, as we can interpret any text only by establishing a third that would allow us to make sense of it:

The solution would seem to lie in a recognition that, at the highest level of generality at which we can apply the metaphor/metonymy distinction, literature itself is metaphoric and nonliterature is metonymic. The literary text is always metaphoric in the sense that when we interpret it, when we uncover its 'unity' [ .. ], we make it into a total metaphor: the text is the vehicle, the world is the tenor. Jakobson himself [ ... ] observed that metalanguage (which is what criticism is, language applied to an object language) is comparable to metaphor, and uses this fact to explain why criticism has given more attention to metaphorical than to metonymic tropes. (Lodge 1977, p. 109)

This would prove the close relatedness of metaphor and dialectics that I have suggested above: The reader has to 'retranslate' the metaphoric operation of the author on the assumption of an existing third, on the basis of which this retranslation can be more or less successful. Fact is, however, that if the linguistic turn itself has shown us anything, it is that language does emphatically not work 'metaphorically', in that it is exactly that 'third' that language, according to Saussure, actually lacks: What characterizes the arbitrary nature of the sign is that no third that would ensure a logical connection between the signifier and the signified can be located; language's negatively-differential character on the level of both signifier and signified precludes any third between the signifiers and the signifieds,

2 It is interesting to note that, as Aristotle, Jakobson includes 'antinomy' (or, as the former puts it, the 'contrary') amongst the metaphoric principles of selection.

3 What is notable is that ever so often metonymy gets reduced to synecdoche-the pars pro toto. I would emphatically claim, however, that synecdoche is closer to metaphor than to metonymy, simply because one aspect of metonymy-the 'space' of 'contiguity in space'-in synecdoche becomes the third, as the toto embraces the pars. 
respectively. Saussure's assumption that the signifiers attain their value only through "opposition" through others is a lame-and failed-attempt to retain some form of dialectics:

The moment we compare one sign with another as positive combinations, the term difference should be dropped. It is no longer appropriate. [ . . ] Two signs, each comprising a signification and a signal, are not different from each other, but only distinct. They are simply in opposition to each other. The entire mechanism of language [ ... ] is based upon oppositions of this kind and upon the phonetic and conceptual differences they involve. (de Saussure 1983, p. 119)

While it is rather strange that the quote ends on "differences" - the very ones he urges us to dispel-there is no reason why the value of a sign, achieved through being different from others, should be conceived as "opposition": 'cat' is by no reasonable means the opposite of either 'hat' or 'cut'. Thus, the negative-differential relationship is one of pure contingency, also known as—metonymy. Enter: Paul de Man.

In "Semiology and Rhetorics" (de Man 1979), de Man takes up Jakobson's rather uneven and uneasy opposition between metaphor and metonymy, in order to give metonymy the due that Jakobson claims it has not been given. De Man's main objective in the essay is, in good old poststructuralist fashion, to show that metonymy plays an even more important role than Jakobson is willing to concede it, and to put into question the 'tendentious' opposition it is based upon. All this in order to show-another well-known deconstructive move - that a clear-cut distinction cannot be drawn, and that Proust's Swann's Way, which de Man analyzes, deconstructs itself. To make this move possible, de Man basically erases reference:

By an awareness of the arbitrariness of the sign (Saussure) and of literature as an autotelic statement 'focused on the way it is expressed' (Jakobson) the entire question of meaning can be bracketed, thus freeing the critical discourse from the debilitating burden of paraphrase. [... It (semiology) demonstrated that the perception of the literary dimensions of language is largely obscured if one uncritically submits to the authority of reference. (de Man 1979, p. 5)

Reference-that is, the metalinguistic aspect-is thus reduced to reflect upon the inner closedness of the literary text; an assumption that Proust's text underscores through its own self-reflectiveness. The text, with its references to reading and other structures of mise en abyme, provides its own metalinguistic interpretation.

Without going into further details, what I am interested in are de Man's conclusions:

A rhetorical reading of the passage reveals that the figural praxis and the metafigural theory do not converge and that the assertion of the mastery of metaphor over metonymy owes its persuasive power to the use of metonymic structures. [ ... ] For the metaphysical categories of presence, essence, action, truth, and beauty do not remain unaffected by such a reading. (ibid, p. 15; my emphasis)

And he describes the difference between the two as follows:

[... ] the difference between metaphor and metonymy, necessity and chance [is] a legitimate way to distinguish between analogy and contiguity. The inference of identity and totality that is constitutive of metaphor is lacking in the purely relational metonymic contact: an element of truth is involved in taking Achilles for a lion but none in taking Mr. Ford for a motor car. The passage is about the aesthetic superiority of metaphor over metonymy, but this aesthetic claim is made by means of categories that are the ontological ground of the metaphysical system that allows for the aesthetic to come into being as a category. The metaphor for summer [...], guarantees a presence which, far from being contingent, is said to be essential, permanently recurrent and unmediated by linguistic representations or figurations. (ibid, p. 14; my emphases) 
What is so strange about this distinction is that, on the one hand, metonymy as part of the syntagmatic axes is relegated to 'chance and contiguity'; on the other hand, the 'programmed patterns' and the 'impersonal precision' (p. 16) of grammar exert their force to ensure that chance and contiguity are being held in check. But then, the syntagmatic axis cannot stand for contiguity and chance any more! Metonymy's own contingency either evaporates when being projected upon the paradigmatic axis, or it is reined in by the rules of grammar. What is it that seems to conspire against metonymy to such a degree that it is repeatedly being invoked, just to be ground to naught between the prominence of metaphor and the logic of grammar? Somehow, dialectics does not seem to work in this case; metonymy seems to be based on a mythic both/and logic, but is being crushed at the same time. On the other hand, there is metaphor which, rather surprisingly, de Man characterizes as evoking a presence that is 'essential, permanently recurrent and unmediated by linguistic representations or figurations'! Proximity-a.k.a. contingency — as de Man rightly observes, can only "pass the test of truth" if it acquires "the complementary and totalizing power of metaphor" and is thus "not reduced to the 'chance of a mere association of ideas'. [ . . ] The relationship between the literal and the figural senses of a metaphor is always, in this sense, metonymic, though motivated by a constitutive tendency to pretend the opposite" (p. 71). The challenge then would be to see through such pretentiousness, and not read literature as metaphoric, but to acknowledge that it might actually just offer the "chance of a mere association of ideas" that defy metaphorico-dialectical totalization. ${ }^{4}$

\section{Narrative and the Problem of Contingency}

In order to illustrate this further, let us take the example of a muthos; to be more precise, a Native American origin myth. In "The Iroquois Depict the World on the Turtle's Back" (Hurtado and Iverson 1994), we learn the story about twins who mutually vie for predominance; a fight that actually already starts in the mother's womb. The right-handed one is born in the normal way, the left-handed through the mother's armpit. The right-handed one tries to do everything the normal way; the left-handed does everything in a 'crooked' manner. A chart of the respective characteristics of the two twins would look something like this (Figure 3):

While thus, as the myth tells us, trying to create 'a balanced and orderly world', the twins still keep on fighting, but neither one can decisively beat the other. In order to solve the conundrum, the story then offers a rather surprising turn: Just once, the right-handed twin lies to the left-handed twin, while the left-handed twin decides to tell the truth. In the final duel, the right-handed twin kills the left-handed one, and throws him "off the edge of the world", but "some place below the world, the left-handed twin still lives and reigns" (p. 22).

Both the oppositional structure, as well as the chiasmic turn that the story takes, lend themselves perfectly to a structuralist, as well as a poststructuralist reading, as the story does not only create oppositional pairs, but also lets them switch places and thus insinuates that none of the binary oppositions is as 'pure' as one might think. However, and this is my main point, narratively speaking all of this hinges on a moment in the story-both twins simultaneously, but unbeknownst to each other, deciding to suddenly change their roles: a highly improbable scenario. But what then is the muthos or the fable in this Iroquois myth? Is it the oppositional structure that, in a Lévi-Straussian reading, looks like an early form of dialectics, or is it a totally contingent turn in a strange story? Well, it was exactly this 'narrative' strangeness or eventfulness that Lévi-Strauss wanted to overcome with his structuralist analyses, in trying to carve out, in a kind of vertical reading, the columns that he so famously introduced in his seminal essay “The Structural Analysis of Myth" (Lévi-Strauss 1955). However, what is getting lost in this procedure is exactly that narratively highly contingent and utterly

4 It is interesting to note that the relative neglect that Jakobson diagnoses as regards work on metonymy can also be observed in poststructuralism. Thus both (Derrida and Moore 1974), in his important essay "White Mythology", and Jean-François, in his seminal work Discours, Figure (Lyotard 2011), focus almost exclusively on metaphor, and all but ignore metonymy. 
improbable moment that leads to the chiasm, that in turn deconstructs the purity of the binary pairs, but that in itself cannot be dialectically accounted for. ${ }^{5}$

\begin{tabular}{|l|l|}
\hline Right-handed twin & Left-handed twin (favored by grandmother) \\
\hline Born the normal way & Born through the armpit, killing the mother \\
\hline Does everything like he should & Does things in a devious way \\
\hline Straight mind & Crooked mind \\
\hline Herbivore & Carnivore \\
\hline Collects berries and fruits & Collects briar and poison ivy; knows about medicine \\
\hline Makes man & ??? \\
\hline Tells the truth & Lies \\
\hline Decides to lie & \\
\hline
\end{tabular}

Figure 3. Structure of the Iroquois Origin Myth.

If that holds true, however, what does the difference between mythical and syllogistic reason that he so emphatically insists on really consist of? As I have argued elsewhere, it consists of a logic that is not syllogistic (a logic, that is, that follows an either/or structure), but cosmo-logic (based upon a both/and structure). ${ }^{6}$ In Lévi-Strauss dialectic-structuralist reading, an important part of this difference gets blurred, in that the narrative moment of contingency that makes the chiasm both possible, but at the same time questionable and 'impure', simply disappears. Only then is the muthos able to introduce the very order that Aristotle ascribes to it.

However, the both/and cosmo-logic itself creates a problem, in that it defies syllogistic reasoning so dear to dialectics from Plato and Aristotle to Hegel and beyond. In fact, we can define a syllogistic contradiction as a special form of contingency: The coexistence in space and time of $\mathrm{A}=\mathrm{B}$ and $\mathrm{A} \neq \mathrm{B}$. Or rather, instances where A and B simply are not oppositions, but differences.

Having looked at contingency from both the Aristotelian and the structuralist side, we are now in the position to distinguish two levels of contingency: An epistemological contingency that characterizes reality proper, upon which either a narrative muthos or a dialectical/metaphorical order can be imposed, and a representational contingency that affects the means by which this order is being imposed. One could argue that, talking about the axes of combination and selection, or metaphor and metonymy, we are in the face of an 'impure' dialectics, as the combinatory character of metonymic narrative and

5 The binary structure, by the way, is by no means strictly upheld. And it is quite telling that the right-handed twin, after having won the fight, even kills the grandmother who favored the left-hand twin. To impose order can entail quite a lot of collateral damage, as the story seems to suggest.

6 Cf. (Claviez 1998). 
the conceptual/dialectical character of metaphor are by no means equivalent: Narrative and metonymy constitute something like a 'first line of defense' against contingency, while the conceptual/dialectical character of metaphor is clearly given pride of place. Myth, then, is emphatically not a compressed or 'mini'-metaphor (or is so only when one chooses to read it dialectically): If anything, myth works metonymically. Rather ironically, Lévi-Strauss, through his dialectical-metaphoric reading of myth, thus purges it of that which is actually its most marked difference to syllogistic thinking: its acknowledgment of a remainder of narrative contingency. Thus, in trying to establish it as an 'other' form of logic (an 'analogic', as he calls it), he deprives myth of what might be most important about it; and, maybe, of that which still makes it such a virulent genre.

\section{Neorealism, Mimesis and Contingency}

The insights gathered through our excursus thus allow us to draw some conclusions that apply to contemporary literature, too. Thus, neorealism - and in our case, Franzen's Freedom-has to address two challenges: On the one hand, it has to face the representational challenges imposed by the linguistic turn; on the other hand, it still tries to represent the contingency of real facts-without, however, giving in to the didactic agenda of classical realism that tries to achieve a consensus by means of a violence-free dialogical deliberation, since - at least on the side of the reality depicted-such an attempt seems doomed to fail: Both alienation and self-alienation are part and parcel of this reality. Moreover, one of the earliest instances of American realism-Henry James' short story "Daisy Miller" - already shows, that even if there exists the wish to make both two persons (who are moreover attracted to each other) mutually decipherable to each other, and to decipher the cultural environment they operate in, success is by no means guaranteed: The tragic end of the protagonist Daisy Miller is caused, in the final instance, through her inability to read her suitor, Winterbourne, and to read the writings on the wall as regards the danger of catching Roman Fever. ${ }^{7}$ That is, even if neorealism were simply to 'go back' behind the agendas of modernism or postmodernism, it would most likely reach the spot again that James reached at the end of his literary career, when all hopes and pretensions to reach 'consensus by dialogical deliberation' are given up in the hermetic short story "The Turn of the Screw" (James 1967).

However, as my new take on structuralism's attitude to metonymy was supposed to show, this latter contingency does not necessarily entail a complete 'blockage' from reality through language. One could define neorealism as an inherently ironic as-if attempt: How can we possibly address reality's contingency if language always poses an obstacle that makes it impossible to get there? That is, what if language were able to represent reality? What if this new realism were to 'mime' - even if only metaphorically, as we now know - a reality ripe with contingencies that cannot be sorted out, as the early James hoped, through a form of 'communicative reason'? And I am using the concept of Aristotelian mimesis here in the sense that Jacques Rancière has given it in The Politics of Aesthetics: Not as "resemblance, as some appear to believe, but the existence of necessary connections between a type of subject matter and a form of expression" (Rancière 2004, p. 53). Now, what 'forms of expression' can a neorealism take whose subject matter is not, as in classic realism, the dialogic creation of a consensus designed to overcome the contingency of the 'real' world, but the sobered realization that this does not work, as well as the realization that the 'forms of expression' themselves are 'infected' or 'poisoned' by the contagious contingencies of language proper?

That is, both layers of contingency are reconnected again in neorealism: an epistemological one and a representational one. The epistemological one is narrative, or the muthos, that forms a first front

7 Winterbourne's attempts to decipher Daisy, and to finally find out who she really is, weave like a thread through the novella: "Poor Winterbourne was amused, perplexed, and decidedly charmed: [... ] Was she simply a pretty girl from New York State-were they all like that, the pretty girls who had a good deal of gentlemen's society? Or was she also a designing, an audacious, an unscrupulous person?" (James 1967, p. 24); "He had assented to the idea that she was, common'; but was she so after all; or was he getting used to her commonness?" (p. 41); "Daisy, on this occasion, continued to present herself as an inscrutable combination of audacity and innocence" (p. 54). 
line to capture metonymically (even if the syntagmatic axis is subjected to the 'laws' of grammar, as we have seen) the contingency of reality. The second one, the representational one, language itself, which is exposed to the same contingencies as is reality, as Saussure has shown. The problem with metonymy, which Jakobson defines as being "more difficult to decipher", could thus be explained by the fact that, qua trope, it belongs to both the syntagmatic and the paradigmatic axis. But if it forms one of the main characteristics of realism, then one could argue that it is so difficult because it contains remnants of this very contingency that dialectics or metaphor try to overcome. Through such remnants, it contaminates-as contingency is prone to do-the metaphorical attempts to overcome it. Or, as de Man puts it: "it fails to acquire the complementary and totalizing power of metaphor and remains reduced to 'the chance of a mere association of ideas'"; or a metonymy "motivated by a constitutive tendency to pretend the opposite" (p. 71). Since de Man is talking about a modernist text by Proust, we might then simply add that what distinguishes neorealism from both modernism and classic realism is that it has given up on just such pretense.

What Susanne Rohr has claimed in connection with Franzen's novel The Corrections-that the novel develops "a fictional reality of disorientation, insecurity and imbalance within the bounds of the seemingly known and familiar" (Rohr 2004, p. 93); a claim strongly reminiscent of Freud's 'uncanny', which is also echoed by Shklovsky's modernist definition, in "Art as Technique", as the defamiliarizing aspect of art-holds even truer for Freedom: No dialogical/dialectical deliberation is able to overcome the almost total collapse of 'recognition' (and we can 're-cognize' only what is familiar, a.k.a. the metaphorical 'third') that the novel traces. Moreover, giving the reader more insights into the Berglund family than they have of themselves, he can witness the total failure of communication, even in everyday language. That is, we as readers have to be able (more or less successfully) to read the protagonists in order to read their communicative failure; another instance of an 'allegory of misreading'. Alienation and self-alienation, that is, affect not only language after the linguistic turn, but are still—or maybe even more-part and parcel of our contemporary, and highly contingent, times. That is why neorealism (or, for that matter, any other genre) cannot possibly serve any other purpose-at least for philosophers of recognition such as the Hegelian Honneth-than as a pathology-diagnostic one. However, I would argue that, if anything, neorealism constitutes a rather 'difficult' negotiation of the basic tenets of any theories of recognition-be they epistemological or representational ones. It is characterized, in a manner similar to late romanticism, by an ironic 'as-if' quality: If late romanticism's irony is inspired by the matured insight that early romanticism's attempt to consciously reach an unconscious state is doomed to fail, neorealism might be defined by the similarly ironic quality to show that, even if one were to achieve referentiality by means to resorting to a metonymic quality in language (representative contingency), a second layer of contingency opens up (epistemological contingency). It thus stands in a matured-ironic relationship to early realism's optimistic assessment that consensus can be reached dialogically: Even if the linguistic means to establish a consensus were available, the transcendental homelessness-to which early realism offered a first reaction, and to which we are still exposed-effectively prevents to reach a consensus in a world characterized by utter contingency. The Freedom that Franzen's novel alludes to is thus mainly the freedom to misread and misrecognize the other and the world around us; this, however, is something that already Hegel was aware of: That freedom depends upon contingency to exist in the first place; otherwise we would simply be the pawns in a dialectical game that might as well go on without us.

What Freedom also shows us is that one of the central assumptions of theories of intersubjectivity - the fact that we, as Fluck puts it with reference to George Herbert Mead, to whose theories Honneth resorts in The Struggle for Recognition, "cannot possibly not know each other because we only learn who we are in interactions with others" (Honneth 1995, p. 75) -is just half of the truth: The claim 'we cannot possibly know ourselves because we only learn who we are in interactions with others' could claim equal validity; as would, for that matter, the statement 'We cannot know ourselves because we cannot know the others through which we allegedly come to learn ourselves'. This hints at the conceptual impasse at the heart of recognition: I need the recognition of others who, qua others, 
are not qualified to recognize me, and thus prone to misread me, and especially my particularity, which is what distinguishes me from then. ${ }^{8}$

I am thus afraid that simply to Houdini-like make the implications of self-alienation go away, as theories of recognition try to do, works neither on a conceptual nor on a historical level. Moreover, if we indeed are who we are only through the input and recognition of others, what does that do to the assumption that we all have a particular potential which we (and others) are ethically urged to help develop? Nor-and again, Freedom (and countless other novels) can serve as examples-does the emotional attachment of a parent guarantee that recognition succeeds, as Honneth seems to presuppose; an emotional attachment that not only precedes recognition for Honneth, but that actually constitutes a precondition of the latter-even if, as I argued, a questionable one.

In the view of Franzen's novel, the one thing we are free to be is to be free to self-alienate, and to mis-recognize others. In fact, freedom might manifest itself exclusively in these categories. The dream to return to a state of referential stability in order to get back to an Adamic, unspoiled state of linguistic transparency, individual authenticity and a disambiguated reality miserably fails, and thus will not do the trick to reconnect us with a world - realistic or romantic-long gone, but that might as well have never existed.

In light of these considerations: What then is the factual status of literature in recognition theory? One recent instance where literature is referred to is Axel Honneth's The Right to Freedom, which Fluck also invokes:

In his more recent study Das Recht der Freiheit, which aims at a comprehensive social theory, references have become more frequent, and include a number of well-known authors, ranging from Henry James, Jane Austen, George Eliot, Charles Dickens, Émile Zola, and Victor Hugo to contemporary writers like Philip Roth and Jonathan Franzen. However, these references are scattered in unsystematic fashion over the 600-page volume and obviously have the function to provide additional anecdotal evidence for particular points of social analysis. (p. 30/1)

This, in turn, is an assessment I absolutely share. This "anecdotal" function is what literature has been reduced to in recent philosophies of recognition; and, as already mentioned, Franzen is an unlikely candidate for key witness to prove their point. While all literature, as Fluck indicates, might be (one way or another) 'about recognition', a short glance into literary history confirms that, if anything, the 'dramas of recognition' that literature has historically staged (and still stages) have become more and more that: tragedies, which not even the playfulness of postmodernism has managed to offer relief from. Dramas usually evolve out of what are either incompatible claims or unfulfillable desires, both of which are at the heart of the problems of recognition: I wish to be recognized by others-who, by being others, read me differently from how I read myself; or I wish to be recognized according to certain qualities that are not deemed worth recognition by society or significant others. And, I assume, not even comedies of recognition would serve effectively as a backdrop for a philosophy of recognition that seems bent on ignoring the insights that literary history might have to offer. However, one might, keeping literary history in mind, re-conceptualize the transition between modernism and postmodernism as just such a transition: from tragedies to comedies of mis-recognition.

This brings me to the following quotation from Fluck, which is taken from the conclusive chapter of his essay:

Still, we should add that this literary call for recognition has a particular status.

This qualification can draw our attention to a special role literature plays in the ethical world.

I think its special contribution does not lie so much in the formulation or legitimation of ethical principles-in that sense, literature is rarely a philosophical genre-but in the articulation of

8 For this, cf. also (Claviez 2013). 
individual claims for recognition. Its starting point are often experiences of misrecognition, of inferiority, weakness, injustice; and its plots consist in the struggle against these experiences, a struggle that can be either successful—often, in fact, triumphantly successful—or end in defeat, which, in a paradox typical of aesthetic experience, can nevertheless provide strong experiences of recognition. But the key point here is that these claims for recognition can be-some would even say should be—radically subjective, self-centered, and partisan. (p. 40)

This is a definition of literature that, in my view, with its emphasis on radical subjectivity, self-centeredness and partisanship, clearly rests upon a modernist paradigm. As such, it certainly is not applicable to all kinds and eras of literature, and it in fact points at the contribution that modernism and postmodernism have made; contributions all but neglected by theories of recognition for which neither radical subjectivity nor its other-radical self-alienation—can serve as a suitable example. If, as such, literature offers a challenge to the latter-but if, as such, it also represents certain moments in literary history - then the question as to why literature plays such a minor role in contemporary critical theory might be answered. If its claims to recognition are indeed 'radically subjective, self-centered and partisan', (and emphatically not intersubjective, not even in its neo-realist varieties), then this tells us a lot about the potential failure or success of recognition.

If we are to recognize another human being, we have to 'read' him or her, as we do an object-with the exception that we might admittedly be able to empathize more with the former than the latter. Empathy, however, becomes a highly problematic process once we turn to Iser's theory of the gaps that constitute and activate the act of reading: If we, as Iser claims, fill the gaps that the text offers, ${ }^{9}$ and that instigate communication as such, with our own background of cultural and personal knowledge, and we presume this also to happen when we 'read' another person, then what happens is that we project our own experiences upon the person in question. If, however, we assume that recognition is geared toward recognizing what is unique and specific about me or others-that is, what emphatically distinguishes me from them and them from me-then filing the gaps with the experiences of those who are designed to do the recognizing means that the gaps will be framed by the contingencies of the horizon of experiences and knowledge of the person who is doing the recognizing. That is, what happens in such a moment of recognition is not that I am putting myself in someone else's shoes, as a colloquialism has it, but that I am putting that someone in my shoes. The other's desire to be recognized clashes with my desire to make him or her 'recognizable' to me, and thus to erase or ignore the very contingency that his/her alterity creates for me. And, if anything, this is what Franzen's Freedom beautifully illustrates. Moreover, if the experiences needed and used to fill the gaps are affected by self-alienation, the entire modern problem reappears with a vengeance.

\section{Towards an Ethics of Literature}

Recognition, that is, might be a 'desire' articulated, in various forms, in all literature. As such, however, it has to reckon - as do all other desires-with counter-desires, obstacles, failures, both social, linguistic, conceptual, as modernism and postmodernism have not tired to inform us, as well as the desire of others. Intersubjectivity, in such a scenario, constitutes as much —if not more—of an obstacle than a solution.

To simply presuppose a desire as a foundational paradigm, as theories of recognition do, is questionable, to put it mildly. And the answer to the question as to what it is that literature can contribute to a theory of recognition is problematic, because (a) the question is, in my view, wrongly put; which is why (b) one answer might lead to the conclusion that theories of recognition would have to reduce literature to "childish" uses, as (Fluck 2015, p. 25) rightly indicates. What literature can do is to expose the basic assumptions of theories of recognition-those about an ethics of paternal care, and those posing a desire as a starting point that all earlier literary theories have shown to

9 Cf. (Iser 1994). 
be unfulfillable-as immature, indeed 'childish' themselves. ${ }^{10}$ That is, the self-assertive task of literature (and its theory) is to unveil the hopeless naiveté upon which theories of recognition are based, while literary history might serve to indicate why this is the case. This is so because the answer to the second question raised at the beginning — what literary paradigm the philosophy of recognition might eventually rest upon-is, I dare say, a rather disillusioning one. From the perspective of literary history, it simply implies an anachronism, a step back. Modernism's self-alienation and postmodernism's linguistic alienation-cum-jouissance might certainly be incompatible with the tenets of recognition; however, and because of this, they hold a high critical relevance for it that we would be well-advised not to ignore chasing the slightly outmoded, if not immature, specters of recognition.

Finally, if we do want to take intersubjectivity seriously-and in a way that not only does away with self-alienation, but that acknowledges the latter's continuing existence and relevance, and maybe merges the two options-then we have to negotiate whether our ethical concerns should indeed take as their starting point the assumption of a unique, but enclosed, subject with a potential that it is expected to achieve, and others that are morally required to help do so. If we indeed are always already exposed to others before we mature into alleged unique subjects-subjects, moreover, as Honneth puts it, 'only realized in relationship to others' - then this requires us to not only see others as potential obstacles (which, in the last instance, any theory that combines concepts of authenticity with moral agency necessarily does), but also as contributors to this very subject; a subject, however, that can then not serve as the exclusive starting point of any ethical consideration. A subject, moreover that, conceived as processual due to the ongoing exposure to the contingency of others, cannot possibly be measured applying the yardsticks of either authenticity or recognition (cf. Claviez 2019).

What would be the role for literature in such a scenario? It could certainly do more than to 'register the failure of fully achieved recognition'-in pointing out recognition's precarious presumptions, and the pitfalls these imply: The most important one being that, if recognition is being withheld-due to whatever reason, even simple linguistic ones-we will always search for a scapegoat that we can blame for this failure: others, society, my incapability to make myself readable. A scapegoat for a process, moreover, the contingent character of which can only appear inherently flawed if presumed to be teleological, no matter how strong the alleged desire for it might be. As to my own life-story, so to any book a wide variety of characters, views and claims contribute-sometimes positively, sometimes in a detrimental manner (which later, however, might turn out to cause some good). Interestingly enough, any CV constitutes but a chain of contingencies. Literature's ethical contribution, consequently, might be to point out the fact that this is the case, and that philosophy's assumptions of the status of the subject-be they based on self-alienation or intersubjectivity-might stand in need of revision. Ironically, literature might indeed be the more 'intersubjective' discourse, in that it helps to show us that any claim to recognition — as 'radically subjective, self-centered, and partisan' it may be-is confronted with others as radically subjective, self-centered, and partisan. But even more: it might show us that this is in fact more of an asset than an obstacle to a subject that is always in the process of becoming, and thus defies any assumption about an 'authentic' subject in need of recognition; a recognition that, consequently, does not only prove to be unachievable-but actually, dangerous, as I have tried to show elsewhere. Dangerous, in that it—as authenticity—defies history (both of single subjects, and as writ large) and its contingent character.

This distinction between the presumptions of a theory of recognition and that of literature can probably best be illustrated with another recourse to Shklovsky's "Art as Technique" (Shklovsky 1988).

10 As Rancière, in his exchange with Honneth (Rancière and Honneth 2016), rightly points out: "[I]f we look at the place of love in the construction of the spheres and forms of recognition, Axel Honneth says at the beginning of the chapter "Patterns of Recognition: Love, Rights, and Solidarity" in The Struggle for Recognition: let us not be bogged down in the romantic ideal of love as the sexual relation between two persons. As a response to this potential danger, he focuses on the relation of the baby to the mother, mostly through Winnicott. But can we really construct a general idea of love on the basis of the baby-mother relationship, which of course restricts it to the dialectic of dependency and independency, of symbiosis, separation, and mutual recognition?" (Rancière and Honneth 2016, pp. 87-88). 
The conception of recognition that its proponents uphold is designed to familiarize us with (that is, re-cognize) the unfamiliar, and thus to shear others (or the Other) of their/its otherness. The liberal technique of reducing any singularity of individual to the abstract number 1 is probably amongst the best-known of such strategies. While we thus recognize what cannot be 'cognized' in the first place, Shklovsky insists that it is art's task to 'un-' or 'defamiliarize' us with the familiar; that is, to urge us to rediscover the very alterity that recognition (and its pre-modern, aesthetic strategies) have to suppress at all cost to ensure its success. Literature, I am afraid—or proud—-to say, is far ahead of philosophy in this regard. And if we presume that the problem of ethics only arises once there is otherness-and that we should not recognize it out of existence-then this is where an 'ethics of literature' can come in.

By way of an ending let me address another facet of contingency that manifests itself in other neo-realist novels, such as Dave Eggers Circles, for example. In the case of this novel, it seems that not so much the question of contingency, but rather the sometimes questionable attempts and techniques to overcome said contingency play an important role. I would argue that this does not devaluate my argument. Not only would the 'neorealistic' strategies to address the contingency of the world by default also have to reflect upon strategies to rein in contingency; they thus address also an aspect of contingency that feeds into a way larger picture: For centuries-that is, at least since the Enlightenment-we have been telling ourselves the story of human development as a story of the succession of allegedly ever more successful strategies to overcome contingency; usually along the lines of myth, monotheism, and syllogistic reason. On the other hand, if anything characterizes not only our literary, but also our philosophical and political landscapes, it is an ever increasing feeling of contingency, precariousness, and exposure toward forces beyond our control—which might want to induce us to rewrite that questionable success story. All our attempts to minimize contingency have obviously lead to creating even more contingencies, rather than less. To maybe induce us to take a different stance towards contingency might be part and parcel of the project of neorealism.

And, as a last point, let me remind us that the problem of contingency has been with us for quite some time-actually, since modern times generously defined. However, in a trajectory that seems to be far removed from our petty debates about truth or untruth, contingency has been tackled in a manner that might prove much more relevant for ethical and political debates. I am talking about mathematical and statistical attempts devoted to The Taming of Chance, as the title of one of Ian Hacking's books has it. ${ }^{11}$ That is, banks, insurances and other economic and political stakeholders and power brokers have devised stratagems not simply to deny contingency, to define it out of existence, or to overcome it at the costs of creating even more contingencies, but to acknowledge it in order to deal with it. Considering this, some of our philosophies seem to be barking up the wrong tree. Some of our literature, however, does not.

Funding: This research received no external funding.

Conflicts of Interest: The authors declare no conflict of interest.

\section{References}

Aristotle. 1906. De Sensu and De Memoria. Translated by George Robert Thomson Ross. Cambridge: Cambridge University Press.

Aristotle. 1995. Poetics. Translated by Stephen Halliwell. Cambridge: Harvard University Press.

Campe, Rüdiger. 2012. The Game of Probability. Translated by Ellwood Wiggins Jr. Stanford: Stanford University Press.

11 Cf. (Hacking 1990). In another seminal study, The Game of Probability, Rüdiger Campe convincingly shows that the rise of the modern novel — and that is, also the realist novel—is strongly influenced by the rise of theories of probability and attempts to "tame chance": "Improbable probability is deeply connected with the development of the novel, or more precisely: with the theory that compensates for the novel's formlessness" (Campe 2012, p. 273); which one could also interpret as its 'artlessness'. 
Claviez, Thomas. 1998. Grenzfälle: Mythos-Ideologie-American Studies. Trier: Wissenschaftlicher Verlag Trier.

Claviez, Thomas. 2004. Introduction: Neorealism and How to Make It New. In Neorealism: Between Innovation and Continuation. Edited by Thomas Claviez and Maria Moss. Amerikastudien/American Studies. Heidelberg: Winter, pp. 5-18.

Claviez, Thomas. 2013. Done and Over With, Finally? Otherness, Metonymy, and the Ethics of Comparison. PMLA 128: 608-14. [CrossRef]

Claviez, Thomas. 2014. Traces of a Metonymic Society in American Literary History. In American Studies Today. Edited by Erik Redling, Winfried Fluck and Sabine Sielke. Heidelberg: Winter, pp. 299-322.

Claviez, Thomas. 2016. A Metonymic Community? Toward a Poetics of Contingency. In The Common Growl. Edited by Thomas Claviez. New York: Fordham University Press, pp. 39-56.

Claviez, Thomas. 2018. Dramen der An(v)erkennung: Kritische Theorie als Literaturgeschichte. In Literatur und Politische Philosophie. Edited by Michael Festl and Philipp Schweighauser. Paderborn: Fink, pp. 21-49.

Claviez, Thomas. 2019. A Critique of Authenticity and Recognition. In Critique of Authenticity. Edited by Thomas Claviez, Britta Sweers and Kornelia Imesch. Wilminton: Vernon Press, pp. 43-58.

de Man, Paul. 1979. Allegories of Reading. New Haven: Yale University Press.

de Saussure, Ferdinand. 1983. Course in General Linguistics. La Salle: Open Court Classics.

Derrida, Jacques, and Francis Charles Timothy Moore. 1974. White Mythology: Metaphor in the Text of Philosophy. New Literary History 6: 5-74. [CrossRef]

Fluck, Winfried. 2015. Literature, Recognition, Ethics: Struggles for Recognition and the Search for Ethical Principles. In Literature, Ethics, Morality: American Studies Perspectives. SPELL 32. Edited by Ridvan Askin and Philipp Schweighauser. Tübingen: Narr, pp. 9-41.

Franzen, Jonathan. 2010. Freedom. New York: Farrar, Straus and Giroux.

Hacking, Ian. 1990. The Taming of Chance. Cambridge: Cambridge University Press.

Hegel, Georg Wilhelm Friedrich. 1991. The Encyclopedia Logic: Part 1 of the Encyclopaedia of Philosophical Sciences. Translated by Theodore Geraets, Wal Suchting, and Henry Silton Harris. Indianapolis: Hackett.

Honneth, Axel. 1995. The Struggle for Recognition. Cambridge: Polity Press.

Honneth, Axel. 2010. Freedom's Right. Cambridge: Polity Press.

Hurtado, Albert, and Peter Iverson, eds. 1994. The Iroquois Depict the World on the Turtle's Back, n.d. In Major Problems in American Indian History. Lexington: D.C. Heath.

Iser, Wolfgang. 1994. Der Akt des Lesens. Munich: Wilhelm Fink.

Jakobson, Roman. 1960. Closing Statement: Linguistics and Poetics. In Style in Language. Edited by Thomas Sebeok. Cambridge: The MIT Press, pp. 350-77.

Jakobson, Roman. 1995. Two Aspects of Language and Two Types of Aphasic Disturbances. In On Language. Edited by Linda R. Waugh and Monique Monville-Burston. Cambridge: Harvard University Press, pp. 115-33.

James, Henry. 1967. Daisy Miller: A Study. In The Bodley Head Henry James. New York: The Bodley Head, vol. XI, pp. 15-78.

Lévi-Strauss, Claude. 1955. The Structural Study of Myth. The Journal of American Folklore 68: 428-44. [CrossRef]

Lodge, David. 1977. The Modes of Modern Writing. London: Edward Arnold.

Lyotard, Jean-François. 2011. Discourse, Figure. Translated by Antony Hudek, and Mary Lydon. Minneapolis: University of Minnesota Press.

Padui, Raoni. 2010. The Necessity of Contingency and the Powerlessness of Nature: Hegel's Two Senses of Contingency. Idealistic Studies 40: 243-55. [CrossRef]

Rancière, Jacques. 2004. The Politics of Aesthetics. London: Continuum, 2004

Rancière, Jacques, and Axel Honneth. 2016. Recognition and Disagreement. Edited by Katia Genel and Jean-Phillipe Deranty. New York: Columbia University Press.

Rohr, Susanne. 2004. The Tyranny of the Probable: Crackpot Realism and Jonathan Franzen's The Corrections. Amerikastudien/American Studies 49: 91-105.

Shklovsky, Viktor. 1988. Art as Technique. In Modern Criticism and Theory: A Reader. Edited by David Lodge. London: Longmans, pp. 16-30. 
Siani, Alberto. 2015. Hegel's Logic and Narration of Contingency. Revista Opinião Filosófica 6: 8-27.

Thompson, Peter. 2014. Hegel and the Metaphysics of Contingency. Verso, July 1. Available online: https://www. versobooks.com/blogs/1639-hegel-and-the-metaphysics-of-contingency(accessed on 10 February 2019).

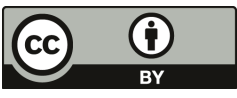

(C) 2019 by the author. Licensee MDPI, Basel, Switzerland. This article is an open access article distributed under the terms and conditions of the Creative Commons Attribution (CC BY) license (http://creativecommons.org/licenses/by/4.0/). 
Article

\title{
The Fallacy of Analogy and the Risk of Moral Imperialism: Israeli Literature and the Palestinian Other
}

\author{
Adia Mendelson-Maoz \\ Department of Literature, Language and Arts, The Open University of Israel, Ra'anana 4353701, Israel; \\ adiamen@openu.ac.il
}

Received: 17 April 2019; Accepted: 30 June 2019; Published: 2 July 2019

check for updates

\begin{abstract}
This article discusses the role of analogy within the ethics of reading. It examines how Israeli literature uses analogies when reflecting on the Israeli-Palestinian conflict. Many literary texts that depict the Israeli-Palestinian conflict draw analogies between the Israeli Jewish people and the Palestinians, between specific individuals on both sides, or between historical traumas. These analogies are designed to bridge gaps and encourage empathetic reading. This article challenges this role of analogy by arguing that analogies may in fact paint an erroneous picture of symmetrical relations, strengthen victimhood that denies responsibility, and can often lead to "empty empathy." Analogies may also create a willfully deceptive understanding of the other, while actually maintaining a narcissistic superior stance. Based on philosophical notions put forward by Emmanuel Levinas, this article suggests a different path to ethical understanding in which the literary text, while still enabling analogy, uses other rhetorical devices to create relationships that suspend it and reveal its imposture.
\end{abstract}

Keywords: ethics and literature; analogy; empathy; Israeli literature; Israelis and Palestinians; Emmanuel Levinas

\section{Introduction}

In almost every study of Israeli literature on the 1948 War, S. Yizhar's "The Story of Hirbet Hiz'a" is given extensive attention. Israeli-born S. Yizhar (Yizhar Smilansky) (1916-2006) is considered one of the main writers of the Palmah Generation in modern Hebrew literature, whose authors documented the experiences of the 1948 war and depicted the lives of native Israelis fulfilling the Zionist ethos. The story, written in 1949, is about a group of Israeli soldiers who are ordered to demolish an Arab village and expel its inhabitants. The story focuses on the soldiers' cruel attitude towards the helpless villagers. Except for the narrator, a soldier who has mixed feelings about these actions, the other soldiers all act with insensitivity, and are completely unaware of the terrible nature of their deeds.

This text is cited so often because it contains an explicit analogy between the Palestinians and the Jewish people, which appears in a few paragraphs. The narrator, an outsider within the group of soldiers, reveals the prolonged tension between his feelings and those of his friends: Unlike the other soldiers, the narrator sees the suffering of the Palestinian villagers. His mode of thinking is based on analogy:

Without intending to, I would suddenly think about how it was with us, at home, [ .. . ] when suddenly there were shots, shots from the border, [ ... ] shots from the distant hills, shots of the night or shots before dawn, and rumors, and lights-out, and something big and serious and threatening and disconcerting, and running, and a secret, and tense listening [... ] A mother, scared to death, would go out to gather her children with a pinched and almost 
stopping heart. How a paralyzing silence of bewilderment, of a famous "let it not be us, Oh Lord!". (Yizhar [1949] 2008, p. 48, my italics)

And later:

Something became clear to me suddenly, in a flash. As if everything at once sounded different, more true-exile, this is exile. Exile is like this. Exile looks like this [... ].

I had never been in exile-I was speaking to myself - I never knew what it is like [ ... ] but they talked to me, and told and taught and repeated in my ears again and again, from every corner, book and newspaper, everywhere: Exile. Pulled all my strings. Our people's challenge to the world: Exile! And it was in me, probably already with my mother's milk. What have we done here today? (ibid., p. 85)

By relating the scene to "how it was with us", the narrator grasps the feelings of uncertainty and enormous fear of the people under attack, and empathizes with the victims. By using the charged Jewish term "exile" (in Hebrew: galut), the narrator makes a connection between his Jewish heritage-the terrible experiences of exile-and the plight of the Arab villagers. The readers, presumably Israeli Jews who, like the narrator, have been inculcated in the plight of exile, can grasp the Palestinian trauma, and recognize the awful truth: That this time we, the Jews, have brought a terrible exile upon them.

The analogy between Palestinian and Jewish history permeates the entire text, and as Yochai Oppenheimer (2014) pointed out, poses an alternative moral point of view. Contrary to the sabra prototype of the "New Jew"-the man of action and the perfect warrior who is brave, devoted to his mission, and willing to give his life to protect his country and its people (Shapira 1996, p. 184) - the story takes the perspective of Diasporic Jews, who were perceived in the 1940s and 1950s as passive and weak, and were accused of accepting their fate "like sheep going to the slaughter" during the Holocaust. Yizhar thus challenged the emerging Israeli culture of masculine strength, while revealing its immoral conduct.

To this day, this story is considered one of the most important and controversial literary texts on the 1948 War. $^{1}$ Yizhar's courageous decision to paint unflattering images of Israeli soldiers, and depict a mechanism that can lead to unethical and unlawful military conduct, earned him both praise and condemnation.

Yizhar's story is a good case study on the role of literary analogy in the context of the conflict between Israelis and Palestinians. In a 2015 volume in Hebrew on the Holocaust and the Nakba (2019, in English), Bashir Bashir and Amos Goldberg attempt to provide a new "register of history and memory that honors the uniqueness of each event, its circumstances and consequences, as well as their differences, but also offers a common historical and conceptual framework within which both narratives may be addressed" (Bashir and Goldberg 2019, p. 5). In their discussions on the plight of the two people, they look for ways to challenge the dichotomy between these two narratives. Hannan Hever, in his introduction to a collection of Hebrew poetry about the Palestinian Nakba, describes how problematic it is for Jewish-Israeli authors to connect these two traumas:

Inequity cried out, yet at the same time, the ones who were responsible for this injustice were entangled in a national war that was perceived by the public as a war over the very existence of the nation. Thus, literary discourse found itself in an extremely deep conflict. On the one hand, it wished to show moral sensitivity towards the fate of the Palestinian people, yet, on the other hand, it spoke from a sense of intense anxiety for the continued existence of the Jewish people, and hence also from an overflowing sense of joy over their victory. (Hever 2010, p. 12)

1 Anita Shapira discusses the changing attitudes towards this story over the years, and its role in shaping the collective memory of the War. See (Shapira 2000). See also (Ginsburg 2014). 
Israeli literature has tended to mirror the history of the Israeli-Palestinian conflict, with its two major crossroads of 1948 and 1967, by raising questions regarding militarism, humanism, the democratic nature of the State of Israel, and the dual position of citizens who are soldiers. Literary representations in different times and contexts have attempted to cope with these ethical dilemmas, while revealing the internal conflict between the humanist tendencies of Israeli literature, which is usually perceived as aligned with the political left, and the ways it deals with Zionist national stances and asymmetric power relations with the Palestinians. Numerous texts that depict the Israeli-Palestinian conflict make analogies between the Israeli and the Palestinian people, between specific individuals from both sides, or between their historical traumas. These analogies, which often go beyond the Holocaust and the Nakba, are driven by the idea that analogy is a major stylistic device for "understanding things beyond our knowledge and senses" (Holyoak and Thagard 1995, p. 9).

In the context of Hebrew poetry, Hever argued that there has been an inability to acknowledge Palestinian suffering. He discusses how poets use poetic devices to cloak violence. Hever suggests a theoretical explanation for the use of analogy in Yizhar's work by positing that it creates a multidirectional binary schism between the "I" (the Israeli Jew) and the Other, which is not oriented towards feelings of responsibility for the Palestinian Other, as positioning the Palestinian as a complete "other" fails to understand or take responsibility for his suffering, since he is seen as a total stranger. Similarly, positioning the Palestinian as equal to the " $\mathrm{I}$ " fails ethically since it positions him as part of the narcissistic self (Hever 2017, p. 24). Thus, as Shira Stav has shown, the connection between the two narratives only goes in one direction: The Palestinian catastrophe can only be grasped by thinking about the catastrophe of the Jews (Stav 2012, p. 86), and this directionality eventually leads to a narcissistic position of moral imperialism.

This longstanding debate on Yizhar's story, and the broader issue of the coupling of the traumas of the Jews and the Palestinians in Israeli literature, are taken in this article as a starting point for a theoretical assessment of the role of literature as a mode of moral investigation, and specifically the place of analogy in ethical criticism. It applies ethical notions developed by Emmanuel Levinas to explore and criticize the use of analogy in Israeli literature in the context of the Israeli-Palestinian conflict. I show that analogies can be deceptive and create a deceitful pretense of understanding the Other, while in fact maintaining a narcissistic superior position. This argument is divided into two threads: The first raises the issues of symmetry and victimhood. The second discusses cases where analogy works alongside empathy, while challenging the nature of this empathy. The final part of this article suggests an alternative approach to an ethical understanding, in which the literary text, while exploring analogy as a basis for new relations, uses different rhetorical devices to suspend its parallelism and reveal its deceptiveness. This suspension and its disclosure may upend the reader's empathy, giving poetic shape to Dominick LaCapra's argument on "empathic unsettlement", and pave the way for greater moral responsibility.

\section{When Analogy Instigates Competition between Victims}

In Amos Oz's autobiographical novel, A Tale of Love and Darkness, he describes his family's journey from Eastern Europe to Israel and the family members' inability to adjust to their new surroundings. Oz (1939-2018), who was born in Jerusalem, was one of leaders of the "Statehood Generation" (or The New Wave) that emerged in Israeli literature in the 1960s, when the State of Israel was rooted in reality and Israeli prose was attempting to break free of the Zionist ethos. This late work is a partial autobiography, which depicts his family and ends with the core trauma of his mother's suicide when he was still a child. A Tale of Love and Darkness is considered to be the masterpiece of one of most influential authors in Israel who was an outstanding spokesman for peace. In the novel, the family history is interleaved with the story of Oz's childhood and adolescence in Jerusalem during the 1940s and the 1950s, and delves into his personal struggle to shape his identity against the backdrop of Zionist national aspirations and the founding of the State of Israel. 
In the following quotation, $\mathrm{Oz}$ analyzes the kernel of the relationship between Israelis and Palestinians and draws a clear-cut parallel:

In the lives of individuals and of people, too, the worst conflicts are often those that break out between those who are persecuted. It is mere wishful thinking to imagine that the persecuted and the oppressed will unite out of solidarity and man the barricades together against a ruthless oppressor. In reality, two children of the same abusive father will not necessarily make common cause, brought close together by their shared fate. Often each sees in the other not a partner in misfortune but in fact the image of their common oppressor.

This may well be the case with the hundred-year-old conflict between Arabs and Jews. The Europe that abused, humiliated and oppressed the Arabs by means of imperialism, colonialism, exploitation and repression is the same Europe that oppressed and persecuted the Jews, and eventually allowed or even helped the Germans to root them out of every corner of the continent and murder almost all of them. But when the Arabs look at Jews they do not see a group of half-hysterical survivors but a new offshoot of Europe, with its colonialism, technical sophistication and exploitation that has cleverly returned to the Middle East —in Zionist guise this time — to exploit, evict and oppress all over again.

Whereas when we look at them we do not see fellow victims either, brothers in adversity, but somehow we see pogrom-making Cossacks, bloodthirsty anti-Semites, Nazis in disguise, as though our European persecutor have reappeared here in the Land of Israel, put keffiyehs on their heads and grown moustaches, but are still our old murderers interested only in slitting Jews' throats for fun. (Oz [2002] 2005, p. 330)

As a Zionist who saw Israel as the sole salvation for the Jewish people after the Holocaust, and as a member of the peace movement, $\mathrm{Oz}$ attempted to understand the nature of the Israeli-Palestinian conflict by proposing a highly appealing psychological explanation for the behavior of the two nations - that both the Jews and the Arabs suffered oppression whose roots are European, and that both evidence posttraumatic responses.

Oz's analogy is structural, and illustrates the basic formulation of analogy. The history of analogical reasoning, and the philosophy of the concept of analogy is extensive (Bartha 2019), and is mainly associated with the philosophy of science and the ways in which analogies in nature can promote scientific theories. In literature and humanistic thought, Aristotle was the first to refer to analogy in Poetics as part of his definition of metaphors: "Metaphor is the application of an alien name by transference either from genus to species, or from species to genus, or from species to species, or by analogy, that is, proportion" (Aristotle [350BC] 1961, Chapter 21, 1457b. 4). Aristotle describes three types of metaphors: A construction from genre to species or from species to genre (relations that resemble what we define today as synecdoche), or from species to species (the classical metaphor), or by proportion; i.e., resemblance by structure (Kraus 2015, p. 178). Metaphor by analogy refers to a situation in which within a group of four things, the second is related to the first as the fourth is related to the third, so that one may substitute the fourth for the second or the second for the fourth (Aristotle [350BC] 1961, Chapter 21, 1457b. 6).

Viewing analogy as a proportion is a key component of structure-mapping theory. Here, analogy identifies both vertical and horizontal correspondences between a selected set of items. According to Mary Brenda Hesse (1966), horizontal relations illustrate similarity (and difference) between domains, whereas vertical relations point to similarity between objects, relations, or properties. Structuralist models of analogy put forward formal criteria for evaluating analogies associated with mapping. Dedre Gentner's more recent structure mapping theory (Gentner 1983) distinguishes between properties and relations. It defines systematic relations between objects, and not between their attributes; whereas structural properties determine an analogy, analogies are about relations and not about knowledge.

The issue of cognitive processes that are involved in analogies has prompted research in the last few decades, resulting in connectionist models. John Hummel and Keith Holyoak argued that "human 
analogical reasoning (as well as other types of thinking) depends critically on the capacity to manipulate structured representations" (Hummel and Holyoak 1997, p. 433). This ability to form and manipulate relational representations refers to the ability to "appreciate analogies between seemingly different objects or events, the ability to apply abstract rules in novel situations, the ability to understand and learn language, and even the ability to appreciate perceptual similarities" (Hummel and Holyoak 2003, p. 220). To understand the basic constraints that govern analogical thinking, these "connectionist models have been directed towards uncovering the psychological mechanisms that come into play when we use analogies: retrieval of a relevant source domain, analogical mapping across domains, and transfer of information and learning of new categories or schemas" (Bartha 2019, sec. 3.5.1). Keith Holyoak and Paul Thagard (Holyoak and Thagard 1995) posited the existence of structural, semantic, and pragmatic constraints, involving the direct similarity of certain elements, "structural parallels between the roles in the source and the target domain" (p. 5), and personal goals providing "the purpose for considering the analogy at all" (p. 6). Clearly, these three constraints are not rigid, and can appear in different settings and with different intensities.

Bashir and Goldberg's introduction to their volume on the Holocaust and the Nakba draws heavily on the structural context of analogy. "These two national narratives," they state, are "connected to two far greater narratives embraced by contemporary global culture ... At the heart of both narratives lie catastrophes, albeit of very different natures." They show that while these two narratives-the Holocaust narrative and the postcolonial narrative-are antithetical and contradict each other, the structure of both narratives bears some resemblance since they reveal "the devil at the very core of modern, liberal, democratic, western civilization [ ... ] committed and continues to commit terrible political crimes" (Bashir and Goldberg 2019, p. 4). Thus, whereas the two narratives are commensurable, applying "another register of history and memory" may offer "a common historical and conceptual framework within both narratives may be addressed" (p. 5).

The excerpt from Oz goes further in presenting the analogy's structural aspect by pointing out the parallels between the victims (Jews and Arabs), and between the oppressors' system of power. The text also embodies the other two constraints formulated by Holyoak and Thagard: Semantics (similarity) and pragmatics (purpose). Alongside the structural elements, $\mathrm{Oz}$ points to the similarity between the experiences of the two nations: He compares the relationships between the Jews and the Arabs to relationships between siblings who have a common father (Isaac and Ishmael in the Bible). The purpose of Oz's analogy is to understand the current situation in which Jews and Arabs are in conflict, instead of uniting and amassing their common strength. His reasoning is that the comparison between Jewish and Arab suffering and the suggestion that this joint suffering is the result of joint traumas, may lay the groundwork for reconciliation.

However, when $\mathrm{Oz}$ compares the Palestinian and the Jewish plight (with its culmination in the Holocaust), the weakness of his analogy as an ethical device is revealed. The Holocaust has become the key component of Jewish identity of our time, within as well as outside of Israel. Since the 1980s, it has been transformed into a symbolic event constituting an ethical epitome and a historical tipping point for the Western world, which shape the way people and societies relate to themselves. Theorists such as Dominick LaCapra, Shoshana Felman, Cathy Caruth, Dori Laub, and others view the Holocaust as the paradigmatic and ultimate trauma (Hunter 2018). It is perceived as an extreme, singular event that must not be compared to any other political context. Thus, within the explicit Israeli political discourse, any reference to the Holocaust when discussing other wars and persecution is condemned, and using this parallelism in the context of the Palestinian tragedy is considered in some circles as borderline treason.

Oz's readers, who are primarily Israeli-Jewish, are used to hearing about the Holocaust within the national story of the Jewish people as victims and their two thousand years of suffering. This position is often inherent to the Zionist narrative, and is frequently expressed in the form of "victim-community," to use Martin Jaffe's terminology (Jaffee 1991). According to this narrative, Jews were persecuted in Europe and sought refuge and a home in their historical fatherland, where they became victims of Arab 
violence. Since "being a victim means being the 'owner' of an irretrievable loss," as Adi Ophir phrased it (Ophir 2000, p. 174), and since there is no cure, compensation, or understanding of the Holocaust, the pain and the loss are still evident to this day. Nevertheless, the philosophical underpinnings of this concept and its ethical value-in the context of constructing a parallelism between the plight of the Jews and the plights of the Palestinians—needs to be examined, in particular as to whether this type of analogy promotes an ethical understanding of the Other.

This article draws on major contemporary approaches to ethics and empathy, and is inspired by the works of Emmanuel Levinas, one of the key 20th century thinkers on ethical criticism. In his analysis of Western philosophy, which he defines as an "imperialism of the same" (Levinas [1969] 2002, p. 87), Levinas describes the subject's search for coherent structures of meaning, while subordinating the particular to the general and reducing the unknown to the framework of "sameness" (ibid., pp. 42-48). Structure-based analogies provide clear examples of this type of reduction and subordination. Reductionist and instrumentalist approaches can occur in any relationship when one party approaches the other with his or her own mode of thinking in an attempt to know and comprehend the other, while in fact only understanding the other in terms of his or her own "sameness". In these cases, the self, as Benda Hofmeyr noted, "tends to assume an instrumentalist approach to all that is other" stemming from inherent self-interestedness, as well as for sustenance and survival (Hofmeyr 2016, p. 177). In literature, this type of perspective may place the reader on an "Olympian height" as Andrew Gibson argued (Gibson 1999, p. 11), which characterizes colonial practices whose aim is to reduce the suffering of colonized others but in fact only deals with what the Western colonizers understand, or misunderstand, to be their suffering.

Oz's analogy implies that both Israelis and Palestinians can see themselves as brothers who share the same traumas. However, he creates a symmetrical structure-based analogy that ignores concrete circumstances, thus producing a structure that is blind to the complexity and uniqueness of each trauma. In Oz's text, the two counterparts are equal victims whose suffering comes from the outside like a natural disaster, such that the Palestinian tragedy is not specified in any way. This view does not include Israeli responsibility for Palestinian suffering, since it draws on the notion that the Jews (like the Palestinians) are passive victims. As Raz Yosef noted (Yosef 2011, p. 143), this position "refrain[s] from dealing with the question of responsibility for the injustices." Instead, the text justifies the actions of Israelis who are just "a bunch of half-hysterical survivors" (Oz [2002] 2005, p. 330).

Oz's text illustrates Levinas's "imperialism of the same" not only by nurturing the depiction of ultimate victims while denying any other consequences, historical contexts, or specifications, but also by taking the paternalistic stance of the friendly therapist of these two nations who can address their suffering as psychological distress. Hence this text, written by an author who championed and was part of the peace movement, exemplifies a presumption of understanding the other while actually remaining on his "Olympian height" and adopting a new type of moral imperialism. In doing so, it fails to produce an ethical understanding or responsibility for the suffering of the other.

Michael Rothberg, in his article "From Gaza to Warsaw: Mapping Multidirectional Memory" discusses two types of analogies, which he terms solidarity and competition. "While the mix of equation and competition concentrate desire and envy [ ... ] the combination of equation and solidarity produces a form of liberal universalism" (Rothberg 2011, pp. 535-36). Rothberg's assessment suggests that as long as the Israeli narrative tightens the analogy between Jews and Palestinians through the Holocaust, they will be caught in a narcissistic movement, in 'competition' rather in 'solidarity'. In these cases, not only is the symmetric picture fraudulent, but the ethical direction is altered. Promoting an understanding of the Palestinian Other while including the Holocaust in the equation (with its extreme cruelty that presumably cannot be compared to any other historical trauma), is an unfair competition that leaves the text in a state of moral imperialism: The Jews, as victims, are inevitably the "winners," but at the cost of failed ethical understanding and responsibility towards the Palestinian Other. 


\section{When Analogy Invites "Empty Empathy"}

In the Mishnaic tractate Pirkei Avot (a compilation of ethical teachings and maxims), it is stated: "do not judge your friend until you reach his place". There are numerous variants on this commonplace ethical concept. In the American context it is often associated with the saying "don't judge a man until you have walked a mile in his shoes", which seems to have originated from a 19th century poem by Mary T. Lathrap, although it is often attributed to a Cherokee aphorism. ${ }^{2}$ In To Kill a Mockingbird, Harper Lee was apparently inspired by this proverb when she wrote that in order to understand an other, you need to climb into his skin and walk around in it (Mueller 2017). These statements emphasize the need to understand the Other by putting oneself in the Other's place. However, the suggestion of walking a mile in someone else's shoes states an intention rather than an actual ability, since a person can never truly be in someone else's position.

This intention is the basis for the concept of empathy, which has long engaged philosophers, psychologists, and literary critics. Empathy refers to the human ability of thinking and feeling "with" the mental states of another person, "looking into" the other's mind, and simulating his or her experience. $^{3}$ Starting in the 18th and 19th centuries with philosophers such as David Hume and Adam Smith who referred to "sympathy" or "fellow-feeling", ${ }^{4}$ to early 20th century thought when the term "empathy" was coined, the concept has been considered as "ethically significant". Simulating the internal perspective of fictional characters or narrators (Keen 2007, pp. 39-40) is perceived as facilitating an understanding of others' minds and promoting ethical actions toward one's fellow human beings.

The extensive scholarly work on the role of narrative empathy suggests that narratives employ rhetorical devices which, by eliciting their readers' imagination and encouraging them to identify closely with fictional characters, prompt "a wide range of ethical responses" (Harrison 2008, p. 258) and operate as "invitations to ethical judgment." ${ }^{5}$ Analogies in literary texts often serve as a conduit for creating empathy since they posit a parallelism between the familiar and the unfamiliar and can enable the reader not only to see the Other, but also to feel with him/her. However, analogy may also fail morally, as shown in the literary example below.

Boris Zaidman was born in Moldova in 1963 and came to Israel at the age of 13. He belongs to a group of contemporary writers in Israel who examine issues of immigration and hybrid identity. In his second book Safa shesu'a (Cleft Lip, Zaidman 2010, p. 207), he describes the detached life of the protagonist, an immigrant who spent his childhood in the USSR, and finds himself in Israel in a continuous state of alienation. The first part of the book describes his army service in a combat unit, a phase that is perceived in Israeli culture as a way to integrate people from different backgrounds into Israeli society. In one of the episodes during his stint in the Occupied Territories, the narrator-protagonist describes a little Palestinian boy who threw a stone that hit the military jeep. The jeep stopped with a screech, and the boy stood

frozen in place like a rabbit before a jeep's headlights [ ... ] but maybe because the kid raised his hands, the analogy of the rabbit fell out of the bottom of his helmet's tin pot, and in its place appeared this image. Of the kid raising his hands with his barrette or cap or whatever it was, in a "Demi Saison" coat that came down to his knees and shorts [ ... . ] this was the image that popped into his head. It was in black and white, blurry, enlarged and poignant.

2 See: https://grammarist.com/phrase/walk-a-mile-in-someone-elses-shoes.

3 For an in-depth study of the concept of empathy, see the collection Empathy-Philosophical and Psychological Perspectives, eds. Coplan and Goldie (2011); see also Hoffman's Empathy and Moral Development: Implications for Caring and Justice (Hoffman 2001).

4 On moral sentiment in 18th century English philosophy, see (Frazer 2010); see also (Keen 2007, pp. 42-48).

5 Scholarly writing on empathy in literature and its ethical significance is widespread. See the influential work by Martha Nussbaum (2001). This idea is also implicit in writings of scholars who refer to notions such as "moral knowledge" or "thought experiments"; for example, Currie (1995, p. 257). See also McGinn's analysis of "ethical understanding" (McGinn 1997, pp. 171-78) and Carroll's presentation of "literary thought experiments" (Carroll 2002, pp. 3-26). 
He even searched for another image [ ... ] less famous and trite, but he couldn't find it. And Jharas and them, and especially he himself, were suddenly cast in the role of them. And the two olive trees in the yard and the ivy that leached off one of the trunk, and this kid's beige flip-flops and the fact that he wore a dirty casquette painted in the white red and green of the Palestinian flag [... ] and not a Polish cap or a French barrette, and the fact that it was bathed, and burnt in sun, and was not the Polish wintery sky, all this did not even tickle this bleak analogy and the fucking feeling that he is now on the wrong side. (Zaidman 2010, p. 31) ${ }^{6}$

Zaidman presents a web of mirroring. The young boy, who tried to object to the Occupation by throwing a stone and is caught by the jeep's projector, looks like a rabbit seized amidst his escape. Immediately afterwards, the picture changes and the narrator sees the most iconic still image of the Holocaust in his mind's eye: The boy from the Warsaw ghetto after the failure of the Ghetto's uprising, with his hands held up in surrender, and the wells of fear in his eyes. This analogy, that the author admits is fairly banal, captures the horrors of the Holocaust in a sort of shorthand but here takes on a new meaning: By equating the Palestinian child to the Holocaust victim, the soldiers, and the narrator among them, become analogous to the Nazis.

Before Zaidman can process this conclusion further, the child's father appears, slaps the boy, and takes him home quickly to safety. However, although the military scene has ended, the protagonist continues to reflect on it, and forms another analogy, which this time is more concrete:

And then he suddenly realized that he was that kid, it was always him. [ ... ] with an at once sober and delusional sharpness, Tulik saw himself in Zelinski street, pushing Igor Shevchenko [ ... . ] and all this was a response to the "Zhydovka Song" that Shevchenko sang to him [ .... . and suddenly his father came and grabbed him by his arm and almost rolled him backwards, right behind his back, like he wanted to shield him, to hide him [....] and his father's hands, you could tell that they were shaking, even through the black leather gloves.

And suddenly he saw that kid with his dirty cap painted with the colors of the Palestinian flag, standing in his place, in the snowy courtyard of the Fifty-Fifth Vladimir Ilyich Ulyanov School, and those kids, who were lucky enough to be born as "first class locals", singing that song to him, singing that song to him. He and the Arabush were both second class citizens—the Zhyd and the Arabush. (Zaidman 2010, p. 33) ${ }^{7}$

The second analogy does not view the Palestinian boy as an example of well-known gruesome historical events, but rather morphs into a more intimate reflection of the narrator himself as a child in the USSR. When he tried to defend himself by pushing Igor, the boy who abused him, he was stopped immediately by his father who knew that Igor was the son of a KGB official. His everyday humiliations as a Jewish boy, and the weaknesses of his parents who protect him by telling him not to try to resist, are suggestive of the shared fate of the narrator and the Palestinians.

In the first analogy, the protagonist is aware of his thoughts and reflects on their banality and remoteness. This is a conscious use of analogy. He compares the boy's clothing to those of the famous image of the Warsaw boy and reflects on the differences in the weather, but understands that the analogy is not only about similarity but is based on structural parallels between historical times and between the Jewish story and the Palestinians'. However, towards the end of the paragraph, Zaidman switches to a different kind of analogy that involves his own experiences. Unlike the general terms of Jewish history in Yizhar and $\mathrm{Oz}$, here the traumas of his childhood appear in the thin body of the Palestinian boy.

6 The quotations from the novel were translated from the Hebrew by Tamar Gershtenhaber.

7 Zhyd is a pejorative term for Jewish and Arabush is a pejorative term for Arab. 
This last scene, as well as other Zaidman stories, creates a dual gaze where he examines contemporary Israeli reality as an adult, but at the same time views his childhood memories through the perspective of the child he once was. As in Cleft Lip, in his first book, Hemingway ve-geshem ha-tziporim ha-metot (Zaidman 2006), his gaze is directed towards Arabs and Palestinians. He describes Arabs who suffer from exclusion and offensive treatment despite Israel's claims of being a democratic and enlightened state, while making analogies to his childhood in the USSR, where the official line was that "all the nations in the Soviet Union are equal and that the big Russian nation keeps and protects them" (Zaidman 2006, p. 120), while in fact Jewish discrimination was rampant. Zaidman's concentric circles of analogies are emotionally effective. They engender a dramatic moment of highly charged reactions that may prompt empathy. However, this empathy may also fail ethically.

Levinas discusses a number of issues related to empathy (Amiel Hauser and Mendelson Maoz 2014) that have implications here as well. In an early essay entitled "Reality and its Shadow," Levinas condemns art as "the very event of obscuring, a descent of the night, an invasion of shadow" (Levinas [1948] 1989, p. 132). Like Plato's criticism of representative art in the Republic, and based on the metaphor from the allegory of the cave (Ben-Pazi 2015, p. 595), he argues that a piece of artwork actually substitutes images for reality: It is distorted, deceiving, and delightful, and these illusions are comparable to sleights-of-hand or catchy tunes that impose themselves on the consuming subject who "is caught up and carried away by [them]" (Levinas [1948] 1989, p. 132). Levinas rejects ontological claims that art is something that can provide knowledge: "art does not belong to the order of revelation. Nor does it belong to that of creation"; it "moves in just the opposite direction" (ibid.) and invokes blindness and passivity.

However, this objection is only one facet of Levinas' attitude toward art. His writings on literature are ambivalent as to whether literature fosters or undermines ethical thought. In Time and the Other, written in 1947, he admits that "it sometimes seems to me that the whole of philosophy is only a meditation on Shakespeare" (Levinas [1947] 1987, p. 72). ${ }^{8}$ Levinas wrote several essays on literary texts that appear in the collection Proper Names (originally published in 1976). Unlike his comments regarding the misleading nature of artwork, in this collection he shows that literature indeed casts "us up upon a shore where no thought can land" (Levinas [1976] 1996b, p. 134). This ambiguity in Levinas' work is bridged by the role of criticism (Staehler 2010, p. 179), which, as Hofmeyr states, involves "drawing [art] out of its self-enclosed world of escapist beauty into the real world of engagement" (Hofmeyr 2007). It is a "response to the completeness of the work of art, to its immobilization of time, to the violent immanent holding of its plastic rhythmic schema and erasure of the absolute" (Riera 2006, p. 127). From this standpoint, Richard Cohen suggests that in his criticism, Levinas may be not be arguing in terms of "the concrete 'literary' world" of Shakespeare, Dostoyevsky and others, but rather from the world of Talmudic Judaism which combines disputes, arguments, explanations, tales and anecdotes with a commitment to the exegesis of "sacred history" (Cohen 2010, p. 160).

Levinas' attitude towards literature invites literary investigation ${ }^{10}$ that encourages the reader and the critic to consider the "difficult but unambiguous imperatives deriving from the larger interhuman

8 See (Cohen 2010, pp. 150-68) on Levinas's assessment of Shakespeare.

9 An example of the role of literature in Levinas's writing is his essay on S. Y. Agnon, "Poetry and Resurrection," published in 1973, where he suggests that the essence of art can be found "between the lines-in the intervals of time, between times -like a footprint that would precede the step, or an echo preceding the sound of a voice" (Levinas [1976] 1996a, p. 7). He focuses on Agnon's short story "The Sign" which combines the memories of Holocaust victims with a dreamlike episode in an abandoned synagogue where he meets the 11th century Andalusian Hebrew poet Ibn Gabirol, but forgets his poem. Levinas considers that the power of Agnon's text lies in its ability to go beyond "the anecdotal or social curiosities, the narrative or fictive element which it is sought," (ibid., p. 10) to a place "older than Saying, by which the non-sense of death is put in question, by which the resurrection begins in death itself." (ibid., p. 15). Levinas reads literature between the lines and "between times," focusing not only on the possibility of encountering the Other, but also as a way "to call us back to error," (Levinas [1976] 1996a, p. 135) confront death and reveal the "tragic affirmation in face of the horror of being" (McDonald 2008, p. 25)

10 See (Eaglestone 1997, pp. 129-68; Robbins 1999, pp. 127-31, 134-54). 
and moral context that inevitably permeates the artwork despite itself" (Cohen 2010, p. 244). This implies being skeptical about readers' real ability to actually enter a character's mind and achieve "a genuine understanding of another person's feelings, thoughts and character" (Gregory 2010, p. 293). In Zaidman's text, we thus need to question the move from analogy to empathy, and inquire whether empathy brings about a state of understanding of the Palestinian Others and becoming responsible for them.

Cleft Lip clearly depicts the ethical sensitivity and self-criticism arising from the flawed moral position of Zionism, and focuses on the difficult experiences of a soldier who thinks for himself and thus, feels confusion and torment. It follows a narrative pattern often dubbed "shooting and crying", in which soldiers are shocked to discover how easily they and their comrades shoot, kill, or commit acts of brutality, find themselves drowning in feelings of torment, guilt, and shame (Mendelson Maoz 2018, pp. 30-33). ${ }^{11}$ In this narrative structure, the Israeli soldiers' feelings and moral remorse are described at length, whereas the Palestinians are little more than stage props. They are described as a group, or as prototypes of what people may think of Palestinians: They are poor, miserable, and unhealthy, wear dirty rags, and do not have a voice. Hence, Zaidman's text is mainly engaged with the hyphenated identity of an immigrant in Israeli society. The analogies with the Palestinians and their emotional impact are subjected to soldier-protagonist soul-searching. Thus, although this creates an emotional impact, the empathy here is directed towards the soldier, his traumatic memories, his struggle to define his identity and his sorrow and guilt, and not toward the Palestinian Others, who are the main victims in this scene. This misleading empathy shows, as suggested by Matthew Sharpe, that "like the image of Narcissus on the surface of the water, the materiality of art draws us in" (Sharpe 2005, p. 35).

In a short piece entitled "A Soft Focus on War" (Zizek 2020), Slavoj Zizek discusses Kathryn Bigelow's film The Hurt Locker (2008) and criticizes the way it prompts a sympathetic reaction towards US soldiers. Zizek compares this movie to two Israeli films on the 1982 Lebanon war: Ari Folman's Waltz with Bashir (2008) and Samuel Maoz's Lebanon (2009):

Such a "humanization" of the soldier [ . . ] is a key constituent of the ideological (self-) presentation of the Israeli Defense Forces (IDF). The Israeli media loves to dwell on the imperfections and psychic traumas of Israeli soldiers, presenting them neither as perfect military machines nor as super-human heroes, but as ordinary people who, caught into the traumas of history and warfare, commit errors and can get lost as all normal people can.

It is easy to discern the falsity of such a gesture of empathy: The notion that, in spite of political differences, we are all human beings with the same loves and worries, neutralizes the impact of what the soldier is effectively doing at that moment.

Zizek blames the Israeli media for generating empathy towards Israeli soldiers (in Lebanon and the Occupied Territories), and depicting them as innocent young individuals who find themselves doing horrible things and later suffer from post-traumatic syndrome and endless sorrow and regret. He argues that this mythical description is driven by ideology designed to reduce public awareness of soldiers' violent conduct. Thus, instead of raising tough questions about their military activities, and

11 The term "shooting and crying" was formulated in the immediate aftermath of the 1967 war, during a time of great euphoria in Israel when the Kotel (the Western Wall) in Jerusalem became accessible again to Israelis, and many biblical holy places in the West Bank came under Israeli control. A book entitled Si'ah lohamin (Fighters' Discourse) that was based on a series of recorded conversations made after the war with kibbutz members including Avraham Shapira Muki Tzur, Amos Oz, and Yariv Ben-Aharon, revealed the shock and mourning in the kibbutz movement over the terrible losses in battle, but also the trauma of war and the soldiers' responses to their exposure to killing (Shapira 1968). Muky Tzur termed the overall feeling that was reflected in the volume "sliha she-nitsahnu" (we apologize for our victory). Later writers, journalists, and historians coined the now-famous phrase yorim $u$-bokhim (shooting and crying), which probably draws on a satirical column in the 1970's in Ha-olam ha-ze by Kobi Niv, about parents who decide, out of patriotism and morality, to call their first son "shooting" and their second son "crying", so that while the first shoots the second can cry (Niv 1976). The column mocked the hypocrisy of the national discourse that encourages the use of military power on the one hand, but weeps in sorrow on the other. 
acknowledging the suffering of their victims, the media and the arts work to elicit empathy towards these young soldiers.

Zizek's accusations can be related to Ann Kaplan's term "empty empathy", which she used to discuss photographs of the Iraq war. Photographs can provoke shock, and immediate empathy, as in the famous Warsaw ghetto picture. However, Kaplan claims that in the case of the Iraq war, "most of the photos offer viewers a chance to empathize with the difficult situation of our marines and ground forces, and mainly with Iraqis whom our forces are helping. It is for this reason that the response can be called 'empty empathy'" (Kaplan 2005, p. 94). The connection between Kaplan's assessment and moral imperialism is clear: Kaplan argues that while empathy can be created by these images, it can also fuel the narcissistic self who only sees the Other in the context of his or her own superiority. In the case of Israeli literature, as long as the Palestinians are marginalized in the texts and the narrative centers on the Israeli soldier, analogy and empathy indeed point to the moral failings of the Israeli side, but fail to promote an ethical understanding and responsibility for the other.

\section{Creating Empathic Unsettlement as Ethical Understanding and Responsibility}

Can Israeli literature find different venues to discuss the Palestinian catastrophe, without subjecting it to the catastrophes experienced by Jews or adopting a stance of moral imperialism? This section discusses an ethical alternative that creates a variant on analogy that is based on two notions: The first is Dominick LaCapra's "empathic unsettlement," and the second is the Levinasian concept of analogy as relations. These notions aim to undermine the structure-based analogy, and respond to both Levinas' criticism of sameness, and the arguments against empathy. To illustrate how Israeli literature can embody this alternative, two examples from Ronit Matalon's prose are discussed.

According to Cathy Caruth, texts on trauma embody the possibility of sounding "the plea of an other who is asking to be seen and heard, this call by which the other commends us to awaken" (Caruth 1996, p. 8). However, when LaCapra argues for acknowledgment of the traumas of the Other, he stresses that "it is very important to distinguish empathy from identification and to explore the specific ways it may and should be articulated with such demands and responsibilities" (LaCapra 2001, p. 212). According to LaCapra, empathy is important in grasping the trauma of the Other, but also taps into the pleasure principle, as one of its aspects links achieving this empathy with arriving to some harmony (p. 78). His concept of "empathic unsettlement" constitutes a barrier (p. 41), since it allows for certain empathy to emerge, but still maintains distance and does not seek resolution and harmony. Bashir and Goldberg view "empathic unsettlement" as a way to achieve radical otherness, and formulate "new structural possibilities that seek to reduce the very likelihood that these traumas will be generated" (Bashir and Goldberg 2019, p. 25).

Emmy Koopman analyzed the concept of "empathic unsettlement" in the works of J.M. Coetzee, and suggests that "empathic unsettlement" can offer a "fruitful 'middle ground' between a 'conventional' engaging narrative which allows readers to understand the represented Other, and disrupting techniques which make clear that understanding the Other can never be complete" (Koopman 2010, p. 237). This creates a "balance between disruption and engagement" (p. 240). Thus, "empathic unsettlement" breaks down any delusive empathy and the tendency to reduce Otherness to sameness, and preserves the reader's sense of unease.

The second option for an ethical alternative is Levinas's concept of analogy as relation, which derives from the analogy he drew between the relationship of every Other and the relationship of Moses to God-to articulate the meaning of Moses's response to God: "Here I am" (Exodus 3, 4). This analogy has puzzled many, and prompted Derrida to discuss it as a "certain analogy" (Derrida [1987] 1991, p. 44). Without analyzing the core of Levinas' theology (which is beyond the scope of this article), presenting the relationship between two Others as analogous to the relationship between Moses and God emphasizes the impossibility of grasping the Other. As Levinas states: "He shows himself only by his trace, as is said in Exodus 33. To go toward Him is not to follow this trace which is not a sign; it is to go toward the others who stand in the trace of illeity" (Levinas 1986, p. 359). 
Kas Saghafi, in his writings on Levinas' analogy, discusses the etymology of "analogy" [ana-logia] - the repetition (ana) of a logos (of a relation or a ratio), "pointing to the possibility of a convertibility or conversion and a reversibility [ . . . ]. Thus, analogy implies a double movement: The repetition of an initial relation and the reversibility or reversal of a relation" (Saghafi 2005, p. 60). Graham Wards discusses the negotiation between sets of contrasts such as "ego and illeity, distance and proximity, finite and infinite, presence and absence, Saying and said" (Ward 2002, p. 191), and suggests that analogy should be considered a relationship "before identity, before subject and object, before positioning" (ibid., p. 190). This puts forward the notion of analogy as relation, which fractures the structure-based analogy: Rather than centering on parallelism or mirroring, it works by building relationships.

These two notions, of "empathic unsettlement" and of analogy as relation, are missing from all above-mentioned literary analogies between Israelis and the Palestinian Other, since they refer to structure and are based on mirroring and reduction. In these examples, the Palestinian Others are described in a very general way and only from the vantage point of the Jewish trauma. These texts aim for resolution and lack convertibility, conversion, or reversibility.

Ronit Matalon (1957-2017) was a major player in contemporary Hebrew literature. Unlike S. Yizhar, Amos Oz, and Boris Zaidman, who are all Ashkenazi Jews with European roots and were unfamiliar with Arab culture and language, Matalon was born to Egyptian Jewish immigrants and raised in an immigrant neighborhood. The nine books she authored constitute an alternative to the canon of Hebrew and Israeli literature. She worked as a journalist in Gaza during the First Intifada and was a social activist and a senior lecturer in Hebrew and Comparative Literature at Haifa University. The episodes below are taken from Matatlon's novels Sarah Sarah (Bliss, Matalon [2000] 2003) and Kol tse'adenu (The Sound of Our Steps, Matalon [2008] 2015), and illustrate how Matalon deliberately chose a different path when describing the trauma of the Palestinian Others.

Sarah Sarah revolves around the long-term friendship between two Jewish Israeli women, Sarah and Ofri. The narrative develops in four main spatial and temporal locations. The first takes place in the early 1980s and describes how the women met. It is set against the ethnic and economic differences between Ashkenazi Sarah and Mizrahi Ofri. The second takes place in the late 1980s during the First Intifada, when Sarah—-then a photographer in the Occupied Territories—marries Udi. The third covers the first half of the 1990s and narrates the birth of Sarah's son, Mims (Emanuel), her relationship with Marwan, a Palestinian Israeli who is studying at Tel-Aviv University, and how she then abandons him, followed by her divorce from Udi. The fourth and final phase describes Ofri's stay in Le Plessis-Belleville, France, until the news of Yitzhak Rabin's assassination ends the narrative, both structurally and chronologically. ${ }^{12}$

Much can be said about complex relationships between Israelis and Palestinians in this novel, including the relationship between Sarah and Marwan. However, here I would like to focus on Sarah's activity in the Occupied Territories, stemming from her job as a journalist and photographer. "Back then she was making two or three trips there a month, with or without the reporter" (Matalon [2000] 2003, p. 10), "she had been working almost around the clock for the last week" (ibid., p. 66). Sarah enters the Territories and experiences the Intifada from first hand. She returns home distressed by what she saw, but this does not stop her from going back. On the contrary, she finds herself attracted and wants to join in. For example, she becomes involved with the Palestinian family who shelters her when she is caught up in riots that break out in the course of her work, and she spends the night at their home: "At eight-thirty the family got ready for bed. They offered her a separate mattress, but she refused. She sat on the couch all night with her legs folded beneath her" (ibid., p. 10). She has also formed a relationship with the family of Busaina, the little girl killed by IDF gunfire: "During the last few months of 1989 she wove her own version of Busaina's story, squeezing

12 For a more detailed analysis of this novel see (Mendelson Maoz 2018, chp. 7). 
the entire intifada into the tiny portrait of the girl standing between her four brothers that stood on the coffee table in her parent's house in Khan Younis" (ibid., pp. 105-6). Matalon does not produce an emotional text that involves feelings of strong empathy; nor does she reflect on any structural pattern or similarity to the Jewish trauma. Rather, she creates a situation in which she positions herself with the Palestinians and not against or opposed to them. This intimacy on the one hand, and inability to achieve emotion on the other, engenders "empathic unsettlement".

An artistic expression of Sarah relation to the Palestinian is evidenced in her refusal to take the remote, flat role of a photographer. As a professional photojournalist, Sarah takes photos for the newspaper, but she also takes pictures "for herself"; that is, she engages in photography as a profession but also as an art. The photos she takes for herself are mainly of people sleeping, including adults, children, Palestinians, and Israelis: "people in Gaza asleep in different positions, different spaces, inside or outside houses; men, women, soldiers, old people, hospital patients, children; together and alone." (ibid., p. 10). In contrast to the commissioned photographs that are placed in envelopes, these photographs have no addressees. They are not placed in an envelope or sent to the person who commissioned them.

She divided them into two groups: commissioned and noncommissioned. The commissioned photos, the ones for the paper, roamed the house in brown envelopes that were transferred from the kitchen table to the phone stand in the hallway, from the bookshelf to the pile of phone and utility bills, from among the scattered newspapers to the couch and under the clothing removed from the laundry lines. She never showed the other ones, the noncommissioned photos; those she arranged in exemplary order in a specially purchased filing cabinet. (ibid.)

Susan Sontag's famous essay "Fascinating Fascism," which was written in 1975, has been seminal in understanding the power of photos in political contexts (Sontag 1975). In the specific Israeli context, Tamar Libes and Anat First discuss the role of pictorial images from the Intifada and their political power, and in particular note "the selection of dramatic images, transmitting emotional, empathy-arousing images that can be simultaneously absorbed everywhere" (Libes and First 2003, p. 62). Pictures have the power to replicate the existing social order by fixating identities, power structures, and intensifying control mechanisms. This is what Gil Hochberg defines as the visual aspect of the Occupation. She claims that the Israeli visual field dominates the visibility of the Occupation, and points to three organizing principles that are responsible for this configuration: Concealment - erasure and denial of the Palestinian situation,-_surveillance and the power of the military gaze, and witnessing that can reveal Palestinian hardship, but is considered subjective and limited in nature (Hochberg 2015, p. 8). Regev Nathansohn uses the term "banal photography" to describe these tendencies toward concealment and surveillance. "Banal photography" is usually shot from a panoptic position that sees everything within the categories of sameness and otherness, in a way that serves the logic of a government or an ideology, and enables control and supervision as well as displaying clear categories of identity, space, and time. This type of photography also presents binary axes such as here/there and soldiers/Palestinians (Nathansohn 2007, p. 130), and thus, appropriates suffering to fit the ideological scheme.

However, Sarah's personal photos of people sleeping constitute a transgression through photography, by providing a gaze that is "disturbing, unfamiliar, likely to lead to fresh thinking, as well as criticism. [ ... ] the imaging unravels its conventional understanding, the categories we are familiar with rule out any possibility for decoding what is presented to us" (Nathansohn 2007, p. 141). As a photographer, Sarah is located in a panoptic position that inevitably invades the privacy of the subject she photographs, yet she chooses to make a difference. While the press photographs do not change power structures, the photos of the sleeping people do not allow the viewer or the reader to categorize them, and thus impede any comparison or contradiction. This photography differs because it will constitute a private archive, which Sarah does not publish. Sarah's noncommissioned photographs negate the idea that "the subject would turn himself into a third entity, material" for other purposes (Matalon [2000] 2003, p. 64). Moreover, in these photographs, the identity of the photographed subjects is not always clear; sometimes they are not doing what is expected of them, there is no clear location, 
binary contrast, or causality (Nathansohn 2007, pp. 147-48). Thus, Matalon again dismantles the structure of power and hence the structure of analogy: The uneasy reflection of the sleeping figures negates any possibility of using the photos within the framework of an ideological or political structure, thus exposing the readers to an ethical moment without offering a quick resolution.

The second example is from Matalon's most personal novel, The Sound of Our Steps. The novel is not defined as an autobiography, but incorporates major experiences and descriptions that hint at the life of the author, in that it depicts an Egyptian-Jewish immigrant family during the 1950s, living in a pre-fab in an immigrant neighborhood on the outskirts of Tel Aviv. Lucette, the protagonist's mother, was raised in an affluent family in Cairo, is well-educated, and speaks both Arabic and French. However, in Israel she has become embittered, speaks inarticulate Hebrew, lives in a derelict house, and struggles to provide food for her children Sammy, Corinne, and Toni, the youngest, who is a reflection of Matalon herself as a child and is frequently referred to as "the child".

Matalon's ability to upend analogies when it comes to discussing the Palestinian Others is best illustrated through the relationship between Lucette and her Palestinian gardener. In the mother's constant attempts to invent a sense of home, she tries to grow flowers by following the guidelines for an ideal garden in a horticulture book. The novel provides detailed instructions on how to plant roses and repeated descriptions of the mother's attempts to grow them. Roses could have been a consolation and made the hovel more like a home. The novel equates the inability to grow flowers with a lack of control over space, to suggest that she, as a Mizrahi woman, is not the master of the land. She hires a Palestinian gardener, and is the only one in the neighborhood who is not afraid of "them". The encounter between the immigrant from Egypt and the Palestinian gardener creates a unique interaction between two groups who have suffered oppression, and is suggestive of an analogy between them. This type of analogy is often found in Hebrew literature in cases where the Palestinians are shown to be analogous to other marginal peoples or disabled protagonists, as in Daniella Carmi's Haiey ha-lila shel Cleo (Cleo's Night-Life, Carmi 1991). In other instances, they are described along with other marginalized protagonists who want to escape from their lives, as in Hadara Lazar's mikan va-hal'ah (From Now On, Lazar 1983) and Dorit Rabinyan's Gader haya (All the Rivers, Rabinyan [2014] 2017), or as analogous to oppressed Mizrahi characters, as in some of Sami Michael's and Eli Amir's works. Oppenheimer claims that in many of these analogies, the relationship between the Palestinian and the Israeli is depicted by the author in a way that ignores notions of national struggle, thus narrowing the characters' historical and cultural identity (Oppenheimer 2008, pp. 325-29).

In Matalon's text, the analogy between Mustafa the gardener and Lucette is interpreted differently. It is clear that in a symbolic context, both Lucette and the gardener cannot grow flowers since neither of them belong to the people who are the masters of the country and the land (Frade Galon and Mendelson Maoz 2019). Furthermore, their mutual connection is also strengthened through the Arabic language. In the novel, Lucette consistently uses the Arabic word "elgnena" to describe her dream garden. However, despite her efforts to have a garden, the flowers die and thus, she decides to draw flowers rather than grow them, turning toward the painting of roses, cyclamens, and poppies.

Every morning she was waiting for him with the coffee, and they began with a review of her work: "nothing to write home about." She surveyed the painting with a critical look. "not so good this time, eh, ya Mustafa? "Good, he disagreed. "why do you say not good? Straight from Paradise they are, these flowers you paint." (Matalon [2008] 2015, p. 366)

However, while depicting the close relationship between the two, Matalon does not let the readers be carried away with this heart-warming analogy. The novel ends when Lucette decides for the first time to go to Mustafa's home, to see how he is doing during a curfew imposed by the Israeli military on the Occupied Territories. Unlike other Israeli texts that describe relationships between Israelis and Palestinians only within the Israeli space, Lucette asks her son to take her to the West Bank, determined to see Mustafa. When they arrive, "Mustafa 'lost his color' when he saw them" (ibid., p. 367). 
They entered the only room of his house [ ... ] sat down on the long sofas, which opened up into beds at night, and looked around them: the entire wall of the room was covered with the mother's flower painting.

[... ] the mother came closer. She almost pressed her nose to the wall and looked: on the areas of the pictures painted brown for the soil, Mustafa's daughters had stuck real reddish soil, on the green gouache of the leaves they had pasted green leaves from bushes and trees, and on the huge flowers painted burgundy, yellow, and purple-petals of red, yellow, and purple flowers, some of them fresh, most of them already wilted. (ibid., p. 367)

Lucette and Mustafa, both of whom are on the fringes of the Israeli consensus, speak the same language and try together to make the land flourish. In this sense, this is a structure-based analogy. However, this last episode not only reveals the differences, but does not let the Israeli component dominate. Unlike the other literary examples discussed here, Matalon takes her reader to Mustafa's apartment, where he lives with his five children in one room with no land. In his apartment, Lucette's painting hobby turns into a vivid picture of the lost Palestinian land. Hence, in these closing lines of the novel, Matalon does not let the reader preserve the parallelism between the Mizrahi mother and the Palestinian worker and reveals its deception: Although both of them love flowers, it is impossible to compare their failure or despair. As with the two sets of photographs in Bliss-the first that supports the basic discourse of sameness and otherness, and the second that blurs them-here too, while the narrative hints at a possible analogy between the sufferings of the Palestinians and the Mizrahi, the final episode changes the order of things and leaves the reader unsettled.

\section{Conclusions}

Analogy can contribute to better comprehension and is usually based on structural parallelism (Holyoak and Thagard 1995, p. 9), yet when it comes to understanding the Other, analogy can be risky. Otherness signifies a radical uniqueness that cannot be conceptualized, thematized, or comprehended, and can never be summed up or reduced to any one general structure or set of attributes (Levinas [1969] 2002, p. 73). This radical separation affects subjects and obligates them to take unconditional responsibility for the Other, who "resists possession, resists my powers" (Ibid, p. 197).

Texts on the Israeli-Palestinian conflict often use analogies to promote understanding. However, these analogies can lead to two ethical flaws. The first shifts attention from the trauma of the Other to a narcissistic dichotomy implying competition between victims for superior victimhood, and the second leads to "empty empathy." Using Levinasian concepts and LaCapra's notion of "empathic unsettlement," I suggest that by preventing the emergence of analogies that can blur the uniqueness of the Other, and by viewing empathy with suspicion, analogy can create a foundation for understanding the Other when it scaffolds an opportunity for relationships. While the literary examples in the early sections of the article show that Palestinian Others and Israelis are usually presented as antipodes, Matalon, a Mizrahi woman author, reveals Otherness in a way that cannot be reduced or discounted, by constructing analogies based on relationships that shatter symmetry and instill unease that may be a basic step toward ethical understanding. In doing so, she employs the poetic alternative of "empathic unsettlement." Will Israeli prose continue to pursue this path, or will it retreat to the much safer standpoint of a moral contemplation of the narcissistic self? Only the next decades of writing on the Israeli-Palestinian conflict will tell.

Funding: This research received no external funding.

Conflicts of Interest: The author declares no conflict of interest.

\section{References}

Amiel Hauser, Tammy, and Adia Mendelson Maoz. 2014. Against Empathy: Levinas and Ethical Criticism in the 21st Century. Journal of Literary Theory 8: 199-218. [CrossRef] 
Aristotle. 1961. Poetics. Translated by Samuel HenryButcher. New York: Hill and Wang. First published 350BC.

Bartha, Paul. 2019. Analogy and Analogical Reasoning. The Stanford Encyclopedia of Philosophy. Available online: https://plato.stanford.edu/archives/spr2019/entries/reasoning-analogy/ (accessed on 2 July 2019).

Bashir, Bashir, and Amos Goldberg, eds. 2019. The Holocaust and the Nakba: A New Grammar of Trauma and History. New York: Columbia University Press.

Ben-Pazi, Hanoch. 2015. Emmanuel Levinas: Hermeneutics, Ethics, and Art. Journal of Literature and Art Studies 5: 588-600.

Carmi, Daniella. 1991. Ha-Lila Shel Cleo (Cleo's Night-Life). Tel Aviv: Ha-kibbutz ha-meuhad.

Caruth, Cathy. 1996. Unclaimed Experience: Trauma, Narrative and History. Baltimore: Johns Hopkins University Press.

Carroll, Noel. 2002. The Wheel of Virtue: Art, Literature and Moral Knowledge. The Journal of Aesthetics and Art Criticism 60: 3-26. [CrossRef]

Cohen, Richard A. 2010. Levinasian Meditation: Ethics, Philosophy and Religion. Pittsburg: Duquesne University Press.

Coplan, Amy, and Peter Goldie, eds. 2011. Empathy_Philosophical and Psychological Perspectives. Oxford: Oxford University Press.

Currie, Gregory. 1995. The Moral Psychology of Fiction. Australian Journal of Philosophy 73: 250-59. [CrossRef]

Derrida, Jacques. 1991. At this very Moment in This Work Here I Am. In Re-Reading Levinas. Edited by Robert Bernasconi and Simor Critchley. Translated by Rubin Berezdivim. London: Athline Press, pp. 11-48. First published 1987.

Eaglestone, Robert. 1997. Ethical Criticism: Reading after Levinas. Edinburgh: Edinburgh University Press.

Frade Galon, Tammy, and Adia Mendelson Maoz. 2019. An Autobiography of Her Own-Matalon's The Sound of Our Steps. The Comparatist, 43.

Frazer, Michael L. 2010. The Enlightenment of Sympathy: Justice and the Moral Sentiments in the Eighteenth Century and Today. Oxford: Oxford University Press.

Gentner, Dedre. 1983. Structure-Mapping: A Theoretical Framework for Analogy. Cognitive Science 7: 155-70. [CrossRef]

Gibson, Andrew. 1999. Postmodernity, Ethics and the Novel. London and New York: Routledge.

Ginsburg, Shai. 2014. S. Yizhar's Khirbet Khizeh and the Rhetoric of Conflict. In Jewish Rhetorics: History, Theory, Practice. Edited by Janice Fernheimer and Michael Bernard-Donals. Lebanon: Brandeis University Press, pp. 164-79.

Gregory, Marshall W. 2010. Redefining Ethical Criticism. JLT Journal of Literary Theory 4: 273-302.

Harrison, Mary-Catherine. 2008. The Paradox of Fiction and the Ethics of Empathy: Reconceiving Dickens's Realism. NARRATIVE 16: 256-78. [CrossRef]

Hever, Hannan. 2010. Al Tagidu Be-Gat: Ha-Nakba Ha-Palastinit Ba-Shira Ha-Ivrit 1948-1958 (The Palestinian Nakba in Hebrew Poetry 1948-1958). Bnei Brak: Sedek.

Hever, Hannan. 2017. Anachnu Shivrei Haruzim (We Are Broken Thymes). Jerusalem: Magness.

Hesse, Marty Brenda. 1966. Models and Analogies in Science. Notre Dame: University of Notre Dame Press.

Hochberg, Gil. 2015. Visual Occupations: Violence and Visibility in a Conflict Zone. Durham: Duke University Press.

Hoffman, Martin L. 2001. Empathy and Moral Development: Implications for Caring and Justice. Cambridge: Cambridge University Press.

Hofmeyr, Benda. 2007. "Isn't Art an Activity that Gives Things a Face?" Levinas on the Power of Art. Image and Narrative Online Magazine of the Visual Narrative 18. Available online: http://www.imageandnarrative.be/ inarchive/thinking_pictures/hofmeyr.htm (accessed on 2 July 2019).

Hofmeyr, Benda. 2016. Levinas and the Possibility of Dialogue with "Strangers". Journal of the British Society for Phenomenology 47: 174-89. [CrossRef]

Hummel, John, and Keith Holyoak. 1997. Distributed Representations of Structure: A Theory of Analogical Access and Mapping. Psychological Review 104: 427-66. [CrossRef]

Hummel, John, and Keith Holyoak. 2003. A symbolic-connectionist theory of relational inference and generalization. Psychological Review 110: 220-64. [CrossRef] [PubMed]

Holyoak, Keith, and Paul Thagard. 1995. Mental Leaps: Analogy in Creative Thought. Cambridge: MIT Press.

Hunter, Anna. 2018. The Holocoust as the Ultimate Truma Narrative. In Trauma and Literature. Edited by J. Roger Kurtz. Cambridge: Cambridge University Press, pp. 66-82. 
Kaplan, E. Ann. 2005. Trauma Culture: The Politics of Terror and Loss in Media and Literature. New Brunswick and London: Rutgers University Press.

Keen, Suzanne. 2007. Empathy and the Novel. Oxford: Oxford University Press.

Koopman, Emy. 2010. Reading the Suffering of Others-The Ethical Possibilities of "Empathic Unsettlement". Journal of Literary Theory 4: 235-52. [CrossRef]

Kraus, Manfr. 2015. Arguments by Analogy (and What We Can Learn about Them from Aristotle). In Reflections on Theoretical Issues in Argumentation Theory. Edited by F. H. van Eemeren and B. Garssen. Cham: Springer, pp. 171-82.

LaCapra, Dominick. 2001. Writing History, Writing Trauma. Baltimore: Johns Hopkins University Press.

Lazar, Hadara. 1983. Mikan Va-Hal'ah (From Now On). Tel Aviv: Ha-kibbutz ha-meuhad.

Levinas, Emmanuel. 1989. Reality and Its Shadow. In The Levinas Reader. Translated by Alphonso Lingis. Oxford and Cambridge: Blackwell, pp. 129-43. First published 1948.

Levinas, Emmanuel. 1996a. Poetry and Resurrection: Notes on Agnon. In Proper Names. Translated by Michael B. Smith. Edited by Werner Hamacher and David E. Wellbery. Stanford: Stanford University Press, pp. 7-16. First published 1976.

Levinas, Emmanuel. 1996b. The Poet's Vision. In Proper Names. Translated by Michael B. Smith. Edited by Werner Hamacher and David E. Wellbery. Stanford: Stanford University Press, pp. 127-39. First published 1976.

Levinas, Emmanuel. 1986. The Trace of the Other. In Deconstruction in Context. Translated by A. Lingis. Edited by Taylor C. Mark. Chicago: University of Chicago Press, pp. 345-59.

Levinas, Emmanuel. 1987. Time and the Other and Additional Essays. Translated by Richard A. Cohen. Pittsburgh: Duquesne University Press. First published 1947.

Levinas, Emmanuel. 2002. Totality and Infinity: An Essay on Exteriority. Translated by Alphonso Lingis. Pittsburgh: Duquesne University Press. First published 1969.

Libes, Tamar, and Anat First. 2003. Framing the Palestinian-Israeli conflict. In Framing Terrorism: The News Media, the Government and the Public. Edited by Pippa Norris, Montague Kern and Marion Just. New York and London: Routledge, pp. 59-64.

Matalon, Ronit. 2003. Sarah, Sarah (Bliss). Translated by Jessica Cohen. New York: Metropolitan Books. First published 2000.

Matalon, Ronit. 2015. Kol Tse'adenu (The Sound of Our Steps). Translated by Dalya Bilu. New York: Metropolitan Books. First published 2008.

McDonald, Henry. 2008. Aesthetics as First Ethics: Levinas and the Alterity of Literary Discourse. Diacritics 38 : 15-41. [CrossRef]

McGinn, Colin. 1997. Ethics, Evil and Literature. Oxford: Clarendon Press.

Mendelson Maoz, Adia. 2018. Borders, Territories and Ethics-Contemporary Hebrew Literature in Shadow of the Intifada. West Lafayette: Purdue University Press.

Mueller, Steve. 2017. Developing Empathy: Walk a Mile in Someone's Shoes. Planet of Success. March 31. Available online: http://www.planetofsuccess.com/blog/2011/developing-empathy-walk-a-mile-in-someone\%E2\% $80 \% 99$ s-shoes/ (accessed on 2 July 2019).

Nathansohn, Regev. 2007. Metsalmim kibush: sotsiologya shel yitsug hazuti (Photographing Occupation: Sociology of Visual Representation). Teoria u-Vikoret 31: 127-54.

Niv, Kobi. 1976. Yorim u-bokhim (Shooting and Crying). Ha-olam ha-ze, December 15.

Nussbaum, Martha C. 2001. Exactly and Responsibly: A Defense of Ethical Criticism. In Mapping the Ethical Turn: A Reader in Ethics, Culture and Literary Theory. Edited by Todd F. Davis and Kenneth Womack. Charlottesville: University Press of Virginia, pp. 59-77.

Ophir, Adi. 2000. The Identity of the Victims and the Victims of Identity; A Critique of Zionist Ideology for a Post-Zionist Age. In Mapping Jewish Identities. Edited by Laurence J. Silberstein. New York and London: New York University Press, pp. 174-200.

Oppenheimer, Yochai. 2008. Me'ever La-gader: Itsug Ha-Aravim Ba-Siporet Ha-Ivrit Ve-Ha-Israelit 1906-2005 (Barriers: The Representation of the Arab in Hebrew and Israeli Fiction, 1906-2005). Tel Aviv: Am oved and Sapir.

Oppenheimer, Yochai. 2014. Aliyato u-nefilato shel ha-si'ah ha-musari (The Rise and Fall of Moral Discourse). In Leumiyut u-musar (Nationalism and Morality). Edited by Efraim Lavie. Jerusalem: Carmel, pp. 281-304. 
Oz, Amos. 2005. Sipur al ahava ve-hoshekh (A Tale of Love and Darkness). Translated by Nicholas de Lange. London: Vintage Books. First published 2002.

Rabinyan, Dorit. 2017. Gader Haya (All the Rivers). Translated by Jessica Cohen. New York: Penguin Random House. First published 2014.

Riera, Gabriel. 2006. Intrigues: From Being to the Other. Fordham: Fordham University Press.

Robbins, Jill. 1999. Altered Reading: Levinas and Literature. Chicago: University of Chicago Press.

Rothberg, Michael. 2011. From Gaza to Warsaw: Mapping Multidirectional Memory. Criticism 53: $523-48$. [CrossRef]

Saghafi, Kas. 2005. 'An Almost Unheard-of Analogy': Derrida Reading Levinas. Bulletin de Ja Sodele Americaine de Philosophie de Langue Franfaise 15: 41-71. [CrossRef]

Shapira, Anita. 1996. Yehudim Hadashim, Yehudim Yeshanim (New Jews, Old Jews). Tel Aviv: Am Oved.

Shapira, Anita. 2000. Hirbet Hizah: Between Remembrance and Forgetting. Jewish Social Studies 7: 1-62. [CrossRef] Shapira, Avraham, ed. 1968. Si'ah Lohamim (Fighters' Discourse). Tel Aviv: Friends of the Kibbutzim Movement. Sontag, Susan. 1975. Fascinating Fascism. The New York Review of Books, February 6.

Sharpe, Matthew. 2005. Aesthet(h)ics: On Levinas' Shadow. COLLOQUY Text Theory Critique 9: 29-47.

Staehler, Tanja. 2010. Plato and Levinas. New York and London: Routledge.

Stav, Shira. 2012. Nakba and Holocaust: Mechanisms of Comparison and Denial in the Israeli Literary Imagination. Jewish Social Studies 18: 85-98. [CrossRef]

Jaffee, Martin. 1991. The Victim Community in Myth and History: Holocaust Ritual, the Question of Palestine, and the Rhetoric of Christian Witness. Journal of Ecumenical Studies 28: 223-38.

Yizhar, S. 2008. Hirbet Hiz'a (Khirbet Khizeh). Translated by Nicholas de Lange, and Yaacob Dweck. Jerusalem: Ibis Edition.

Yosef, Raz. 2011. The Politics of Loss and Trauma in Contemporary Israeli Cinema. New York: Routledge.

Zaidman, Boris. 2006. Hemingway Ve-Geshem Ha-Tziporim Ha-Metot (Hemingway and the Rain of Dead Birds). Tel-Aviv: Am Oved.

Zaidman, Boris. 2010. Safa Shesu'a (Cleft Lip). Or Yehuda: Kinneret, Zmora-Bitan, Dvir.

Ward, Graham. 2002. Speaking Otherwise: Postmodern Analogy. In Rethinking Philosophy of Religion: Approaches from Continental Philosophy. Edited by Philip Goodchild. New-York: Fordham University Press, pp. 187-211. Zizek, Slavoj. 2020. A Soft Focus on War. In These Times 35: 30-2.

(C) 2019 by the author. Licensee MDPI, Basel, Switzerland. This article is an open access article distributed under the terms and conditions of the Creative Commons Attribution (CC BY) license (http://creativecommons.org/licenses/by/4.0/). 


\title{
Article \\ Affect and Porosity: Ethics and Literature between Teresa Brennan and Hélène Cixous
}

\author{
Michelle Boulous Walker \\ Faculty of Humanities and Social Sciences, School of Historical and Philosophical Inquiry, The University of \\ Queensland, St Lucia QLD 4072, Australia; mbw@uq.edu.au
}

Received: 31 July 2019; Accepted: 8 October 2019; Published: 11 October 2019

check for updates

\begin{abstract}
In her posthumously published work The Transmission of Affect, Teresa Brennan challenges the modern ego's understanding of itself as self-contained. This illusion, she argues, is supported by what she refers to as the "foundational fantasy". In explaining what this means, Brennan rejects a bounded sense of the self, arguing that affect (both positive and negative) circulates energetically between subjects. In patriarchal cultures, mothers (and "feminine beings") act as repositories of projected fear, typically carrying the greater burden of the negative affects-anger, aggression, and envy. Importantly, Brennan's work brings the question of intersubjective boundaries to the fore, arguing that these are open, and that any account of ethical relations between self and other needs to acknowledge this. Drawing on pre-modern sources, she develops a new theory of intersubjective and energetic affectivity and, in a positive vein, offers love-in the form of attention and discernment-as the positive gift of affect that can potentially circulate between bodies, infusing intersubjective relations with life. Brennan's work on the transmission of affect offers a bold and very political philosophical intervention into early twenty-first century ethical accounts. Her exploration of the intricacies of our relational entanglements with others and the material world challenges our understanding of what it means to be a self in relation to others. In effect, her account of the transmission of affect highlights the other's vulnerability to my affect, to my hostile projections, even as it accounts for the flow of affect in both directions. In a slightly different way, Hélène Cixous offers us an account of our relations with others that focusses on the self's openness to the force of the other, the self's vulnerability to the dangerous other. Here, the other is the focus of a potential threat, a potential undoing of the self. For Cixous, writing is the place of witness to the unfolding of this vulnerability or porosity between two (entre deux). While this essay focuses on Brennan's philosophical account, and the potentially paradoxical nature of her work to produce a theory of affect, it offers a brief discussion of the ways in which Cixous's focus on literature and writing provide a different frame for appreciating the challenge that Brennan's work makes. It explores the important ways in which Cixous extends Brennan's philosophical concerns to the domains of literature and writing. Throughout her work, Brennan calls for us to invent or reinvent a vocabulary for the exploration of discernment, the protective attitude of thoughtfulness that opens us to the other. Cixous's work, I argue, embodies this call in hopeful and optimistic ways. As such, it allows us to think of literature and writing as privileged sites for the exploration of our complex intersubjective relations.
\end{abstract}

Keywords: Teresa Brennan; Hélène Cixous; affect; porosity; vulnerability; entre deux; ethics; philosophy; literature 


\section{Introduction}

Since her untimely death in 2003, there has been a slowly growing engagement ${ }^{1}$ with Teresa Brennan's challenging work on the transmission of affect, work often depicted as supporting an "affective turn" 2 in critical and philosophical studies. Throughout her writing, Brennan explores the intricacies of our relational entanglements with others and the material world, claiming that, contrary to the illusion established by what she refers to as the "foundational fantasy", individual subjects are not self-contained. Objectivity posits an individual, insulated from affective connections with others. Brennan rejects this, arguing that affect (both positive and negative) circulates energetically between one subject and another. In patriarchal cultures, mothers (and "feminine beings") traditionally carry the burden of negative affects—-such as anger, aggression, and envy—-by becoming repositories of projected fear. Brennan's work brings the question of intersubjective boundaries to the fore, arguing that these are open, and that any account of ethical relations between self and other needs to acknowledge this. She develops a new theory of intersubjective and energetic affectivity. In a positive vein, Brennan offers love-in the form of attention and discernment-as the positive gift of affect that circulates between bodies, enhancing the intersubjective relation. Her work on the transmission of affect offers a bold and very political philosophical intervention into early twenty-first-century ethical accounts.

Hélène Cixous's work on the ambiguous entre deux relation ${ }^{3}$ provides us with an account of intersubjectivity in terms of porosity, permeability, and danger. For her, the entre deux charts the dangerous (though not solely destructive) porosity of the vulnerable space of longing between the self and other. While vulnerability is often thought of as a weakness, Cixous's work offers an account that hovers between a destructive (threatening) gesture and a regenerative (intimate) openness. Here, we can think of Cixous's account of vulnerability in terms of a susceptibility to wounding (Boon 2013, p. 85), an opening to the other in terms of the transmission of affect. As with Brennan's work on affect, Cixous's investigation of porosity takes us beyond the limits of a strict boundary between self and other, and it does so importantly in terms of literature and writing. Cixous's porous self deflates the illusion of what Brennan refers to as the contained-self. I conclude this paper by briefly exploring the important ways in which Cixous extends Brennan's very philosophical concerns with affect to the domains of literature and writing. Throughout her work, Brennan calls for us to invent or reinvent a vocabulary for the exploration of discernment, the protective attitude of thoughtfulness that opens us to the other. Cixous's work, I argue, embodies this call in hopeful and optimistic ways. As such, it allows us to think of literature and writing as privileged sites for the exploration of our complex intersubjective relations.

\section{The Transmission of Affect}

Brennan begins The Transmission of Affect (published posthumously in 2004) by revisiting and extending her earlier work ${ }^{4}$ on "the foundational fantasy", the illusion of self-containment. Her aim is to offer a philosophical account of the "intelligence of the flesh", a paradigm "capable of handling intentional and affective connections between and among subjects and their environment" (Brennan 2004, p. 78). The intelligence of the flesh is Brennan's term for discernment, the work connecting thinking to sensation, or the attentive attitude of thoughtfulness. It is this that exposes the

1 This includes significant feminist engagement, though not exclusively: Jardine et al. (2007); James (2006); Ahmed (2008); Gorton (2007); Figlerowicz (2012); Gunew (2009); Blackman (2008); Labanyi (2011); Rice (2008); Muñoz (2007); Holding (2007); and the philoSOPHIA 2017 Annual Conference, the theme of which, "Affect and Social Justice", honored Brennan's legacy in the field. http://www.philosophiafeministsociety.com/conference-2017-1 For a discussion of the events surrounding Brennan's death, see Harari (2011).

2 For notable contributions to the "affective turn" or the "turn to affect", see Massumi (1995); Sedgwick and Frank (1995); Gregg and Seigworth (2010); Berlant (2011); and Pedwell (2014).

3 The entre deux involves a staging of otherness, a passage between the self and the strangeness of the other, an event "which evicts us from ourselves" (Cixous and Calle-Gruber 1997, pp. 8-9).

4 See Brennan $(1992,2000,2002)$. 
illusory nature of the ego's belief in its self-containment, whereby challenging much of our modern philosophical, cultural, and political intuitions in the West. Such intuitions arise with the emergence of a bounded conception of the self, allowing us to assert our isolation and containment as fully separate and independent subjects. Brennan maintains that the self-contained Western self is a construction dependent on projecting unwanted affects, such as anxiety and depression, outside or beyond us. In order to be effective, she writes, "the construction of self-containment also depends on another person (usually the mother, or in later life, a woman, or a pliable man, or a subjugated race) accepting those unwanted affects for us" (12). The transmission of affect works simply through "energy and its unconscious repression" (12). Repressed affect is either projected outwards, toward and onto the other, or-less frequently-introjected inwards, toward the self.

Containment, Brennan contends, is constructed rather than given or natural, and it is the foundational fantasy that helps us to understand how (in the West) it is common, in the modern age, that we experience ourselves as contained and separate from others, as individuals who can remain largely unaffected by the thoughts, feelings, and investments of others. "Common sense" dictates that " $\mathrm{I}$ " exist within the strict limits of my own visible corporeality. The transmission of affect challenges such common sense, offering an explanation for precisely how we connect or are bound to one another at the energetic level: "the level at which my affect enters you and yours, me" (14). Additionally, it provides greater depth to Brennan's earlier account of the foundational fantasy, providing an alternative way of thinking through the consequences of an illusory self-containment. It explains "why we are likely to judge the other, to project certain affects on the other" (14), and to see ourselves as superior and separate (111). It also explains "why we are willing to see the other as the origin of negative affects, such as envy and aggression, which we would rather disown in ourselves" (14). For Brennan, the foundational fantasy is grounded in an archaic and undiagnosed aggressive projection on to the mother, who is expected to carry the burden of the negative affects (due, presumably, to her abject association with nature and corporeality). She works closely here with the object relations theory of writers such as Wilfred Bion and Melanie Klein, ${ }^{5}$ modifying this somewhat to argue that women in general carry the negative affects. Evidence of this can arguably be seen in the disproportionate levels of domestic violence directed toward women in intimate patriarchal contexts, a consequence of an undiagnosed and unconscious association of all women (rather than solely the mother) with abject nature and corporeality. Brennan writes: "Women, I hazard, regardless of whether they are mothers, have carried the negative affects ... [however] a better term than 'women' would be 'feminine beings,' by which I mean [all] those who carry the negative affects for the other. ${ }^{6}$ These are most likely to be women, but the disposition of the negative affects varies, especially when racism is a factor" (15). Brennan suggests that women, people of color, and marginalized groups are often targets for the hostile projections of negative affect. Such projections compound in the case of intersectional oppressions. By acknowledging in her work the connection of both racism and sexism with the projection of negative affects, Brennan offers us a nuanced way of posing potentially intersectional philosophical questions regarding the prevalence of violence in contemporary intersubjective relations; violence here understood as a potential consequence of negative affect.

In what we can interpret as a prescient gesture, Brennan links her observations of hostile projection onto oppressed groups with the question of borders and boundaries, ${ }^{7}$ highlighting the fundamental insecurity at the foundation of the contemporary contained-self. Is it possible, she asks, as the

5 Bion (1961) and Klein (1957). See also Boulous Walker (1998, pp. 141-44).

6 Brennan's statement here can be read alongside Julia Kristeva's work on misdirected abjection, i.e., the manner in which all women (not only the mother) stand in for the abject as targets of a degraded and dangerous corporeality. See Kristeva (1982) and Oliver (1993, pp. 48-68).

7 "Have boundaries come to matter because self-definition by projection is less available than it was during the last few sexist and colonial centuries - there are now too few willing receptacles-or because of an accumulation of environmental-inflected affects. Either way, boundaries may matter now because there is too much affective stuff to dispose of, too much that is directed away from the self with no place to go" (Brennan 2004, p. 15). 
sexist and colonial legacies of past centuries are challenged, that less traditional opportunities for projection exist? If so, does this account (in the West) for the increasingly neurotic policing of our (personal/social/political) borders?

... the Western individual [is] especially more concerned with securing a private fortress, ${ }^{8}$ personal boundaries, against the unsolicited emotional intrusions of the other. The fear of being 'taken over' is certainly in the air, although the transmission of negative affect generally is not recognized for what it is. Boundaries, paradoxically, are an issue in a period where the transmission of affect is denied. (15)

In a period of mass migration, the ongoing Syrian crisis, Brexit, and Trump, it is tempting to think of the isolationist stances of many countries, governments, and political movements in terms of Brennan's account of the negative affects. Private fortresses and personal boundaries enlarge to encompass nation states and national frontiers-all intent on securing borders against the threat of the unfamiliar and invasive other; intent, too, on projecting unwanted affect on to a scapegoated other. In this sense, Brennan's work can be helpful for thinking through the projection or transmission of negative affect in terms that link the personal with the public, the self with the State. ${ }^{9}$ Here the body politic has the potential to operate in a manner not dissimilar to the body-projecting hostility and aggression out beyond its own borders. Colonized communities, the "Third World", and others operate here as the "feminine beings" co-opted to accept such hostile projections.

For Brennan, these ideas concerning the transmission of affect have a pre-modern European history that she thinks is virtually lost by the eighteenth century. For example, in France in the sixteenth century, Michel de Montaigne's writing on energetic relations between young and old and, in the seventeenth century, Nicolas Malebranche's work on the emotions (especially sadness), both indicate an appreciation of energetic transmission. This line of thought is disrupted (though not entirely lost) after the seventeenth century. With an emphasis on sight- "the sense that renders us discrete"-the eighteenth century (the siècle des lumières) secures individual boundaries (17). ${ }^{10}$ By the nineteenth century, sight has become "the first of the senses, and to this day the only sense, to attain objective status" (17). ${ }^{11}$ The idea of objectivity as somehow free of affect arises along with the subject/object distinction, a distinction isolating the self from others and the world around it. As we have seen, this contained or bounded self founds a fantasy of discrete isolation, of separation and of distance (19), establishing reality as contained affect:

The Western psyche is structured in such a way as to give a person the sense that their affects and feelings are their own, and that they are energetically and emotionally contained in

8 Brennan's reference to the self as "a private fortress" recalls Lacan's discussion of the self, imagined as a fortress, in the famous "Mirror Stage" essay; see Lacan (1977).

9 Brennan's work linking self with the State parallels an aspect of Norbert Elias's early sociological work, where he couples a bounded (or self-contained) sense of the self with an equally bounded sense of society. See (Elias 1991). Thanks to Matthew Lamb for suggesting this link.

10 Susan James challenges this, suggesting that "many eighteenth-century writers [e.g., David Hume and Adam Smith] acknowledge the existence and significance of passionate transmission" (James 2006, p. 104). James notes, though, that there is a significant change in understanding (around this time) relating to the mechanisms that move the affects. Rather than entering or disturbing our bodies, the affects of others work on our imagination. Accordingly: "a broadly physical interpretation of transmission gives way to a broadly psychic one, which is compatible with, and may provide evidence for, a comparatively resilient conception of the boundary around the self. Ultimately, it could be argued that accounts (such as Smith's) "analyses sympathetic transmission as taking place mainly in thought, and as only minimally dependent on the body" (105).

11 "... nineteenth-century romanticism is the place where transmission retreated to, and like most retreatants, lost touch with social reality, for ill as well as good. The idea that the emotional connections between beings have an energetic force of their own, by dint of magnestism and romantic association, became less scientifically respectable" (18). For a discussion of the "nobility" of sight and its complex links with objectivity in the Western imaginary, see Jonas (1953) and Boulous Walker (2017, pp. 104-8). 
the most literal sense. In other words, people experience themselves as containing their own emotions. $(24-5)^{12}$

Charles Taylor's work on early-modern sources of the self explains this in terms of a change from external to internal accounts of ethical and moral being. For Taylor, the early-modern period is accompanied by "an internalisation of moral sources" or passions, with "the sources of moral strength" no longer seen as outside the self. Taylor describes the appearance of a bounded conception of self as a move away from an external account of affect, a move that instrumentalizes and internalizes the self's rational control over body, world, and passion (Taylor 1989, p. 151). ${ }^{13}$ Taylor's description of the historical emergence of an internalized sense of self is helpful for explaining why Brennan's recovery of a pre-modern externalized self appears literally out of place in the contemporary world. He writes:

"Our modern notion of the self is related to, one might say constituted by, a certain sense ... of inwardness ... In our languages of self-understanding, the opposition 'inside-outside' plays an important role. We think of our thoughts, ideas, or feelings as being 'within us' ... We are creatures of inner depths ... [This] is in large part a feature of our world, the world of modern, Western people. The localization is not a universal one, which human beings recognise as a matter of course ... Rather it is a function of a historically limited mode of self-interpretation ... the localization is bound up with our sense of self, and thus also with our sense of moral sources ... when a given constellation of self, moral causes, and localization is ours, that means it is the one from within which we experience and deliberate about our moral situation. It cannot but come to feel fixed and unchallengeable, whatever our knowledge of history and cultural variation may lead us to believe". (Taylor 1989, pp. 111-12)

Brennan's return to an externalized account of affective transmission offers a creative reworking of repressed pre-modern ways of thinking of the self, a reworking that forces us to engage with what Taylor refers to as our fixed and unchallengeable beliefs concerning the constellation of self and moral cause. In doing so, she counters the isolating repressions of the foundational fantasy-and the self-contained or bounded subject this gives rise to-to explore what I have already referred to as the intelligence of the flesh. It is here, she maintains, that the body is implicated in its own thinking. The body's "consummate intelligence" outruns the "slower linguistic consciousness, which formulates the reasons for our actions, claims intentionality after the fact, but is not the only intentional force within us" (146 emphasis added). There are, she claims, "subjective, affective, and driven paths embedded in flesh and blood"; there are "intentions beyond those of the conscious self, although the conscious self works hard to convince itself that its actions are done for its own ends" (146). With this, Brennan rethinks intentionality in a direction that would not be out of place, I think, in Maurice Merleau-Ponty's important late phenomenological work. ${ }^{14}$

Brennan opposes the ego or ego-consciousness with what she refers to as the discerning I, the "Other I" (162), or the "organizing soul" (163). This couple (ego/“Other I") founds a series of ongoing oppositions that play between the poles of the self-contained subject and the intelligence of the flesh. ${ }^{15}$

12 Self-containment coheres with self-absorption and Brennan argues that the foundational fantasy disposes the self to perceive "activity as mindless when it is not directed from the standpoint of self-interest" (136). While constructing a self-contained barrier against the other, the foundational fantasy is also involved in promoting an inertia that slows the subject energetically (147).

13 See James (2006, pp. 103-4) for a brief comparison of Brennan's and Taylor's accounts.

14 Indeed, a discussion of Maurice Merleau-Ponty's early work on the body-subject, embodied consciousness, and his reworking of intentionality is also appropriate here. Surprisingly, there is only one brief mention of Merleau-Ponty's work in Brennan's text (Brennan 2004, p. 108) and this is in reference to his account of subjectivity as subject to a spatial operation. See Merleau-Ponty $(1962,1968)$.

15 Brennan's work is structured through a series of interconnecting binaries, though terms such as attention and discernment are meant to undo or deconstruct any simple opposition between, for example, mind and body, i.e., to demonstrate the embodied nature of consciousness. Brennan states that her thinking in binaries approximates "the palpable experience of being pulled in two directions" in relation to the other, e.g., to be angry and to criticise, while simultaneously being drawn to listen to and communicate with the other (120). 
While the ego is tied to judgment, projection, and the negative affects, the "Other I" is the locus of discernment, love, and living attention. The ego is preoccupied with "me" and "my interests", and acts in ways that threaten others in the pursuit of short-term self-interest (163). We can think of the ego as the site of the spontaneous emotions (negative affects), and the "Other I" as the domain of the senses. The senses are the vehicles of attention - "the seneschals of attention" which connect the cognitive faculty of linguistic thought with the "fleshly knowledge or codes of the body" (136). Sensory registration "bypasses perceptions structured from the subject standpoint" in order to search for a language of soft reason to circumvent the ego (137). The senses, Brennan reminds us, are not the emotions; they are, rather, "the vehicles for their discernment" (137).

The ego-consciousness, Brennan writes, "knows less than the senses whose multiple communications battle with the ego's censorship and denial." Both the senses and the information channels of the flesh "are intelligent, aware, and struggling either to overcome or get through to a slower, thicker person who calls itself I, or worse, me" (138). The ego and the senses both speak; the ego a language of the affects, and the senses a language of soft reason..$^{16}$ Whether soft reason infiltrates our ego-consciousness depends largely, as we will soon see, on opportunities for the education of the senses in the arts of discernment, love, and attention. ${ }^{17}$

\section{Attention and Affect}

Of the many couples Brennan constructs, the distinction between attention and affect is possibly the most illuminating, providing as it does a key to Brennan's thinking on the subject. While both direct energy toward the other, they do so in considerably different ways. Attention toward another can carry with it negative affect or self-interest, but this is different to attention that originates in love. "Attention to something other than oneself, or the living energy that enlivens another without affective penalty, is not the same as an affect directed toward another, because the affect carries a message of self-interest along with the attention it rides on" (41). Self-preservation and self-interest ${ }^{18}$ strengthen $^{\prime}$ the ego, which thrives on negative affects such as anger, anxiety, and fear. In fact, Brennan claims that the ego is simply a constellation of affects formed around the subjective standpoint (118). The egoistic constellation or gathering of affect reinforces the aggressive barriers of self-containment. For Brennan, the transmission of negative affect is evident in the processes of judging and projecting. Passionate judgment in the form of comparison (envy and humiliation or narcissistic superiority) distances the self from the other through fear, anxiety, and paranoia (109) and by generating aggressive reactions. This egoistic constellation is, Brennan claims, increasingly solidified "as the Western centuries progress" (106). For Brennan, the hardening of the negative affects is a social phenomenon, with the consequence that transforming them requires political as well as personal work (139). ${ }^{19}$ In former times in the West, the aggressive quality of the affects were to some extent disciplined and possibly even cathected by social ritual designed to dissipate the energy of negative affect. Spiritual exercises, religious practice, and strict codes of manners ${ }^{20}$ have all served in different ways and at different times to counter the extreme spectrum of negative affect:

16 Brennan's work, here, brings to mind Emmanuel Levinas's distinction between a coercive reason and a noncoercive "sweet" reason. See Levinas (1998).

17 Brennan links the senses with feeling, distinguishing them thus: "By 'sensing,' I mean the deployment of smell and hearing as well as open vision, while by 'feeling,' ... I mean the accurate and rapid interpretation of this information via language. Feelings are sensations that have found a match in words" (19). Elsewhere, she refers to the "educated feelings" (122).

18 Brennan claims that "the place of self-interest, or the subject-centred standpoint, is at the bottom of the prejudice against the intelligence of the flesh" (140).

19 And further: "In political as well as personal cases, changing the disposition of the affects (from passivity-inducing and raging judgments of the other to love or affection) requires practice and knowledge. The understanding and deployment of feelings is critical in both endeavours as the means for discerning affects and reconnecting with the original knowledge of the senses" (139).

20 Angela Nagle's outstanding work on manners in relation to current debates around the myth of "political correctness" is relevant here; Nagle (2017). 
The other I, the one who once struggled with demons, then fought the passions, and now negotiates with the ego, is less and less in evidence. This is especially apparent in the decline of religious practices and civil codes of courtesy ... civil and religious codes may be remnants of a conscious knowledge of transmission. In cultures where knowledge of transmission is unconscious, these codes have less meaning and are easily displaced by arguments that one should be 'free to express one's feelings'. As the stoically inclined realized long since, if freedom means anything, it is freedom from possession by the negative affects. (118 emphasis added)

For Brennan, affect can partially be understood through the psychoanalytic lens of the death drive. As we know from Freud, stress, anxiety, envy, and aggression work in the service of the death drive to undo connections and to destroy things. Affect, Brennan claims, "works against connective growth rather than for it" (36); as such it results in a loss of energy and a depletion of the subject. This is no doubt why the ego is so concerned with its own self-preservation, and while this can very clearly be to the good, it can also provide the foundation of an aggressive injustice toward the other-an energetic projection of negative affect designed to release hostility and to wound and deplete the other. Affect in the service of self-interest calculates advantage for the ego and severs links with the other, including the otherness of one's own bodily self (141). By focusing on its own ends, the ego sets itself up as judge in all interactions involving the other; in fact, judgment is the motor of the projection of the affects.

\section{Judgment as the Projection of Affect}

In Brennan's account, judgment involves a kind of Hegelian projection by the self onto the other, or by the master onto the slave. Judgment frees the subject from its own negative or aggressive affects, but only if the other is willing to carry the projected affect (111). ${ }^{21}$ "For the one who is projected upon, the drive becomes an affect, a passionate judgment directed inward, a judgment that constitutes a kind of hook on which the other's negative affect can fix" (111-12). The subject's projected judgment, if taken on by the other as aggression, can be turned inward and experienced as depression, leaving the other depleted and lacking in energy. This projected judgment temporarily frees the subject of his or her negative affect. The transmission of affect is thus Brennan's way of speculating on what we can call the porosity of the energetic exchange between subject and other at the intersubjective level.

... when I judge the other, I simultaneously direct toward her that stream of negative affect that cuts off my feeling of kinship from her as a fellow living, suffering, joyful creature ... The act of directing negative affects to the other severs my kin tie with her by objectifying her. I make her into an object by directing these affects toward her, because that act marks her with affects that I reject in myself- 'these affects do not exist in me, but in her.' I assume that she does not feel as I do. At the personal level, the othering underpinned by judgmental projections is evident in the scapegoating that occurs in most familial or professional communities. At the cultural level, these judgmental projections feature in othering by race or sex or sexual orientation. Here, the other, collectively, becomes feminized,

21 The question of the other being willing to carry the affect is a complex one. What does the term "willing" convey here, a fully conscious awareness, or something less than this? If we consider that Brennan's account focuses on women and "feminine beings" as those most often the recipients of projected affect, then Simone de Beauvoir's account in The Second Sex could be helpful. Recall that Beauvoir inquires into the nature of woman's willingness to be other to man's absolute subject. From here, she questions whether this amounts to an act of moral fault on the part of woman, or whether the category of oppression can help us to see this in another light: "our perspective is that of existentialist ethics ... There is no justification for present existence other than its expansion into an indefinitely open future. Every time transcendence falls back onto immanence, stagnation, there is a degradation of existence into the en-soi-the brutish life of subjection to given conditions - and of liberty into constraint and contingence [object-being]. This down fall represents a moral fault if the subject consents to it; if it is inflicted upon him, it spells frustration and oppression. In both cases it is an absolute evil. Every individual concerned to justify his existence feels that his existence involves an undefined need to transcend himself, to engage in freely chosen projects" (Beauvoir 1984, pp. 28-29, emphasis added). 
that is, styled untruthful by nature, too emotional, less logical, more superstitious than us reasoning beings. (119 emphasis added $)^{22}$

Judgment, for Brennan, is the state of being possessed by the affects. Discernment, as we will see, is the ability to detach from these affects-to be self-possessed. Grief, anxiety, and fear are states that allow negative affects, such as anger, to take hold (119). It is these affects that we then project in our various passionate judgments of the other, diminishing our abilities (both in judging and being judged) to concentrate and to pay attention (126-7). Judgment deploys the energy of the negative affects either by projecting externally as anger toward the other, or by introjecting internally as depression.

If we conceive the moment of judgment as the moment in which we forcefully embrace or project an affect, then we can accept that the judgment itself is a deployment of energy directed toward an object, and as such, an affective force in itself. But because the stream of judgments one makes in daily life takes place in the context of affective transmission, the lessons learned from the comparison of states of feeling are constantly interrupted by waves of affect. It is not only one's own inner states that are the objects of a meditative investigation by reflection and evaluation, as they were for Descartes and Hobbes. It is also a question of oneself and the other. (126)

Whether projected or introjected, judgment disrupts our attentive faculties, diminishing our abilities and opportunities for self-reflection and for civilized relations with the other. In this sense, the ego isolates itself further from the other and the world. When judgment turns to coldness, or more particularly to cold calculation, attention is suspended in favor of a preoccupation with one's own position and a narrowing of one's own focus. "It forecloses the feeling intelligence at work in 'evenly suspended attention' ${ }^{23}$ in which one is open to new ideas about the other". And because the feeling intelligence "works by making connections between new and existing ideas, any constraint on it (such as a preoccupation with prestige) is a constraint on the soul's growth through knowledge" (131). A hostile or calculating judgment, in Brennan's account, closes down our relations with the other and our future possibilities in and through our selves. It does so by consciously denying the affective connectivity (and its consequences) that circulates energetically between subject and other.

\section{Attention and Discernment}

We have seen that attention and affect are at the heart of Brennan's energetic account of intersubjectivity. We have looked briefly at affective transmission and the projections of judgment that sustain this energetic transfer. It is time, now, to look at attention and the role it plays in Brennan's account of discernment which, for her, counters the negative projection of judgment. While judgment attaches to and is possessed by the affects, a cultivated attention provides us with the means to detach from these. Brennan has many ways of talking about this attentive mode but, in each case, it indicates a living energy devoted to contemplation, reflection, and love. Both love and reason are names she ascribes to the living attention that allows us to detach from the negative affects. ${ }^{24}$ While judgment

22 And further: "When Rousseau in Émile, or On Education demands that Sophie be educated to lie, while Émile only speaks the truth, he is doing no more than putting the realities of modern affective projections into words. By encouraging attitudes of suspicion, or (worse) encouraging the idea that a privileged class, sex, race, or caste is free of dissembling, emotionality, or stupidity, one comes to overvalue one's own capacities" (119). We can think of Brennan's "feminized other" as those recipients of the feminine side of the "symbolic distribution" that Luce Irigaray explores throughout her work. In this sense, the "symbolic distribution" that separates reality out (hierarchically) into mind/matter, culture/nature, and masculine/feminine can be understood as a judgmental projection of a patriarchal worldview. See Irigaray (1985).

23 Brennan borrows the phrase "evenly suspended attention" from Freud's use of the term, referring to a state in which we attend lightly and non-deliberately by refraining from "confirming what one already knows" in order to remain open to new ideas about the other. (Brennan 2004, p. 197, n. 20).

24 Brennan writes: " ... reason and love are both names for aspects of living attention; living attention is the condition of reasoning and the embodiment of its connective ability as well as the gift from the mother to the child or the lover to the beloved" (41). 
involves either the projection or introjection of affect, attention detaches somewhat paradoxically by permitting us to embrace the affect. What I think Brennan means here is that through discernment and living attention a different form of judgment is possible, and while she does not refer to it in this way, I suggest that it comes close to Jean-François Lytotard's notion of indeterminate judgment-a judgment that judges in the absence of criteria. ${ }^{25}$ For Brennan, this paradoxical detaching and embracing of affect allows us, with the help of concentration, attention, and reflection (a concentrated change in thought), to resist and ultimately to transform the affect and thus to modify its energetic pathway. This transformation, however, is no easy task and is only possible in climates where love, hope, and optimism flourish (129). ${ }^{26}$ In such climates, we can face the affect without the fear or anxiety that in other contexts bind us to it.

While Brennan ties affect and judgment with the death drive, she sees living attention as an expression of the life drive-the principle that organizes, binds, unites, and connects. Acting and thinking are the results of attention in the service of the life drive, and intellectual concentration exists where and when the subject is permitted to thrive (36). The field of living attention is, for Brennan, the life drive directed toward "a perpetual act of love" (117).

Attention is attentive to the inner silence that occurs in the cessation of projected affect. In this state one can literally attend to the affect; one can reflect on the negative affect one experiences. This simultaneous embracing/detaching involves "an exercise in feeling, but feeling of a calming and discerning variety" (128). By liberating reflection, one is able to disarm or disrupt the cycle of negative and aggressive affect. ${ }^{27}$

The "Other I", rather than the ego, is the agency that gathers attention in order to discern those affects capable of disrupting concentration, reflection, and focus. In this, it supports the best work of philosophy and the philosopher. Brennan maintains that it "directs attention away from fantasy and distraction", providing us "an alternative to the subject-centred focus" (129). The attentive mode of the "Other I" bypasses the projected and introjected pathways of judgment in becoming a conscious consciousness (155) capable of expressing or putting into words what has been overlooked or repressed in the porous space between subject and other: "the more conscious we become of what we repress ... or ignore, the less we think in projected and judgmental terms, the less consciousness is drowned in the swamp of affects" (155). In order for the "Other I" to attend to this ignored or repressed space between self and other, we need to cultivate "attention to the pathways of sensation in the body" (153).

Such attention is the work of discernment, and Brennan argues convincingly that to discern is to challenge the obstinate and well-worn pathways of affective transmission. While the negative affects result in the projection or introjection of judgment, attention (pre-eminently living attention) results in discernment - a faculty altogether different from the judgmental judgment that Brennan describes. Like attention, discernment helps us simultaneously to embrace and detach from the affects. "Discernment, in the effective world, functions best when it is able to be alert to the moment of fear or anxiety or grief or other sense of loss that permits the negative affect to gain a hold. Discernment then is allied to a position in which one receives and processes without the intervention of anxiety or other fixed obstacles in the way of the thinking process" (119-20). Discernment works to reconnect thought to affect, thus permitting us conscious awareness of the transmission of affect. Once affect is conscious and discerned, we have options for how we are able to respond to and deal with the negative affects. The illusion of self-containment in the founding fantasy helps to perpetuate the less than conscious appreciation of the transmission of affect (114). As self-contained, discrete, and insular beings, our

25 This point requires a paper in its own right. See Lyotard's The Differend (Lyotard 1988) and my discussion of it in Boulous Walker (1998, pp. 68-84).

26 Brennan notes: "That optimism also effects a biochemical shift (where different hormonal directions take over from others) is now a matter of record" (129).

27 "One lets go of the affect by examining its course or by allowing the course of other, calmer, feeling to assert itself. This examination means exercising attention, which is literally an aid to growth, whether given to oneself in the process of liberating reflection (antithetical to narcissistic fantasy) or to those who need it" (128). 
consciousness (understanding) is actually less than conscious, in that our negative projections toward others remain opaque to, or hidden from, our conscious minds. As we have seen Brennan claim, while knowledge of the transmission of affect was, in the West, once conscious, the "deadening, passifying affects" of the modern age have worked to repress this knowledge. As a consequence, the problem of discernment-of how we practice a discerning attention-becomes a major concern in the contemporary world (117). Philosophy is key here, as ancient philosophical practice reunites us with what we might call attentive discernment. Brennan writes: "forms of reflective or meditative analysis have been in practice since the origins of philosophy (and this practice originally constituted philosophy)" (117). I think philosophy in this ancient form is attentive discernment, and its roots in what Pierre Hadot would refer to as "spiritual exercises"28 support Brennan's account of the need for personal and political transformation. Philosophy becomes, once again, a way of life, a practice or series of reflective exercises offering us opportunities to perfect our relations with our self and with others.

Discernment is the practice that bridges the senses with the intellect, searching for an expression or words to communicate feelings that may otherwise remain mute, undisclosed. Feelings, in Brennan's account, are sensations which have been expressed. Discernment works:

by sensing (touching, hearing, smelling, listening, seeing) and the expression of the senses, particularly in words. It works by feeling (sometimes in the dark), and it works deductively, often with insufficient information; it makes mistakes when it is rushed to conclude before its time (it is rushed by the ego, which always needs a plan) or when it is delayed by the ego (which is always anxious about doing the wrong thing). Discernment, when it doubts the ego's judgment, registers as a feeling. Sometimes such feelings can be articulated with relative exactitude; they can be named, and reasons for their existence can be adduced. But this, precisely, requires a vocabulary; that is why we defined feelings as sensations that have found a match in words. (120)

So, discernment is an expression of the senses and one that registers as a feeling when it finds itself at odds with the ego's judgmental projections. This fine process of discernment has much to say (I think) to Lyotard's work on judgment, the différend, and the injustice that registers as feeling. ${ }^{29}$ Both Brennan and Lyotard provide us with a philosophical or ethical vocabularies to begin thinking through our intuitive modes of intersubjective exchange with the other. There is a connection, too, with Hans Ulrich Gumbrecht's literary work on reading for Stimmung "to follow configurations of atmosphere and mood in order to encounter otherness in intense and intimate ways" (Gumbrecht 2012, pp. 12-13). Gumbrecht refers to this experimental form of reading in terms of "discovering sources of energy in artifacts and giving oneself over to them affectively and bodily-yielding to them and gesturing toward them" (Gumbrecht 2012, p. 18). Ultimately, reading for Stimmung transforms the inner self in vital and energetic ways, reminding us, too, of the importance of writing and literature in a discerning exploration of the other and the self.

Earlier, I referred to the importance of the education of the senses in the art of discernment if the language of soft-reason is to have any chance to infiltrate ego-consciousness. As we have seen, Brennan claims that the education of the senses and the education of the feelings is inadequate in the modern world, and that given the decline of religious codes and codes of courtesy, philosophical practices of discernment become all the more important. Practices of comparison, detachment, and living attention promote the discerning qualities required for a conscious awareness of the transmission of energetic affect. Brennan refers to these practices as habits of personal discernment. She writes:

28 See Hadot $(1995,2002)$.

29 Lyotard (1988). 
The production of habits appropriate to discernment is a matter of personal practices involving comparison, recollection and memory, and detachment. These practices are held in common in the meditative tradition in philosophy, in psychoanalysis, and in meditation itself ... Personal discernment, in summary, involves evaluations of one's inner states and evaluations of the origin of the affects. These are effected by detaching from one's passionate judgments and affective depressions, and by observing their sequence. One discerns these things with attention. $(126,130)^{30}$

While Brennan's descriptions of the philosophical practices of discernment may appear to occupy the preserve of the initiated, it is important to remember that her insights are founded on what we might refer to as a range of "everyday" practices that provide us relief from an unthoughtful or unthinking relation with negative affect. These, very simply, revolve around a conscious, intentional, and attentive relation with love. For example, Brennan claims that the other feels it when we offer love or the gift of our attention, and that the negative affects are transformed when love "or its variants (wit, reason, affection)" undo aggression (135). For Brennan, "the transformation of the affects at large requires being in the world, rather than living the life of the mind. It requires subjecting oneself to eddies or even torrents of affects, while somehow maintaining equilibrium. Such is the practice of souls who, when assailed by envy or contempt or rage do not take it personally, for they know that these are forces that possess even the finest souls, whose discerning agencies sometimes cower in the corners of their possessed minds, waiting for it to be over" (135). Kindness, Brennan claims, is simply the refusal "to pass on or transmit negative affects and the attempt to prevent the pain they cause others"; it is the "protective attitude [or thoughtfulness] that stands between another and the experience of negative affects". Love is "seeing the other in a good light, giving them the good image, streaming one's full attentive energy toward another and another's concerns, rather than one's own" (124). Kindness and love are simple and everyday interventions, ones that literally position us as thoughtful beings or bodies between the other and the negative projections. By putting our bodies on the line, we refuse to perpetuate (unthoughtful) hostility and aggression. We choose connection rather than separation. We listen and wait, where fools-in other circumstances-may choose to rush in.

Attention is tied to consciousness-to Brennan's conscious consciousness (attentive to its own potential projections) - and the more we practice living attention with and through discernment the less we are held by projected and judgmental affect, the "less consciousness is drowned in the swamp of affects" (155). But, for Brennan, this kind of consciousness is dependent on inventing or reinventing a language appropriate to the intelligence of the flesh, as presently we are ill equipped to connect sensation, affect, and word (153):

"Extending conscious sensation, finding the words or images, means grasping the nuances of fleshly grammar and alphabets". (155)

All of this requires connecting thinking to sensation (157) and, again, this is what Brennan means by the intelligence of the flesh. ${ }^{31}$ It requires, too, a conscious awareness of the myriad ways in which we are affectively and energetically connected to the other and to the living world. In essence Brennan is clear that this "shift downward into the physical", or the material, leads us back to where philosophy, in the West, begins (163). ${ }^{32}$ This arguably elemental practice provides us with a future philosophy or ethics - an attentive awareness of the delicate web of self, other, and world.

30 We can think of Simone Weil's work on attention and grace alongside Brennan's work on attention and discernment (Weil 1951, 1995, 2002). See my discussion of their relation in Slow Philosophy (Boulous Walker 2017, pp. 180-82).

31 Brennan refers to the "resurrection of the body" and by this she means attention to the senses in order to extend conscious understanding (159).

32 "Then we will know how the form-giving capacity inheres in the very nature of energetic matter, now as it always has done. We will feel it and know in a united body and soul that the matrix was never, and is never, passive; it is simultaneously active and receptive, intelligent and substantial, as giver of life" (163). 
Brennan's gesture back to the origins of philosophy in the West is important and this has much to do with restrictive modes of modern thought. The contained subject-the individual imagining itself as isolated from affective relations with others-is the same subject who inhabits a certain mode of modern philosophical work. Emmanuel Levinas has spoken of this, reminding us of the violence of a coercive reason, where philosophy risks incorporating its other (and the other's otherness) into the Same. Philosophy reduces its subject to an object and contains by assimilation-reducing the foreignness of the other to its own self-knowledge and understanding. For Levinas, in its negative forms, the reasoning will risks appropriating the other and thus foreclosing any understanding of the intricate intersubjective bond. He writes of: "[T] he notion of an intellectual activity or of a reasoning will-a way of doing something which consists precisely of thinking through knowing, of seizing something and making it one's own ... an activity which appropriates and grasps the otherness of the known. A certain grasp... Knowledge as perception, concept, comprehension, refers back to an act of grasping" (Levinas 1989, p. 76).

We can think of Levinas's point here in terms of the violence of the modern ego, indeed in terms of certain forms of philosophy as negative affect. If we do so, then this raises the question of philosophy's suitability to explore and account for the transmission of affect—or, at least the suitability of a certain form of philosophical work to do so. Is Brennan in danger of working within a tradition that paradoxically reinforces the very forms of subjectivity and knowledge she hopes to challenge? Is there a risk that her philosophical gesture will echo philosophy's appropriation of the other? Interestingly, Cixous warns: "philosophy has always wanted to think its other, to interiorize, to incorporate it. From the moment it thinks its other, the other is no longer the other but becomes the same" (Cixous 1992, p. 90). ${ }^{33}$ Brennan is, I think, well aware of the risks of philosophy in its more restricted forms, in its less than ethical modes. She is aware, too, of those important moments throughout the history of philosophy in the West, when philosophers speak across the chasm that separates self from other, undoing the negative affect of projection that keeps the two apart. Although Brennan mentions Levinas's philosophy only once, and in passing (Brennan 2004, pp. 194-5 n. 2), we can say that his philosophy engenders the kind of noncoercive sweet reason or the soft voice of reason that Brennan applauds (Brennan 2004, p. 138).

While Brennan's gesture might well risk echoing philosophy's assimilation of the other, I would argue that she escapes this fate by writing on the borders between philosophy and two of its most notorious "others"-psychoanalysis and feminism. These practices offer Brennan the opportunity to shift terrain and modify her "philosophical" gesture, i.e., to stop short of simply theorizing or incorporating affect. In effect, these practices provide her with a passageway to the domains of literature and writing. They provide her a passageway to an arguably more nuanced exploration of affect, one that I think we can better appreciate by considering Cixous's work on porosity, vulnerability, and writing.

\section{Reading Brennan with Cixous}

In the introduction to this paper, I noted that Cixous's work on the entre deux relation explores the space of vulnerability between self and other (Cixous 2006). Briefly, now, I would like to conclude by offering a few thoughts on how we might think of her focus on the vulnerable relation in terms of Brennan's work on the transmission of affect, and by emphasizing that Cixous's work transfers this focus on our porosity toward the fields of literature and writing. Why is this significant? Because Brennan argues for the importance of language and words to symbolize the protective attitude of thoughtfulness. She reminds us that discernment works, in large part, by providing words for the

33 Cixous's relations with both philosophy and "writing" are complex. Throughout her work, she "moves between philosophy and poetry, while remaining unfaithful to both" so as to draw our attention to the limitations of a strictly bordered and conceptual discourse reduced to the functions of naming and concluding (Buys and Polatinsky 2009, pp. 79-80). 
expression of the senses, articulating feelings, naming sensations, adducing reasons: "this, precisely, requires a vocabulary; [and] this is why we defined feelings as sensations that have found a match in words" (Brennan 2004, p. 120). Cixous's work on writing and literature provides this ethical vocabulary, words to help us chart our way through the complex modes of intersubjective exchange. Words to encounter otherness in intense and intimate ways. Words that affect us bodily, opening us to the other in vital and energetic ways. This is helpful because Brennan calls for us to invent or reinvent a language appropriate to the intelligence of the flesh (a discerning language), so as to connect sensation, word, and affect:

"conscious consciousness is only possible when we invent or reinvent the words to say it. The transliteration into language from the minutia of sensory knowledge and its sifting may be processes entirely unknown to consciousness at present; the lifting of affective and projected judgments may be felt only as a sense of openness to others and a renewed ability to learn, but it marks the beginning of something more. Extending conscious sensation, finding the words or images, means grasping the nuances of fleshly grammar and alphabets. It means describing and accounting for those sensations, which entails translating them into the everyday currencies of speech and so extending the range of their visualization". (Brennan 2004, 155 emphasis added)

Cixous offers us such a translation for the everyday. Throughout her work, she examines the ways that writing encodes the intensities in our affective relations, offering us both a record of these intensities, and a process that links to (and symbolizes) what Brennan refers to as discernment. For Cixous, writing and literature are the places of the unfolding of a vulnerability to the other-a revelation of that vulnerability. We can, I think, suggest that Brennan's ethical account of the affective and energetic connection between self and other is, essentially, an account of the consequences of what Cixous refers to as our porosity. Simply put, I am vulnerable to your projections, as you are to mine. I am open to you, as you are to me. But what is the nature of the porosity that Cixous explores? What does it mean to say that the porous space between self and other (the entre deux) is characterised in terms of a potential danger?

To understand the kind of vulnerability that Cixous explores in her writing, we need to acknowledge the different way she frames the relation binding self with other. Throughout her work, she emphasizes an extreme ambiguity in this relation at odds with more singularly hostile Hegelian accounts of intersubjectivity. ${ }^{34}$ For Cixous, the ambiguous nature of our being involves a complex dialectic between intimacy and threat, one that opens us to the possibility of risk. Indeed, in her work Stigmata, Cixous explores the intricate connections between vulnerability and wounding. Here, she argues that writing allows us to bypass our defenses in order to reach inside the open wound we carry as a result of our vulnerable opening to the other. Writing permits us something like a fearless access to the totally foreign sense of the other (Cixous 1998). ${ }^{35}$ What is ambiguous in this account, is the sense in which vulnerability channels a relational and life-affirming connection with the other, while simultaneously acknowledging the possibility of threat and violence. As such, writing, like vulnerability itself, is understood-at its best-as a transformative experience opening us to the full complexity of our porous being. In writing we encounter the wound and the scar. In The Day I Wasn't There, Cixous writes: "With my mouth open and all my teeth gleaming on display I was like a wound that I kept reopening even when I wanted so badly for the scar to heal. My smilingness was beyond my control ..." (Cixous 2006, p. 15). Cixous links the wound, porosity, and an excessive receptivity with the confining and enveloping context of the other:

34 Cixous claims that the Hegelian other is simultaneously both hostile and distant, threatening the self with loss-the loss of property, prestige, freedom and, potentially, life (Cixous 1981, pp. 48-50).

35 For a discussion of the relation between vulnerability and wounding, see Gilson (2011). 
"It's this human porosity that bothers me and I can't escape since it is the fault of my skin, the extra sense which is everywhere in my being, this lack of eyelids on the face of the soul, or perhaps this imaginary lack of imaginary lids, this excessive facility I have for catching others, I am caught by persons or things animated or unanimated that I don't even frequent, and even the verb to catch I catch or rather I am caught by it, for, note this phrase, it's not I who wish to change, it's the other who gets his hooks in me for lack of armour". (Cixous 2006, p. 18)

Throughout her work Cixous charts the play between a destructive force and a regenerative openness in the ethical and literary spaces of the entre deux. It is this play (between destruction and regeneration) that marks the space as vulnerable-open to a porous longing between self and other. ${ }^{36}$ As we have seen, the entre deux is, for Cixous, the space of a profound ambiguity (Boon 2013, p. 86) enabling an ethical encounter (or staging of otherness) between self and other to take place. This encounter is simultaneously both intimate and threatening, because the self is open and vulnerable to "the horrifying Other" — to difference. While vulnerability is typically characterized as a liability, a trembling, or a weakness (Boon 2013, p. 85), ${ }^{37}$ Cixous's work offers a more nuanced account of susceptibility as a "wounding", one that hovers between horror and regeneration. As such, the porosity that makes me vulnerable to the other does not in any simple sense result in a solely destructive outcome (Boon 2013, p. 86). As Cixous says, "one can think loss other than in the negative" (Cixous 1992, p. 67). One can, as well, think vulnerability other than in the negative. The porosity (permeability, penetrability) that exists between me and the other is the possibility of my openness to the other and to the world, and this can be for better or for worse (Cixous 2006). This kind of vulnerability involves an "active and ongoing engagement" with danger (Boon 2013, p. 85), a dangerous porosity that is simultaneously intimate (opening) and threatening (foreclosing). ${ }^{38}$ We can, with care and some hesitation, understand this ambiguous vulnerability in terms of the distinction Brennan draws between living attention and negative affect. Cixous's play between opening and foreclosing traces an arc similar to the one drawn between Brennan's discerning ability to simultaneously detach and embrace the affect. As such, Cixous's work permits us to think of Brennan's transmission of affect as the ambiguous site of a vulnerability that moves energetically and porously between a susceptibility to wounding (and an ability to wound) and a life-affirming opening to the other; it is a longing that literally transforms. In this sense, Cixous's porous self provides a counter to the "contained-self" we have seen Brennan identify in the founding fantasy, thus claiming allegiance with the intelligence of the flesh. Cixous's self speaks to Brennan's "Other I" or "Discerning I", the fully conscious consciousness of living attention and love. And it does so through writing.

Writing toward the other establishes a body-to-body passageway (a porosity) between the self and the other, one that Cixous claims as transformative. Writing is "the passageway, the entrance, the exit, the dwelling place of the other in me-the other that I am and am not, that I don't know how to be, but that I feel passing, that makes me live- that tears me apart, disturbs me, changes me" (Cixous 1986, p. 85). Writing is, to use Brennan's terminology, a kind of discernment in practice, a

36 Sonja Boon charts the importance of longing and intimacy alongside the "threatening encounter with a horrifying Other" throughout Cixous's work (Boon 2013, p. 85). Boon's analysis provides an insightful perspective on the significance of vulnerability and wounding in both the structure and meaning of Cixous's works. She notes that "while vulnerability may well be an opening, a wound, a stigma, Cixous's interest lies in our response to this wounding: do we close it up, sewing it tightly together to avoid any possibility of contagion? Or do we allow the wound to blossom, opening ourselves to new encounters and new possibilities, however joyous or painful they might be? In this way, Cixous suggests the necessity of considering vulnerability - as porosity - as both a point of horror and a promise of regeneration" (Boon 2013, p. 86). In this regard, Boon explores the "haunted" porosity of Cixous's book, The Day I Wasn't There [2006], in terms of "the longing that must remain eternally unassuaged" (Boon 2013, p. 87).

37 Cavarero (2011, pp. 30-31) rejects the equation of vulnerability with helplessness, arguing that while we can move beyond helplessness, our vulnerability remains with us throughout our lives. For a discussion of Cavarero's distinction, see Drichel (2013, pp. 3-4).

38 While the entre deux entails the play between opening and foreclosing, Boon observes that in The Day I Wasn't There it becomes, at times, "a space of undoing rather than foreclosure" (Boon 2013, p. 94). 
giving and a generosity that mirrors Brennan's acts of kindness and love. Indeed, for Cixous, writing is foremost a gift - a feminine gift of grace, orienting the one who writes towards life and the preservation of life (Sellers 1996, p. xiii). It is an act of generosity that acknowledges our debt to life. Writing establishes an intimacy and openness with the other that propels us beyond our limits towards a transformative future. Writing involves patience and waiting, a movement toward the other in passion and in grace.

In Cixous's early essay, "The Laugh of the Medusa", she already engages a positive account of porosity, one that explores the living boundaries of the other. Here, she characterizes writing as an in-between that passes entre deux - an undoing of the work of death:

"To admit that writing is precisely working (in) the in-between, inspecting the process of the same and of the other without which nothing can live, undoing the work of death-to admit this is first to want the two, as well as both, the ensemble of the one and the other, not fixed in sequences of struggle and expulsion or some other form of death but infinitely dynamized by an incessant process of exchange from one subject to another. A process of different subjects knowing one another and beginning one another anew only from the living boundaries of the other: a multiple and inexhaustible course with millions of encounters and transformations of the same into the other and into the in-between ..." . (Cixous 1976, p. 883)

If we were to ask what writing does, Cixous would remind us that it opens us to the other and thus to risk. Writing opens us to "the risk of other, of difference, without feeling threatened by the existence of an otherness, rather, delighting to increase through the unknown that there is to discover, to respect, to favor, to cherish" (Cixous 1986, p. 78). In risk, writing symbolizes and gives voice to our vulnerable selves, our porous selves. While it gives voice to our vulnerable and porous selves, writing is itself vulnerable and porous. Writing detours from the concept in order to be. In writing, Cixous's vulnerable and open self, counters the "ego consciousness" that we have seen Brennan depict in terms of self-preservation and self-interest. Her "self" attends and receives, slowly approaching the other with an effort that undoes the ego with its "pretense of mastering things and knowing things" (Cixous 1987, p. 20). For Cixous's self, approaching the other involves the "tender attentiveness of slowness" (Cixous 1991, p. 65), an intimacy that unfolds in infinite time (Cixous 1992, p. 3). Slowness founds the ethical relation with the other, and Cixous grounds this slowness in writing-a practice that has the ability to transport us to unfamiliar terrain (Boulous Walker 2017, p. 156) and to open us "onto the infinite registers of the other" (Cixous 1992, p. 135). Indeed, Cixous thinks of her own writing as a kind of attention, a writing by "[s]he who looks with the look that recognizes, that studies, respects, doesn't take, doesn't claw, but attentively, with gentle relentlessness, contemplates and reads, caresses, bathes, makes the other gleam" (Cixous 1991, p. 51). This ability to make the other gleam captures something of Brennan's focus on discernment, kindness, and love. While Brennan focusses on philosophy as an ethical passage toward the other, Cixous explores writing as a privileged form of this ethics. Why read Cixous with Brennan? Because Cixous understands that in writing, we begin the delicate task of inventing a vocabulary for the exploration of discernment, the protective attitude of thoughtfulness that connects our thinking with sensation, thus opening us to the other in hopeful and optimistic ways.

Funding: This research received no external funding.

Conflicts of Interest: The author declares no conflict of interest.

\section{References}

Ahmed, Sara. 2008. Sociable happiness. Emotion, Space and Society 1: 10-13. [CrossRef]

Beauvoir, Simone de. 1984. The Second Sex. Translated by Howard M. Parshley. Harmondsworth: Penguin.

Berlant, Lauren. 2011. Cruel Optimism. Durham: Duke University Press.

Bion, Wilfred R. 1961. Experiences in Groups and Other Papers. London: Tavistock. 
Blackman, Lisa. 2008. Affect, Relationality and the 'Problem of Personality'. Theory, Culture E Society 25: 23-47.

Boon, Sonja. 2013. Vulnerability, Longing, and Stigma in Hélène Cixous's: The Day I Wasn't There. SubStance 42: 85-104.

Boulous Walker, Michelle. 1998. Philosophy and the Maternal Body: Reading Silence. London and New York: Routledge.

Boulous Walker, Michelle. 2017. Slow Philosophy: Reading Against the Institution. London and New York: Bloomsbury.

Brennan, Teresa. 1992. The Interpretation of the Flesh: Freud and Femininity. London: Routledge.

Brennan, Teresa. 2000. Exhausting Modernity: Grounds for a New Economy. London and New York: Routledge.

Brennan, Teresa. 2002. Globalization and Its Terrors: Everyday Life in the West. London: Routledge.

Brennan, Teresa. 2004. The Transmission of Affect. Ithaca and London: Cornell University Press.

Buys, Anthea, and Stefan Polatinsky. 2009. The Provocation of Hélène Cixous: Philosophy in Poetic Overflow. Mosaic: An Interdisciplinary Critical Journal 42: 79-93.

Cavarero, Adriana. 2011. Horrorism: Naming Contemporary Violence. New York: Columbia University Press.

Cixous, Hélène. 1976. The Laugh of the Medusa. Translated by Keith Cohen and Paula Cohen. Signs 1: 875-93. [CrossRef]

Cixous, Hélène. 1981. Castration or Decapitation? Translated by Annette Kuhn. Signs: Journal of Women in Culture and Society 7: 41-55. [CrossRef]

Cixous, Hélène. 1986. The Newly Born Woman. With Cathérine Clément. Translated by Betsy Wing. Minneapolis: University of Minnesota Press.

Cixous, Hélène. 1987. Reaching the Point of Wheat, or A Portrait of the Artist as a Maturing Woman. New Literary History 19: 1-21. [CrossRef]

Cixous, Hélène. 1991. "Coming to Writing" and Other Essays. Edited by Deborah Jenson. Translated by Sarah Cornell, and Deborah Jenson. Cambridge: Harvard University Press.

Cixous, Hélène. 1992. Readings: The Poetics of Blanchot, Joyce, Kafka, Kleist, Lispector, and Tsvetayeva. Translated by Verena Andermatt Conley. Hemel Hempstead: Harvester Wheatsheaf.

Cixous, Hélène. 1998. Stigmata: Escaping Texts. Abingdon: Routledge.

Cixous, Hélène. 2006. The Day I Wasn't There. Translated by Beverley Bie Brahic. Evanston: Northwestern University Press.

Cixous, Hélène, and Mireille Calle-Gruber. 1997. Hélène Cixous, Rootprints: Memory and Life Writing. Translated by Eric Prenowitz. London and New York: Routledge.

Drichel, Simone. 2013. Reframing Vulnerability: "So obviously the problem ... "? SubStance 132: 3-27. [CrossRef]

Elias, Nobert. 1991. The Society of Individuals. Edited by Michael Schroter. Translated by Edmund Jephcott. Oxford: Basil Blackwell.

Figlerowicz, Marta. 2012. Affect Theory Dossier: An Introduction. Qui Parle: Critical Humanities and Social Sciences 20: 3-18.

Gilson, Erinn. 2011. Vulnerability, Ignorance, and Oppression. Hypatia 26: 308-32. [CrossRef]

Gorton, Kristyn. 2007. Theorizing Emotion and affect: Feminist engagements. Feminist Theory 8: 333-48. [CrossRef]

Gregg, Melissa, and Gregory J. Seigworth, eds. 2010. The Affect Theory Reader. Durham and London: Duke University Press.

Gumbrecht, Hans Ulrich. 2012. Atmosphere, Mood, Stimmung: On a Hidden Potential of Literature. Translated by Erik Butler. Stanford: Stanford University Press.

Gunew, Sneja. 2009. Subaltern Empathy: Beyond European Categories in Affect Theory. Concentric: Literary and Cultural Studies 35: 11-30.

Hadot, Pierre. 1995. Philosophy as a Way of Life: Spiritual Exercises from Socrates to Foucault. Translated by Michael Chase. Oxford: Blackwell Publishing.

Hadot, Pierre. 2002. What Is Ancient Philosophy? Translated by Michael Chase. Cambridge: Harvard University Press.

Harari, Fiona. 2011. A Tragedy in Two Acts: Marcus Einfeld and Teresa Brennan. Melbourne: Melbourne University Press.

Holding, Cory. 2007. Review: "Affecting Rhetoric". College Composition and Communication 59: 317-29.

Irigaray, Luce. 1985. The Power of discourse and the subordination of the feminine. In This Sex Which Is Not One. Translated by Catherine Porter. Ithaca: Cornell University Press, pp. 68-85. 
James, Susan. 2006. Perspectives on Teresa Brennan's The Transmission of Affect. Women: A Cultural Review 17: 103-6.

Jardine, Alice, Lundeen Shannon, and Oliver Kelly. 2007. Living Attention: On Teresa Brennan. Albany: State University of New York Press.

Jonas, Hans. 1953. The Nobility of Sight. In The Phenomenon of Life. New York: Harpers Row, pp. 135-55.

Klein, Melanie. 1957. Notes on some Schizoid Mechanisms (1946). In Envy and Gratitude: And Other Works, $1946-63$. London: Tavistock.

Kristeva, Julia. 1982. Powers of Horror: An Essay on Abjection. Translated by Leon S. Roudiez. New York: Columbia University.

Labanyi, Jo. 2011. Doing Things: Emotion, Affect, and Materiality. Journal of Spanish Cultural Studies 11: 223-33. [CrossRef]

Lacan, Jacques. 1977. The Mirror Stage as Formative of the Function of the I as Revealed in Psychoanalytic Experience. In Écrits: A Selection. Translated by Alan Sheridan. New York: W.W. Norton, pp. 1-7.

Levinas, Emmanuel. 1989. Ethics as First Philosophy. In The Levinas Reader. Edited by Seán Hand. Oxford: Basil Blackwell, pp. 75-87.

Levinas, Emmanuel. 1998. Otherwise than Being, or Beyond Essence. Translated by Alphonso Lingis. Pittsburgh: Duquesne University Press.

Lyotard, Jean-François. 1988. The Différend: Phrases in Dispute. Translated by Georges Van Den Abbeele. Minneapolis: University of Minnesota Press.

Massumi, Brian. 1995. The Autonomy of Affect. Cultural Critique 31: 83-109. [CrossRef]

Merleau-Ponty, Maurice. 1962. The Phenomenology of Perception. Translated by C. Smith. London: Routledge and Kegan Paul.

Merleau-Ponty, Maurice. 1968. The Visible and the Invisible. Translated by Alphonso Lingis. Evanston: Northwestern University Press.

Muñoz, José Esteban. 2007. 'Chico, what does it feel like to be a problem?' The Transmission of Brownness. In $A$ Companion to Latina/o Studies. Edited by Juan Flores and Renato Rosaldo. Oxford: Blackwell, pp. 441-51.

Nagle, Angela. 2017. A Tragedy of Manners: Trump and the new age of anti-PC transgression. The Baffler 36. Available online: https://thebaffler.com/salvos/a-tragedy-of-manners-nagle (accessed on 30 July 2019).

Oliver, Kelly. 1993. Reading Kristeva: Unraveling the Double-Bind. Bloomington: Indiana University Press.

Pedwell, Carolyn. 2014. Affective Relations: The Transnational Politics of Empathy. New York: Palgrave Macmillan. Rice, Jenny Edbauer. 2008. The New "New": Making a Case for Critical Affect Studies. Quarterly Journal of Speech 94: 200-12. [CrossRef]

Sedgwick, Eve Kosofsky, and Adam Frank. 1995. Shame in the Cybernetic Fold: Reading Silvan Tomkins. In Shame and Its Sisters: A Silvan Tomkins Reader. Edited by Eve Kosofsky Sedgwick and Adam Frank. Durham: Duke University Press, pp. 1-28.

Sellers, Susan. 1996. Hélène Cixous: Authorship, Autobiography and Love. Oxford: Polity Press.

Taylor, Charles. 1989. Sources of the Self: The Making of Modern Identity. Cambridhe: Cambridge University Press. Weil, Simone. 1951. Waiting on God. Translated by Emma Craufurd. London: Routledge and Kegan Paul. Weil, Simone. 1995. Gravity and Grace. Translated by Emma Craufurd. London: Routledge.

Weil, Simone. 2002. The Need for Roots: Prelude to a Declaration of Duties Toward Mankind. Translated by Arthur Willis. New York: Routledge.

(C) 2019 by the author. Licensee MDPI, Basel, Switzerland. This article is an open access article distributed under the terms and conditions of the Creative Commons Attribution (CC BY) license (http://creativecommons.org/licenses/by/4.0/). 

Article

\title{
The Answer is Paracritical: Caribbean Literature and The Limits of Critique
}

\author{
Jay Rajiva \\ Department of English, Georgia State University, Atlanta, GA 30307, USA; jay.rajiva@gmail.com
}

Received: 29 April 2019; Accepted: 11 July 2019; Published: 16 July 2019

check for updates

\begin{abstract}
I argue that both Rita Felski's postcritical model (as articulated in The Limits of Critique) and its academic reception are made possible only by ignoring or erasing African-American and Afro-Caribbean modes of engagement with art that predate and complicate the critical-postcritical binary. To counteract the vanguardism of this trend in literary studies, I pair Caribbean philosopher-poet Edouard Glissant's meditation on the origins of Creole speech as an indirect language of "detour" with Nathaniel Mackey's theorizing of black art as "paracritical" - a mode that assimilates performance and critique, language and metalanguage, and that sits adjacent to (and not against or behind) traditionally academic discourses of engaging with literature. If Glissant provides the cultural and philosophical frame for an Afro-Caribbean way of reading literature, Mackey supplies the artistic metaphor par excellence of the paracritical hinge, voiced in the idioms of jazz and blues. Finally, I examine how Glissant and Mackey's ideas find formal and aesthetic expression in Trinidadian-Canadian author Dionne Brand's 2005 novel What We All Long For, paying attention to the reader response engendered by the adjacencies of violence, empowerment, possibility, and desire in the novel. In order to analyze What We All Long For, we must promote the liveliness and vivacity of the reading experience and put the text under ethical scrutiny, evincing the paracritical faculty that Afro-Caribbean art demands: commingling the twin pleasures of reading and interpretation, establishing a counter-hegemonic model of literary engagement that implicates the reader without stripping away reading's pleasure.
\end{abstract}

Keywords: ethics; reading; postcritical; Afro-Caribbean literature; African-American literature; paracritical; Glissant

\section{Introduction}

In The Limits of Critique (2015), Rita Felski argues for a return to the pleasurable moods of readerly engagement, contra the paranoid, tired, and joyless state of critique she describes as the prevailing mode of literary criticism. Opening with the polemic that critique is "limited, not limitless ... that it does some things well and other things poorly or not at all", Felski offers a satirical yet recognizable image of the literary critic "holding a shield, scanning the horizon for possible assailants, fearful of being tricked or taken in", trapped "in a cycle of punitive scrutiny and self-scrutiny," in self-imposed exile from "a swathe of intellectual and experiential possibility" (Felski 2015, pp. 8, 12). The rise of the hermeneutics of suspicion, the obsession with critique at a clinical distance, detachment calcifying into ethical paralysis: in crystallizing these academic trends, Felski exhorts the reader to appreciate what literature makes possible, situating "ourselves in front of the text" instead of "looking behind the text-for its hidden causes, determining conditions, and noxious motives" (p. 12). Felski's argument is incredibly persuasive, partly because she is such an engaging prose writer, and partly because the insightfulness of her approach provokes at least two feelings in her readers: familiarity, on the one hand-aren't we all sick to death of critique?-and surprise, on the other, at how she able to offer such a "timely and diagnostically acute" (Beckwith 2017, p. 332) summary of both the problem and its 
solution. Critique, Felski avers, is not always or even often the best tool we have to approach a work of literature.

Proponents of Felski's stance have positioned postcriticism as an ethical way to revitalize humanities scholarship in an age when deconstructionist methodology has been accused of allowing right-wing "alternative facts" and endless moral relativity to proliferate. ${ }^{1}$ Felski herself frames the postcritical turn as a defense of the humanities, offering "a positive vision for humanistic thought in the face of growing skepticism about its value" (Felski 2015, p. 186). Conversely, her critics tend to perform their ideological opposition to her position through the vehicle of critique: pointing out weaknesses in her model (Best 2017, p. 338), or questioning the advisability of turning literary criticism into little more than "fandom", through the mechanics of "corporate restructuring" (Robbins 2017, p. 372).

Pause, though, and reflect on the cultural and spatial sensibilities of this arc: critical, then postcritical, with the underlying literary canvas left unrevealed. The vast majority of critical discourse on these debates revolves around Anglo-American fiction, broadly speaking, within a western, white intellectual tradition. The authors usually invoked fall squarely in the vanguard of that intellectual tradition: Woolf, Richardson, Nabokov, et al. It's a strange kind of tunnel vision, in which progress from critique to postcritique operates in the hermetically sealed environment of the Western academy. Robbins comes closest to articulating the larger ethical problem by observing that "socially engaged criticism" is already addressing the issue of critique more effectively than Felski's book, which he characterizes as too preoccupied (ironically enough) with "faultfinding" (p. 371). But this characterization is so abstract that it leaves room for nothing but a return to the same arena in which critique and postcritique are seemingly locked in mortal combat. The question remains: Why does the postcritical 'turn', which urges scholars to abandon the detachment and suspicion of critique in favor of affect, sympathy, and enjoyment, seem to be unable to acknowledge its own literary-cultural lineage?

In the article that follows, I argue that both Felski's postcritical model and its academic reception are made possible only by ignoring African-American and Afro-Caribbean modes of engagement with art that predate and complicate the critical-postcritical binary. To counteract the vanguardism of this trend in literary studies, I pair Caribbean philosopher-poet Edouard Glissant's meditation on the origins of Creole speech as an indirect language of 'detour' with Nathaniel Mackey's theorizing of black art as 'paracritical' — a mode that assimilates performance and critique, language, and metalanguage — and that sits adjacent to (and not against or behind) traditionally academic discourses of engaging with literature. If Glissant provides the cultural and philosophical frame for an Afro-Caribbean way of reading literature, Mackey supplies the artistic metaphor par excellence of the paracritical hinge, voiced in the idioms of jazz and blues. Finally, I examine how Glissant and Mackey's ideas find formal and aesthetic expression in Trinidadian-Canadian author Dionne Brand's 2005 novel What We All Long For, paying attention to the reader response engendered by the adjacencies of violence, empowerment, possibility, and desire in the novel. In order to analyze What We All Long For, we must promote the liveliness and vivacity of the reading experience and put the text under formal scrutiny, evincing the paracritical faculty that Afro-Caribbean art demands: commingling the twin pleasures of reading and interpretation, establishing a counter-hegemonic model of literary engagement that implicates the reader without stripping away reading's pleasure.

\section{Detour and Caribbean Speech}

Felski and her critics, of course, do not possess an ironclad monopoly on this tendency to universalism. Indeed, we can see in this debate a reflection of the old and familiar pattern of colonial violence, in which nonwhite and nonwestern modes of experience are erased, with the very act of erasure forgotten. In Poetics of Relation, Edouard Glissant offers a précis of this violence, by way of

1 See "But What about Love?" (Fuss), “Reading for Our Lives" (Beckwith), and “Critique is Ordinary” (Love 2017) for cogent defenses of Felski's position. 
a single crystalline trope: filiation, the projection outward that informs both history ("Myth") and narrative ("Epic"), "setting out upon the fixed linearity of time, always toward a projection, a project" (Glissant 1997, p. 47). Glissant's critical eye fixes upon filiation as an "imperative" that produces the very history, in the West, that ascends to the status of a given. The continuous "retelling (certifying)" of a creation story "guarantees that this same filiation" is reproduced in the world: one presumes that this Christian account of experience is the only possible account, treating the current time and place-the product of such a formation-as inevitable and universal (p. 47). Here, Glissant moves toward philosophical exegesis through an implied question: how does the Caribbean, the implied Other of this filiation or arrow-like trajectory, define itself in a tacitly white and Christian founding myth?

The Christianity of this founding myth is evident in the act of "universalizing linear time-before and after Christ", and thereby inaugurating "a chronology of the human race into general use, initiating a History of Humanity" (p. 48). Time, in other words, surges outward and forward, producing a world in which objects exist to be known and mastered in sequence. Later, this Christian filiation finds its "objectivized vision" in the scientific principle, which defines "the human race within the network of evolution" (p. 48). The eventual outcome, for Glissant, amounts to an epistemological violence, in which the "opacity" of the Other must be subsumed to the "transparency" of the western subject (p. 48). The choice, for the Other, is either assimilation or eradication.

Myth, then, contains a violence that is below the register of conscious thought, grounded as it is in an unacknowledged circuit of epistemological projections. In this circuit, the fear is of contamination—of mixing, rather, with all the xenophobic underpinnings of fascism in 1939 Germany, the long history of white attempts to legislate against 'miscegenation' in the US, the recurring demonization of immigrants and immigration. All gesture back to this filiative connection, the "legitimacy" of which is "disrupted by the abduction of Helen (with its threat of mixing the blood of East and West)" (Glissant 1997, p. 50). To the fear of mixing Glissant opposes Creolization-the encounter with difference and continual transformation in the Caribbean that characterized the colonial period. The chain of islands constituting the Caribbean, each marked by successive waves of colonization over hundreds of years, forms the terrain for transformation, defining the region through three terms: choq (shock), métissage (mixing), and the linguistic synthesis of Creolization. In this process, Creole dialects of the Caribbean emerge through what Glissant describes as a continuous series of "forgettings":

Forgetting, that is, integration of what it started from: the multiplicity of African languages on the one hand and European ones on the other, the nostalgia finally for the Caribbean remains of these. The linguistic movement of creolization proceeded through very rapid, interrupted, successive settlings of these contributions; the synthesis resulting from this process never became fixed in its terms, despite having asserted from the beginning the durability of its structures. (Glissant 1997, p. 69)

Only impermanence is permanent, leading to synthesis without unity or transparency. In this way, Glissant attempts to position Caribbean ontology as a way of understanding the broader world, a challenge to the tyranny of Western filiation. The synthesis, he notes, is never fixed or settled, but rather ontologically open. Glissant, true to his background as both philosopher and poet, implicitly turns to artistic models to situate his ontology. The heuristic of forgetting comes to us, he observes, from the material and spatial logic of slavery: enslaved persons in the plantations of the Caribbean and the US South, having no other recourse, took on the "obligation to get around the rule of silence" that enslavement compelled. The threat of violence, of reprisal or punishment from an overseer, militated the language of the enslaved toward detour, indirection, introspection, a welling forth of "snatches and fragments" (p. 69). From the historical condition of enslavement, then, comes an ontology that refutes filiation, embraces mixing, indeed is constituted by the very mixing that was forbidden in colonial and plantation hegemonies.

If Creolization distributes experience and rejects transparency, it pushes us to think through artistic and literary experience over and against the western model of filiation. In Glissant's account of how Creole dialects form from the violence of plantation slavery, three modes emerge: the "direct" 
speech necessary to complete manual labor, the "stifled" speech of those who were historically denied literacy, and "deferred or disguised speech, in which women and men who are gagged keep their words close" (p. 73). Creole, then, turns the circumspection forced on the enslaved into a strength, which is the polyphony and indirection of Afro-Caribbean art, ranging from jazz, blues, and reggae to the poetry of Derek Walcott and the fiction of Toni Morrison. Glissant locates this tradition within what he refers to as the échos-monde, the collective sum of each individual act of artistic creation, which Relation, as an ontology or metaphysical theory of being, is charged with preserving. Such acts, born perforce in the violence of enslavement, include "Negro spirituals and blues, persisting in towns and growing cities; jazz, biguines, and calypsos, bursting into barrios and shantytowns; salsas and reggaes, assembled everything blunt and direct, painfully stifled, and patiently differed into this varied speech" (p. 73). Note the richness of possibility achieved by an ontology of detour and continual synthesis. For Glissant, penetrating the "surface" of outward appearances to access an inner truth merely replicates, on a symbolic level, the violence of enslavement. By contrast, indirection and detour, the hallmarks of his ontology, reject western ideas of depth and transparency as methods of understanding the experience of the Other, and look flawed or enfeebled only if we take the western model (that Glissant has critiqued so movingly) as the unreflective basis for experience. Yet this is precisely what is at issue in the contemporary postcritical debate, which is underpinned, I suggest, by a correspondingly unreflective model of linear progress within a western cultural tradition.

\section{Paracritical "Blue"}

This movement of Glissant's, to be sure, is not without cost to the reader. If the object of analysis is the underlying epistemology that underwrites colonialism, which informs the idea of progress outward in violent arrow-shaped momentum, it follows that we too must move, circumnavigate the object, shift the lens, in short, undergo a critical displacement that leaves us proximate, via detour, to different ideas and fresh linkages. From this angle, we are closest, then, to the poet and intellectual Nathaniel Mackey's Paracritical Hinge, a collection of essays and interviews that connects the study of poetics to musical critique, both aesthetically and politically engaged with African-American and Afro-Caribbean music and literature. I want to put Glissant and Mackey in an indirect sort of conversation, not necessarily reading one through the other, but establishing a critical-spatial relationship keyed to magnitude: quantal criticism, one might say, born of thematic and cultural proximity. If Glissant's text is the philosophical basis for considering Relation as the basis for ethically informed reading, Mackey underwrites that connection, I suggest, by providing a direct artistic link from Afro-Caribbean history to contemporary forms of African-American art, such as jazz and blues. Reading Glissant and Mackey together, in other words, provides us with an alternative conceptual model for engaging literature, one that challenges the paired oppositions of critique/postcritical, distance/closeness, and suspicion/celebration so prevalent in the academic establishment.

At the outset, Mackey draws our attention to diaspora and topography, suggesting that the same broken origins of Creole speech that Glissant discusses are inextricable from correspondingly broken landmasses. In the poetry of Barbadian author Kamau Brathwaite, Mackey reads an "insistence" formed by echo and indirection, from Mother Poem, which finds the speaker lamenting that "the child/is born to splinters//broken islands/broken homes", to Islands, with its emphasis on "not only 'cracked note', 'cracked mother', 'cracked ground', and 'broken tongue', but also 'history ... / ... stripped and torn' (A 162, 180, 187, 210, 216)" (Mackey 2005, p. 35). These recurring images coalesce into what Mackey describes as "the fragmentariness of insular topography, the islands' lack of the relative coherence possessed by larger land masses", forming a "fractured wordscape" in which "the very ground, geography itself" accentuates this sense of fragmentation (p. 35). The cracks in this landscape form the objective correlate to the movement of Creole that Glissant identifies. Language, born out of the surveillance and trauma of the plantation, acquires resistant and subversive meanings: it comes out of the cracks even as it becomes constitutive of the cracks as well, a kind of emergent or alchemical transformation. Mackey identifies this rawness in Brathwaite's writing, experience that emerges split 
and reticulated, shaping the child's relationship to history, land, and language. The certainty that subtends filiation, as a Western and Christian concept, is absent. At the level of topography, Mackey reminds us, the islands of the Caribbean —in this instance, Barbados - are lands without the "relative coherence possessed by larger land masses" (p. 35). Perspective is by definition both fragmented and fractal. Everything must be approached via detour and indirection; depth and transparency are chimeric. The arrow can never fly outward in a straight line.

If, for Mackey, the fragmentation of Caribbean topography clears a conceptual space to approach and absorb art, it also asks us to develop the capacity to apprehend "blue" moments in music, instances of artistic creation that include intellectual meditation, affect, intimacy, and sensuality:

James Hillman suggests that blue "deepens the idea of reflection beyond the single notion of mirroring, to the further notions of pondering, considering, meditating". William Gass writes that blue is "the color consciousness becomes when caressed". That's what we hear when we hear Miles, who said he saw colors when he played, and who would seem to have seen blue a lot: the sound of consciousness being caressed. Just as a certain withholding we hear in Billie Holiday's voice heightens, by way of contrast, the emotional extremity her lyrics announce, Miles's less-is-more approach appears to make deliberative thought audible, palpable-deliberative thought itself, not simply the decisions at which it has arrived. (Mackey 2005, p. 144)

Here, Mackey's thought follows a trajectory that is not only indirect-echoing or signing the earlier discussion of Glissant and Relation-but also blue, in both idiom and style. Mackey makes his claims through a discussion of the work of Billie Holiday and Miles Davis, whose most famous popular recording is titled Kind of Blue, and for whom the emotional and spiritual resonance of "blue" notes obtained, at a visceral level, in much of the music he made, and for his listening audience. By focusing his analysis on two African-American artists whose work has achieved a permanent imprint in the popular consciousness, Mackey makes it impossible to return to the taxonomy of moods and activities that Felski proposes (Friedman 2017, p. 345) without feeling stifled, as if one were re-entering a sensory deprivation tank but forced to pretend that it offered the full range of the senses.

Blue notes have multiple meanings, even within a musical context. They refer sometimes to a style of phrasing, as described above, sometimes to the black keys on a piano that sound sharp and flat notes, and sometimes to variations in tone that are subtler in degree than is typically found in European and western music - a piano, for example, allows one to play whole tones and semitones, but not quarter-tones. Phrasing, I would suggest, is what binds these three related definitions of blue notes together, what allows Mackey to talk about African-American and Afro-Caribbean idioms in a manner that draws out both their uniqueness and the lack of attention black art receives in the wider world. In the academic vanguard, black writing is "multiply marginalized", in part by a tacitly racist distinction between "a formally innovative willingness to incur difficulty, on the white hand, and a simple disclosure of innovative content, on the black" (Mackey 2005, p. 172). This distinction, for Mackey, fuels "the relative invisibility of African American writing that seeks to advance content outside the prescribed or expected limits and/or to be formally innovative or experimental" (p. 172). The very mode of innovation is thus contaminated by an unspoken agreement that its art, philosophy, and practitioners are white, leaving black modes of viewing the world on the margin, or not even discussed at all.

Earlier, I asked how we might activate a sense of critical engagement with literature that does not treat progress as the purview of Anglo-American literary trends. One way to reconfigure the terms of the debate-moving beyond the critical-postcritical binary-is to continue to view it at this different angle, by considering the cultural implications of reading postures that we tend to take for granted. To achieve this goal, I invoke Mackey's call for fiction to "'sit in' with the kinds of critical and analytic discourse characteristic of colloquia, to pursue the possibility of fiction collaborating with those kinds of discourse" (Mackey 2005, p. 152). Sitting in, of course, is a musical term, endemic to the act of improvisation on which jazz, for example, is built: a musician sits in on a session and improvises, on 
the spot, out of a repertoire of shared musical knowledge-pieces of music, common chords, keys, and scales, and so on-adjusting phrasing, pace, and note choice to suit the mood of the moment. In this model, our mode of engagement is already athwart and paratactic to the critical-postcritical binary: we traverse a set of possibilities that encompasses both positions, prepared to read fiction "that wants to be a door or to support a door or to open a door permitting flow between disparate orders of articulation" (ibid, p. 152, emphasis added). This mode of interpretation is not a decadent outpouring of art for its own sake, sealed away from real-world concerns, but rather marked by an indelible political and ethical urgency. Miles Davis recorded Kind of Blue in 1959; Ralph Ellison, in music criticism of the same period, characterized jazz as an art form resistant to white police surveillance through the way it bends notes "to hear and see around corners" and "outmaneuver the rigidities of a taxonomic grid" (ibid, p. 151). To be blunt, black artists and critics have been writing around, through, and against the artistic text—combining critique, appreciation, affect, aesthetic, and commentary-long before the topic of postcriticism become fashionable in the academy. The type of vanguardism characterized by both Felski and her critics is thus untenable; black idiom and historical context have robbed it of intellectual weight.

We come to Mackey's signature term, the 'paracritical hinge', from which the collection of essays takes its name, and which, in its most expressive form, articulates a posture of reading literature that historicizes and acculturates the act of reading beyond the terms of the postcritical debate. The paracritical hinge, as a literary model, allows

flow between statement and metastatement, analysis and expressivity, criticism and performance, music and literature, and so forth. It traffics in a mix - a discrepant, collaborative mix-of idioms, genres, registers, dispositions. (Paracritical is meant, of course, to echo and to be analogous to such terms as paramedical and paralegal, its prefix indicating an auxiliary, accessory relationship to criticism, a near equation with or a close resemblance to criticism. Merriam-Webster's Eleventh Collegiate Dictionary defines a hinge as "a jointed or flexible device on which a door, lid, or other swinging part turns." I'd like to suggest a translative project or prospect in a quality so often attributed to the music, the quality-the verb, not the noun-known as swing. Hinge's work as verb highlights contingency, haunted by tenuousness and risk, an intransitive creaking well worth bearing in mind. The coinage wants to suggest that improvisation, the pursuit of new expressivity, whether musical or literary, is an operation best characterized by the prefix para -, an activity supplemental to more firmly established disciplines and dispositions, an activity that hinges on a near but divergent identity with given disciplines and dispositions ... (Mackey 2005, p. 152)

Paracriticism functions as a type of traffic, a vibrant mix marked by tenuousness and risk, the outpouring of improvisation as literary creativity, an intellectual method of engagement that does not abandon affect, but one that remains "supplemental" to the literary establishment, to critique and postcritique and so on. One might add that proponents of literature on the cultural margins of the Anglo-American academy have been frequently compelled to adopt a paracritical stance simply in order to place that literature on the public radar. ${ }^{2}$ Only rarely have writers on the margins been afforded the luxury of dissection so common to the hermeneutics of suspicion. One can only submit to the analytic microscope if one is already at the cultural center, if the text has become worthy of critique's suspicious mood. Otherwise, literature outside the cultural vanguardism of critique tends to be viewed as a transparent "window" onto another world (Damrosch 2003). The reading posture constructs the text as native informant (Spivak 2013); aesthetic innovation is left at the door. Or as George Elliott Clarke trenchantly puts it: "The trap that too many critics fall into ... is that, in seeking to broadcast their own sermons against racism, sexism, imperialism, classism, and homophobia, they

2 See The Location of Culture (Bhabha 2004), A Critique of Postcolonial Reason (Spivak 1999), and The Empire Writes Back (Ashcroft et al. 2003) for what are, by now, canonical critiques of the colonial or neocolonial center. 
either reduce the writers to the status of sociologists or they bleach their work of aesthetic value" (Clarke 2000, p. 164). Paracritical reading, by contrast, keeps the engagement with aesthetics alive without sacrificing pleasure, affect, or the posture of critique.

\section{Reading for the Blue Notes}

Thus far, I've characterized paracritical reading as a corrective to the postcritical debate, one that pulls apart hard distinctions between critique and postcritique by virtue of its placement within a correspondingly paracritical tradition of African-American and Afro-Caribbean thought. In the final section of this essay, I briefly turn to a work of literature that exemplifies the aesthetic, intellectual, and affective registers that paracritical reading permits: What We All Long For, a 2005 diaspora novel by Trinidadian-Canadian author Dionne Brand.

A pocket outline of Brand's novel: formally working in an Afro-Caribbean literary and artistic tradition, recalling the aesthetic choices of Toni Morrison's Jazz, What We All Long For tracks the second-generation diasporic experience of its main characters in a narrative mode that positions relationships as physical, temporal, and literary adjacencies. Tuyen, the second-generation Vietnamese-Canadian artist, has returned to the urban neighborhood that her immigrant family left years ago, but struggles to distance herself from her parents' grief over losing her brother Quy when they fled Vietnam. Alongside her artistic pursuits, Tuyen also harbors an unresolved desire for her friend Carla, a half-Italian, half-black bike courier haunted by her mother's suicide and burdened by the impossible task of watching over her brother, Jamal, who is in and out of Toronto's Mimico correctional facility and whose identity has been negatively molded by constant police surveillance. $\mathrm{Oku}$, the son of Jamaican immigrants, is forced to conceal his artistic and musical aspirations from his embittered and abusive father, even as he, in his turn, desires Jackie, who runs a clothing store and whose parents were forced to emigrate to Toronto from Nova Scotia following racialized displacement.

Much has been written on the spatial and diasporic possibilities of What We All Long For. Johanna X.K. Garvey, for example, reads Brand's novel through Glissant's concept of errantry: that is, a concept opposed to connections "based on origins, genealogies, hierarchies of power, and fixed identities," focused instead on lines of affiliation "formed in relation, shared space, and overlapping paths not yet mapped". Errantry, according to Garvey, provides an ethical framework for reading a novel in which "a first-person narrator observes the movements of four young Torontonians who reject or resist their immigrant parents' longings and whose own conflicting desires belie the idea of a singular 'we' or 'all' acting as a unified citizenry" (Garvey 2011, p. 767). As a method of "expressing loss—of her brother and family stability—and of connecting to her surroundings," Chris Ewart notes, "Tuyen chisels away at a cathartic lubiao (a larger than room-sized signpost-like sculpture)," foregrounding "her 'diasporic haunting' (Chariandy, 105) by recording the 'longings' of strangers in her neighborhood 'to make them public'" (Ewart 2010, p. 154). For Jenny M. James, the novel's treatment of diaspora "demonstrates that all bonds of attachment bring with them a necessary emotional vulnerability and physical risk, a fact intensified for communities in dislocation" (James 2016, p. 51), while Joanne Leow suggests that the novel sets "the locality of the city in opposition to its global, Cartesian plotted location", producing a literary rendering of Toronto that is "not mappable" but "rooted and powerful [through] the form of its physical space" (Leow 2012, p. 199). Building on these arguments, I want to interpret Brand's novel as a structural and aesthetic invitation to 'sit in' with a different kind of reading, one that places Felski's activity categorizations - curating, conveying, criticizing, and composing — to one side, in order to enter a paracritical mode.

The novel begins with snatches of impressions couched in musical registers, cool in the blue sense of the term-neither major nor minor, missing the third tone of the scale that would establish one mood's prevalence over the other. The city described, Toronto in the early 2000s, is evanescent, fragile, burdened with the expectations of its inhabitants but also subsumed to a kind of impossible longing, a wish, beneath the melting snow and ice that swells the river ways of the city, a desire for certainty undermined by the ruthless passage of spring. "Don't make too many plans or assumptions, don't get 
ahead of yourself", the third-person narrator warns, foreshadowing a later phrase: "What happened next happened" (Brand 2005, pp. 1, 10). Recall the description of "consciousness being caressed" in Mackey's account of blue notes in music, of jazz's most reflective moments, and observe how the intellectual and the physical are not binaries but companions, each sutured to the other in a linkage that gently grafts seemingly opposed critical postures. Three pages, comprising the briefest of chapters, are devoted to Toronto as both subject matter and setting for the novel that follows, in what amounts to a similar narrative "caress" across theme, locale, metaphor, and narrative expectation.

Such a caress undoubtedly has a readerly dimension. It invites a response, but one predicated on connection and transgression, not the hard edges of detachment. The basic question implicit in the postcritical debate- whether to read with and for the text, "for our lives" as Beckwirth puts it, or in a posture of coolly critical detachment, searching every corner of Brand's prose for clues to meanings the novel itself isn't allowed to grasp-is undone by how the novel invites us to engage the text: by turns ominous, playful, serious, political, poignant, and reflective.

This type of engagement, I argue, forms the basis of an Afro-Caribbean register of reading, one that is neither critical nor postcritical, but paracritical, in all the dimensions of the term. Consider the dislocation of the environment. We obtain an image of Toronto not merely in springtime, but convulsed by the weight and memory of snowstorms past, located specifically on the train, the subway, which carries thousands of Torontonians to and from destinations at all points in a vast city. The train, in motion, already contains passengers, then admits three more, each one granted a brief but evocative description:

One of them has a camera, she's Asian, she's wearing an old oilskin coat, and you want to look at her, she's beautiful in a strange way. Not the pouting corporate beauty on the ad for shampoo above her head, she has the beauty a falcon has: watchful, feathered, clawed, and probing. Another one's a young black man; he's carrying a drum in a duffel bag. He's trying to find space for it on the floor, and he's getting annoyed looks all around. There's an enviable loose physical allure to him. He has a few days' growth on his face, and when he smiles his eyebrows, his eyes-his whole face can't help its seduction. The third is another woman, she might be Italian, southern. She's bony like a mantis in her yellow slick plastic coat, except her mouth has a voluptuousness to it, and her eyes, the long eyelashes weigh them down ... They're talking now about some friend of theirs whom the young man loves. (Brand 2005, pp. 2-3)

Apprehension, convention, description, subversion: the narrator moves along the train, disgorging this description of four of the novel's five main characters (Tuyen, Oku, Carla, and, in absentia, Jackie, the object of Oku's desire). Highly sensual, possessing a knowing kind of gaze, the narrator speaks with a colloquial intimacy, as if discussing these young Torontonians with an unnamed friend whose reactions are left off the page. Aesthetic bliss sits adjacent to possible traumas written on Tuyen's "watchful" face, but the narrative motion is as ephemeral as the impressions on the moving subway train. The fifth character, Quy-the grifter-manipulator whose self-titled chapters gradually infiltrate the 'main' text-is partially present, in the unnamed description of another passenger on the train:

And jammed in a seat down the car there's a man who hardly understands English at all, but he hears the tinkle of laughter, and it surprises him out of his own declensions on fate-how he ended up here and what's to be his next move, and how the small panic that he feels disgusts him. He rouses himself from going over the details of his life, repeating them in his head as if to the woman reading a newspaper next to him. The laughter pierces him, and he thinks that he's never heard laughter sound so pure, and it is his first week in this city. Only when he was very, very little-a boy—then he heard it, he remembers. (Brand 2005, p. 4)

A mystery has been proffered. Who are these young train passengers, and why are they important? What is the relationship of this unnamed man to the young people whom the train's "taut silence" 
(Brand 2005, p. 3) is trying its best to subdue? Desire here fits in some way within the container of queer diaspora, resisting the static idea of an "imaginary homeland frozen in an idyllic moment outside history" and instead telescoping queer experience through "a past time and place riven with contradictions and the violences of multiple uprootings, displacements, and exiles" (Gopinath qtd. in Garvey 2011, p. 767). Redolent with "mutual longings and the bonds that they have formed with each other in Toronto, as well as the ways that they often miss each other" (Garvey 2011, p. 767), the quartet evince a kind of spontaneity to being in the world, an acquiescence to motion and to unpredictability. But the as-yet-unnamed fifth character, the passenger with only a rudimentary understanding of English, reminds us of the need to look "around corners", recalling Mackey's invocation of Ellison and jazz music as an illustration of African-American responses to white hegemony. Quy, then, forecloses any sense of Toronto as the site of utopian experience.

Substantively, the four young Torontonians-Tuyen, Carla, Oku, and Jackie-occupy the lion's share of the novel. Theirs is a kind of narrative givenness that destabilizes the singularity of perception, as shared experiences of memory and the past bleed from one character's focalization into another, over and across chapter divisions. The ambivalent color that surrounds Jackie remembering her parents' night life at the Paramount club, site of the "good times, dancing and fighting and styling" but now "all gone" (Brand 2005, p. 183), invites critique and warmth, but also gestures to the gentrification of a predominantly black Toronto neighborhood, conjuring up the "de facto segregation" in Halifax (Brand 2005, p. 182) that forced the whole family to move to Toronto in the first place. In every lavish, sepia-toned memory of the Paramount, the novel swings, to use Mackey's verb, suggesting a cool but resonant form of narrative movement that operates within spatial and readerly adjacencies, so that the poignancy of the Paramount's closure is not confined strictly to Jackie's recollection. Memory spills into the next chapter, which finds Oku desperately remembering all the music he wanted to play for Jackie, including Charlie Rouse, Billie Holiday, and John Coltrane, all adding up to a blue representation of his desire for Jackie, "Rouse's hoarse velvet horn" functioning both a metaphor and a visceral encapsulation of the intimacy that he craves (Brand 2005, p. 184).

For what transpires in this scene, and in Brand's novel generally, neither critique nor postcritique is sufficient. Keep in mind Sarah Beckwith's moving response to The Limits of Critique, in which she argues that "[ $\mathrm{t}$ ] he alternative to [critique] is not to be uncritical", but rather "to exercise, refine, and develop our capacity for judgment and to read again for our lives" (Beckwith 2017, p. 336, emphasis added). So much weight can be read into that tiny adverb "again", a glimpse of a trajectory in literary studies taken to its tedious extreme, leading to "widespread fatigue with the mind-gripping, monotonous, monopolistic doxa of critique ... its well-defended protection of its own high ground; its stubborn, earth-scorching, hegemonic appropriation of sophistication and viewpoint" (Beckwith 2017, p. 332). But there is no 'again' afforded to the Afro-Caribbean position of being at risk in spaces policed by institutional racism, by white surveillance. The capacity for pleasure is not there to be regained, innocent and unsullied, after critique's tyrannical reign. Even the words routinely associated with critique- " questioning, accusing, unearthing, not wondering, acknowledging, judging, evaluating" (p. 332)—reflect the disciplinary and surveillant characteristics of institutional white scrutiny. Only vanguardists have the luxury of questioning, from a safe critical distance. Only those in the hermetically sealed bubble of Anglo-American criticism are capable of being so taken by Felski's "call for interpretive inventiveness" (Fuss 2017, p. 353), as if black artists, writers, and intellectuals had not been engaged in the same task for decades already.

By contrast, and per Mackey, "black centrifugal writing reorients identity in ways that defy prevailing divisions of labor" (Mackey 2005, p. 171). Brand's novel performs as much as it critiques institutions of power, and thus invites the reader to enter into the same paracritical mode, in which the echoes of subdued or disguised speech that we find in Glissant acquire artistic expression as a counter-hegemonic mode of being. Pleasure is not forsaken, because it never had the luxury of being suspended in the first place. Movement through the narrative space of the novel is of necessity paracritical, in the same way that Carla, the courier, is forced to confront the ugliness, ambience, 
possibility, and hegemony of urban Toronto as she bikes across its surface, experience always fading away into the remembrance of a past feeling no longer suited to a present moment (Brand 2005, pp. 28-29). All these feelings are always to hand.

Quy, conversely, provides an ominous type of connection between the characters, "the forgotten and yet powerful component of globalization [acting as] a shadowy narrative that cannot be documented in any systematic way or fixed with any particular identity" (Leow 2012, p. 207). Lost in the flight of Tuyen's parents from Vietnam, he winds up spending his childhood years in the refugee camp of Pilau Bidong, experiencing abuse, violence, and trauma before making his way, as an adult, to North America. Quy's recollections of his experience are marked by distrust and cynicism, his entire posture determined by the need to conceal his intentions, and to manipulate those around him. We are never given absolute certainty that he is Tuyen's long-lost brother; the name Quy means "precious" in Vietnamese, but can also be phonetically rendered in the French as a question ("qui?" or "who?"). Eventually "discovered" by Tuyen's brother Binh, who runs a black-market electronics operation, Quy becomes the target of unexpected violence at novel's end: dozing in Binh's car while Binh is inside his parents' house (breaking the news that they have found their missing brother), Quy is stabbed by Carla's brother Jamal, who is trying to rob the car with an accomplice. The trajectory that brings Jamal to target this particular car is random, in one sense: Jamal has no idea that Quy is the brother of his sister Carla's friend, and is driven primarily by "an obsession with material wealth and objects as symbolized by the 'rich motherfuckers ... [with] great cars to boost in garages off roadways called crescents and drives' (316)" in Toronto's Richmond Hill neighborhood (Leow 2012, p. 210). But Jamal's desires have been shaped by the white Toronto police apparatus, in which he is always already a criminal body, serving as a powerful thematic push toward the violence of the novel's conclusion.

The trauma that Quy suffers-ambiguous to the last, in that it's not even clear whether he will die or be rescued-is thus driven by a kind of paracritical momentum that effectively sidesteps the question of narrative plausibility, forcing the reader to swing. What happens next happens, to echo Quy from earlier in the novel. At the novel's conclusion, Quy's trauma acts an ethical check on the euphoria of transnational possibility, but it's a check that is profoundly blue in affect, leaving us with the fatal caress of consciousness as Quy lies "half-dead by the road", deliriously imagining his parents "finally running out of a doorway toward him, running toward him, and the road between them is like water, and they both grab him as they should have and his mouth splits open and all the water spills out" (Brand 2005, p. 317). The expectation against which we were warned at the start of the novel - not to make plans, not to get ahead of ourselves, because what happens next happens, whether we're prepared for it or not-has now spilled into the plot, inviting a moment of reverie in which we're forced to consider the novel as artistic performance alongside a critique of its thematic and ethical meaning.

Immediately after this stark reminder "of the ways the plight of the Vietnamese 'boat people' is shaped by the same transnational structures of disparity that define the seemingly more secure communities of the West" (James 2016, p. 62), the novel closes with the almost banal normalcy of Carla anticipating, with pleasure, the sound of Tuyen "chipping and chiselling away next door" (Brand 2005, p. 318). Though there is a body bleeding out to possible death just adjacent to our readerly perception, we are directed here to a moment in time before Quy's stabbing, and invited to hold these dissonant images in mind as we finish the act of reading. This is stylistic and narrative swing that keeps the moods of tenuousness, risk, suspicion, shock, and languor all concurrently in play. It has the feeling of improvisation, though it is not improvised, and functions as the supremely blue moment at which Brand's novel decides to bow out, not because we have reached 'satisfactory' closure, but because the indwelling creative possibilities of the moment have reached their apotheosis. The paracritical session, one might say, is over. Viewed "as a polyphonic ensemble, shuttling between different narratorial perspectives" (James 2016, p. 45), What We All Long For compels us to imagine itself playing past the parameters of its own textual life. What we do with this metastatement is, of course, up to us as readers, as it could only ever have been. Whatever reaction we have-appreciate, condemn, question, categorize-must sit in with the social and aesthetic context that the novel has generated without being 
its pure corollary. Our paracritical detour has taken us away from the critique-postcritique cage match, though close enough to keep their struggle still in view.

Have I inadvertently succumbed to the normative academic tendency to critique? Perhaps, just a little, not critique tout court, as Felski would have it, but a kind of critique, blue around the edges and in the gaps. As I began this article by noting, The Limits of Critique is brilliant precisely because of the way Felski awakens us, her readers, to a sense of our own intellectual torpor. It is refreshing to stretch, to turn our attention to the very business of critique, so that we may avoid being inhabited only by the urge to diagnose. In a real sense, Felski's book has created the occasion for my argument (for the arguments of many!); denying this relationship would be the height of churlishness. I have taken this detour into Afro-Caribbean poetics not to diagnose and dispose of critique or postcritique, but to expand the vocabulary for framing the terms of this debate, bringing the richness of African-American and Afro-Caribbean intellectual thought into a conversation on how to read literature. In so doing, I hope we may find the door open, in future, for other counter-hegemonic modes of engagement. "The given," Mackey notes in a suitably parenthetical comment, is after all "only the beginning" (Mackey 2005, p. 152).

Funding: This research received no external funding.

Conflicts of Interest: The author declares no conflict of interest.

\section{References}

Ashcroft, Bill, Gareth Griffiths, and Helen Tiffin. 2003. The Empire Writes Back. New York: Routledge.

Beckwith, Sarah. 2017. Reading for Our Lives. PMLA 132: 331-6. [CrossRef]

Best, Stephen. 2017. La Foi Postcritique, on Second Thought. PMLA 132: 337-43. [CrossRef]

Bhabha, Homi K. 2004. The Location of Culture (Routledge Classics). New York: Routledge.

Brand, Dionne. 2005. What We All Long For. Toronto: Vintage Canada.

Clarke, George Elliott. 2000. Harris, Philip, Brand: Three Authors in Search of Literate Criticism. Journal of Canadian Studies 35: 161-89. [CrossRef]

Damrosch, David. 2003. What Is World Literature? (Translation/Transnation). Princeton: Princeton University Press.

Ewart, Chris. 2010. Terms of Disappropriation: Disability, Diaspora, and Dionne Brand's What We All Long For. Journal of Literary and Cultural Disability Studies 4: 147-62. [CrossRef]

Felski, Rita. 2015. The Limits of Critique. Chicago: University of Chicago Press.

Friedman, Susan Stanford. 2017. Both/And: Critiqu and Discovery in the Humanities. PMLA 132: 344-51. [CrossRef]

Fuss, Diana. 2017. "But What about Love?". PMLA 122: 352-5. [CrossRef]

Garvey, Johanna X. K. 2011. Spaces of violence, desire, and queer (un)belonging: Dionne Brand's urban diasporas. Textual Practice 25: 757-77. [CrossRef]

Glissant, Edouard. 1997. Poetics of Relation. Translated by Betsy Wing. Ann Arbor: University of Michigan Press.

James, Jenny M. 2016. Frayed Ends: Refugee Memory and Bricolage Practices of Repair in Dionne Brand's What We All Long For and Kim Thúy's Ru. MELUS: Multi-Ethnic Literature of the U.S. 41: 42-67. [CrossRef]

Leow, Joanne. 2012. Beyond the Multiculture: Transnational Toronto in Dionne Brand's What We All Long For. Studies in Canadian Literature 37: 192-212.

Love, Heather. 2017. Critique is Ordinary. PMLA 132: 364-70. [CrossRef]

Mackey, Nathaniel. 2005. Paracritical Hinge: Essays, Talks, Notes, Interviews (Contemporary North American Poetry). Iowa City: University of Iowa Press.

Robbins, Bruce. 2017. Not So Well Attached. PMLA 132: 371-6. [CrossRef] 
Spivak, Gayatri Chakravorty. 1999. A Critique of Postcolonial Reason: Toward a History of the Vanishing Present. Cambridge: Harvard University Press.

Spivak, Gayatri Chakravorty. 2013. An Aesthetic Education in the Era of Globalization. Cambridge: Harvard University Press.

(C) 2019 by the author. Licensee MDPI, Basel, Switzerland. This article is an open access article distributed under the terms and conditions of the Creative Commons Attribution (CC BY) license (http://creativecommons.org/licenses/by/4.0/). 
Article

\title{
Attention, Representation, and Unsettlement in Katherena Vermette's The Break, or, Teaching and (Re)Learning the Ethics of Reading
}

\author{
Cynthia R. Wallace \\ Department of English, St. Thomas More College, University of Saskatchewan, Saskatoon, SK S7N 0W6, Canada; \\ cwallace@stmcollege.ca
}

Received: 24 July 2019; Accepted: 11 October 2019; Published: 16 October 2019

\begin{abstract}
Theories of literary ethics often emphasize either content or the structural relationship between text and reader, and they tend to bracket pedagogy. This essay advocates instead for an approach that sees literary representation and readerly attention as interanimating and that considers teaching an important aspect of an ethics of reading. To support these positions, I turn to Katherena Vermette's 2016 novel The Break, which both represents the urgent injustice of sexualized violence against Indigenous women and girls and also metafictionally comments on the ethics of witnessing. Describing how I read with my students the novel's insistent thematization of face-to-face encounters and practices of attention as an invitation to read with Emmanuel Levinas and Simone Weil, I explicate the text's self-aware commentary on both the need for readers to resist self-enlargement in their encounters with others' stories and also the danger of generalizing readerly responsibility or losing sight of the material realities the text represents. I source these challenges both in the novel and in my students' multiple particularities as readers facing the textual other. Ultimately, the essay argues for a more careful attention to which works we bring into our theorizing of literary ethics, and which theoretical frames we bring into classroom conversations.
\end{abstract}

Keywords: ethics; attention; representation; responsibility; decoloniality; indigenous writers; gendered violence; Levinas; Weil; pedagogy

Katherena Vermette (2016) novel The Break begins with the land. A mysterious first-person voice explains "the Break" as a "piece of land just west of McPhillips Street", a narrow field about four lots wide that interrupts all the closely knit houses" and holds the hydroelectric towers and wires that run through the city (3). The speaker explains the history of the land, how it "was likely set aside" when "all that low land on the west side of the Red River was only tall grasses and rabbits" (3), how houses were eventually built around it on lots just small enough to deny the Eastern European immigrant inhabitants voting rights, how in the 1960s Indigenous folks "started moving in, once Status Indians could leave reserves", and how now it is a neighbourhood full of both "big families, good people", and also "gangs, hookers, drug houses" (4). Thus contextualizing in time and place, these opening three pages also allude to "my Stella", one of the novel's central characters, and "everything she's been through" and to how it was snowing "when it happened" (5). The foreshadowing is foreboding, but the tone here is gentle, the voice a sort of knowledgeable welcome.

As I read the novel when it was first published, I suspected it would teach well. So far it has, in a first-year composition course, a second-year interdisciplinary course on social justice and the common good, and a graduate seminar on literary ethics. Part of the resonance derives from the novel's representation of places and people familiar to my students at the University of Saskatchewan; the setting is Winnipeg's North End, the characters mostly Métis. The novel's central conflict is the rape of a young woman, Emily, the police investigation of who is responsible, and a large cast of characters' attempts to care for each other and themselves in the wake of great wrong. While this content is 
difficult (I include a trigger warning in class and on the syllabus and offer an alternative assignment) it also lends to the novel an underlying urgency to which most of my students respond very favourably.

Formally, however, I think students find the novel compelling in part because it is a bit of a whodunit. ${ }^{1}$ After the mysteriously voiced introduction, the narrative opens with a scene of police questioning Stella, the witness of the crime, at her kitchen table. From there, the chapters skip around in time and place and are focalized through different characters. It is up to readers to put the pieces of these relations together, and to work alongside Tommy the police detective to figure out who perpetrated the assault. Because of both the unfolding mystery and the character-driven narration that invites emotional investment, students report that the book is hard to put down. ${ }^{2}$

The pleasure provoked by the page-turning mystery sets up a familiar tension between aesthetic enjoyment and ethical engagement. What does it mean to find satisfaction in reading a story about a character's violent assault? What does it mean to render in compelling prose a reality-the grossly disproportionate violence against Indigenous women — so prevalent that the Canadian government in 2016 commissioned an official inquiry into the crisis (National Inquiry into Missing and Murdered Indigenous Women and Girls 2019)? How do we grapple with questions of mimesis and verisimilitude as we approach a text undeniably about a human experience so ethically and politically urgent?

Yet The Break is not a guilty bystander in these debates about ethics and aesthetics but a theorizing participant, for the novel is self-aware in this regard. This awareness manifests especially in the character Tommy, the keen young police investigator, who serves as a double for the reader, both exemplifying the need to pay careful, minute attention to another's story and also exposing the problem of finding pleasure in piecing together the parts in order to solve the crime. This, I argue, is one element of the text's ethics, which together with its insistent thematizing of face-to-face encounters and responsibility resonates with a great deal of the theorizing of literary ethics done over the last three decades. Through Tommy's metafictional exemplification of the dangers of using someone else's story for one's own pleasure and the text's insistent commentary on the power of attending to a suffering other, the novel suggests an ethics of reading that resists mastery, self-aggrandizement, and ultimately colonization while instead inviting self-suspending attention and being-for-the-other. In other words, Tommy's problematized role in the mystery plot seems to replicate an ethics of reading literary scholars developed in the 1990s, largely in conversation with the work of philosopher Emmanuel Levinas.

However conveniently such an interpretation aligns with much of the discourse of literary ethics, though, Vermette's novel both offers and undermines this ethics of reading through another character who may also act as a double for readers and a foil for Tommy-Stella, the witness to the rape. If Tommy can be read as The Reader of Western philosophy, furiously scribbling and rescribbling his notes and nearly laughing out loud with joy when he discovers more details of the crime, Stella stands for readers who find themselves responsible in the act of witnessing a suffering other yet in the particularity of their own position find this responsibility an impossible burden. In other words, the novel's ethics of reading is double-edged, implying both the critique of readerly mastery derived from Levinas (and, I add here, Simone Weil's celebration of self-giving attention) and also the risk of a generalized ethics of reading that assumes all readers are powerful subjects to begin with and that Western philosophy offers universally helpful conceptualizations. Ultimately, The Break reminds us not only that how we read, or what I have called elsewhere an ethics of readerly attention, but also what we read, or the ethics of literary representation, matters a great deal in questions of literary ethics. Even more crucially, which texts we bring into our theorizing of literary ethics makes all the difference in the world, a point we would do well to remember as the conversation continues.

1 In fact, in addition to being an Amnesty International Book Club selection, the novel was also a Sunday Times Crime Book of the Month in February 2018.

2 It may not be common practice to discuss pedagogy in scholarship theorizing literary ethics, but I am increasingly suspicious of this division, particularly given the importance of context and community for our reading practices. In this essay I will weave my own close reading of the text with accounts of classroom discussion. 


\section{Theorizing}

Scholars have devoted significant effort to mapping the so-called ethical turn in literary studies that gained momentum at the end of the twentieth century (see Buell 1999; Gibson 2005; Eskin 2004; Eaglestone 2004). Many of these mappings share a sense of the tension between two main tendencies: one emphasizes literature's content, its capacity for complexity and the "particular" (Nussbaum 1990, p. 37), its implied authors (Booth 1988), and its ethical and political representations. Andrew Gibson (2005) calls this strand "Moral Criticism", and Lawrence Buell (1999) associates it with the tradition of Matthew Arnold and F.R. Leavis, philosophers like Martha Nussbaum and Richard Rorty, and also multiculturalism (7-8). Moral Criticism is concerned with representational content, with what readers' encounters with narrated characters and situations can change in them, a concern I see extended in more recent reconsiderations of empathy on the part of literary scholars like Suzanne Keen (2007) in Empathy and the Novel and both cognitive psychologists and neuroscientists turning to literature. ${ }^{3}$

Another strand, which Gibson terms "the New Ethical Criticism" ${ }^{4}$ has tended to focus less on literature's content and more on readers' relationship to the text. This strand emphasizes vocabularies of "alterity, interpellation, call of the other, answerability, ethical responsibility, openness, obligation, event, doing justice, witnessing, hospitality, singularity, particularity, or the gift" (Eskin 2004, p. 561). It draws, as Buell notes, on deconstruction and Continental philosophy more broadly, perhaps most importantly on the metaethics of Emmanuel Levinas (8-11). Levinas' influence is notable in the vocabularies of responsibility and face-to-face encounter that permeate much of the New Ethical Criticism in the 1990s and early 2000s. ${ }^{5}$ Famously hyperbolic, Levinas [1957] (1993) writes of the way encountering an other's face confronts the self with an endless responsibility for that other; the other's vulnerable gaze "opens the very dimension of the infinite, of what puts a stop to the irresistible imperialism of the Same and the I" (110). Levinas begins his philosophy with this face-to-face encounter, insisting that "Justice well ordered begins with the Other" (112).

Doris Sommer (1994) exemplifies a common mode of appealing to Levinas when she turns to him in her essay "Resistant Texts and Incompetent Readers" to help her discuss how certain literary forms resist readers' propensity "to reduce otherness to sameness" (534; cf. Levinas [1957] 1993, p. 91). The point here is not modeled by two characters' relationship to each other but by the aesthetic characteristics that shape the relating of text and reader. Indeed, for all its emphasis on otherness, much of the New Ethical Criticism is effectively a structural ethics of reading; it describes (and at points prescribes) the relationship of a reader to a text. Derek Attridge (2004) book The Singularity of Literature perhaps most explicitly highlights this tendency, as does his contribution to the 1999 PMLA issue in which he writes, "Reading involves working against the mind's tendency to assimilate the other to the same, attending to that which can barely be heard, registering what is unique about the shaping of language, thought, and feeling in a particular work" (25). Reading thus leads to responsibility, Attridge (1999) claims: "Responsibility for the other involves assuming the other's needs, being willing to be called to account for the other, surrendering one's goals and desires in deference to the other's" (27). Again, Attridge draws on Levinas here not to describe the relation of two people but of a reader faced with a text.

While we may be two decades on from the heyday of the New Ethical Criticism, Levinas' influence continues apace, as do theories of the ethics of reading. ${ }^{6}$ Many of these literary critical appeals to Levinas continue to blithely overlook the complexities introduced by both his philosophy's imbrication with Judaism and by feminist philosophers' criticisms of his gender-talk. In other words, as Adam

\footnotetext{
3 I am thinking here, for example, of Hakemulder (2000); Iacoboni (2011); Koopman (2015); and Oatley (2016).

4 Robert Eaglestone (2004) also divides the field into two but calls the two sides "wings": "roughly, a more narrative-based neo-Aristotelian 'wing' and a more deconstructive 'wing'" (595).

5 Early book-length studies of Levinas and literary ethics include Newton (1995); Eaglestone (1997); Robbins (1999); Gibson (1999).

6 More recent examples include Hale (2009); Hughes (2010); Wehrs (2013); Attridge (2015); and Wallace (2016).
} 
Zachary Newton (2001) argues, to do justice to Levinas means attending to the sum total of his writing, recognizing the way his philosophical and religious work are interanimating. Likewise, to do justice to the sum total of humanity means recognizing with Gayatri Spivak (1992) that for Levinas, the "subject-ship of ethics is certainly male" (76). ${ }^{7}$ As I argue in Of Women Borne: A Literary Ethics of Suffering (2016), when literary scholars deracinate Levinas' writings on ethics from both his Jewish context and writings and the discursive context of feminist philosophers' critique of his assumptions of male subjects and feminine passivity, we risk undermining the very efforts we make to be responsible. This elision of religion and gender matters, I argue, because so much of the vocabulary of passivity and limitless responsibility for another that literary scholars derive from Levinas rings with echoes of western norms of feminine self-giving care, which are themselves rooted in certain biblical traditions. As Erin Biviano (2007) and others argue, to borrow from Levinas without the accompanying critique risks relegating the vulnerable to a position of greater vulnerability. Further, as I argue throughout this essay, to theorize a universal paradigm of reading carries with it risks of generalizing the experience of those already in power.

At the same time, my own sense is that we need an ethics of reading - a description and prescription of how one ought to read — now more than ever, in a world even more technologically mediated than Zygmunt Bauman (1993) imagined 25 years ago in Postmodern Ethics, when he asserted that the "moral self-awareness is the most evident and most prominent among technology's victims" (198). As J. Hillis Miller (1987) warned in The Ethics of Reading, "the attractions of inattention are immense" (3), and as so-called "attention merchants" seek to monetize individuals' attention and digital social media platforms engineer society, ${ }^{8}$ my students increasingly describe an existence in which reading a full-length book is a difficult exercise, not to mention having a face-to-face conversation. Maryanne Wolf (2018) supports my students' anecdotes with larger-scale research in Reader, Come Home: The Reading Brain in a Digital World, which confirms the sense that students' (and scholars') attention is increasingly divided by the way our lives are infused with smaller and smaller bits of textuality, disrupting our capacity to engage in sustained reading and reflection (72-73). And the consequences are not only textual; media studies professor Douglas Rushkoff (2019) describes university students with such difficulty coming face-to-face with a human other that he explicitly tells them to practice making eye contact.

In other words, we have plenty of reason for investigating what it means to do justice to a literary text and how such texts might invite us into practices of attention that can help us resist the blend of hyperattention and attention deficit that grows out of the current digital economy. While J. Hillis Miller (2015) himself has recently (and rather cynically) denied much reason for teaching literature now apart from pleasure and perhaps the capacity to spot fake news, I would argue that an ethics of literary attention explores the relationship between reader and text in part to suss out the possibilities of reading as an exercise that develops our capacity to attend in general.

Such an approach returns us not just to Emmanuel Levinas but also to Simone Weil, who famously argues in Waiting for God (Weil 1973) that "school studies", even geometry homework, can train students' capacity to attend to both God in prayer and a suffering other. For Weil, attention is the ethical practice par excellence; it "consists of suspending our thought, leaving it detached, empty, and ready to be penetrated by the object" (111). This passive (and also inescapably gendered) openness to the other for the sake of the other's being in the world sounds very much like Attridge's Levinas-inspired description of readerly ethics. Yet while Levinas' face-to-face encounter is rooted in phenomenology, a descriptive claim about how reality works, how the intersubjective encounter precedes being, Weil's theory of attention is more explicitly normative. She argues that the practice of this kind of "empty, waiting" attention (112) in school exercises can form in students the capacity to help "someone in

7 Also see Irigaray (1993) and Chanter (2001).

8 For an excellent scholarly overview of the attention economy, see Citton (2017). Other recent book length projects on attention include Watson (2017) and Odell (2019). 
affliction" (115), to "give one's attention to a sufferer", which "is a very rare and difficult thing" (114). For Weil, such attention, codified here in the Judeo-Christian vocabulary of "love for our neighbour", "simply means being able to say to him: 'What are you going through?'" (115). Weil acknowledges that attending to a suffering other is both simple and nearly impossible, but she nevertheless centers her entire ethical paradigm on this face-to-face engagement.

Weil's writing is no less implicitly gendered than Levinas' and certainly no less inflected with religion, though in Weil's case, Christian rather than Jewish, ${ }^{9}$ and the embeddedness of her ethical theorizing within explicitly Christian allusions makes it perhaps harder for scholars to elide the religious root, though a surprisingly large number try. Both philosophers are notoriously hyperbolic, their style difficult, their metaphors stretching toward the literal. They share a sense of the radical importance of attentive interpersonal encounter and the biblical mandate of responsibility for an other inherent in the other's vulnerability, even to the point of self-sacrifice. ${ }^{10}$ Weil, though, brings the explicit vocabulary of attention that resonates so powerfully in the contemporary moment, leading to her work's rising popularity in literary theory, as in Yoon Sook Cha (2017) Decreation and the Ethical Bind: Simone Weil and the Claim of the Other.

Still, Weil's ethics of responsibility for the other carries with it just as much risk as Levinas' of inviting vulnerable subjects to sacrifice too much. For this reason, I maintain that in our literary ethics a structural, apparently universal, relationship between text and reader, abstracted to the level of theory, is not enough. On its own, it misses too much - not just the importance of gender, religion, race, and other forms of particularity, but also the question of from whose experience we are theorizing. Much of the literary critical conversation on ethics has focused on Dickens, Henry James, or J.M. Coetzee, with a significant exception for philosophers' love of Jane Austen and a veritable cottage industry on Toni Morrison. Some of the more influential recent books on literary ethics continue to show surprisingly limited attention to writers outside the traditional canon, with the result that the literature itself may not highlight the risks of elevating a self-giving, passive, endlessly responsible Reader (implicitly but never admittedly modeled after a self-sacrificing mother or messiah).

However, like so many contemporary texts written by women of color, The Break suggests both an ethics of readerly attention - an ethics of reading founded in the novel's own metafictional self-commentary, one that invites a conversation with Levinas and Weil-and an ethics of representation-a challenging of the abstracted Reader with a devastating reminder of the particularity and complexity of not the Reader but readers, not the Moral Subject but moral subjects—and that Western philosophy may not be the only or best source for thinking about ethics.

\section{Attending}

At the level of representation, The Break certainly highlights the complexity of things, not only through its multiply-focalized narrative structure but also through its representation of these multiple characters' psyches. Even in the face of the assault and the subsequent hospital stay and investigation, Emily's family members and friends negotiate their concern for her with their own memories of the past and worries in the present. The novel demonstrates how each character is complexly motivated and sees from a different angle, embedded in her own life. This complexity is in addition, of course, to the novel's striking verisimilitude on the urgent ethico-political topic of physical and sexual violence

9 Levinas (1952) was famously critical of Weil for her deeply problematic relation to the Jewish tradition, as in his essay "Simone Weil Against the Bible". For a helpful reading of the relationship between the two philosophers' ideas, see Gillian Rose (1993) essay "Angry Angels: Simone Weil and Emmanuel Levinas".

10 While not many creative writers were reading Emmanuel Levinas' philosophy in the mid-to-late twentieth century, many of them were reading Simone Weil, whose work was first translated into English in the 1950s. Turning to Levinas-who was familiar with Weil's work and famously disapproving of her-to parse out literary dynamics that likely derive from Weil's influence does not feel quite right. These scholarly dynamics warrant further thought. 
against Indigenous women and girls, violence so dire that the final report of the National Inquiry into Missing and Murdered Indigenous Women and Girls (2019) ${ }^{11}$ termed the phenomenon "genocide".

Yet read in terms of the New Ethical Criticism, The Break also seems to suggest a metafictional ethics, an ethics of paying attention that is also an ethics of reading. Such an ethics is not a thing apart from the novel's representational content but a concurrent lesson in how to attend to the painful reality. The novel suggests such an ethics, in part, through its insistent thematizing of looking, particularly looking at others' faces, and the thematics of responsibility. In the interpersonal encounters of the characters, this thematics of looking and face-to-face encounters accrues a broader significance through repetition: the refusal of responsibility that could arise from face-to-face relating is overwhelmingly coded negative in the text, whereas attentive face-to-face encounters, which register the vulnerability of the other and provoke responsibility and active caretaking, are overwhelmingly positive. This explicit thematics parallels Levinas and Weil in notable ways, ways that make the novel particularly resonant as an intervention in a literary ethical discourse already in conversation with the philosophers.

The importance of sincere attention to others, and particularly the shared gaze of the face-to-face encounter, is perhaps most powerfully demonstrated in scenes of its absence. The narrative dramatizes two such scenes, both in characters' memories, with devastating results. In one such memory, Stella recalls a high school party at which her friend Elsie was sexually assaulted, and the scene is rendered in repeated terms of failed attention: Stella "didn't notice all the other guys following" Elsie and a boy upstairs; "none of the girls noticed" how long they were upstairs (202). When Stella and her cousin Lou finally bring Elsie downstairs, "no one looked up and everyone was partying again like nothing happened" (204). But something did happen, although following the familiar mechanisms of trauma the details remain in "big, blank spaces where all the answers should be" (205). ${ }^{12}$ What Stella and Lou discover when they go upstairs to find their friend is chilling: "Elsie was the first thing they saw once they turned the corner. Elsie's beautiful curly hair pressed to her face by a large hand. The scene became clearer with every step" (202). As Lou screams at the young men and tries to cover her friend's body with a blanket, "Stella only watched Elsie's face, still pressed into the pillow, her mouth open, her hair damp" (203).

If in Levinas [1957] (1993) terms, in the face of an other "one is confronted with the mandate, 'You shall not kill,'" in contrast with the desire to possess, own, or use an other (109), it is not accidental that the rapist presses Elsie's head down, avoiding the ethical challenge implicit in her face, which would "put [his] freedom into question" (115). Of course, one can reject the implicit ethical command in another's face, but this scene dramatizes with horrifying concreteness the refusal of a face-to-face encounter that could be the foundation of an ethical relating. It is also painfully echoed in the eventual scene of the attack on Emily, which comes late in the novel, and which uses the repetitive vocabulary of her rapist's "hand over her face" $(308,309)$.

It is also not accidental that in the grammar of the sentence describing what Stella and Lou witness when they turn the corner, Elsie is described as the "first thing" they see. This phrasing is both common grammatical usage and also an implication of the way, as Weil (1965) argues, force turns a human into a thing (6; also see Levinas [1957] 1993, p. 97). ${ }^{13}$ The novel further highlights this devastating result as it repeatedly depicts Elsie after she has been assaulted as emptied of agency and the capacity for human connection. She is "just limp, like she was passed out but her eyes were open" (203); she "just looked off at nothing. Her eyes looked dead" (204). Years later, when she sees Elsie on the street, Stella notes that her "face looked older than it should have", but Stella intentionally walks by "real close, so their

11 (National Inquiry into Missing and Murdered Indigenous Women and Girls 2019).

12 Consider Sommer (1994): "In some resistant texts, silence is the willed muteness of trauma, a defensive armor against humiliating or panic-provoking memories" (538). Against a sense of willed muteness, however, is Simone Weil (Weil 1973) insistence that those who are traumatized by malheur, or affliction, "have no words to express what is happening to them" (120), an idea taken up in much twentieth-century trauma theory.

13 The "thingification" implicit in oppression also calls to mind Martin Buber's I-Thou paradigm. 
eyes could meet. Elsie saw her but there was no recognition, her eyes were as blank as they had been that night. Still dead" (207). Again, this blankness depicts a recognizable trauma response, but in the vocabulary of the novel, and of Levinas and Weil, it is significant that what Stella seeks is a face-to-face human encounter, and that Elsie's capacity for such an encounter seems to have been cut off. And while readers do not realize it at this midway point of the novel, by its end they will also recognize the heartbreaking after-effects of Elsie's trauma on the next generation, as the pieces come together to reveal that Elsie's daughter, conceived in that assault, is the perpetrator of the assault on Emily.

Similarly embedding the characters in a narrative of the after-effects of sexual violence against Indigenous women, Cheryl remembers the doctors' failure of responsibility toward her sister Rain, who was sent away from the hospital when she presented herself after being beaten up, also in terms of the doctors' failure of looking: "They didn't even treat her. Just put her right back out in the street. Didn't even look, just thought she was another drunk and didn't care" (180). This failure of looking, of attending to a suffering other, precipitates Rain's death that night, as she wanders with a head injury in the freezing temperatures. Such failure is emphasized even more strongly by the implicit contrast with what immediately follows, as Cheryl's daughter Lou hears this story again and almost in response attends to her niece in the hospital bed: "I go over to Emily and look at her for a long time. She smiles up at me, an apologetic smile that makes me want to cry all over again" (181). Lou's face-to-face encounter with Emily, her attention to Emily, manifests as a stark contrast to Rain's much earlier treatment in the familiar setting of the hospital.

Indeed, Lou is one of the characters who consistently practices sustained acts of looking at others, a practice that the novel signals as good, even restorative. Again and again, Lou (the only character whose section is narrated in first-person) describes others' faces: "Ziggy's little face all white bandages" (175), Sunny's "young face [that] seemed to have aged" (175), Jake's "face pale in its pain" (175), her "mother's face struck red, wet and folded into itself" (175). Lou looks at others as a way of reading them, assessing their wellbeing (not coincidentally, she is a child welfare social worker) in order to be able to better care for them. In the hospital, Lou not only looks at Emily "for a long time" but also at Cheryl: "I look at her long, my poor mom and all she's been through" (180). The phrasing here echoes Weil's paradigmatic ethical question, the miracle of looking at a suffering other and asking what they are going through. Lou attends to others in a way that opens up space for caring.

We see this caring, and the healing it can bring about, in the experience of Emily's best friend Zegwan, or Ziggy, as well. Sick with guilt that she did not keep her friend from being hurt, Ziggy finds herself squarely in her father's gaze: "He keeps looking at her" (212). When she finally admits how ashamed and guilty she feels how she "couldn't do anything", "didn't do anything", her father, again, "looks at her, right in the eye like he does" and asks, "What could you have done?" (213). The passage is repetitive, again stating, "He keeps looking at her" (213), but the repetition emphasizes the sustained interpersonal connection and the importance of the character's attention. When he empathizes with her feeling of shame but insists she has nothing to be ashamed of, that there "was nothing [she] could've done" (214), the words seem to genuinely free Ziggy from her shame and empower her to seek out Emily, whom she asks to visit in the hospital, and thereby expand the practice of paying attention to a suffering other rather than hiding in isolation. When the friends reunite in the hospital, "Ziggy looks up and looks at Emily closely" (307), and in a powerful display of mutuality "Emily looks at her friend", whose face was also beaten up on the night of the attack, and asks, "Does it hurt?" (306). This question is another variation on Weil's, an other-oriented expression of attention and care that highlights the degree to which Emily is not just a victim but a surviving subject. ${ }^{14}$

Of course, characters who do not share Lou or Ziggy's father's capacity to look at others, particularly suffering others, and pay attention to what they are going through are not all morally

14 Flora, mostly known as Kookom in the novel (Cree for grandmother), and her daughter Cheryl also exemplify this capacity to look at others. When Stella goes to visit, her "Aunty Cher" "looks Stella up and down, examining her the way Kookoo does" (194); likewise, "Kookom's cloudy grey eyes look up at Stella, all seeing" (195). 
suspect. Like Elsie, many of the characters struggle to make eye contact, or turn their faces away from others, from a place of pain. When Emily "turns away from all of them" earlier in the narrative and "begins to cry even though she tries to hide her broken face" (183), the novel certainly does not suggest this is an ethical failure but an understandable outgrowth of her trauma. In her sorrow over her daughter's experience, Paul likewise struggles at points to make eye contact (185), though she does "stud[y] her girl", whose "face seems so tiny, the wounds there bigger somehow", which leads to Paul's sense of feeling useless and exposed rather than a capacity for caring responsibility (182). In other words, in the novel's insistent thematizing of faces, looking, and caring responsibility, difficulty looking is not always a moral flaw: sometimes it results directly from suffering, a point made even more inescapably in the gradual revelation that Phoenix-homeless, abuse survivor, daughter of Elsie, described repeatedly as one other characters do not attend to-is herself the one who sexually assaulted Emily.

To be clear, these scenes are not metaphors for reading: to render them as such would be a great injustice against their representation of a reality that is all too real. Instead, they are a robust and consistent interpersonal ethical paradigm within the novel. Yet The Break does invite metafictional theorizing about the attention we pay to a text in the character of Tommy, the young police detective who takes on Emily's case with his reluctant partner Christie. Tommy is keen and earnest. While the novel opens with a scene of Tommy, Christie, and Stella silent around her kitchen table, "all looking down or away" (7), subsequent pages and chapters highlight Tommy's desire to take Stella seriously, even though his older partner shrugs her off as a "crazy dame" (68). After they leave Stella's house, even though Christie has said there is nothing to the case, Tommy calls multiple hospitals in search of a clue (78). Tommy cares about the crime Stella has witnessed, and eventually the assault Emily has experienced, in part because Indigenous women remind him of his mother (75). He is deeply invested in the case, even going to his mother for advice as it unfolds.

Tommy's compassion for Emily and her family, his resistance to Christie's apathy, and the fact that he is one of the novel's focalizing characters, invite readers' identification: he is a likeable guy, in part because of his persistence as a Métis police officer taking his partner's racist microaggressions. And the opening for readers to identify with Tommy is not just a result of his characterization: it is also a structural element of the mystery genre, which, as Alan Goldman (2011) argues, generally functions by setting up readers to identify with the detective as their double in parsing out the narrative's clues (268). Goldman asserts that this functions both cognitively, as readers both work with and compete with the character-detective in figuring out the details of a crime (265), and also emotionally, as readers empathize with the detective's feelings and experience and also seek to understand the perpetrator's motivations (267).

The Break takes this genre-driven invitation to associate detective with reader one step further by insistently associating Tommy with textuality. From the narrative's first scene, Tommy is associated with writing, "The younger one goes over his scribbled notes, the paper of his little coiled book flips and crumples" (7). Interviewing Emily in the hospital, he "checks his little book" (185). Later we read that he "has painstakingly written and rewritten all his notes" (220). In a way, Tommy's textual practices almost seem to suggest he is not just a double for readers, seeking to piece the narrative together, but for literary critics, perhaps most damningly when we read that he "takes notes, makes reports" (76) that too frequently "become just words on a screen" (77).

Yet the narrative also echoes an uncomfortably apt readerly experience in Tommy's work to solve the mystery as it presents his more-than-altruistic interest in the case. Stella notes from their first encounter that while Officer Christie appears "bored", "the younger one, he's so young, is eager, maybe even excited" (8). Tommy intuits the crime Stella reported may have been a rape, though Christie insists it is not, and back in the car he keeps "listening for a sex assault" on the radio, "wondering if one will be reported. He's kind of hoping for it, just to prove the old guy wrong" (72). The idea of hoping to hear a sexual assault reported for any reason is troubling. The discomfort is increased in the scene when Tommy first questions Emily in the hospital, as she speaks, "he feels excited for 
some reason" (124). He has to force himself to "speak slowly", and soon "He can't hold in his odd excitement. It all seems so real and he's going to fix it" (124). As details come out, "He has to swallow to keep from sounding too excited"; he "wants to shout but stays calm and collected" (126); after Emily provides another detail, he "smiles. Elated" (127). In the hall outside the room, he keeps smiling.

In an almost obscenely explicit way, Tommy's pleasure in discovery dramatizes the risk of gaining aesthetic pleasure from a text about another's suffering. Tommy's excitement, his delight in uncovering these clues, is in a certain sense understandable. It is also structurally fundamental in the mystery genre: readers' pleasure is rooted in reconstructing a scene of violence that they can retroactively witness. But even as its genre invites it, Vermette's novel will not let us forget how problematic such pleasure can be. In the terms of the New Ethical Criticism, Tommy reminds us of the dangers of seeking to master a narrative in a way that primarily enlarges the self.

Perhaps ironically, it is Officer Christie who takes the wind out of Tommy's sails. In the hall, Christie congratulates the smiling Tommy: "You're now the proud owner of one hell of a ... rape case" (127). We read, "Tommy's face melts down, slowly" (127). As the case continues, so does Tommy's attentive persistence, but tempered now by the realization of what a serious and painful situation it is. Instead of pleasure in uncovering details, Tommy feels embodied empathy for Emily: "it hurt[s] to look at her" bandaged face (291). As he begins to realize who the perpetrator is, he resists the knowledge, again, perhaps aligned with readerly experience: "It has to be [guys]", he says and thinks. "It has to be" (295). It takes his mother's advice and stories to convince Tommy that it is possible for a young woman to violently sexually assault another, but even so he feels unsettled: "He wants everything to be different. He wants the simplicity of finality, but it's never like it is in the movies. It always lingers on" (302).

Tommy's experience begs to be read as metatextual commentary on the novel's own open-endedness. My students resonate powerfully with his discomfort at the idea Phoenix is guilty of the crime. What begins as pleasure in the clues falling into place is disrupted by the very shape of the narrative, and Tommy's experience dramatizes that development. Even at the moment of the resolution, the narrative unsettles us, and in so doing it offers a serious lesson in the dangers of, in Sommer (1994) words, reading any story to "feel aggrandized, enriched by the appropriation and confident that our cunning is equal to the textual tease" (528).

\section{Witnessing}

If Tommy doubles as the reader of the mystery in his role as detective, Stella doubles as reader in her role as witness to the crime. In Levinasian terms, once faced with the event she sees from an upper window in her house, Stella is rendered in some sense inescapably responsible. The narrative opens after the event of witnessing, after Stella has called the police and waited hours for them to arrive, and so readers are introduced to the story's events not by sharing her full view of the assault but through her reconstruction of it, her testimony to the police officers. Though they express repeated doubt that the assault was sexual, Stella is sure she saw a rape from the second-storey window when she went to calm her crying baby in the night. She is sure she saw a "really tiny woman" (9).

As the novel unfolds, it is clear that Stella feels the weight of her responsibility to the woman she saw being attacked. This responsibility coalesces around the fact that she did not go out to the woman but stayed inside, ostensibly out of the competing responsibility for her three children: she tells the police, "It looked bad, so I called 911. But I couldn't do anything, my baby was crying so hard. He's teething" (10). Starting at the beginning again, the officers ask whether she went outside or talked to the person, and after Stella shakes her head she feels "shame" (11). Later, after the officers have pieced together the crime Stella witnessed with a hospitalized girl, Stella feels she is "horrible" (162). She seems to be judging herself for not going out to help the girl, a sense confirmed by the scene that arrives in the novel's center, a retelling of the night's events, in which we read that Stella did not stay with her crying baby after all but, after calling 911, "ran downstairs but then stood, frozen in the kitchen" (172). Stella overcomes her frozenness to put on her husband's boots but then hears another 
of her children cry; she opens the door but the alarm goes off and she cannot remember the code; her eldest child calls for her, but Stella issues a reassurance and continues to open the door, then "stopped again": "The woman was sitting up, alone ... But Stella just watched her" (172). Again, Stella tries to go out, and again stops: "She shook her head. Knowing she should do something, not knowing what to do. What could she do?" (173). Her children keep calling, and Stella keeps standing there, until finally she tells herself the police will help, and then runs back upstairs "to her screaming kids" (173).

In class discussion, I ask my students whether the novel suggests a judgment of Stella: faced with a vulnerable, suffering other, she wavers between helping and turning away. Faced with the radical needs of an other she does not know, an other out in public, she retreats to her private domestic sphere, choosing to attend to her children, crying but unwounded, rather than the other whose wounds demand her attention. Confronted with risk to her own person, as the assailants have fled the scene but could return, Stella retreats up the stairs to watch through her window.

Stella herself continues to be wracked with guilt over her inaction: she cannot seem to shake her sense of unfulfilled responsibility, not only in this scene but to the grandmother she has not visited for months and eventually returns to. "I feel so awful, Kookoo", she tells her grandmother, "You don't even know"; "I'm not a good person at all" (333). Despite her Kookom's reassurances, other characters voice harsh judgment. When Emily's grandma Cheryl tells her friend Rita that the witness had not gone out to help the girl, Rita cannot hide her "disgust": "So she, like, saw it happening and did nothing? I can't fucking believe that" (342). Cheryl reminds Rita that Stella called the police, but Rita asks again, "she couldn't do anything? Nothing?" before repeating twice in conversation, "she should have" (343).

I ask my students: do you agree with Rita's judgment? The room is divided.

Next, I ask, are we Stella? Students who chuckle uncomfortably when I ask if we are Tommy are silent now. There is a way in which the question is obvious: like Tommy, Stella is distinctively associated in the novel with stories and textuality, associations that issue a metafictional invitation. As her Kookom tells her late in the narrative, "You have always been a storyteller, a story keeper, a watcher" (335). This assessment rings true with what has preceded it in the narrative, for it is in Stella's chapters, Stella's memory, that the novel frames stories of a shared girlhood experience of sexual harassment (165-170) and of Elsie's rape (202-205). It is in Stella's memory that we read the fullest account of Rain-her mother-turned away from the hospital and sent out to die in the cold, and how Stella "learned all the facts" through newspaper articles, police reports, and repeated questions to her family, in order to piece together these details into a "story" (272).

The novel thus invites an association of Stella and reader-as-witness, rendered responsible when faced with the text. As Attridge (2015) writes, "we can draw on Levinas' insistence that responsibility is not something we choose to take on, but something we find ourselves already seized by .... Thus I would argue that we are constituted as literary readers by the responsibility for the work that imposes itself upon us" (126). This responsibility is "for the other-ultimately, for the other's survival" (126). In Attridge's description, which he admits is not an "extrapolation" Levinas would have accepted (126), the reader is responsible for the wellbeing and survival of the text; in Stella's case, the other for whose wellbeing and survival she is rendered responsible in her act of witnessing is most immediately a sexually assaulted young woman, a fact the novel will not let us forget even as it also invites a metafictional reading.

Stella, like Tommy, is a double for readers and perhaps even especially professional readers. Highlighting her role as a watcher, a keeper of stories, a witness, I ask my students again, is Stella us? Does the novel invite judgment of anyone confronted by an other in need who does nothing to help, who turns away from the responsibility implicit in the act of witnessing, in the very act of reading?

These questions imply a normative edge, a doubled ethics of the text that is both interpersonal and aesthetic. But it is almost impossible to render these questions into the fully abstracted sphere of reader and text. Attridge continues to insist that an ethical approach to literature is about "treating a work as an event", rather than solely considering "anything to be learned or deduced from it" (124), but he also 
admits that "a responsible reading of the words on the page can't avoid attending to the strands that tie them to the world they arose from" (126). In The Break, the strands that tie these representations to the world invoke the urgency and painfulness of the all too real phenomenon of sexual violence, and violence against Indigenous women and girls in particular, a phenomenon embedded in gendered, raced, and colonial histories and systems of injustice.

Indeed, particularity disrupts our tendency to generalize: not categorical "otherness" or "alterity", but the specific details and identity of both survivor and witness. The novel stages this negotiation of the general and the particular in Stella's horrifying realization that the anonymous "tiny woman" she saw from a distance is actually her own cousin. Stella's haunted sense of unfulfilled responsibility is profound even before she gains this knowledge, although she does try to calm herself by agreeing with her white husband that "it's not like anything happened to us or anything": "She tries to remind herself of this too. Nothing actually happened to her. She wasn't hurt, her family wasn't hurt, not at all" (160). The distance implied here, that one can care less about a stranger than a family member, does not align with responsibility as Levinas or Weil would construe it, and it also does not sit well with Stella's own conscience. Nor does the text allow it, as only pages later she discovers from her Kookom the terrible irony that the assault victim in fact is family (171).

This revelation leads to the re-narrated scene at the center of the novel that tells more fully what happened that night, the one in which Stella attempts over and over again to go out to help the small woman but again and again stops. The new information about the young woman's identity reframes the scene, by making more explicit Stella's attempts to fulfill her perceived responsibility and also revising in her consciousness who the woman was, staging the transition from general to particular. "She pulled the door open and stopped again. The woman was sitting up, alone. Emily was sitting up alone in the snow, pulling on her pants. But Stella just watched her, watched Emily through the glass, fogged by the cold" (172). As the scene dramatizes Stella's revised memory of the night, Stella's horror at what she saw, and what she could not quite manage to do, intensifies: "She saw the woman, girl, Emily, saw her get up, so slow, and limp a step" (173). This real time memory revision-not just a woman but a girl (Emily is only 13 years old), not just a girl but Emily—renders the scene even more painful, not just because Emily is family but because Emily is particular.

This negotiation of general and particular manifests as well in the novel's insistent thematizing of faces and face-to-face encounters. In Tommy's consciousness, "all those women blend into one, their faces so similar. The young girl, poor Emily, tiny and broken in the hospital bed, her aunt with the haunting eyes, looking so carefully, and the witness lady, so relieved they didn't think she was crazy anymore. They all look the same-same long dark hair, straight and shiny, same almond eyes, almost" (221). Tommy's blending of the women into one derives in part from their family resemblance, a fact the novel repeats (for instance, 160, 194). Yet it also highlights the risk of stereotyping, lumping all these Indigenous women into a categorical victim, a risk visible as well in Tommy's association of these women with his own mother and her experience of domestic violence.

The importance of particularity in the face-to-face encounter is rendered even more explicitly in Stella's fully narrated act of witnessing, for as she insists in her second account to the police that she "couldn't see any faces" (162), the revelation of Emily's identity also revises her memory of whether she saw the rape survivor's face. In the re-remembered scene of witnessing, it is not just that the woman's face becomes Emily's face, as her identity moves from categorical gender to Emily's name. Instead, we read that Stella in fact did see the girl's face in the original scene: "For a second, her face was aglow in the light, and the snow dancing around her, and Stella wanted to scream" (173).

This ultimate confrontation with the assault survivor's face seems to be the last straw that freezes Stella in inaction and leads her to turn away. Coupled with the scene's earlier description of how Stella after seeing the woman in the snow at first "paused there, remembering something she hadn't thought of in a long time" (172), this tension between the general/anonymous and the particular face is a clue, a beckoning. In the classroom, we pause over this scene. We attend to its most minute details in the closest of readings, open to it, tentative, careful. When the pieces click into place and we feel that 
thrum of satisfaction, we think guiltily of Tommy's pleasure. We talk about the impossibility of moral purity, the risk of engagement.

This is what we discern: the very details of Emily's rape, the winter snow, the "bottom naked", recall the details of Stella's mother's death, details we only learn later in the narrative (272). This "story" that Stella has pieced together and kept as a "story keeper" may be the "something" she remembers but has not thought of in a long time. That recollection would explain the subsequent internal battle Stella fights as she tries to go out to help the young woman. Likewise, the face Stella sees later takes on a different significance in light of the fact that Stella looks just like her own mother Rain (160) and that she also looks like all the other women descended from her Kookom $(194,220)$. In other words, the face Stella sees in the distance may make Stella want to scream and then freeze her in inaction not because it looks like Emily but because it looks like her own self, like all her relatives, like her lost mother. This indeterminacy points to both the overwhelming accrual of pain for these women in general and also the pointed particularity of a singular life.

A painstakingly careful reading of the scene, one that requires a rereading of the passage in light of later scenes and revelations, opens up the degree to which Stella is not a free subject, with full capacity to respond by taking responsibility, but a specifically traumatized witness. Stella's own particularity disallows an easy moral judgment of her inaction. The recognition of what her husband patronizingly calls her "past" (15), of her prior experiences of sexual harassment, her witnessing of Elsie's rape, her piecing together of her mother's story, not to mention the childhood loss of her mother, disrupts our capacity to generalize her experience as a witness without reference to the specific. Stella's experience, her centrality in the text, her haunted sense of limitless responsibility, invites questions about the ethics of witnessing. It even invites us to practice the kind of readerly attention that models careful, slow, open, and risky care for a textual other. But it unsettles us with the reminder that at its root, the face is not a category but a singular, individuale. fac The reader is not a free, untraumatized moral actor but bears any number of burdens when facing a given work of literature.

\section{Relearning}

A rigorous assessment of literary ethics in all its modes is more important now than ever as the structures of daily life in Western culture undermine our capacity to pay attention, as language and story are used to justify rendering others things rather than responding to the vulnerability implicit in their faces. How easily we stereotype, flattening a nuanced human being, attributing guilt, justifying our refusal of responsibility. With great difficulty do we look at an other and ask, with full openness, "What are you going through?"

Literary writing does something singular; it is a Saying that disrupts the Said (Levinas again), a "questing toward what otherwise may be" (Adrienne Rich's phrase), an event that asks us to partner in its own creation (this is Attridge and also Weil). It both prompts and challenges naïve conceptions of mimesis, but I am convinced that it is too late in the game for any of us to deny the importance of its ethical content in favour of its form alone. The Break represents something indisputably related to reality; faced with this novel, I am rendered responsible not just to partner in its creation as an aesthetic event by giving it my full and hospitable attention but to do something in the world it represents. The only way to claim that literary texts as a rule do not represent reality and invite responsibility is this is to theorize without being in conversation with any of the many, many texts that $d o$. This is an essential challenge for literary scholars moving forward.

But not everyone who reads this novel is a literary scholar, nor can everyone who reads it respond in the same way. If Tommy teaches us a lesson about the risks of readerly mastery and aesthetic pleasure in a story of suffering, Stella reminds us that different readers read from different positions and that to generalize limitless responsibility may further marginalize the already marginalized. This diversity manifests powerfully in the space of the classroom as a reading community, where male students often express surprise at the ubiquity of sexual harassment in the novel while women nod with weary familiarity. Likewise, settler students often express dismay at the structural inequalities 
that lead to so much of the novel's suffering, connecting the text's dynamics with statistics and histories they are learning in Indigenous studies, history, and sociology classes, often with shock at how little they knew of these realities before coming to university. Indigenous students, though, particularly in the first-year course, have been more likely to talk to me after class or in a writing assignment about the novel's familiarity, which paradoxically has both provoked pain and also a deep sense of relief at for once recognizing sisters and aunties, fathers and brothers in a literary text assigned on a university syllabus. And then there are the students who choose to excuse themselves from the reading and the discussion, aware enough of their own particular pain to own that facing this literary text would not bring good into their lives or the world. The anecdotes are instructive: the plurality of readers is a reality we would do well to bring more fully into our theorizing of literary ethics. And this plurality parallels the plurality of ethical systems at work in the world, another point our literary ethics may not yet have fully enough addressed.

As The Break begins with the land, it ends with the land, and specifically with ceremony on land south of the city, where "the bush closes in ... like a quick greeting hug" (340). Kookom has died, passing on the matriarchal role to Cheryl, and she gathers with her family on this land outside the city to smudge with sage and sit and sing together in the steam of the sweat lodge (344-45). Emily is there with Zegwan, and Cheryl notes both the girls' "resilience" and also the way Ziggy's face is still wounded, the way Emily "still walks with a limp, and even here, with only her family around her, she sits with her body curled into itself like a turtle ready to retreat inward" (339). The resolution here is by no means happy, but it is strong and full of love. The novel's final pages narrate both the immensity of the group's ongoing pain-Cheryl notes, "They're already so broken, could they even break any more?" (344)—and also the renewal brought by the ceremony, by the gathering of community. The possibility of Emily's healing seems to inhere in these two related practices, ceremony and community, as does the healing of her family and friends, broken by witnessing her pain as well as their own individual burdens.

This ending is illuminating in its reminder that ethics is so often embedded in spiritual traditions: not just that Levinas' philosophy is best understood in conversation with his essays on Judiasm or Weil's in terms of her quasi-Christianity, but that the characters in The Break live and act within the practices of their own spiritual and philosophical traditions. The caring attention they devote to one another throughout the text, the concerted looking, the open listening, the concrete acts of help and practice of presence, may not be most fully explained by Western philosophical models of face-to-face encounter and attention. A more consonant source may be Nishnaabeg scholar Leanne Betasamosake Simpson (2017), who in her work describes finding in other Indigenous stories "A way of living that was full of community. A way of living that was thoughtful and profoundly empathetic. A way of living that considered, in a deep profound way, relationality" (22). Simpson connects this way of being in the world to the land, to the land that has been dispossessed by settler colonialism and the land to which Indigenous people relate not through possession and conquest but "connection-generative, affirmative, complex, overlapping, and nonlinear relationship" (43). This description of relationship to the land also describes the relationships among Vermette's characters; in fact, it describes the very form of her novel. In other words, while I have been arguing that The Break has a great deal to teach scholars about the New Ethical Criticism, the New Ethical Criticism may not have quite so much to teach us about The Break.

As it turns out, Kookom is the one who can teach us about the Break, and The Break. Eventually we realize that it is her voice-Kookom's, Flora's- that narrates those sans-serif sections between chapters. Kookom's voice as the storytelling elder opens the novel, framing its setting and characters, victims, witnesses, and perpetrators alike, in a history of dispossession from the land, the reference to the Red River (3) an allusion to the Métis uprising, to the negotiations of settler colonialism, to the strength and also the losses. Kookom's voice as the storytelling elder notes that while others do not notice this strip of land through the city, she has "always loved" it, would walk through it noticing the way elderly folks would plant gardens in it, "all nice and clean", the way looking down at the 
grass would let you forget you are in the city (5). You do not notice it if you are not paying attention, Kookom says. You do not notice the land if you are not looking.

I did not notice the land when I moved here seven years ago, to Canada, to Saskatchewan, to Treaty Six Territory and the homeland of the Métis, did not realize how indivisible it was from Indigenous ways of being in the world. I had never learned about how similarly indivisible the land was from assessments of structural injustice, from violence against Indigenous women and girls, from the questions of what justice and healing might actually look like going forward, questions of concrete responsibility. Nor did I notice the importance of the land in The Break when I first read it, my eyes skimming past those opening pages into the urban setting, plot, and drama. Only rereading and rereading did I begin to see. This seeing sent me to books like Simpson's and Glen Sean Coulthard (2014) Red Skin, White Masks and Robin Wall Kimmerer (2013) Braiding Sweetgrass, books that insist on the material, insist on the land. It sent me to sessions on my campus where I listen with every part of me I can muster to Cree and Métis elders and poets and scholars, floored at everything I never knew. It taught me all over again that my generalizing paradigms, of literary ethics, of postcolonial theory, of feminism, break, once again, under the weight of particularity.

To admit this, as a scholar, as a teacher, means returning to the humbling space of nonmastery, of a responsibility to keep learning. It means, as I have been saying here, challenging received theories, but also admitting that I have work to do if I am going to do justice to this text and so many others in the space of the classroom: decolonizing my theory and my teaching by decentering my own expertise. But as I face my students in all their minute and extraordinary particularity, confronted by the multiplicity of their differences from me and from each other, and as I ask them to face this text with me, I recognize the work as worthy. I have already been rendered responsible: but I endeavor, to the extent of my own capacity, to offer the kind of attention asked of me. This work is endless. It is also good.

Funding: This research received no external funding.

Conflicts of Interest: The authors declare no conflicts of interest.

\section{References}

Attridge, Derek. 1999. Innovation, Literature, Ethics: Relating to the Other. PMLA 114: 20-31. [CrossRef]

Attridge, Derek. 2004. The Singularity of Literature. London: Routledge.

Attridge, Derek. 2015. The Work of Literature. Oxford: Oxford University Press.

Bauman, Zygmunt. 1993. Postmodern Ethics. Oxford: Blackwell.

Biviano, Erin Lothes. 2007. The Paradox of Christian Sacrifice: The Loss of Self, The Gift of Self. New York: Crossroads. Booth, Wayne C. 1988. The Company We Keep: An Ethics of Fiction. Berkeley: University of California Press.

Buell, Lawrence. 1999. Introduction. In Pursuit of Ethics. PMLA 114: 7-16.

Cha, Yoon Sook. 2017. Decreation and the Ethical Bind: Simone Weil and the Claim of the Other. New York: Fordham University Press.

Chanter, Tina, ed. 2001. Feminist Interpretations of Emmanuel Levinas. University Park: Pennsylvania State University Press.

Citton, Yves. 2017. The Ecology of Attention. Translated by Barnaby Norman. Cambridge: Polity.

Coulthard, Glen Sean. 2014. Red Skin, White Masks: Rejecting the Colonial Politics of Recognition. Minneapolis: University of Minnesota Press.

Eaglestone, Robert. 1997. Ethical Criticism: Reading After Levinas. Edinburgh: Edinburgh University Press.

Eaglestone, Robert. 2004. One and the Same? Ethics, Aesthetics, and Truth. Poetics Today 25: 595-608. [CrossRef]

Eskin, Michael. 2004. Introduction: The Double 'Turn' to Ethics and Literature? Poetics Today 25: 557-72. [CrossRef]

Gibson, Andrew. 1999. Postmodernity, Ethics, and the Novel: From Leavis to Levinas. New York: Routledge.

Gibson, Andrew. 2005. Ethics. In The Johns Hopkins Guide to Literary Theory and Criticism, 2nd ed. Edited by Michael Groden, Martin Kreiswirth and Imre Szeman. Baltimore: Johns Hopkins University Press.

Goldman, Alan. 2011. The Appeal of Mystery. The Journal of Aesthetics and Art Criticism 69: 261-72. [CrossRef] 
Hakemulder, Jèmeljan. 2000. The Moral Laboratory: Experiments Examining the Effects of Reading Literature on Social Perception and Moral Self-Concept. Amsterdam: John Benjamins.

Hale, Dorothy. 2009. Aesthetics and the New Ethics: Theorizing the Novel in the Twenty-First Century. PMLA 124: 896-905. [CrossRef]

Hughes, Robert. 2010. Ethics, Aesthetics, and the Beyond of Language. Albany: State University of New York Press. Iacoboni, Marco. 2011. The Ontological Priority of Representations: The Case of Mirror Neurons and Language. Language and Dialogue 1: 7-20. [CrossRef]

Irigaray, Luce. 1993. The Fecundity of the Caress: A Reading of Levinas, Totality and Infinity, 'Phenomenology of Eros.'. In The Ethics of Sexual Difference. Translated by Carolyn Burke, and Gillian C. Gill. Ithaca: Cornell University Press, pp. 185-217.

Keen, Suzanne. 2007. Empathy and the Novel. Oxford: Oxford University Press.

Kimmerer, Robin Wall. 2013. Braiding Sweetgrass: Indigenous Wisdom, Scientific Knowledge, and the Teachings of Plants. Minneapolis: Milkweed.

Koopman, Eva Maria. 2015. Empathic Reactions after Reading: The Role of Genre, Personal Factors, and Affective Responses. Poetics 50: 62-79. [CrossRef]

Levinas, Emmanuel. 1993. Philosophy and the Idea of the Infinite. In To the Other. Edited by Adriaan Peperzak. Purdue: Purdue University Press, pp. 88-119. First published 1957.

Levinas, Eammanuel. 1952. Simone Weil against the Bible. In Difficult Freedom: Essays on Judaism. Translated by Seán Hand. Baltimore: The Johns Hopkins University Press, pp. 133-41.

Miller, J. Hillis. 1987. The Ethics of Reading: Kant, de Man, Eliot, Trollope, James, and Benjamin. New York: Columbia University Press.

National Inquiry into Missing and Murdered Indigenous Women and Girls. 2019. Available online: https: //www.mmiwg-ffada.ca/final-report/ (accessed on 20 June 2019).

Newton, Adam Zachary. 1995. Narrative Ethics. Cambridge: Harvard University Press.

Newton, Adam Zachary. 2001. Versions of Ethics; Or, The SARL of Criticism: Sonority, Arrogation, and Letting-Be. American Literary History 13: 606-37. [CrossRef]

Nussbaum, Martha C. 1990. Love's Knowledge: Essays on Philosophy and Literature. Oxford: Oxford University Press.

Oatley, Keith. 2016. Fiction: Simulation of Other Worlds. Trends in Cognitive Science 20: 618-28. [CrossRef] [PubMed]

Odell, Jenny. 2019. How to Do Nothing: Resisting the Attention Economy. New York: Penguin Random House.

Robbins, Jill. 1999. Altered Reading: Levinas and Literature. Chicago: University of Chicago Press.

Rose, Gillian. 1993. Angry Angels: Simone Weil and Emmanuel Levinas. In Judaism and Modernity: Philosophical Essays. Oxford: Blackwell.

Rushkoff, Douglas. 2019. Team Human. New York: Norton.

Simpson, Leanne Betasamosake. 2017. As We Have Always Done: Indigenous Freedom Through Radical Resistance. Minneapolis: University of Minnesota Press.

Sommer, Doris. 1994. Resistant Texts and Incompetent Readers. Poetics Today 15: 523-51. [CrossRef]

Spivak, Gayatri. 1992. French Feminism Revisited: Ethics and Politics. In Feminists Theorize the Political. Edited by Judith Butler and Joan W. Scott. New York: Routledge, pp. 54-85.

Vermette, Katherena. 2016. The Break. Toronto: House of Anansi Press.

Wallace, Cynthia R. 2016. Of Women Borne: A Literary Ethics of Suffering. New York: Columbia University Press. Watson, Gay. 2017. Attention: Beyond Mindfulness. London: Reaktion Books.

Wehrs, Donald R. 2013. Levinas and Twentieth-Century Literature: Ethics and the Reconstitution of Subjectivity. Newark: University of Delaware Press.

Weil, Simone. 1973. Waiting for God. Translated by Emma Craufurd. New York: Harper and Row. First published 1951.

Weil, Simone. 1965. The Iliad, or the Poem of Force. Chicago Review 18: 5-30.

Wolf, Maryanne. 2018. Reader, Come Home: The Reading Brain in a Digital World. New York: Harper.

(C) 2019 by the author. Licensee MDPI, Basel, Switzerland. This article is an open access article distributed under the terms and conditions of the Creative Commons Attribution (CC BY) license (http://creativecommons.org/licenses/by/4.0/). 



\title{
Article \\ Sonic Rhetorics as Ethics in Action: Hidden Temporalities of Sound in Language(s)
}

\author{
Steven B. Katz \\ Emeritus College, Clemson University, Pendleton, SC 29670, USA; skatz@clemson.edu
}

Received: 17 October 2019; Accepted: 14 January 2020; Published: 29 January 2020

check for updates

\begin{abstract}
Sonic rhetorics has become a major area of study in the field of rhetoric, as well as composition and literature. Many of the underlying theories of sonic rhetorics are based on post-Heideggerian philosophy, new materialism, and/or posthumanism, among others. What is perhaps similar across these theories of sonic rhetoric is their "turn" from language and the human in general. This short essay explores sonic rhetorics by examining three temporal dimensions found in language. Specifically, the essay focuses on the more obvious sonic dimensions of time in prosody, and then at deeper levels temporal dimensions in a couple of brief but revealing examples from ancient languages (classical Greek, and Biblical Hebrew). Further, this essay suggests some ways in which time is related to ethics in practice and action. For example, just as time is involved in the continuous creation of our increasingly vast, expanding, infinite but bounded universe, Levinas might say that time is necessary to create the ethical space, or perhaps "hypostasis," one needs for the possibility to encounter "l'autre" - the Other. Beyond prosody, propriety, even kairos, are hidden temporal dimensions of language that may render sonic rhetorics forms of ethical practice.
\end{abstract}

Keywords: sonic rhetorics; non-linguistic turn; time; space; ethics; prosody; etymology; Plato; Heidegger; Levinas; Alterity; the Other; orthography; classical Greek; Biblical Hebrew; the reversible vov

\section{Introduction: A Background of Sound}

Sonic rhetorics is undergoing an increasingly loud and noticeable boom. A growing number of scholars in cognate rhetorical fields have turned their auditory attention to sound as meaningful if not fundamental in both teaching and researching rhetoric, writing, literature, and philosophy, e.g., (Ahern 2018; Detweiler 2019; Gunn et al. 2013; Hawk 2018a; Measel 2020; LaBelle 2018; Novak and Sakakeeny 2015; Osborn 2016; Overall 2017; Patterson 2020; Rickert 2005, 2013; Rickert and Salvo 2006; Stedman 2012; Sterne 2012; Stone 2015). Generally, sonic rhetorics concerns itself with the multiple dimensions of rhetoric as sound. Sonic rhetorics, like "rhetorics" generally, can include literary as well as nonliterary texts, events, objects, natural/ecological sounds, etc., either in combination with visual or virtual stimuli or in isolation, as aural-born phenomena and/or as acoustic elements in soundscapes or larger entangled environments (Patterson 2020; Rice 2012, 2020).

The study of sound in rhetoric as sense (or nonsense)—the possible "meaning" of sound in language — can be said to have begun with (Plato 1961a, 1961c) but also may be found in more pre-Socratic lyrical poetry (Walker 2000), and perhaps even earlier in pre-Homo sapient pre-history (Rickert 2016). Sound was the hallmark of sophistic rhetoric that Plato fought against, in which style is a form of knowledge (Enos 1993; Kerferd 1981); in late Ciceronian theory of oratorical rhythm as an aural, temporal intuition of "truth" (Cicero 1939, 1942; Leff 1989; Mendelson 1998; Katz 1996); Medieval and Renaissance debates about Attic vs. Baroque prose styles and methods of figuration and scansion (Croll 1989; Ong 1958; Ramus 1983); research into the sophistication and intricacies of prosodic and musical notation of the song-poems of the Troubadours (Whigham 1979); and the 18th century Elocutionary Movement with its renewed emphasis on human (and nonhuman) sound, delivery, and 
gesture/motion (Sheridan 1968; Austin 1966; cf. Bulwer 1974; Darwin 2009; Hawhee 2016). And this is just the briefest history of the musical properties of language in the field of rhetoric!

Although the study of sound in modern rhetoric and composition can be said to have begun with the images and metaphors of writing as "felt sense," "dissonance," and "musical organization" (Perl 1980; Odell 1993, p. 232; Elbow 2006), respectively, the birth of late 20th- and early 21st-century approaches to sonic rhetorics has been attributed to Katz's (1996) book, Epistemic Music of Rhetoric (Gries 2019; Hawk 2018a). However, the contemporary study and teaching of sonic rhetorics goes far beyond old-fashioned approaches, such as Katz's, that analyze literary (and nonliterary) language and style as music, and affective and/or cognitive responses to sound sound (cf. Ceraso 2018; Measel 2020). These new approaches include post-Heideggerian and/or phenomenological studies of sound and/or posthumanistic tracings and analyses of technological production and disseminations of sound (e.g., Rickert 2013; Rickert and Salvo 2006; Hawk 2018a, 2018b).

Given the diversity of this "subdiscipline," it is only to be expected that different conceptions, definitions, and even terms of sonic rhetorics ("the music of rhetoric," "sonic rhetorics," "aural-born rhetorics") have emerged. Some of the subsequent treatments of rhetorics variously called (or not called) sonic rhetorics are predicated on senses connected to the human body, and some apparently on senses disconnected from the human body-refocused on or furbished by "natural" sounds (Ahern 2018) or technological sounds (Rickert 2013) or aesthetic sound (Osborn 2016). Some sonic rhetorics consider magical, spiritual psychic, or psychagogic exploration (De Romilly 2013; Rice 2020; Stephens and Katz 2019). Some (pre)sonic philosophies and rhetorics zero in on and wrestle with the movement of the body, including natural bodily "functions" and their symbolization (Burke 2007; Hawhee 2009; Katz 2015b; Rueckert 2007), as well as the sensuousness movement of the symbolic form of language in consciousness (Cassirer 1955; Katz 1996); physical motion and dance (Hawhee 2013); theatre sound (Kaye and Lebrecht 2015; Patterson 2020); and the rhetoric of every kind of music, including jazz and hip-hop (Clark 2015; Carson 2017).

What is perhaps similar across many of these theories of sonic rhetorics is their turn away from language (the non-linguistic turn), and the human in general (the non-human turn). This is not surprising either, given the scientific, philosophical, and cultural contexts of new materialism and posthumanism (e.g., Barad 2007; Barrett and Boyle 2016; Bryant et al. 2011; Harman 2018; Hawk 2018a; Holmes 2013; Ahern 2018; Ceraso 2018; Detweiler 2019; Overall 2017; Pilsch 2017; Stone 2015). I will not critique or criticize any of these theories and studies. Rather, I applaud their diversity and encourage their development in (re)focusing the field of rhetoric on "the natural world"—on the nonhuman as well as aesthetic (sonic), on objects and animals and events in worsening physical climates and the social environs of the Anthropocene (Comstock and Hock 2016; Morton 2009, 2012, 2013; Propen 2018; Zylinska 2014). I will only point out in passing a few caveats and concerns ${ }^{1}$. What I want to do in this

1 The old Baconian questions and philosophical qualms concerning not only objectivity but whether we ever "get out of" language, bodies, minds, limited senses, human consciousness, have not gone away. The issue of how we perceive (hear), relate to, and know external reality would seem to be particularly important in questions concerning nonlinguistic being and the nonhuman world. This is not the same issue about the relation of posthumanism to humanism (see (Braidotti 2013; Wolfe 2013). Cf. an interesting and sophisticated debate between Boyd (1993) and Kuhn (1993) about the role of metaphor in the construction of scientific fields, and whether or not metaphors in science lead researchers out to causal structures of the physical world [see Appendix A]). The issue is ontological as well as epistemological. The as is about the undeniable fact that at different levels we (and other things too) are constituted in relatively stable bodies and minds (more on this below), from which we perceive and "know." As the Copenhagen School of quantum mechanics was good at pointing out, despite technological development, our limitations as human beings persist, and the 'human variable' may always have to factor into any probability equation (Heisenberg 1958; Bohr 2010; cf. Katz 1996). Despite Entanglement Theory in new materialism, and a corresponding "demoting" of the power of language (see Barad 2007, esp. chp. 7), most of our thinking and discussion about sonic rhetorics take place in language (the echo of the origin of the (re)sound is located in the ear, depending for its mediation in the limited human sense of hearing). We may need to (re)remember that almost everything we do as humans is in and through the agency of language as "symbolic action" (see (Burke 1952, 1966, 1969; cf. LaBelle 2018); see Katz (2015b); Katz and Rivers (2017) for a more nuanced discussion of Burke in relation to posthumanism).

The question of how humans know is a decidedly postmodern one, focused as it is back on the human and on language - a take with which most scholars in sonic rhetorics today would probably take umbrage. But to some degree, 
little essay is propose that there still may be some hidden sonic dimensions of sound "left behind" in language, and that they have some attendant ethical components and implications that might be important to consider in sonic rhetorics. This 'linguistic (re)turn' necessitates revisiting language via rhetorical and stylistic analysis, as well as some etymological work based on classical Greek and esoteric hermeneutics based on Biblical Hebrew, and therefore are epistemologically registered and referenced in the terms of the limitations of the human senses, mind, science, and technologies-the vagaries of human response and the uncertainties of all human knowledge and experience. This short essay quickly explores three dimensions of language underrepresented in sonic rhetorics: (1) Prosody; (2) Etymology; (3) Orthography.

Because a foundational "key" to sound (and ethics) is time, I will advance some notions of time not usually talked about, and then (1) touch on some more obvious sonic elements of time in prosody or poetics; (2) quickly dip into the history of a single passage and word of classical Greek and its temporal translations, and finally (3) point to a hermeneutic approach to the letters of the alefbet themselves as well as a meaningful temporal dimension of grammar in Biblical Hebrew. My choice of passages, languages, and methodologies is not systematic in the ordinary sense; rather, it is driven in part by the efficacy of examples, by my own hermeneutic access (and limitations) to different languages, and some hidden but highly revealing and significant sonic dimensions of time in those languages as ethical actions in "literary (and nonliterary) practice.

Before proceeding with these three analyses, we must quickly (re)examine our notions of time.

\section{2. (Re)Introduction to Time in Rhetoric/Rhetoric as Time}

The concept of time or timing in rhetoric is an ancient one. We have already, albeit quickly, reviewed the attention to the study of time in the history of rhetoric in the study of oratory, elocution, prose style, and song. A concern for propriety in eloquence, the perfect unity of form and content

on what I call 'the spectrum of linguistic determinacy', language influence thought, from a little to a lot. Derrida (1982) asserted that all philosophy is metaphor, and even Heidegger focused in on the role of language (Heidegger 2010b), sound in language (Heidegger 1971a), and poetry itself (Heidegger 1971b, 2014) in the construction of his philosophy of Being (Heidegger 2010a). A couple of related issues are pertinent to the study of sound and ethics, the purview of this essay. First, one is somewhat pressed to find discussions of sound as or in relation to ideology, such as the uses of sonic rhetorics for propaganda purposes, past, present, or future (cf. Birdsall 2012; Goodman 2012; Haynes 2016; LaBelle 2018). Second, one is seemingly less hard-pressed to find discussion of sound in relation to an ethical consideration of phronesis, or "ends." Scholarship concerned with teaching seems to consider ethics more (although that is a generalization [see Morton, passim]). One suspects that the ideology of sound, like sound itself, are assumed to be "natural," and thus "neutral" if not "wholesome," and therefore are already and always good. How much of "the value" of sound as pedagogy and praxis is driven by "naturalism," "metaphysical empiricism," or "technological imperatives"? In the past I have argued that even "social-epistemic" rhetoric is not ideologically neutral or necessarily good (Katz 1992, 1993; cf. Moses and Katz 2006; Katz and Rhodes 2010); the same may be said about sonic rhetorics. A wonderful new proclivity in sound studies is to regard ideology and ethics as questions of "access" and "circulation" — "praxis" — in advocating and using sound to teach environmental awareness, social justice, and equality (e.g., Ceraso 2018; Danforth et al. 2018; Gries and Brooke 2018; Hawk 2018a). Elenchi. Should we inquire about phronesis (ends) as well as praxis (means)? Can we keep sonic issues from being about technological values only, the way Hawk (2018b), or Ahern and Mehlenbacher (2019) do? Should we question phronesis itself? And what about our belief that we can overcome any perceived "deficiencies" of human bodies by medical/pharmaceutical means, genetical manipulation, or prosthetic enhancements? I am not talking about "Ableism" here, but existential election: the point at which the 'healthy' posthuman morphs into transhuman, with its new attendant ontological, epistemological, and physical alterations and commitments, none of which are ideologically or ethically neutral. Further, how much is the absence/presence of ideology/ethics in sonic rhetorics connected to if not the result of the dismissal of language ("the nonlinguistic turn") and a decentering of the human (the "nonhuman-turn"). I see some danger here, but also justifications and value: sonic rhetorics are rightly focused on ecology-not only on acoustic ecology, but on damaged ecology - on the polluted environment, on human-made global warming, and on violent climate change in the Anthropocene (see Comstock and Hock 2016; Morton 2009; Pilsch 2017; Propen 2018; Zylinska 2014). Even when the study of the human and language is precluded, these scholars/studies rightly see sound studies as a way of enhancing our awareness of the nonhuman physical world and our effects on it through increased attention to sound. But even though we may be "entangled" with all living and nonliving things, we are still constituted at several levels of physicality, with bodily awareness and consciousness. Even though we are also part of the random flux, we are beings who mostly use language to negotiate and reconstruct the material world (Burke, passim; cf. Katz and Rivers 2017). So when we develop theories, are we merely extending metaphors (whether "active" or "passive" epistemic access (Boyd 1993; see Appendix A))? As I have asked before, can we continue to develop indeterminate methods to work with sound as well as affect (Katz 1996; cf. Katz 2015a)? Can we transcend current human consciousness (Katz 2015b, 2017; Katz and Rhodes 2010; Katz and Rivers 2017)? 
at every moment of persuasion (Cicero 1939, 1942), and kairos, the relationship between rhetoric and ever-changing historical context and thus discourse as a time-event rather than a static object (Miller 1991), are important considerations of time in rhetoric. Of course, one of the "keys" to the study of sound (in language or music, in linguistic or nonlinguistic objects and events) is time. Just as time in astrophysics seems to be involved in the continuous creation of the increasingly vast, infinite, and unknowable physical space, so too with phenomenological-ethical time-space. For example, for Heidegger time allows the possibility to one's death as the "Event Horizon" and source of Dasein, of true Being-in-the-World (Heidegger 2010a). For Levinas, another ethical possibility of the time-space relation/expansion is to encounter, through increasing Alterity, or "hypostasis," l'autre- "the other" (or "Other," perhaps G/d)," which for Levinas may be the ultimate ground and goal of ethics (e.g., Levinas 1981, 1987, 2000).

But the issue of time in rhetoric (beyond historical chronology or audience measurement, beyond propriety, beyond kairos, even beyond prosody in prose), is immediately engaged anew in other possibilities of hidden sonic dimensions of language and literary practice and its relation to ethics. In the time-space constraints of this essay, I will investigate at least three dimensions of rhetorical-linguistic time that are perhaps concealed in the languages in which we live. Somewhat like Heidegger, but with so much less knowledge and moving in the opposite direction-into language rather than through and away from it in the ultimate search for Alethia (truth) through Dasein (Heidegger 2010a; cf. Heidegger 1971a, 1971b, 1977, 2010b, 2014)_I will attempt to "unconceal" three aural-temporal dimensions of language that might underlie studies of sonic rhetorics as ethical action in literary practice. These three dimensions are: (1) prosody; (2) etymology; and (3) orthography. We will see that time and ethics are involved in each one of these dimensions.

How should we think about time? The following are some assumptions and assertions.

(1) As Einstein postulated, time is a fourth dimension of space; but as String Theory and Quantum Entanglement (Greene 1986; Barad 2007) predict, there may be multiple, perhaps countless dimensions of space, and thus multiple dimensions of time-or no discernible difference between time and space at all. Size-wise, these extra dimensions of space could be the tiniest of pockets, to entire alternate universes, to all universes-a theory the late (Hawking 1988) also entertained.

(2) In his undefended but not published doctoral dissertation, the poet and philosopher T.S. Eliot (1989) argued that there are a least two dimensions of time: physical time, and temporal consciousness-time as we experience it. However, if these two dimensions are not in sync (and how can we know whether they are or not), the results are temporal crises in the history of empiricism and "objectivity" that parallel and rival the epistemological problems of language/thought and spatial referents which have haunted Western philosophy and science from Heraclitus to Quantum Entanglement (see Kerferd 1981; Barad 2007).

(3) We do not really know what time is. Unlike space, time is invisible. Like causality (Hume 1999), we only assume its potential, see its (chronological) effects. We do not see the law of causality and have no other experience of it. So too with time: we can't see how it operates/acts. And unlike space, in which we move in three dimensions, it seems we can only move forward in time. In addition to its physical invisibility, time as a process of expansion toward death has been given a role in 20th century philosophy of ethics, where it becomes the "Event Horizon" for Dasein and a possible realization of fuller (human) being (Heidegger 2010a), or an eternal moral space for the discovery of Alterity - where meeting the Other becomes possible, and thus a primary grounds of a new ethics of relationships (Levinas 1969, 1987, 2000).

(4) We cannot stand still in time as we can do in space, even if we stand absolutely still in space (even in death we continue to decay, for most organic and inorganic entities until there is nothing left). We move in and through time, and time moves in and through us.

(5) Time may not only be a dimension; it also appears to be a force, a force that moves, a force that moves everything with it - a tremendously destructive force that slowly ravages everything, both 
animate and inanimate objects alike. (Hence the urgency we find in Being and Time for the fully cognizant human to recognize his/her own death, embrace it, and to give it and life full meaning.)

(6) But time also would seem to be a force that opens with space, not only for the otherwise anonymous self to move into aware subjectivity (Levinas 2001), or to move in space to a temporal position that makes possible an encounter with (an)Other (Levinas 1987) and perhaps ultimately—but never-G/d (Levinas 1969, 2000); but also in the physical expansion of the universe a million miles per second in every direction. The action of time as a force, then, is an expression in language (Steiner 2013; cf. Levinas 1981) of metaphysics as well as science-which makes and takes physical as well as ethical movement and consciousness outward and into the future even possible.

(7) Diane Davis (2010) argues that for Levinas ethical obligation is "preoriginary," which "temporally" probably would place it before the big bang and before the creation of time and space, making language 'sacred' and rhetoric "first philosophy." For Levinas (1981), this prelinguistic reality, a phenomenological "realm" of being that exists outside time and space "beyond essence" (Levinas 1981), is the ground of Alterity, the first possible "encounter" with (an)Other, and "inessential solidarity" (Davis 2010). A reading of Levinas' earlier work (e.g., Levinas 1987, 2000, 2001) might imply that subsequently, without time (and space), whatever time is, we might not be able to move, morally or physically at all: we would be frozen in whatever space is, without motion-and if sentient, painfully naked consciousness shivering in a void. (But cf. Levinas 1981)

(8) It is in the property of time as a physical force, as a movement ripping open space, opening the universe before us (or as local motions also at-a-distance-"Quantum Entanglement") where we begin to hear tone, time, sound which (perhaps like ethics for Levinas), seems to arrive out of a primal 'nothingness' (Levinas 1981; Zuckerkandl 1956). But if we are looking to material time for a physical counterpart to the nonspatial, atemporal "preoriginary" basis for "inessential solidarity" as the potential ground of ethical relations (Davis 2010), time as a moralizing physical force may serve that role in Heidegger's concept of Being, but it may not do so for Levinas. "The title and the content of Otherwise than Being or Beyond essence alert us to the priority Levinas gives to his ongoing contestation of Heideggerian thinking. Otherwise then Heideggerian being; beyond Heideggerian essence" (Cohen 1998, p. xiii; cf. Katz and Rhodes 2010). We will return to these issues at the end of the essay.) Regardless, it seems evident that nonlinguistic sonic experiences, from cosmic radiation from the Big Bang to music, whether ethical or not, reaches and affects us through language and the world, which acoustically command and ethically demand that we hear, listen, respond, and attend to sound, if not also to our ethical responsibility to (the) face (of) the Other (cf. Davis 2010). Time as a physical force opens up language and the world through science and poetry (see Heidegger 1971a, 1971b, 2010b, 2014).

It is here that we will turn to our first example of the hidden temporal dimensions of sonic rhetorics in language, in this case in prosody, poetics-and its moral positionings and literary practices as sound.

\section{The Prosody of Time and Ethics}

Certainly, we hear and feel not only the force of time in the rhythm of a poem that is musical and performed, but we also understand how poetry uses time, as music does, to create and toy with affective and cognitive expectation of emotionally meaningful sound (see Meyer 1956; Zuckerkandl 1956; Huron 2008). But if we are especially attentive readers (or talented writers), we also can create and/or hear 'linguistic pockets of time' in the sounds of poems as human-made sonic objects. In the rhetoric of poems as human sonic objects, these linguistic pockets of time can be predicated and predicted on traditional prosodic elements of poetry, poetics (see Table 1). 
Table 1. Pockets of linguistic time in prosody.

\begin{tabular}{|c|c|}
\hline Prosodic Element & Sound-Time Equivalent \\
\hline Image & "Tone is an image of time ... a time image" (Zuckerkandl 1956) \\
\hline Assonance, consonance, alliteration, rhyme & Repetition of sounds in time \\
\hline Rhythm and meter & Repetition of time in sound \\
\hline Line length/breaks & Duration \\
\hline \multicolumn{2}{|l|}{ Figures of speech } \\
\hline \multicolumn{2}{|c|}{-repetitions, variations, substitutions, additions, omissions of sounds see (Quinn 1995; Meyer 1956; Katz 1996) } \\
\hline
\end{tabular}

Poetry, especially formal poetry, uses forms and styles to explore time by routing ideas and sounds around the nooks of line breaks, the crooks of rhyme, the running repetition of expected and heard beats (meter and rhythm), the crannies of specific forms that expand and contract and reflect the back/wash of recurring refrains and rhymes, or flow steadily on. These linguistic pockets of time, these prosodic elements we create and hear in poems, become the sonic rhetorics of poems as sound. Poems as sonic objects also create aural and temporal arguments that are ethical (see Katz 2017; Stephens and Katz 2019). However, with these traditional prosodic elements we have direct but not unproblematic access to the temporal dimensions of poems as sonic objects, and their ethical arguments (see Katz 1996; Whigham 1979; Croll 1989; Measel 2020) via revealing albeit still limited analysis. ${ }^{2}$ These linguistic pockets of time created in the rhetorical bodies of poems as sound do not always point outward and are not directly connected to external referents (Heidegger 1971a, 2010b). Yet rhetorically, time, invisible except to the ear, can ethically critique the referential meaning/spatial content of poem and culture. But it is almost always the case that spatial, referential meaning will 'visually overrun' the temporal dimensions of poems, which then become objects of interpretation rather than performance (Katz 1996; cf. Katz 2017; Stephens and Katz 2019). Thus, contextual content and culture is often useful or necessary to make relatively specific sense of the "meaning of music" (Meyer 1956). Thus, the temporal dimensions of poems as sonic objects are easy to rhetorically miss, especially when the content itself is highly ethically charged. The following volatile villanelle composed by the author from phrases spoken or tweeted is a "perfect" example of how the rhetoric of a poem as sonic object itself may constitute and act/enact temporally ethical arguments. Because I am going to ask you to ignore context and foreground the prosodic dimensions of time, I am going to blind the poem as much as possible. We do not have to and will not discuss the content of the poem per se. Please listen, and we will "see" you on the other side.

Untitled

"What the hell's happening out there in space?

Believe me, there's no man-made climate change!

My people tell me it's a big disgrace!"

“Mar's next—best people—I don't care race.

A Space Force will also be tremendous.

So what the hell is happening in space?"

“They're bringing drugs, they're bringing crime-that face!

2 How do we research and talk about time without destroying it by our literary and rhetorical methods of analysis and practice, which seem to always remain grounded in Newtonian space-time modes of consciousness, just as New Physics is? (Katz 1996, 2015b). In keeping with both Heidegger and Levinas, I would say that the first ethical action that sound (whether natural, voice, musical instruments, machines, writing) demands of us as conscious beings is the imperative to listen attentively, to really hear, to respond in kind, to perform, to practice in life. One answer to the question how to avoid destroying time (and affect) with our methods is to ground our methods in poetry (Heidegger 1971b, 2010b, 2014), although in terms of ethics and essence I think that Levinas as well reveals the paradoxicality of this proposition (e.g., Levinas 1981). 
We have no borders; they're laughing at us!

Many say it's a terrible disgrace."

"The Putin witch hunt is a huge mistake.

If you're listening, let's be friends, Russia.

(But what the hell is going on in space?)"

"The news is all made up, totally fake!

There's no obstruction, no collusion, no quid pro quo.

It's a hoax, witch hunt, disaster, disgrace!"

"No puppet, no puppet: I will invade,

any sh' holes with oil if they don't have white folks.

Just look what's happening in outer space."

"I'm like a genius—a very high IQ—smarter than, than my generals!

Who knew it would be so complex?

Fine people on both sides: it's a disgrace."

"I'm shutting down the government, closing the border, will separate

families to prevent more American carnage.

And also what happens in outer space."

"We need to build that wall; but who will pay?

Mexico!! Our nation's being overrun by savages!

It's a sin, what's happening, a disgrace."

"I read somewhere, and I'll say it again:

Wouldn't it be great if Putin were our friend?

Then what the hell is happening in space?

Whatever. It's a total disgrace."

It is very difficult to get beyond the speaker and the referential-ethical meaning expressed here (they are right in your face - and not in a Levinasian way (Davis 2010), but rather the opposite). But can you hear time through the screed? Much of the poem is obviously referential, a dialogic interaction between the personal/cultural sphere of affect/art and the public/political sphere of discourse that does the rhetorical work of criticism and raises ethical questions all on its own. But if we stop there, prosody will teach us nothing about time and ethics in the language of the poem as a sonic object. The literary form of the villanelle in all its temporal dimensions, holds and remolds, squeezes, cajoles, and critiques the referential and contextual content of the poem. The villanelle qua rhetorical-ethical action temporally manipulates and comments through overall form (musical organization), line length and breaks (duration), rhythm and meter (time in rhetoric), and the sonic repetition of refrain and rhyme pattern (rhetoric in time). These temporal dimensions (as prosodic pockets) of poems-sonic objects made out of language-critique content and each other in real time.

- The villanelle reveals things that would not be revealed in prose or any other poetic form.

- The villanelle's overall form, the repetition of refrains and lines, the restricted rhyme scheme, and the usually tight syllabic line lengths (10 syllables) or meter (iambic pentameter) are all temporal elements that do sonic and rhetorical work.

- Because of the constantly recurring lines (the first line of the first tercet reappears as the end line of stanzas 1,3, and 5, and the penultimate line of the quatrain; the last line of the first tercet reappears as the end line of stanzas 2 and 4, and the last line of the quatrain), and to some degree a lack of variation, the villanelle is the perfect form to capture and reproduce a speaker's own penchant for repeating whole phrases, as well as using circular logic. 
- This villanelle is longer than the traditional villanelle of five tercets and a quatrain. Instead of six stanzas, it has ten. This poem physically recreates a speaker who "runs over time," goes off-script, adlibs, all the while circling around and repeating himself, almost verbatim. We see this in the line length too, in places where, in conjunction with content, the lines deliberately "run over" the meter.

- If line length as duration constitutes temporal ethical criticism, Lines 1-13 are in perfect syllabic meter for the villanelle: ten syllables each, establishing the standard. However, the syllabic meter of the villanelle form allows lines to run over and amok (especially noticeable when the line runs way over), exposing the ramble, ruckus, and rot (see L14, where line length calls attention to the fabrication, and L19, where line length calls attention to itself as an empty, stupid boast. L22 and L26 create similar sonic/temporal effects).

- $\quad$ L4 and L7, in maintaining the 10-syllable count, force some other figures of omission (Quinn 1995), in this case ellipses, to linguistically and temporally unconceal prejudice, as well as broken grammar and non-sequiturs.

- There also are lines where the form of the speaker (temporally if not physically, as it were) come up "short" (nine or less syllables), as in L20 and L31, thus critiquing the statement that time ethically undermines.

- A high level of generality and limited diction of the poem is highlighted by the traditional villanelle's syllabic metrical count and recurring refrains and lines.

- $\quad$ Rhyme (sound in time), along with rhythm and meter (time in sound) are temporal dimensions par excellence. In this villanelle, the rhyme of the two refrain lines are fairly consistent: "space," and "disgrace," two words that are constantly repeated, creating something like obsession. But all " $\mathrm{b}$ " rhymes throughout the poem, although clever, introduce sour rhyme into the temporal scheme: "change," "tremendous," "us," "Russia," "folks" "complex," "carnage," "savages ... " The off-end rhyme, sometimes rather distant, jangles across the time-space of these lines, as well as within and across lines [internal rhyme].

The villanelle as a sonic object in language-including and particularly its overall form and style, its refrains, its rhyme scheme, and its line lengths and breaks-is a direct temporal form of ethical criticism, which Cicero knew was a "natural intuition possessed by everyone" (1942) and the final arbiter of truth (1939). And it is a good thing that it is natural, for who reads at this level but literary and rhetorical scholars? While many of the sound effects are obvious to us, and have some kind of affective effect on listeners or readers, the temporal "value" of poetry as sonic objects are rhetorically more esoteric and obscure than ordinary language use, where the sound is still heard but the ethical role of time is often hidden and goes undetected.

\section{Deep Sound, Time, and Ethics}

While not as theorized as prosody which becomes a basis for understanding the sonic rhetorics of poetic objects, or as historically tectonic as the significant variations and Weltanschauungen of different languages, there are also multidimensional pockets of linguistic time created by and contained in the etymology of words-what we might refer to as 'deep sound'. These pockets of time are not merely the result of the chronological development of the denotations and connotations of words spoken and written in any language, but also are temporal distortions of diction that result with the always "inaccurate" and already metaphorical usage of each word and its vicinity, at each layer of linguistic history. Because of the passage and upheavals of history, local time distortions of meaning, with ethical implications, also can be seen in attempts at translation, which are usually problematic but also revelatory.

For an apt example of a discussion about music and language in classical Greek, let us turn to W. D. Woodhouse's translation of the Plato's Gorgias (Plato 1961b). There (502c-d) Plato has Socrates ask:

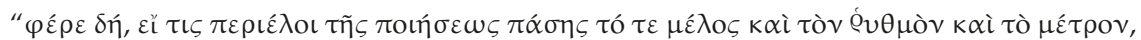

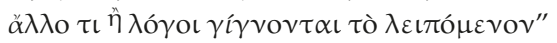


(phere dē, ei tis perieloi tēs poiēseōs pasēs to te melos kai ton rhythmon kai to metron, allo ti $\overline{\mathrm{e}}$ logoi gignontai to leipomenon)

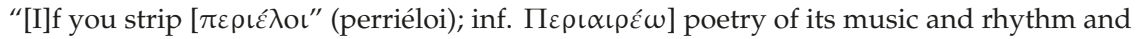
meter, wouldn't what remains be nothing but speech?"

If we "take a moment" to focus on the Greek word Plato uses for "strip" here, " $\pi \varepsilon \rho \iota \varepsilon$ 入ol," we might strain to hear other dimensions of time-not only just below the surface, in the chronological, etymological history and/or the surrounding grammar of each word, but in translations as well. (Indeed, coded deeply beneath any text is the creation of "other texts" based on the long history of each word and their differential relations, but now newly assembled, although their organization is far less coherent or intelligible. This temporal 'subtext' is further concealed by translation, as well as contemporary usage - but is always and necessarily present nevertheless—a hermeneutic dimension of texts that Heidegger was acutely aware and made central to his philosophy.)

These hidden dimensions of linguistic time, located around, under, and through each word and its grammatical usage, can be understood as pockets of sonic rhetorics. The sonic rhetorics created by etymologies (in translation or not) are based not only on horizontal duration, as is the case in poetry (e.g., the line), but also on vertical duration and extension, which is also the way metaphor works (Boyd 1993; see Appendix A). In this case, the act of stripping is vertically ordered in Table 2 by my admittedly subjective judgment concerning the increasing velocity of the denotation and connotations of the translation of "strip." Here, the relative and 'ethical soundings' of the language becomes equated with the speed and thus violence of the rhetorical act. (The detail in Table 2 was gleaned and quoted from the Tufts University's Perseus Project/Greek Word Study Tool (2019)).

Table 2. Etymological pockets of time in translations of the Greek word $\pi \varepsilon \rho \iota \varepsilon$ גoı, "strip".

\begin{tabular}{|c|c|c|}
\hline LSJ & Middle Liddell & $\begin{array}{l}\text { According to the Increasing } \\
\text { Velocity of the "Rhetorical Act" }\end{array}$ \\
\hline $\begin{array}{l}\text { A.1 } \\
\text { take away something that surrounds } \\
\text { strip off } \\
\text { remove } \\
\text { A.2. } \\
\text { make void } \\
\text { cancel a vow } \\
\text { A.3. } \\
\text { strike off } \\
\text { cancel an item in an account } \\
\text { II. passive } \\
\text { to be stripped of a thing } \\
\text { have a thing taken off or away from one }\end{array}$ & $\begin{array}{l}\text { I. } \\
\text { to take off something that surrounds } \\
\text { take off an outer coat } \\
\text { take away } \\
\text { strip off } \\
\text { II. PASSIVE } \\
\text { II. Pass. Also acc. } \\
\text { to be stript (sic) of a thing }\end{array}$ & $\begin{array}{c}\text { take away something that surrounds } \\
\text { take off something that surrounds } \\
\text { take off an outer coat } \\
\text { take away } \\
\text { remove } \\
\text { To be stripped of a thing } \\
\text { stripped off } \\
\text { strip }\end{array}$ \\
\hline
\end{tabular}

My point if not my argument here is that the length of time it takes to say a word, or to say it in translation, bears some relation to and in effect temporally recreates/represents for listener or reader the experience as a sensuous movement of sound as intellectual content in consciousness (Cassirer 1955), or as a "symbolic act" (Burke 1966), and so has at least some validity, since the act is taking place through the sonic rhetorics of language — the sound of the words. The same sonic reality occurs when you look up other possible Greek verbs for "strip." The alternate words/translations not only point to different grammatical relations, spatial referents, and sometimes wildly different meanings, but also contain in themselves actions of varying durations as part of their definitions, highlighting not only the difficulty of translation but also the varying temporal dimensions of meaning, and their ethical import in a text. (I deliberately discuss the sonic rhetorics created by etymological time and velocity of words rather than the grammar of verb tenses in classical Greek. The next section looks at Hebrew grammar.) 


\section{Ethical Letters and the Sonic Creation of Time}

There seems to be another rhetorical tradition, rooted in another classical language, in which time as well as space are believed to be created in language itself, by and through the letters of the alphabet-a sonic rhetorics in which the world is text, reality (already) written. I am not talking about postmodernism, with its focus on signification without final signifieds, although they are closely related through scholars like Derrida (1976), Handelman (1983), and Bloom (1975) and in part are derived from this ancient language and tradition begun over 5781 years ago and still used in sects of different religions, although relatively unknown outside the Jewish religion. This sonic rhetorical dimension of language and grammar, and the alphabet itself, though often heard, is relatively unknown or not understood, even by the Jewish people, many of whom nevertheless participate in it in services and rituals, or hear it in sermons without realizing its rhetorical significance (Katz 1995a, 1995b, 2003, 2004). (This was partly deliberate, as the ancient rabbis, sages, and mystics treated this knowledge as sacred, dangerous, forbidden knowledge). As Joseph Dan (1998) comments, it is very difficult to flip the relation of language and reality, and to think that texts spoken and written are reality-sonic reality I would add - and that the physical objects in the world are the signifiers. This Jewish tradition is not only ancient, but also deep and rich, and I will only have time to barely scratch the surface of one letter, and point to some other work I have done for those interested. I have dubbed this tradition "the rhetoric of the Hebrew alefbet," a Jewish mainstream theory and practice perhaps somewhat different in its persistence if not wholly unique from the Greek and Roman hegemonic one we have inherited, and a theory and practice still adhered to in different ways in different branches of Judaism today.

In past work, I have argued that the rhetoric of the Hebrew alefbet might constitute an ontological, or perhaps more precisely, an orthographic basis for what I have called a "Jewish sophistic" (Katz 2009). In "The Epistemology of the Kabbalah: Toward a Jewish Philosophy of Rhetoric" (Katz 1995a), I argued that based on the alefbet, this Jewish sophistic, not chronologically but philosophically, generally speaking would fall somewhere between Platonic and sophistic epistemological positions. Further, I have examined how the Hebrew Bible (the Tanakh) itself might constitute or at least represent a rhetorical "theory" quite different from most Greek and Roman concepts of persuasion (Katz 1995b, 2003, 2015a). And like Harold Bloom's reading of the Kabbalah in Kabbalah and Criticism (1990), we might read this tradition—-begun in the opening words of the Tanakh—with a set of hermeneutical principles known as the Baraita of the 32 Rules (see Strack and Stemberger 1996; Katz 2015a). Without getting into detail or going into depth, these principles were developed through the Rabbinic period (200 BCE-400 CE) while under Roman occupation, along with more fanciful Midrash (and to a lesser extent in the more legalistic and logical Talmud), and perhaps reached their fullest fruition in the various Kabbalistic texts that arose from the 1 st through the $16^{\text {th }}$ centuries. Alive and still learned, practiced and actively used today in sermons of all denominations, the latter five of these hermeneutic principles in particular might seem for us to be part of a different "sophistic" rhetorical tradition. For believers, these hermeneutic principles are not merely concerned with invention and persuasion, but also and ultimately with creation. And not merely the creation of 'social-epistemic' reality, but of physical reality - the entire material universe, space and time included.

In three major religions that draw on the Tanakh, G/d, creates the world/universe in the first line of Genesis (read right to left): (Bereshith bara Elohim eth hashshamayim v'eth ha'arets). "In the beginning G/d created the heaven and the earth." And how does

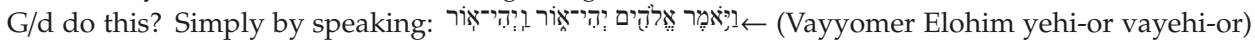
"And G/d said 'Let there be light and there was light'." G/d speaks creation into being. (Some mystics believe that G/d merely opened his/her mouth, and out of this divine silent sonic act the universe was born.) In this rendition of Judaism, Christianity, and Islam, G/d is the master rhetorician. This is the ultimate power of rhetoric for which rhetoricians long-to create not just symbolic action, consubstantiality, a social construction of reality, but "physical reality" itself see (Burke 1952, 1966; Handelman 1983). Further, in the Jewish tradition, especially the esoteric (and guarded) mystical one of Kabbalah, God does not just speak creation; G/d writes it down beforehand, using the Hebrew alefbet. In Judaism, as in 
postmodernism, (e.g., Derrida 1976), the world is already written! And it is "settled" convention that writing literally comes first: Moses was given not only the Ten Commandments, but also the written Torah on Mt. Sinai; or Moses wrote it down; or ... (see Handelman 1983; Katz 2003). The Oral Torah was compiled much later, during the Rabbinic period, finally giving us the Talmud.

As I have also suggested, the Jewish G/d is thus 'the ultimate sophist' (Katz 2009). En arkhêi ên ho Logos_ "In the beginning was the Word" John (1:1) declares. But in Judaism, the Word is not made flesh for sacrifice and redemption, as it is in Christianity; the Word remains language, the world a sonic rhetorics-the coughing, smoldering, broken, cryptic, musical remnants of spoken and written letters left over from the first act of linguistic creation: the language of the universe. G/d grows more and more distant and eventually disappears in the original Hebrew Bible when compared to Christian versions of "The Old Testament" (Miles 1995); only the alefbet remains. In Judaism, G/d is ultimately unknowable, as well as quite changeable (Miles 1995). And in Hebrew, G/d's holiest 'incarnation' is a Name, the Tetragrammaton yud, hey, vov, hey (Figure 1):

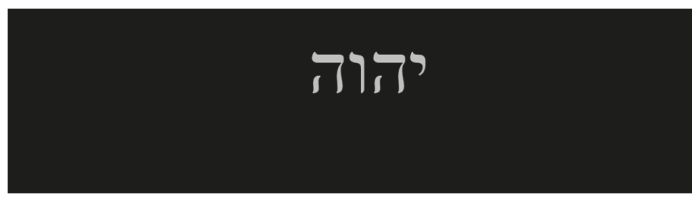

Figure 1. The Tetragrammaton (read right to left).

This Name, usually transliterated as Jehovah or Yahweh, is literally unsayable-physically as well as by taboo and tradition. This too is "sonic." But what does it have to do with time and ethics? In Kabbalah and the mystical tradition generally within Judaism (as well as in astrophysics (Hawking 1988)), creation starts with the smallest point possible, in the Eyn-Sof - the inconceivable "nothingness," which is also G/d). This is a sonic rhetorics of hidden temporalities "in ethical action" - the sound of language/reality itself as spoken by G/d, and reembodied in the Torah and Talmud, and in every letter of the alefbet. To conclude our discussion, then, let us focus on just one letter-the third of the four letters of the Tetragrammaton, vov-in itself, and in relation to the other three letters of the Tetragrammaton, and the sixth letter of the Hebrew alphabet with which by some accounts G/d created the universe. In Kabbalah, and the mystical tradition generally within Judaism, creation starts with a point, the smallest of the Hebrew letters, the Hebrew letter, yud —, - and extends and expands outward, and then down through the vov: 1. As Harralick writes,

[T] he [yud is in a] state of concealment and obscurity, before it develops into a state of expansion and revelation in comprehension and understanding. When the "point" evolves into a state of expansion and revelation [ ... ] it is then contained and represented in the letter $\mathrm{n}[\mathrm{hey}]$. The shape of the letter $\mathrm{B}[\mathrm{hey}]$ has dimension, expansion, breadth [ ... ] to indicate extension and flow downward to the concealed worlds. In the next stage this extension and flow are drawn still lower into the revealed worlds [ ... ]. This stage of extension is contained and represented in the final letters, [vov] and $\mathrm{n}[\mathrm{hey} \mathrm{...} \mathrm{].} \mathrm{,} \mathrm{[vov],} \mathrm{in} \mathrm{shape} \mathrm{a} \mathrm{vertical} \mathrm{line,}$ indicates downward extension. (Zalman, qtd. In Haralick 1995, p. 156)

One result of this interpretation or "drash" on the letter vov/the Tetragrammaton, is that in it we hear that $\mathrm{G} / \mathrm{d}$ creates the entire universe and everything in it, including all time and space through the speaking and/or insertion of the letter of the Name into nothingness, into the void (Figure 2). 


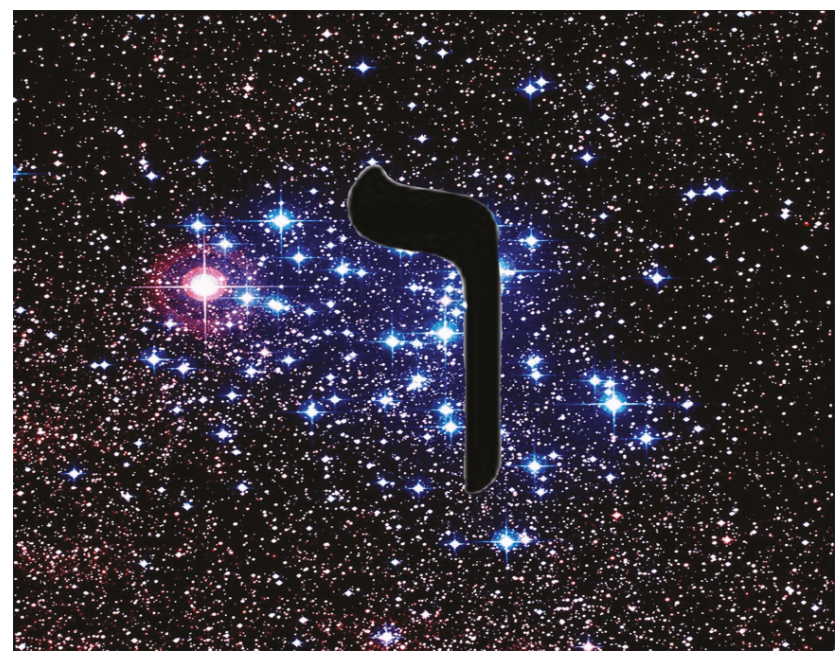

Figure 2. The Vov and Moral Space-Time.

I have dubbed the massive explosion of letters as objects and events that followed this sonic rhetorical act the 'Jewish big-bang theory' (Katz 2003). This hidden linguistic act sonically creates a rhetorical and physical reality, a spatial-temporal and still expanding realm as an orthographic, moral universe where the Hebrew letters themselves are presumed to be ethical, sacred, holy, and are treated as such by the observant (see Katz 1995a, 2003, 2004). In another Kabbalistic tradition, that of Rabbi Isaac Luria, the omnipresent G/d must withdraw from a tiny space in order to allow room for the creation of the universe (Vital 1999; cf. Burke 1966). In sonic production terms, this rhetorical physical act might be akin to creating, in the nothingness of a digital file, the necessary "acoustic room" into which sound or writing can then be recorded. One might relate this to Levinas' philosophy of ethics (passim) as well, where time (and space) are necessary for the possibility of Alterity, which might lead to the face of the Other(s), and ultimately G/d ... but probably not all of G/d, for Levinas' philosophy can be understood at least in part to derive in complex ways from Jewish tradition as well (e.g., Levinas 1981, 1990a, 1990b, 1998).

But there is another sonic feature of the Hebrew letter vov that involves issues of grammar and interpretation. The vov is almost always translated as the conjunction "and," and can be attached to almost any word. Grammatically, "AND" is a coordinate conjunction; it makes things equal. "And" is also a time referent, a temporal marker (a sentence that begins with "And" explicitly implies that something came before: "And G/d said ... "). And "and" can rhetorically create the illusion of simultaneity in language, a medium that unfolds lineally. And think about the figure of speech, polysyndeton, and the deliberate repetition of coordinate conjunctions (Quinn 1995): "and" rhetorically creates a sense of multiplicity, of prolixity, of procreation, if for no other reason than because there are literally more words! In the King James version of the Bible, the vov is translated as "and," giving us all of these conjunctions:

And God said: "Let there be light." And there was light. And God saw the light, that it was good; and God divided the light from the darkness. And God called the light Day, and the darkness he called Night. And there was evening and there was morning, one day. And God said: "Let there be a firmament in the midst of the waters, and let it divide the waters from the waters." And God made the firmament from the waters which were above the firmament; and it was so. And God called the firmament heaven. And there was evening and there was morning, a second day. Bereshith (Genesis) 1:1-1:8 
But in Biblical Hebrew, vov has several additional grammatical functions that relate to sonic rhetorics in fundamental ways. In one of these functions, vov Hahipuch (the "vov of reversal," also called the "vov conversive," or the "vov consecutive") not only gives us all those conjunctions "and," but also when attached to a verb can shift its tense (a temporal dimension of Hebrew totally lost in translation). When the vov of reversal is attached to a past tense verb (the perfect tense because the action is completed), the vov often changes the past tense in Biblical Hebrew into the future tense (the imperfect tense), and vice versa. We have already seen this: ראוֹ "Let there be light and there was light." Note that in Hebrew the form of the verb (highlighted in green) is the same in both cases: the first, future/imperfect tense (used as an imperative), preceded by the vov of reversal, is repeated in the same form, even though it is translated in and out of Hebrew as if it were past/perfect tense (which would be rishaya-"there was"). Without the grammatical vov of reversal, or its sonic rhetorical effect, the translation would read, and we would hear: Let there be light and there will be light. (Heresy!)

This kind of detail regarding the grammatical and rhetorical functions of letters and parts of letters is very typical of the rabbis of Talmud and Midrash (see Handelman 1983; Katz 2015a). But why and how is this significant for us? Because this "theory" sonic rhetorics and time is built right into the grammar and alphabet of Biblical Hebrew, into the letter vov. The effect of this rhetoric of the alphabet, in this instance alone, is to create not only an alternate rhetorical theory and tradition, but timelessness, eternity in the text. And with Levinas, an originary letter to which to respond (cf. Davis 2010). Because of vov of reversal, in Biblical Hebrew, the first act of creation in the Five Books of Moses, through the Prophets, to the last pages of the Writings, has happened, is happening, will always happen! (We see this in the Passover seder, for instance, where G/d annually frees the contemporary reader/celebrant from bondage in Egypt.)

This essay is not a Luddite, or perhaps more accurately, Antediluvian tract on sonic rhetorics. I have written before on the possible relations of the rhetoric and/or hermeneutics of the Hebrew alphabet, Object-Oriented Philosophy, and the Anthropocene (Katz 2015a, 2015b). The grammar of the Hebrew alefbet itself, every letter about which innumerable tomes have been written, constitutes a hidden temporal, ethical, sonic rhetoric, one that underlies Jewish rhetoric and religion and still informs Jewish teaching and scholarship today. The meaning of the vov of reversal is not without its controversies, of course (cf. Weingreen 1959; Cook 2010; Bamildele 2014). But if we accept vov as a grammatical inflection, the rhetorical effect of all the vovim is to create timelessness, making everything in the Hebrew Bible always present, always sounding, always occurring.

As we have discussed, a "preoriginary obligation" (Davis 2010), the inessential ground of ethical relations for Levinas hints at a prelinguistic and thus perhaps a divine or sacred moral source. And G/d certainly does figure in a lot of Levinas' work (Levinas 1990a, 1990b, 1998). In this context, the Hebrew letters also can be considered to be "preorginary" (as they are for many orthodox, Chasidic, and other Jews), an infinite but also pre-primordial mystical alphabet out of which writing and speaking a sonic moral space-time is born (see Katz 2003). One does not have to believe in the Hebrew G/d, or even that language is reality, to understand the power of the language, such as sacred pledge of the oath, for example (Agamben 2011). The hidden temporality of the Hebrew alefbet "appears" to be a theory of sonic rhetoric as an orthographic-material reality, one that by its operations and origins is often assumed to be ethical. Is it a sonic rhetorical theory in which language is not only a manifestation of time, but the cause and content of it; a sonic rhetorical theory in which language is a moral reality? קו ונדיד רצון Ken y'hi ratzon: "May it be so."

Funding: This research received no external funding.

Acknowledgments: Much earlier versions of parts of this essay were presented at the "Roundtable on Rhetorical Temporalities" with Diane Davis, Thomas Rickert, Michelle Ballif, and Daniel Gross, at the Rhetoric Society of America Conference, Minneapolis, MN, 31 May 2018; and at the session "Temporalities in Transition: The Epistemic Music of Rhetoric by Steven B Katz-22 Years Later. An Interview-Performance," with Mari Ramler, Michael David Measel, and Amy Patterson, at the "Symposium on Sound, Rhetoric, and Writing," organized by Steph Ceraso, Eric Detweiler, Joel Overall, and Jon Stone at Belmont University, Nashville, TN, and Middle 
Tennessee State University, Murfreesboro, TN, 7-8 September 2018. The author wishes to thank all these fellow participants and organizers for their formative contribution to his thinking, and others in attendance who offered valuable suggestions. The author wishes to acknowledge in great appreciation the very specific and extremely useful comments of the two anonymous peer reviewers for Humanities, which helped him immensely in revising and (re)focusing this essay. Penultimate but not least, the author gratefully acknowledges the tireless work of Addy Enlow for her earlier help as Research Assistant with the graphics in both presentations, and many other important little matters too numerable to name. Finally, the author (especially and again) wishes to express his sincere gratitude for the generous advice and ongoing assistance of Professor Adam Newton, Special Editor of this issue of Humanities, for his brilliant insight and guidance in bringing this second article to print, and for his continuing support and friendship. Any errors in fact or judgment are mine.

Conflicts of Interest: The authors declare no conflicts of interest.

\section{Appendix A}

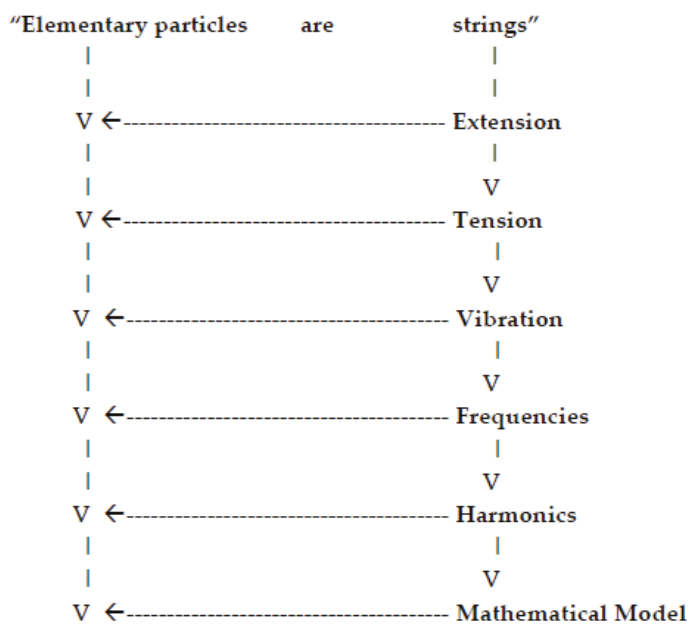

Figure A1. Metaphor Extension in Superstring Theory.

Superstring Theory attempts to address the problem of "complementarity" — the particle or wave phenomenon, among others—in quantum mechanics (Bohr 2010; Heisenberg 1958). In the 'metaphorical proposition' "Elementary particles are strings," the metaphor of the "string" is used to extend the concept of "elementary particles." Properties that belong to string are transferred to the concept of elementary particles as a way of understanding and even measuring the particles, and developing Superstring Theory. Because a string has extension, a subatomic particle has extension; because they have extension, they can vibrate; vibration can be measured in frequencies, which can be quantified and mathematical models created, etc. This is only the very beginning of this metaphor, and Superstring Theory. The same question about metaphor extension may apply to sonic rhetorics: Do we ever get out of our metaphorical models, to the "actual" substance/causal structures of the world? (Based on Greene 1986; cf. Boyd 1993; Kuhn 1993).

\section{References}

Agamben, Giorgio. 2011. The Sacrament of Language: An Archeology of the Oath. Translated by Adam Kotsko. Palo Alto: Stanford University Press.

Ahern, Katherine Fargo. 2018. The Sounds of Rhetoric, The Rhetoric of Sound: Listening to and Composing the Auditory in Writing. Ph.D. dissertation, North Carolina State University, Raleigh, NC, USA.

Ahern, Katherine Fargo, and Ashley Rose Mehlenbacher. 2019. Response, Listening to New Voices: Silence, Repair, Hybridity. Edited by David Beard. International Journal of Listening 33: 168-72. [CrossRef] 
Austin, Gilbert. 1966. Chironomia or A Treatise on Rhetorical Delivery. Edited by Mary Margaret Robb and Lester Thonssen. Carbondale: Southern Illinois University Press.

Bamildele, Olalekan Olusegun. 2014. The Vav Consecutive and Its Impact on the Tense-Aspect-Mood System of Biblical Hebrew Verb. Ogbomoso: The Nigerian Baptist Theological Seminary, Department of Biblical Studies, Faculty of Theological Studies.

Barad, Karen. 2007. Meeting the Universe Halfway: Quantum Physics and the Entanglement of Matter and Meaning. Durham: Duke University Press.

Barrett, Scot, and Casey Boyle. 2016. Rhetoric Through Everyday Things. Tuscaloosa: University of Alabama Press. Birdsall, Carolyn. 2012. Nazi Soundscapes: Sound, Technology, and Space in Germany 1933-1945. Amsterdam: Amsterdam University Press.

Bloom, Harold. 1975. Kabbalah and Criticism. New York: Seabury Press.

Bohr, Niels. 2010. Atomic Physics and Human Knowledge. Mineola: Dover.

Boyd, Richard. 1993. Metaphor and Theory Change: What Is 'Metaphor' a Metaphor For? In Metaphor and Thought, 2nd ed. Edited by Andrew Ortony. Cambridge: Cambridge University Press, pp. 481-532.

Braidotti, Rosa. 2013. The Posthuman. Cambridge: Polity Press.

Bryant, Levi, Nick Srnicek, and Graham Harman, eds. 2011. The Speculative Turn: Continental Materialism and Realism. Melbourne: Repress.

Bulwer, John. 1974. Chirologia: Or the Natural Language of the Hand AND Chironomia: Or the Art of Manual Rhetoric. Edited by James W. Cleary. Southern: Illinois University Press.

Burke, Kenneth. 1952. A Rhetoric of Motives. New York: Prentice Hall.

Burke, Kenneth. 1966. Language as Symbolic Action: Essays on Life, Literature, and Method. Berkeley: University of California Press.

Burke, Kenneth. 1969. A Grammar of Motives. Oakland: University of California Press.

Burke, Kenneth. 2007. Essays Toward a Symbolic of Motives, 1950-1955. Edited by William H. Rueckert. Lafayette: Parlor Press, pp. xi-xxi.

Carson, A. D. 2017. Owning my Masters: The Rhetorics of Rhyme and Revolution. Ph.D. dissertation, Clemson University, Clemson, SC, USA.

Cassirer, Ernst. 1955. The Philosophy of Symbolic Forms Vol. 1: Language. Translated by Ralph Manheim. New Haven: Yale University Press.

Ceraso, Steph. 2018. Sounding Composition: Multimodal Pedagogies for Embodied Listening. Pittsburgh: University of Pittsburgh Press.

Cicero. 1939. Brutus, Orator. Translated by H. M. Hubbell. Cambridge: Harvard University Press, pp. 306-509.

Cicero, Marcus Tullius. 1942. De Oratore Book III. In De Oratore III, De Fato, Paradoxa Stoicorum, De Partitiones Oratoriae. Translated by H. Rackham. Cambridge: Harvard University Press, pp. 1-185.

Clark, Greg. 2015. Civic Jazz: American Music and Kenneth Burke on the Art of Getting Along. Chicago: Chicago University Press.

Cohen, Richard A. 1998. Foreword. In Levinas, Emmanuel, Otherwise Than Being or Beyond Essence. Pittsburgh: Duquesne University Press, pp. xi-xvi.

Comstock, Michelle, and Mary E. Hock. 2016. The Sounds of Climate Change: Sonic Rhetoric in the Anthropocene, the Age of Human Impact. Rhetoric Review 35: 2. [CrossRef]

Cook, John A. 2010. Reconsidering the So-Called Vav Consecutive. Ancient Hebrew Grammar. Available online: ancienthebrewgrammar.files.wordpress.com/2010/05/recvavcons.pdf (accessed on 16 January 2020).

Croll, Morris W. 1989. Style, Rhetoric, and Rhythm. Edited by J. Max Patrick, Robert O. Evans, John M. Wallace and R. J. Schoeck. Princeton: Princeton University Press.

Dan, Joseph. 1998. Jewish Mysticism: Late Antiquity. Northvale: Aronson, vol. 1.

Danforth, Courtney S., Kyle D. Stedman, and Michael J. Faris, eds. 2018. Soundwriting Pedagogies. Available online: https://ccdigitalpress.org/book/soundwriting/ (accessed on 5 January 2020).

Darwin, Charles. 2009. The Expression of the Emotions in Man and Animals. Edited by Paul Ekman. New York: Oxford University Press.

Davis, Diane. 2010. Inessential Solidarity: Rhetoric and Foreigner Relations. Pittsburgh: University of Pittsburgh Press.

De Romilly, Jaqueline. 2013. Magic and Rhetoric in Ancient Greece. Cambridge: Harvard University Press.

Derrida, Jacques. 1976. Of Grammmatology. Baltimore: John Hopkins University Press. 
Derrida, Jacques. 1982. White Mythology: Metaphor in the Text of Philosophy. In Margins of Philosophy. Translated by Alan Bass. Chicago: University of Chicago Press, pp. 207-72.

Detweiler, Eric. 2019. Sounding Out the Progymnasmata. Rhetoric Review 38: 205-18. [CrossRef]

Elbow, Peter. 2006. The Music of Form: Rethinking Organization in Writing. College Composition and Communication 57: 620-66.

Eliot, T. S. 1989. Knowledge and Experience in the Philosophy of F. H. Bradley. New York: Columbia University Press.

Enos, Richard Leo. 1993. Greek Rhetoric Before Aristotle. Waveland: Prospect Heights.

Goodman, Steve. 2012. Sonic Warfare: Sound, Affect, and the Ecology of Fear (Technologies of Lived Abstraction). Cambridge: Harvard University Press.

Greek Word Study Tool. 2019. Perseus Digital Library. Available online: www.perseus.tufts.edu/hopper/ morph?l=perie\%2Floi\&la=greek\&can=perie\%2Floi0\&prior=tis\&d=Perseus:text:1999.01.0177:text=Gorg.: section=502c\&i=1\#lexicon (accessed on 1 April 2019).

Greene, Michael. 1986. Superstrings. Scientific American 255: 48-60. [CrossRef]

Gries, Laurie, and Collin Gifford Brooke, eds. 2018. Circulation, Writing, and Rhetoric. Logan: Utah State University Press.

Gries, Laurie. 2019. Editorial Statement. Enculturation: A Journal of Writing and Culture 28. Available online: http://enculturation.net/node/7102 (accessed on 22 January 2020).

Gunn, Joshua, Greg Goodale, Mirko M. Hall, and Rosa A. Eberly. 2013. Auscultating Again: Rhetoric and Sound Studies. Review Essay. Rhetoric Society Quarterly 43: 475-89. [CrossRef]

Handelman, Susan. 1983. The Slayers of Moses. New York: New York Press.

Haralick, Robert M. 1995. The Inner Meaning of the Hebrew Letters. Maryland: Jason Aronson, Inc.

Harman, Graham. 2018. Object-Oriented Ontology: A New Theory of Everything. Torrance: Pelican.

Hawhee, Debra. 2009. Moving Bodies: Kenneth Burke at the Edges of Language. Columbia: University of South Carolina Press.

Hawhee, Debra. 2013. Bodily Rhetorics: Rhetoric and Athletics in Ancient Greece. Austin: University of Texas Press. Hawhee, Debra. 2016. Rhetoric in Tooth and Claw: Animals, Language, Sensation. Chicago: University of Chicago Press. Hawk, Byron. 2018a. Resounding Rhetoric: Composition as Quasi Object. Pittsburgh: University of Pittsburg Press. Hawk, Byron. 2018b. Sound: Resonance as Rhetorical. Rhetoric Society Quarterly 48: 315-23. [CrossRef]

Hawking, Stephen. 1988. A Brief History of Time: From the Big Bang to Black Holes. New York: Bantam Books.

Haynes, Cynthia. 2016. The Homesick Phonebook: Rhetoric in an Age of Perpetual Conflict. Carbondale: Southern Illinois University Press.

Heidegger, Martin. 1971a. On the Way to Language. New York: Harper and Row.

Heidegger, Martin. 1971b. Poetry, Language Thought. Translated by Albert Hofstadter. New York: Harper and Row, pp. 91-142.

Heidegger, Martin. 1977. The Question Concerning Technology. In The Question Concerning Technology and Other Essays. Translated by William Lovitt. New York: Harper \& Row, pp. 3-35.

Heidegger, Martin. 2010a. Being and Time: A Revised Edition of the Stambaugh Translation. Translated by Joan Stambaugh. Albany: The State University of New York.

Heidegger, Martin. 2010b. Country Path Conversations. Bloomington: Indiana State University Press.

Heidegger, Martin. 2014. Hölderlin's Hymns "Germania" and "the Rhine". Translated by William McNeill, and Julia Ireland. Bloomington: Indiana University Press.

Heisenberg, Werner. 1958. Physics and Philosophy: The Revolution in Modern Science. New York: Harper.

Holmes, Steven. 2013. Actants, Agents, and Assemblages: Delivery and Writing in an Age of New Media. Ph.D. dissertation, Clemson University, Clemson, CA, USA.

Hume, David. 1999. An Enquiry Concerning Human Understanding: And Other Writings, Independently published.

Huron, David. 2008. Sweet Anticipation: Music and the Psychology of Expectation. Cambridge: MIT Press.

Katz, Steven B. 1992. The Ethic of Expediency: Classical Rhetoric, Technology, and the Holocaust. College English 54: 255-75. [CrossRef]

Katz, Steven B. 1993. Aristotle's Rhetoric, Hitler's Program, and the Ideological Problem of Praxis, Power, and Professional Discourse. Journal of Business and Technical Communication 7: 37-62. [CrossRef]

Katz, Steven B. 1995a. The Epistemology of the Kabbalah: Toward a Jewish Philosophy of Rhetoric. Rhetoric Society Quarterly 25: 107-22. [CrossRef] 
Katz, Steven B. 1995b. The Kabbalah as a Theory of Rhetoric: Another Suppressed Epistemology. In Rhetoric, Cultural Studies, and Literacy: Selected Papers from the 1994 Conference of the Rhetoric Society of America. Edited by John Frederick Reynolds. Hillsdale: Erlbaum, pp. 109-17.

Katz, Steven B. 1996. The Epistemic Music of Rhetoric: Toward the Temporal Dimension of Reader Response and Writing. Carbondale: Southern University Press.

Katz, Steven B. 2003. Letter as Essence: The Rhetorical (Im)pulse of the Hebrew Alefbet. The Journal of Communication and Religion 26: 125-60.

Katz, Steven B. 2004. The Alphabet as Ethics: A Rhetorical Basis for Moral Reality in Hebrew Letters. In Rhetorical Democracy: Discursive Practices of Civic Engagement. Edited by Gerard Hauser and Amy Grimm. Hillsdale: Erlbaum, pp. 195-204.

Katz, Steven B. 2009. The Hebrew Bible as Another, Jewish Sophistic: A Genesis of Absence and Desire in Ancient Rhetoric. In Ancient Non-Greek Rhetorics. Edited by Carol Lipson and Roberta A. Binkley. Lafayette: Parlor Press, pp. 125-50.

Katz, Steven B. 2015a. Socrates as Rabbi: The Story of the Aleph and the Alpha in an Information Age. In Jewish Rhetorics: History, Theory, Practice. Edited by Janice Fernheimer and Michael Bernard-Donals. Waltham: Brandeis University Press, pp. 93-111.

Katz, Steven B. 2015b. Burke's New Body? The Problem of Virtual Material, and Motive, in Object Oriented Philosophy. KB Journal: Journal of the Kenneth Burke Society 11.

Katz, Steven B. 2017. Pentadic Leaves (poem and video of performance). KB Journal 12. Available online: https://kbjournal.org/pentadic-Leaves (accessed on 11 December 2019).

Katz, Steven B., and Vicki W. Rhodes. 2010. Beyond Ethical Frames of Technical Relations: Digital Being in the Workplace World. In Digital Literacy for Technical Communication: 21st Century Theory and Practice. Edited by Rachel Spilka. London: Routledge, pp. 230-56.

Katz, Steven B., and Nathaniel Rivers. 2017. A Predestination for the Posthumanism. In Ambiguous Bodies: Burke and Posthumanism. Edited by Chris Mays and Nathaniel A. Columbia: University of South Carolina Press, pp. $142-61$.

Kaye, Deena, and James Lebrecht. 2015. Sound and Music for the Theatre, 4th ed. New York: Routledge.

Kerferd, G. B. 1981. The Sophistic Movement. Cambridge: Cambridge University Press.

Kuhn, Thomas S. 1993. Metaphor in Science. In Metaphor and Thought, 2nd ed. Edited by Andrew Ortony. Cambridge: Cambridge University Press, pp. 533-42.

LaBelle, Brandon. 2018. Sonic Agency: Sound and Emergent Forms of Resistance. Sonics Series (1); London: Goldsmiths Press.

Leff, Michael. 1989. Burke's Ciceronianism. In The Legacy of Kenneth Burke. Edited by Herbert W. Simons and Trevor Melia. Madison: University of Wisconsin Press, pp. 115-27.

Levinas, Emmanuel. 1969. Totality and Infinity. Translated by Alphonso Lingis. Pittsburgh: Duquesne University Press.

Levinas, Emmanuel. 1981. Otherwise than Being, or Beyond Essence. Translated by Alphonso Lingis. Pittsburgh: Duquesne University Press.

Levinas, Emmanuel. 1987. Time and the Other [and Additional Essays]. Pittsburgh: Duquesne University Press.

Levinas, Emmanuel. 1990a. Difficult Freedom: Essays on Judaism. Translated by Sean Hand. Baltimore: The John Hopkins University Press.

Levinas, Emmanuel. 1990b. Nine Talmudic Readings. Translated by Annette Aronowicz. Bloomington: Indiana University Press.

Levinas, Emmanuel. 1998. Of the God Who Comes to Mind, 2nd ed. Translated by Bettina Bergo. Standford: University of California Press.

Levinas, Emmanuel. 2000. Entre Nous. Translated by Michael B. Smith. New York: Columbia University Press.

Levinas, Emmanuel. 2001. Existence and Existents, 2nd ed. Translated by Robert Bernasconi. Pittsburgh: Duquesne University Press.

Measel, Michael David. 2020. Elucidating Attitude in the Keyboard Compositions of Kenneth Burke: Listening for Musical Gestalt and Aural Affect. Ph.D. dissertation, Clemson University, Clemson, SC, USA.

Mendelson, Michael. 1998. The Rhetoric of Embodiment. Rhetoric Society Quarterly 28: 29-50. [CrossRef]

Meyer, Leonard B. 1956. Emotion and Meaning in Music. Chicago: University of Chicago Press.

Miles, Jack. 1995. God: A Biography. New York: Knopf.

Miller, Carolyn R. 1991. Kairos in the Rhetoric of Science. In A Rhetoric of Doing: Essays on Written Discourse in Honor of James L. Kinneavy. Edited by Stephen P. Witte, Neil Nakadate and Roger Cherry. Carbondale: Southern Illinois University Press, pp. 310-27. 
Morton, Timothy B. 2009. Ecology without Nature: Rethinking Environmental Aesthetics. Cambridge: Harvard University Press.

Morton, Timothy B. 2012. The Ecological Thought. Cambridge: Harvard University Press.

Morton, Timothy B. 2013. Hyperobjects: Philosophy and Ecology after the End of the World (Posthumanities). Minneapolis: University of Minnesota Press.

Moses, Myra, and Steven B. Katz. 2006. The Phantom Machine: The Invisible Ideology of Email (A Cultural Critique). In Critical Power Tools: Technical Communication and Cultural Studies. Edited by J. Blake Scott, Bernadette Longo and Katherine V. Willis. New York: The State University of New York, pp. 71-105.

Novak, David, and Matt Sakakeeny, eds. 2015. Keywords in Sound. Durham: Duke University Press.

Odell, Lee. 1993. Theory and Practice in the Teaching of Writing: Rethinking the Discipline. Carbondale: Southern Illinois University Press.

Ong, Walter. 1958. Ramus, Method, and the Decay of Dialogue. Cambridge: Harvard University Press.

Osborn, Matthew. 2016. Surprise. Sensibilities, Auralities, and Aesthetics of Rhetorics. Ph.D. dissertation, Clemson University, Clemson, SC, USA.

Overall, Joel. 2017. Kenneth Burke and the Problem of Sonic Identification. Rhetoric Review 36: 232-43. [CrossRef]

Patterson, Amy. 2020. Soundscapes for Social Change: Community and Consciousness through Sound Design Rhetorics. Ph.D. dissertation, Clemson University, Clemson, SC, USA.

Perl, Sondra. 1980. Understanding Composing. College Composition and Communication 31: 363-69. [CrossRef]

Pilsch, Andrew. 2017. Invoking Darkness: Skotison, Scalar Derangement, and Inhuman Rhetoric. Philosophy and Rhetoric 50: 336-55. [CrossRef]

Plato. 1961a. Cratylus. In The Collected Dialogues of Plato Including the Letters. Edited by Edith Hamilton and Huntington Cairns. Translated by Benjamin Jowett. Princeton: Princeton University Press, pp. 421-74.

Plato. 1961b. Gorgias. In The Collected Dialogues of Plato Including the Letters. Edited by Edith Hamilton and Huntington Cairns. Princeton: Princeton University Press, pp. 229-307.

Plato. 1961c. Republic. In The Collected Dialogues of Plato Including the Letters. Edited by Edith Hamilton and Huntington Cairns. Translated by Paul Shorey. Princeton: Princeton University Press, pp. 575-844.

Propen, Amy. 2018. Visualizing Posthuman Conservation in the Age of the Anthropocene. Columbus: Ohio State University Press.

Quinn, Arthur. 1995. Figures of Speech: Sixty Ways to Turn a Phrase. London: Routledge Press.

Ramus, Peter. 1983. Arguments in Rhetoric Against Quintilian. Edited by James J. Murphy. Translated by Carole Newlands. DeKalb: University of Northern Illinois Press.

Rice, Jeff. 2012. Digital Detroit: Rhetoric and Space in the Age of the Network. Carbondale: Southern Illinois University Press. Rice, Jenny. 2020. Awful Archives: Conspiracy Theory, Rhetoric, and Acts of Evidence. Columbus: Ohio State University Press. Rickert, Thomas. 2005. Language's Duality and the Rhetorical Problem of Music. In Rhetorical Agendas: Political, Ethical, and Spiritual. Edited by Patricia Bizzell. New York: Lawrence Erlbaum, pp. 157-63.

Rickert, Thomas, and Michael Salvo. 2006. The Distributed Gesamptkunstwerk: Sound, Worlding, and New Media Culture. USA Computers and Composition 23: 296-316. [CrossRef]

Rickert, Thomas. 2013. Ambient Rhetoric: The Attunements of Rhetorical Being. Pittsburgh: University of Pittsburgh Press. Rickert, Thomas. 2016. Rhetorical Prehistory and the Paleolithic. Review of Communication 16: 352-73. [CrossRef] Rueckert, William H. 2007. Introduction. In Essays Toward a Symbolic of Motives, 1950-1955. West Lafayette: Parlor Press. Sheridan, Thomas. 1968. A Course in the Lectures on Elocution. New York: B. Blom.

Stedman, Kyle D. 2012. Musical Rhetoric and Sonic Composing Processes. Ph.D. dissertation, University of South Florida, Tampa, FL, USA.

Steiner, George. 2013. Grammars of Creation. London: Faber and Faber.

Stephens, Eric James, and Steven B. Katz. 2019. Rhetorics, Ethics, Poetics: A Psychagogic Interview with Dr. Steven B. Katz: On the Occasion of the 25th Anniversary of the Publication of "The Ethic of Expediency: Classical Rhetoric, Technology, and the Holocaust". Enculturation 28. Available online: http://enculturation. net/Rhetoric_Ethics_Poetics_Katz_Interview (accessed on 16 January 2020).

Sterne, Jonathan. 2012. The Sound Studies Reader. London: Routledge.

Stone, Jonathan W. 2015. Listening to the Sonic Archive: Rhetoric, Representation, and Race in the Lomax Prison Recordings. Enculturation 19. Available online: http://enculturation.net/listening-to-the-sonic-archive (accessed on 16 January 2020). 
Strack, Herman L., and Günter Stemberger. 1996. Introduction to the Talmud and Midrash. Translated by Markus Bockmuehl. Minneapolis: Fortress Press.

Vital, Chayyim. 1999. The Tree of Life: The Palace of Adam Kadmon. Translated by Donald Wilder Menzi, and Zwe Padeh. Northvale: Jason Aronson, Inc.

Walker, Jeffrey. 2000. Rhetoric and Poetics in Antiquity. New York: Oxford University Press.

Weingreen, Jacob. 1959. A Practical Grammar for Classical Hebrew. Oxford: Oxford University Press.

Whigham, Peter, ed. 1979. Volume I: The Music of the Troubadours. Santa Barbara: Ross-Erikson.

Wolfe, Cary. 2013. What is Posthumanism? Minneapolis: University of Minnesota Press.

Zuckerkandl, Victor. 1956. Sound and Symbol: Music and the External World. Princeton: Princeton University Press. Zylinska, Joanna. 2014. Minimal Ethics for the Anthropocene (Critical Climate Change). Edited by Tom Cohen and Claire Colebrook. Ann Arbor: Open Humanities Press.

(C) 2020 by the author. Licensee MDPI, Basel, Switzerland. This article is an open access article distributed under the terms and conditions of the Creative Commons Attribution (CC BY) license (http://creativecommons.org/licenses/by/4.0/). 

MDPI

St. Alban-Anlage 66

4052 Basel

Switzerland

Tel. +41616837734

Fax +41 613028918

www.mdpi.com

Humanities Editorial Office

E-mail: humanities@mdpi.com www.mdpi.com/journal/humanities

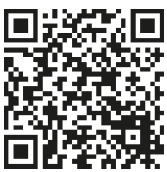



MDPI

St. Alban-Anlage 66

4052 Basel

Switzerland

Tel: +41 616837734

Fax: +41 613028918

www.mdpi.com 